\title{
HANDBUCH DER TROPENKRANKHEITEN
}

ZWEITE AUPLAGE

ERSTER BAND

\author{
HERAUSTEGEBEN VON \\ PROE. DR. CARL MIENSE
}







\section{Handbuch}

der

\section{Tropenkrankheiten}

Unter Mitwirkung von

Prof. Dr. A. Baelz-stuttgart, Prof. Dr. P. Bassett-Smith-Haslar, Dr. P. van Brero-Lawang, Dr. V. Bruyant-Lille, Prof. Dr. A. Calmette-lille, Prof. Dr. R. Doerr-IVien. Sanitätsrat Dr. A. Eysell-Kassel, Priv.-Doz. Dr. P. Kunth-Berlin, Prof. Dr. P. Kransp-Bonn, Prof. Dr. W. B. Leishman-London, Prof. Dr. A. Looss-Kairo, Dr. W. G. Mac Callum-Baltimore, Hofrat Dr. L. Martin-Diessen, Mrof. Dr. K. Miura-Tokyo. Physikus Dr. Otto-Hamburg, Prof. Dr. A. Plelm-Berlin, Dr. R. Pöch-Wien, Prof. Dr. F. Pho-Tenedig, Marine-Generalarzt Prof. Dr. R. Rnge-Kiel, Prof. Dr. Th. Rumpf-Bonn, Dr. V. Russ-Wien, Dr. A. van der ScheerHaag, Prof. Dr. K. Schilling-Berlin, Dr. V. Schilling-Torgan-Hamburg, Regierungsrat l'rof. Dr. A. Schuberg-Berlin, Prof. Dr. G. Sticker-Bonn, Marine-Generaloberarzt Prof.

Dr. H. Zieman-Charlottenburg

herausgegeben von

Prof. Dr. Carl Mense

Zweite Auflage

\section{Erster Band}

Mit 200 Abbildungen im Text, 10 schwarzen und 2 farbigen Tafeln

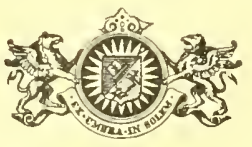

251488

Leipzig $\diamond$ Verlag von Johann Ambrosius Barth $\diamond 1913$ 
Übersetzungsrecht vorbehalten.

Copyright by Johann Ambrosius Barth, Leipzig. 1913. 


\section{Vorwort zur zweiten Auflage.}

Dic unemïlliche Arbeit emer stets wachsenden Zahl von Forshern hat seit dem Erseheinen der ersten Auflage dieses Handbuches die Tropenmedizin gewaltig gefördert. Wiehtige Beobachtungen und Entrleckungen haben weite Strecktn des I'nbekamnten erhellt und die Grenzen unserer Kenntwisse vorgeschoben, nicht selten aber anch alte Anschaumgen ersehïttert und nene Aufgaben gestellt.

Der Lmfang dieses Sammehwerkes ist daher bedentend gewachsen, zumal neben der Medizin auch die mentbehlichen sogenannten Hilfswissenschaften, richtigtr gesagt, die anderen Zweige der Naturwissensehaft, immer eingehender Berïksichtigung erfordern.

Einzelne Absehnitte sind zu selbständigen Bänden herangewaehsen, andere haben nen anfgenommen werden mïssen und weitere Jitarbeiter haben ihre Unterstützung geliehen, um in dem Gesamtwerke dem Leser einen unfassenden Überblick n̈ber die Tropenkrankheiten zu bieten.

Kassel, Pfingsten 1913.

Dr. C. Mense. 



\section{Inhaltsverzeichnis.}

Seits

Vorwort

Verzeichnis der Abbildungen $\mathrm{X}$

Verzeichnis der Tafeln

Dip Lrankheitserreger uml Krankheitsuberträger unter den Irthropoden. Von Dr. Adolf Eysell.

Eiuleitung

Literatur (Arthropoden. Illgemeines)

\section{Die Krankleitserreger ïherdragender Gitiederïbler}

Crustacea, lirebstiere

Arachnoüdea. Spinnentiere.

Aearina (Milben)

Zecken

Allgemeines

Morphologie

Anatomie.

Binlogie

Systematik

Irginsidae

Ixodidae

Fang, dufhewalırung und Versand

l"utersuchung.

Prophylase, Feinde.

Literatur .

Hexipoda (Insekten)

sipluneulata

I. läuse

Allgemoines

Morphologie

Inatomie und Physiologie

Biolonie

systematik

Pediculidae.

Anthewabrung und Untersuchung

Prophylaxe und Therapie

II. Haarlinge -

Literatur (läuse und Ilaarlinge) 
Hllemenes

Horpholugie

Auatomic und Phrsiologic

Biologie... . . .

Sistematik.

Membranaceї...... . . . . . . . . . 58

Redıviidae. . . . . 61

Fang, Autbewahrong, Untersuchmo . . . 66

Proplyylaxe, Feinde . . . . . . . . . - 07

Literatur . . . . . . . . . . . . . 65

Psyllomorphà (1öhe) . . . . . . . . . . . . . 11

Vlermeines . . . . . . . . . . . . 71

Morpliologie . . . . . . . . . . . . . . . . .

Anatomic und Physiologie. . . . . . . It

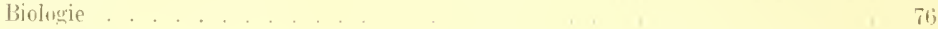

Systematik. . . . . . . . . . .

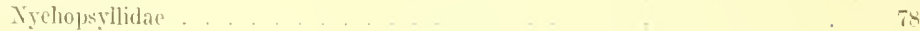

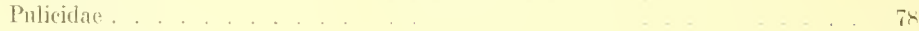

Sareopsyllidae . . . . . . . . S 1

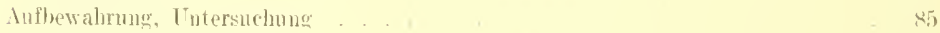

Propliviaxe. Feincle . . . . . . t t ti

litratur. . . . . . . . . . . . . T

bipteral (Zweillügler) . . . . . . . . . . . . .

Mllgemeines . . . . . . . . . 8!

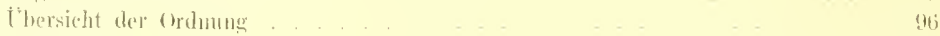

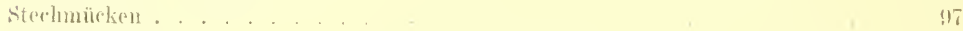

Horphologie . . . . . . . . . . .

$\begin{array}{ll}\text { Anatomie und Physiologie. . . . P } & 102\end{array}$

liologie . . . . . . . . . . . . . 115)

Systematik . . . . . . . . . . 118

Kuliziden und Anopheliden _...... 121

Fang, Aufbewahrung, Tersand. 195

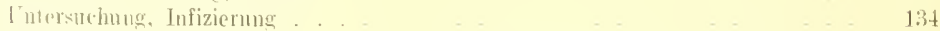

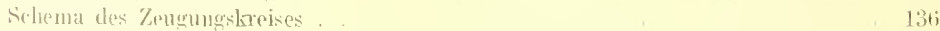

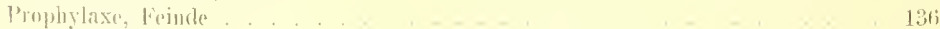

Talteleklitus . . . . . . . . 142

literatur . . . . . . . . . . . . . 145

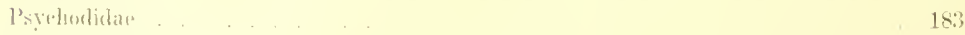

l'hirmomidac . . . . . . . . . 183

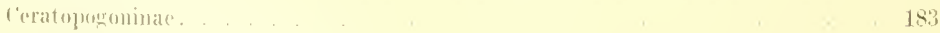

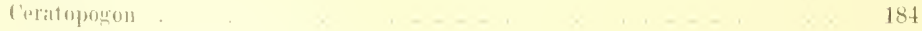

lilratur. . . . . . 184

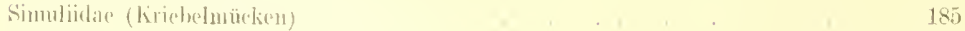

Simulial _........ . . . . 186

$\begin{array}{lr}\text { literatur. . . . . . . . . } & 187\end{array}$

Blephatorericlas . . . . . . . . . . .

l'umplira. . . . . . . . . . 188

Tabanidae (Bremsert) _. . . . . 185

Nlecmeines . . . . . . 188

Morplologie . . . . . 189

Antromie, I'hysioloerio. . . . 190 
Biologie

Site

sistematik.

P'allgoniina

Tabaninae.

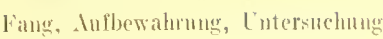

Prophylaxe, Feinde.

Literatur .

Isilidae. .

$1911 ;$

Mrsscidae.

1.97

Mlıseal.

197

sitomoxys

197

filosininal.

Nllwemeine

Jorphologie

Anatomie und Physiologie.

Binlogie

Systematik.

Fang, lufhewahrung. Versand

Prophylaxe, Feinde. . . 212

Jiteratur .

Pupinara (Lausfliegen). . . . . 217

Allucmeines . . . . . 17

Morphologie......... 18

Anatomie, Physiologie. . . .

Biologie ...........

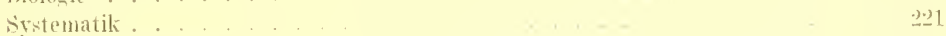

Fing, Infhewatumg usw. . 2. 221

Literatur . . . . . . . . .

B. Die Krankheitserreger unter den Gliederfïßten

Crustacea, Krebstiere

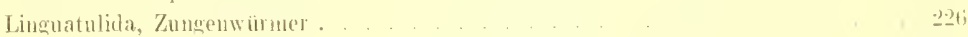

linguatulat . . . . . . . . . . . . . . . . . .

Porocephalus . . . . . . . . . . . . . . . . .

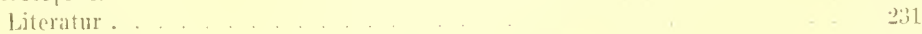

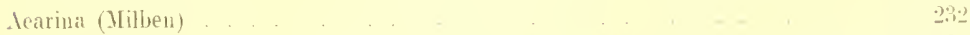

Sareopticlae . . . . . . . . 232

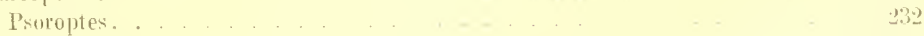

Dernodicilae..2.?

Trumbidiidae.

Leptus..........3

liedani ...

Flublieber . . . . .

Tetrantehidae ............

Tarsonemidae . . . . . . . .

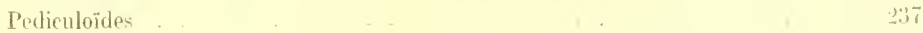

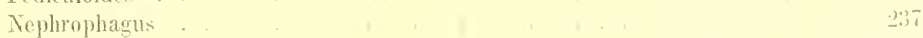

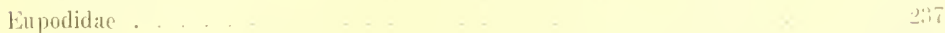

Tydels

tramasidae. . .

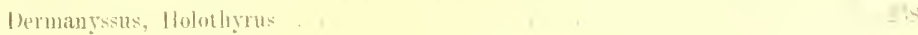


Thern Irphidae

Trroulyphus

[i]yeiplalerus

Rhizorlyphus

Histiogaster

Literatur.

Irincïta (spinnen) . . . . . . . . . . . . . . . . . 240

('hiracanthim . . . . . . . . . . . . . . . . . 241

Epeira . . . . . . . . . . . . . . . . . . . . . 241

Tarantula . . . . . . . . . . . . . . . . . . . . 2. 24

Trochosa . . . . . . . . . . . . . . . . . . . . . 24:

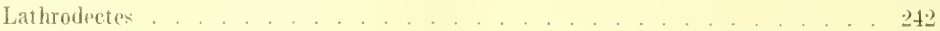

Mygale. . . . . . . . . . . . . . . . . . . . . 243

Theraphosa . . . . . . . . . . . . . . . . . . . . . . . 243

Solifugae (Wakenspinnen) . . . . . . . . . . . . . . . . . . . 243

Gialeodes... . . . . . . . . . . . . . . . . . . . 243

Literatur (Spinnen und $\mathbb{W}$ alzenspinnen) . . . . . . . . . . . . . . . . 243

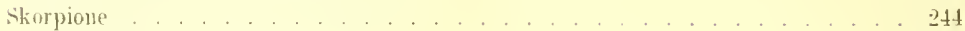

Buthidae . . . . . . . . . . . . . . . . . . . 245

Buthus . . . . . . . . . . . . . . . . . . 245

Indroctonus . . . . . . . . . . . . . . . . . . . . . . . . . 245

Isometrus . . . . . . . . . . . . . . . . . . 245

Telegronidae . . . . . . . . . . . . . . . . . . . . . . . 245

Telegonus . . . . . . . . . . . . . . . . . . . . . . . . 245

Pandinidae . . . . . . . . . . . . . . . . . . . 245

Pandinus unt seorpio . . . . . . . . . . . . . . . . . . . 245

Literatur . . . . . . . . . . . . . . . . . . . . . . . . . . . . . . . . . . . . .

Il yriayoda (Tausendfüßler) . . . . . . . . . . . . . . . . . . . 246

Lithobius . . . . . . . . . . . . . . . . . . . . . . . . . 46

scolopendra . . . . . . . . . . . . . . . . . . 246

literatur . . . . . . . . . . . . . . . . . . . . . . 247

Insckten . . . . . . . . . . . . . . . . . . . . . . 247

l'oleoptera . . . . . . . . . . . . . . . . . . . . . . . 247

Lepidopteril . . . . . . . . . . . . . . . . . . . . . . 248

Ilymenojtera. . . . . . . . . . . . . . . . . . . . . . . 248

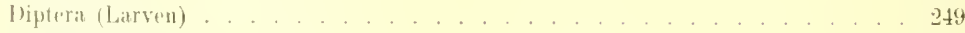

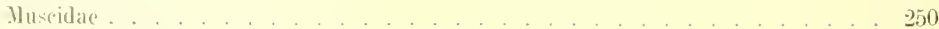

1. Myiais muscida) . . . . . . . . . . . . . . . . . . . . . 250

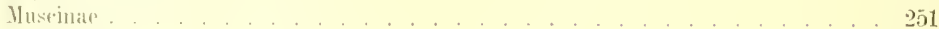

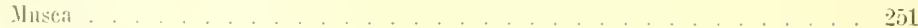

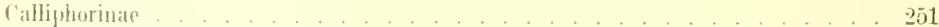

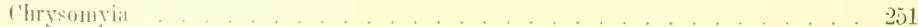

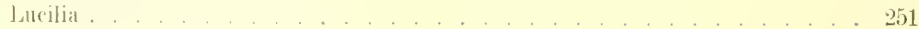

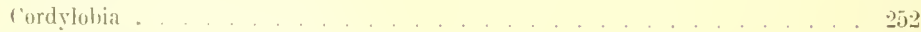

Aurhmerortylit . . . . . . . . . . . . . . . . . . . . . 254

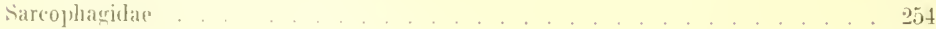

Sareoplaga . . . . . . . . . . . . . . . . . . . . . . . . .

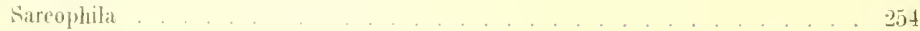

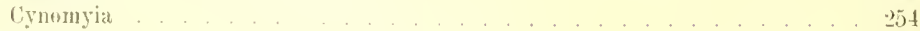

Antlomvidae . . . . . . . . . . . . . . . . . . . . . . . . . . . . . . .

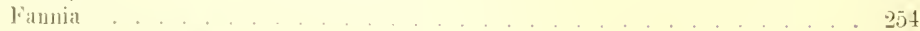

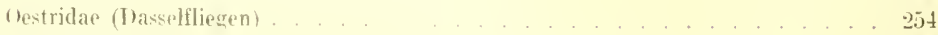

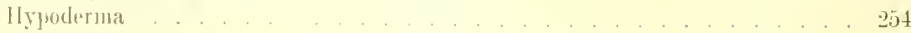

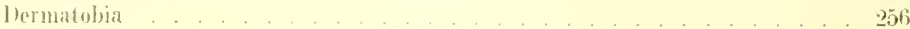


(Mylasis oestrom

Dir Phlebotomen. Fon R. Doerr und V. RüB, Wien.

Allgemeines

Biologie. . . . . . . . . . . . . . . . . . . . . . . . . . . . . . . 270

Vermehrung, Entwicklung usm. . . . . . . . . . . . . . . . . . . . 374

Tutersuchng, /ucht . . . . . . . . . . . . . . . . . . . . . . . . . . 277

Prophylaxe . . . . . . . . . . . . . . . . . . . . . . 278

Andere Phlehotomen . . . . . . . . . . . . . . . . . 279

Literatur . . . . . . . . . . . . . . . . . . . . . . 280

Taleherklïrumg . . . . . . . . . . . . . . . 28 


\section{Verzeiclunis der Abhildungen.}

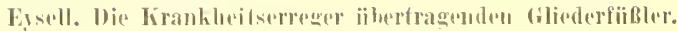

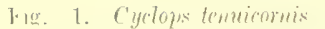

. 2. Kectenchedikeren rou jund ;

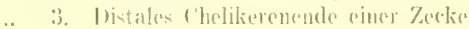

.. 4. Quersehnitt durch den Rï̈sel riner Kecke.

. 5. Riissel von Ormilhudonus moubuta + .

.. (i. Kilanemgliedor von Irodes rivimes, Plantarfläclue

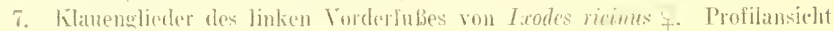

s. Längsehnitt dureh die Ieclianelene des Zeckenrüsels. . . . . . . .

4. Jagen voll lrufes mimiatus

10. Verdanungi- und Itmungsoreane ciner Kerle 


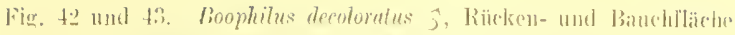

Seit.

"4. l'ediculus enpitis, sagittalschnitt durch (len kinpl

.. 45. Indiculus capitis, Querschuitt durch den kopil.

46. Phthivius pubis, Tractus intestinalis.

. 47. Inthivius puthis, wribliche freschlechtsteile

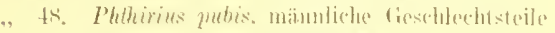

. 49. Ilnemutomyzas aleplantix $f$.

, 50). P'edientus eapritis

"51. Pedirulus capitis, Eiribrre

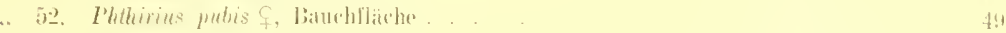

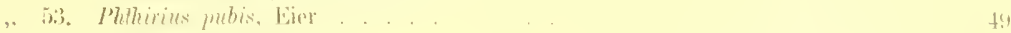

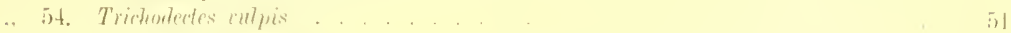

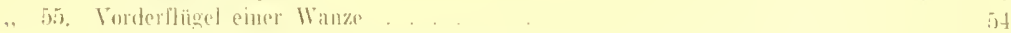

., 56. Siehuabebasis eimer Wanze . . . . . . Bti

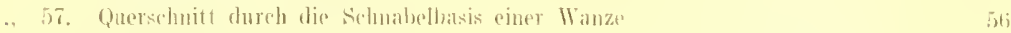

.. 5s. Nepa cinerea, Mumberkzeuge . . . . . . . . . 5i

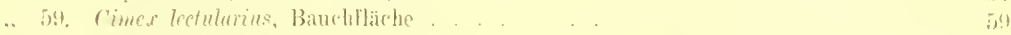

.. tio. Cimex lectulurius, Thorax von oben . . . . . 5, 5,

.. (i). Siabethorste von ('imex lectulurius. . . . . (i)

. (i2. Beine von Cimex und listmia. . . . . til

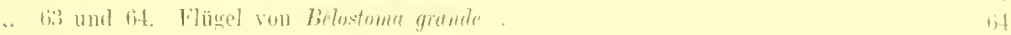

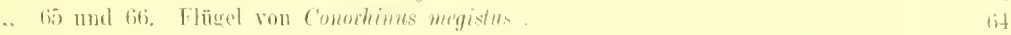

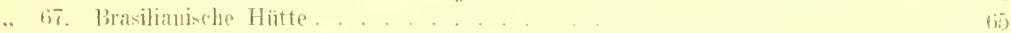

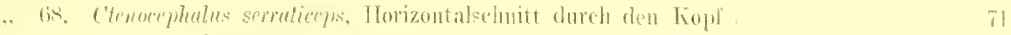

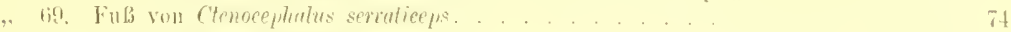

.. 7). Larve von P'ule.e imituns . . . . . . . . . . . . . . . 77

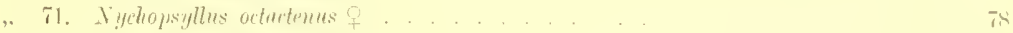

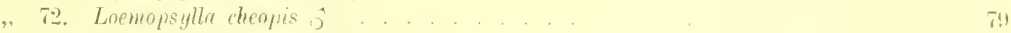

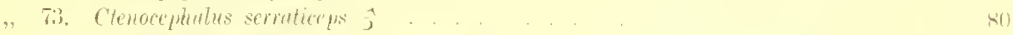

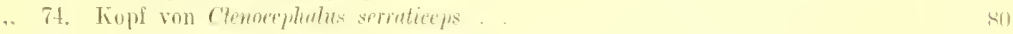

. 75. Ceralophyllus fusciutus j...... . . . . 81

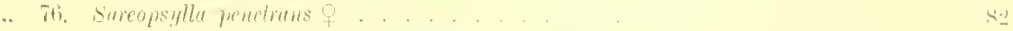

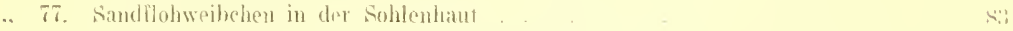

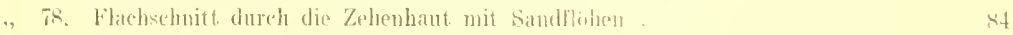

, 79. Hinterenule von tureopsylla in der Hant . . . . . S4

.. si). Sandflähe in ter Zehenhant. . . . . . . . . bit

,. Si. Simditoh in der Sohlendaut.... . . S4

., \$.). ('hinesische Flohialle . . . . . . . . . . . . . .

.. 83. Tönnchempuppe der Tsetse. . . . . . . 51

"St. Larvenhant von Cule, ........ . . (4)

"85. Kropl miner Blepharozerite. . . . . 91

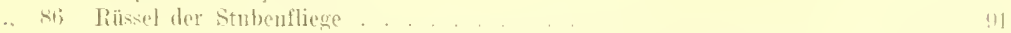

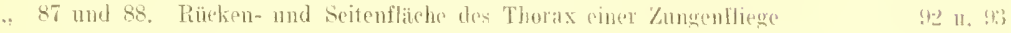

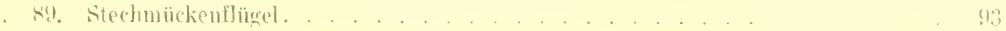

90. Sitechmiuckenboin . . . . . . . . . . . . . . . . . . . . . . . . .

. 41. Tubums lingi, Eier, Larve, 1'upme. . . . . . . . . . . . (15)

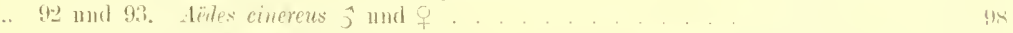

,. 44. Taster von tëdrs cinereus . . . . . . . . . . . . . .

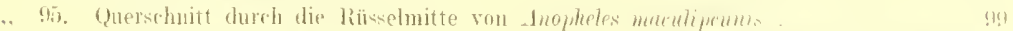

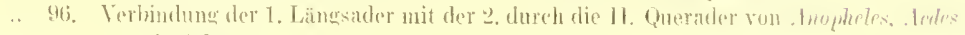

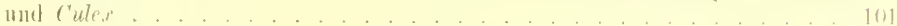

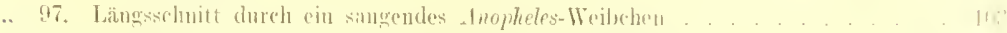

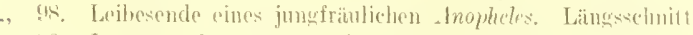

.. $\quad$ 19. Innere nud äubere Goxchlechtsteile von deates $\hat{j}$

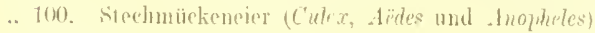




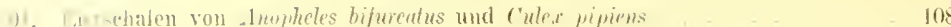

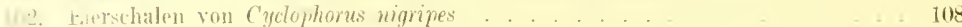

(1). Stigmenhof vou thophetes macntipumis . . . . . . . 110

104. Distales Ende des Sipho von Culex ammulatus . . . . . . 110

10i. Larre von Anopheles und Culex, Ruhestellung . . . . . . 111

1ei. Shmienpuppe einer stechmücke . . . . . . . . . . . . 111

107. Endsegmente mud Ruderplatten vou Stechmï̀chempmpen _ _ _ . . . . . . 111

108. Stechmïckenpuppe unmittelbat vor dem Sellüpfen . . . . . . . . 113

109 und 110. Schlïpfende Stechmüeken . . . . . . . . . . . . . . 112

., 111. Terlassene Puppenhiblle (Exuvie) von oben gesehen . . . . . . . 113

.. 112. Entstehung der Śpalten und Jappen der Puppenhülle . . . . . . . 114

.. 113. Becherglasversuch . . . . . . . . . . . . . . . . . . . . 114

.. 114 und 115, Sitz von Culex und Awophles . . . . . . . . . . . . . 116

. 116 und 117. Culex pipiens o und s. Kopl von der seite. . . . . . . . . 118

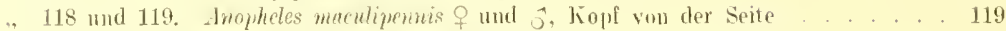

.. 120 und 121. Culex (Stegonyia) faseiatus ô und o . . . . . . . . . . . . . . 1233

, 12.). Reagenzglas mit gefangenen Stechnicken . . . . . . . . . . . . . . . . 126

., 123. Glasreuse . . . . . . . . . . . . . . . . . . . . . 126

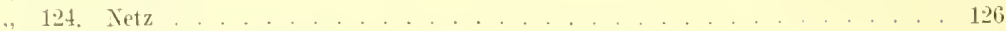

.. 125 und 126. Weißhlechsieb vou ohen und durchichnitten . . . . . . . . . . . . 128

. 127. Vivarim . . . . . . . . . . . . . . . . . . . . . . . . 129

"128. Feuchte kammer zur Stechmïckenzucht . . . . . . . . . . . . . . . . . . 129

.. 129 und 130. Nadehn der Stechnïrken . . . . . . . . . . . . . . . . . . . . 131

. 131. Blechdose mit Stechmücken . . . . . . . . . . . . . . . . . . . . 132

" 13:) und 133. Stechmücken versandfertig in spiritus. . . . . . . . . . . . . . 133

. 134. Schnitführung bei Untersuchumg aul Plasmodien . . . . . . . . . . . . . . 134

.. 135. Zengumgskreis . . . . . . . . . . . . . . . . . . 137

, 136. Zısehüttum cines sumples. . . . . . . . . . . . . . . . . . 138

. $1: 37$ und 138. Fhbbett vor und nach der Reguliernug. . . . . . . . . . 139 ı. 140

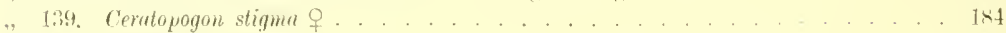

, 140. Simulia repturs o. . . . . . . . . . . . . . . . . . . 186

. 141. Simulia reptans , Flügel. . . . . . . . . . . . . . . . . . 186

. 14.2 und 143. Simuliu reptens, Larve und Puppe . . . . . . . . . . . . . . 187

"144. Curupire torientium, Fhüg) . . . . . . . . . . . . . . . . . 188

.. 145. Kopf und Fibiler von Tubanus, Chrysops und Marmatopota . . . . . . . 18!)

. 146. Flügel von Clirysops caecutims . . . . . . . . . . . . . . . . . . . . 194

.. 147. Flägel von Tabrnus bovinus . . . . . . . . . . . . . . . . . 195

.14s. Stomoxys calcitruns . . . . . . . . . . . . . . . . . . . . 199

.. 149, Jumbende titessina morsitans. . . . . . . . . . . . . . . . . . . . 201

.. 150 und 151. Kupl' dor Zungenfliege vou vorn . . . . . . . . . . . . . . 20

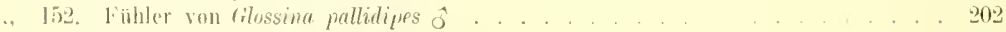

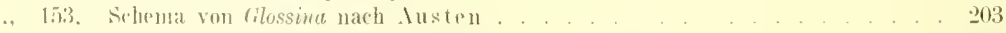

. 15t. Ilypopyerium von Gilossine morsitans. . . . . . . . . . . . . . . 204

. 15.5. Labellum riner Zangenflioge . . . . . . . . . . . . . . . . 204

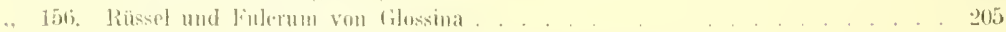

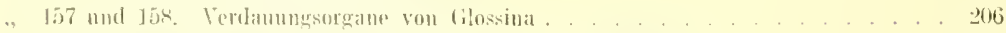

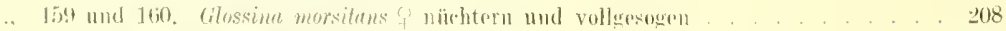

16il. Cilossina palpatis j . . . . . . . . . . . . . . . . . . . 210

,. lii2. Cilossine morsiturs f. . . . . . . . . . . . . . . . . . . . . . . 211

.. 16i3. Vilossinu fusea f. . . . . . . . . . . . . . . . . . 212

., Shit. Lipoptena ervit o. . . . . . . . . . . . . . . 219

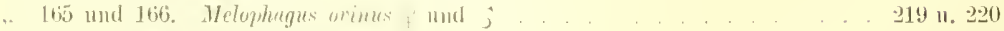

. 167. Lipoptence werit. Flünel . . . . . . . . . . . . 222

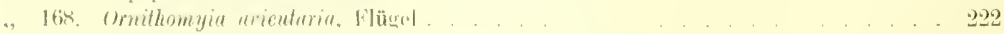

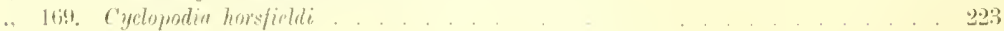




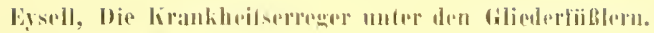

Fig. 170. Linguetula minurie

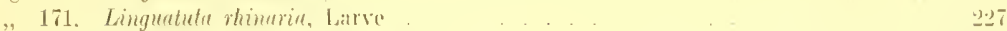

.. 172. Porocephalus moniliformis. . . . . . . . . . . . . . .

, 173. Pentastomum constrictum . . . . . . . .293

.. 174. Porozephahularve in situ ........ 2;0

.. 175 und 176. Porozephahssarve in der kapsel und trei. 2:30)

.. 17i. Porozephahuskopl von ter l'nterseite. . . . 2.3)

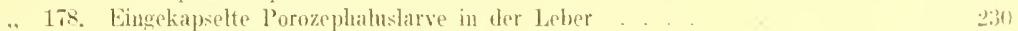

. 179. Tyroglyphus longior, vit, custellanii .......... 2:ix

„180. Skorpion, Mediansehnit . . . . . . . . . . . . . .

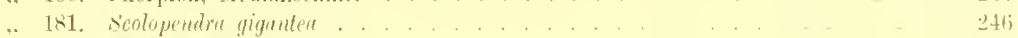

, 182. Musce vomitorie. Larve . . . . . . . . . . . . . . .

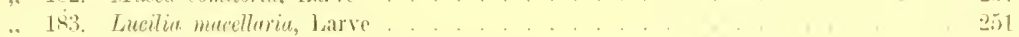

„184. Cordylobire anthropophagu . . . . . . . . . 252

" 185-187. Larven von Cordiglotia anthropoplutga . . . . . . . . 52

"188. Dasseltsenle nit Cordylobit-Larve . . . . . . 253

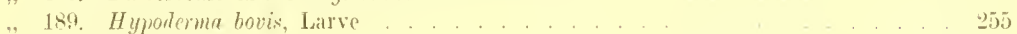

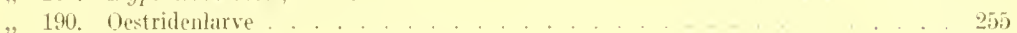

" 191. Hantmanlwurf . . . . . . . . . . . . . . . . . . . . .

" 192. Dermatobia eyaniventris, Larvell . . . . . . . . . 257

Doerr und Ruk, Dir P'hlehotomen.

Fig. 1. 5. und 6. Anteunensegment . . . . . . . . . . . . . . . . 266

. 2. Aderschema des Flïgels von Phlebotomus nud C'ulex . . . . . . . . 267

.. 3. Hinteres Abdominalende eines Phlebotomus of von der Seite . . . . . . . . 는

. 4. Hinteres Abdominalende eines Phlebotomus jo von der seite. . . . . . . . 268

,5. Iunere Genitalorgane des $\hat{\jmath}$. . . . . . . . . . . . . 270

.. 6. Reaktionen nach Phlebotomusstichen ... . . . . . . . . . . 273

. 7. AuBeres fenitale von Pllebotomus permiciosus of . . . . . . . . . . 279 



\section{Verzeichnis der 'Tafeln.}

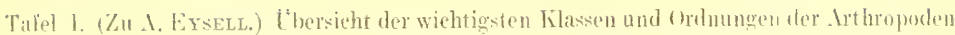
Hach seite 2

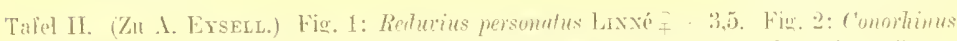

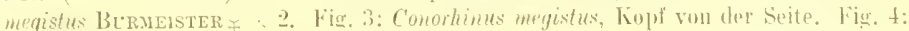
Leibesende des $\hat{j}$. Fig. 5 : Leibesende des . . . . . . . . . nath site 62

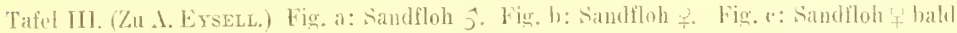
nach dem Eindringen in die Hant heranspräpariert. Fig. d: Votderansicht eines aus der Hant leranspräparierten noeh nieht ausgerciften Sandfuhweibehens. Fig. c: Fast ausereiftes sandflohweihehen aus der Haut heranspripariert. Hig. f: Torderansicht eines aus der Haut lerauspräparierten ausgereift en Sandfloluweibchens. Fïg. !: Kopf-Thoraxabschnitt eines in der llaut ausgereiften sandflohweibchens. . . . nach side 8.2

Tafel IY. (Zu A. Erseld.) Fig. a: Anopheles ziemenni . Fig. b: Anophelestarve. Fig. c: Ano-

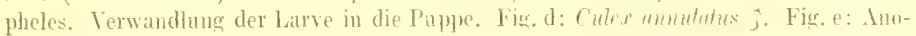
phelesprippe . . . . . . . . . . . . . . . . . . nach sieite 110

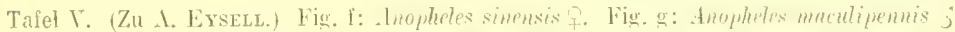

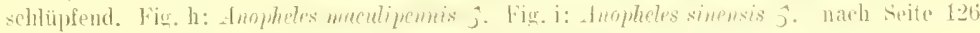

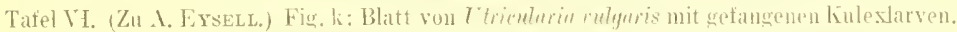

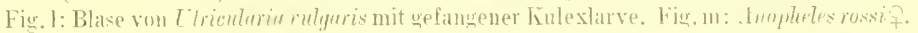

nach sieite 13 it

Tafet VII und VIII. (Zu A. ErsziL.) Jorphologie und Anatomie der stedhnicken nach seite 14

Tafel IX. (Zu A. Erseld.) Fig. 1-13: Anophetentlüret. Fir. 14 17: Tropicaoozyten nach seite $14 t$

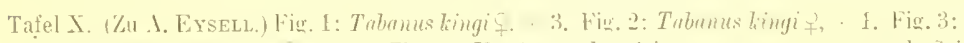

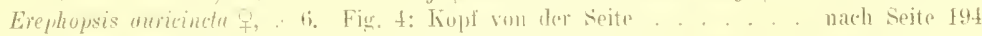

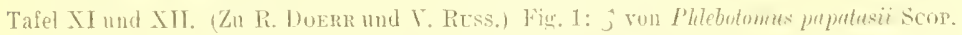

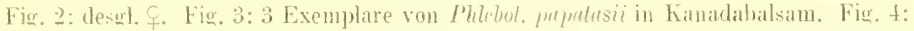
hopf von Phleb. papatasii der Ventralseite. Fig. 6: Hiuteres Abdominalende des Männchens abgetrennt. Fig. 7 : Flügr, dureh Abpinseln von Haaren und schnpen befreit. Fig. s: Anseinandergebreitetes männliches (renitale. Fig. 9: Reife, knapp vor dem. Iuschlüpfen stehende Puppe, st ark verurüBert. Figr. Y0: Puppe, hinks das hintere Dbdominalende mit den Resten der letzten Larvenhaut unl den 4 Kandalborsten der Larve. Fig. 1t: Hälite eimes Eies. Fig. 12: Puppen, halbschenatisch, rom Riücken gesehen. Fig. 13: silunit dureh eine lmago j, gefärbt mit Ilamalaun-Eosin. Fig. 1f: Eine stäker veruroberte, behadre Borste der Larwe.

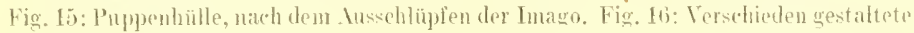
schuppen von den Brinen und lihugeln des Lnektes. Fig. 17: Relativ junge Larve, von whers gresenen 



\section{Die Krankhoitserreger und Krankheits- überträger unter den Arthropoden.}

Von

I)r. Idolf Eysell.

Eiuleitung.

Die Arthropoden zählen in den meisten ihrer Kilassen, ja sogar in der Mehrzihl der Ominungen und in vielen Familien Arten, welehe Gesmulheit und Leben des Henschen und seiner Haustiere direkt oder inclirekt gefährden.

Von den Polen nach dem Äquator him nimmt die Zahl der sehädlichen Arten fortwährend zu, so da B clie GlichlerfüBler naturgemäß clen Tropenarzt in erster Linie interesvieren müsien.

Als Krankheitserreger betätigen wich die Arthropoden und sehädigen so direkt Mensehen und Tiere dadurch, daßsie in den Körper ilurer Wirte eindringen and sich dort als stationäre Parasiten ansiecleh (Arachnoïdea, Diptera usw.), oter dadureh, daß sie als Ektoparasiten Hantkrankheiten verurachen und ihren Opfern vergiftete Wrunden beibringen.

Ciewisse Käfer, die spanische Fliegre Lylla vesicutoria z. B. und die (ilkäfel (Melor), enthalten das auberst giftige Cantharidin, gewise schmetterlingsraupen rufen dureh die Berülrung ihrer giftigen Haare die heftigsten llautentzundungen hervor. Spinnen und skolopender spritzen beim Beißen muttels ihrer krallenförmigen durchbohrten lïiefer Giftstofle in die Wunden shrer Foinde und Bentetiene ein. Skorpione und akuleate Hymenouteren (Bienen, Wespen usw.) und Imeisen (namentlieh . Mutllen) können beim Stechen durch eingeführte Gifte die sehmerzhaftesten Lokalenseheinungen und oft anch gefährliche Algrmeinekrankungen veranlassen. Alle parasitischen Arthropoden, soweit sie vermöge ihrer Hundwerkzeuge in der Jage sind, die Hant ihres Oyfers zu durchdringen, führen beim Blutsangen giftige Drüsensekrete in die Säftemasse ihter Wirte ein.

Wreit gefährlicher abcr werchen die Gliederfüßler für Mensehen und Tiere als Krankheitsüberträger. Die Rolle, welehe sie bei dieser Gelegenheit spielen, ist eine auberordentlich vielseitige:

1. Ansteckungsstoffe, die an ihrem Körper beim Berühren kranker Mensehen und Tiere, oder von Exkreten und bejektionen soleher haften gehlieben sind, künnen rein meelanikch auf gesunde übertragen werden und bei diesen dieselben Krankhesten hervorufen.

2. Mit solchen Stoffen können durch leckende oder darüber kriechende Arthropoden sipeisen. und Getränke verunreinigt werden, die dann in den Tractus intestinalis Gesmudel gchant, dort ebenfalls ihre krankmachenden Wirkungen entfalten. 
3. (a) jirderfiibler, die pathogene Vikroorganismen an jhrer Körperoberfläche oder in ilırenı

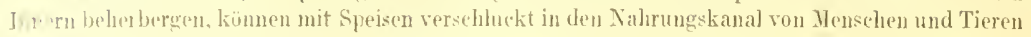
reraten und dann pine Infektion bewirken.

f. II äimatopliage. Irthopoden këmnen Infektionen dadurch hervorrufen, daß sie

a) beim stcelen mit den hesehmutztess Stiletten krankmachende stofle in die Sätemasse des Wirtes rinimpfen, dab

b) släter in die gesetzte Wuncle meelaniseh (dureh liratzen z. B.) infektiöse lieime geprebt werdou, die aus dom liote oder dem leibesinlalte der zerquetschten Parasiten stammen, daß

(*) beim sangakte mit dem stots in die Wunde einfliebonden șeiehel and dem ansgeprebten Inhalte tes Vorratsmagens pathogene l'rotisten oder Wurmiarven in die saftemakse des Befallenen eindringen und sieh hier raseh vernehren.

In den unter 1, 2, 3, ta und 4 b angegebenen Fällen nemmen wir die Gliederfïßler "Zwischenträger" von Krankheitskeimen, im Falle te dagegen sind sie entwerler die ,Zwisehenwirte" oler : 11 irte" der krankmachenden Kleinlebewesen.

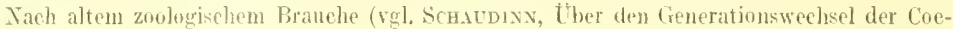
eidien, Zool. Jahrbücher, Riel. 13, H, 2, 1900) nemnt man einen Parasitenträger damn einen ,Neben"oder, ,Zwischenwirt", wemn der Srhmarotzer in semem Leibe nicht an das Ende seiner Entwicking gelangt, mit anderen Worten nicht gesehlechtseif wird. So sind das Sehwein für Taenia solinm, die Stechmücke liur Filarien, ,Zwischenwirte", der Nenseh aber, in dem sich die Finne zum Bandwurm, die Filarjenlarve zum gesehlechtseiten Tiere entwickelt, ist der , Wirt" dieser sehmarotzer. Umgekehrt ist Ino phe l"s der ,Haujetwirt" ader sehlechthin der , Wirt" des Plusmodiums, G]ossina ther, Mirt" dor Tryprnosomen, wälrend der Menseh in diesem Falle sich nit der NebenroHe des, Zwischenwirtes" hegnïgen muß, eine niederdrïekende Tatsache in des lugen vieler, die in keiner Lage und um kinen Preis ihren antliropozentrischen standpunk aufgeben möehten.

\section{lite Ilaupturerkinale der Irthopolen sind die folgendeu:}

1. Der gewöhnlich gestreckte Körper is bilaterial symmetriseh gebaut.

2. Er zerfällt in ungleichartige Alsehnitte (Segmente, Vetameren), welehe meist. gruppenweise zu lïrperregionen höherer Ordnung (Kónf, Brust, Hinterleib) miteinander verselmelzen.

3. Der ganze Könper wird durch ein ehitiniges Hautskelett, in das noeh mineralische Substanzen eingelagert sein können, geschïtzt.

4. Paarige Gifiedmaßen die aus mohreren beweglich mitcinander verbundenen Teilen bestehen, liönnen aus jerlem Körpersegmente entspringen.

5. Die Arthroporlen hesitzen cine einheitliehe Leibeshöhle, welehe mit dem Blutgefäßsystem in offener Terbindung steht.

6. Eine Bauehganglienliette und ein Rïekengefäß (Herz) sind (meist) vorlanden.

7. Der Darmkanal zerfällt in drei genctiseh und morphologiseh wohl unterschicIne Abschnitte, den Torderdarm (Stomadaeum), den Mittelarm (Mesenteron) und d('n Endilarm (Proctodeum).

bie Arthropoden gehören somit zu dem Tienreis der Protostomier, das leilit sic sind Zölomaten mit ventralem, in der Sehlundptorte erlualtenem Prostona, währencler Aftersekundär am Hinterende entstanden ist.

Jahes ihrer Körpersegmente trägt ursprünglich ein Paar an der Bauchseite 'ntsprinumbe geghederte Anhänge. Die vordersten Segmente rerwaehsen bei allen Glierlofüblen zu dem einheitliehen kupfe, dessen ursprünglieh lokomotorisehen Zwecken divencle Anhänge eine Unwandlung in Simneswerkzeuge (Antemen) und Mundwerkenge (Mandibehn, Maxillen) erfahren haben.

Auch die Brustabsehnitte können unteremander verwachsen und so den ein-

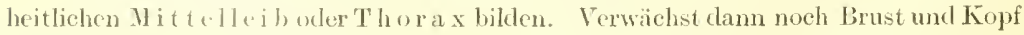
miteinander (wie z. B. beiclen Spinnen), sonennt mandiese Teile Kopf brustst ü $k$ (Képhathorax). D(r Hinterleib (Ablomen) behält meist seine Gliederung bei, 



\section{Übersicht der wichtigsten Klass}

Jö̈rper wurnnfürmig, mit eirem Antennenpare und zahlreichen kurzen klanenbewaffneten 2 Stmen dureh Biischeltracheen:

1. Klasse: Onychophorn (Peripatus.)

(Kleine walzenfürmige Tierchen, mit Silugmund, vier Paaren stummelförmiger Rumpfextrem 11. Kiasse: Tardigrada (Bärtierehen).

Fast ausschlice Plich wasserbewohnende und durch Kiemen atmende Gliederfïßler, mit zwei Antemenpaaren und dopjelistigen Extremitäten, dic mejst anch an den Ablominalsogmenten entspringen:

III. Klasse: Cinstacea (Krebstiere). \begin{tabular}{c|c}
$\begin{array}{c}\text { Zahl der körper- } \\
\text { segmente und } \\
\text { Gliedmaben- } \\
\text { paare }\end{array}$ & so h w a n ke n d: l. Unterk \\
& konstant: 1]. I'nterklas
\end{tabular}

Luftatmende Arthropoden, deren liopf und Brust meist zu einer kopfbrust (hephalothorax) verschmolzen sind. Djese trägt zwei Kieler- und vier Beinpaare. Der nicht immer gesonderte Hinterkeil, besitzt keine Beine:

IT. hilasse: Irachnoidea (Spinmentiere).

Körper in Kopl und Rumpf gesondert. Der liopf trägt ein Fühlerpaar und ein bis drej Jieferpaare. Jer langgestreckte Rumpf zeigt keine deutliche Sonderung in Brust und linterleib; er besitzt an last allen Riugen ein oder zwei Paar gegliederter Beine, deren Endglied mejst nur eine Kralle triigt:

V. Jilasse: Myriapoda (TausendfüBter).

Im Imaginalzustande dureh Tracheen at mende Giliculcrfiibler, deren hö̈rper stets in Lopí, Brist und Hinterlejb gesondert ist.

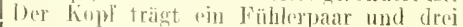
Thieferpatate: pin P'ar tisterlose Oberkieler und zwe l'alre tastertragender Lnterkiefer, deren proximales zusammenwachsend die Interlipye bildat. Die Brost trägt drei l'aar Beine und meistens zwej Patar Fliget. 1) as Alsomen besitzt für gewöhnlich keine deutliehen ciljedmaßen:

VI. Klasse: Hexupoda (Incelsten).

An den liörperingen je $z$ we i Beinpare. Li in Geschlechtsuffinung an der Basis des zweiten li: An den Kürperringen je e i n Beinpaar. Z w e bindung stehendes KieferfuBpaar. Fühler vic

Abromen rom hephalothorax gesondert, diesem breit ansitzend $\mathrm{n}$. deutlich gegliedert.
Kopf nicht gesondert. Liopf- Hinterleib brust nicht ge- streckt, ghedert.

liopf gesondert. Brust gegli dibeh scherenförmig . Hinterleil Hinterle
förmig . 
und Ordnungen der Arthropoden.

oaren. Bureh die in list allen Metameren echten Arthropoden strenga unterscheidend.

1. Herz fehlt. Hatutatmer.

\section{Entamostraca (niedere kiehse)}

Iulueostraca (höhere lirebse).

kt, wnrmfömis. Statt der beine zwei Par es Mumules strhende thiken.

eiförmig, gedrungent. Beine wohl antwickelt . nterende. Nandibetn klauenförmig, die Ausleend

2. gewötht, $f-s$ gliederig. Handibeln seberen-

Mandibehn und Tastro klanenfömig. Listes Beimpaar fühlerförmig:

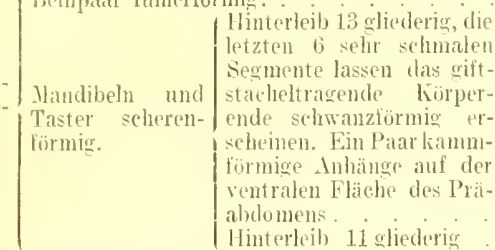
Hinterleib 9 griederig. langrestreckt. Man-
1. (Mehmune: I'hylleportu.

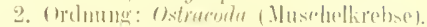

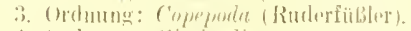

t. Oodnume: Cimisediu.

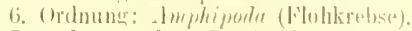

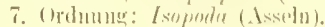

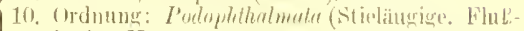
krebs, Hummer).

1. ()rohmurs: Linguatulida (Kungenwänmer).

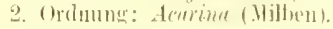

3. ()rdnung: Aranfïlu (sipinnen).

4. Orelmung: (J)ilimiden (Afterspinuen).

5. Ordnune: Petipului (Creibelskorpiono).

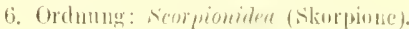

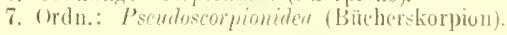

8. Ordmung: solifugue (Walzenspinnen).

ryatr, keine Kieferfübe. Fühler $\mathbf{i}$-s gliederig. atares.

ferpatse und ein mit piner Ciftarise in lerderis. Cieschlechtsöffunng am Kïrperende.

1. Ordnung: Jiploporla (Juhus).

2. Oretmung: ('hilopodu (sicotopendra).

mort oder beibend. Körper behaart oder bele mit guben Bursten oder einer Sipringrorichtung d oder stechend und samgend. Thoraxringe ler verwachsen igleich. Mundwerlizerese beibend. Unterlippe eineil gerliederten schabol (Rostrum) umgedwelkzeuge stechend und silugind oge dentlich rmeinander alogesptzt. Mhutheile

Hinterfü̈gel schwingkiolhchen. Wlle drei BrinstJlundteile samgend oder sterlyend und simgend Beide Flügehpaase hiutig, netzföming geadert.

ng forderiligel zis horniem oder lederartigen becken umgebildes. Hinterflüg(e] häutior. Nundteile beifend. . . . . . . . st- Flüged häutig, beschuppt. Mundteile rimen n- im Rubezustande aufgerollten Silueriastil en. bildend

- Flïgel häntig, durchsichtig, ästig gendert. ig. Mundteile beibend and leckend

1. Orduung: Apterugenen (Irinsekten).

2. ()rdnung: riphunculale (Läuse n. Haarlinge).

3. Ordume: torthopteru (Ciradilitgler).

4. (Irdumuer: lihynchota (sehnabelkerfe).

5. Urdunas: Psyllomeorlha (Fiöhe).

6. Ordnung: Diptera (Zweithügler).

7. Ordnung: Neuropteru (Notzlügler).

8. Ordnung: Colenplert (kïfer).

9. Ordnung: Lepidoplera (Sichmetterlinge).

10. Ordnung: II ymenoplere (Ilautllügler). 
. 


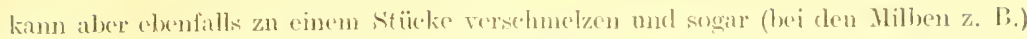
damn noch mit dem Képhalothorax verwatehen.

Die Extremitäten des dlitulloilus sind stots lokomotorische organe,

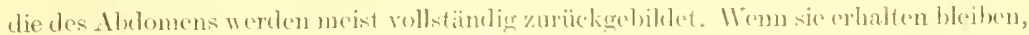
kömnen sie chenfalls als bewegungsongine gelwatubt werelen oder auch andere Verwenclung finulen.

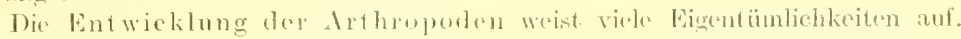

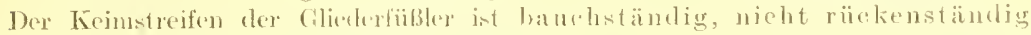

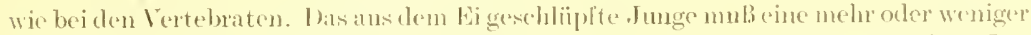
vollkommene Verwandlung chrelmateben, bis as die Imaginalform erreicht. Dist einzehen stadien dieser Metamorphose sind durch Häutungen seharf vonrinander gretrennt.

\section{Literatur.}

(Arthropoden. Allgemeines).

1840 Jidss1\%, L., Nomenclatoris Zoologiei index universalis.

1638 M.ororavdi, L., De fusectis.

1852- 1952 Imales de la Soe. entom. de france.

1907 - 1912 Imnals of Tropiral Nedieine and Parasitolngy. Bd. I-Vl. Livoruool.

1897 1912 Irchiv für Schifl's- und Tropwlyygiens.

1897 1912 Archives de Parasitolugie. 16. Bde Paris.

19041911 BiLfotr, A., First-fomutl Report of the Welleome Research Laboratories at the Gordon Memurial Collegr, Fhartom.

1911 Derselbe und Archibald, Second Review of some of the Recent Mamees in tropical Iledicine, Hygiene and Veterinary science. Supplement to the fourth Report of the Wellome tropical Researches Lahoratories.

1889 Birch-Hirscheld, F. V. und A. Jonne, Die tierisehen und fflanzlichen Parasiten des Mensehen und der Hanstiore. In Birch-Hinscheeqo's Lehrbuch der path. Anat. 4. Ausg. Bel. 1.

1890 Blancharn, R., Traité de la Zoologie médicale.

1908 Boss, J. E. Y., Lehrbuch der Zuologie.

1904 Bürser, C., Zur Srstematik der Ifexaloden. Zool. Anzeiger Bd. 27, S. 5l11f.

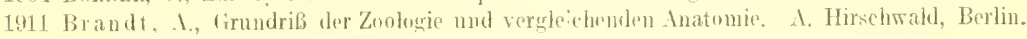

1899 BRandt und RatzeblRt;, Medizinische Znologie.

J8Rt Brass, A., lie tierischen Parisiten des Menschen. Kassel.

1908 Braux, M., Die tierischen l'arasiten des Menschen. Mit einem klin.-tlexap. Anhang von Otтo SEIFERT. Würzhurg.

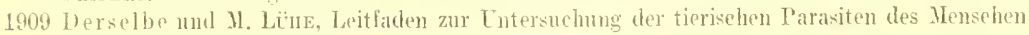
und der Haustiere. Wüzhurg.

1908 19] B Bulletin de la Soeiété do Pathologie potique. Paris.

1835) Bunueister, H., Handhueh sler Entomologin. lierlin.

1910 Casteldaxi, 1 . and 1 . J. Chalagers, Mamial of tropical Medicine. Lomdon.

1886-1912 Centralblatt fuir Bakteriologie und Parasitenkunte. Originale 1.-66 Bd. und Referate 1. $-55 . \mathrm{Bl}$.

1950 f'tacs-GrubBen, Lelirbuch der Zoologie. 8, Mult. Marbung.

1 s98 Crare, C. F., The transmissmu of disease by eertain insects: ticks, bedbugs, ants ete. New Youk

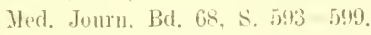

1849 Crvier, G., Le rigne animal distrihué d'après son organisation. Nouv. Éd. Insectes, Arach-

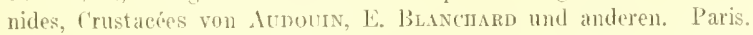

1909 Daniels, C. W. and F. Wrismox, Tropical Medieine and Hygiene. 1. Teil. London.

1910 Derselbe and A. Aconck, Tropical Medieine and Hygiene. 2. Teil. London.

1905 Le Daxtec, Précis de Pathologie exotique. Mit 162 Figuren im Text. Paris. O. Muini.

1900 T) bretilh, W., Dermatozaires. Pratique dermatologique. Bd. 1. Paris.

1859 Ercolani, G. B., Nuovi elementi teorico-patice di medicina vetemaria. Bolngna. 
1775 Fabricius, J. C., Systema Entomologiae.

1792-1794 Derselbe, Eutomologia srstematica emendata et ancta. 4 Bde. Hafniae.

1798 I) rselbe, supplementum Entomologiae sţstematicae. Ifafniae.

1910 Forel, A., Das Simuesleben der Insekten. München.

1847 Frex nnd Leuckart, Vergleichende Anatomie der wirbellosen Tiere.

1724-1736 Friscir, J. L., Beschreibung von allerlei Insekten in Teutschland. 2 Bde.

1911 Gedoelst, L., Synopsis de Parasitologie de l'homme et des animaux domestiqnes. Lierre et Bruxelles.

1752-1778 DE GEer, Mémoires pour servir à l'histoire des Insectes. 7 Bde. Stockholm.

189 - 1901 Ciegexbaur, C., Vergleichende Inatomie der Wirbeltiere mit Berücksichtignng der Wirbellosen. 2 Bde.

1863 Gerstaecher, C. E. A.. Die Arthropoden. Handbuch der Zoologie von Peters, Carus und Gerstaecker. Leipzig.

1859 Gerrais, P. rt P. J. vax Benedex, Zoologie médicale; exposé méthodique du règne animal. Paris.

1884-1886 Fraber, V. und O. Taschenberg, Bilder aus dem Tierleben. 3 Bde. Leipzig u. Prag.

1907 v. Graff, L., l)as Schmarotzertum im Tierreich. Leipzig.

1911 Gunart, J., Les Parasites inoculatenrs de maladies. Paris.

1904 Itandursch, A., Zur Srstematik der Hexapoden. Zool. Auz. Bd, 27, S. 733.

1800 Hecler, A., lie Schmarotzer mit besonderer Berühksichtigung der für den Mensehen wichtigen. München und Leipzig.

1909 Hextschel, E., Das Leben des Süßwassers. München.

1910 Hertwig, R., Lehrbuel der Zoologie. 9. Anfl.

1592 Iloefnage, G. und J. Hozfnagel, Archetypa Studiarue Patris Georgii Hoefnagelii JacobusF. genio duce ab ijuso sculpta, omnibus philomusis amié D: ae perbenigné communicat. Inn: sal: 1592. IV partes. Francofurti ad Moenum. Ohne Text. Jede der Kupfertafehn am Kopfund Fubende mit läteinischen Sprïchen und Versen. - Die einzelnen Figuren ohne jegliehe Untersehrift sind so lebenswahr, taß fast jede sofort zu diagnostizieren ist. Ein Bild von Aeschna grandis anf Tafel 3 Pars II ist lis heute noch nieht übertroffen. (Am Kopfende der Tafel stelit: „Dedit mihiDomimus Artem mercedem meam et in illa laudabo nomen ejus." Hoernagel zeigt durch diesem Ansspruch, daß er sich seines Wertes wohl bewußt ist. Am Fuße der Tafel ist za lesen: ,Nee Fabis nec Allio libenter vescor". Es malnt der Antor in feiner und launiger Treise mit diesen Worten den crfreuten Beschaner, auch an des Künstlers Jagen zu denken und durch Kanf seines selbstvolegten Werkes eine Dankesschuld abzutragen.)

1850 v. d. Hoevex, J., Naturgesehichte del wirbellosen Tiere.

1801 Jördexs, D. J. H., Entomologie und Helmintologie des menschlichen Kürpers, oder Beschreilung und Abbildung der Bewolner und Feinde desselben unter den Insekten und Würmern.

1901-1912 Jommal of Hygiene. Bd. 1-12. Cambridge.

1898-1912 Journal of tropical Medicine and Hygiene. Bd. 1-15. London.

1893 Kolbe, II. J., Einführung in die Kenntnis der Insekten. Berlin.

1902-1909 Korschelt und HeIDER, Lehrbuch der vergleichenden Entwicklnngggeschichte der wirbellosen Tiere. Allg. Teil. Lfg. 1-3,

1855 lǘchenuerster, F., ] lie in und an dem Körper des lebenden Wenschen vorkommendem Parasiten. Abt. I: ] lie tierischen Parasiten. Leipzig.

1815 - 182.? DE LAmanck, J., Histoir maturelle des animaux sans vertibres. 7 Bde. Paris.

18351845 horselbe, Dasselbe. Ed. nouv. 11 Bde. Paris.

1899 Liмmint, Ki, las Leben der Binnengetässer. Leipzig.

1806 L.ATRL1l.LE, I. A., Genera crustacen rum et insectorum.

1815 LEACH, II. E. I tabular view of the external characters of four classes of animals, which LinNi: arramgard under lnspetil.

1886--1901 Leurkart, R., Jie Parasiten des Henschen. Fortgesetzt von G. Brandes, Leipzig.

1886 Leunis-Lunwa, Syonosis der Tierkunde. 2 Bde. Hannover.

1857 Jexpic, F., Lehrbuch der Histologie des Mensehen und der Thiere. Hanm.

1758 Lixsi, C., Systema Naturae. Regmm animale. Holmiae. 
1910 v. Lisstow, O., Die śchmarotzer der Menschen und Tiere. Leipzig. Quelle und Deyer. 1909 Vaxtmufel, P., İber den gegenwirtigen stand unserer lementis von der Bedentung der Arthopoden als thertrager ron lnfektionskrankheiten teei Wirbeltieren. Zoologisches Zentralblatt. Bu, 16. Nr. $2 / 3$.

$185+$ Mhartixy, Naturgesehichle der für die lheilkunde wichtigen Tiere.

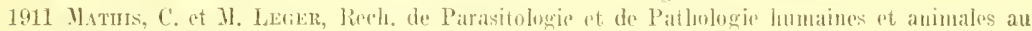
Tonkin. Paris.

1906 Vhavin, P., Les Thertes buvelus de sing. Paris.

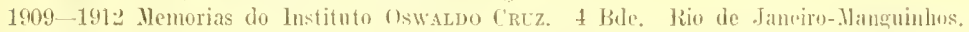

1905-1906 Mexse, C., Ilandibuels der Tropenkiamlieiten. 3 Bde. Leipzig.

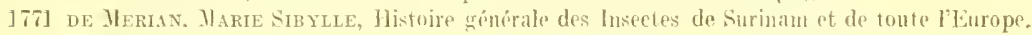

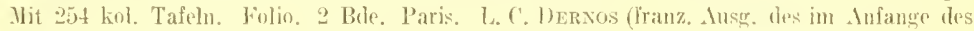

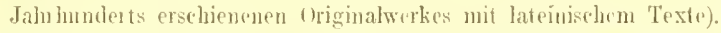

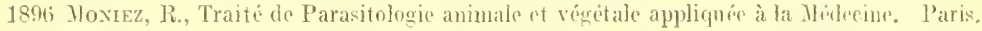

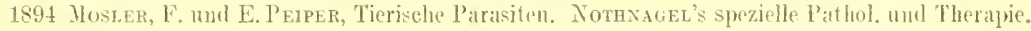
V1. Wien.

1904 I ieselben, Dasselbe. 2. Auflage. Wien.

J634 Hocfetics, T., Inseetorum sive minimorum animalmm theatrum. Icuntur.

1877 Merray, A., Economic Entomology. Lonion.

1904 Neyed-Lemire, M.. Tarasitolngie animale. 2. Aufl. (Prieis de Méderine, Nr. 1). Paris,

1899 Nutrall, G. II. F.. On the riole of insects, arachnids and myriajods, as earriers in the spread of haeterial and parasitie diseases of man and animals. Joln Ifopkins liospital Reports, Bd. VIll. Ar. 1 und פ. Baltimore.

1835 Orix, .llgemeine Naturgesehichte.

178) Pallas, Ienes lusectornm.

1793-J813 PaNzer, G. W. F., Famne Insectomm Germaniae luitia oder lentschlands Tnsekten. Xürnberg.

3829 - 1844 Derselbe, Dasselbe, fortgesetzt von Herrich-Schäffer. liegensburg.

1908-1912 Parasitology, 1 suppt. to the Jomrn. of Hygiene. 5 Bde. Cambridge.

1901 Perroxcto, E., I Parassiti dell' nomo e degli animali utili e le piü communi mallatip da essi prodotte. Profilassi e cura relativa. Milano.

1895 Ralllet, A., Traité de zoologie médicale et auricole. ㄹ. Anil. Paris.

1839 Rispar, F. Y., Reeh. l'hist. nat. sur Jes inseetes murbipares. Gaz. des hopitaux.

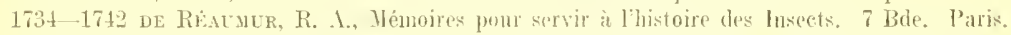

1746-1761 Roesel vox loskinuF, A. J., Der monatlich heransgegehenen Insekten-Belustigung erster his vierter Teil. Niumberg.

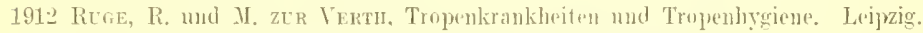

1910 salaxoce-Jpix, II., Precis de Pathologie Thopreale. Paris.

1816 s.lugxy, J. C.. Mémoires sur les animaux sans vertibes. J. Part. 1. Fase. Paris.

1910 scnetbe, llie Krankheiten dor warmen Länher. \&. Aufl. Jena, F, Fischer.

1791 Schraxk. I'., Enumeratio Insectorum Austriap.

1909 Sergext, Eon. Les insertes Piqueurs et Suceurs, Paris

190s Steprexs, J. W. W. and s. R. Cmmstophers, The practieal study of Malaria. 3. Aufl. London.

1758 swamerday. J.. Bibel der Matur. Leijrzik.

1911 Takan, T., Phe hygienischen Verlialtnisse der lusel Formosa. Dresten.

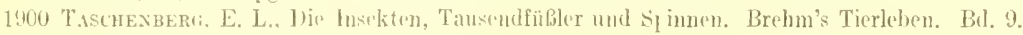
Leipzig und Wien.

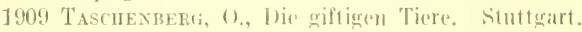

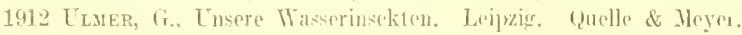

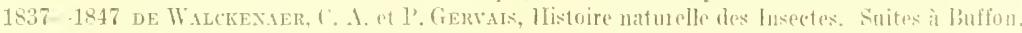
Paris.

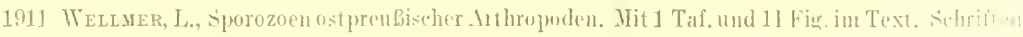

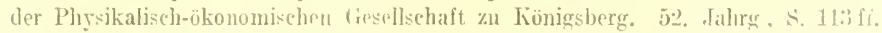

1891 Zachıris, O., Die Tier- und Planzenwelt des sübwassers. 2 Bde. Lripris.. 
14:? ?)-1912 Zeitschrift für Hygiene nnd Infektionklankheiten. 72 Bde.

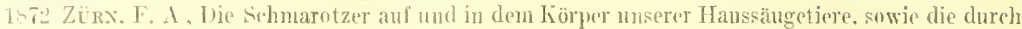
erstere verandabten Krankheiten. deren Behandhung und Verhütnng. Teil 1: Die tierischen Parasiten. Woimar.

\section{A. Die Krankheitserreger ïbertragenden Gliederfïssler.}

Die beiden crston Klasien der Arthropoden (Peripatus und die Bärtierehen) haben für den Tropenarzt vorläufig keine Bedeutung, da sie bisher weder als Krankheitserreger noeh als Krankheitsiiberträger angeselunldigt worden sind.

\section{Kirebstiere, Crustacea.}

Die dritte Klasse dagegen zählt in der dritten (Ordnung (Copepoda) unter der Gattung Cyclops (len Zwicchenwirt von Filaria medinensis, dem Guincawurm (Fig. J).

Fig. 1 .

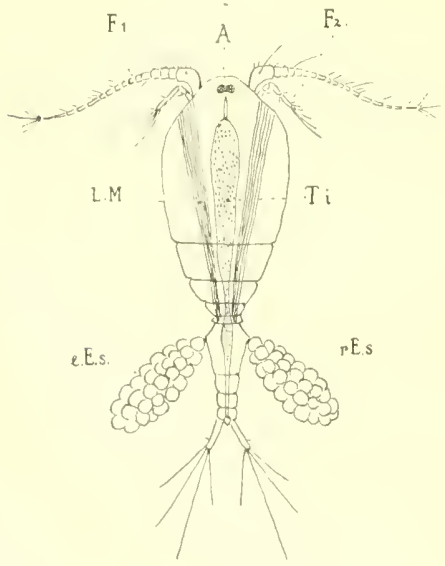

Yit dem Trinkwasser wird das infizierte Krebschen in den Magen des spiteren Wirtes eingefülırt. Die dureh die Verdanung bef'eite Wurmlarve durehwandert den liörper ihres Trägers' und siedelt sich sehlieblich im Unterhantzellgerebe, namentlich dem der Beine an.

Cyclops temuicomis Claus, f (Original). A. Ange, $F_{1}$ erstes Fühlerpatar, $F_{2}$ zweites Fiullerpaar, T.i. Tractus intestinalis, L.M. Längsmuskel, r.E.s. rechtes Eiersäckchen, l.E.s. linkes Eicrsäckchen.

\section{Spinnentiere, Arachnoïlea.}

Zahbeiche Wirte und Ċherträger von krankheitserregenden Bhutparasiten enthält damn die viexte Klasie der Giederfïl.jer, die Arachnö̈dea oder spinnentiere. Die gefülıliele'n Arten gehören sämtlich der 2. Ordnme (Acarina) an.

\section{Die Milhen (Acarina)}

sind kleine Arachnö̈leen von godrungenem durebaus ungegliedertem Körperbau thre Mundworkzenge sind, je naebdem sic zum BeiBen oder Stechen und Saugen 
dienen solkn, ron mannigfaltiger (iestalt. D)ie Oberkiefer (Mandibeln) sind demgemä̈ bald rorstehende Klanem- ofler Scherenkicher, hakl pinzichloure Stilette.

Die jungen I iere (Larven) besitzen drei, lie Nymplen und erwacherenen Milhen

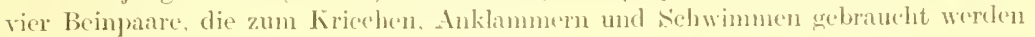
kömmen.

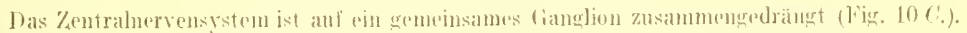
Angen künnen fehten werer sind in dinem oder zwei l'aaren vorhanden. In den Vorderdarm mündet

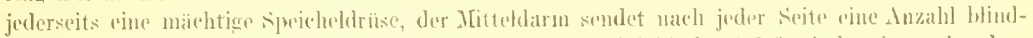

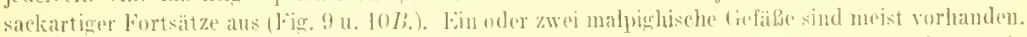

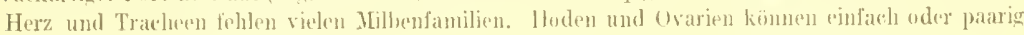
auftreten. Jie lkarinen lecen fïer.

\section{Übersicht der Interordnungen und wichtigsten Familien der Mkarinen.}

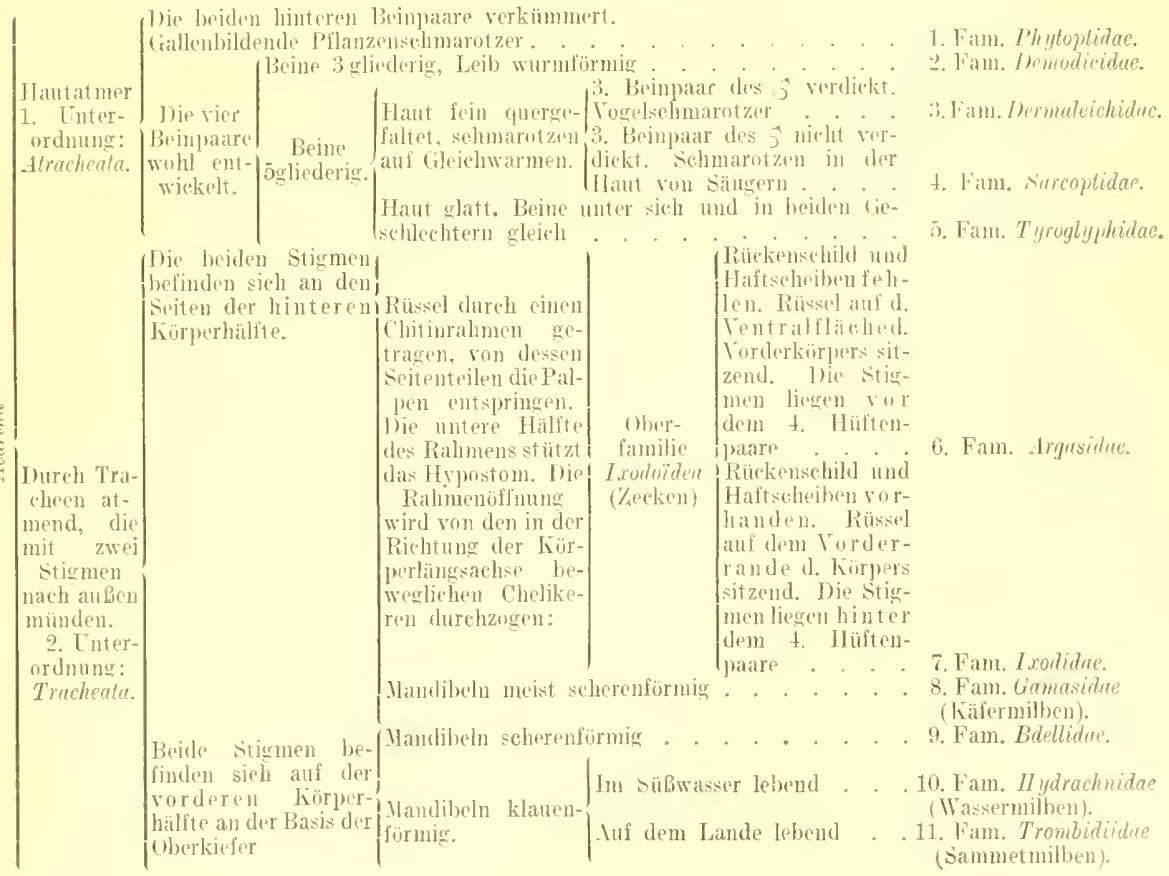




\section{Die Kerken.}

\section{Allgemeines.}

Die Zecken (französisch Tiques, Ricins, engliseh Ticks, italienisch Zecehe) sind die größten aller Milben, sellst ilue Eier sind noch mit bloßem Auge gut zu erkemnen. Nüchtem plattgedrïckt erscheinend. schwellen sie beim Blutsaugen auch in torsoventraler Richtung mächtig an. Ihre Länge schwankt zwischen Bunchteilen eine's Millimeters (Larren) und 2,5 Zentimetern (vollgesaugte weibliche Tiere der größeren Arten). Durch Blutaufnahme kann das Gewicht der W'ejbchen um mehr als das Hundertfache steigen (IIyalomma aegyptium), sie erlangen in diesem Zustande die Größe einer Haselnuß und darüber. Die Mämnchen sind nur wenig kleiner, als die ebeu geschlüpften Weibehen der gleichen Art, bleiben aber, da sie wenig oder gar keine Nahrung mehr zu sich nehmon, später an Grölie gegen diese ganz beträchtlich

Fig. 2.

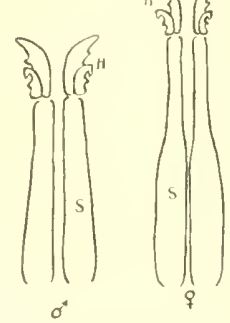

Chelikeren ron ô und ${ }^{30} / 1$. (Original.) s. Sichaft, II. Haken.
Fig. 3.

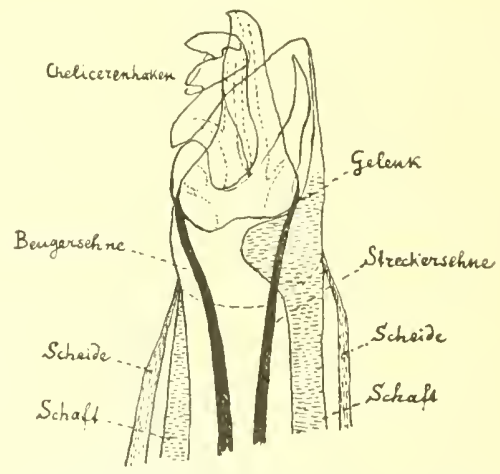

I) istales Chedikeremende einer Zeoke. Haken durch den $M$. erector aufgerichtet: Stellung bejm Einstich.

(Nach Nuttall, Cooper und Robinson.)

zurüek (s. Fig. 14 u. 15). Diє Haut der Zecken ist lederartig, warzig oder feingewellt und gestreift (an die Epidermis unserer Fingerbeeren erimnernd). Inre Farbe ist für gewöhlich ain dunkles Bram veler Rotbram; bei manchen Arten unterbreehen zierliche bunte Fiecke und Zeichnungen die sonst rinfarbige Oberfläche. Die llännehen sind durchgehends wesentlich dmulster gefärbt, als die weiblichen Tiere.

T)e Rüssel der Zecken ist viel cinfacher gebaut, als die stechenden Mundwerkzevge der Insediten; während sich z. B. der Steehmückenrüssed ans 7 Teilen zusammensetzt, zählt der liüssel der Zecken deren nur 3, er besteht aus dem unpaaren dureh Verwathmig der Maxillen entstandenen Hypostom und den beiden Chelikeren (Alandibehn) (Fig. 8 u. 17). Gestützt werden diese Mundteile dureh die Rüsselbasis (Fig. 4), einch verschieden gestalteten (hitimahmen, der einem quergestelten, aufgerichteten Ringe nicht mähnlich sielnt. 


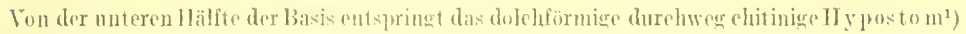

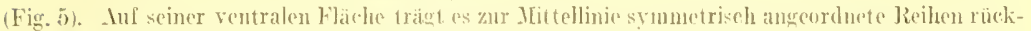
wäts geriehterer Ziihue (Radula), anf der dersalen pine tiefo Rimne, the mit den beiden Chelikeren einen IFohlramm, das situgrolur, bildet (Fig. 4). Jede Cholikere besteht aus pines proximalwirts weiter wertenden Chitimöhre, dem sehafte, und trägl auf ihrem vorderen (distalen) binde Klaumer-

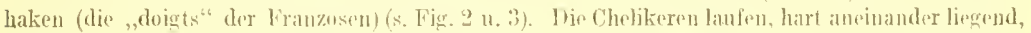

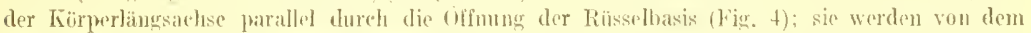

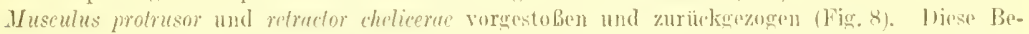

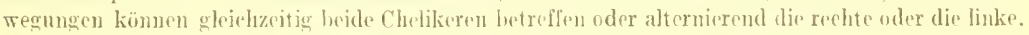
Auferdem seheint noch rine Rotation der Chelikeren um ilue Längsachse möglich zu sein.

An den Rïssel schmiegen sich jedexerts die Maxillarjalpen an; sie entspringen ron den vorderen äuberen Eeken der Rüsselhasis mel sind bei den Argasiden vier-, bei den lxodirlen dreigliederig (Fig. 5, 16 u. 17).

Fin. $\bar{j}$

Fig. 4.

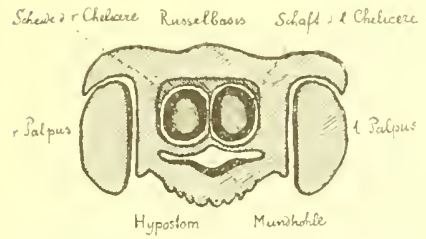

Querschnitt durch den Rüssel einer Zeeke. (Ilalbschematisch. Original.)

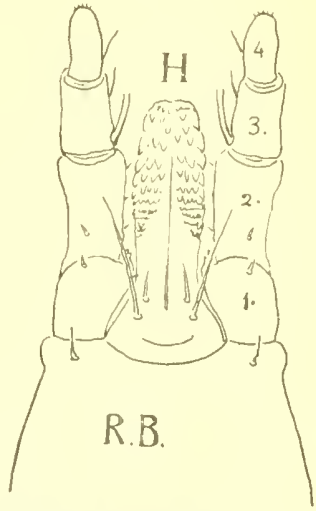

Urithodorus mombrata MuRRAY, ㅇ. ${ }^{66}$ i. (Tach NetTall.) Rǘssel von unten. 1. 2. 3. 4 . erstes his viertes ilied des linken Palpus, II. Hypostom, R.B. Rüisel!basis.

Die Rüsselbasis und alle ron ihy getragenen und gestützten Teile sind bei den einzelnen Gattmoen und Arten versehieden gestaltet und haben deshalb grobe systematische Bedeutung.

Die Zeeken atmen durch Trachren, welehe in Büschelform ans Lufthammern ent-pringen. die unter den beiden Stigmen gelegen sind (Fig. 10). Die Stigmen befinden sich (bei vollgesaugten Tirren am Grunde von trichterfömigen Hanteindrücken) zu heiden Seiten der hinteren Körperhälte; ihr Hof (Peritrem) int bei clen cinzelnen Arten verschieden gestallet.

Die Beine ter Zerken setzen sich aus neun Gliedern zusammen: der Hiifo, dem Troehanter, dem Fonur, der Tibia und fünf Tarsalgliedern, deren letetes eidi Paar liäftige Klauen trägt. Luf der Dorsalseite des zweiten Vorelertubetiodes liegt ein borstenumstanclenes (irühehen, das Hallersche Organ (Fig. 2s. 34. 35, o u. i),

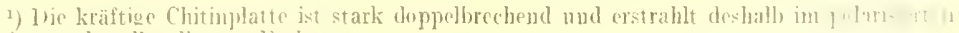
Lichte in prachtwoll gelbroter Fitrike. 
Dir 11 etamorphose der Zexden (namentlich der Argasiden) ist cine un rollfiommene. es untersteiden sich die Larren durch Fehlen des vierten Beinparires, die Nymphen ehenso wie die Lalven dureh den Hangel äuberer Gesehlechtsteile und das Fehlen des Gedicehtsclimorphismus von den erwachenen Tieren.

Alle Zecken sind blutsangende Parasiten namentlich der gleichwarmen Wirbeltiere.

\section{Morphologie.}

Tor wegen wolkommener Virshmelzung der drei Hauptabsehnitte aus einem einzigen stück bestehende Körjer der Zecken zeigt für gewöhnlich eine elliptische oder eifömige Gestalt. Bei blutgeschwellten Tieren kömnen die Seitemränder des Leiber geradlinig, ja sugar (durch Zuriekblejben der Stigmenplatten) nach innen ausgebuchtet erscheinen (Fig. 25 11. 26). Die Zecken sind dorsoventralwärts abgeplattet (Fig. 18a) und viele rom ibnen (lxodes z. B.) ähneln deshalb selbst noeh bei maller Leibesfüllung einem Haiskorne oder dem Ricinusamen (, Ricins").

Aus dem Gesagten rgibt sieh, daB man bei den Zecken in ter Hauptsache eine Rücken- und eine Banchfläche unterscheiden kann, welche dureh die Kö̈perrandfläche mitcinander verbunden werden.

Die Rüekenfläche, wesentlich einfacher gebaut, als die Bauehfläche, trägt bei den Ixvdiden den R ̈̈ckenschild (Seutum), welcher bei den Argasiden fehlt (Fig. 25, 26 n. 2I). Mas Sentum bedeckt bei dem männliehen Ixodiden fast die ganze Rï̈kenfläche, nur an den Seiten mul am hinteren Körjerrande einen schmalen Saum freilasend (Fig. 25); bei den wriblichen Tieren, den Nymphen und Larven ist es wesentlich kleiner unl bedeckt nicht cimmal die vordere Körperhälfte voll-tändig (Fig. 26 u. 12).

Der Rïckenseluld zeigt an seinem Vorderrande eine tiefe Einkerbung, die bestimmt ist die Rüsselbasis in sich anfzunehmen. Hierdurch entstehen am Vorthersehildrande zapfenförmigre äuBere Erken, Sieapulate, welehe versehiedene (iröbe und Grestalt Zeigen kömen (Fig. 36). Vom Scheitel des Winkels, den die Scapula und die sedildplatte hildet, entspringt jederseits die Xatke nfurehe; sie lat pine sichelfurmire Gestalt (Konkavität nach an Ben geriehtet) und rerflacht sieh mach rüekwairts derartig, dab sie selhst bei den Woibchen nur ausnalunsweise lis zum Hlinteriande des Sentums zu verfolgen ist (s. Fir. 34).

AuBer den Kankenfurehen treffen wir auf dem Rücken der Mäunchen eine das Sentum seitlich und hinten umlaufende Randfurche, he den Weibchen anf der häutigen hinteren Rürkenhälfte fine Mittelfurche unt zwei seitenfurchen (s. Fig. 34 ).

Sämtliche Furehen bezeichnen dir Stellen der Körperdecke, an deren lnnenfläehe sieh die dorseventral verlaufenden Muskeln ansetzen.

AuBer diesen Furclen lemenkt man manehmal zwei kleine poröse Felder, die etwas vertieft in der thöhe der dritten und vierten Fiöte der Medianlinie wenähert und symmetrisch zu ihr angeorduet wahrgenommen werden. Sie wurden vorlänfig mit dem indifferenten Namen der Räekenyrühechen belegt, da ilre Bestimmung noeh unbekannt ist (s. Fig. 36 u. 42).

Die Bauchfläche hietet naeh Art, Geschlecht und Alter der Tiere einen recht versehiedenen Anblick. Bei der Lave zeigen sich hier nur die thei Hüftempare und der After (Figr. 13), bei der Nymphe gesellt sieh das vierte Hüftenpar und die bejden Stigmata hinzu. während die trwachenen Tiere anberdem noch die ron der Afteröfnung weit abgeriiclite in cler Nähe der Rüsschasis liegende Genitalöfnung erkennen lassen (s. Fig. -27).

Bei den Argasiden liegt auch der ganze Alundapjarat auf dem vorteren Drittel der Banchfläche (lig. 201 11.22$)$.

Wie der Rürken, se zeigt anclı der banch der Zecken charakteristische Furehen, welehe von den beiden hinteren medianen Korperiffnumgen ausgehen, dic Genital- mo Analfurehen (Fig. 28). 


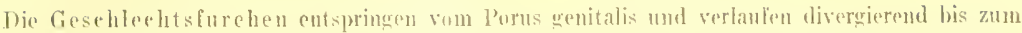

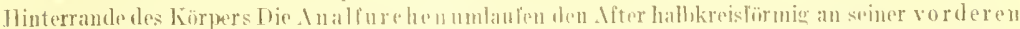

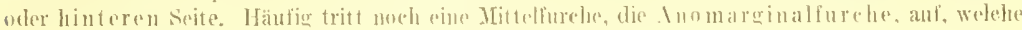

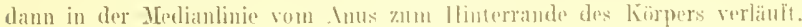

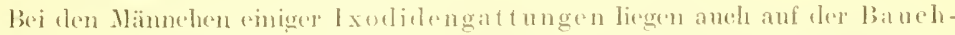

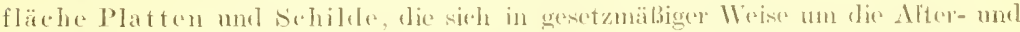

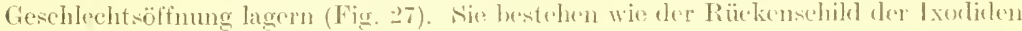

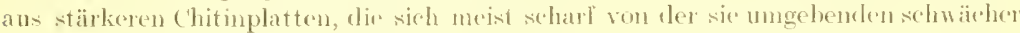
chitinisienten gewöhnlichen Epiclermis aloleben.

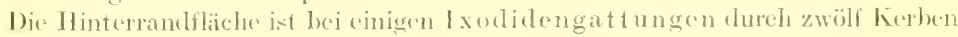
in alf Läppehen geteilt (Figr. :33, 36i).

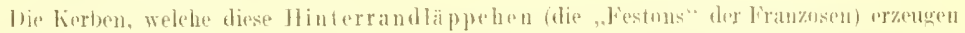

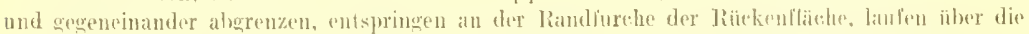

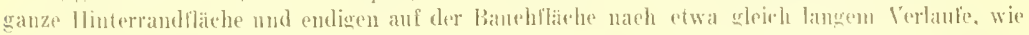

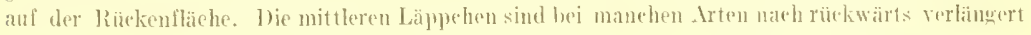
und ragen dann lingerförmig über den Hinterrand hinaus.

Ein sehwanzartiger cinziehlarer Anhang ist für cinzelne Arten rin sehr charakteristisches Vorkommen (s. Hig. $41-43$ ).

tuf dem hinteren Teile der sieitenfläden liegen die s't igmen, deren Perit reme sich oftmals anch noch aut cher Banchfläche ausbreiten (lig. :35, 37, 401).

Dic Torderrandfläche trägt bei den Ixoditen in einen tixfen Auschnitte die Rüsirelbaxis mit den Muntteilen und Maxillarpalpen. Ihre Verbindung mit al'm Vorkerköper ist cine gelentiatige und gestattet neben sehwachen seitlichen seler ansgiebige Scharnierhewegungen in dorsoventraler Richtung.

Uber die ganze Körperoberfläche der Zeeken sinel punktförmige Grübehen verteilt, welche je nach Lage und Hänfung wichtige systematinche Mlerkmale alogeben. Sie entsprechen oftmals den dustührungsgäng('n der Hauthösen mnd kömnen aneh

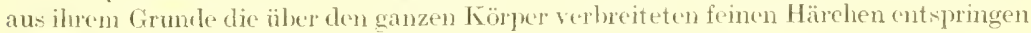
lassen (Fig. 36. 3s).

Die fieschlechtstiere und Symphen bexitzen acht. die Laven der Zexken nur sechs beine. Diese sind sämtich nach dem glcichen Typus gobaut unl entspringen

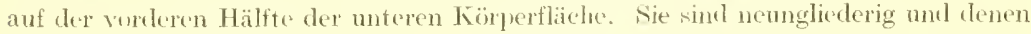
der Inseliten älnulich.

Verbunden werden sie mit der kö̈perhauptunass durch die wenig beweglichen 11 ï $f$ ton (1) (Coxae). (s. Fir. 27. 3t, 35, 1 ), die wir deshalh gewihnlich als erste Beinglieder zihhlen. Die Hötten sind unrecelmäbig viereckige Chitinselealen, welehe an ihren Ereken oftmals in form von Stacheh oder burnen ausgezosen exchejnen; an ihren Rändern können zahnartige Vorsprünge anftreten. Bei den Männehen und ebengeschtüften Wribehen liegen sie nahe beieinander, während sie bei sangenden Weibehen weit auseinanderriukten kionnen.

Als kurzes Verbindungsglied folgt mu ter Troebanter (2) (s. Fie. 27, 34, 35, 2). Auf diesen dann vier längere Gileder, das Femur (3). die Tibia ( $t$ ) und die beiden ersten FuBolieder (5 und 6), welehe gewionlieh l'rotarsus und T'assus genannt werden. Trochanter, Femur. Tibia und die beiden ersten FuBgleder sind im wanzen von zplindriseher restalt und eininder ähnlich grobut. Tollkommen abweichend dagegen von diesem Bantypus sind die drei distalen Tarsen (T, 8 und 9) der J xomliden. ${ }^{1}$ )

T)as dritte FuBghed, winzig dem ersten und zweiten gegenuber, ist wïfolförmig und an seiner

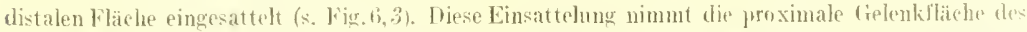
relativ langen, umgekehrt kegelfirmigen vierten Fubeglietles auf (s. Fig.ti, 1), wel.hes mit seiner distalen:

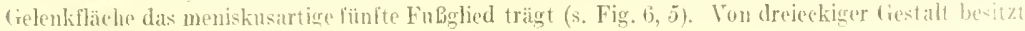

1) Die hetzten FuBghieder der Argasiden zeigen ähuliche Furmen und Virbindunef 1. folen aber hicr nielıt näher beschrieben werden. 
\& seinen Sejten entsprechend drei Felonkflichen, die eben genamte proximale und zwei distale, welehe die hohe Beweghelkeit der beiden Klauen des Zeekenfubes crmögliehen (Fig. 6 n. $7 \mathrm{~K}$.).

Vun der ventralen Fläche des vierten und fünften FuBglicales entspringt bei den Ixodiden, die den (erwatlsenen) Irgasidn fehlonde Haftseheibo (pulvillus), eine längsgefaltete, eiförmige Ifombran, die zusammengelegt namentlich bei Seitenansieht wohl den Eindruek eines pulviths

Fiig. 6 .

K.

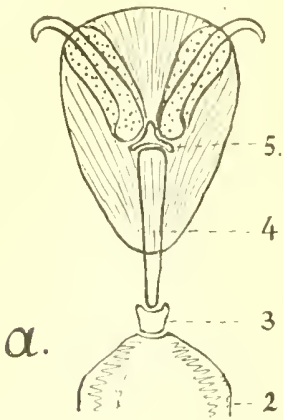

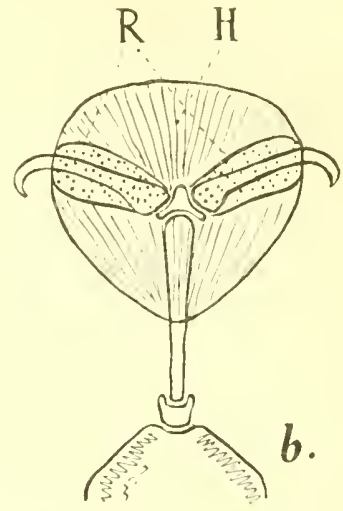

Klanenglieder-von Ixodes ricinus. Plantarfläche. (schematisch. Original.)

K. Klauen. $h$. Chitimrimen, II. Haftsehtibe, 2,-5. zweites bis fünftes Tarsalghed.

Die Zahlen in Fig. 6 u. 7 bezichen sich aut die FuBglieder, ('s würden also die Glieder 2 in Fig. 6 und 7 den Giliedern 6 in Fig. 27 nud 34 entsprechen.

rines Polsters, hertorrufen kann. Den Krallen entsprechend und sie anfuehmend sind in die Haftscheibe zwei stärker chitinisiarte Rinnen eingelagert (s. Fig. 6 u. 7 l $)$. Beim Aufsetzen des Fußes werden die Krallen gespreizt und die Haftscheile fächerförnig entfaltet (Fir. 6b), ein Vorgang, den man unter dem Yikrokkop an zwisehen hohlgeschliffnen owgektträgem liegendem lebenden Tjeren leicht mo schön beobachten kann. ${ }^{\mathrm{T}}$ )

Die: Sinnesorgane der Zeeken sinul noch wenig erforseht und lassen, namentlich betreffs ihrer Funktion, noch viele Fragen offen.

Wenn Ozallen (fazettierte Augen kommen ïberbaupt bei den Milben nieht vor) vorhanden sind, so liegen sie bei den Ixodiden in flachen Jiuchten des Rï̈ekmsehildrandes ctwa anf der Höhe der zweiten Hüftplatte (Fig. 29, 32, 36, 38, 42), hei den Argasiden anf der wulstförmigen Erhehung. wekhe dem Körperrande parallel lauferd die Ansätze der Beine mmieht (änBerer Hüftenwnlst), mud zwar zwisehen erster mul zweiter Häfte. Es handelt sieh meist nm ein Augenpaar; nur in seltenen Fillon wird bej Argasic ('n (Ornithodorus sevignyi) (in zwejtes Angenpaar angetroffen, was dann wejter rüekwärts gelegen ist (Fig. 23).

1) Ein klassir-rle's Brisjiel dafür, daß uns der Anthropromorphismus für gewöhnlieh auf die äresten llokzwe fiblort, ist die Benennung der (idicder des Zeckenbeines. Es besteht aus fünf und nieht wie das Säugertuin in seinem Ober- und lntersehenkel ans zwei Teilen.

bje Coxa liallt als limmplskls letteil natürlich zunächst eimmal ans. Wenm nun unbedingt anthropomorphisiort werden mul, so würden wir als erstes Glied etwa pin Profemur haben. (Die Rechnung stimmte schon Jräller schlecht, und deshalb wurde hier der Trochanter als Flicken eingesetzt.) Lis würde danm das Femur, die P'rotibia, clie Tibia und sehließlich die MLetatibia folgen, an welche sich der FuB mit seinem trei Tarsen anschlösse.

Passender als die heutign wären dirse berciehnungen auf jeden Fall, aber sehön sind sir nieht. Es wird endlich Z Zeit, dab wir fïr die Extrenit attenglieder der Arthropoden andere Bezejchnungen findens und einJübren. 


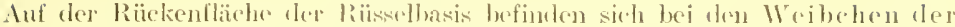

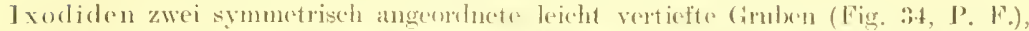

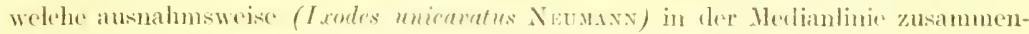

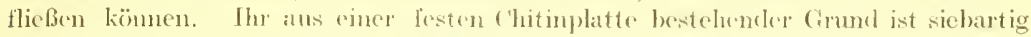

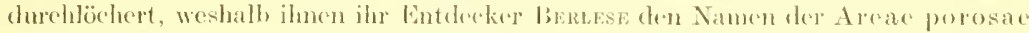
gegeben hat. Da zahlreiche Ganglienzellen in dis Hohtzylinter der lopenplatte eingelagert sind, haben wir es hier fraghes mit rinen Simesorgan an $1 \mathrm{~mm}$, dessen Funktion aber moh vollkmumen dumkel ist.

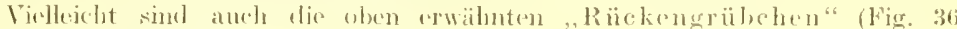
und 42) Sinnesorgane.

Un die Ehre Ohr ofler Nitse zu sein, streiten sich zwei fimnesorgane, die in zweiten Tarsalghede des crston Beinpatars sïntlicher Zedken und im dritten ?alpengliede elè Irodiden gelegen sind.

Das erste, nach seinem

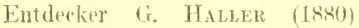
Hallek relies Ojgan (Fing. 27 und 34 ) genaunt, liegt allf der Porsalilitche des zweiten libwhedes ersten Beinpares dem distalen Ende genähert. lis stellt ein mit dümer durehluehter Chitinhant bej den Irgasilen fehlend) gedecktes Grübehen dar, in das zallireiche simmeshatare eingelagert sind. HALLER, glaubte in ihm das Gehororean der Zeeken gelunden zu habesl, wäluend neuere Versuche von LAHLLE es walrsedheinlich mar.len, dab hier das Geruchsorgan vorliegt.

Ein ähnlicher Ifuhlraum ist ouf dor ventralen Fio lio des dritten palpengliedes der Ixodiden gelegen (Fig. $2 \mathbf{T}$, Fig.

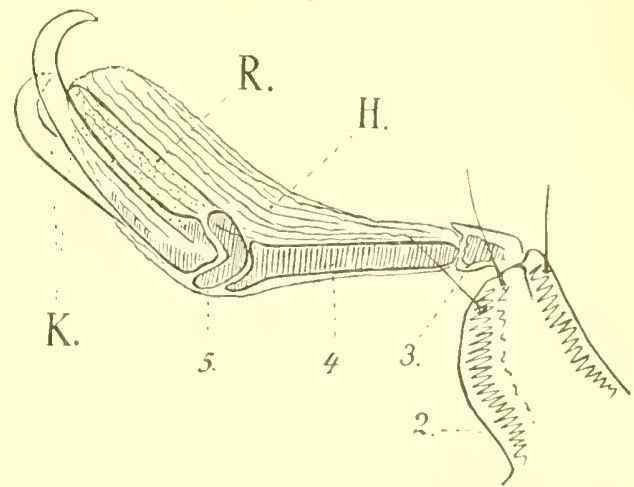

libuenglieder des linken Vorderlubes von Ixodes ricinus Profilansichn. (Original. Camera bucida).

K.. Klanen, Re. Chitinrime, II. Haitscheibe, 2--5. zweites bis liiultes Tarsalsied.

$35,39)$; auch or nillert sich sehr

der spitze des foliedes. Seine

kreisrunde offmung ist von einer dïnnen Chitinhaut lïckeulos geschlossen. Diese M[embran trägt anf ibren zentralen Partien einen Sinneskegel, der nuch vielfach falsehlith als viertes Glied des Ixodidenpalpus gedeutet wirl.

Inab wir hier das (bhr der \%ecke vor uns hahen, ist narh dessen itmlicher Lage bei vielen Insekten nieht unwalurseheinlich. Girobe Bedeutmug alser düfte einem Gehörorcan bei schmarot\%enden Milben überhaupt nicht zukommen. und es seheint deshalb bei den tieferstehenden Argasiden rollstimding zu felten.

\section{Inatomie.}

Die Organe der Atmmos sind bei ten Zecken in den rejeloverzweigten Tracheensystem gegehen (Fig 10).

Die Luftröhren entspringen bej den Xrmphen und den erwachsemen Tieren ans don Wänden viner grugen liammer, welehe jederseits unter dem Stigmenlofe gelegen ist, Den Lart u

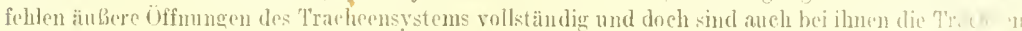
ebenso mit Luft gefüllt, wie es in den späteren Stadien der Fall ist. Ther diese Tatsath. wir 7 sich 


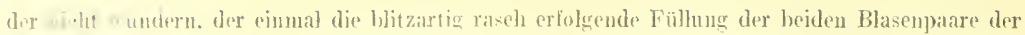

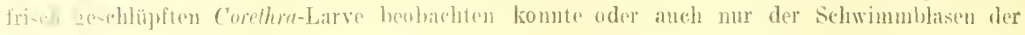
Fi lie sich erinnert.

Die. wie schon oben angegehen. verschieten groben, versehioten gestalteten und rershieden gemusterten Peritreme tragen mehr oder weniger exzentrisch gelegene (Offungen (Maculae), wetehe den Luftaustauseh zwischen liammer und äuberer Atmosphäir rermitteln.

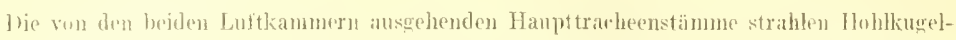

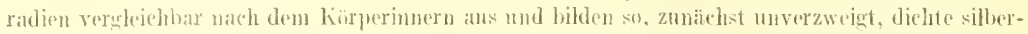
glämzende Bütchel. Bale] teilen sie sich dann unt geben im weiteren Verlanfe inmer nene Ästehen ab, die, wenn sie die lledianebene erreichen, vielkach Verlindungen mit den Traeheen der anderen kürperhaillte eingeleen (Firg. 10 T.1.) und sieh bis in die äuborsten Enden der Taster und Beine veringeroll bssen.

Wie die Luftröhren der Insekton. so sind atuch the Tracheen der Zecken sebbst bis zu den feinsten Verzwrigungen in iluen Wanten alueh eine (thitinspirale verstäkt.

1) ic Ferdanumgsorgane (Fig. s. 9, 10) setzen sieh zusammen aus den Mundteilen mit den Speicheldrüsen, dem Ösuphagus und dem Magen mit seinen blindsack-

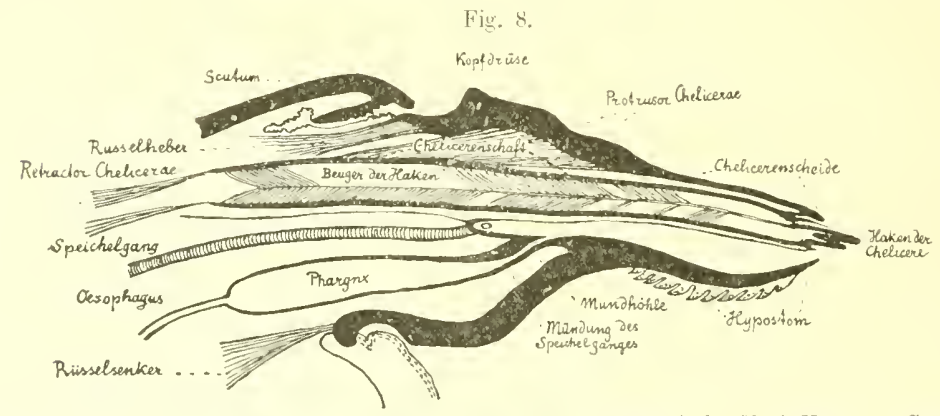

Längsehuitt duch die Medianehene des Zeekenrijsels. (1lalbschematiseh. Nach NutTald, Cooper mol Rosmsox.)

fömigen Anhängen. Einc offene Velbindung des Magens mit dem Enddarme wurde fribler von vielen Autoren angenommen, heute id)er wird sie wohl von den meisten bestritten.

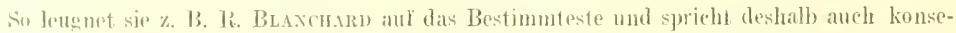
quenterweise nicht melu ron enem Anus, sondern mu noch ron einem t'roporus der Zecken,

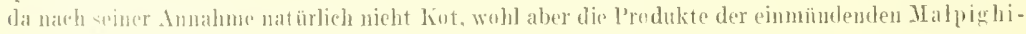
schen lietialine in den linddarm geclangen könuen.

Wine [uber follt; mächtige, in die Mundlöhle führende speicheldrüsen und zahlerehe cinzellige Drüsen in der Epithelsehicht des Magens und der Zökalwänele sincl digeregen vortanelen.

Durch die situgriihre des Räisseds getangt das Bhut des Wirtes in die Mundhöhle der Zeke. Nach rïekwärts zeigt diese eine blindsakartige Verkingerung, auf deren Grund alie beiden Enelöfnumgen der Ductus salivales liegen (Fig. s). Ton hier-

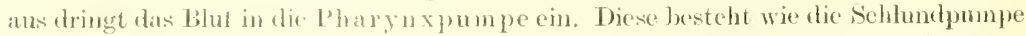
Jer blutsaugenden bipturen aus drej festernden (hitimplättehen, die in vollkommen gleicher Weire wie diese beregt werden und wirken. Eine in der Mitelebene 
liegende gerade verlaufende sipeiseröhre betörtert dann die Nahrung in den Jlagen und seine Inhäng̣e:

ber. Ilagen (Fig. !) u. 10), ein in der Kïjpermitte gelegener Sack, sendet nach

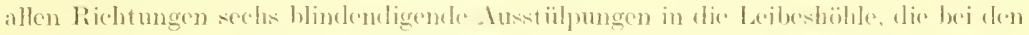

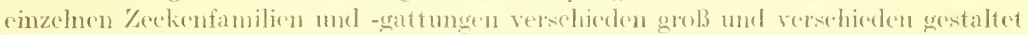

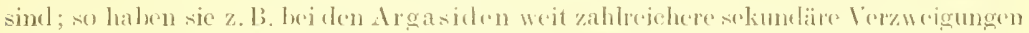
(Fig, !) als bei den l xodiden. Alle Treile des Magens und seiner Anhänge zeigen lebhalte peristaltische bervegungen.

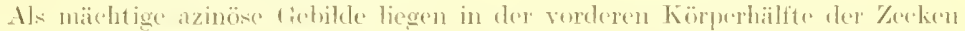

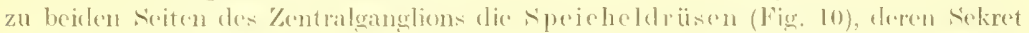

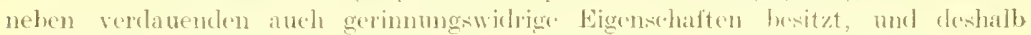
beim Saugalite in die 1 unde cingeprebt wirl.

Fig. 10.

Fin. !4.

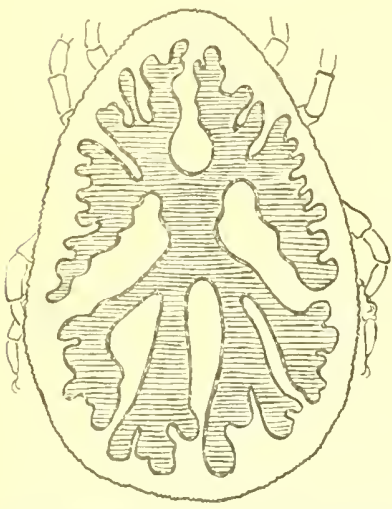

Argus minintus C. l. Kocn. Ton oben. fOriginal, nach einem stücke meiner Sammlung mittel: Camera luciclat gezeichnet.)

Der blutgefüllte Magen mit seinen dendritiseh veristelten Blindsäclien schimmert dureh die dariberlimenden Teile.

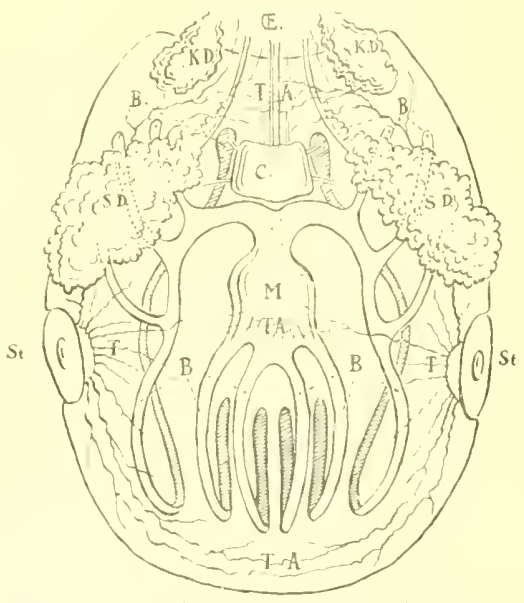

Verdanumgs- nnd It mungsorgane einer Zecke (Schematisel. ()riginal.)

()E. ()sophagus, K.I). Koplidrüse in der Medianehene durcheluniten und nach den seiten anseinander. geklajpt, B. Blindsüleke dest) armkanals, C. Cianglion,

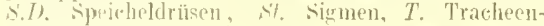
büschel. T.A. Trachealanastomosen, H. Maten.

Die Exhretionsorgane sind in den beiden Malpighischen GefäBen und den schr zahlreiehen Haut drü̈sen der Zecken gegehen. Die Nieren (Vasa malpighia) werden durch unverzweigte leicht gew undene. Röhren gehildet, welche die Verdaumgnorgane umsehlingen mol cinen ähnlichen Bau besitzen, wio ihn die Malpighisehen Gefälbe der In:ckten zeigen. Thre Absonderungsmodukte (Ham,äure, Guanin uw.) entlecren sie in den Endram.

Die ein- oler mohrzelligen Hautdrüsen liegen in Hypuderm, der Matrix der ehitingen Epidermissehicht. Thre feinen zylindrisehen Ausfülnungsgänge durehsetzen die Chitimleeke und gelangen so aut die Körperoberfläche. Sie sonderm nelun Abwchrst oflen ${ }^{1}$ ) in der Hauptsache die gleichen Produkte ab, wie die Malpighiseluen Getäße.

1) Die Zecken werden fon den meisten insektenfressenden Vögeln vershnualn. 
I)ic Koxaldrüsen. welche nehen den Hüften des ersten Beimpares ausmünden, somblen beim Saugen und während der Begatturg größere Mengen eines dünnfliissigen rekretes ab.

Der dieshlorhtsapparat der mämbichen Zecke besteht aus einem muparigen Hoden ron dem jederseits ein Tas deferens abgeht. Die beiden Vasa deferentia treffen in der Nähe der (ieschlechtsöffnumg wit dem Ansführmgsgange der lappigen, relativ sehr großen Prostata zusammen.

Jis ebenfalls umparige () varium des Weibehens (die Geschlechtsdrüsen der Zecken sind wie die Tasa deferentia und die Ovidukte beweisen dureh Tersehmeizung eines Drïsenpares in der Medianebene entstanden) schickt an beiden Seiten die geschlänguten Eileiter in einen geräumigen YTterus, der mit ciner Spermatleke in Verbindung steht. An der Grenze von Vagina und Vulva münden damn noch, ron beiden seiten liommenkl. die Ausführungsgänge zwejer sehlanchförmiger Drüsen in den Gischleehtskanal rin.

Außer den Inskeln der verschiedenon Körperanbänge durchziehen regelmäbig angeordnete Iluskelpfoiler vder streifenförmig gruppierte Muskelbündel den Zeckenleib in dorsoventraler Richtung. Sie üben naturgemäß cinen stetigen, durch ihren Tonus bedlingten Zug auf dic Körperoberfläche aus, und geben so Veranlassung zur Bikhung ron Gruben und Furchen, deren charakteristische stellnng und gesetzmälsiger Terlauf als wichtige systematische Merkmale hohe Berleutung bei der Identifizierung der Familien, Gattungen und Arten gewimen.

\section{Biologie.}

Wem auch die Terwandlung der Zecken nur als eine sehr unrollkommene lnazelnet werden kann, su stehen doch die die Eihülle verlasienden Jungen noch anf eimer viel ticferen Entwicklnngsstufe, als die Nymphen mu Geschlechtstiere; man nemut sie deshall, Larren.

lhre Atmungs- und Geschlechtsorganc münden noch nicht auf der Könperoberfläche ans und das viurte Beinpar feht ihnen. Wie weit die inneren wrgane der Tiere in der Entwiekehng vorgesehritten sind, ist noch vielfach dunkel und jedenfalls sind sie nach dieser Richtnng hin ein selır dankbares Feld für künftig. Forswhungen. Wie den Larven die Creschlechltsöfnungen fehten, sol fehlen ihmen anch die sekundären Gieschlechtsmerkmale. Wie Ixodickenlarven ähneln mehr

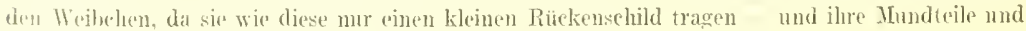
Pallyen wesentlich feiner gebant sind, als die der Jiämnchen.

Fig. 11

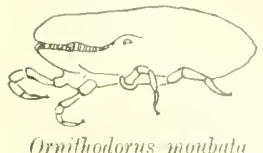

MIтRAY. $6 / 1$.

Tymphe in der Häuung leegritten. Profilansiclit. (Nideli NetTali. U. Whit-

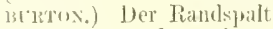
geht hart über dem sitigma mach riickwirts weiter.

Nach etwa $8-10$ Tagen häuten sich ${ }^{1}$ ) die dureh B]utaufnahme stark vergü̈Bert(n jungen Zecken zum ersten Male, es entstejgt die Nymphe der an den Körperrändem sieh spaltenden Exuvie (Fig. 11). Die Nymphe ist in Gegensatze zu der Larre ein achtbeiniges Wesen. dessen Trateensystem num auch mit der äuBeren Atmosphare in offener Varbindung steht; eine Geschlechtsöflnung dagegen und anfälliger sexualdimorphismus wird noch rermifit.

Trot\%dem läßt sieh bei aufmerksamer Lntersuchung in diesm Entwieklungsstadium das Gesehteeht vieler Arten sehon sicher bestimmen, So gribt Lanlle an, dab die dänge dur sichilde der männlielen Xymphen von Booptitus gröbar, als die der weib-

1) Kum Zwecke dor Häntung verlassen die Tiere mit nur seltenen Ansnahmen (Boophilus) ilnen Wirt und verbergen sjeh in der Erde, unter (tras, in Manerritzen, Steinspalten m, dygl. Wir geben in der folgenden Darstellung die bei boophilus beobacliteten Verhäitnisse wiedes. 
liehen, und dab dies Verhältnis ein durchants konstantes sei. Anch die tiribe und der Ban der

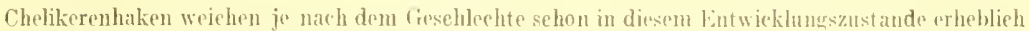
roneinander ab. Den wirhtirsten Linterseheet aber zeigen die Chelikerenschälte, die denen der

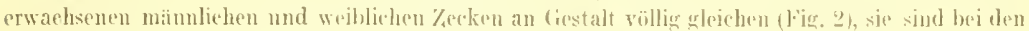

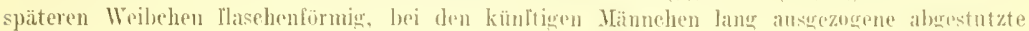
liegel.

Die revilieh genährte Nymphe verwandelt wich mach etwa div gleichen \%eit, die die Larve bratuehte, in das gesehlech tsreife Tier, das sehom nach wenigen Tagen zur Begattung schreitet. Ungetähr 1 t Tage später begimnt clie Liablage, die je nach

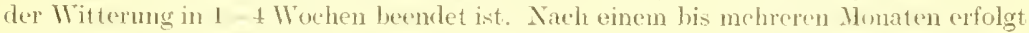
dam das Schliipfen der Jungen. Der ganze Lehenshuf wïrks also bei Boophilus unter günstigen ['mständen kium länger als 7-8 Woehen danern. Das eben (iesagte gilt aber nur für die naeh der Eiablage sterbenden Ixodiden; die jahrelang lebenden

Fig. 12 .

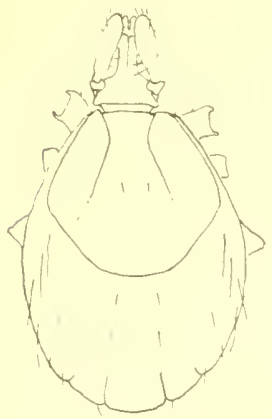

Fig. 13.

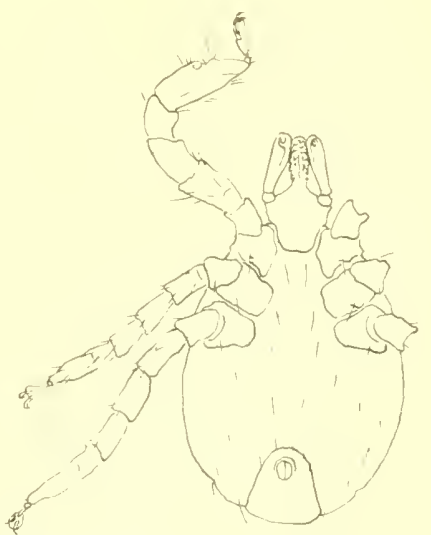

Isodes ricinus Lixid. Larven. (Nach Xuttald.) Fig. 12. Rückenfläehe. Fig. 13. Banchfläehe.

Argasiden worfen ihre Haut viel häutiger ab und selneiten nach jeder weiteren Häutung zu neuer Eiablage.

Die Menge der mit bloßem Auge noeh erkembaren kngeligen oder eiförnigen Zeckeneier ist bei den txodiden eine sehr grobe, sie kann bis zu Tausend und mehr steigen, bei den drgasilen ist sie eine etwa zelunfach geringere.

Die zur Eiablage schreitenden Zecken verlasseu regelmäBig den blutspendenden Wirt und zichen sieh in gecignete Sehlupfwinkel zurüek.

Die friseh gevehlïpften Larven (Fig. 123 n. 13) kriechen an benachbarten Pflanzenstengeh. Grashalmen u. dgl. in die Höhe und warten, sich mit den hinteren beinjuaren festhaltend, anf vorbeiziehenul. Wreidetiere, an dereu streifendem Haarkleide sie sich mit dem weit ansgebreiteten und fühlerartig tastenden vorderen Beinpare rasch verankern. Lounstir komnte an einem einzigen Girahalme über gom Zeckendarven zälulen; den meisten von ihnen gelingt es ja natürlieh unter sulehen Verhältuison

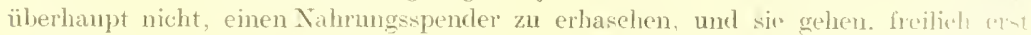

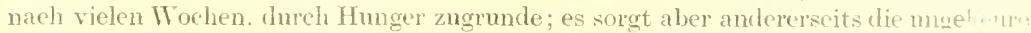
Fruchtharkeit der Zeckenmutter dafür, daß das Engeziefer nicht ausstirlut. 
In den arsten beiden Lintwicklungszuständen sind beide Geschleehter - der Ausdruek ist nicht mberechtigt, dem sicher sind bei Larven und Nymphen sehon che spezifisch mämnliehen und weiblichen Keindrüsen angelegt - eifrigst daranf bedacht, durch Einverlcibung der nötigen Baustoffe ihren lï̈rper zu vergrößern und zu seiner eigentlichen Bestimmung tüchtig zu machen. Geschlechtsreif geworden seheinen die Mimnehen der meisten Arten eine weitere Nahrungsanfnahme nieht mehr zu henötigen, sie crfüllen su bald als möglich ihren Lebenszweek und gehen damn Kraftlos geworden rasch zugrumele, während die befruehteten Weibehen noch wochenlang weitere Nahrung zur Entwieklung und Reilung ihrer Eier anfuchmen miissen.

Die Begattung erfolgt, wie schon oben angeleutet, wenige Tage nach der zweiten (Ixodiden) vder dritten (Argasiden) Häutung, durch wetehe die Zecken als geschlehtsere Tiere die Nymphenexuvie verlassen.

Eime vollkommene Einsicht in den Begattungsvorgang haben wir hente noch nieht. Sicher wissen wir nur, dab er niclit in der Wejse wie bei den hnseliten erfolgen kann da die Zcckenmännchen Fig. 15.

Fig. 14 .

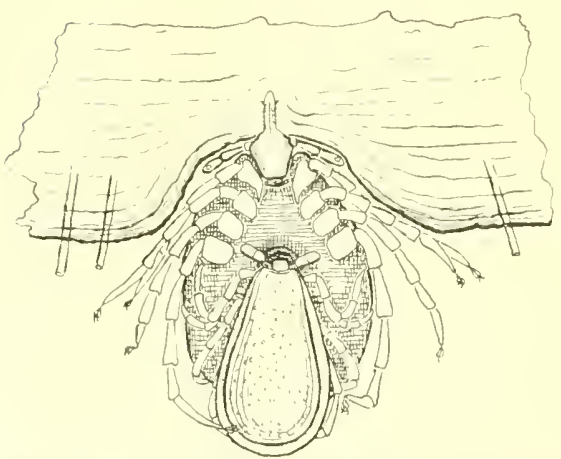

Ixodes ricimus, Lisai, 12/1. (Origina!. Camera lueida.) Kopulierendes Pärchen ins der Weiche eines Rothirsches. Stelhng des Mämehens auf einen jüngeren Weiluchen.

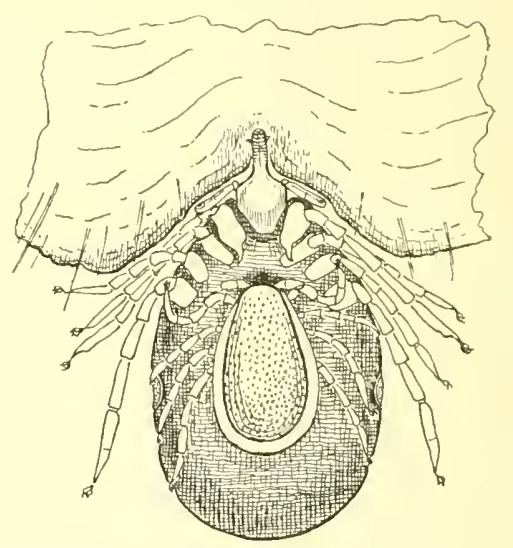

Ixodes ricinus, Lixxè. ${ }^{12} / 1$. (Original, Camera lucida.) hoponlierendes Pärchen aus der Weiche eines Rothirsehes. Stellung des Männchens auf einem älteren Weibchen, dessen Leib dureh reichliche Xahrungsaufnahme stark ausgedehnt ist.

finen P'nis nicht besitzen. Der mämnliche Geschlechtskanal ist an seiner Hiundung ein einfaches kellu, der Yagina der Weibehen sehr ähnlich gebaut.

Man nahm daher zunächst an, daß wahrend des Begattungsaktes die Geschlechtsioffungen der mäunlixhen und wijblichen Tiere durch Aneinanderlagermng eintach miteinander verbunden wirden und labs ser Samenllïssigkeit ein Hinibertreten in den weibliehen Gesehlechtskanal ennïglicht worde. Man fand aber die tagelang miteinander verbundenen Tiere niemals in dirser Stellung, sunden bemerkte stets, dafs das Männehen sich an das Weibehen mit seinen vier Brinpaaren und seincm in die Vagina eingelülıten Rüssel anklammerte (lïg. 14 u. 15). DE GeEk war der erste. der diesen lorgang bei Irodes ricinus um die Nitte des 18. Jahrhunderts beobachtete

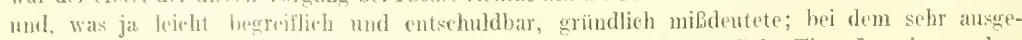

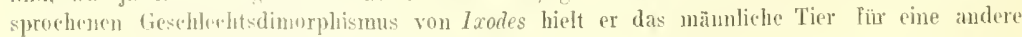
Art, die auf dem jlm bekaunteren weiblichen Holzbock sehmarotze.

Als man dann den begattungsvorgang bei den spiunen genauer kenneu lernte, sehien die Immahure, dab der Rïssel das hopulationsorgan der Zecken sei, nicht mehr allzu gewagt. Auf den crsten Blick erseheint diese Begattungsweise so unerhört, daß mehriach sogar von Arzten, denen 


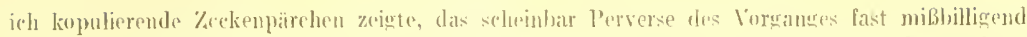

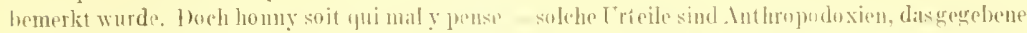
kiopulationsorgan der mannlichen Zeeke ist num aimmal der Rüsel und des lablb besteht auch hier der alte Siatz zu Recht: naturalial unu sunt turpia.

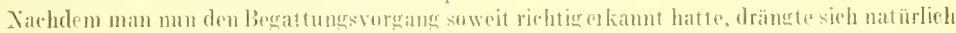

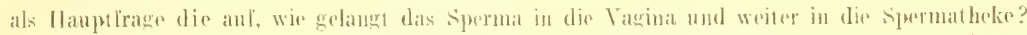

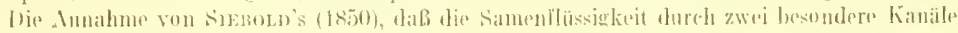

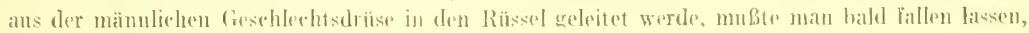
da die Kantile nicht aufzulinden waren.

Lews beshachtete 1901 in den Winkeho, welche die untersten Ziihne der Radula mit dem

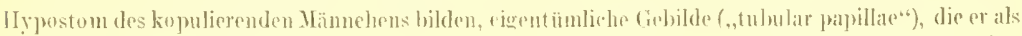
spermatophoren deutete: seiu befund ist, suviel mir bekannt, bis heute vou einem anderen Forseher nieht bestatign worden.

Dit wir nun wissen, dab bej der sehn großen Bewexdichkeit der Rüsselbasis es den weiblichen Zeeken leicht fillt, ilıren Fïssel hinter der als lececröhre vorgestülpten Vạina der Bauchwand fest anzupressen. so liegt es nahe, anzunehmen. dab anch die Mämohen den Riüsel in ihren Ge-

Fig. 16.

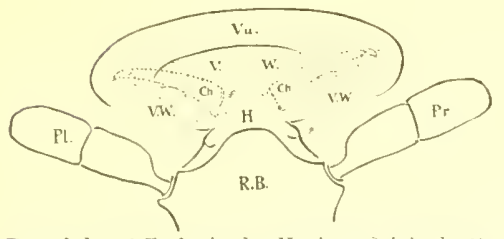

Rüssel der ô Zecke in der Varina (original). ${ }^{60 / 1}$. Jie stark gespreizten Chrlikerenlaken sieht man dureh die daräbroliegenden Weichteile hindurehsehimmerı. Ju. Vorderer Rind der Vilva, I.H. stark gedehnte Vaginalwand. Ch. Chelikerenhakes. II. Hypostom. R.B. Rüsselbasis, P.l. linker Palpus, P.r. rechtor Palpus.
Fị. 1 i.

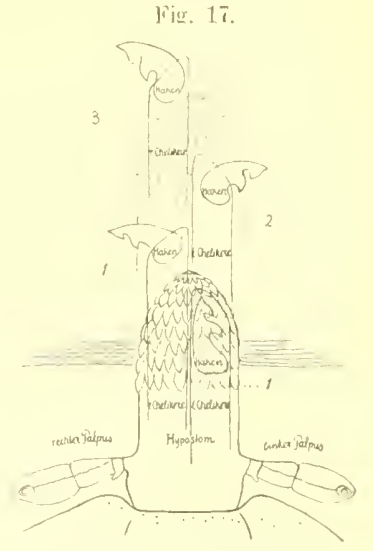

Lu dis Haut cindringender Zeckenrüssel. (sehematisch. Original.)

DieZahleu gobeu die Stellung der Stilette in der Zeittolge der einzelnen Phasen an.

schlechtskanal za stoBen vermögen und dimm das spermalveladene Hypostom in die Seheide der umschlungenen Weilohlen einführen; f hemotaxis und die den Spermatozoen edgene Lokomotions-

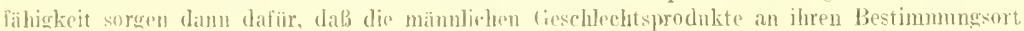
gelangen. Deukbatr ware ja anch, dib der wihremel des tagelang dauernden Begattungsaktes aus-

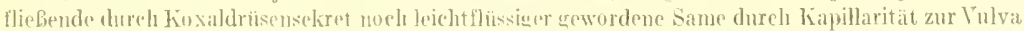

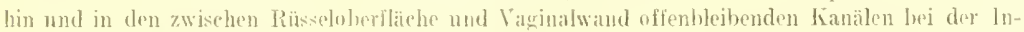
spiration des angesogen und in die Tiefe weitor geleitet wirde. Tirse Kanale entstehen hei der

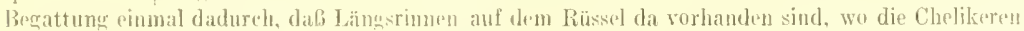

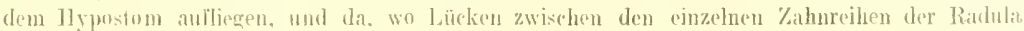

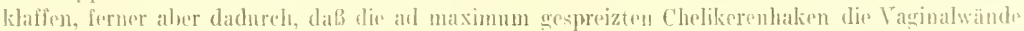
stark auscinander zichen und su suitliche Lühgsfurchen entstehen lassen (Fig. 16i).

Die Finführung des.männlichers Rüssels in die Vagina erfolgt jedenfalls in . 111-

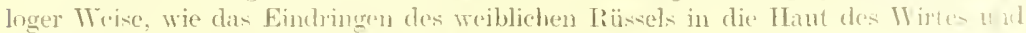
zwar in den späteren Phasen dieses Torgingas. 
Das weibliche Tier b'nutzt zunäehst sem lanzettfömiges, mit feinster distaler Schneide versehenes Hypostom. um alie Epidermis seines Opfers zu ritzen. Die Bewegung erfolgt um eine am Grunce der Rüsselbasis in der Hedianebene liegende rertikale dehre. In die so entatandene Irundrinne dringen die distalen Enden der C'belikeren ein und verankem sich dureh Spreizen ihrer Haken (Fig. 17). Das Eindringen wird den (Thelikern dadurch wesentlich erleiehtert, daßsie die Torwärtsbewegung mit einer rotierenden repbinden. Diese erfolgt um die horzontal liegenden Aehsen ihrer Sehäfte und läßł die feine’n Zähnehen des freien Randes der Cholikerenselıcide in Wirkung treten. Jst so die erste Verankerung des Rïissels gelungen, so stößt das 'Tier eine thelikere weiter ron' und verankert sich mit deren Haken von neuem an tietieferer Stelle (Fig. 17). Nun wirlit die andere (helikere in gleicher Wreine; dam folgt wieder die erste usw., bis der Rürsel in genügende Tiefe eingedrungen ist ${ }^{1}$ ). Bei diesem Mechselspiele fällt den Hypostom eine vollhommen passive Rolle zu, es wird einfach weitergeschleift und kann the Leistung der Chelikeren nur dadurch unterstützen, daß sich seine nach rückwärts sehanenden Zähne in das Kutisgewebe einhalien.

Es ist ja selbstrerständlieh, daß ein mögliehst leises und sclonendes Auftreten, cine müglichst geringe Belästignug des Wirtes - als unrïhmbehe Ausnahme hestätigt der ,reizende $e^{\text {th }}$ Floh nur die Regel - den Schmarotzer sein Ziel am ehesten erreiehen lißt. So wundert man sich stets von ne'uem darüber, wir ummerklich sich stechende Dipteren auf die Ilant ihrer (oyfer niederlassen med wie wenig schmerzhaft ihre stiche sint. Dber weit ühertroffen werden sie in dieser Hinsicht merkwürdigerweise von den Zeeken mit ihrem viel kräfiger, um nieht zu sagen plumper gebauten Steehrüssel. Ein über die Ilaut kriechender Holzbock wird nur höchst selten gefühlt und das Eindringen seines Riissels kaum walurgenommen. So ist es mir nach Waldspazicroängen zweimal begegnet. dab ich am Oherlid sitzende Ixodesnymbhen erst am folgenden Morgen beim Wasehen des Gesichtes bemerkte - und doch bin ich nichts weniger als gefülllos.

Wic krätig die so erz'ugte Verankerung des Tieres ist, erkennen wir daran. daB die Hant des Wirtes schijeblich an der Einstiehstelle einen tief eingezogenen Triehter biklet (Fig. 14 u. 15), dešcen Wände die dem Zeckenkörper fest anliegenden Palpen und Beine mit ihren Scitenflächen herühren, olme ihrerseits zur befestigung des 'Tieres auf seinem Opfer etwas beitragen zu können: wir sehließen es ferner aus dem Tmstande, dab beim Tersnche, den Schmarotzer aus der Hant seines Wirtes zu ziehen, fast regelmäBig Teile des Rüswels in der Wuxde stecken lieiben. Hänfig werden sogar die ganzen Cholikeren samt ilmer Musulatur bei diescr. Gelegenheit ans dem Zeekenleibe heransgerissen.

Will das Tiur selbst seine Verbindung mit dem Wirte lösen, so sehlägt es die ('helikerenhaken nach einwärts (Fig. 3), zieht wie samt den Chelikerenschäften in ihre Foheiden zurück, löst durch Iorsallexion der Rüscellasis die Zähme des Hỵostoms aus den Masehen des Kutisgewebes und kam dam die Numdteile leicht aus der. Wrunde heritubeben.

lm Regensatze zu der Mehrzahl der blutsangenden Arthropoden, die wie die Fliegen. Flöhe und Wanzen z. B. nach kurzer Zeit vollgesogen und gesättigt den gütigen Gastgaber rerlassen, verharen von den \%ceken die Ixodiden wenigstens tagelang. ja manchmal ihr ganzes Leben saugend auf ihrem Wirte. So findet man die

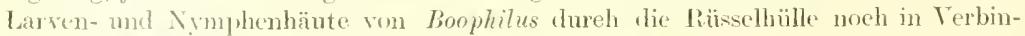
domg mit der lliant ihrer Opfer, und erst das zur Eiablage schreitende Weibehen und das lebensmüid. Männehen verläBt seinen Trägcr.

1) In ganz analuger Treise erlolut das Findringen der sitcehmückenstilete, das ich im Jahre 1903 mit dem sterennikroskoj, zuerst beobachtete und in Mtaxa's Troponkrankheiten, 1. Aufl. Bd. II S. 53 besclurith). Ihe Bau ihrer Stilette spricht mit Bestimmtheit dafür, dab die

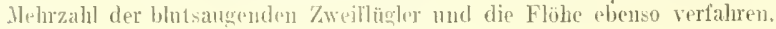




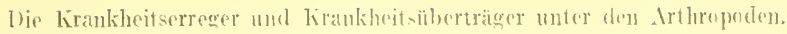

Bei diesem Verhalten der Tiore wirl Nahrungsaufnahme und Begatlung gewöhnlich zusammenfallen, für die I xodiden möghe ich dies wenigsens ammebmen. DiL

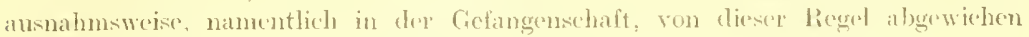

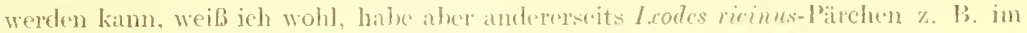

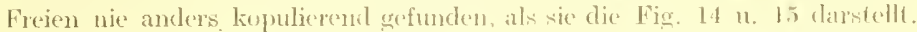

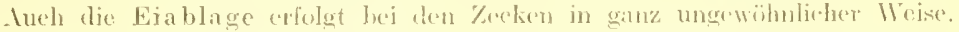

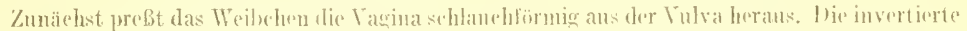

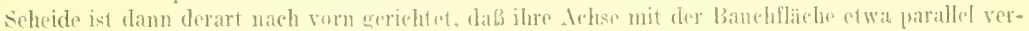

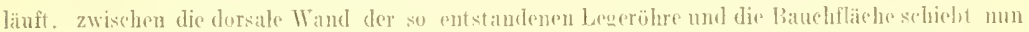

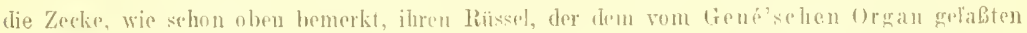

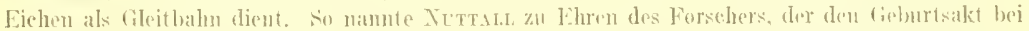

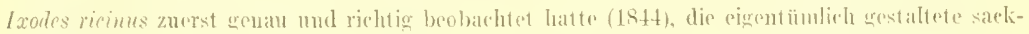

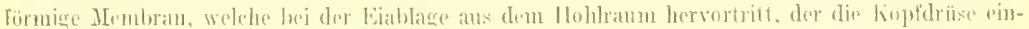

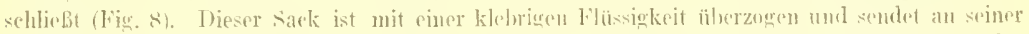

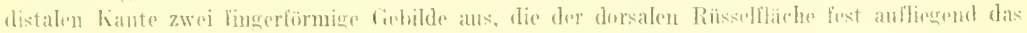

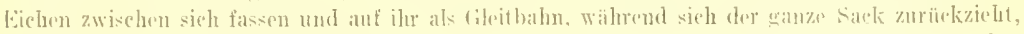
fortsclateilin. Am Rückenschile angekommen wirl es dann mit den schen dort befindtichen, früher

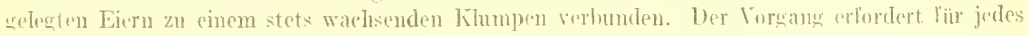
Ei nicht ganz eine Himute an \%eit.

Die eiförmigen Eiehen hahen bei Boophitus aumlutus eine Lä̈nge von 0,5, eine Breite ron $0.4 \mathrm{~mm}$, können aber bei anderen Arten (Amblynmme. Omithodorus) bis zu $1 \mathrm{~mm}$ lang verden. Ihre Farbe ist ein dunkles Braun; fie leaterartiog Eilant ist strukturlos und nicht mamentiert.

\section{Systematik.}

Wem auch in Laufe der Ietzten Jahrzehnte von verseliedenen Forichern neue Zcckensyteme anfgestellt wurden. so konnte sich doch keines ron diesen allgemeine dnerkennung rershaffen, und es gilt anch hente noch dir lstt ron ('. L. Kor H aufgestellte srstematische Ubersicht als die heste mol branchbarste.

Die Zecken zerfallen in zwei wohluntershisene Familien, die tieferstehenden Argarielen und die zu höherer Entwieklung gelangten Ixodiden.

Die $M u n d t e i l e$ der Argasiden liegen auf dem rorkeren Drittel der unteren Körperfläche in einer hesomderen Nische, dem sog. Kamerostum; ihre Haut ist in allen Teilen des Körpers ron gleichmäBigr.l Besehaffenheit.

In Ixodiden dagegen tragen ihre If undteile an der vorderen Körperrandfläche. Thre Haut ist an bestimm ten weharf begrenzten Körperstellen stärker chitinikiert, so tab hier schildförmige P'latten auftreten; in beiclen Geschlechtern lommt anf tiese Weise der Rüekenschild und bei den Männchen häufig aux Bauchschilde zustande, dic clamn meist in eler Umgebung des Afters liegen. Die letzten Fußgheder fler I xodiden tragen welur rollkommen und zweekmäBig gebauto Haftschejben, welehe den wrachsenen Argasiden fehlen.

Bei Botrachtung iher Rürkenflache wrelen wir demnach bei den (erwaehsen'n) Argasiejen rom IIundtcilen ïlxrhaupt niehts zu wehen bekommen und anch rege!-

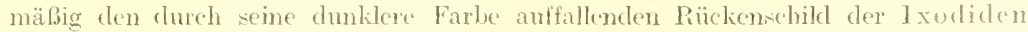

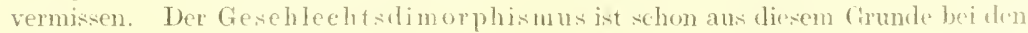
Argasiden riel wenger ansgesproehen. als bei den Ixodiden. 


\section{Argasidae.}

Die Argasiden zerfallen in dic beilon Gattungen Argas und Ornithodorus. Der Körper bon Argas ist abgeplattet (einer linse vergleichbar) und crscheint

Fin 18.

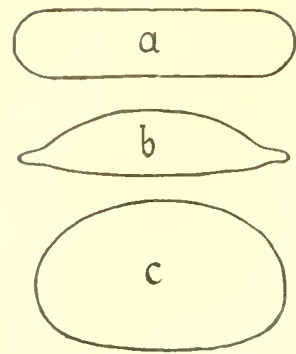

Lmrisse von Quersehnitten dureh den Leib von u. Irotes, b. Argus, e. Ornithodons: (original. schematisch.) (leshalh) bei oberflächlicher Betrachtung wanzenähnlich. J)er Körperrand ist zugesehärft und sicht wic umwiumt aus (, Sammzecke"). Ein Frontalschnitt durch (lic leibesmitte würde infolgedessen etwa den in Fig. ish dargestellten T'mriß zeigen. Die Argashaut ist runzelig.

Ornithodorus dagegen ist von mehr kugeliger (iestalt (emer Erbsc oder Noceabohne vergleiehbar), die Randfläehe ist breit und gewöllt (Frontalschnitt: Fig. 1se). Rücken- und Bauchfläche sind von tiefen Furchen durchzogen. Einige Arten besitzen Augen. Die Haut ist warzig.

\section{Gemils Argas Latreille.}

I)ic 11, zum Teil nocls zweifelhaften Arten ron Argas simblarqualis Netmans. brevipues Baxks, brumpti Neumax, cuenerinus Neumax, hermumi Audorix.

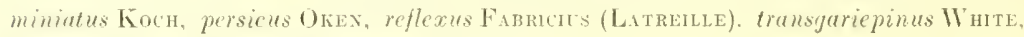
transersa Baxis und vespertilionis LATRETLL.

Ton diesen sind die wiehtigsten Argas reflerus (die ,.Taubenzecke") und Argas persicus (die, persiche Wanze").

\section{Argus reflexus Fabioms}

ist der Riese unter seiuen näehsten Terwandten, er kamn bis zu $10 \mathrm{~mm}$ Länge, hei $7 \mathrm{~mm}$ Breite erreichen. Seine Farbe ist ein liehtes Bramgellb. Der Körper der Zeeke ist eiformig mit naeh vorn gelegener, stark ausgezogener spitze. l)er $0.2 \mathrm{~mm}$ breite Köpersaum zeigt feine radiäre Fältehung und ist (namentlieh bei hungernden Tieren) nach obun umgebogen (reflexus). Zahireiche in radiaren Reihen zusammenstelzende Gïubchen sind regelmäBig über Rücken und Banch verteilt. Wer Anus ist fast in der Mitte der Banchfläche gelegen. Die kjeinen Peritreme lass'n bei tupenvergriberung um die Macula radiäre streifung erkennen und erseheinen halbmondförnig. Das an seinem. Vorderende alugerundete Hypostom trägt auf der distalen Partie seiner ventralen Fläche zunichst 3-4 Reihen feiner Zähnehen, denen ganz unvermittelt zwei Reihen

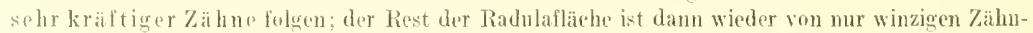
chen besetzt. Irie männlichen Tiere sind durchgehends kleiner, als die Weibehen; ihre Genit al-

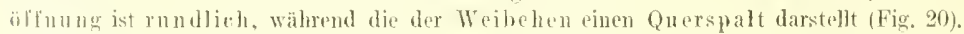

lrgus reflerus kommt hente noeh. wemn auch sedten geworden, in den Taubensehlägen und Iliblnerställen Jeutschlands und lolands vor. Nur ilure gesehützten Iufenthaltsorte ermöglichen diesen Tiren, die wie alle Argasiden höhere Wintertempraturen beanspruchen, ads unser dentsebes Klima sic hietet, ein beschränktes Furtkummen. Wit der Abnahme dieser Zecke ist anch die dureh

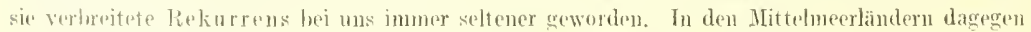
(namentlich Xordafrika) wird die Taubenzerke noch häufiger angetroflen.

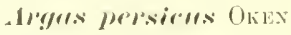

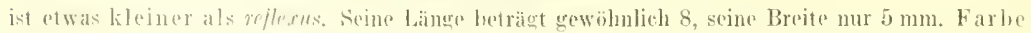
brangelb. Linperform dieselhe wie bei refless. mu in den vorderen Partien weniger ver-

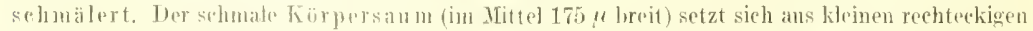

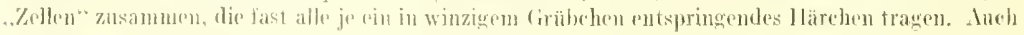

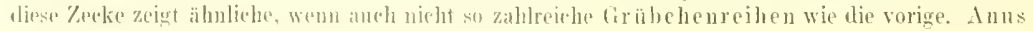




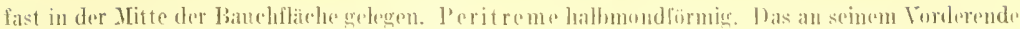
abgestutzte Hypostum zeigt in der driften, vierten, fünften und seehsten Reihe selur

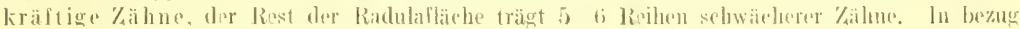

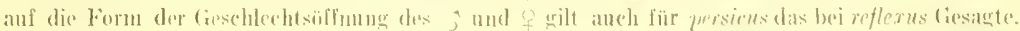
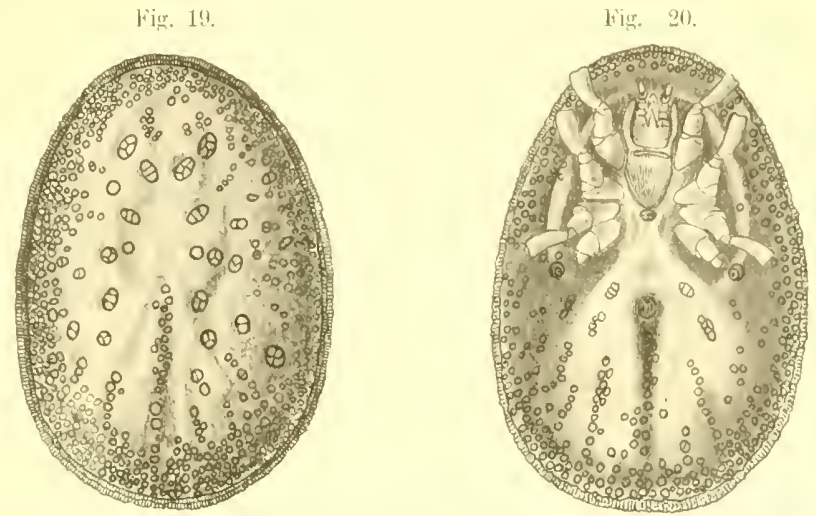

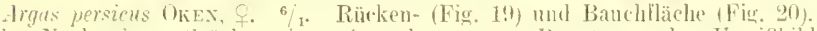

(original. Naeh einem stüek meiner Sammlnng unter Benutzung der Lmridibilder von S.M.MoN und STILES gezeichnet.)

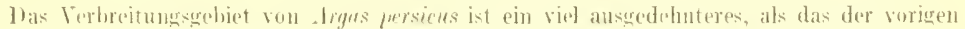
Art. Die Zecke wurde in Rubland, Turkestan. Persien, Kleinasien, China, Igyjten, dem Sudan Tubien. Alrerien, anf der Insel Mlauritius nud an Kalp gefunden. Aneh sio wird hesehnldigt die

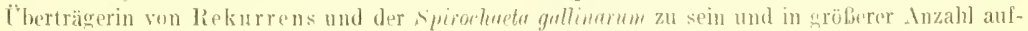
tretend schon allein darch ihre Blutgier den Tod namentlich jüngerer Vägel herbeizuführen.

Fier. 21.

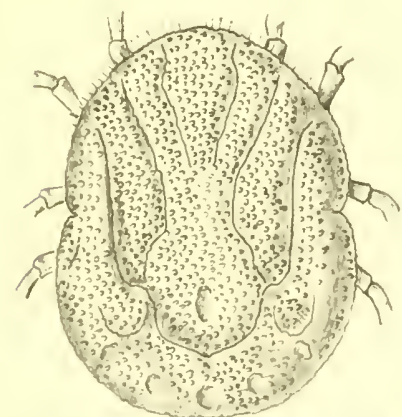

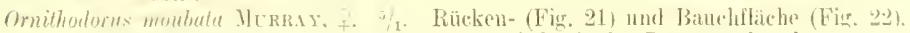
(Nach Yutrale und aus I Wofeers, Lehrbuch ter Protozoenkunde.)
Fig. 2.2.

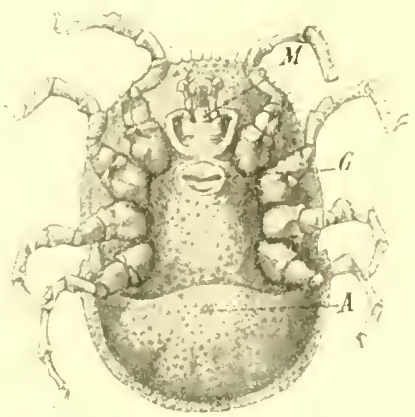

-2. Cienus Grmithodorus Kón.

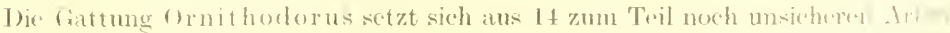
zusimmen. Ich führe hier nur die Namen der wahrseheinlich enten Ant a dit. 


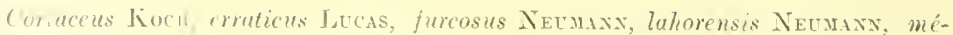

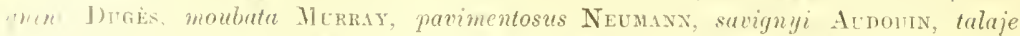

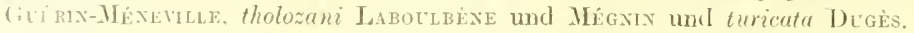

Tom disen interesiorm ms (als Überträger der Reenrrens africana) hauptsächlieh

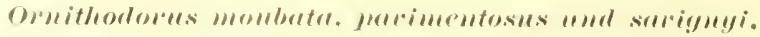

clie Jäulig eine Länge vou 111, he einer Breite von 7 mu erreiehen. Sie gehören somit zu den größten Arten dor Gattung und bilden eine Gruppe, deren Tertreter so nahe miteinander verwandt sind, da.p man ohne Kwang annehmen kamn, ('s lrandle sich hicr nur um Varietäten derselben Spezies. So zieht Neturs, der gegenwärtig herlentendste Zuekensystematiker, O. moubata als ear. caeca zu 0 ). savignyi und gibt als einzigen Unterschied ron $O$. savignyi für $O$. pavimentosus an, daßseine Wärzchen etwas flacher seien.

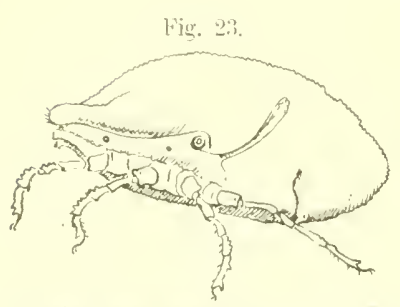

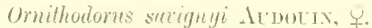
Prolit: die Lage des Ingen nud des stigmas zeigrad. (Nawle Nutrile und IV.ARBL'RTOX.)

Fig. 24.
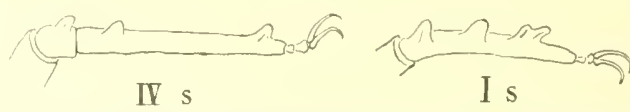

Im. und TYm. Die Höeler auf dem 2. Tarsalelied des ersten und vierten beines von Omithodons moubutu. Is. und IV's. Die Höcker ant dem 2. Tarsalglied des ersten und vierten Beines von thmithodons suvignyi. (original. Nach Stïeken aus meiner sammlung mittels der Camera lucida gezeiclmet.)

Gemeinsan ist den trei Arten eine tiefe Qnerfurehe, lie sich zwischen den Hüften des vierten Beinpares und dem After über die ganze Banchfläehe hinzieht, dam an der AuBenseite der vierten Cosa nach vorn verläuft, hier nach

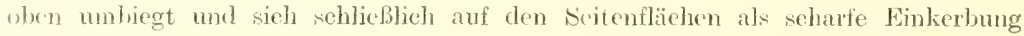
l,is zur Rïckenfläche hin verfolgen läßt. Die Käickenfläl'he wird von Längs-und Schrägfurchen durehzongen, die naeh de'm vorderen Leibesende hin fächerförmig ausstrablen. (Fig. 2I und 22.)

Dice schwarzbram gefarbte Haut ist ron zahlreichen Warzen bedeckt, zwischen denen borstenförmige Härchen stchen, die namentlieh am Vorderrande gehäuft sind mol deslalb hier mehr auffallen. Die Tarsen und Hundteile der Tiere sind häufig werentlich beller (his zu braungelb), als der übrige Körper.

Während drmithones surignyi (Fig. 23) vier und 0 . parimentosus zwei Augen hesitzt, ist O. moubalu llind. Has zweite Tarsalghed des vierten Beinpaares von 0 . surignyi und $U$. purimentosus

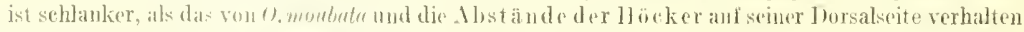
sich bei 0 . surignyi und (). pucimentosus wie $1: 3$, bei 0 , moubatu dagegen wie $3: 4$ (Fig. 24). Auch das

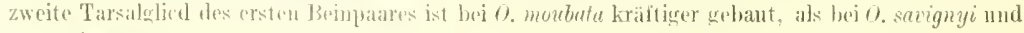
1). paximentosits. 
Das Vorkommen von O. sacigmyi wirl ans allen Trókn Afrikis mol aus siidasion beriehtet. (). moubata ist die in Mlittedatrikal am häufigsten benhachtete Art, während 1). pavimentoses bisher nur in wenigen Stürken in Groli-Namaland getunten wurde.

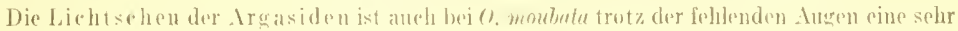

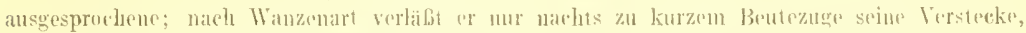

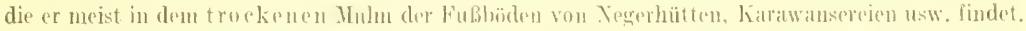

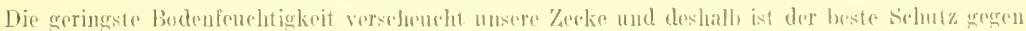

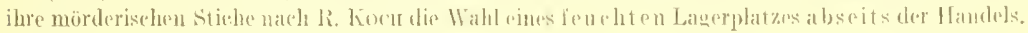
straben.

Wemn anch die meisten Ornithodorus-drten - woranf schon der Nanne hindentet - Togelparasiten sincl, so stoben wir doch in O. moubata umb t). mégninianf Ausnahmen. Während $O$. moubeta hauptsächlich Afensehen befällt, sucht rlie anerikanisehe

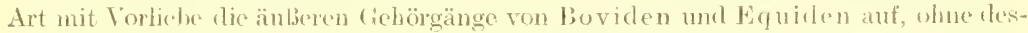
balb die gleichen Körperhöhlen von Homo sapeens gänzlich zu meirlen. Jan mennt

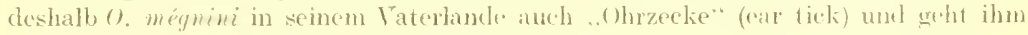
mit (i).ingieloungen erlolgreich zu Leibe.

\section{Ixodidae.}

Im Gegensatze zu den fïr die menschliche Pathologie so auberorchentich wicht igen Argasiden sind unter den Ixodiden bis heute noch keine Überträger von Krank heiten anf den Henschen einwandfrei nachgewiesen worken. T'm so größere be dentung aber haben sie als Vermittler versehiedener mörderiseher Epizuotien.

Sic sind dic Wirte der Parasiten des Texasfiebers, des afrikanischen Küistenfiebers mul des Blutharnens der emropäisehen Rinder, der Hundegelhsueht and gewisser Babesinsen bei Pferden und Sohafen. Die Verhuste, welche anmikanischen Zaichtern z. B, allein dureh das Texasfieber erwacheen, belaufen ich auf weit übor 250 Millionen Mark jährlich.

Die Ixodiden zähien in zehn Gattungen eine auberorkentlich viel größere Anzahl von Arten, als sie the Argasiden besitzen.

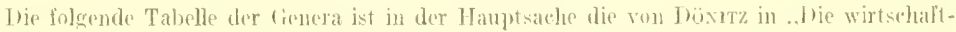

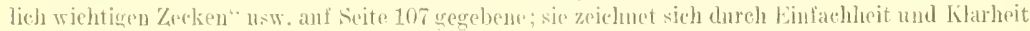
alls.

\section{Inorlintue.}

a) Palpen lang: $\left.{ }^{1}\right)$ I. Tuterfamilie Ixodince

b) Palpen kurz: II. Lnterfamilie Rhipicephulime.

\section{Ixodinae.}

Analfurche als Querbogen vor dem After gelegen. Keine Augen .... Ixodes. 1 Analfurche als Querbogen hinter dem liter gedegen, oft seitwärts bis zur

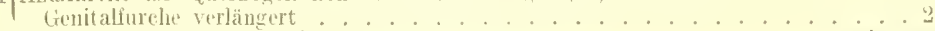
oliene Augen, keinp Iualplatten . . . . . . . . . . . . lponomma.

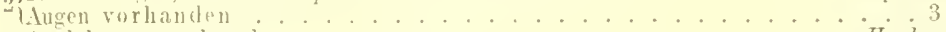
Jnalplaten vorlanden . . . . . . . . . . . Hyulomma.

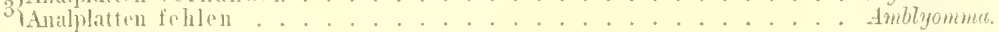

\section{Rhipiccyihalinae.}

g keine lugen, koine Analplatten. Zwerites Palprnerlicel seitwärts vor1 springend .................... Ithemaphysulis.

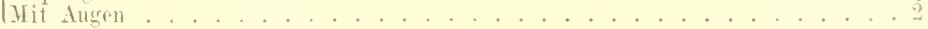

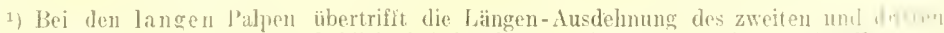
Gliedes teren Breitendurehmesser rrheblich, bei den kurzen ist das Engekehrte der Fin. 
Wit Inalplatten, Rüsselbasis sechseckig, mit vorspringenden Seitenecken . . 3 2) Ohu Analplattrn. Rüsselbasis sehmal, viereekig. Coxa IV heim ô viel größer

Erstes Palpenghed am ventralen Innemande höbistens mit einer Borste. stigmen kreisumd. o o hne dnalfurclie.

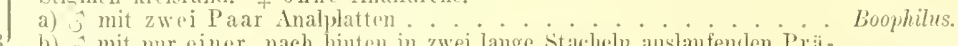

3 b) mit mur einer, nach hinten in zwej lange stacleln auslaufenden Prit-

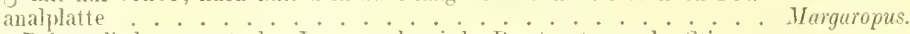

Erstes Palpenglied am ventralen Inmenrande viele Borsten tragend, stigmen

kommaformig. + mit Analfurehe. $\hat{o}$ mit einem Paar Analplatten. . Rhipicephalus.

Es sehließt sieh hier dann noeh das nevertings von Nuttall und Warburtox anfgestellte Genus Rhipicentor an, welehes zwisehen Rhipicephalus und Dermacentor stcht, und der ersten fattung in der Riieken-, der zweiten in der bauehansieht gleicht.

Fig. 26.

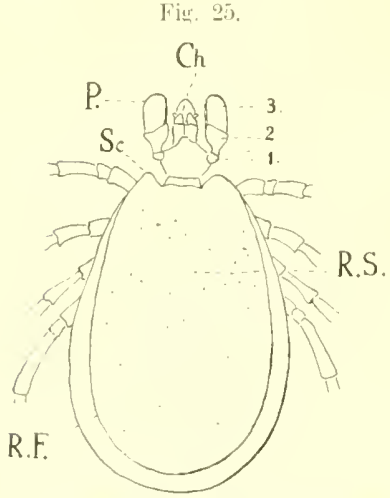

Ixodes riminus Lisxi, $\hat{o}$. Rüekenfläche (original.)

Ch. linke Cholikere, $P$. linker Palpus, 1. 2. 3. 1.-3. Glied des reshten Palpus, L.S. Rizickensthild, $R \cdot F$. Randlurehe, Sc. linke Scapula.

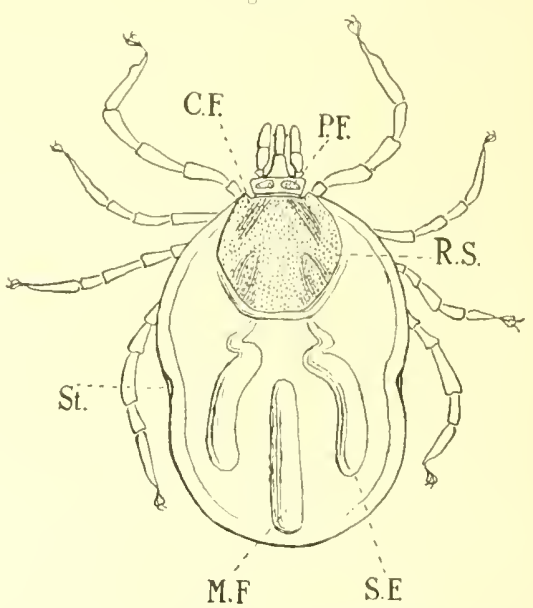

Irodes ricinus Lisat. T. Rïekenlläehe (original). P.F. rechtes Iorenleld, $R . S$. Rückensehild, S. $F$. rechte Seitenfurche, M.F. Nittelfurche, st. Stigma, C.F. Nackenfurche.

\section{Indolinar.}

\section{Genus Ixodes Iatreille.}

Von den zahlroichen (es sind deren meh als fünfzig bekannt) Ixodes-Arten wollen wir nur Ixodes ricinus L. näler betrachten, da c' der Typus des ganzen Genus, ein Kumopolit mul a lex notorische Üherträger eine wichtigen Bovidenkrankheit (rles...Blutharnens") ist.

\section{I.xolles ricillus LINNÉ.}

1) ie Cirundistue unserer Zorke ist in beiden Gesehlechtern ein mehr oder weniger dunkles Rothraun. Dhe stärker 'litinisierten Kärperteile zeigen immer auch kräftigere Tingierung, und deshalb erseheinen die Mimmehen stets dmnkler gelürbt als die weiblichen Tiere. Die liörperform ist

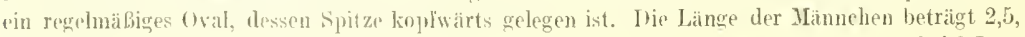
ilıre Breite $1,4 \mathrm{~mm}$; die etwas gröberen Weibhen kömen voldgesogen äber $1 \mathrm{~cm}$ an länge bej $0,7 \mathrm{~cm}$ 


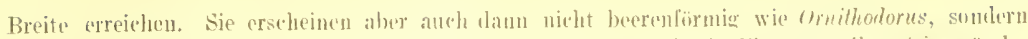

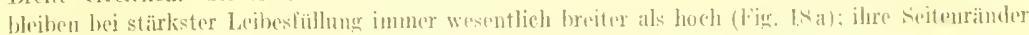

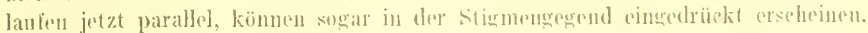

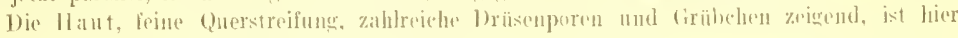

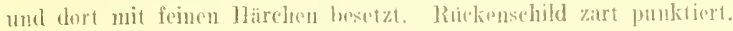

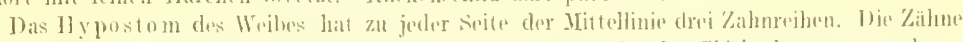

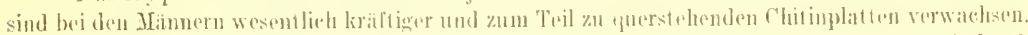

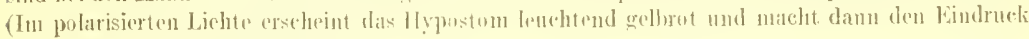
eines, flammenden seluwertes..)

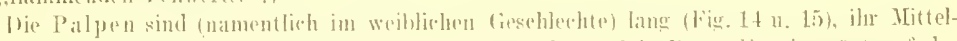

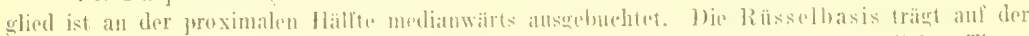

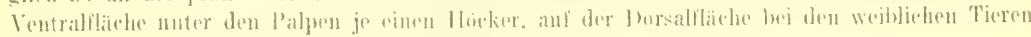

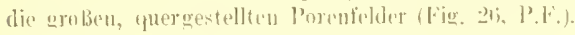

Fir. 97.

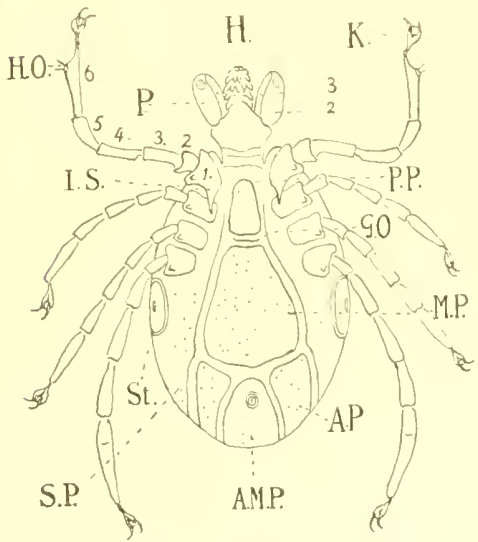

Ixodes ricinus Lxwi: $\hat{j}$. Batlelilache (Original).

H. Hypostom, P. rechter palpus, \& und : zweites und dritıes cilied des linken Palpus, $K$. lilanenglied mit Hatscheile, P.P'. Prägenitaiplatte, G.U. Geschlechtsöffnung, H.P. Vittelplatte, sP. Ejomeralplatte, A.I. Pillanalplat te, A.M.P. Analplatte, Nt. Stigma, I.S. Imenstachel der rechten rrsten Hiiftr, 1. Hülts, 2. Trochanter, 3. Femur, t. Tibial.

5. Protarsus, 6. Tarsus, IIO). Holler'sches Organ.
Fin. 28.

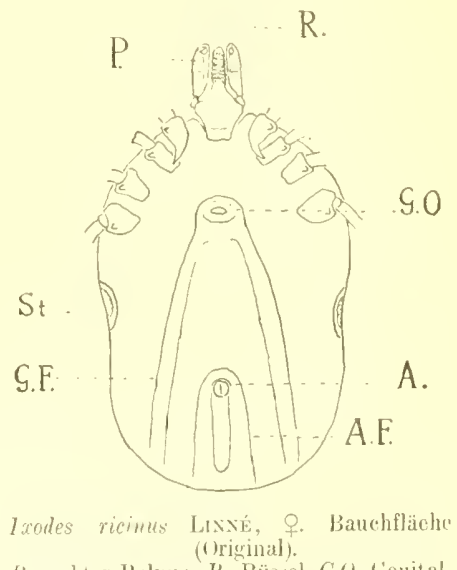

I'. reehter l'alpats. Ri. Rüssel, G.O. lienitalblinumg, 1. Hiter, J.F. Neteriurche, G.F. Genitalfureles, st. Stigna.

Das "rste Hüftenpaar ist auffallend bewerdicll. Sein Hinterrand ist an der lunenever bei beiden faschlechtern in eine lange spitze ausgezogen, walurend die hintere AuBenecte aller Coxae einen kurzen, aher kräftigen Dorn trägt.

Die Peritreme sind fast krejorund. Die Anaflurele, welele den lffer bogenfïrmig an

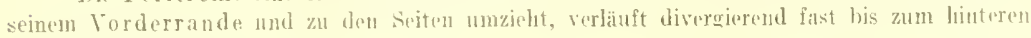
hïrperrankle (Fig. 97 11. 28).

bie mïnnlichen Tiere tragen aul der Bauchfläche sicben stärer chininisierte l'latten.

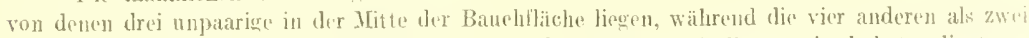

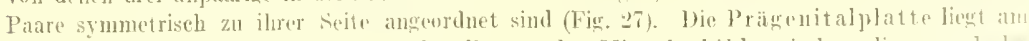

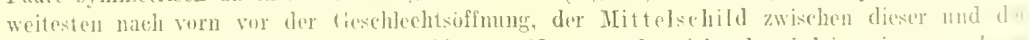

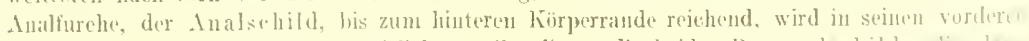

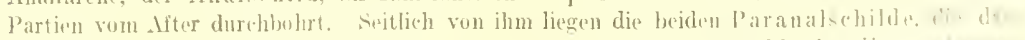

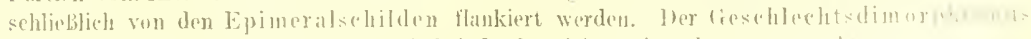

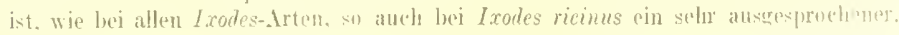


1) bu lahen nnserer Zecke rerden in einem Satze bis zu tausend und mehr Stïck gelegt; te sinul vus waler Form, dunker Farhe und $0.5: 0,4 \mathrm{~mm}$ grob. Tach etwa sechs Woehen ent*lilingen iluen die sechsbenigen, anlangs hell geförbten Larven.

In alken Weltteiten (Anstralien?) ist Irodes ricinus L, gefunden worden und vielerorts sogar als die hei weitem häufigste Zeeke. In Thentschland häht sich der ,.Holzbock" am licbsten an den Rändern von Waldwiesen anf. Jerkw ürdigerweise gehören fast alle Tiere, die den Jensehen befallen (im ejgentliehsten Simne des Wort('s), dem mittleren Lebensstadinm an, e's sind sog. Nymphen.

In Geyensatzos zu Omithodoms monbatn sehent Ixodes riminus Bodenfenchtigkeit nieht. Die Zecke ist vollkommen winterhart. Wom auch die Hauptentwicklungsperinde von 1 . ricinus in die bessere .Talureszeit fält (Temperaturoptimm 20-250 C), so werden doch kopulierende Pärehen anch im Winter noeh angetroffen. (The in den Fig. 14 u. 15) abgebildeten Tiere wurden Jitte Tovember 1911 und am 12. J anu il 1912 auf Hirchen gefunden.) Die meistun Zecken werden woh! den Winter der gemäBigten Zoue nicht überstehen. Spät befruchtete Weibehen und vor allem dic Fier, we lehe meist ungefährdet die kalte Jahreszeit überdanern, sorgen für die Erhaltung der Art.

Ixodes ricinus vertäBt vor jedn' Hautung und zur Eiablage regelmäßig scinen Wirt und sncht Budenverstecke auf. Die kurzlebigen MLïnehen nehmen höehstwahrseheinhich nach dem Nymphenstadium eine Blutmahlzeit nirht mehr cin, falben uach der Kopulation zur bide nud gehen dann raseh zucrunde.

Die übrigen Ixodinengattungen sind so nahe miteinander verwandt, daß3 wir sie gemeinsan besprechen liönne'n.

Die Gruppe zählt in ihren Reihen die schönsten und größten Virtreter der ganzen Familie, wälmend andererseits anch wieder sehr kltine, stark abget)lattete Arten (Aponomma) rorkomme'n.

Beheimatet ist das nur vier Arten zählende Genus II yalomma hauptsächlich in Atrika, nur $H$. syriasum ist auch in den östliehen Nittehnereändern und in Indien cefumden worden.

Die Ciattung A fonomma (etwa dreimal soviel Arten) kommt in den versechiedenster Teilen der alten Wolt mol in Australien vor, wälurend das artenreichste (weit über lnundert spezies) ferms Amblyomma in allen Weltteilen, namentlich auch in Anerika, angetroffen wirk. Die meisten Vurtreter der Gruple sind Tropenbewohner.

Viele von ilnen fallen hei prächtigem dilanze clureh kontrastreiches, zum Teil sugar motallisehe Farleen mol sehr wirkungsvolle Zeichnumg auf.

Densehen werelen kaun ron ibnen angegriffen. Unseren Haustieren seladen nur sehr wenige Arten (II yalomma regyptium z. B.) furch die immerhin beträehtlichen Bhtverhste, die sie bei ihnen vernsachen kömnen, ohne jedoeh krankheitserregende Prutozoxn einzumplen. Die meisten Virtreter der Gruppe werten auf Säugern (crobwild) angetrotfen. virle aber auch (so das ganze Genus I ponomma) auf Reptilie's.

\section{Genus II yatomma ('. L. Ko'}

1)ie an Riande des Rürokenschibles stohemlen Ozallen (je eine auf joder Seite) sincl hallokngelig. Palpen relativ selrr lang. Dorsalfläche der Rüsselbasis dreieckig. J) Hänuhen halxn ein oder zwei Paal Analplatten, zwisehen denen nach hinten gerielotete, zitzenfömige, an der Spitze stark chitinisierte Zapfen stchen, diw then hinteren Körperrant überragen. Hintere AuBenecke des ersten Hïftenpares dareh tiche Einkrobung in zwei Dorne gespalten. Peritreme kommaförmig. Hlintorrandïplehen meist vorhanden.

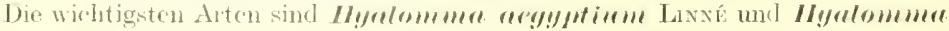
s!jrirculul C. L. КОсн.

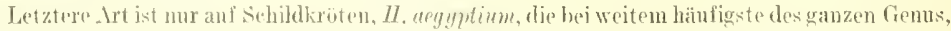

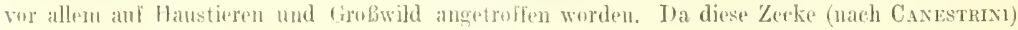



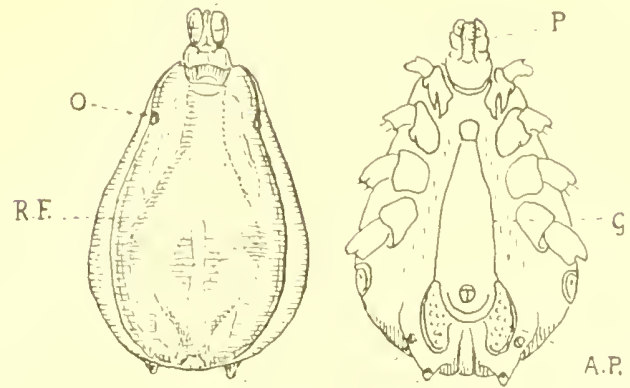

$\mathrm{ChZ}$

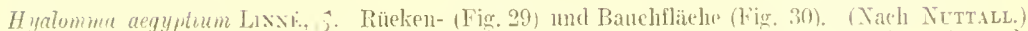
R. Ribsel, P' linker ['alpus, G. Genitaliurche, I.P. linke Analplatte, ('h.z. Kitpfen mit stark elitimisierten sputzen, R.F. Randhureht, Q. Ange.

lis zu $t$ g Blut in sich aufnelumen kamn. fügt sir bei masenhaltem dufurem den Züchlern nicht

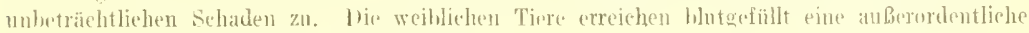
Gröbre (üher gem Länge bei $1.8 \mathrm{~cm}$ Breito).

\section{Genus Amblyomma (. L. Konн.}

Die flachen (selten sehwaeh gewöh)ten) Ocellen sind weiter nach vorn gerüekt. a]s hei Hyalomma. Palpen, namentlich das zweite Glied, sw hr lang. Dusalliärhe der Rïiselhasis meist vicreclig. Analschilde fehlen. Dafïr aber treten bei den Männelen in stets ungerader Anzahl kleine (hitinplatten (Fig. 31) ant. die sich direkt an den Vorderrand der Festoms anlehmen (von Dijnta zuerst gesehen und "bauchplättehen" genamt). Peritreme dreieckig oller kommaförmigg (Fig. .32 u. 333).

Die bekanntesten drten sinel low-

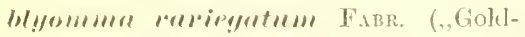
zecke"), in trojpischen Afrika vorkommend

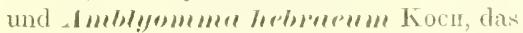

Fig. 31.

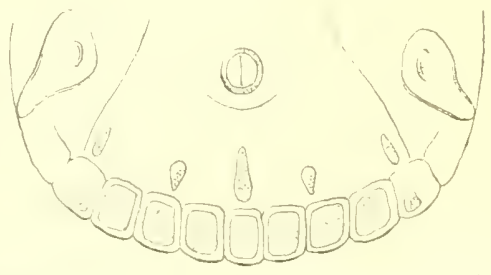

imblyomma spec., $\hat{s}$. Bauchplättchen. (1)riginal nach einem stücke meiner sammlung.) hauptsäelolich in Siirlafrika gefunden wird. aber anch noch in Deutsehostatrika und Kamerun angetroffen worden ist. Juch diexe beiden Zecken kömen gesättigt falst die GröBe von flyatomma aeyyptium erreichen.

Die bunten, farbenprächtigen Amblyommenmännelien werden in Sammlungen vis]

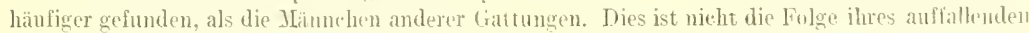

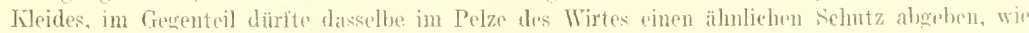

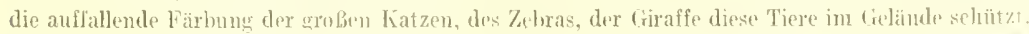
Der Grund ist wohl dem Lmsind zuznsehreihen, dab auch die Amblyommenmännelen blu

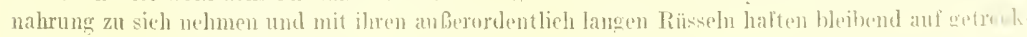
neten Fellen zu uns gutimuren.

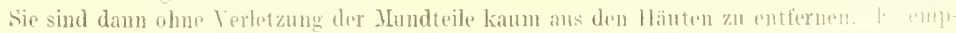

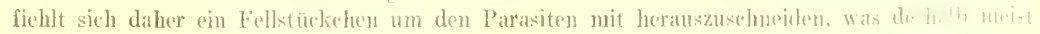



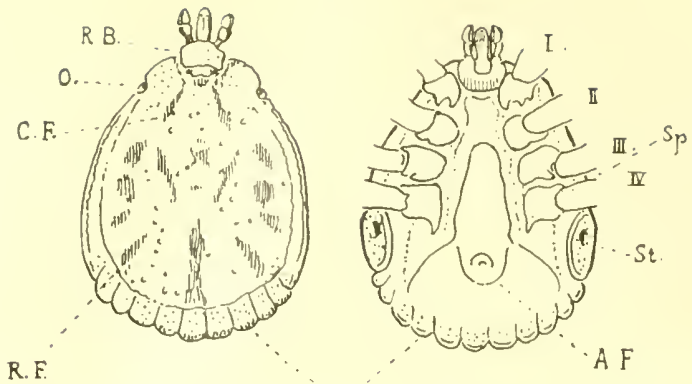

R. L.

Amblyommu Cooperi Nuttalt und Wranutitus, ô. Rücken-(Fig. 32), und Banchfläehe (Fig. 33). (Nach XetTall und Warmetitox.)

R.B. Rüsselhasis, I. Auge, C.F. Nackenfurche, R.F. Randfurche, R.L. Randläppehen. A.F. Afterfurche, st. Stigma, Sp. Stachel der hinteren imeren Ecke der 4. 1hülte. I. II. III. IV. 1.-4. Hüfte.

sehr unauffälligr und ohne die Hänte zu entwerten gesehehen kann, weil sieh die Zecken meist in den Weirhen und Achseln ihrer Wirte festsetzen.

\section{Gemus A ponomma Neumax.}

unterseheidet sich (rigentlich nur duch seine Augenloxigkeit und die fehlenden Banchplättchen von der wrigen Gattung. Die kleinen Tiere sind niiehtern stark abgeplattet, haben aber einen relativ sehr loreiten Leib, so daß der Körperumriß beinahe als Kreis erscheint. Auscehlieblich auf Reptilien sehmarotzend.

\section{Ihipicephatinge.}

Die seehs Gattungen der Lnterfamilie hahen sämtlieh wesentlieh kürzere Palpen und Mundteile, als die Ixorlinen.

\section{Genus Haemaphysalis (: L. Kond.}

Augenfehlen. Palpen kegrlförmig, der proximale Rand des zweiten Ciliedes weler breit und desIall, den AuBcmrand der Rüsselbasis scitlich weit überragend. Dormalfläche der Basis viercekig. Analplatton fehlen. Landläppehen rorhanden. Peritront der Männchen ei- oker kommaförmig, der Weibehen rumdlieh. Sexual(limophismus w rnigr ansgesprochen. Die Räiekenfläehe des ersten Troehanters trägt eine cigentïmliclae Jueliclfömige Vorwölbung (Fig. 34).

Die etwa :31 Arten zählonde (

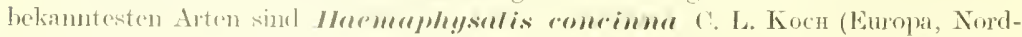

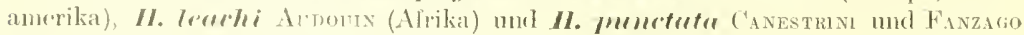
(liosmopolit).

IIarmaphysatis sehmatotzt anf umseren Hanstieren und auf Wik, die Larven auch auf Reptilien. Sir schaden, in größerer Anzahl vorhanden, wohl elureh Blutentzichung, ohme alrer lirankhriten zu ïhertragen.

Die auch bej uns ausnahmsweje einmal gefundene, zimmlbraune H. punctata zidehnet sich durch zahlreiche grefiederte llärchen an ventraten Immenrande (namentlich des zweiten Gliedes) 
des l'alpus alus. Das dritte l'alpenglied trägt auf seiner ventralen Fliche cinen starken, rückwärts-

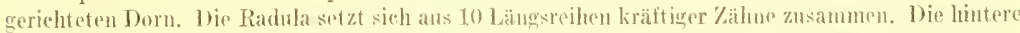

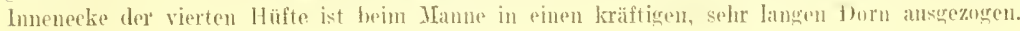

Fig. 34 .

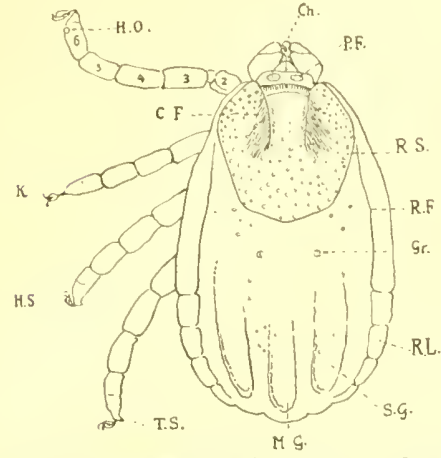

Haemaphysulis punctata CANESTRINI und FAXZAGo, Rückenfläche. (Nach L. L. RoвiNsox.) H.). Halber'sehes Organ, C.F. Naekenfurche, $\bar{\swarrow}$. Nanen, H.心. Haftscheibe, T.S. Tarsalsporn, H.6. mittlere Hinterrandgrube, S.G. seitliehe Hint errandgrube, R. L. Randläj\}\}chen. Gr. Rüekengrübehen, R.F. Randfurche, R.S. Rüekensehild, P.F. Porenfelder, Ch. Chelikeren, 2 Trochanter, 3 Femur, 4 T'ibia, 5 Protarsus, 6 Tarsus.
Fir. 35.

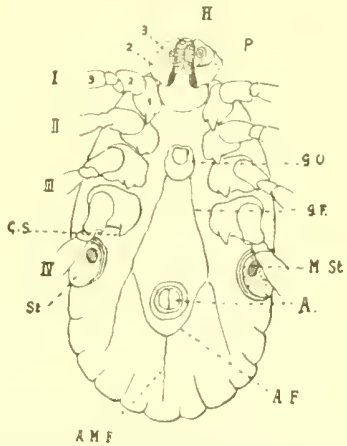

Huemaphysalis punctute Caxestrixi und Faxzago, 으. Bauchfläche. (Nach L. E Robixsox.) H. Hypotsom, P. linker Paljous, G:O. Genitastloffinmo, G.F. Genitallurche, H.St. Macula des Stigmas (Stigmenfleck), 1. After, A.F. Afterfurche, A.M.F. Anomedianfurche, St. Stimma, C.S. Sporu der 4. Hiifte, 1. Hüfte, 2. Troehanter, 3. Feniur, 2 zweites, 3 drittes blied des rechten Palpus.

Die folgende aus den Gattungen Dermacentor, Rhipicephalus und Rhipicentor znsammengesetzte (iruppe zeigt ebenso wie Hacmaphysalis eine meint wohl entwickelte Analfurehe die den After bogenförmig anf seiner Hinterseite mmzieht und seitwärts weiterstreichend häufig den Innenrand der Gesehlechtsfurchen erreicht. Die Tiere sind gewöhnlich einfarbig, cimzelne Arten, namentlich im männlichen Gesehlecht, auch bunt.

\section{Genus Dermacentor C'. L. Kincu.}

Hit kleinen, runden, wenig erhabenen Augen. Palpen kurz und diek. Dorsalfläche der Rüsselbasis viereckig, die kurzen Seiten nach auben geriehtet. Analplatten fuhlen. Randläppehen vorhanden. Peritreme oval oder kommafömig. Die Hüften sind an der hinteren Innenecke tief eingekerbt. Bei den männlichen Tieren nehmen die Hiiften von der ersten bis zur vierten häufig an Gröbe zu, juhlufalls ist bei allen Arten das letzte Hüftenpadr das größte. Das distale Encle des zweiten Tarsalgliedes ist gespornt. Der Rüekenschild (namentlich der Hämnehen) mit meist sehr auffälligen, bunten Zeichnumgen bedeckt (Fig. :36 u. 37).

Ton don etwa ein Viertelhundert iiber die ganze tirde verbreiteten Itermacentor-Arten sind die bekinntesten reticulutus Fans. (Europa, Asien) nur!

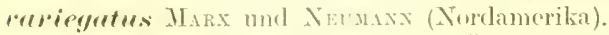

Dermacentor reticulatus soll der Überträger einer Hundepiroplismose sin:

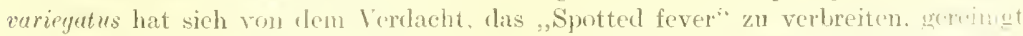

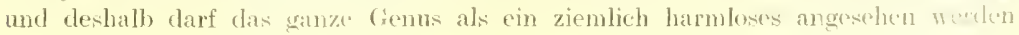




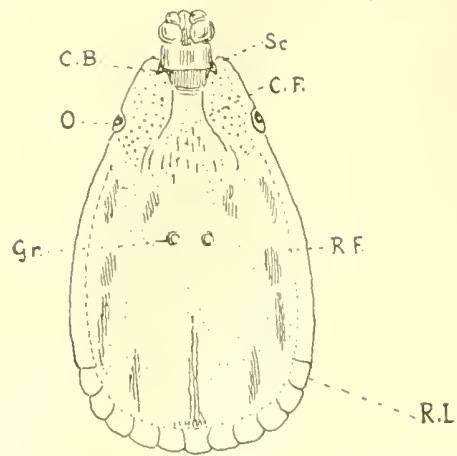

Fig. 3i und 37.

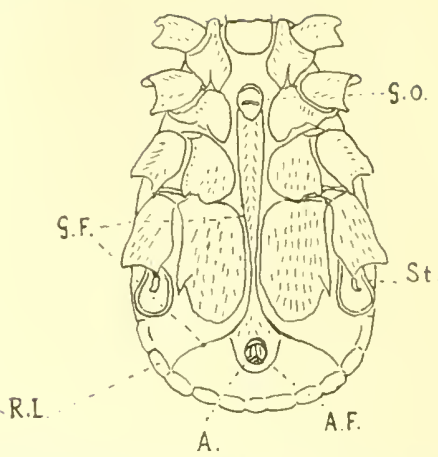

Dermacentor variegutus var. Fümschadalus Nin MAx, ô. Rücken- (Fig. 36) und Bauchfläche (Fig. 37 (Naeh Neumins.)

C.B. Horn der Rüsselbasis, O. Luge, Gr. Rückengriuhchen. Sc. Sehulter (Scapula), C.F. Nackenfurehe, R.F. Randfurehe, R.L. Randlippehen, G.F. Grnitallurehe. A. After. A.F. Afterfurche, s't. Stigma. G.O. Giesehleehtsöffmung.

\section{Genus Rhipicephalus C. L. Korn.}

Augen vorhanden, meist flach, manchmal halbkugelig. Palpen kurz, erstes Glied, auf cler ventral'n Fläche plattenfömnig verbreitet, trägt bis 7 geficelerte Borsten. Radula aus 6 Zahmeihen gebildet. Dorsalfläche der Rïsselbasis gewöhnlich

Fig. 38 und 39 .

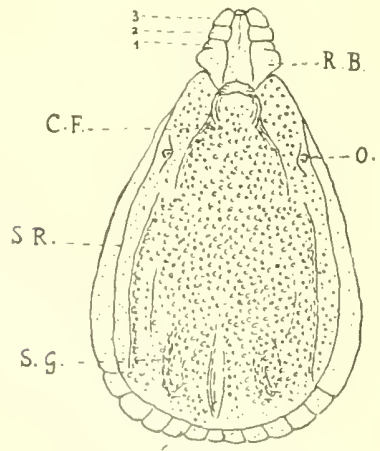

$M G$

lihipicephalus bursa CaNestrixi und Fanzago, $\hat{0}$. Rüclienflache. (Nach Rosmnson.)

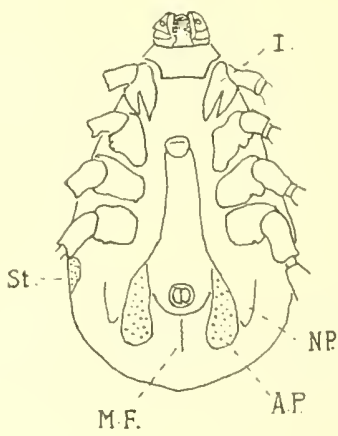

Rhipieephalus sanguineus, LATREILle, ô. Bauchfläche. (Naeh NutTall.)

123 erstes, zweites, drittes Tasterylied, C.F. Nackenfur he, S.R. Schildrand, S.G. Seitliche Hinterrandgrube, M.G. mittlere IIinterrandarnbe. O. Anwe, R.B. Rüsselbasis, St. Stigma, M.F. Mittelfurehe (Anonarginaliurebe), A.P. Afternlatte, $X . P$. Nebenplatte, $I$. Coxa prima mit :in Berem und innerem sporm.

scehsechig. Analplatten stets vorhanden, hänfig auch Nebenplatten. Randläppohen wohl entwickelt. Schwänzehen manchnal vorhanden. Peritreme kommaförmig. (coxa I tief gespalten. innerer Sporn viel kräftiger. (Fig. 38 u. 39.) 
Die meisten der mehr als 30 Arten zählenden Rhipioephalin sind Afrikaner, doch kommen auch wichtige spuzies in Europal, Asien und eine in Amerika ror.

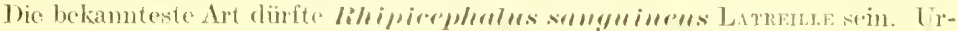
sprimglich wohl aueh Afrikanerin und die gemeinste Hundezecke dor warmen Länder, wurele sie durch ihre Wirte äber die ganze Erole verloreitet.

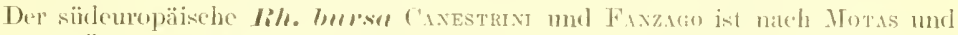

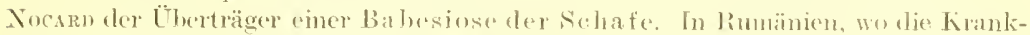
heit am häufigsten vorkommt, wirt sie Careeag genamnt. Lih. simus (. L. Kocu

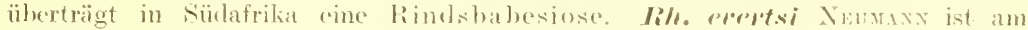
Kap als Wirt cines anf Equilen ïbertragharen Piroplasmas mul les Texasfieberparasiten gelïrchter (Theiler).

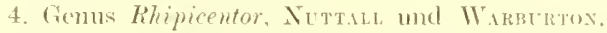

Angent rorhanden. Palpen kurz. Dorsalfläcle der Rüssclbasis sechserkig, äubere Ecken weit ausladent. Analplatten fehlen. Peritremo dreieckig $(?)$ oler kommafömig $\left(0^{\dagger}\right)$. Randläppehen rorhanden. Coxal tief gespalten. Coxa IV

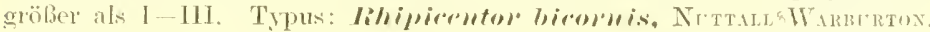

Fig, 40.

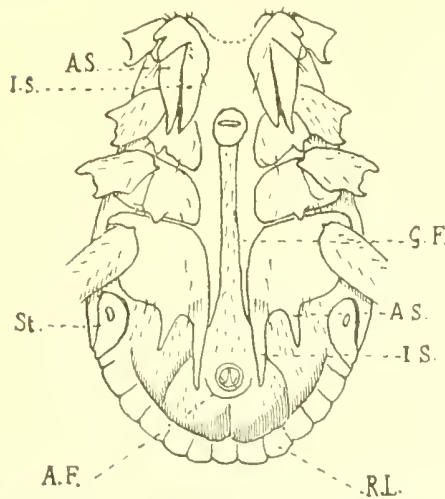

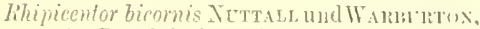
j. Baturhflache. Nach Tutrall. -l.s. und I.S. Auberer und imnerer sporn der ersten und vierten Hüfte, st. stigma, A.F. Niterfurche, $L . L$. Randläpproben. G.F. Cienitalturele.
Jije. 11

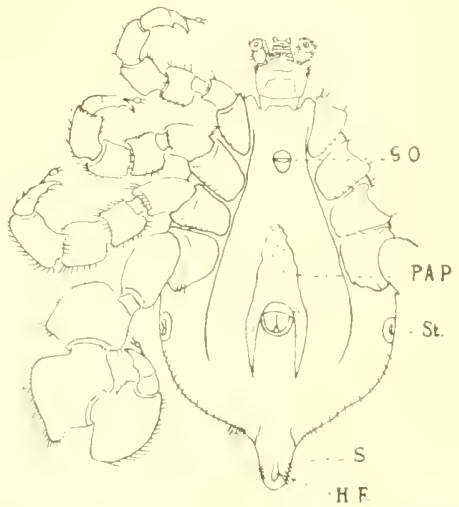

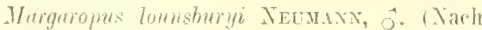
Nervari:

fr.(). (ienitaloflmmg, P.A.P. Präanajulate. st. Sitioma, s'. Schwanzchen mit $H . F$. lakenfirmigem Fortsatze.

Die noch verbleibende, kleine Gruppe (vom vielen Autoren in eine Gat tung zusammengefabt) läBt eine Analfurche vermisien. Sic enthält das tür die Tierpathologie wichtigste Gems Boophilus und das Genus Margaropus. Beide Genera zäblen nu' je zwei Repräsentanten.

\section{Gromus Margaropus, Kinsch.}

Augen vorlanten, bei den Weibchen an den AuBenecken des schmaten

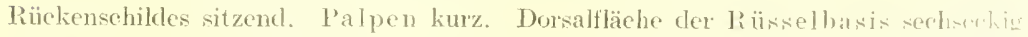
Präanalschilı nach hinten in zwei lange Spitzen verlaufend, die den Anus ented-

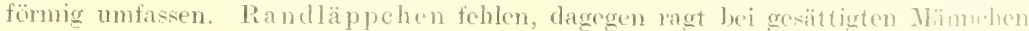


eine schwanzförnige Ausstïlpung ans den Hinterrande hervor. Poritreme rund bri beiden Geschleehtern. Hüften kegelfömig. Die Beine nehmen in allen Gliedern an Dieke und Länge rom ersten bis zum letzten l'aare stetig zu; das letzte Par erseheint auf seiner Oberfläche geperlt (Name!).

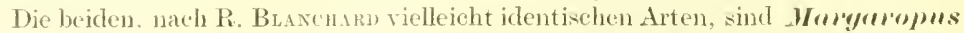

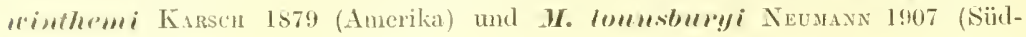
afrika).

\section{Genus Boophilus, CrRtuce.}

Angen rorhanden, ähnlieh stehend wie bei Margaropus. Palpen kurz, die einzehen sehr breiten Glieder daehziegelfömig übereinandergelagert. Dorsalfläche der R üsselbasis seehseckig. DerR ückenschild des Männchensstark gewölbt und glänzend, der des Weibehens sehr klein und sehmal, an seinem Hinterende in ein Dreieck auslaufend. Zwei Paar Analsehilde vorhanden. Randläppehen fehlen. Scluwänzchen vorhanden oder fehlend. Peritreme rund. Hüften kegelförmig, das erste Paar an der hinteren Imenecke eine flache Einkerbung zeigend. (Fig. 42 12. 43.)

Fin. 42 and 43 .
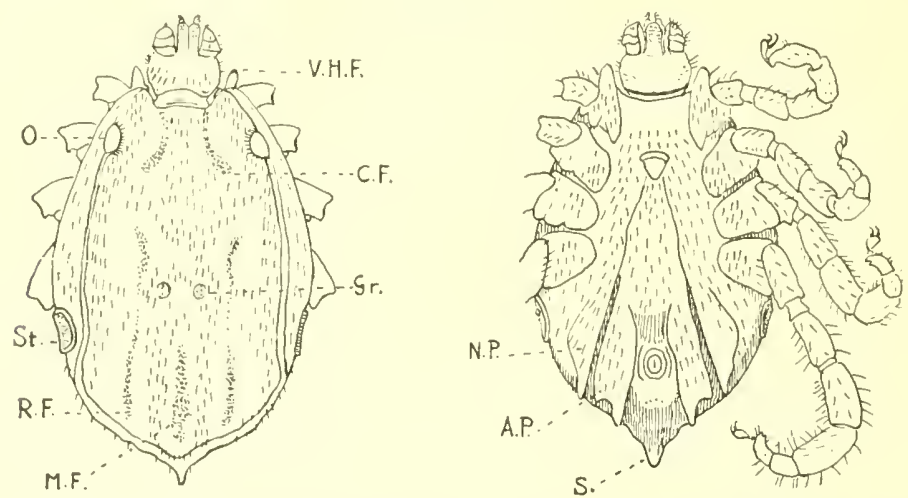

Boophilus decoloratus Koch, $\hat{0}$. Rücken- (Fig. 42), und Bauchfläthe (Fig. 43). (Naeh Nuttald.) (). Lnge, St. Stigma, $F \cdot F$, seitliche Hinterrandfurehe, H.F. mittlere Hinterrandfurche, Gir. Rückengribehen, C.F. Xackenfurche, T.H.F. vorderer Hüftenfortsatz, N.P. Nelienplatte, A.P. Afterplatte, S. Sichwänzehen.

Die Gattung zählt nur zwei Arten, die so nahe miteinander rerwandt sind, (lal.s sie Neumax zu ciner einzigen zusammenzieht. Sie morseheielen sieh allein durch die Hinterenden der Analplatten, die bei $\boldsymbol{I}$. ammulutus abgestutzt, loei IB. derolonotus in langt, oftmals den Leibeshinterrand ïberragende spitzen ausgezogen sind. 1) ir sie auch verschiedene Verbreitungsgebiete haben (annulatus ist Nordamerikane's, wälscend decoloratus hanptsächlich in Arika vorkommt), empfiehlt es sich doch wohl, die bejelen Arten gelten zu lasen. Boophitus ist mit Rhipicephalus so nahe verwandt, disls Verwechslungen leicht vorkommen können.

\section{buophilus anduletus tiar.}

Die \%eke ist sehr klein, der Hann nur $2 \mathrm{~mm}$ lang, selbst noch kleiner, das Weih $2,5 \mathrm{~mm}$ nüchtern, kamn jedoch bhtgetüllt ïber $1 \mathrm{~cm}$ an Länge erreichen. Die Farbe der Tiere ist ein lichtes (iranbramn. 


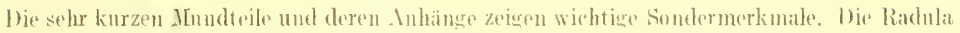
besitze of Zahureihen. Dats arste Palpenglied trigt ant seinem rentralen lmemrande, meistens

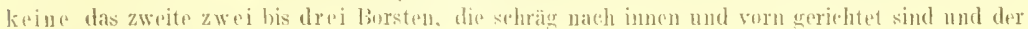
Ventralilache des Hypostoms autheren.

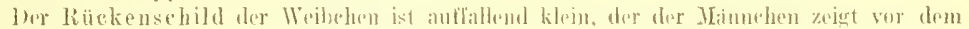

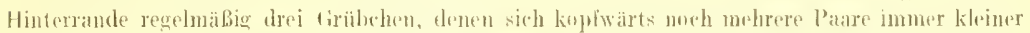

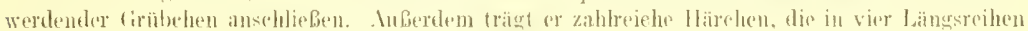
anterordnet sind.

Die Inalschifde sind scluäg nach innen und hinten abgestutzt und an der hinteren Innenreke leicht gezipfelt.

Wo die Boophilus-Zecke auftritt, fohlt nur selten das 'T'xasfieber. Wegen ihres meist unglaublich zahlroichen Vokommens auf dem einzelnen Wirte kimn we auch immunen Tieren durch ihren Blutdurst den arheblichsten Scharden zufügen.

\section{Fang. Lufhewahrume und Versand.}

Sehwierigkeiten, wie sie z. B. bein Fange der leicht leschwingten Dipteren und dkr sprunggewandten Flöhe entstehen können. kummen bein Einsammeln der trägen, meist sogar dureh festeste Anheftumg an ihren sitz gebannten Zceken nicht. vor. Dagegen macht e's der letztere L'mstand notwendig, leim Ablösen der Tiere vonihren Wirten die größte Torsieht walten zu lassen, weil sonst gar zu lejeht die mit ihren Kkammerhaken im Gewebe rerankerten ('helikeren ats dem Zeekenleibe horansgerissen werden oder das Hypostom abbricht und somit für die Erkennung der Art hochwichtige Teile verloren gehen.

Es empfichlt sieh deshalh zunächst che Tiere mit ciner Öl-odor Potroleumschieht zu überziehen, um sie so zu ersticken. Bei lebenden Wirten werden wir schon deswegen immer so verfahres, weil wir sonst aueh diese schïligen wïrden. Die alltägliche Beobachtung lehrt, dab sitzengethichene Inndteile mindestens eine stärkere Entzündung und häulig Eiterung in der L'mgebung der Einstichstelle lervorrufeus.

Hat man es mit getöteten Wirtstieren oder deren Fellen zn tun, so schucidet man am besten kleine Hautstïckchen mit der daranlsitzenden Zecke ans; das häbt sieh in then meisten Fällen leicht. und ohne der Decke erheblichen schaden zuzutïgen, bewerkstelligen.

larven, dic manchmal aueh in den Gichörgängen ihrer Wirte sieh aulhalten md damn nach einem Öleingub herauskiechen, wirt man am leichtesten im Gelände+, namentlich auf Viehtriften, fangen kömnen. Auf einem firashalme sinel sehon viele Hundert der winzigen Tierehen gefunden worden. Da sie hier auf vorbeiziehende Weidetiere warten, um sieh ihnen anzuheften, su lassen sie sich gelegentlich auch eimmal durch einen Wolllapjen, hen man über dic Wriese hinschleift, täusehen, und können so in grolier Zahl gefangen werden.

Argasiden sind schon sehwieriger zu bekmmen, da sie nur nachts auf ihren IVirten angetroffen werten und sich nur kurze Zeit auf ilnen aufhalten; sie müssen, wenn man seine Nichtruhe nicht opfern will. in ihren Verstecken aufgesucht worden.

In der Crefanguschalft lasen sich unter seeigneten Verhältnissen, namentlich wemn man den Tieren anch Yahrung oder wenimstens: Wasser bietet, Zecken viele Monite, Argasiden sugan"

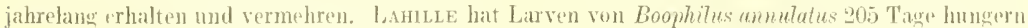

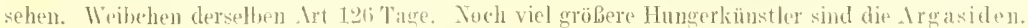

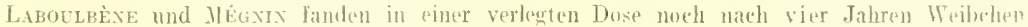
voll Argas persicus und omithodoms tholozmi labend vor. Argus reflexus soll nach LABortuix. sogar sechs Jahre hungern künnen.

In bezug auf Konsorvielung und Tersand gilt für die Zecken dilswilla, was weiter unten für dic ritechnüchen angegeben ist. 


\section{I'nteramelung.}

Die Oberlïchenverlältnisse les Zeckenliörpers und seiner Anhänge werden an beston am lebenden Tiere bei aulfallendem Liehte unterseht. Für die Benteilung mancluer feinen, in versohidenen Ebenen gelegenen Einzelheiten empfiehlt es sieh cin Stereomikroskoj, zu verwenden. Scitliehe, dureh ane Beleuelitungslinse zurammengefabte Stralnlen dassen uns dam oft (selbst mit dem einfaehen Mikroskop) noch Einzelheiten wahmehmen, die vorher immer ïberselsen wurden.

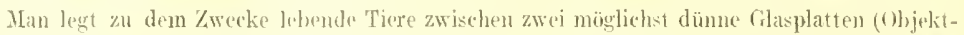

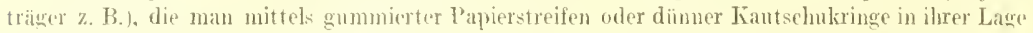
whiilt. Werden grïbere Zecken so zul stark gedrückt, so ist es vorteilhafter Objektträger mit llohlschliflazetten zu verwenden, die nit eincu gewöhnliehen ador wenn uötig einem zweiten fazettierten (objeditrïger überdeckt in den meisten Fällen Raum genug zwischen sich lassen, um das Tier nicht zu stark zn komprimier'm, und es doch in der gew unschten Lage lalten.

So bibt sich (sellost be relativ starker Vergröberung) z. B. der Bau und dic Bewegungen der letzten drei Fubglieder mit der Haltscheibe bei aufrallendem und durehfallendem Liehte bester als in jeder anderen Weise erkennen und benbachten.

Bei auffallendem mol tangierendem lichte lassen sich natürlich aueh getrocknete Tiere nit Torteil mutersnchen; nur müssen wir uns dann stets daran erinnern. daß wir Mumien vor uns haben, die in viclen Teilen versehrumpft und deshalb, in ihron Oberflächmverdältnissen mehr oder weniger, rielfach aber recht erbeblich। rerändert sind.

Wollen wir ganze Tiere bei Aurchfallendem Lichte untersnelen, so müisen wir ilsre Leiber vorher mögliehst. durchseheinend maehen.

l)as läBt sich in der bekannten 11 eise mit 10\% kaliłösung oder noch hesser und raselor mit reiner dureh wenge Tropfen Glyzeris llüsig gemachter liabolsäure erreichen. Durch kali caustienm-Lösumer werden hei höherer Temperatur (Siedehitze) seht raseh, oder durch genügend langes Stedienlassen $(1-3$ Wochen) auch hei Zimmerwärme alle Teile des Zeckenkörpers bis auf das Chitin zerstöt und sulhst dieses sthlie Plich glasartig aufgehellt, ohne zu quellan und seine furm zu verändern. ] lats letztere ist freilich nur dann der Fall. wem es in waisserigen Hedien verbleibt.

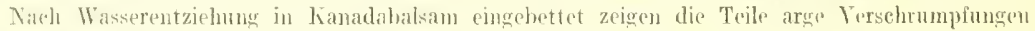
und Terlagerungen. Die Tachteile allzugrober Transparenz kömen durch Fäbung mit Fuchsin oder Pilsinsane in wässeriner Lirsung teilweise bestitigt werden.

Die Anfhellung mittels liarbolsiare hat noeds anberdem den sehr urofeen Vorteil, dab die Inukehn und Eingemerde der Tiere crhatten bleiben und der Beobachtung zugänglieh gemacht merdin kimum.

Th die imneren Weichteile direkt nnd möglichst mverändert beobachten zn

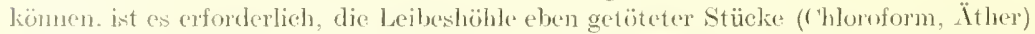

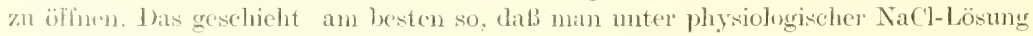
mit möglielst lemem Coorensehen Seheerchen den Körperrand der Zeeke entfernt.

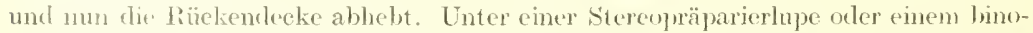
kulären Miliroskope (sehwache Objektive) werden mun die Eingeweide unittels feiner. gestielter Xadehn anseinandergezogen nut zeigen uns so mögliehst lebenswahr ihre form und bewergmg.

Will man einzelne Trile. z. B. Rüsscel, Palpen, Beine, als mikroskopische Präparate erhalten,

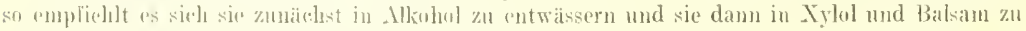
übertragen. Xind vinfacter und raseluer gelengt man zum Ziele, wenn man die Teile fär einge Stunden in Azcton rinlegt und daun direkt in lienadabalsam überführt.

Sehr schöne Gesantbilder von den oberflächliehen Teilen der Rïcken- und Bauchwand erhält man durch Abschaben des Weichteile von den durch den Seherenschnitt erlangten hejen Körperhälften mittels cines feinen Skalpells. J)ie entwässerten 


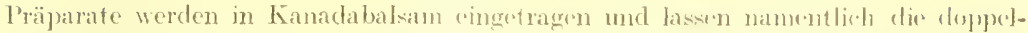
brechencten chitinteile im pelarisienten Liche in wunderbare farbenpacht leryortreten.

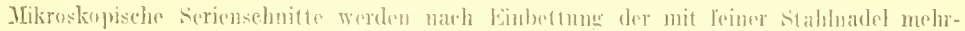

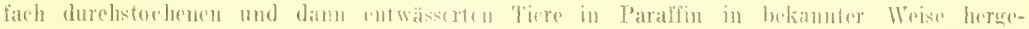

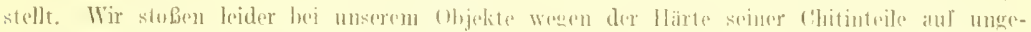

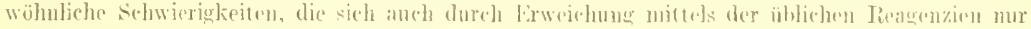
in sclur unvollkwmmener Weise holy

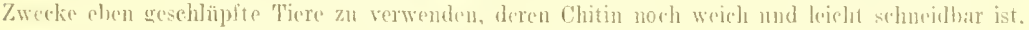

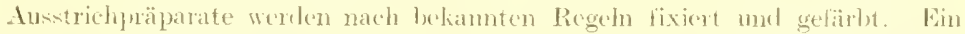

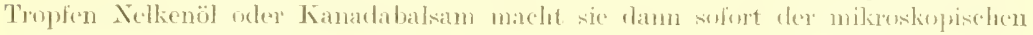
Cntersuchung zugänglich.

\section{Prophylaxe, leinde.}

Zecken von ihren Opfern durh Eimeiben von stark riechenten um] giftigen

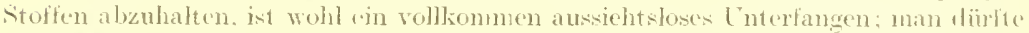
auf diesen Wege noeh wenger erreichen. als z. B. bei Stechmiicken. Bremsen, Föhen, IVanzen n. dgl. Die befallenen Haustiere kefreit man clurch Absuchen und meturlach wiecholte Arsenikbäder von ihren Peinigern. Abreibungen mit Rohpetrolanm,

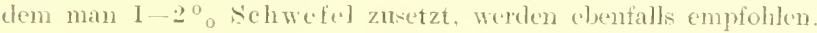

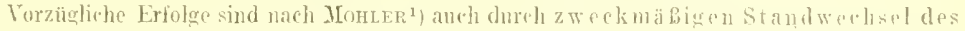

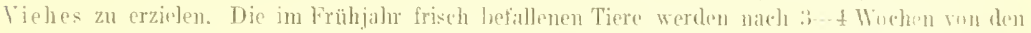

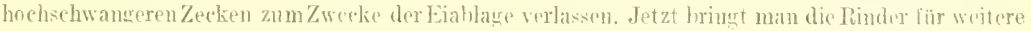
14 Tage anl eine zweite, (a)enfalls engegatterte (irasliache, wo sie nun anch den litest der etwal

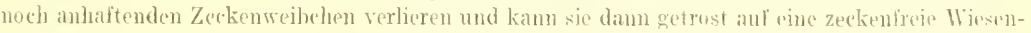

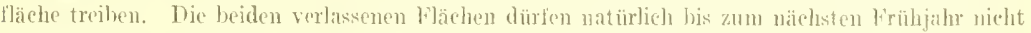

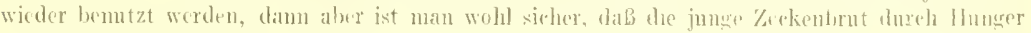
zugrunde gegangen ist.

Leider gibt das Wild und linzukommende kranke Hanstiere immer wieder nene Inledaliuns-

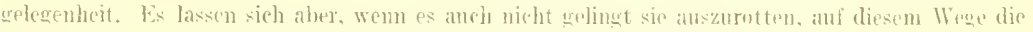
wefährtirhen Zacken immerhin in wirkungswllster Wrise verminderus.

Noch ausichtshser ist leider eine vollständige Terniehtung der Argasiden, selbat auf einem nur beschränkten Giebiote.

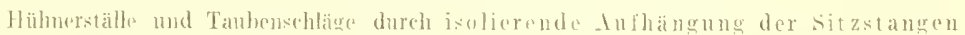

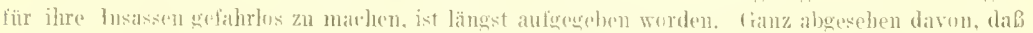

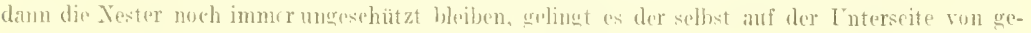

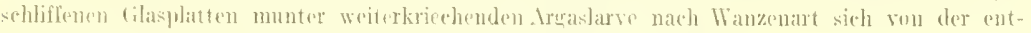

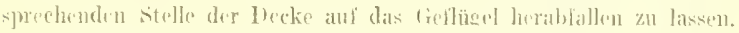

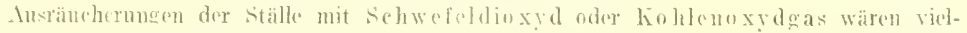

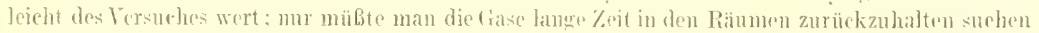
und die Prozedur mehriach wiederhenten. Gin Verkleben der Ritzen und spalten würde sich

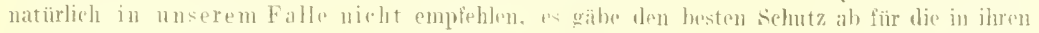

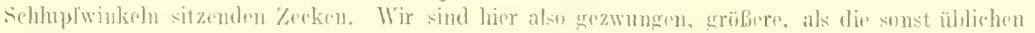

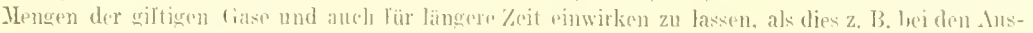

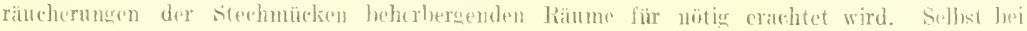

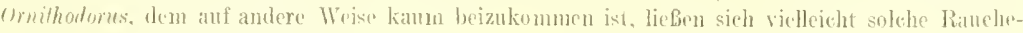
rungen mit Forteil verwenden.

Gegen die Gefahrendere Ornithodorus-stiche kömnen sich europäische lieisende.

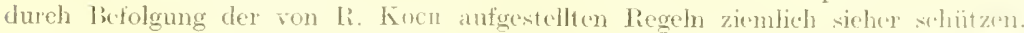
Er warnt ror der Übrmachtung in Negerhütten, Karawansereien uml an! troekenen Stcllen, in der Nïhe ron Handelsstraßen.

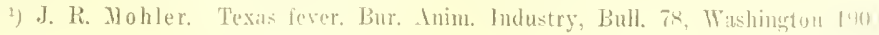


list man trotzlem gezwungen in Negerhütten und Rasthäusern zu ïbernachten, s) soll man nach Sichlolxt: (dies Handbuch, I. Aufl, Bd. 3) Wasser ïber den Berlen des Wohn- und Schlafraums atuggieben, hohe Schaftstiefeln anziehen und die Betpofosten mit I'etroleum hefeuchters.

Der mähtigste Feind der Zecelen ist der Hunger. Sehon im Larsenstadium tallen ihn die meisten zum Opfer. clat es nur äuBerst wenigen gelingen diurfe, einen Ilirt zu erreichen.

Sehr erfolgreiche Foinde habon wir dann wohl anch im Pflanzenreiche zu suchen. Niedere Piłze werden unter ibmen ebenso anfäumen, wie sie das unter den äbrigen Arthropoden tun.

Die von ihmen ülwertragenen Blutparasiten sehädigen watiulieh auch ihre Wirte. die Zceken. und führen in der nötigen Anzaht vorhanden ihren Tor herbei.

Ton Afotazuen sind es namentlich die Dipterenlarven, die Zeckeneier vernichten. Das gleiche ist veltach von Ameisen berichtet worlen, die auberten auch noch mit Vorliebe farven annehmen. Weblas stellte fest, daB Phonergates bicoloripes, cine Wanze (Retuviule) in Westafrika so häutig beim Answangen von Zecken betroffen wird, das dieses Vorkummis den Einwolmern von Angola wohl bekannt ist und sie dic Wanze drshall, anch mit einem besonteren Namen belegt haben (Ochindunch: der Verfolger). Höchst wahricheinlich werlen anch Laut- (C'urabiden) und Raubkäfer (Staphyliniden) eine ihren IVeg kreuzende Zeeke nicht versehmähen.

Reptilien heteiligen wich olexilalls und w is es seheint manchmal mit grobem Erfolge - es lehrt fies das beliannte Beispiel von on aika - aun Verniehtungsliample gegen die Zecken.

Von Vöge'n dagegen werden ,ie, wahrseheinlich wegen ihrer widerwärtigen Hautselsete (Kuxalelrïsen!), nur selten getressen.

Cnter clen sängornscheint die Ra tie ein sehätzbarer Zeckenvertilger zu sein die einzige 'l'ugend, die ihr wohl bis heute nachgerühmt worden ist.

\section{biteratur.}

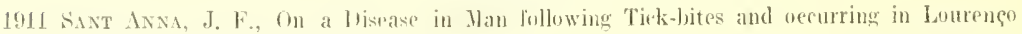
Marques. l'arasitology, Bd, 4 , S. 8т.

1911 de Bealrepare Irationo, H., Xotas solure ixididas hrazilciros. Mem, do Instit, Oswaldu Fruz, Bil, Ill, Fat'. 2.

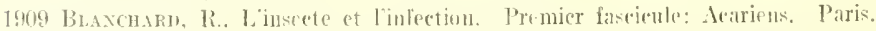

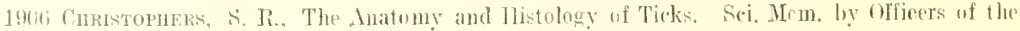

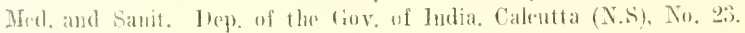

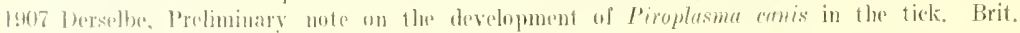
med, journ. 1‥ Tamiar

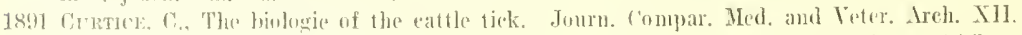

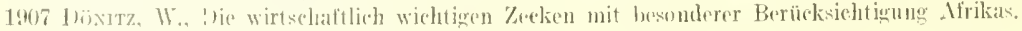
laipzige. I. .1. Burt\%.

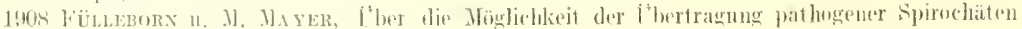

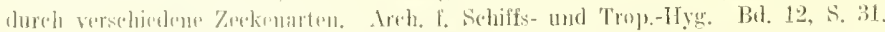

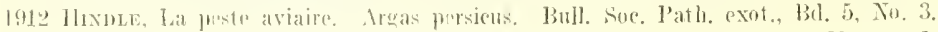

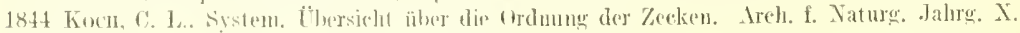
Berlin.

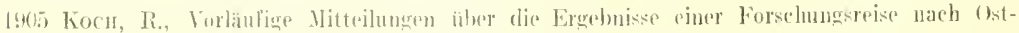
afrikil. Thentselue med. Wochencelur. Mr. ti.

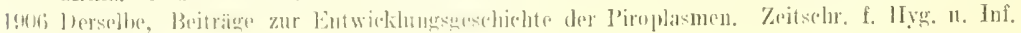
Bu. 54. 


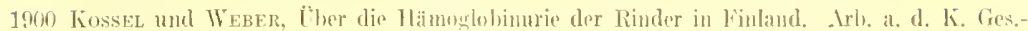
Ant. XYll.

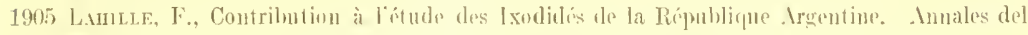
Ministero d. Agrie. Seereion de Zonterniat ret. Tol. II. No. a.

1910 Llistumax, Sir W. B., Olservations on the meclanisul of infertion in liak fever and hereditary transmission of spirueharta lutteni in the tick. Transactions of the Soe of Trop. Hed, and TYe., Vol. III, Xo, 3, \&. 77 95, 2 Taf.

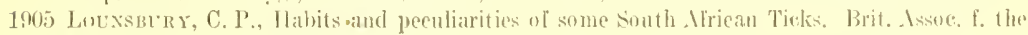
Mly. Sei., seet. ]), South Mliriea.

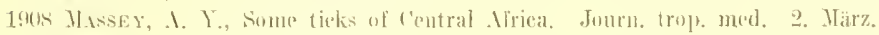

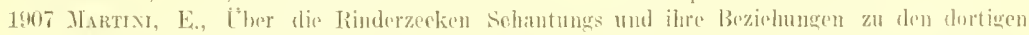

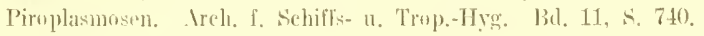

1911 Mlorer, X. B., Transmission of spotted fever hy other than Nentana and daho ticks. . Tourn. infeet. discases. 11. 2.

1911 1hrselhe. Transmission of spotted fever by the tick in nature. Elwula.

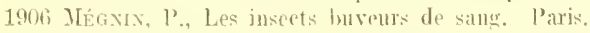

1911 JIEtz, K., Irgas reflexus, die Taubenzecke. Honatshefte für prakt. Tirrheilk., Bo. 2.2.

1907 llonder, E. E., The tramsmission of yaws by ticks. Journ. of trop. Wed. 15. November.

190s MärLess. B., Experimentelle stndien über die t'bertragung des Riickfalllieber's dureh Zeken. Zeitichr. 1. Hyg. Bel. 58.

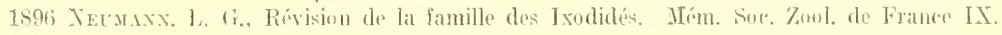

1897 Derselloe, Rev. d. l. Lam. d. Ix. Th. X.

1899 Dirselbe. Rev. d. l. fim. đl. Ix. Ih. XII.

1901 Derselbe, Rev. d. I. tam. d. Ix. 1b. XlY.

1902 Derselbe. Totes sur di's Jxodidés. Areh. de Parasitologie VI.

1899 Xettall, G. H. F., On1 the role of insects, arachnids and myriapods, as earriers in the spread of bacterial and parasitic diseases of man and animals. Johns Hopkins Hospital Repurts, VIJI.

1908 Tittall, Cooper and Robinson, The structure and hiology of Inemuphysulis punctutu, fanestrini and Fanzagn. Parasatology I.

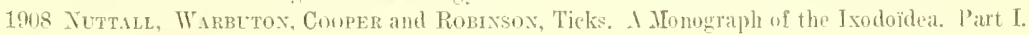
The Argasidae. Cambridge.

1911 I) ieselbem. Tieks. I monograple of the Ixudoïdea. Part If (Netrall and Warbuton). Irodoüdur. Sect. I. Classifieation, sect. II. The gemus Itodes. Cambridge.

1911 Jieselben, A momograph ol the Ixodoidea. Biblography of the Irofoidea. Cambridge.

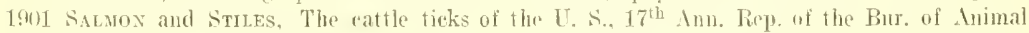
Industry. Washington.

1906 Schrisise, C., Rïekfallfieher. Handb. der Tropentirankh. von X[exse, 1. Aufl., Bd. IIL.

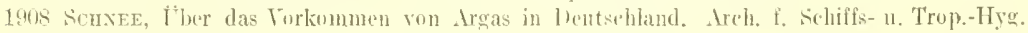
Bd. 12. S. 32 .

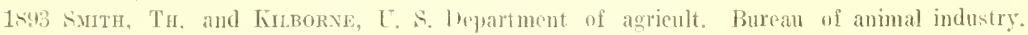
Bull. Ni. 1. Wrashington.

19ug Themer, 1. The inlluenere of cold on ticks and Piroplasma parvum. Bull. sore. path. exot, Bel. I. s. tól.

1909 Hersolbe. Transmission des spirilles et des piroplasmes par diflérents espèces de tirtnes. Bull. soc. path. exot. Bd. 21. S. 293.

1910 Deuselbe, Texasfieber. Rotwasser mud Gallenlarankheit der Rinder. Zeitsclur. f. Infuktionskr.. paras. Jirankls, und Hyg. d. Tanstiere. Bd. 8, s. 39.

1907 Wellax r. C., Prel. notes on some bodies fund in ticks. Brit. med. journ. 20. Julí 


\section{Insekten, Hexapoda.}

Die Hexapoden sind Eutracheaten mit drei Beinparen an dem dreigliedrigen Thorax und finblosem Abdomen.

In versehiedenen Ordnungen zählt diese Klasse die wiehtigsten Krankheitsïbroträger, die wir aus dem Stamme der Arthropoden kemen.

\section{Siphunculata.}

\section{Die Läuse.}

v. Prowazer (Studien üher süngetiertrypanosomen. Arb. ans d. Kaiserl. Gesundheits-

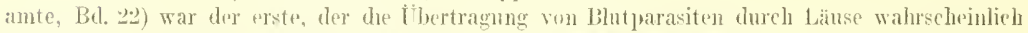
machte; er beobaclitete im Tahrungssehlanch von Huemutopinus spinulosus Burn. Entwicklungsformen des Trypunasona loveisi und in der Tat ist damn spaiter die experimentelle C'bertragnng der Rattentrypanosemen durch Länse Nory und McNEaL (The life history of Trypenosoma levisi

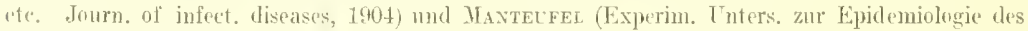
rurop. Rüekfallfiebers, tentralblatt f, Bakt. Ref. Bd. 42, 1908) gelungen.

fer letztgenanute - Iutor zeigte ferner, dab die liattenrekurrens durch Haemutopinus übertragen werden kann (MANTELfel, Experim. Lntersuch, znr Epidemiol, de's europ. Rückfallf. Arb. aus d. Kaiserl. Gesundheitsamte. Bd. 20, 1908) mut Bobachtungen von Mackie (The part played by Penticulus corporis in the transmission of relapsing fever. Brit. med. Journ. 1907) und Sierrext and Foley (Fievre récurrente du Suld-(1)anais et Pedieulus restimenti. Bull, soc, path. exot.

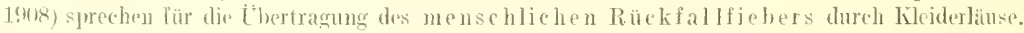

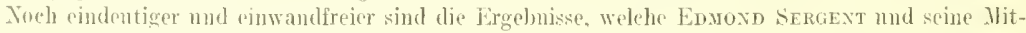

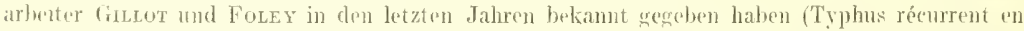
Ayérir. Sa transmiscion par les poux. C. r. soe. biol. B.. 70, S. 1039 und La spirillose nord-africaine

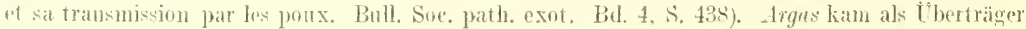
uicht in betracht, wohl aber waren alle liranken mit Läuse'n behaltet und . Afeen dureh Länse, von we kranken entnemmen, zin infizieren.

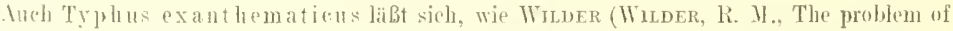
transmiscion in Typhnsfever. Jumrn. int. discases. Bd. 4. s. 9) zeigte, durch Läuse von Itle zu

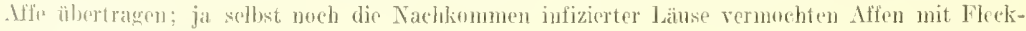
tylums 2.1 inlizioren.

Uhemetopims oris soll nach Bostert anch Milzbrand von sehal anf schaf, eine andere

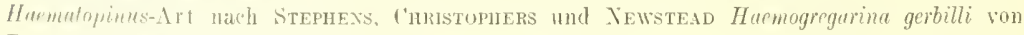
Ratte aul Ratte ühertragen kïmnen.

Dic Läuse frimzösisch Poux, englisch Lice (Singul, Louse), itahieniseh l'jdoechi, werelen lesute noeh von vicken Entomolegen mit den Ha arlingen (Mallophagen) als eine ('ntedordnung der Rhynehoten betrachtet. Claus-Groben vereinigt sie mit den 'Termiten mo den Holzläusen zu der Insektenorhung der Corrodentiu. Die Ihnhbliteit der Länse und der Harlinge ist num einerseits eme so große, der Lntrischied zwischen diesen und den Termiten und Psociden :ushrerseits ein so auffallonder. tals ich die von 11 ensert 1891 aufgestellte Ordmmg Siphunculate als dorchams zu Recht bestehend ansehen muB, um so mehr, als die phyletische Zugehörigkeit der Anophuren und Mallophagen zu den Rhynchoten doch als cine sehr fraghiche zu bezeichnen ist. 


\section{llgentrines.}

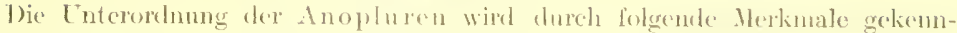
zeichnet:

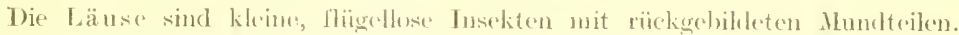

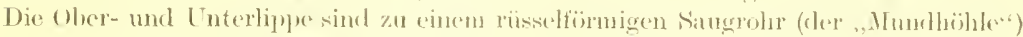

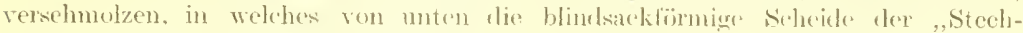
borste" einmintet. Die strehborste setzt siel zusammen ans dem IIypopharyx

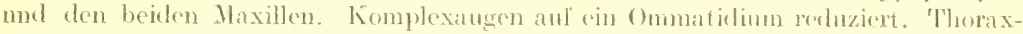

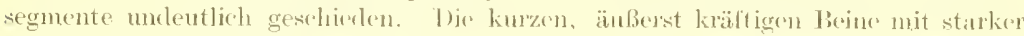
Kralle bewaffnet und deslath zum Anklanmern und kilettern vorzigglich geeignet. Entwieliung direkt.

Die Läuse leben parasitiseh anf der Haut von Sängotieren unrl saugen lBlut. Die ei- ofler birnfömigen Eicr (Nisse) werden an slie Haare (oder Kleider) fles Wirtes angeklelit.

\section{Morphologie.}

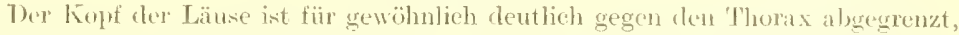
wharend dieser vom Ablomen sich weniger gut abhebt oker gar mit ihm verschmilat.

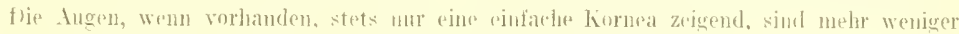
reduzierte Komplexaugen, die denen der spinnen im Bane ahush.

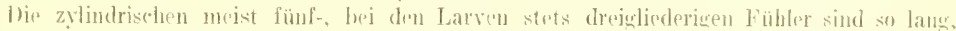
als der hoppl, und stehen an dessen seiten ror den Jugen. Auf das kïrzere und rtwas kraftigere

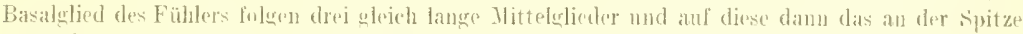

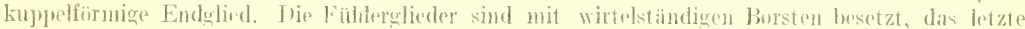
trägt an seinem distalen Ende fine Grupje von (i-10) Simneshaaren.

Durch einen kurzen aber krïtigen Hals hängt des hopf mit dem ei- orler kastenfömigen 'Thorax zusammen. Ton der unteren seitenkante der Brust entspringen die drei relativ kurzen Beinpetare, die im ganzen einheitlich gebaut und meist gleich kräftig sind. Sie setzon sich zusammen aus foxa, Trochanter, Femur, Tibia und einem Tarsalgliede. das auf seinem distalen Ende eine mächtige, einsehlagbare Kralle trägt.

Das meist eifömige Abdomen ist meln waniger dentlich gegen den 'Thorax abgesetzt oder rollkommen mit ilım verschmolzen. Heist lehlen Tergite unu Sternite. bie I'leurite treten häufig als dunkelgetärhte ('hitinplatten (Fig. 50) auf, können aber chentalls vollstänclig vermibt werlen.

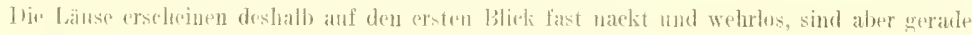

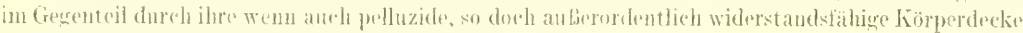

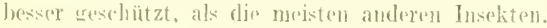

Thas Abchmen zeigt an den seiten vielfach tiefe Buchten, und erseheint deshalb

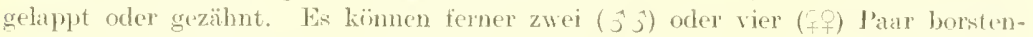
hestandme Zaplen an der hinteren Hälfte seiner Seitenkanten auftreten. Das Leibesende ist in der Mediancbene gespalten (ff) oder ganzrandig und abgexundet $(\hat{j} \hat{j})$. Die einzehen regmente tragen Borstenreihen.

\section{Inatumie und Plusiologie.}

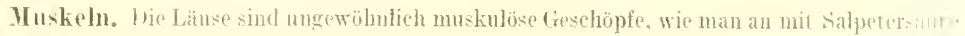

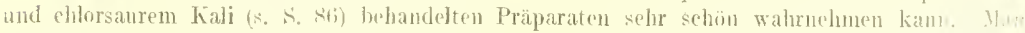

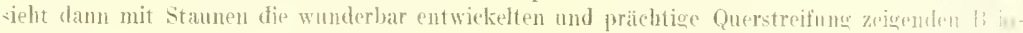

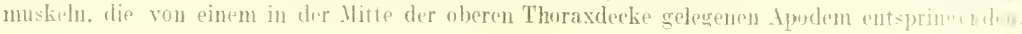


Jadiar verlaufonden Brustmuskeln und die Quer- und Längsmuskeh des Hinterleibes. Die Ein-

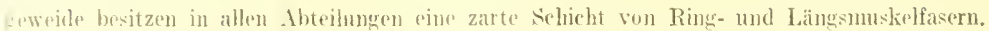

Das Nervensystem setzt sich aus ()her- und L'nterschlundganghion und drei Brustknoten zusammen, deren letzter am größten jst: Bauchganglien fehlen, Die abgehenden Nirvenstämme sind dem mäehtigen Muskelmassen mtsprechend wohl entwickelt: rin spmpathisches System versuregt die Eingeneide.

Die Atmungsorgane der Jänse sind nach dem Typus der Kibse gehaut, die Lamina der Hiauptröhren verhältni:mäBìr sehr weit, Jip großen Tracheenstämme nehmen ihren Anfang von 14 stigmen. die znnäehst in eine knowponlörmige Ampulle führen und anf den Körperseitenthirhen trelegen sind (Fig. 52).

That erste Stigmenpaar befindet sich anf dem llesothorax, die folgenden 6 anf dem 3 . bis 8 . Aludominalsegment (nur eine tnoplurenfamilie, die Echinophthiriden, besitzt anch noch anf derm lletathorax und dem 2. Shdominalsegmente Atmungsöfmungen, also im gauzen 18 Stigmen). In jeder körperhälfte verliuft, der Längsachse etwa parallel, cin zickzackformig gewundener

Fing. +4 .

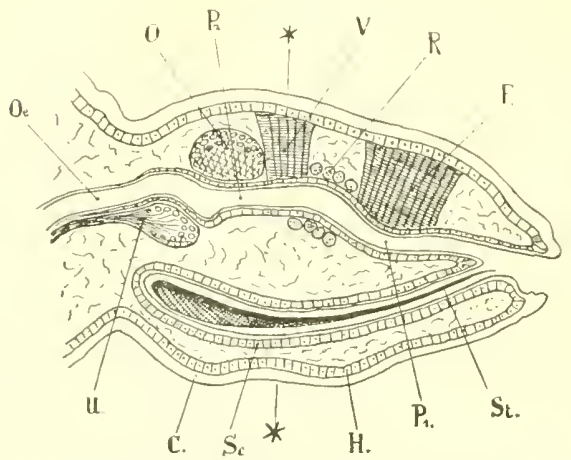

Sagittalschnitt dureh den liopf von Pediculus capitis. (Halbsehematiseh. Oriminal.)

1. Nundhohle, $P_{1}$. Vordere Pharynxpmmpe, $f_{2}^{\prime}$. Hintere Pharyenpume, Oe. ()esophagus, $F$. Jlusenlus frontipharyogens, $Y$. Jusculus vertipipharyngens. $R$. Ringmuskeh. St. "Staehn". Se. St achelscheide, 0. Oberes

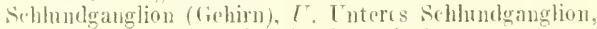
II. Hypudermis, C. ('uticula.
Fir, tis.

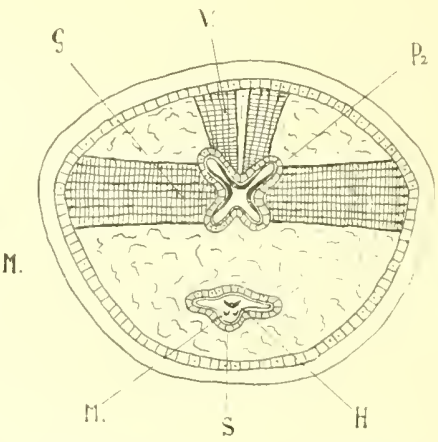

Quersehnit dureh den hopf von Pediculus cupitis alu f der 11 öh der besternten $(*)$ linie der Figur 44 .

(Halbschematisch. Original.) $P_{2}$. Hintere Pharyx rulus verticipharyngeus, $G$. Museuhs (ienopharyngeus dexter, II. Hypopharynx, H. Rechte Naxille, S. Stachelschejde.

Hauptrachenstanm, der im 8. Segmente durch einen gleielkriltigen Querstamm mit seinem P'artum von der andiren soite in Terbindung tritt (s. Fig. 52). Aul der Höhe der Thorakalstigmen biegen die beiden Hatuptstimme in einem recliten Winkel medianwärts ab, um dann bogenförmig durch den ITals in dip Schädelkapel einzudringen. Querstämme verbinden in meist geradlinigem Verlaufe die Längsstimme mit den cinzelnen Stigmen. Starke Äste werden aus den Längstracheen-

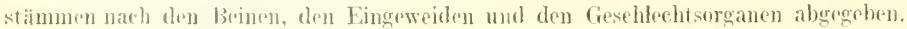

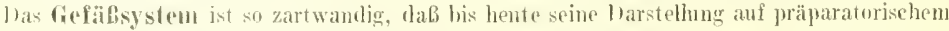
Wege noch nicht gublürkt ist; bej eben geschlïptten Larven und frisch gehänteten 'Tieren kamn man almer pine eleutliche l'ulsation des Ruckensweraibes leicht wahrnelmen.

Der Lrnälırmngsapparat dar bäuse zerfällt in einen Vorder-, Mittel- und Hinterkarm.

Der Vorkfordan wird durch die Mundhöhle, den gedoppelten Pharynx und dir Speiserölure gebildet. 
Die Mundöffnung ist mit einem Kranze vou einsehlagbaren Haken besetzt. Die Numbhöhle kann rüsselartigr vorgestiilpt werden und umgibt dann scheirlenartig die weit aus der Anndölfomeng hervergestobene Stechborste.

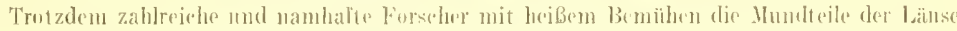

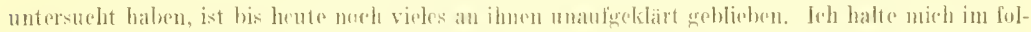

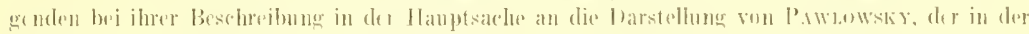

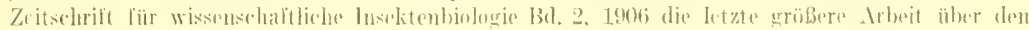
Gegenstand veröffentlieht hat. Lir studierte die Terile an sehnittserien und berürksielitigte (wie

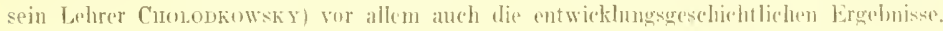

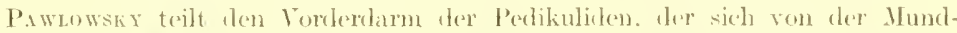
öffomng bis zum Magen erstreekt, in viex Abshonitte ein, nämbeh 1. die Mundhöhle, 2. den Munddarm. 3. den l'haryngealappanat und 4. dic eigentliehe speiseröhre. (Wir werden später sehen, haß diese Bezejchmmgen nicht gerade glücklich gewählt sincl.)

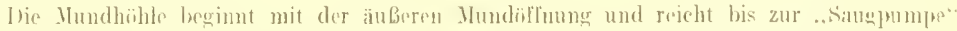
(..elem Mundelarm*). In sie hinein ...mündet von unten die Stachelscheide, cin unter de'm lorderdarme bis zum hintersten Tejl des linfifs sich hinstreckender blindsack". In dieser liegt der ihr

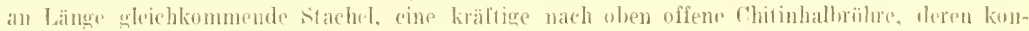

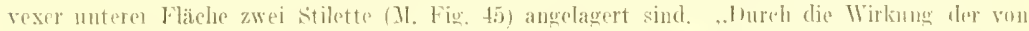

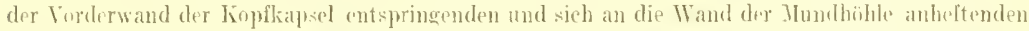

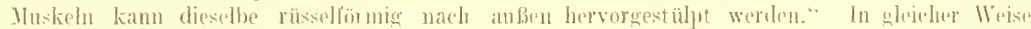

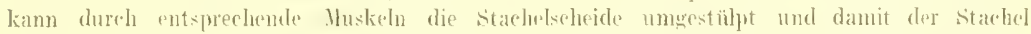

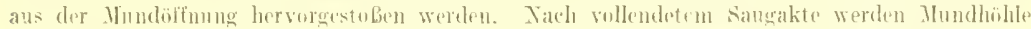

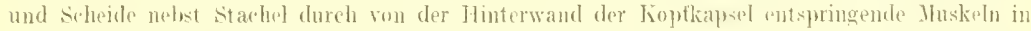
die Ruhelage zurïelggezogen.

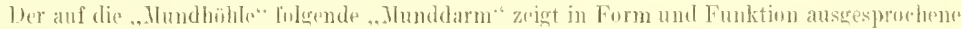

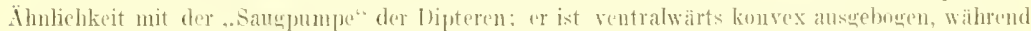

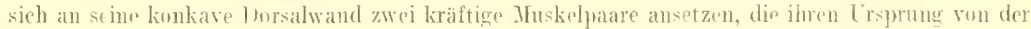

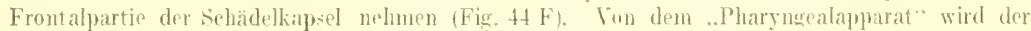
.. Yunddarm" durch Yuskelringe getremnt. wekche bei ilirer Zusammenziehung die beiden letztgenannten Vorderdarmabchnitte vollkwmmen voncinander abschlieben. Zwisthen dipsen Mluskelreifen entspringen ron der l)armwand starke naeh ten seiten der liopthaped hinzirhende Juskelbündel. Diese und ein an der (irenze des. .P Pharyngealitpparates" und des eigentlichen Gsophagus

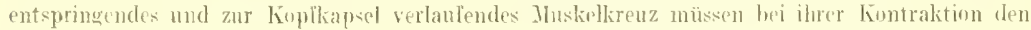
.Pharrngealapparat" "rweitern. Dhe ganze Innenfliehe des Vorderdarmes ist mit einur Clitin-

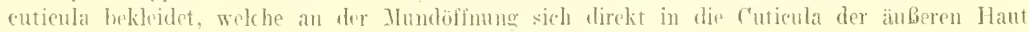
verlint.

,... In dir stelle, wo der . Inuddarm in die Hölle des Pharyngealipparates übergeht, bildet

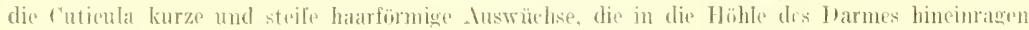

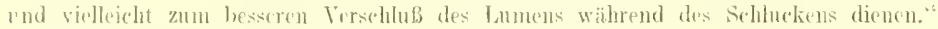

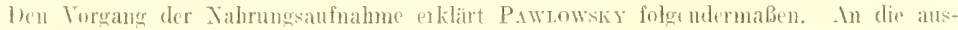

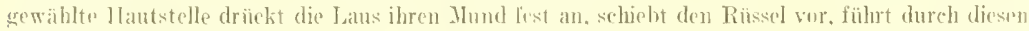
hinclurch ten stachel nnd stabt ihn in die Haut des Wirtes rin. ${ }^{1}$ ) Beim . Inlang des Saugens sind die Musculi orbiculares (Fig. $44 \mathrm{R}$ ) kontrakiert und das Lumen des entsprechenden Atrechittes des Vurderdarmes dicht geschlossen. Indem mun die hebenden Jluskeln der sangpumpe sich kontrahieren, wird in der letateren en luftleerer Raum gebidet, in welehen das Blut cinströmt. solvald mun die Höhle der Pumpe (des, ,Hunddarms") mit Blut gefültt ist, erscllaflen die Mlusculi orbi-

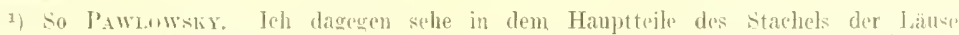
nur das Ende des Ausfülırunexganes der Speicheldrüsen (don IIrpopharvis) um ein zu:

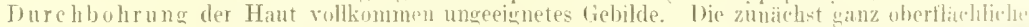

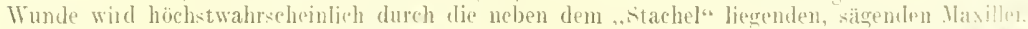

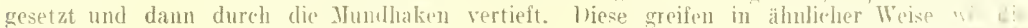
Thelikerenhaken der Z e cken weiter und bewirken so genügend tiofes Eindringen des liu w? und schliebleh die Verankerung dex Parasiten in der Haut des Wirtes. 
wares umi ̈̈flnet - wh die Höhle des Pharvneralapparates; da aber glejehzeitig dic hebenden Muskiln der saugpumpe ersehlaffen und die Ilühle der letzteron zusammenfällt, so wird das Blut in die Höhle des. .l'haryngealapparates" mod weiter in die speiseröhe fortgetriehen. - "Der Munddarm nud Pharỵgenlapparat bilden zusammen eine otwas unvollstäudige — weil nur mit finer Klappe versehene - Druck- mol Saugumue. bie andere Klappe wird gewissormaBen threlı den Bhutdruek in den Geläben tes Wirtes ersetzt."

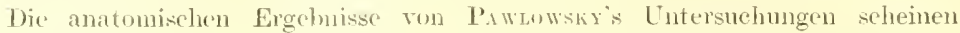
mir die phrsolugischen Schlubfolgermgen an Wert erheblich zu ïbertrelfen.

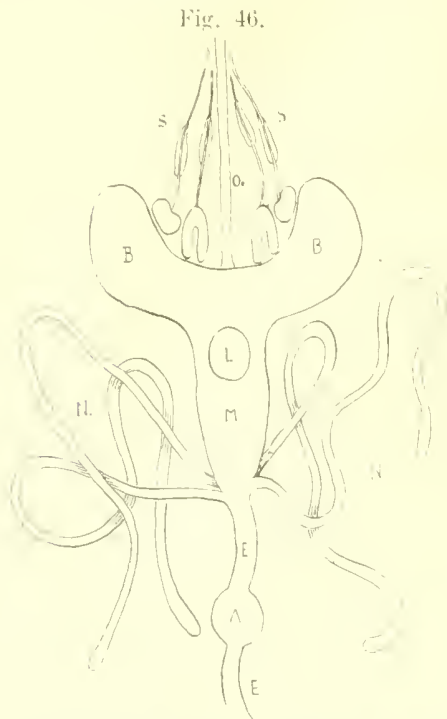

Trantus indestimalis yon Ththrims pubis.

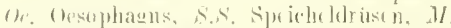
llittrlearm (Masen) mut seincon bejelo

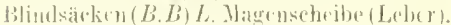
E.E. Findelam nit some Impulle (.1).

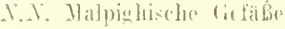

Die ,haarförmigen Auswüchse" der ('uticula an der Grenze der beiden mittleren Abschnite des Vorderdarms diuften mit dem VersehluB des lumens während des Selshuckens wohl nichts zu tum haben, sondern ats die Endigungen der Geschmacksnerren anzusprechen sein (rgl, dic analogen Bildungen bei den Strehmücken usw.).

So unvollkommen, als ihn l'Aw Lowshy hinstellt. scheint mir der Saugaplarat der Laus gar uicht zu sein. Tem ersten tkt des Sargens sehildert Pawlowsir fraglos richtig, bein zweiten aber zieht er die zahlreichen Erwoiterer des ,I'haryngealapparates" nicht gebülrend in Rechmmng. Wenn nämlich die Heber des. MIunddarues” und die Ringmuskeh erschlatem, so begimen die vom, "Pharyngealapparat" nach der liopfkapsel ausstrahlenden IFskelbündel sich zunammenzuzichen und damit diesen Teil des Vorderlarmes beträehtlich zu erweitem. Auch ohne einen Ëberdruck an der Mnodoffunng wird durch diesen Vorgang das in den beiden ('rsten Abschmitten des lorderdarnes enthaltene Bhot in den . Pharyngealapparat" himeingezogen. Num schlieben die Ringmuskeln den .. Hundelarm” vom, P'haryngealapparat" wieder ab und es hebt der erste Akt von nomem an, während die $\mathbb{T}^{2}$ ände A(e, , Pharyngealapparates" kollabieren umb so natürlich das Blut in den (Osoplagus writer befördern.

1)ic Läuse crforen sich lemmach im Gegensitz zu den ïbrigen stechenden mud sausconden lusekten (also namentlich den hämatophagen Dipteren) einer doppelten Sing- und thuckpumpe ${ }^{1}$ ) und führen anBerdem noch einen exzentrisch

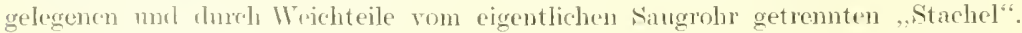

An den P'latynx schließt sieh die gerade verlanfende ziemlich enge Sueiseröhre

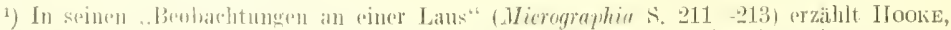
dab er eine Laus anl seiner Thad Blut saugen ließ. Bei dieser Gelegenheit sir , thrust its nose very

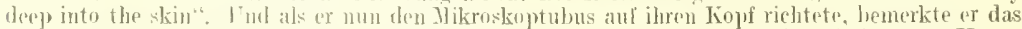
folgende: ,there semu'd a contrivanee. somewhat resembling a I'ump, pair of Bellows, or Heart, for by a fery swilt srstole and diastole the flood seem d drawn from the nose, and foreed into the

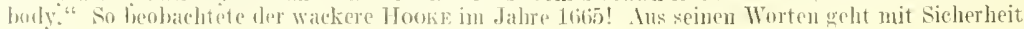

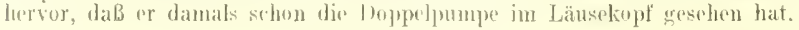




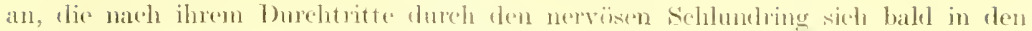
oralen 'Teil des Miteldames einsculit (ligg. 44 u, 46).

Dieser, der sogemannte Magen, ein im ganzen spindelfirmiger, selur erweiterungslähiger Schlauch, liegt mit seiner Hauptathe ebenso wie der (J)ephagus in

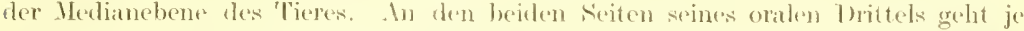
ein grober Blindsack ab, und dureh diese beiden Apyendizes orseheint der ganze Magen

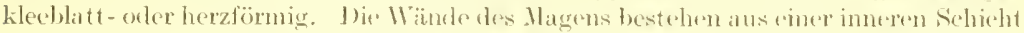
ron großen granulierten Zellen, anf diese folgt eine zarte binclegewedslamelle, die

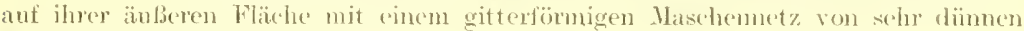
Muskelfasern belegt ist.

An der Grenze des Mittel- mol Enddarmes münden die vier Malpighischen Gefäbe ( $\mathrm{X}$ in lig. tii) in letzteren ein, die den typischen ban der Kerbtiernicren zejgen. Nicht am Ende. Wie somst gew öhnlich, sondern in seinen mittlertan Teilen

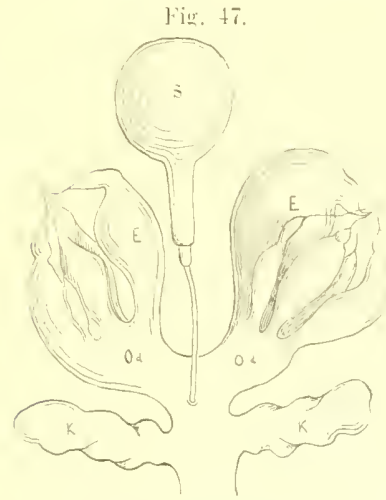

Wiejbliche lieschlechisteile von Phthirius putis.

S. sipermatleke. E.E. Je cine der tiant rinkammeriugen Eiruluren des reclaten nud linken (Dariums. Od.t). Rechter und linker ovidukt, K.K. Reehte und linke Kittdrüse.
Fis. 45 .

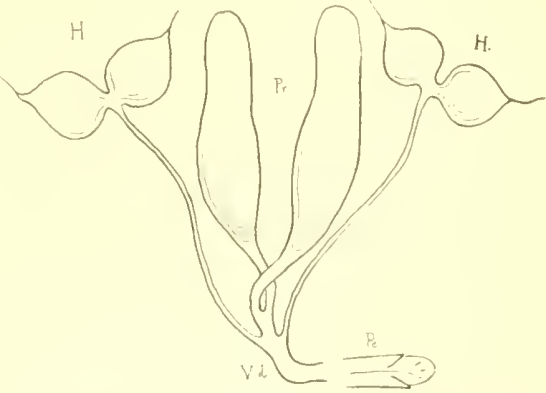

Mämoliche fresehlerlotstei]e von Phthirme pulis:

H.H. Revliter und linker lloden, Pr. Rechte und

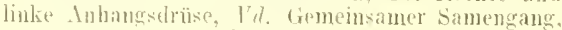
Pe. Penjis.

liegt die bekannte kugelige Enweiterung des Enddarmes (Anpulle) mit den sechs spindelförmigen , Rektaldrüsen" in ihrem Innern.

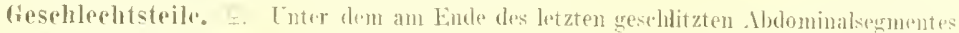
liegenden Lfter befindet sich der sicheideneingang. Ihe kurze Tagina teilt sich iiher ilmen bejelen Kittdrüsen gahelförmig und geht so direkt in die beiden je füuf Eirïhren tragenden Eileiter iiber.

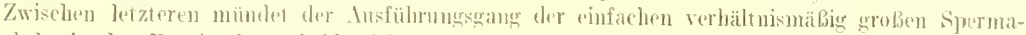
theke in den Fornix der scheje (Fim. 47).

j. Vie Ansfïlurungsgänge der godopledten, zwiebelförmigen Testikel vereinigen sielı alsbald nach ihrem . Justritte aus den brisen zu dem Vas deferens der rechten und linken sicite.

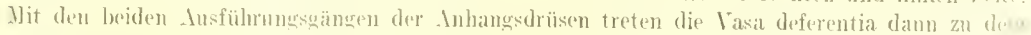
gemeinsamen Samengange zusammen, der in den von einer Chitinrölure nuscheideten Penis fi fue

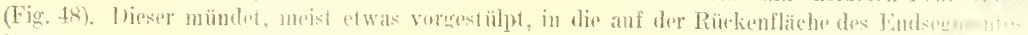
Jiegende Koake. 


\section{Biologie.}

T)je Läuse werden als stationäre J'arasiten natiurlich immer nur da gefunden, wo ihre Wirte, die von ihnen befallenen Säugeticrarten, vorkommen. So sind die Kopf- und Kleiderlaus Kosmopoliten, so wirl die Filzlaus überall da angetroffen, wo sich Angehörige rler kaukasisehen Rasse niedergelassen haben.

Die höheren Sinnesorgane der Anopluren sind jedenfalls nur sehwach entwickelt und wenig funktionstiichtig. Der Tastsinn und vielleicht noeh der Geruch diirlten die volliommensten Vermittler der äußeren Eindrücke scin.

Fig. 50).

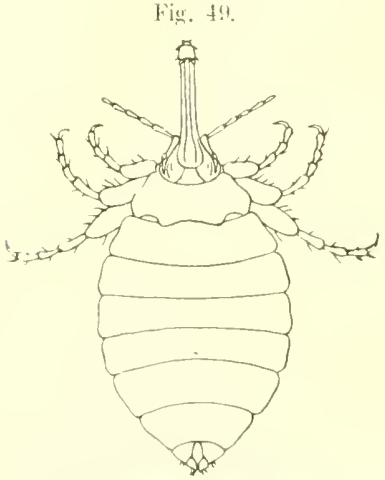

IItemalomyzus elephutix o.

(Narh Newmax.)

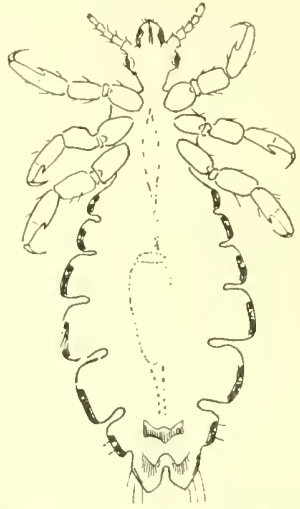

Pediulus erpritis de fieer o. ${ }^{30}{ }_{1}$. Baturebliache

(c)iginal. ('amera lueida.)

Unter von den Jahreszeiten unberinfluBten eigenklimatischen Verlültnissen lebend vermehren sich die Läuse stetig.

Die Lage der änBeren Geschlcehtsteile macht es wahrseheinlich, daß die Begattung bxi den Jäusen in älmljcher Weise wie bei den Flöhen vor sich geht (s. S. 74).

Die weiblichen 'Tiere setzen ihre Eier (Nisse) vor allen an den Haaren ihrer Wirte ab und kleben sie hier mittels des Sekretes illrer Kittlrüsen fest.

Die Larren heben schon nach wenigen Tagen den kunstroll gebauten Deckel vom (horion ab unel verlassen clam die Eihülle; nach mehrmaliger Häutung sind sie in einigen ITochen (frühestens nach 18 'Tagen) erwachsen und fortpflanzungsfähig.

\section{Systemalik.}

1)ie [Tnterordnung der Anopluren zorfallt in vier Familien: die Pediculiden

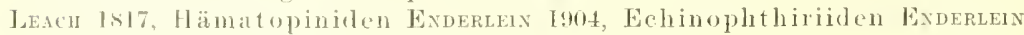
I!o4 whel Ilämatomyziden ExDERLEx 1904.

Die Morkmalo der einzelnen Familien sind nach ENdenLein folgende:

1. Beine zu klanunerbeinen ungewandelt. Tibia und Tarsus mejst solor kurz und thek. Tibia mit danmenartigem Fortsalz. Kouf vorn whe röhrenartige Verhängerung . . . . . . . . 2

Beine nicht zu kiammerbejnen umeswandelt. Tibia und Tarsus selur ling und schlank.

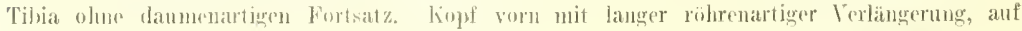

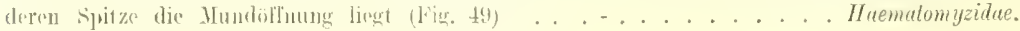


2. Körper diek und plump. Heso- und Yetatberax jederseits mit einem stigma, rin wem-

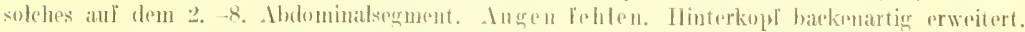

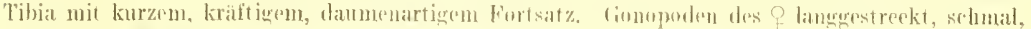

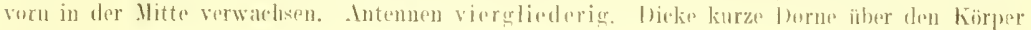
verteilt

3. Körper flachuedrückt. Nur auf unt Mesothorax jedersoits ein stigmid, rin ebensolehes

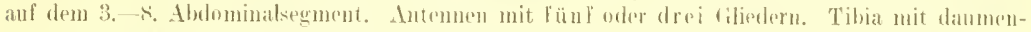
artigem fortsatz.

a) Augen grob, vorgewöht, deutlich pigmentiert, Riïssed karz. . . . Pediratidue.

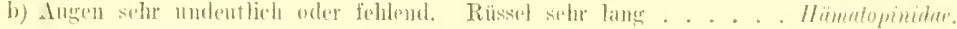

Nur Angehörige der Familie der Pedikuliden schmarotzen aud dem Mlonsehen, während die sämtlichen Gattungen der Hämatopiniden (z. B. anf Sius), Eehinophthiriiden (auf Phoca) und Hämatomyzirlen (aul Elephess) sich ans 'Titrschmarotzern zusammensetzen.

\section{Pediculidae.}

Die beiden Unterfamilien unterscheiden sich dadureh, dab lie wrachsenen Pedicininae (Pedicims Gere. - Nicht auf Homo sapiens schmarotzend) dreigliederige, die P’ediculinae fünfglienlerige Antemnen besitzen.

Die charaktere der beilten Pediculinengattungen sind:

1. Alle Beine kraftig. Daumenartiger Fortsatz der Tibien sehr lanır und düun. mit kriltigen bormen bestet. Tordorbeine etwas gedrungener und kraftiger, als die ährigen. Abdomen langwestreckt, mäßig sclumal, die segmente nicht zusammengedrängt, uhne seitliche zaptenartige Fortsatze. Das zweiteitige Endregment (Telson) trägt hintell auf der linterfliche jederseits einen kegelartigen fortsatz. Conopoden des hakenartig nach innen getogern. .

Pediendus 1.

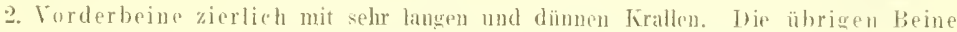
sehr kraftig mit kurzen und dicken lirallen. Daumenartiger Fortsatz der Tilja kurz und krätig. Abdomenkurzund breit. 1. -5. Adudominalsement sehr dicht zusammengeviringt,

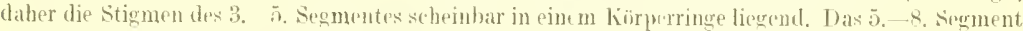
mit seitliehen zapfenartigen Furtsiltzen, der vorletzte lang, der letzte sehr lang. Thals zwei-

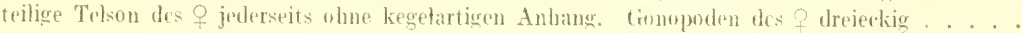

Phthirius LEAcil.

\section{Perlirulus apditis de GeER 17TS.}

(Pedieulus ordinarius Redi 1671, P. humanus L. 1758, P. cervicalis Latreiden 1803).

Die Kopflans ist über die ganze Erde und in allen Menschenrassen verbreitet; in Amerika soll sie schon ror Ankunft der Europäer vorhanden gewesen sein. Sie lebt fast aussehlieBlich auf der behaarten Kopfhaut des Menschen ${ }^{1}$ ) und wiru mur höchst sclten an anderen behaarten Körperstellen angetroffen.

lurw Farke richtet sich nach der des Traicers; sehr dunkel bis vollkommen sehwarz sind dir anf Negern schmarotzenden Läuse, gell, die ter Jonguten (Chinesen und Japaner), orangerot die der Jlotentotten und mehr weniger belloran je nach der Haarfarbe die der Europizer.

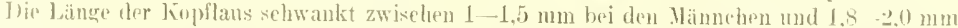
bei den Weibehen. Die Vännehen treten in wesentlieh geringerer Zahl auf, das Terhailtnis ist et wa 1:4.

l)er kingl von P'ediculus capitis ähnelt einem l)reieck mit abserundeten kicken, sein orales Finde crseheint deshall rundhogenfömig.

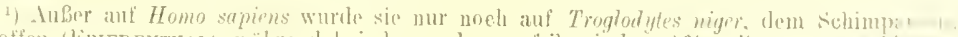

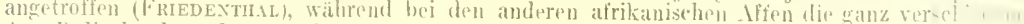
Art Pediculus liemadryue vorkommit. 
Ihe Seitenflitehen des hörpers sind starker elitinisiert und dunkler. so daß namentlich die Abdominalsegmente schwarz gräudert erscheinen.

fịg. 51.

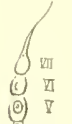

(0) $\square$
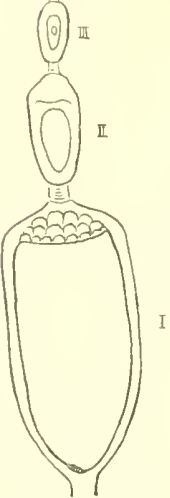

siebenk ammerion

Eirühre roll

Pedicutus enpitis.

Das Weibehen klebt 50-60 eiförmige, $0,6 \mathrm{~mm}$ lange Eier (Fig. 51. 1) an die Haare reines Wirtes, the in etwa fi Tagen atsgeher. Die jungen 'Tiere brauchen nur 2-:3 Wochen zur rolkkommenen Entwicklung und Erlangung der Gesehlechtsreife.

\section{Pentimlus restimenti Nitzsch ISIS.}

(Pedifulus corporis DE Geer 1778, P. tabescentium. Alt 1824.)

Die Kileiderlans ist abenfalls Kosmopolitin und in den Tropen und subtropen anBerordentlich verbreitet.

Hore morphologisehen Tnterschiede gegen Pediculus capitis sind sehr geringe; wolll ist sie griber und kräftiger gehaut (Kürperlänge des ô 2-3, des + 4-5 $\mathrm{mm}$ ), als ilue Konkmrrentin, aber von dieser sonst nur durch die firstalt des Kopfes und seiner Anhänge vorschieden. Wie liopfform ist eine langovale, iln vorderer hontur ein Spitzhogen, de Füller sind länger und schlanker als die von Pediculus capitis.

Die stärker beharten Hautflächen meidet Pediculus vestimenti, or hält sich in den Falten und in den Fadenzwischenräumen grobgewebter Kleidungsstïcke auf. (,.Die Kleiderlänse gueken, wie ans Fenstern, aus den Liicken, welehe die Fadenkewze lassen, heraus" ptlegte mein alter Lehrer R. zu sagen.) Sein Lieblingssitz ist der Hals und Nacken; dam bref̈̈llt er' aber auch die iibrigen 'Teile des Rmmpfes. Unter' den ïberhängenden Rändern vernachlässigter, durch heftiges Kratzen entstandener Geschwiire werden Kleidcrlänse manchmal massenhaft angetroffen.

Die in Mittel 0,8mm langen Eier von Pediculus vestimenti werden bis zu so St ïck an die Innentläche der Kleidungsstücke angeklebt. Die Jungen schlüpfen schon nach 3-4 Tagen and erreiehen in 15- is 'Tagen das Ende ihrer Entwickhng.

Phthivius puthis J. 1758.

(Pediculus inguinalis Red 167], Pedifulus inguinalis Remcuard 1759, Phthirius inguinatis LEACH 1S15.)

Dic Länge der Männehen heträgt $0,8-1,0 \mathrm{~mm}$, dic der Weibehen bis 1,2 mm. Die Farbe der Filzlaus ist cin schmutziges Grangell, oder Hellgrau.

Dic Filzlans, welehe fats nur Angehörige der kaukasischen Rasse befällt, zeichnet sich ror den anderen P'ethknlinen dureh den sehr gedrungenen Körperbau ans. Das Hulomen ist anf das Engste mit dem Thorax verschmolzen, der Kopf ebenfalls mit einem mur iuberst kurzen Halse mit dem 'Whorax vereinigt.

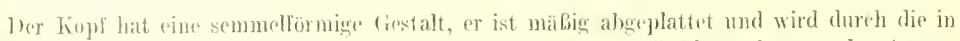

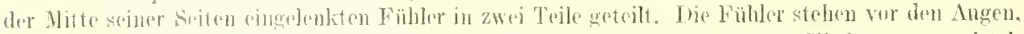
sie sind kurz und bri iuscewachsenen Tieren Tünfoliedorig. Die vier ersten Glieder tragen wirtel-

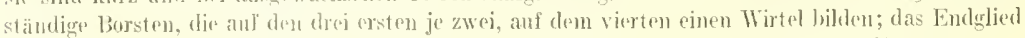
lat anf der distalen Jlälfte the Borste und an der Spitze $6-8$ stäbehenformige Fortsätze.

the drej Thoraxsegmente sind mitejnander verschmolzen. die Beine an ten seitliehen J'artien der Tnterfläede des Brustkorbes eingevenkt. Sie sind im ganzen naclı dem gleiehen Trpus

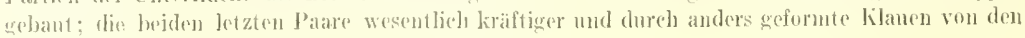


Vurderbeinen untersehieden. Alle Beine hahen nur cin Zehenghed. I je llüfe ist Crei in Azetalulum

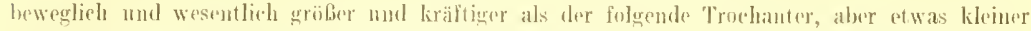

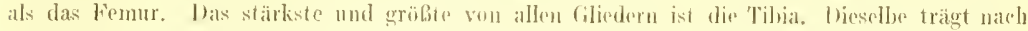
vorn geriehtet cimen daumenförmigen dieken Chitinstift, hinter weledem sie ansgehöhlt erseheint. Im distalen linde der Tibia ist der eingliederige larsus mit seiner starken Chitinkralle angebracht, die an dem vorderen Brinpalare an konkaven lande mit kleinen spitzen,

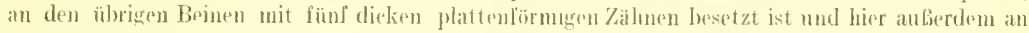

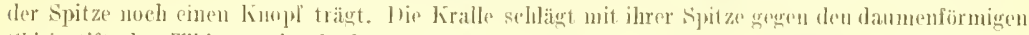

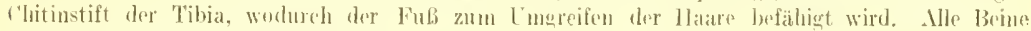
sind mit feinen Bersten besetzt.

Das Abdomen setzt sich ans neun siegmenten zusammen, die keine anscesprochene Trenmungslinie erkemnen lassen; die Grenzen werden nur dureh seichte Vertiefungen markiert. Juder

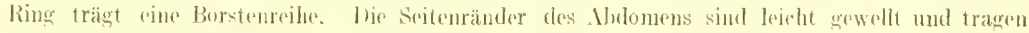

Fï. 53 .

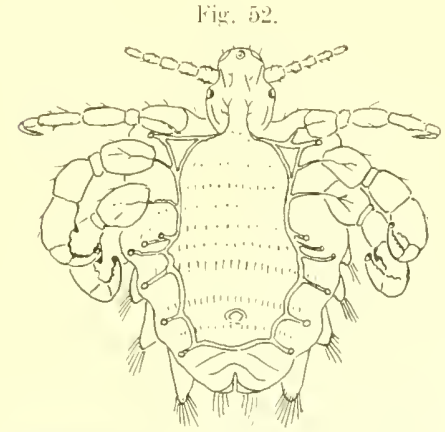

Phthirius pubis L. o $^{30}$. Bauchtläche. (()riginal. Camera heida.)

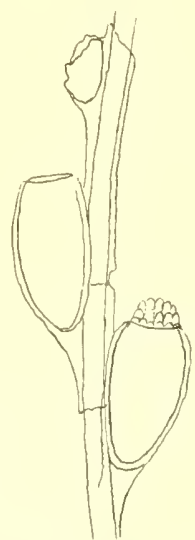

Eior vou Phthirius putis $L$. (O) riginal. Camera lucida.) ${ }^{30}$.

anberdem jederweits vier vorspringende Zapfen gerade genenüber den vier hinteren . budoninalstigmenparen. Boim Weibehen sind sie gröber, Leim lÿnnehen sind die zwei vorderen Paare leinalle rudimentär geworden; sie nehmen von vorn naeh hinten an liröße zu. I jese Zaplen sind mit croben liäftigen Borsten besetzt, deren Zahl ebenfalls von vorn naeh hinten wächst und bei den Weibern stets gröber ist, als bei den Mïnnern $(q 5-10, \hat{j} 3-7)$. Auberdem tragen die beiden letzten Zaptumpare je cinen aus der Burstenreihe heraustretenden kriftigen Ilorn. 1)as abgerundete Ablominalende des $g$ ist an seinem Rande mit 5 - 6 , das gespaltene des 9 mit vielen Haaren besetzt. llo lingsgerichtete spaltfömige Kloakenölfnung des lient auf der Banchflache und ist bedeekt und gesehützt von zwei mit starken Borsten bewachsenen hilappen, die durch besondere Ifuskchı geülfuret und gesehlossen werden kömmen.

Da die Eiröhren der Filzans nur jecinen Feim enthalten, kam dieselbe auch im günstirsten lalle nieht mehr als zehn Eïer antwickeln und absetzen.

Interessant und wem rorhanden ein untrügliches diagnostisehes Merkmal sind die bei manchen mit Phthiriasis behafteten Mensehen anftretenden bis pfennigstiickgroßen, , Il a eula e coerulea e", die taches bleues der Franzosen. Ob es sich: hier um die Folgen einas toxisehen Erythems (Duguet) oder um einen in de Speicheldriisen der läuse gebildeten und beim Saugen eingeimplten Farly-1 handelt, wie OppenherM annimmt, ist noeh nicht entschieden. 


\section{Iufbewahrung und Tntersuchung.}

Läuse trocken zu konservieren empliehlt sich nicht wegen der Kleinheit der (1)jekte und der starken Veränderung. welche sie unter diesen Verhälnissen durch Sehrumplung erfeiden. Nan helpt sie deshalb am besten in $75^{\circ}$ o Alkohol auf oder in Glyzerin nath rorhergehender ${ }_{4}$ stiundiger behandlung mit kochendem Wasser.

An zweckmäßigsten werden sie, in Glyzerin oder balsam gebettet als nikroskopice be l'räparate der Sammlung einverleibt.

Jurch Behankllung mit Kalilange lassen sich die Weichteile vollkommen varflüssigen. während die chitinigen Kïrperteile erhalten bleiben und nach Entlemung des fewebsbreies (dureh vorsichtiges Auspumpen fler angestochenen Leibeshöhle. was am besten dureh ott wiederholtes Drücken mittels einer Präpariomadel ofles zwischen feinen Pinzettenbranchen unter Wasser gexchieht) sehr ansehauliche (1)jekte abgeben.

Will man die Weichteile (namentlich dic Muskulatur) meiglichst mit erhalten. so ist rin mehrtägiges Einlegen in Salpetersäure und Kalinnehtorat (s. S. sfi) vorzuzichen.

Man entwässert die Läuse, dbenso wie andere fnsektrn, am besten in Azeton und ïberträgt sie daun lirekt in Kanadabakam (s. S. 36).

fchnittolgen und Färlungen werken in bekannter Weise hergestellt.

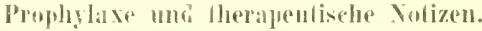

Durch Ficinliehkeit une] Vermeirlung aler Infektionsgelegenheit kann man sich die Läuse sicher vom leibe halten, vie sind deshalb anch in erster Linie l'arasiten der ungebildeten. ämeren und unreinlicheren Schichten der Bevïlkermang.

Alle l'edikuliden und ilure Brut lassen sich durch Reiben ter befallenen Körpesstellen mit äther- orker benzingetränkten Wattebäuschehen leiclut abtïten und von der Kinperoberfläche entfernen. Auch P'erubalsam wird gerïhnt, besonder's aber' Sublimatessig (1:3001). Weniger wirksam sind Sabadillessig und Petrolem. Neben der Giftwirkmng tritt bei sliesen Witteh stets auch noch die rein mechanisehe in die Bscheinung: sie verstopfen die Stignata der sehr Juftbediüftigen Anopluren und fïhreis so ihre Erstickung herloei.

Bei Kleiderläusen sincl natürleh Leibwäsche und Kleidmng mit reiner zu verfausehen und die befallenen Stïeke dureh Hitze nurl Auswaselien zu desinfizieren.

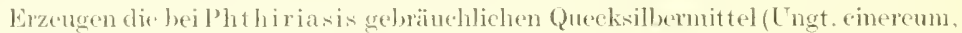
Suhlimatspiritus und bei Befall der Wimpern und Brauen (ngt. Hydr. oxyd. flav.) die oft recht mangenehnen Ekzene, so ist auch hiser von den anderen oben angefühten Mitcln (namentlieh dem Ither und benzin) Gebrauch zu machen.

\section{(Anhang.)}

\section{Die Haarlinge.}

Die l'nlerordnung dor 11 allophagen (Haarlinge. Pelzfiesser) lebt in zahl-

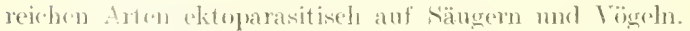

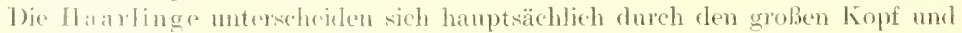
den nirbth verwachsemen Thorax von den luälsen.

Thr Körper ist flathgedrükt. Der Kopf wesentlich breiterals der Brust-

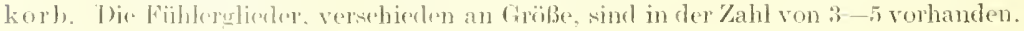

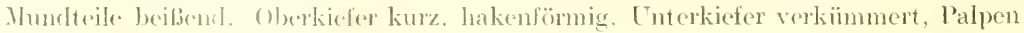


meist felblend. Interlippe mit kurzen zweigliederigen 'Tastern, Wherlipere narpartig.

Ein kropt ist vorhanden, das Horz schy kurz. Die leblesser besitzen, wir die läuse, vier Hoden.

Entwickhng lirekt, olme vollkommente .Hetamestphose.

bie Mallophagen (rmähren sich in der llauptsacher vom Oberhautgebilden: den jungen Handen. Fetern und Hautschäppeben ihrer Wirte, sind aber gelegentlich auch

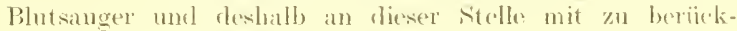
sichtigen

Figur $5 t$ zeigt das typische Bild voll Trichodertes mulpis, einer trt, die diner des verbreitroten Gattumgen angehört.

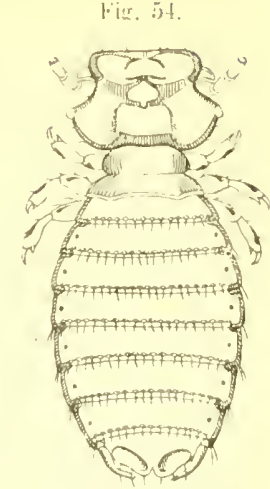

Tinderdectes inlpus.

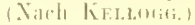

\section{Lileratur.}

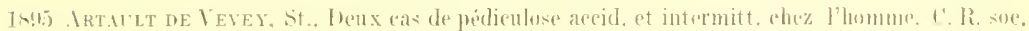
biul. Nir. 24, s, fist. Paris.

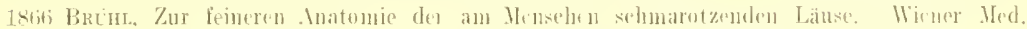
Worchensir.

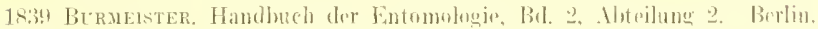

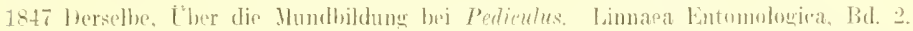

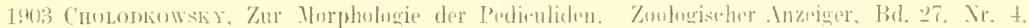

19n! Drrselbe, Zur Kenntnis der Hundwerkenge und sistematik der Pedienliden. Zandegiseher Inzeiger, Bd. 28. Mr. 10.

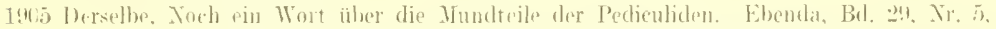

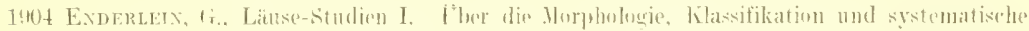
Stellung der tnopluren, nebst Bemerkungern zur systematik der lnsektenordnugen. Zoologiseher Anzeiger, Bd. 2... Nir. 4.

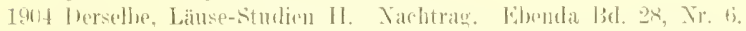

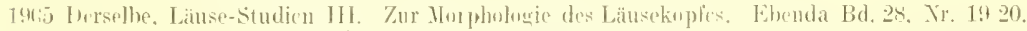

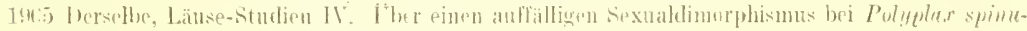

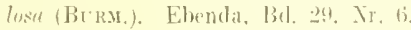

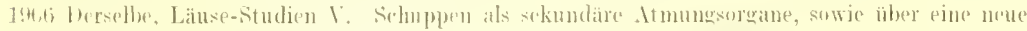

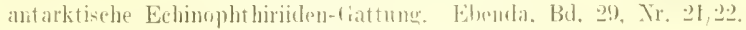

list tremel. Inspeda Eprizu, Leipzig.

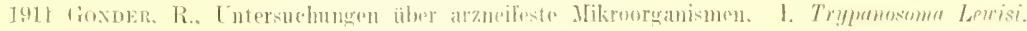

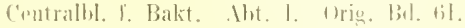

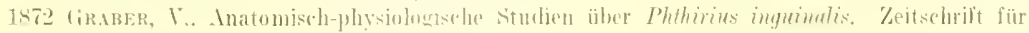
wiscensehaftlicte Zonlogin. Bal. 2:-2.

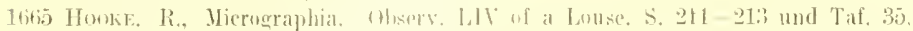

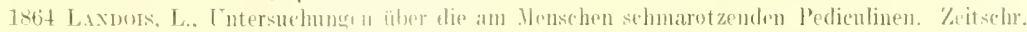
I. wiss, Zonl. Bd. 14.

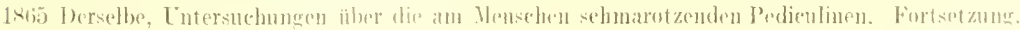
Ehentia. Bd. 15.

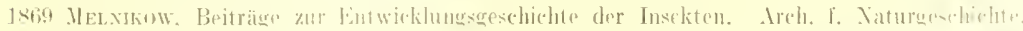
Bd. 35.

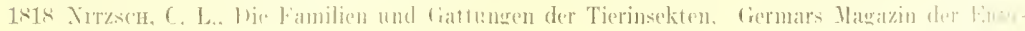
mologie, Bd. :?. 
th.1 Osborx, H., The pediculi and millophaga affecting man ete. Bull. Mr. 7. U. S. Departm. of Agrieulture. Washington.

1906 Panlowskx, E. İber den Stech- und Sangapparat der leclieuliden. Zeitsehrift für wissensehaftliehe Insektenbiologie, Bd. 2. Ileft $5-7$.

18 O P1AGET, Les pedienlines. Leyde.

1885 Therselbe, Les pedieulines, supul.

1671 RED1. F., Experimenta eirea generationen Inseetorum. Amsterdam, Andreas Frisius. (Auf 23 Taff. 35 fïr ihre Zeit iiburraschend gute Abbildungen von Läusen und Haarlingen.) 1866 Schöpte, On phthiriasis and on the strueture of the mouth in Pediculus. Annals and Hagazin of Tatural History. Bd. 17, 3. Ser. London.

1910 SERGExt et Folex, Recherehes sur la fièvre récurrente et son mode de transmission dans une épidémie algérienne. Annales de L’Instit. Pastenr. $24^{\mathrm{e}}$ Amnée, Mr. 5.

1858 Srmox, Die Hautkrankheiten dureh anatomisehe Tutersuchungen erläutert. S. 274. Berlin. 1882 strröbelt, Anatomie und Physiologie von Haematopmus tenuirostris. Düsseldorf.

1735 Swamerdan, J., Bijbel der nature. Leydae. 


\section{Iaalbflügler, Hemiptera.}

\section{Die Wanzen.}

Die Wanzen wurden erstmals am Ausgange des vorigen fahmunderts als Krankheitsüberträger angeschuldigt. Es war Tictlx, dor im Nahmugsschlauch von ('M dic Spirochacta obermeiri nachwies und dort ziemlich lange lebend beobachten komnte. Später sind dan Nutrald, Manteufer md Mackie Rekurrensiibertragungen anf gesunde Tiere mittels infizierter Wanzen gehmgen.

Daß auch Pest durch Wanzen übertragen werde, vermutete man schon lange. Nach rergeblichen Versuchen von Nuttall und anderen glückte es VérjBitsis im Jahre 1908, gesunde Tiere durch Wanzenstiche zu infizieren. Auch mit dem liote scheidet Cimex lectularius nach Aufnahme von Pestbut virulente Pestbazıllen aus. Nenere Beobachtungen ron Bulfour (Fourth Report of the Wellcome 'lrop. Res. Lab. 1911, S. 203) machen die Cbertragmg der Pest clurch Wanzen ron Menseh auf Menseh ebenfalls sehr wahrseheinlich.

Wenn wir num noch dureh Patjox erfahren, daB Cimex rotundatus Kala-Azarparasiten im Magendarmkanal weiter entwickelt, wem Hepper md Husbanw und Mc Watters in den Wanzen die Überträger des indischen Fleekfiebers

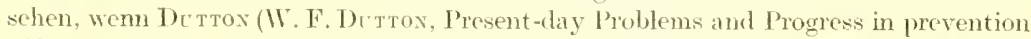
of 'Typhoid Ferer. Journ. americ. med. assoe. 16. Oct. 190!n) beobachtet, da B 'T yphus mach Wanzenstichen auftritt, Debaxy sie für die Verbeiter der indischen epi-

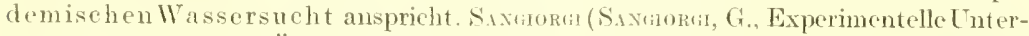
suchungen über slie Ühertragung der Protozoënblutparasiten durch Cimex lectulerius. Centralbl. f. Bakt. 1911, Bd. 57. S. 81) in ilmen die Überträger von Trypanosomen vermutet und seliließlich Maxsing (New York Merlical Times, April 1912) sie beschuldigt, die epidemische Kinderlähmung (Poliomyclitis) zu übertragen, so genügt dies Sündenregister wohl, wm die Cimicidac aller Beachtung wert erseheinen zu lassen.

Auch eine andere Hemipterenfamilie, die Reduvidae, hat duch dic Entdeckung von CHaris, daß Conorhinus megistus das Schizotrypanum cruzi überträgt. hohes Interesse für den 'Tropenarzt gewonnen.

Die Wanzen, englisch Bugs, französisch Junaises, italienisch ('imici, gehören zur Ordnmg der Rhynehoten (Schnabelkerfe), deren Enterordnum II'miptera heteroptera sie biłden und zerfallen in die beiden großen (truppen it ? Landwanzen (Geocores oder Gymnocerata) und der Wasservinzen (Hydrocores oder Cryptocerata). 
1)ic Wasserwanzen ${ }^{1}$ ) können in der Notwehr ihre Angreifer empfindlich sterhem. saugen aber niemals blut von gheiehwarmen. und sind deshalb an dieser stelle nicht weiter 7.1 herücksichtigen.

\section{Mlgemeines.}

Die IJ

Sie sind Hexapoden. versehen mit zwei Flügelpaaren; das vordere ist in seiner proximalen Hälte lederartig. den Flügeldeeken (Elytren) der Käfer vergleichbar, in seiner distalen Hälfe dagegen häutig. We Hinterflügel sind loäutig, faltbar und

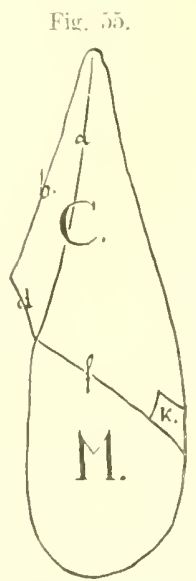

Rexhter Vorterthiggel viller Wanze.

(Schemat. Uriginal.)

1'. Coriums.

11. Nembran,

a. Serhlıbnaht,

b. Schilelrand,

d. Sichlubrand.

i. Nembramalis.

li. licilstuck. werden in der Riuhelage inter den gekreuzten, wagerecht lem Körper aufliegenden Vorlerflügehn verborgen. Beide Flïgelpare këmnen bei parasitisch lebenden Arten teilweise oler vollkommen rersehwinden.

Wundtrile stechent und sangent entipringen am Torderrande des Kopfes ${ }^{2}$ ) und haben die Form eines Rïssels ofler solmabels (liostrum). der aus der gegliederten Interlippe und der zipfelfömigen oberlippe gebiklet wird: er umschließt die sitilette seheidenartig. Fühler +5 gliederig.

Der erste Brustring grob, frei beweglieh. Fübe imeist 3 gliederig.

Die Entwickelung der Wanzen geht ohne eigentliehe Metamorphose vor sich unt ist somit eine direkte.

Nur aus den beiden Gymnozeratenfanihen der C'imicidae und dor Reduvidae kemnen wir blutsaugende und Krankheiten ïbortragende Arten.

\section{Morphologie.}

Die Wanzen sind meist schön gebante und vielfach prächtig gefärbte Tiere; aber leider wird ter gute erste Einlruck balk verwischt, wem man ihe üblen Eigenschaften kennen lernt.

Der relativ kleine Koj ist meist in den ersten Brustring eingesenkt; nur die Notoneetidae besitzen cinen gröberen glockenfömigen Kopf, der fler Vorderbrust breit aulsitzt. Doic - fadenformigen Fiih ler der Geocores (Gymnocerata) sind grob, lïnger als der Kopf und bestehen aus $4-5$ Gliedern; die $3-4$ gliederigen Jïhler der Wasserwanzen (Cryptoerata) sind lilein. dick und kürzer als der kopt, sic werten ressteekt inter den weit vorspringenden Augen getragen. Wohlausgebildete komplexamgen sind stets vorhanden, oft auch ein hinter diesen liegendes (ozellempatr. Der gegliederte kissel (., schnabet") wird ungebraucht gegen die Interseite der brust zurückgesehlagen.

bie drej fluclaxpinge sind deutlieh akembar. Der erste (I'nothorax) ist meist grob wat frei heweglieh, wälmend die beiflen folgenden (Meso-mel Metathorax)

1) Nicht allein vou liurkellsebwimnar (Nolomedu), der zum Stechen stets bereit von

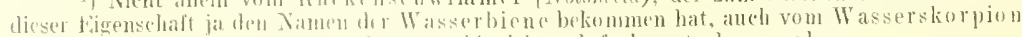

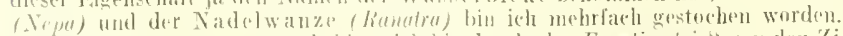

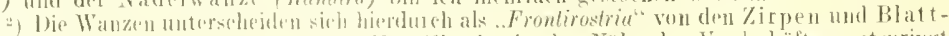

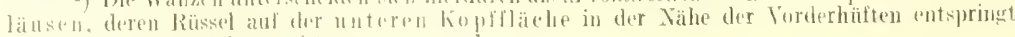

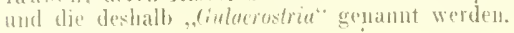


hänfig mitcinander verwathen. Iuf dem Jusothorax liegt zwischen den fiugel-

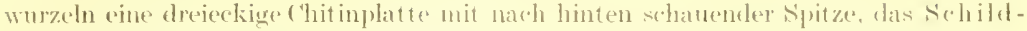
clen. Die Beine sind gut ansgebildet und nath dem bekannten Typus der Klasises

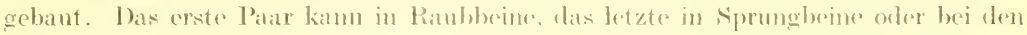

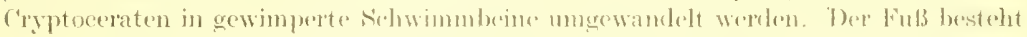

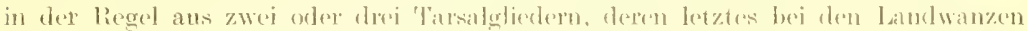

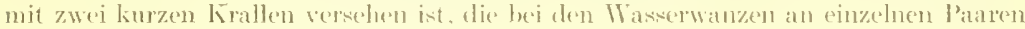
fehlen kïnnen.

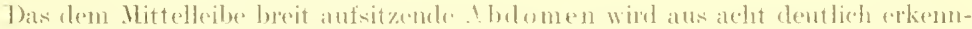

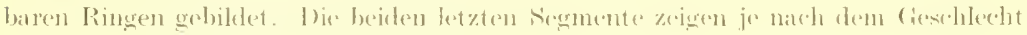
des Trägers eine verselinefent Bitdung.

\section{Inatomis: und Playsiologie.}

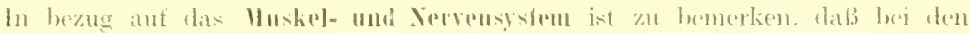
fliegenden Wanzen die binstmuskeln stärker ontwiekelt sind, als bei den flügellosen. Beispringenden und sehwimmenten Arten ist die. Muskulatur des hinteren beinpares,

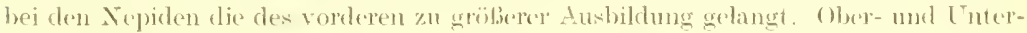
sehlundganglion und estes Thorakalganglion sind stets als getronte Knoten vorhanden; die äbrigen Thorakal- und Ablominalganglien liegen zon einem einzigen mächtigen Nervenknoten versehmolzen im meso-metathorakalen Teile des Mittel]eibes.

Die Imungsorgane steden mit der Aufenwelt durch zwei Par Thomkatund fïnf Patar Abdominalstignen in l'erbindung.

Tratetus intestimalis. Der Nahrmessehlaned der Wanzen zeefallt wie des aller lnsekten in den V'order-, Mittel- mal Endularm.

ber Vorderdarm setzt sich aus den Alundteilen, der Phargnxpumpe und dem ().sophagus zusammen.

1) In Innteile der Wanzen bilden als Ganzes einen rïscelartigen Anhang des distalen Kopfendex. der von alters her den sehr bezedehnenten Niamen des tè hn a bels trägt. In der liuhelage wird er mehr oder weniger bauchwärts eingekniekt getragen, häufig sogar in eine auf der unteren Lopf- und 'Thoraxfläche befindliche Rimne eingelagert. Ter Schnabel besteht aus (Ober- und Unterlippe, welehe in der hängsiehtung rinnenförmig \%usammengehogen beim Ineinanderlegen eine Röhre entstehen lassen, die das stilettbïndes scheidenartig umgibt.

Den Hauptanteil an ales Rïsethiklung nimmt die Lnterlippe (Labiuns). Sie verjüngt sich spitzenwärts und setzt sieh aus drei oder vier Gliedern zusammen. In ihrem Anfangsteile bleibt ein langansgezogener dreieckiger Dorwalspalt über, der (lureh Einlagerung der Oberlippe (Labrum) gesehlossen wird.

Der Schnabel als Ganzes kann durch Muskeln, die von fler Innenwand der Kopfkapsel entspringen mol sich an die Innenwände der oberlippe und des firmelgliedes der Interlipue ansetzen. gehoben mel gesenkt werden. Da nun die einzelnen Glieder dex Labiums noch durch eigene. Ituskeln in beliebiger Richtung gegeneinanter bowegbar sind, ist das lierf imstande. sein stiletbündel an jeder gewinseliten stelle anzusetzen. Die Scheide gibt somit dem Staehel wohl die gewünschte Rithtung. funktioniert aber nieht als Saugrohr.

Der stachel (Fig. 57. 5s) besteht ans den beiden Oberkiefern (Maudibelit) und den beiden Unterkiofern (Daxillen), welche rinnenfömig gestaltet und hart aneinanalerliegend das Saugrohr bilden. Thre distalen Enden sind zugespitz ilu.

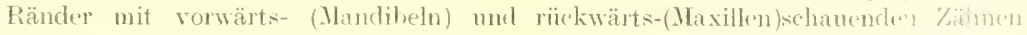
bewaffnet. Das Stilettbündel wird durch das Labium, welches zur V'erstärk mescens. 
imenwand mit ('hitinringen ausgestattet sein kamn (Fig. 5s, ('), zusammengehalten. In die Kopfkapsel cingetreten, fahren die Kiefer anseinander und geben so Raum für die zentral gelegene, große Pharyxpmpe. An die stark verbreiterten proximalen Enden der Fiefer (Fig. 5s. a.a. und x.x.) setzen sieh kräftige Protrusoren nul Retraktoren an. Auch ron den Wanzen wird das Stilett nieht als Ganzes in die Haut des Wirtes eingestoßen. sondern seme cinzelnen Teile gehen abweehselnd sägend (Mandibehn) und sieh verankernd (Maxillen) vor.

1)as Saugrohr mündet in clie langeiförmige Pharynxpumpe ein. An ihre kräftigen Chitinwände setzen sich von der Kopflapsel entspringende Muskeln an.

Fig. ill.

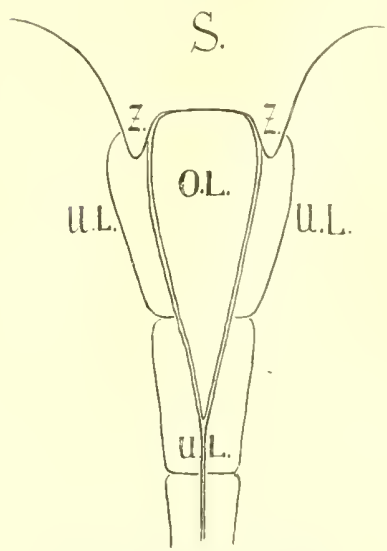

Schuabelbasis einer Wanze.

(Schematisel. Original.)

z. z. Zapfenlormige Fortsätze dex Stirn, $S$. Stirn, $U L$. Oberlippe, $U L$. $T L$. Erstes Glied der Unterlippe, $I^{t} L$. Zweits Glied des Lnterlippe.
Mit dem Mitteldarm verbindet sie der gerade verliufende, zartwandige Oesophagus, der in das Abdomen eingetreten sich sofort in den spindelförmigen, geräumigen Magen einsenkt. Der Ma gen (riehtiger.Mittcharm) verengt sich in seiner hinteren

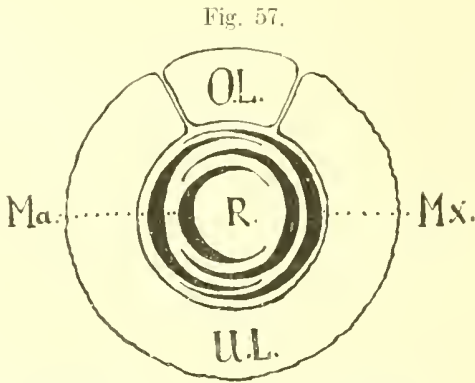

Querschnitt durch die Sehnabelbasis einer Wanze. (Sehematisch. Original.) OL. Oberlippe, $T L$. Unterlipre, Ha. Nandibel, Mr. Haxille, R. Saugrohr.

Hälfte betrüchtlich und wird deshally an clieser Stelle von einigen Autoren als Dïnndarm bezeichnet, eine bencnnung, die schon deshalb nicht als zutreffend angesehen werden kamn, weil es bei verschiedenen Familien (den Nepiden z. B.) zur Bildung eines zwriten Magens in diesem Abschnitte dos Nahrungssehlauches kommt. Der Mitteldarm hat bei den phytophagen Hemipteren eine beträchtliehe Größe, und selbst bei den blutsaugenden Arten übertrifft er die Körperlänge noeh nm das Doppelte. An den Mitteldarm schließt sich dann sofort die Rektalampulle und der Mastdarm an; nach knrzem Verlauf mündet der Enddarm in dem runden After naeh auben.

Ale 'Teile des Nahrungsschlauches werden dureh eine Tunica propria gest ïtzt, dic Intima des crsten und letzten Absehnittes wird ron einer dümnen Chitinkutikula geliklet, während der Mitteldam mit den typisehen Verdaungaszellen belegt ist. Eime zirkuläre mnd longitudinale Huskelfaserselicht ïberziebt sämtliche ron der tharynхритце analwärts gelogenen 'Teile des Traetus intestinalis.

bie Wanzen besitzen, in dieser Beziehmng ron den übrigen Insckten stark bevolzugt, vier l'ar speichalliasen. die schon $L$. Defour bekannten großen und 
kleinen kugeligen und die von I. Laxnors entdeckten schlauchförmigen und verästelten.

Die großen kugeligen bei ('imex lectulurins fast 1 mm langen Speichelehoüsen sind ron grüner Farbe and liegen in clen vorderen Teiken des. Drlonens. Batd nach seinem Anstritte aus der Driise spaltet sich Ior clmeh eine (hitinspirale in seinem Innern stets offen gehaltene Ausfïhrungsgang in zwei kopfwärtstrebente. Iste. Der eine ron diesen wirkl bald rïcklänfig mul senkt sieh direkt inden Anfaugsteil des Magens: ein, während der andere sieh in die Speirhelpumpe argicßBt. Diese vor der Pharynxmmpe, in dem ron den divergierenden proximalen Hälften der Maxillen und IIandibeln gebikleten Winkel gelegen. stellt einen glockenförmigen Hohlranm dar und ergießt ihren Inhalt mit I'mgehung der l'haryxpumpe direkt in ras Saugrohr des Rïssels (Fig. is, (r.).

bas zweite kugeligeDrüsenpaar besitzt nur einen gröliten Durchmesser ron $0.3 \mathrm{~mm}$, ist an den vorderen äuberen Ausbuchtungen des Magens angeheftet und führt sein sekret ibreh je einen Gang in die Ploaryxpumpe ab. Das gieiehe tm die in ihrer Nähe liegenden schla uch förmigen speichelrlǚsen, während die dem Grophagus aufliegenden verästelten Drüsen ihre Absondernugen durch kurze Gänge in die speiseröhre beförlern.

Die vier Malpighischen GefäBe zeigen den für die Klasse charakteristisehen Bau und münden an der Grenze des Nittel- und Enddarmes in letzteren (in.

Ein den Hemipteren eigentiimliches Organ ist die nierenförmige Stinkrlrïse, welche den

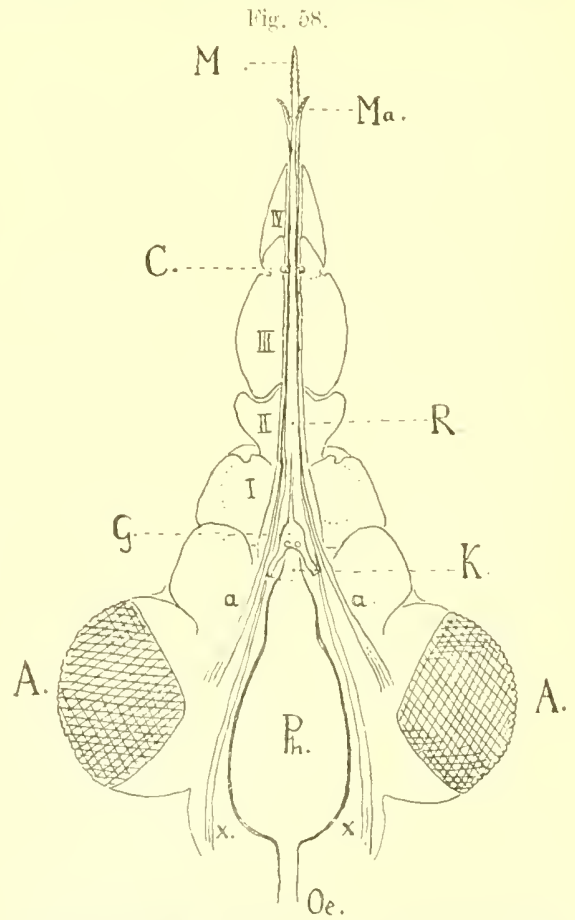

Vepa cimmen. Ifundwerkyenge. Trilweis erganzter optischer Horizontakehnitt. (Griginal. Comera lucida.) Hu. Waxille. H. Nandibel. C. Chitinring, $R$. Sang-

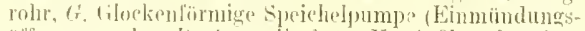
üfnungen der Ductus snlivales), $K$. CimBliernförniger liolben der sipeichelpumpe, a. a. Proximale Handibelenden, $x$. x. P'roximalo Yaxill,nenden, Ph. Pharynxpumpe. Op. Mesopliagus, 1. A. Nugen.

Nachbarn den Namen ..punaises" cingetragen hat. Sie liegt auf der Innenfläche des Mesosternums und ist bei vielen Arten auffallend, gelb ocler rot, gefärbt. Thr öliges Sekret sammelt sieh in zwei großen blasigen Säeken und gelangt dureh einen kurzen Gang, der in der Mittellinie vor den beiden Hinterliüten ausmündet, aut die Körperoberfläche.

fieschlechtsteile. Die Männehen hesitzen jederseits einen aus sieben Gehläu when zusammengesetzten Hoden. Die Weibehen haben zwei aus chonsutin Eiröhren gebilkete (warien, aber nur eine Samentasche. Auf dem letzten (athtan) 
Leshesringe des j befindet sich otwas vor dem After die Geschlechtsöffunng mit denn krallenförmigen, meist sejtich abweichenden Penis. Die Vagina mündet in eined einfachen Lüngsipalte auf der Ventralfläehe des siebenten Segmentes; zu den Seiten drer Vulva befinden sieh zwei flïgelfömige, nach hinten gerichtete Anhänge.

\section{Biologie.}

1) ie Entwieklnng der Hemipteren ist eine direkte: ein Puppenstadium fehlt: the eben aus dex Eihaut geschlüpten Laven sinct sehon den crwachsenen und fortpflanzungsfähigen 'flieren ähnlich. Es fehlen ihnen zwar noch dies Fïgel, die nach ler dritten aler vierten Häntung wohl in Form von stmmmeln auftreten. aber erst nach ber letzten ihre vollkommene Gröbe und Entwieklung erreichen. Die Nahrung der Larven besteht, wie die der Wrwaehsenen, aus pflanzliehen oder tierischen säften. die stets nur dem lebenden pflanzliehen oder tierisehen Wirt" dureh den eingefüluten stech- unl Sangrïssel entzogen werken.

1) je sonstigen Lebensgewohnheiten der Wanzen sind in den einzelnen Familien so rersehiedene, dab ich jedesmal bex der Besprechung der fiir die menschliehe Pathologie wiehtigen drten auf diesellen besonders eingohen werle.

\section{Sigstematik.}

bie Halbflügler (Hemipteren) bilden eine Lnterordnung der lihynchoten, weil sie gemeinsam mit den Zirjen (Homopteren) und den Blattläusen (Phytophthiren) einen sehnabelformigen stech- und Saugrissel besitzen. Die übrige Organisation und Jebensweise der Angehörigen dieser drei Unterorehungen ist abes eine so versehiedene, dab man sie richtiger als ( $r$ dnungen in die Klasse ler Inseliten eimreihen wïrde.

1) He Hemifteren werden zunächst in die beifen großen (irupgen der Landwanzen (Geocores) mal Wasserwanzen (IIyelyocores) eingeteilt. Die ersteren stredken ihre langen und anffäligen Fühler weit aus und heiben deshalb auch Gymnocerata, wälusud die Wasserwanzen ihre wesentlieh kleineren Antennen an ten seitenflächen des koptes unter den stark vorspringenden Angen verbergen und deshall cryptocerata gemannt werden.

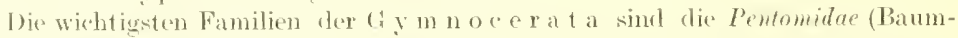
wanzen). Corëldue (Randwanzen), Lygaëdue (Langwanzen), C'tpsidue (IBlindwanzen), Itrmbranacei (Hantwanzen), Reduciedar (Sehreit- oder Raubwanzen) und IIydrodromiei (Wasserläufer). Die der ('ryptoeerata die Vepidee (Wassersorpione) unul Votomectider (Rö̈lienschwimmer).

Fïr alen Tropenarzt haben als Krankheitsüberträger bis jetzt un die Hautwanzen und dir Reduviden lieslentung erlanert.

\section{Membranacei.}

1)er ovale föruer tle Hantwanzen ist in dorsorentraler Richtung flachge-

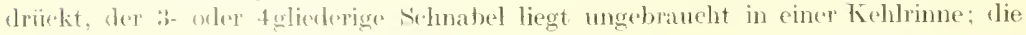
Fühler sind tglierlerig. l'muktangen fehlen mejst. Jie 3gliederigen Fiiße besitzen keme Itaftläppehen.

Ka den Hantwanzen gehört die fiir uns wehtigste und vedoreitetste Gatumg

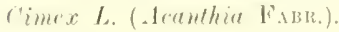


Cimerex lestulurius lawsis.

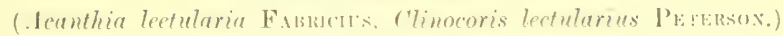

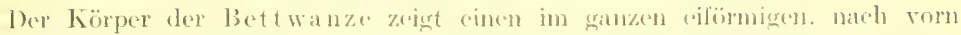

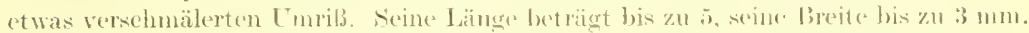

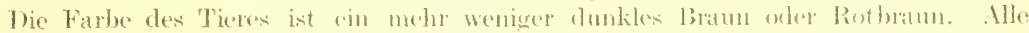

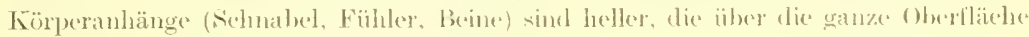
verbreiteten borsten und llatre gollo grääbt.

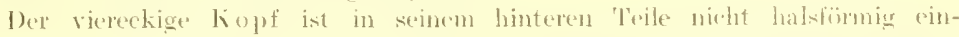
gesehnürt. Es trägt auf seiner Lorderfläele zwei zaptenförmige Lrbebungen, die den

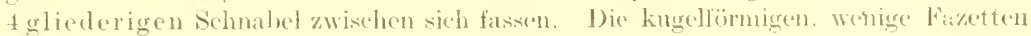
tragenden Augen sind ron schwarzer Farbe und stark vorsmingend. Zwisehen ihnen

Fig. $5 !$.

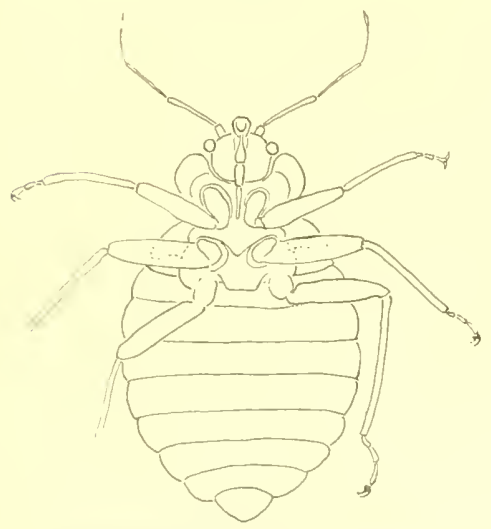

(imex lectularius LrXXe. (Griginal.) Batuchílärher.
Fïir. (it).

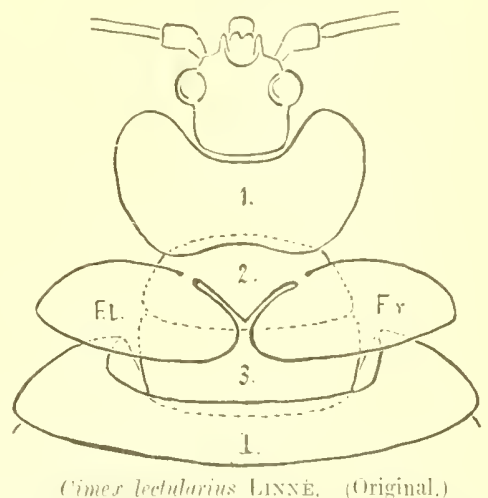

Thurax ron oben. 1. Erster Brustring (Prothomax), 2. sichildehen des zweiten Brustringes (Hesothorax), $F$. 11. $F$ r r link r und rechter flïgeldeckenstumme!, 33. Ditter Brustring (Jetathorax), I. Ereter Bancluing.

und dem schnabelgrunde setzen sich die fadenförmigen Fühler an. Ihr erstes Glied ist kurz und dick, die thei folgenden sind "twa gleichlang. das zweite et was kräftiger als die beiden Endglieder. Die Fihherspitze ist schwath keulenförmig verelickt.

burch eine tiefe Einkerbung, die die hintere Kopfhälfte aufnimmt, erhält der Prothorax eine Herz-oker siehelform; seine seitenteile sind verbreitert, abgerundet und st stark zusammengedrückt. dab sie häutig erscheinen. Das Schildchen des Mesothorax ist dreieckig und wird auf seinen Aubenseiten ron den rudimentären. muschelförmigen Flügeldechen begrenzt (Fig.60, 2. F. r., F.1.). Der dem Mesothorax breit aufsitzende ILet athorax zeigt keinc Flügelspuren.

Der erste Ring des aus acht Segmenten bestehenden Abdomens unfalit die hinteren 'Teile des Metathorax in ähnlicher Weise. wie dies der Prothorax den hinteren Teilen des Kopfes gegeniiber tut (Fig. (io, 1.).

Die kurzen $\mathrm{H}$ ïften. wohk in tiefen Gruben auf den äuberen Flächen der drai Thorakalsternite liegen, sind dureh wenig auffallende T'roehanteren mit den hriftigen schenkeln rorbunden. Die Tibien sind die längsten (Hieder des Wanzenb-tne mol tragen auf der distalen lnuenecke eine Bürste (Fig. 152, 1. 11. 11I.): cine Rolle wo 6 kräftigen bornen befindet sich auf ihrer ventralen Endliante beim dritten, wine 
whe ron 3-4 Dornen an derselben Stelle des zweiten Beinpaares (Fig. 62, III. II.). T)r kurze sïbelförmig gekrïmmte Fu B besteht aus 3 Gliedern, deren erstes an seiner distalen Inmenecke cinen Dorn, deren letztes kräftige Klauen trägt.

Über die ganze Köpperoberfläche der Wanzen sind Borsten und Haare verteilt. I) Form der Borsten ist eine ganz ungewöhnliche, sie sind säbelförmig gebogen, am

Fir. 61.

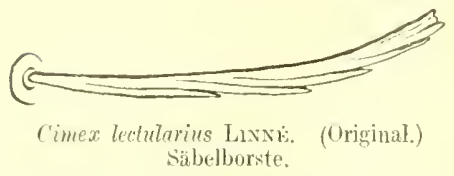
abgestutzten Ende häufig schwach gegabelt und anf ihrer konvexen Seitenliante gezähnt (Fig. 61); sie entspringen, überall in fast gleichmäßigen Abständen stehend, von allen Flächen des liopfes mol Rumpfes (mit Ansnahme der mittleren Teile der Unterfläche des Hinterleibes, die gewöhnliche Borsten tragen) und den proximalen Gliedern ihrer Anhänge. Die ebenso langen, normal geformten Haare stehen auf den drei distalen Gliedem des Schmabels (Labiums), dem dritten und vierten Fühlergliede, den Tibiencnclen und auf säntliehe Tarsen.

Als Heimat der Bettwanze wird der Orient (Indien) angesehen. Jedenfalks hat sie sich schon sehr früh in den Mittelmeerländern ausgebreitet, dem sie war den Griechen als Koris, den Römern als Cimex bereits in Altertume bekannt. In Deutschland (Straßburg i. E.) wird sie im 11. Jahrhundert zuerst erwähnt und soll nach England von ten aus Frankreich vert riebenen Hugenotten eingeschleppt worden scin. Skandinavien war im Anfange des vorigen Jahrhumderts noch wanzenfrei. Jetzt ist Cimex lectularius über die ganze Erde verbreitet, so zwar, claß sie in größeren Städten, namentlieh aber in Verliehrsentren, viel häufiger auftritt, als a uf dem flachen lande.

Die Bettwanzen führen ein so ausschließliches Nachtleben, daß als sicheres Nittel gegen ihre Stiche empfohlen wird, in befallenen Sehlafräumen das Licht nicht auszulöschen. Am Tage verbergen sie sich hinter Tapeten und Bildern (diese entfernen und die Wände übertünchen!), hinter getäfelten Wänden, in den Falten von Torhängen, in Mauerritzen und Hansgerät, vor allem in den Spalten schlecht gefügter Iolzbettstellen (deshalb eiserne Bettstellen vorzuziehen!). Ihr papierdünner Körper (,.Membranacei"), der ihnen erlaubt, die engsten Schlnpfwinkel aufzusnehen, und ihre Fähigkeit jahrelang zu hungern, erselweren ihre Ausrottung moemein; es kommt noch hinzu, faß hungemde Wanzen wahrseheinlich außer dem Menschen noeh andere T'amblïter, vor allem Vögel (Tauben, Schwalben) ${ }^{1}$ ) annehmen, vielleicht sieh sogar, wie dies die Reduviiden tun, mit Insektenblut begnügen und kannibalischen Gewohnheiten huldigen.

Dic liettwanze ïberwintert leieht, (la sie selbst starke liälte gut verträgt.

Nach ('ingetretenor Dunkelheit sucht die Wanze ihre Opfer auf. Vorkehrungen, wie sir mit Lifolg gegen Argasiden (Omithodoms) angewandt werden, Bestreichen (fer Bettpfosten mit Pctroleum, Einstellen derselben in wassergefüllte Gefäße nüitzen nichts, da sich die Bettwanze in diesem falle einfach von der Zimmerdecke auf den Schläfer fallen läßt. Ciesättigt zieht sie sieh dann sogleieh in ihre Schlupfwinkel zurück. Auf ihre Stiche reagieren die einzehen Menschen sehr rersehieden; manche werlen durch sie kaum belästigt oder in ihrer Nachtruhe gestört, andere kömen sehon des wirkrlichen Tranzengeruehes wegen nicht schlafen, haben beim Steehen

1) Man hat J'ibler die auf Fledermänsen, in 'Taubensehlägen und Schwalbennestern gefundenen Wanzen als besondere Arien (pipistrelli, columburius, himudimis) buschrieben, sie unterscheiden sich aher von lectulurius ahsolut neht und kïnnen desalb nur als Bettwanzen angesproehen werdin. 
lebhafte Schmerzempfindung unel bekommen stark juckende Quaddelu und Frytheme.

Mehrmals im Jahre, in der gemäBigten \%one nur während seincr wärmeren Hällte, legt die Betwanze ihre weißlichen, bis 1 mm großen lin in der /ahl ron 40 bis 50 St ïck; sie sind walzenförmig und dureh einen 1)ecked geschlossen. Die hell gefärlut(n)

I. II. III. Cemex lectularius Livié. Erstes bis drittes Tibienende mit den Tarsen. Bürste auf der plantaren Fliche des schienbeinendes, das am ersten Beinpaare keine Dorne, am zweiten deren $\frac{4}{x}$ und am dritten deren (i) trägt.

a. $b$. Redurins personulus Livis. a. Solle auf der plantaten Fläche des letzten Tibiendrittels von unten, $b$. dieselbe ron der seite geselien.

(Otiginal. Cumera lucide.)

Das Kotwanzenbein ist ein schönes Beispiel dafür, daß die Natur mit möglichst wenigen Baustoffen die gewollten Wirkungen hervorbringt.

Ein Z y linder ron gleichem Durchmesser wiurde keine grobere Festigkeit besitzen, als das schlanlse lioffelförmige Ende des Reduviusschienbeines und seinem Zwecke virl weniger zu entsprechen rermögen.

Fig. (i⿱⺈).

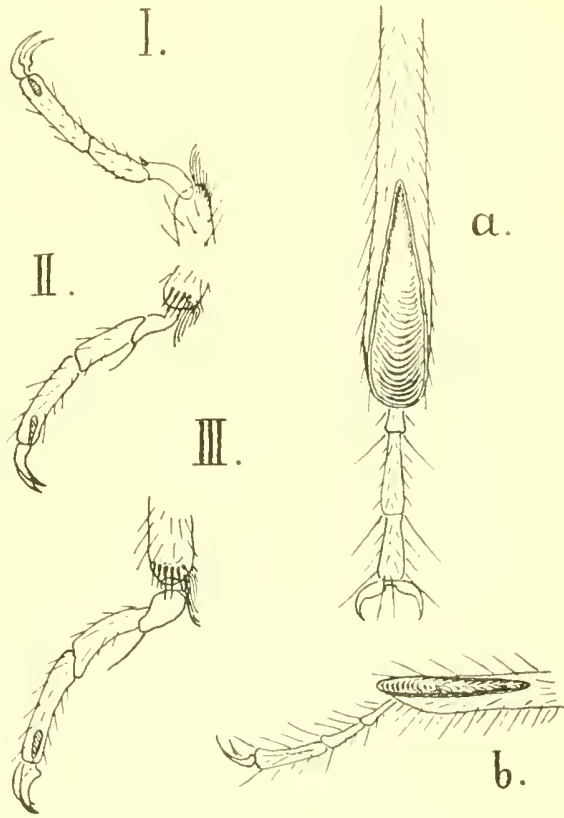

La rven schlïpfen nach \$-10'Tagen aus und erreichen nach mehmaligen (4) Häutungen in 11 - 12 Honaten ihre volle Entwieklung und Geschlechtsreife.

Noch drei andere Arten der Gattung Cimex sind aufgestellt und beschricben worden. Sie sind sämtlich l'arasiten des Mensehen und unterseheiden sich so wenig von Cimex lectulurius, daß sie von den meisten Entomologen mur als Varictäten oder Lokalrassen angesehe'n werden.

Es sind dies Cimed roduntatus Sigxoret, 1852 zuerst von der Insel Réunion beschrieben, aber auch in der Tropenzone der alten Welt weit verbreitet Cimex macrocephalus Fieber aus südasien und Cimes ciliatus Everuand 1841 aus Kasan. Auch in ihrem biologischen Verhalten schließen sich diese drei "Arten" engstens an Cimex lectularius an.

\section{Reduviidae.}

Kopf frei vortretend, länglich, fast zylindrisch, mehr oder weniger gentis in den hinteren Fartien halsförmig verengt. Schnabel der ventralen Körver. fläche nicht aufliegend, sondern von ihr abstehend, 3 gliederig. Fïhler peitsihen- 
riming. dïm und ling, 4 gliederig. l'unktangen meist vorhanden. Torderrieken wnlstig und höckerig, durch eine guere Einschniurung in eine kleinere vordere und rine gröbere hintere Hälfte geteill. Hemielytren olne Keilstïcke (Fig. (i.j). Beine lang. die 3 glierlerigen FüBe auffallend kurz, ohne P'ulvillus.

bie Reduviden sind schlanke, schön gebaute und vielfach bunt gefärbte 'l'iere. Sie stellen die größten blutsangenden Arten unter den Wanzen und unter den Arthoporlen iibrhaupt; sic sind hauptsächlich 'Tropenbewohner. Die Mehrahl der Fanilienangehörigen huldigt räuberischen Gewolmbeiten, sie fallen schwächere Insekten und Arachnoüdeen an, tïten sie tureh ihre Stiche und saugen sie aus. Diese Eigenschaft macht sie für den Menschen zu beachtenswerten Wohltätern; so rertlgt nuser Reducius personatus L. mit Vorlicbe Bettwanzen und Phowergates bicoloripes

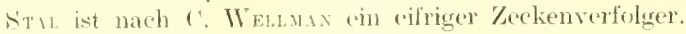

\section{Rerlurius persomotus Lassé.}

Der länglich eiförmige Körper der Kotwanze miBt 15 -1s mm, ist hinter der Leilsesmitte an breitesten und rerseheint in ganzen ziemlich abgeflacht. Anf allen seinen Teiten, besonders aber an den Flügeln und Beinen, sind lange und dichte Haare verteilt. Die Farbe ist ein dumkles Schwarzbraun. die Füblerwurzel, die Kinie und 'Tarsen sind wesentlich heller. bis lelungelb, gefärbt, an der Membrannaht (Fig. 5.jt.) der Flïgeldecken befindet sied ein schmutzig weiber Strieh (Taf. I. Fig. 1).

Der Kopf ist nur wenig länger als breit. Die groben nierenförmigen Augen liegen etwas hinter seiner Hitte und nähern sich anl der ventralen Fläche mehr. als auf der dorsilen. Dic beiden groben, stark ghänzenden (rzellen stehen auf zwei Höekern. die sich an der hinteren oberen Ecke der Komplexangen erheben. Hinter ihnen verengt sieh der Kopf halsfömig und tritt durch cine halblirgelige (aelenkfläche mit dem pfannenförmig ausgelöhlten Prothorax in Verbindung. Die Fühler sind kïrzer als der Körper, dex an der Spitze lehmfarbige Fïhlerhöeker erhebt sieh dicht vor den Fazottenangen. Die 4 gliederigen Antennen sind peitsehenförmig und versehmälem sich spitzenwärts stetig; das erste und vierte Glied ist kürzer, als die beirlen mittleren (ilicrler. Der gekrïmmte, pfriemenförnigge Sehnabel erteicht die Wurzel der VorderLuiften; die Cnterlippe ist 3 gliederig, ihr mittleres ctuled ist das längste.

Vorderviucken vor semer llitte tief quer- und auberdem längsgefureht; das burch die Querfurehe alogetremnte grobsere, proximale Feld des Prothorax wird rou \% ci gratförmigen Längsleisten in drei napförmige lertiefungen geteilt. Das verlältnismäBig grobe, dreiechige thehildehen ist in eine kidfömige Spitze ansgezogen. I) Fe Fügeldecken lasien den Leibesrand nur wenig horvortreten.

Siintliche licine sind fast gleich stark, das letzte Paar länger, als die vorderen, natunentlich in seinen mitteren Gliedern. D)ie vier Vorderschienen mit langriformiger. proximalwärts zugespitzter sohle auf der Ventralfäche ihres distakn 1)rittrls (Fig. tiz, a.b.). Die drei Fubglieder nehmen rom elsten zum dritten an länge zu. das polsterlose Endgliefl trägt zwei lange kräftige Klanen.

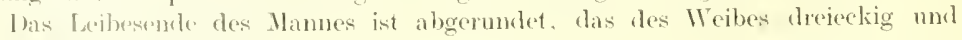
in der Mittellinie grestaltent.

Redunius formutus ist ein in ganz Enropa verbreitetes llaustier. Tagsiilser verbirgt ar sirll in dunklen Zimmerecken, hister llöbeln usw, und kommt (ast bei einbecthender Dunkelheit aus scinen Sehlupfwiukeln hervor. Da er

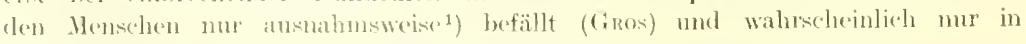

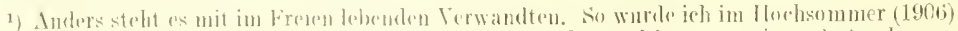

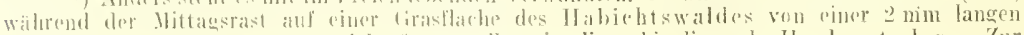

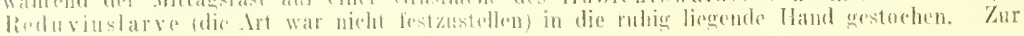




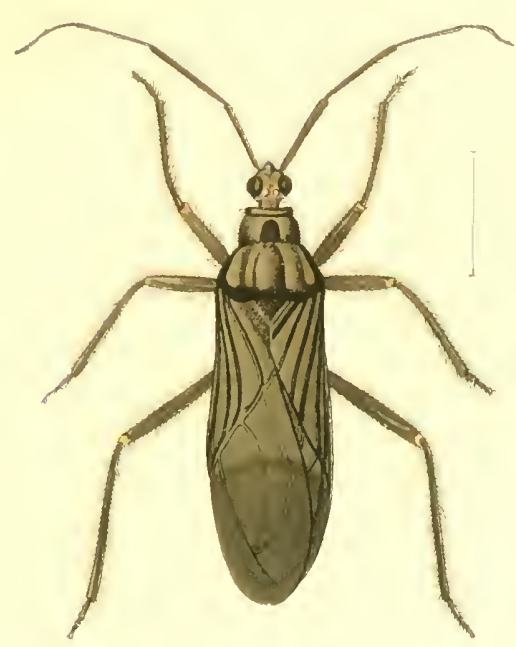

1.

Reduruls personalus Lane $4+3,5$

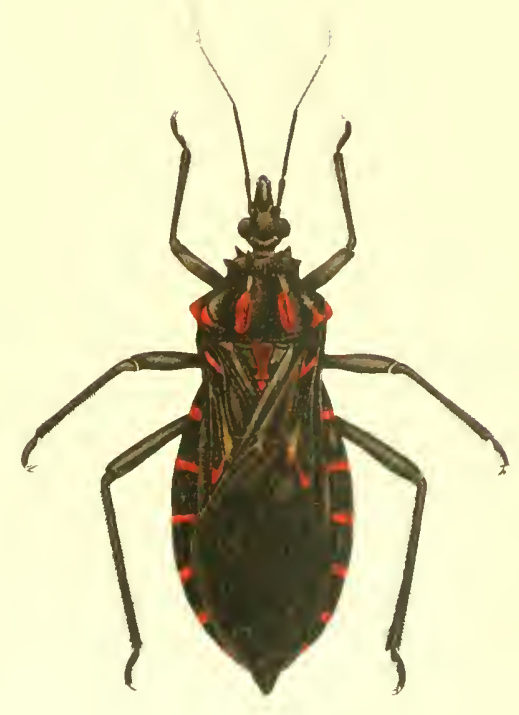

2 .

Conorhuns megustus Burmetstor 12

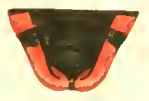

't

bilienente dos :

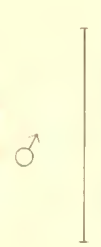

Tinurhinther

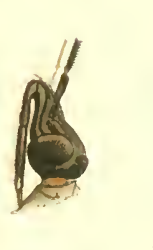

3

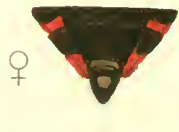

5 Kopf ron der Secte

Letbesende des y 

der Notwehr stieht (wenn z. B. der Sehlafente einen zufällig ïber sein (iesieht kriechenden Reduvius durch eine unsinlte und nieht ganz zweeknübige Abwelur-

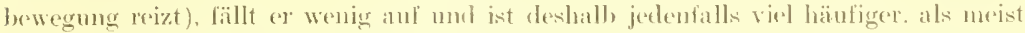
angenommen wirt. Dizu kommt noels, dab die lieduviuslarven ihren Kärper regel-

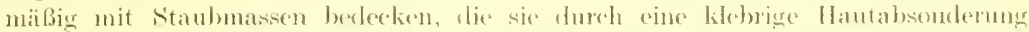

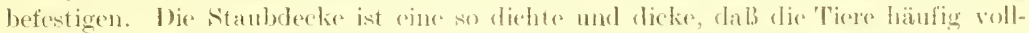

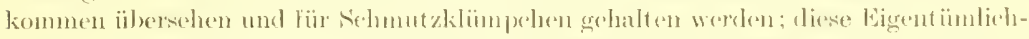
keit hat unserem Redurius den Brimamens personatus, der Maskierte doder die Lotwanze eingetragen. Die Litren häuten sich viermal und erlangen iiber rin Nomphenstadium nach 11 - $1:$ Sonaten ihre volle Entwieklung.

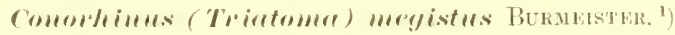

bie . Kegelnasen" sind in den 'Tropen der alten und nenen Welt in zahlerichen Arten vertretene Wanzen. Aul den ersten bilick sind sie mit Sicherheit als white Reduviden (rgl. 'Taf. 1. 1. 11. 2.) zu erkimmen. In ihrer ganzen Gestalt und ihren Grebaren unterscheiden sie sieh von Redurins persomutus z. B. in nur wenigen l'unkten.

1) fer fiir den 'Tropenarzt wichtigste Ant, Comorhinus megistus Burs., ïhertrïgt

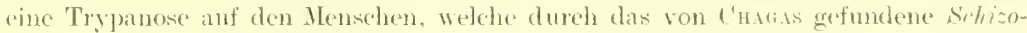
trypanum (ruzi verusacht wird. $\left.{ }^{2}\right)$

Conorhimus megistus erreieht in weiblichen freshlecht cine Lünge von $28-32 \mathrm{~cm}$.

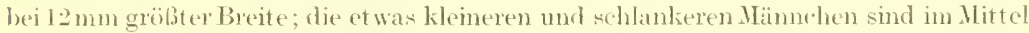
$2.5 \mathrm{~mm}$ lang und ! mm breit; ex ist somit der gröbte blutsaugende Gliederfübler, den wir kemen. Seine Körperformen sind de unseres Reduvius pronsofus, mit dem ar anch die Grundfarbe gemein hat. Die behatung dagegen ist eine sehr viel spärlichere. als die der Kotwanze. Von der glänzend schwarzbramen Körperoberläche heben sieh regelmälbig angeortnete scharlachrote Flecke sehr wirkungstoll ath (s. Fig. ?. Taf. I). Sie stehen zu viert auf der hinteren Hälfte des Vorderrickens. Ferner befindet sieh ein dreieckiger roter Fleck auf fem Schildchen, je ein soleher aut den Flïgeldeckenwurzeln, dex distalen spitze des lederatigen vorderen Hälte der ll'mielytren mul anf lev dorsalen und fentralen liäche der llinterrandecken dex ersten bis sechsten Banchringes. ${ }^{3}$ )

Der lange kiggedförmige Kopt trägt in semem hinteren Drittel die groben stark rorspringenden Augen. Die weit vonemander entfernten Nebenaugen steden noch mehr rückwärts. Fïhlerhöcker verhältnismäbig klein und dïnn. Antennen borstenfömig. kaum von halber körperlänge; das erste Gled ist das kürzestr mu iiberragt die .Nase" nicht. Das zweite ist so lang. als das dritte und vierte zusammengenommen. D) ziemlich gerate Schnabed liegt der Körperunterfläche heinahe auf (Taf. 1. Figr. 3), er erreicht nur a usnalumsweise (bei den f) dic Vorderhüften. Die Cnterlippe int : gliederig. ihr mittleres tilied ist das längste.

Strafe für den türkiselurn I'berlall wanderte das Tier ins \%yankalinmelas und befindet sjeh noch heute in meiner sinumbug.

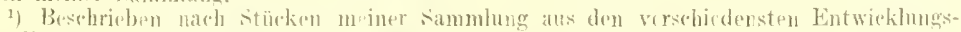

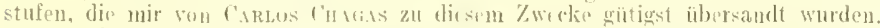

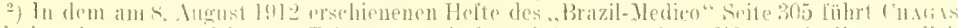

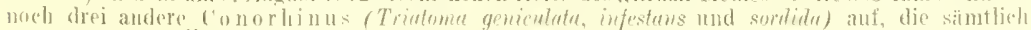

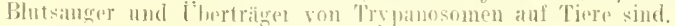

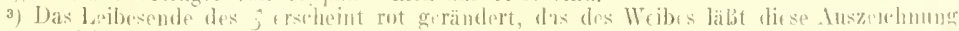

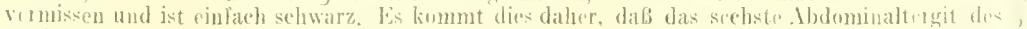

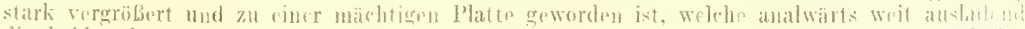

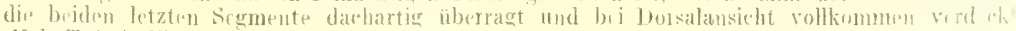
(Vgl. Tal. 1, Fing. 4 und is.) 
Eine flache Querfurehe teilt den Vorderrücken in zwei Hälften, die wiederum durch eine ticfe Tängsfurche in je zwei Felder zerfallen. Die beiden vorderen sind halbkngelig gewölbt und tragen je emen zitzenfömigen (hitindorn. Die beiden hinteren Felder werden von zwei gratartigen Längsleisten durchzogeu und nach außen

Fìg. 6.3.

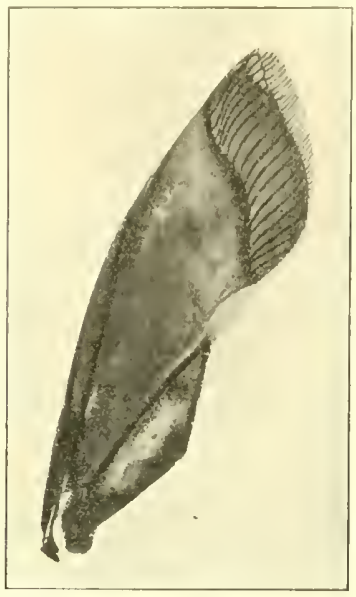

Fig. 64.

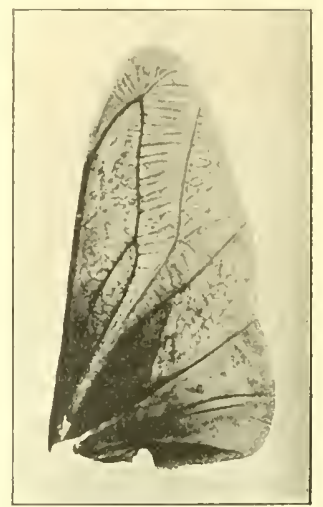

Belostoma grande LıNe: (Figg. 63 u. 64). (Original. Dirckter photographiseher Abdruck.) Fig. 63. Rechter Vorderflügel.

Fig. 61. Reshter Hinterflügel vollkommen entfaltet.

Fig. 65.

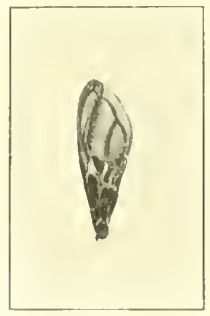

Fig. 6t.

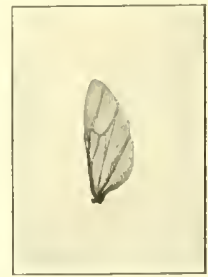

Conorhimus ministus Bermeister (Figg. 65 n. 66). (Original. Direkter plotograplischer Abdruek.) Fig. 65. Rechter Vorderflügel.

Fig. 66. Rechter Ilinterflugel vollkommen entfaltet.

durch gratartige Erhebungen des Vorderbrustseitenrandes begrenzt. Auf den Vorderenden dieser vicr (xute steht je ein Dorn, ein kräftiger aber kürzerer Doru befindet sich ‘lann nocll auf den rïckwärts gelegenen, rot gefärbten Partien der breiter und flacher gewordenen Lüngsleisten. Diese gratartigen Leisten geben der analwärts sieh stark verbreitornd'n, an ihrem Hinterrande abgermudeten Rïekenfläehe des ersten Brustringes ein kragen- oder fäeherfömiges Aussehen. Die Spitze des Schildehens ist verhältnismäßig kïrzer und kräftiger, als die von Reduvius. 


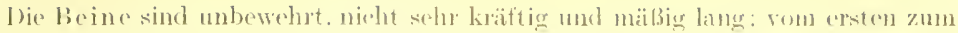

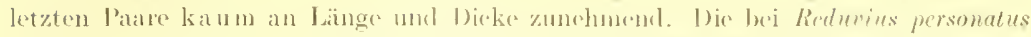
so wohl entwickelten 'l'ibiensohlen sind bei c'onorhines megisles nut leicht angealeuter.

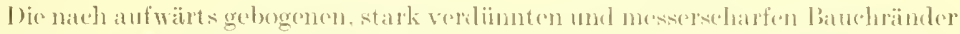
iiberragen (im Gegensitze zu Reduvius) diezusammengelegten fïlugeldecken

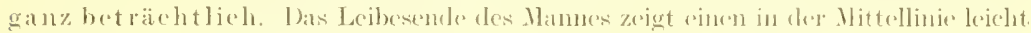
angekerbten, bogenförmigen L'mub, das des Mribes ist dreieckig.

Iig. $1 i \bar{i}$.

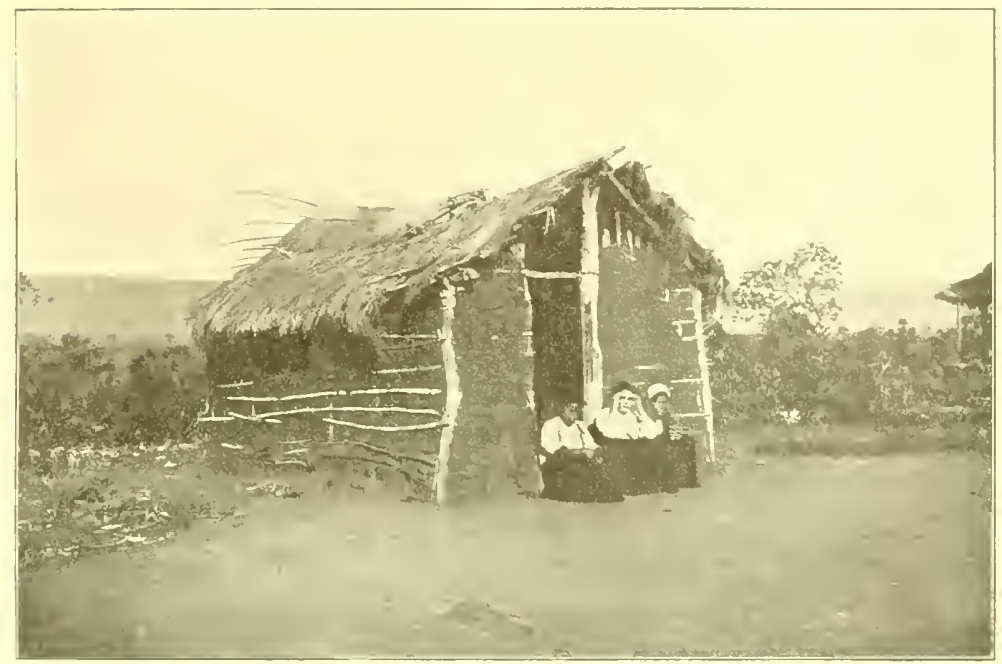

Brabilianicele Eingeborenenhïtte. (t)riginalaufnalme von ('. ('usıis.)

In folgenden biologiscleen Abechinte gebe ich in der Hauptsache die mir gewordenen Ditteilungen von ('mustis und Nisis wioler.

Conorhimus megistus ist ein in ganz Brasilien und den Grenzgebieten verbreitetes Haustier. Sein Lieblingsaufenthalt sind die primitiven Hütten (Fig. (i) ) mit Lehmwänden und Strohdächern. wie sie von den Eingeborenen bewohnt werden: aber auch hesser gebaute Häuser werten befallen, wenn wie günstige Schlupfwinkel bieten. Die Kege]nase verbirgt sich tagsüber in clen Ritzen ter Wäncte, zwisehen den Halmen des Daches und unter hohlen FuBböden. In Wagenremisen, Sichemen, Pferde und ltähnerställen wirc sie chenfalls sehr häufig angetroffen und verschmäht auch das Lilut des dort eingestellten Tiere keineswegs. So kommt es, daß durch Fuhrwerk, Sättel und l'ferdegeschirr ('onorhinus (namentlich junge Larven. die unsere Bettwanze an firöbe nicht ïbertreffen) auf weite Entfernungen versehleppt wird uns nengegrünlete Ansiedlungen sehon nach kurzer Zeit infiziert gefunden werden. Fiir gewöhnlich dagegen handelt es sich lxei der Verbreitung von ('onorhinus um Kontakiinfektion: Larven und Nymphen lirieclen in benachbarte Wohnuäume. erwachecus

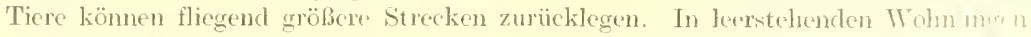
finclet man schon nach 4 Wochen kemen Conorhinus mehr. 
Die Kegeluasen verlassen nur nachts nach dem Verlöschen der Lichter ihre Śchlupfwinkel. lanfon an den Wänden mmer und suehen auch nu um diese Zeit ihne Oyfer anf. Dhe rielfach gelnunchten Iängematten schützen wohl gegen die ersten Fintwiclingsstufen, werden aber von den fliegenden Imagines leicht erreicht.

Trotz der Größe des 'Tieres ist sein Stich fast schmerzlos: er hinterlälst weder eine sichtbare Wunde, noch fiihnt er zu lokalen Entzündungserscheinungen. So kommt es. daB Kinder ruhig weiterschlaten. während die Riesenwanze') an ihrem Gesicht festgesaugt ihre Bhutmahlzeit abhält und viertelstundenlang dort verweilt.

Das Gesieht des Schläfer's wird ron Conorhinus hesonder's bevorzugt : man nennt ihn deshalb auch in vielen Gegenden lirasiliens, barbeiro", den Barbier. Die vielfach fiir' (in anderes Tier angesehene flügellose Nymphe wird meist mit dem Namen, ,'atculo" belegt, der gewönhich für hartschalige Käfer gebraucht wird.

Die zwei Millimeter langen tomenförmigen, gedeekelten Eier sind von einem glänzenden (horion umgeben. In den ersten 10-II Tagen gelblich weiß, nehmen sie rom 12. 'Tage ab ein rosenrotes Kolorit an, das allmählich dunliler' wird, so da bs sie an 20. Tage rot erseheinen. Je nach der 'Temperatur kriechen die jungen larven in 21- 40 'Tagen ans. Thre rosenrote Farbe clunkelt in s Stunden bis zum Sehwarzbram mach. Nach 5 Tagen halten sie ihre erste Blutmahlzeit ab und suchen dam nach frühesten: 2-3 Wochen ein neues opfer.

Die erste Häntung erfolgt nach 45 'Tagen, die zweite nach 2 -3 Monaten, die llritte nach 4-6 Monaten. Wuch die vieste Häutung wird das Tier zur Nymphe; es hat dam beinahe die (röße des Mämnehens erreicht und zeigt deutliche Flägelstummel. Nach den'Häutungen bekommen die 'Tiere jedesmal ihre rosenote Färbung wieder, die aber bald der nomaldmnklen Farbe weicht. Das Nymphenstadium dauert $40-50$ 'Tage.

Ein Männchen vollendete seine Entwicklung vom Ei zur Inago in 260 'Tagen; ('s ist dies die kïrzeste ron NEIS beim Laboratoriumsversuche beobachtete Frist. Imagines geworden beginnen die crwachsenen Wanzen nach achttägiger Puhe Blut zu sangen, vollzichen die sich über viele Stunden erstreckende Begattung und legen nach efwa 50 'Tagen ihre ersten Eier ab. Jie Zahl derselben ist gewöhnlich $8-12$, kamn aber bis zu 45 Stïck betragen. Ein Weibehen legte in 5 Monaten 38 mal, im ganzen 218 Eier.

Bei genügender lieuchtigkeit kann Conorhimus meyistus lange Zeit fasten; ein Weibchen, welches NErrA ron Britisch-Gn yan a zugesehickt wurde, legte diese Reise in einer kleinen Schachtel zurtick uncl kam 57 Tage nach seiner Absendung noch lebend in Manguinlos an.

Die Lebensdaner der Kegelnase beläuft sich anf melnere Jahre, und da sie ihn Fähiglieit, zu infizieren bis an ihr Ende bewaht, kann eine einzige Schizotrypanumträgerin ganze Familien krank machen. In jeden Alter kann die Wanze aufgenommene Hämoflagellaten in ihrem Körper zur Entwieklung bringen mel mit ihnen dann den Mensehen infizieren. 1)a anch die männlichen Tiese der Bhtnahrung bediufen und sich gelegentlich anstecken, sind sie abenso gefährlich, als die weiblichen Wanzen.

\section{Fang, Infbewahring, I ntersiehmo.}

Die butsaugenden Hemipteren sind fast ansmahmslos Nachttiere. Sie werden infolgedessen am sichorsten angetroffen, wemn man einige Stunden nach Somen-

1) Tha doch ist sie wiederum unr ein \%werg gegen die surinamische Nepide Belostoma grande

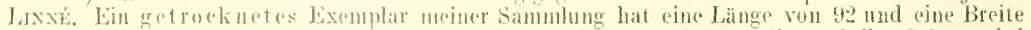

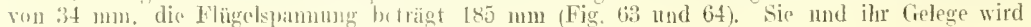
von den einguburenen Indios als Leckorbissen verzehrt. 
untergang die Schlifräume, Viehstïlle usw. grell beleuchtet: die flüehtenden Wanzen sind dann leieht zu erhaschen.

In feuchten Behältnissen lassen sic sieh gefüttert viele Monate an Leben erhalten und zu Versuchen verwenden.

Die Farben der Winzen rerändern sich in konservierenden Flïsigkeifen und bei Tageslicht rasch; es empfichlt sieh deshall, stets auch genadelte 'Tiere in verdunkelten Kästen antzubewahren.

Zu anatomischen Lntersuchungen eignen sich am besten frisch getötete (licnzin, Chloroform usi.) IT:uzen.

Handelt es sich $11 \mathrm{~m}$ elie Horstellung mikroskopischer Priparate, so gelten die

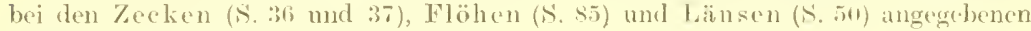
Methoden auch tiir dic Hemijeteren.

\section{Prophilaxe, Feimile.}

Gegen Wanzenstiche kann man sich ziemlich sicher darlurch schützen, dab man dir Lichter in den Schlafzimmem brennen läBt. Da es aber nicht jedermanns Sache ist, in hellen Räumen zu schlafen, und Moskitonetze wohl gegen größere ( omorhinen, nicht aber gegen deren Brut und die dureh alle Ritzen sehlï̈pfonden Bettwanzen schützen, bleibt nur der Yernichtungskrieg gegen das Ungezirfer übrig.

Zunächst ist es nötig, die Schlupfwinkel der Tiere möglichst zu beseitigen. Tapeten, Vorluänge, Bilder, überflüssige Möbel usw. sind zu entfernen und zu verbremnen oder wenigstens in genügender Weise zn desinfizicren. Hölzerne bettstellen sind wenn irgend möglich mit eisernen zu vertauschen. Nanerritzen und spolten in getäfelten Wänden sind zu verschmieren oder auf andere Weise rollkommen anszufiillen.

Örtliche Anwendung von kochendem Wasser, Petroleum, sublinatlösung, einer Enulsion von metallisehem Quecksilher in Eiweiß und was sonst noch alles für diesen Zweck angegeben worden ist ${ }^{1}$ ), muB zicmlich winkungslos bleiben, da es vielen Wanzen gelingt. sieh vor dem Verderben in sicherheit zu bringen und später wieder zurïckzuwandern.

Tiel wirksamer sind deshalb) Räucherungen mit Schwefeldioxyd (s g Sulfur auf jeden Kubikmeter des zu desinfizierenden Raumes), Formalindämpfen, Sehwefelkohlenst off dïmpfen orler Z yanwasserstoffgas (Homaro). Da die Anwendung dieser Stoffe (namentlich des letzeren) mit Gefaliren verknüplt ist, empfiehlt es sich, dieselbe nur dureh geschultes Personal vornehmen zu lassen. Am wirkungsvollsten werden natïrlich solche Ma Bnahmen dann sein. wenn sic sich über ganze Strabenviertel erstrecken nud auf Anordnung der Behörden mindestens jährlich einmal gleichmäBig und gleichzeitig ausgefüht werden.

WVie alle Insekten, so sind natürlich auch den Wanzen niedere Pilze gefährlieh. Aus dem Tierreiche aber erstehen ihnen wohl noeh weniger Vernichter, als den übrigen Arthropoden, da sie durch die Sekrotc ihrer Stinkdrüsen den meisten Angreifern sofort widerlich worden. Nur die eigenen Ordnungsgenossen befehden sich. untercinanker. So ist es eine oft festgestellte Tatsaehe, daß Reduriidae (namentlich Reduvius personatus) ('imicidae (Cimex lectularius) töten und answaugen. Auch Kannibalismus ist des öfteren bei Cimex beobachtet worden.

1) In letzter Zeit ist Terpentin von G.Lxould als, ,sicheres" Nimzenertilgume mittel warm empfohlen worden. (tndian Med. (iaz, - Okt. 1912.) 


\section{Literatur.}

1843 .ичот. C. J. Г. at A. Serville, Histuire maturelle des Insectes Hémipteres. Paris.

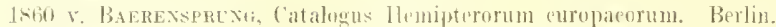

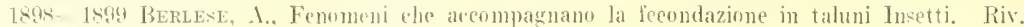
die Patologia vegetale. Bd. VI U. V'll.

1:12: Busckock, B., In the resistance of Cimed lectularius to various reagents, Powders,

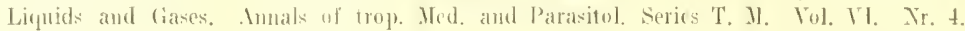
s. $415 \quad 428$.

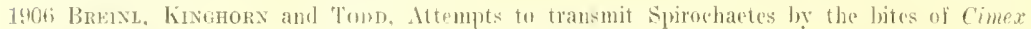
lectulurius. Liverpool siletol of trope med. B[em. XXI.

1902 Carrazi, 1)., La borsa di Berlese mella cimice dei letti. Intemat. Monatseler. Anat. Phys. Bil. 19.

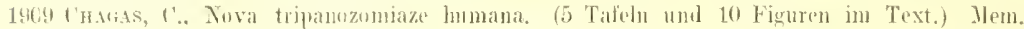
Inst. (1)w. I'ruz. Bul. 1. 11. 2..

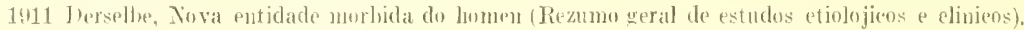
Ebenda, Bd, 3, 11. 2.

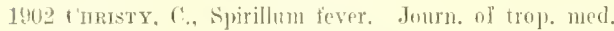

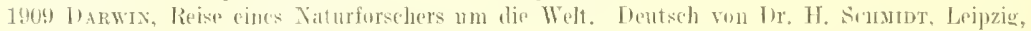
krönets Verlag. (Cunothimus megistus.)

1908 Defany, F. H., Epidemic dropsy or Beri-Berj in Eastern-Bengal. The Indian med. Gaz. Mr. 3.

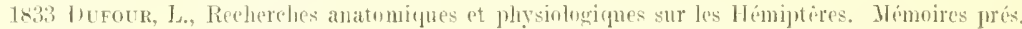

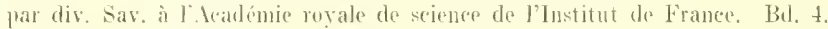

1904 Exdenledx, 1i.. Phthirocoris, eine nene zu den Heniencephaliden gehörige Rhrnehotengattume

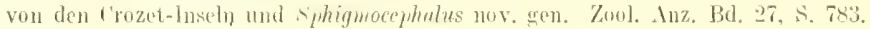

$18+1$ Eversuax, E., quadam insecturum species novae. Bull. soc. Imperer. de Tatural. Huscou XI, S, 351.

1803 Fabrules. J. C.. systema Rhymgotorum. Brunswig.

1807 Faléen, Mmographia eimieum. Hahiae.

1829 Therselbe, llemiptera sinecrat descripta. Lund.

1861 Fieber. F. X., llip europaitiden IVemipteren. Wien.

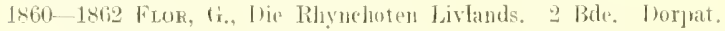

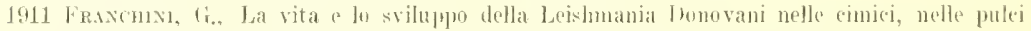
e nei piducechi. Mataria e mal. dej praes. cald.

1912 Gaxgete, The Destruction of Bugs with turpentine. Indian Hedical Gazette - oct.

1773 de Cieer, C., Mém. pour sorvir à Thistoire des inscetes. Bd. 3, s. 296. Stockholm.

1903 Gotscilicin, E., L’ber Protozuenfunde im Blute von Flecktyplunskanken. Dentsele mod. Wuchensedir. Jalne. XXIX, Nr. 19.

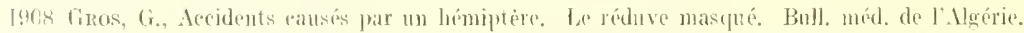

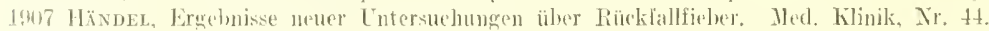

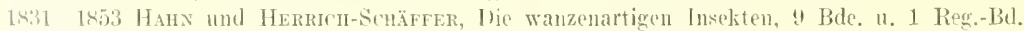
Xïrnherg. (1010 meisterlaft gezeichnete und vorzüglich kolorierte Mbbildungen auf 324 Talledil. no. $^{\circ}$

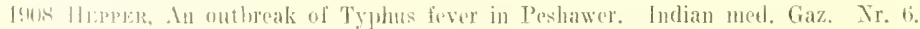

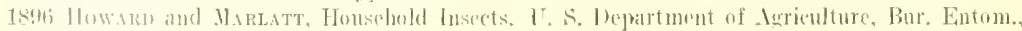
Bull. Nr. 4 (Now Series).

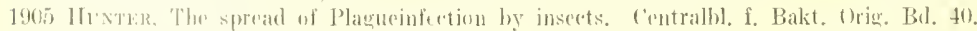

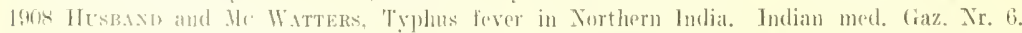

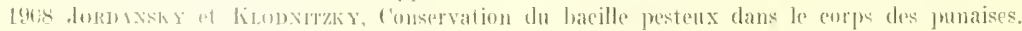
Aun. de J'Instifut Pasteur. Bd. ㄹ.

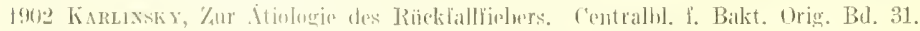

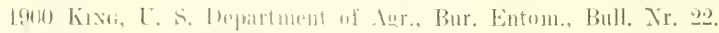

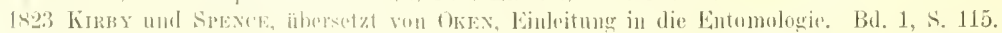

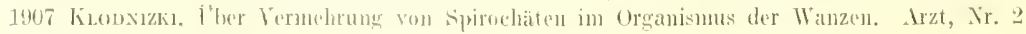
s. 7it. (liussisch.) 


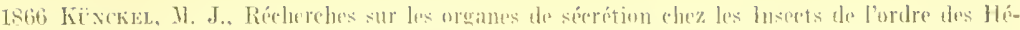
miptirts. ("tmpt, rent. Xr. 10, s. 43;',

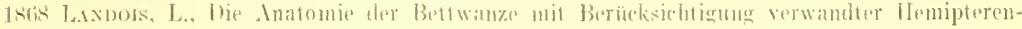

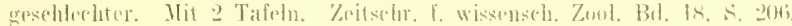

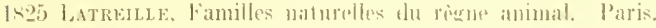

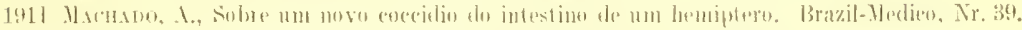

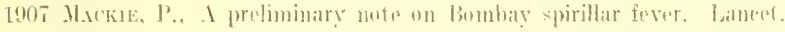

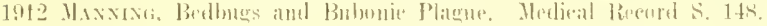

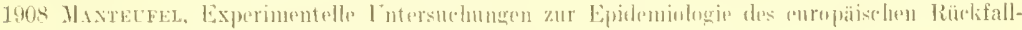

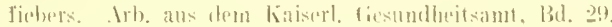

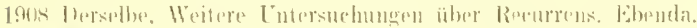

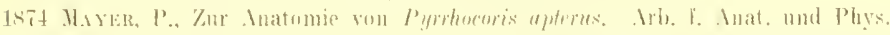

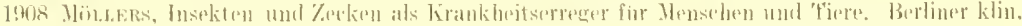
Mochenschr. Mr. 13 .

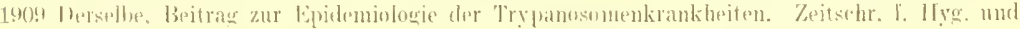
lili. Bil. (6.2.

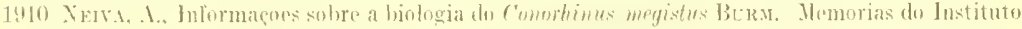

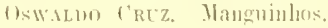

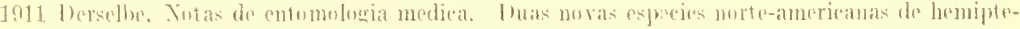
ros hematop̧hagos. Brazil-Mcdico. Amo XXV, Nr. 42.

1908 YETEL-Lemdre, II. J'récis de Parasitolugie humaine.

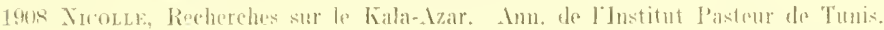

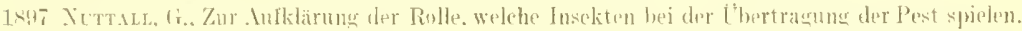
Pentralbl. f. Bakt. Orier. Bul. 23.

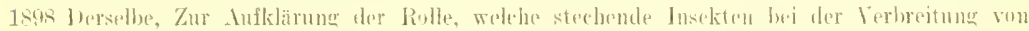

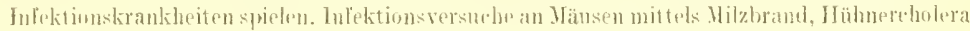

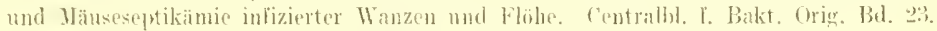

1907 flerselbe, lusects as earriers of diseases. Intornat. Hyeienelionereb, Bul. 2.

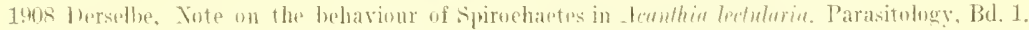

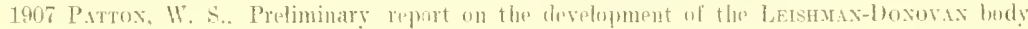
in the bed-bug. Feimtilic memuirs by affieers of the med. and sins, department of the tiovernment of India. Tew series Xr. 27 .

1408 thersolbe, Cimex roduntatus Signoret. Records ol the Indian Husmam.

1908 lwselbe, The Life rycle of a species of frithidia parasitic in the intestinal tract of fromis fossum FABR. Areh. f. Parasitmkunde, BH. 12, s. 131.

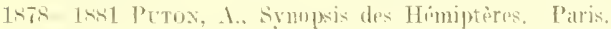

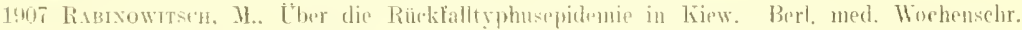

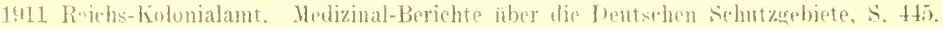

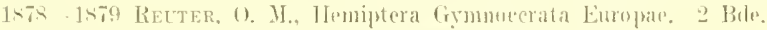

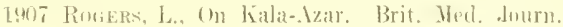

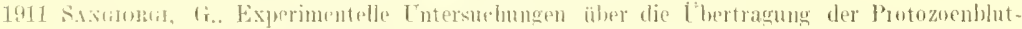

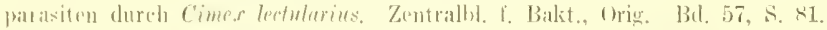

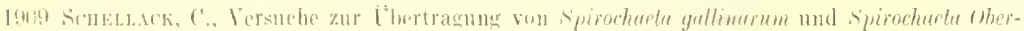

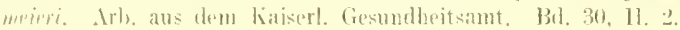

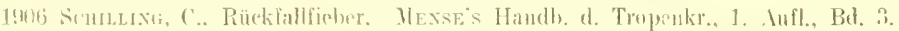

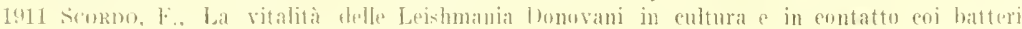

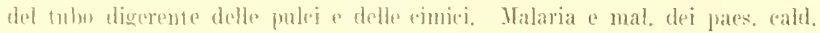

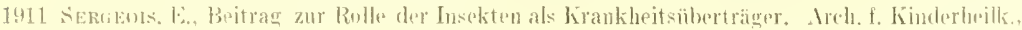

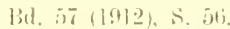

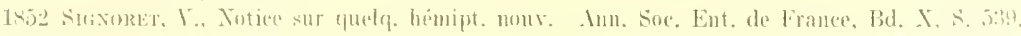

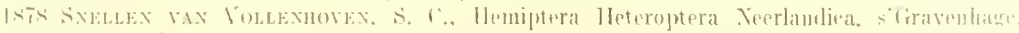

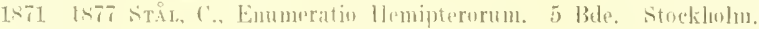

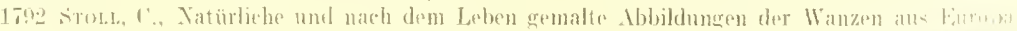

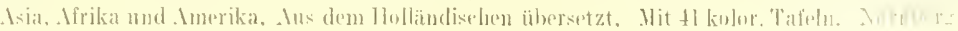

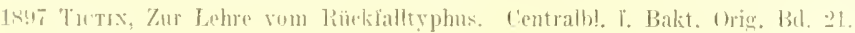




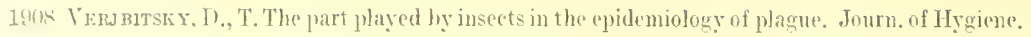
Bd. 8, Mr. 2.

1911 Thaxxa, G.. Contrihusão para "s estuto de anatomia pathotogica de .. Yolestia de Carlos Chagas". Hom. Inst. Osw. Cruz, Bd, 3, s. 276.

1906 Welluax, F. C., sobre um insecto hemiptero que se alimenta do propagator da Espirillose huniana "atacal vexasionalmente o Hlomem. Polytechnia, Be. 3, Mr. $4 / 5$.

1907 Derselbe, Bionomische Beobachtungen an Phonergates bicoloripes Stiz. Dentsche Entomol. Zeitschr., S. 377.

1907 Woronkow, N., Zur Anatomie von Acanthia lectularia L. Nachrichten der haiserl. Gesellsch. von Liebhabern der Taturwissenscls. XCVIII. 


\title{
Psyllomorphat."
}

\author{
I. Die Flöhe.
}

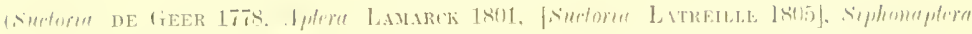

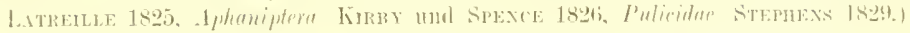

Dic Flöhe (französisch Puces, englisch Fleas, italionisch Tulei) haben als Pext- mol Kala-Azar-C lerträger erkamt für den Tropenarzt vine lube bedentung getwintule.

\section{Illgempines.}

Der Körper des Flolies ist sejtlich zusammengedrüelit. Der Kopf halbrifömig, seme olsere Fläche abgerumetet uler wekig. die untere elen; mit seiner ganzen hinteren. Ieicht konkaven Fläche dem I'rothorax aufsitzend.

Die Il undwerkzeuge, stechend und saugend, bestelen aus einem Paare an Rande gezähnter Mandibe-no die mit dem Labrum-Epripharynx das traugrolor bilden. aus der in zwei Taster gegabelten Interlippe, welehe die Stilette scheilenartig umgib und einem Pare plattenfömigers, drei- ofler vicreckiger Maxillen, denen sieh viergliederige Taster zugesellen (Fig. (6s, 72. 74. 76).

Kein Floh bexitzt Fazettenaugen. Ozellen, wem vorhanden, stets ror den fïhlern stehend. Die dreigliederigen fiuln ler liegen in emer cirube (Fig. (jo).

ber Thurax besteht aus drei foncinander getrennten lingen, die sich je ans dem dorsal gedegenen Notum, dem rentral gelegenen Stemit und den seitlichen Peuriten zusammensetzen. Abdomen aus zehn segmenten gebiklet. dic beiden letzten stark ausgexpochenen sexualdimorphismus zeigend. Am Kople. der Brust und den Banchringen könmen Stachelkämme (Kenidien) auftreten (Fig. 71. 73. 74, 75).

lieine scitlich zu*anmengedrïckt, Je vielen Arten zum springen eingerichtet. vom ersten narh dem letzten beinpare hin an Länge und Breite zunchmend. Hüften und schenked stark entwiclist. Fïbe fiunfgliederig. Endglied mit zwej gegahelten

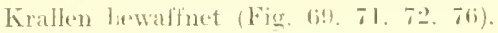

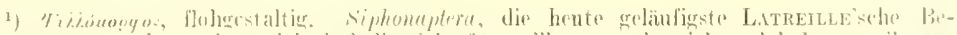

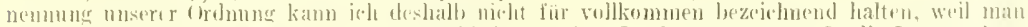

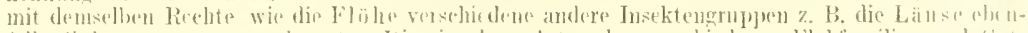

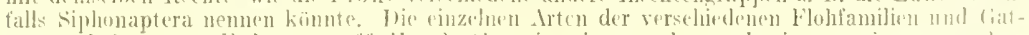
tungen haben sämtlich sn anffallend äbereinstimmende und eigenartige murpho-

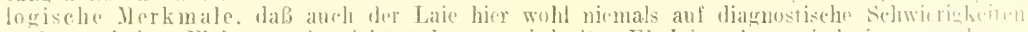

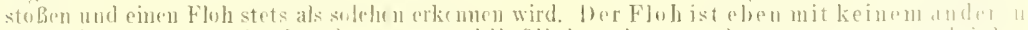

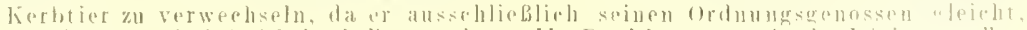

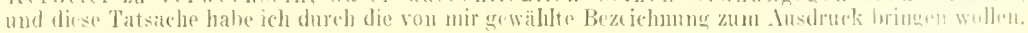


Die Verwantlung ist eine vollkommene. Larve raupenförnig (Fig. 70), 14 glieclerig. Die Wumienpuppe liegt in enem Kokon. Die Flöles sinu temporäre oler stationäre l'arasiten der (Aleichwamen.

\section{Morphologie.}

Die Farle der Föhe schwankt zwisehen gelhlichweib und dunkelloraun und zwar nicht allein nach den verschiedenen Arten. somclem häufig anch bei demselben lnelividum zu versehiedenen Lelonszeiten.

Alle jungen febengeschlünten) liahe sind schr hell gefärbt und dunkelu in den folgenden Tagen erhebliehnath. Die sattesten Farben zeigen die Puliziden, wähend die Xyehopsylliden gelh his gelhbram und die weibliehen sarcopsylliden als stationäre schmarotzer im urößten Teile iltrer kiirperoberfliche sogar nur milehweib gefäbt sinel.

Der seitlieh zusammengedrïickte Körper aller Flöhe ist in der Familie der Nychoperliglen, namentlich in den vorderen Teilen, langgestreckt und beinalıe wurunförmig zu nennen (Fig. 71), während er bej den P'uliziden (Fig. 72, 73, 75) und vor allem bei den Sarkopsylliden (Fig. T6) wesentlich kïrzer und gedrungener erseheint. Der. Hinterleib ist bei allen Arten der mäehtigst entwiekelte Teil des Körpers.

Alle Ektoskelettringe sind analwärts zu dem sog. Kollare ausgezogen, so dab die Kopfliapsel uml die chitinigen regurentaldeeken des Thorax und cles Abdomens über die jeweits folgenten Körperringo dachziegelartig linibergreifen. Ein gleiches Verhalten finten wir bei keinem anderen Insekt wioder, werden aber dureh es an elie. Schuppen und Bauchplatten der Peptilien (namentlich (ler schlangen) erinnert, welehe aus denselben biologisehen Grünten eine älubliche Anordnung zeigen. Die einzehen Segmente der Flöhe sehen durch das Ubergreifen iter ribkwärts gelegenen ('hitinkragen wie ineinander gesehachtelt aus. Diese Eigentümlichkeit vertunden mit dem plattgedrückten und liopfwärts wesentlieh rerschnälerten Körper und den ausnahmslos nach hinten geriehteten Haaren. Borsten. Dornen und Stachelkämmen erleichtert dem Fluh das rasche Vorwärtsgleiten in Hairwakle seines Virtes ganz ungemein. Ein "Zurück" dagegen kennt rler ritterliche springer in bramen Selmppenpanzer iiberhaupt nicht - ...empre avanti!" ist sein Wahlsuruch.

Eine bei keinem anderen Arthroporlen beobachtete Eigentümlichkeit zeigt anch der Konf der Flobe, er besteht beiden an tiefsten stchenden und ursprïnglichsten Aychopsylliben aus zwei gegeneinander beweglichen segmenten, deren (irenze an vorkeren liande der Fühlergrube gelegen ist. (Fig. 7l). Bei den l’uliziden und Sarkopsylliten ist eine freie Terbindung zwar nicht mehr vorhanden, es befintens sieh aber an eler gedachten Stelle ('hilinhildungen, die sich nur als durch GeJenkflächenverschnolzung entstanden erklären lassen (()UDEMAss).

ber stets verhältnismäßig kleine Kopf der Flöhe erreieht bei ten Sarkopsylliden die relativ beträchtlichste Gïibe (Fig. 76).

De Thrsalliathe des Kopfes ist mejst gewälbt und zeigt infolgedessen bei seitenansicht für

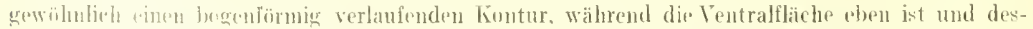

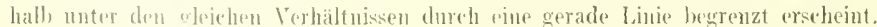

Die Ilundfeile der Flöhe sind hej den Nyehopsylliden nach linten und unten gerichtet. Wilhrend sie bei den Puliziden fast senkreeht aul der Ventralfläebe des Kopfes stehen und leei den śarkopsylliden sogar nach vorn selaturn.

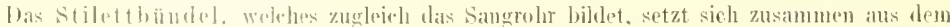

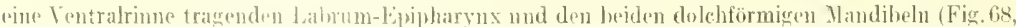

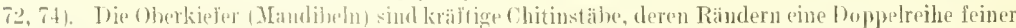
Sä̈regilnue aufsitzt. Die MLndiłe'n werden durch ilıre Forn gewaltig gefestigt, sie sind medianwärts ansarebuchtete Hohbinnen und zeigen dementsprechend auf dem Quersehnitt einen sichelïrmigen 


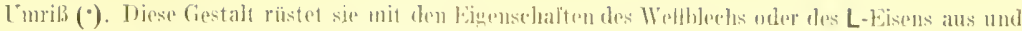

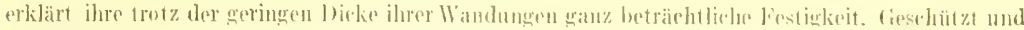

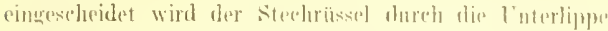
und ihre beiden Taster. Xarle auben von den genamuten

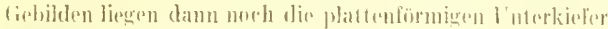
(Maxillen) und ror diesen die viergliederigen Maxillar-

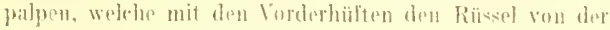

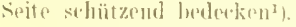

Die dreigliederigen Fïhler setzen sich aus

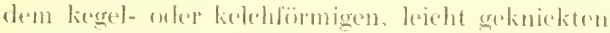
Basalglicele, them scheilenförmigen zwriten uncl dem kolbenfirmign dritten filiede zusammen (Fig. bs LA.). Mas Eudglied wiml häufig lurele liefe Einschnitte, die die ganze l'eripherie umlaufon kïmrn, in aine gröbere Anzahl rom lamellen

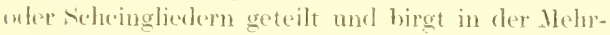

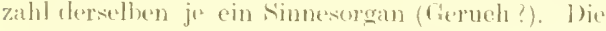
nach hinten und unten gerichteten Fibhler liegen in tiefen Gruben (Fig. (is), so dafo sie in Ruhestellung the Körperoberflache nicht iibrragen. ber rom vorderen hoptingmente gebildete Vorderrand der Fïhlergoube ist häufig in eine dünne ('hitinlamelle (Kollare) ansgezongen, welehe die Anteme teilweis berbect und beim Virwärtsgleiten des Tieress schuitzt.

Der Lnteramel des Kopfes und die Wrangengegenul tragen oftmals Ktenirlien. lie sich ans einer verschieden groben Zahl ron kräftigen, clunkelbrangefärbten Chitinzinken zusammensetzen. Die hintere Kopffläche sitzt ltem Prothorax in seiner ganzen Breite auf und ïlergreift ihn stets nit cinem wohlentwickelten Kollate.

Die drei beweglieh miteinander rer. bumbenen Thorakalringe werlen in ihren Deeken aus dem spangenförmigen Tergit (Notum). dem ähnlieh gestalteten stemit und den seitlieh gelegenon Pleuriten (Epimerum. Epristernum) gebiklet. Am Hinterrandecles Promotums belinklet sich hänfig cin stachelkamm. Der . Hetathorax trägt

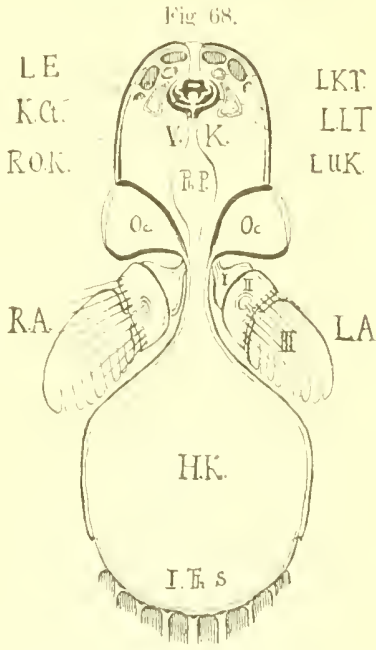

Th. Cen

Horizontalswhite durede den Kofti

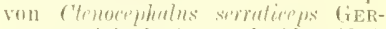

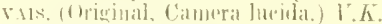
Voriere (orile) Liopflälfte. K.C\%. Vusdere Zinkin des hoptikteniriums. L.E. Labrum-iguipharyax (1)berliphem. lít).K. Rechter (berkicfer (.Mandibul). L.L.T. Linker Lippentaster. L.l.K. Linkere Interkiefer (.Waxible). L.K.T. Linkes liefertaster (Haxillaryalpus). Ph.l'.

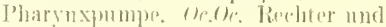

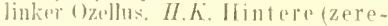

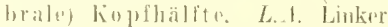
Fibliler (1. Basalylied, IJ. mittleres, 111. Enelulind). hi.l. Reehtor kiihler. 1.Th.t. Fistos Thorakalsegment. Th.Cten. Nendeniun des ersten Thorakalsormentes.

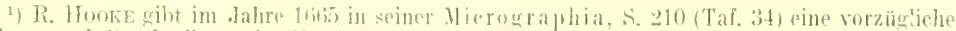
Abbildume und Buschreibung des lingles (namentlieh der Jundteile) von Pulex. sie ist die beste,

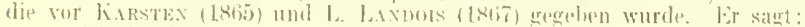

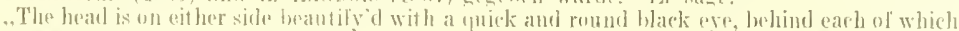

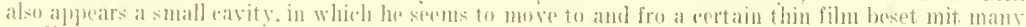
small transparent lairs, whieh probably may be his ears; in the forepart uf his lead, betwoen the two fure-legers, he bas two small long jointed feelers, or rather smellers, which have four joints, and are hairy. like these of several other creatures: hetween these, it las a small probestis, or

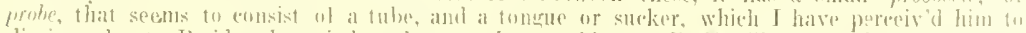

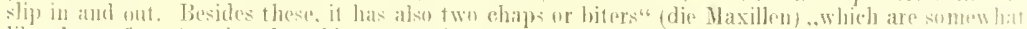

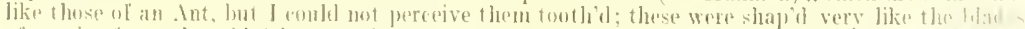

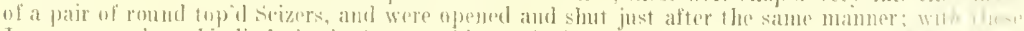

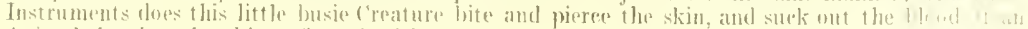
Animal, luating the skin milamed witl at small round red spot." 
meist ein mächtig entwickeltes Kollawe, was dam molurere der ersten Abdominalseguente ühergreifen kann (Fig. 7(j) mel lange Zeit merkwüudigerweise für Flügelstummel gelalten wurle. Die längenentwicklung des Thorax ist bei den Nychopsy lliden an ausgesprochenstem, man lat sie deshalb mit liecht Dolichothorucici genannt. Bei den P’uliziden hält sie wich in mitteren Grenzen (Mesothorucic) und geht bei den sialsopsylieten ganz beträchtlich zuriek (Brachythoracici), so dals bei ihmen das erste Ahdominaltergit stets lreiter ist, als sämtliebe Thorakaltergite zusammengenommen.

Fom unteren inBenrande der lsustringe ent-pringt je ein Bein, welches aus Coxa, Troxhanter, Femur, Tibia und fünf Tarsalglicelern zusammengesetzt ist. Die Coxae mux Fenora sind scitlich stark zuwammengedriekt mol mächtig entwickelt, namentliels ist dies bei dem dritten l'are, den in manchen Familien zu sjoungbeinen gewordenen Hinterbeinen der Fall. Die Länge der Tarsen und ihre liewaffnumg int hei den cinzelnen Arten versehieden (Fig. 69!).

Fìg. 69 .

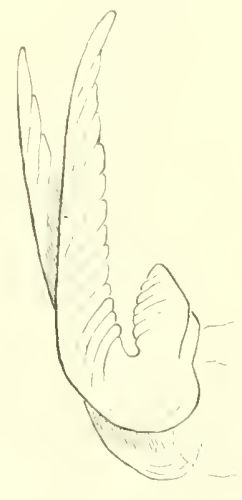

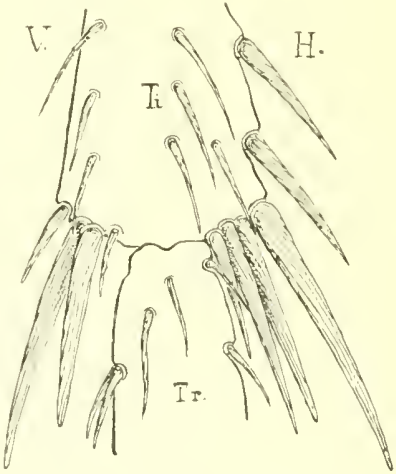

b)

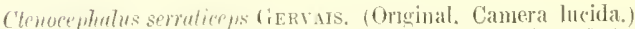

a. Klauen der Finhe des etritten Beinpaates. b. Tibistarsaledenk des dritten Beinpaares. F. vordere, II. lintere Kante der Tibia (Ti.). Tr. Erstes Fubolicd. (Dorne an der Vorderkante rechts-, an der Hinterkante linksgewunden.)

Der massigste Teil des ganzen Flohlö̈pers, das A belomen, zeigt bei vielen Arten in männliehon Geschlechte einom koukaven, im weiblichen cinen komvexen Dorsalliontur; es ist lamm also beim ciförmig, leim ô dagegen bohmenförmig gestaltet. Wälurend der begattung sitzt das weibliche Tierstets aul dem liäcken des Mämehens, mol durch diesen Cnstand mag die eigentiimliele Ausbuentung des mämblichen

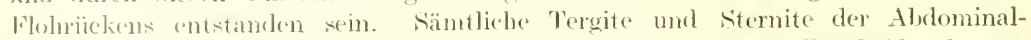
segmente greifess ebenfalls wieder dachziegelartig übereinander. Die beiden letzten sind vollsommen abwerichend von den voranfgehenden acht Abdominalsegmenten gehant mul zeigen ansgesprochenen sexualdimorphismus.

\section{Anatomie nud Pluysiologie.}

Die quergestreilten Tinmpf- mul Extremititenmuskeln sind bei den Flöhen vorzïglieh entwielselt; dwels melurtägiges Einlegen des ganzen Tieres in kemzentrierte

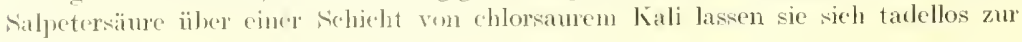


Anschauung bringen; die sollkommen cutlärbte und wasserklat gewordene ('hitin-

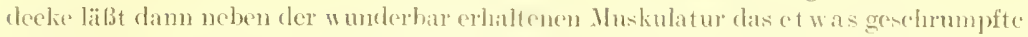
Nervensytem und die anderem Orgingrujex'n in sitn sehr gut crkennen.

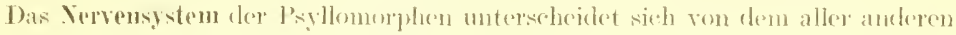

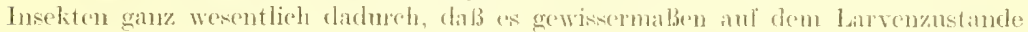

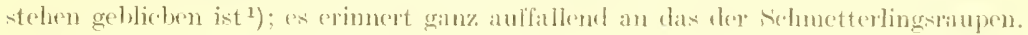

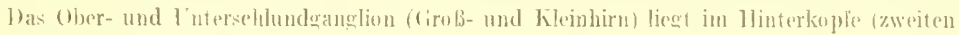

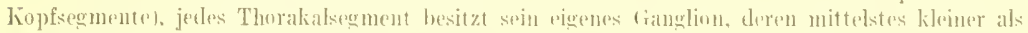
das crste, deren letztes (das M[etatherakaleanglion) aber gröber als alle anderen Vervenlineten ist. Li fi.leen mun die Baucheranglien und zwar ateht Xervenknoten beim j, sieben heim fileh

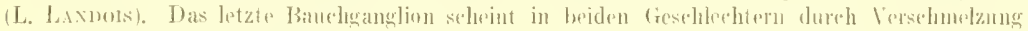

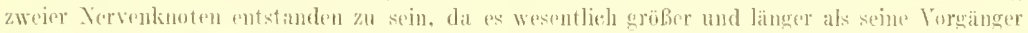
ist und vier Kervenpare aussendet, während jene stets mur zwei Paare ants sich hervorechen lasesen. Sämtliche Kunten sind deutlich roneinander getrenut und stehn dureh je zwei krittige lommissuren miteinander in Verbindung.

Die vier Yervenpare des Oberschhumelganghoms nebst den drei l'atren des Eleinhirns versorgen ausichlicßlich den Kopf und seine Anhänge (sinnesorgane und Alundwerkzenge), fle mäehtigen Thorakalganglien innervieven in der Hauptwache die Bewegungsorgane, die Banchganglien, dic Atemmuschn und dic Muskulatur der Gexchlechtorgane. Ein wohlentwickeltes sympathisehes Systrun versorgt die Eingewricle.

Die Itmmosorgane sind nach dem bekanuten Typun der Klasice gebaut. Das exste Stigmenpar gehört dem Mesothorax an, the acht folgenten befinden sieh auf den Abdominalsegmenten mit Ansnahme des nemten und zehnten. Die Stignem crscheinen als rumele Grübchen, von deren vordicktem Rande eine Anzahl ratliärgestellter Härchen entspringen, die sämtlich nach innen gerichtet die Atmungsöfinumg bedecken mul so das Eindringen von Frenulkörpern verhüten.

Dic I'ulsationen des Riuckengnfäbes lassen sich bei elen wenig gefärbten Nychops.rlliden und den Larven der P'uliziden leicht beobachten. Bie Blutmenge scheint eine geringe und die Körperche'n anffallend klein zu sein.

Der Vahrunguchlanch ter flöhe weicht von dem anderer lnsekten (namentlich auch von dem (ler Dipteren), so sehr ab, dab dieser (Tmstant allein hätte hinreichen sollen, zu verhüten, daß unsere orrhung lange Zeit als ein Appendix der Zweiflïgler betrachtet wurke.

1)as Lahrum (Epigharynx) gelat direkt und ohue sichthare (irenze in die schlauchformige Inndhöhle des Flohes iiher, dif sielt hald zu der spindelformigen Pharynxpumpe erweitert; an diese schliebt sieh die sehlanchlörmige speiseröhre an, welche etwa den gleichen Durchnesser wie das Mundrohr lowitzt. Im weiteren Verlanf tritt der Ösnphagus dureh den nervösen Schlundrine, durchzieht, mu üher der Ganglienkette liegend, den Thorax und mündet otwa auf der lowhe des ersten Bauchringes in den kegelfürmigen Kaumagen (Proventrieulus) ein. Thie lnnenwände des Proventriculus sind mit zilhlreichen, leichtockrummen, relativ hohen Chitiustäben besctzt, die

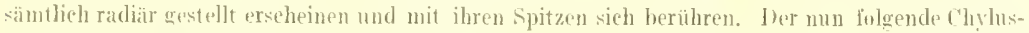
magen übertriflt den Proventrieulus an liröbe um etwa dassechsfache, die Ring- und längsmokelı, welche am Tratus intestmalis in seinem ganzen Vorlauf angetroffen werden, sind am Hauptmanen besonders stark entwiekelt und halten ilın während der Verdanung in steter peristaltischer Bewegung. Die Innenwand der Tunica propria des Magens üherzieht eine einfache Zellenlares, die physiologisch den Verdaunngselrïsen höherer Tiere n'ntsuriclut.

$\left.{ }^{1}\right)$ Auch in vielen anderen Punkten ihrer äuberen und imeren Organisation haben tlin lit he einen ausgesprochenen larvalen Charakter bewahrt und geben sich dureh diesen l'mstant ats rin uraltes ] usektengeschlecht zu crkennen. 
Der sick danu anschließende kurze und enge Darmkanal nimmt in seinem Anfangsteile die vier Malpighisehen Gefäbe anf und endigt mit cinem relativ sednr groben birntörmigen llastdarme, der sechs spindelfömnge liektaldrïsen einsehlielst.

Einen Vorratsmagen (Saugmagen) besitzen tie Flöhe nicht. Sie untersdeiden sieh durch diesen Cmstant ron den Dijeteren und vielen anderen Insekten.

In der wberen Hälfte des Abdomens liegen die biasenförmigen sipeichelArüsen, ein l'aar an jeder seite.

Ihre Ansfïhrungsgänge, deren Winde durcts eine Chitinspirale gestïtzt werden, vereinigen

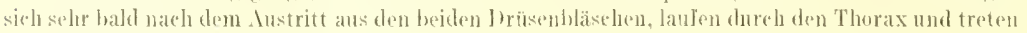
kurz vor ibrer Eimmïndung in den Pharynx zu einem gemeinsamen Rohr zusammen.

An der gleiehen Stelle entleeren die zahlreichen sch ha ue hfömigen speiebel-

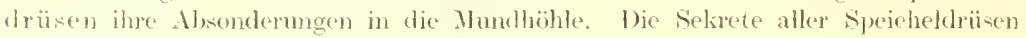
werden beim Saugakt ven dem hohlnadelfömigen Latmum-Epipharynx in the Wunde des Wirtes cingefülnt.

Die Eim-tichstelle wählt der Fkoh, wie man bei jedem Versuehe ron nemem

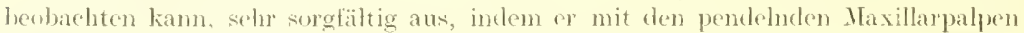
das Operationsfeld eingehendst ahtastet. Am passenden orte dringt er mit den Mandibeh, wie alternierend rorsehiebend, in die liutis cin. Das Labrum folgt den Oberkiefern, ohne sich aktiv beim Einstich zu beteiligen. Afle ïhrigen Mundteik bleiben auf der Hautsberfläche des Wirtes zurück und weiehen beim Vordringen der Stilette mehr und mehr seit wärts anc, die Labialpalpen können sogar vollständig umgesehlagen sich an die Wangengegend des Tieres ankehnen. Nach fünf bis zehn Winuten ist der Saugakt bermeligt. bejote Geschlechter luedïrfen der Blutnahrung und halten bei guter Gelegenheit mehrmak täglich ihre Mahzeiten ab.

dienehterhfsteile. Die Vagina mündet zusammen unit dem Rektum in die Kleake ein, deren dreieckige, nach unten spitz ausgezogene Öfnung rom zahlreiehen starken Borsten umstanden wird. Iluren oberen Rand begrenzt das spangenförmige Tergit des zehnten Abdominakegmentes, über dem damn das neunte Tergit mit seiner so aubarertentlich eharakteristischen Simmesplatte (Pygibum) sichtbar wird.

Die immeren dresehlechteteile des - werden gebildet vom clen beiden, aus je fiinf Eierschüiren bestebenden Ovarien, die mittels ihrer ovidule in den Tterus cinmë̈nten und cler ursprïnglich doppelt angelegten, bei den meisten Arten aber nur noch in Einzalbl rorhandenen spermatheke, die zusammen mit len Kittrïicengange in den aberen Abelmitt der Vagina fiilurt.

Das höelst kompliziert gebaute Kopulationsorgan der männlichen Nyehop.yllicten und P'uliziden liegt, im liuhezustande in seinen proxinalen Partien spiralig aulgerollt, in den binteren unteren Teilen der Leibesbölite.

Die aus den beiden eichelformigen Foden entspringenden Vasa deferentia

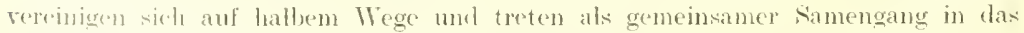

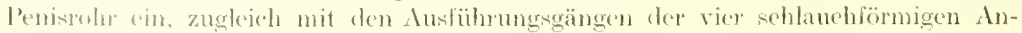
hiangadriit:cil.

\section{Biologie.}

Die relatir sethe groben (11.4 $11.5 \mathrm{~mm}$ ) Eier der Nychopsylliden und Pu-

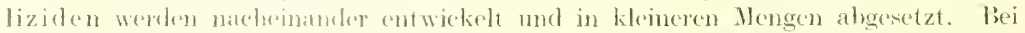
Ien tiakopeylliden dagegen gelangen tie wexentlich keweren Wier in großer Zahl Elevilkzeitig zur Rivile und werden dann auf einmal alsgelegt. Fast alle Föhe setzen ihre bier auf den boden abs. 
Naeh wenigen (3-6) Tagen kriecht die sehe loewegliche Larve aus. Hhr weiblich ge-

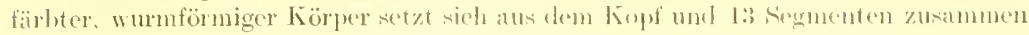
(rig. 70$)$.

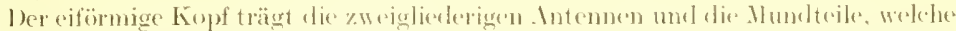

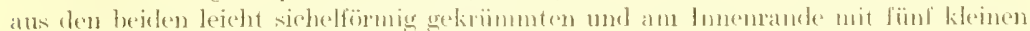
Zähnehen versehenen Mandibehn, zwei Maxillen mit ihren kurzen Thatern, der (oberund der linterlipute bextehen.

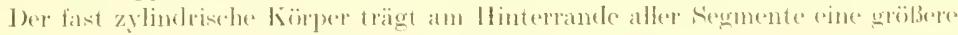

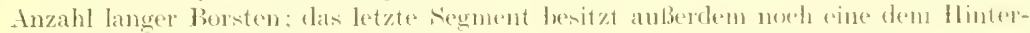

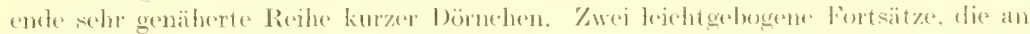

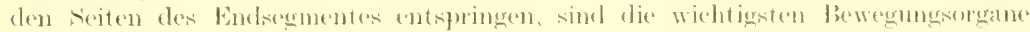

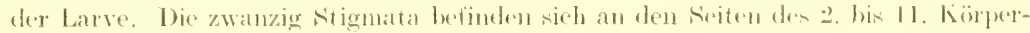

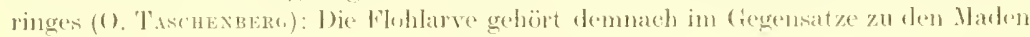
der Dipteren usw. zu den peripmeuntisehen larven.

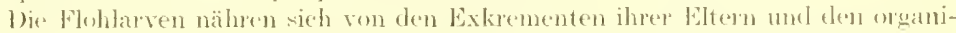

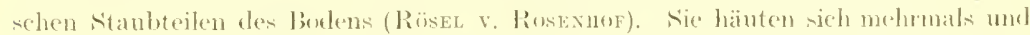
sehickon sieh nach etwa :- : Woehen zur Terpulpung an.

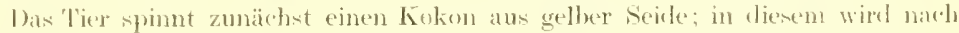
2t Stuneten die tertige Nymphe angetreflen. Die sehr hellgefärbte Mumienpuppe der Hible zeigt in allen iluren feilen sehon eine solehe Ähnliehlient mit der Fie. 70. Imago, dall man bereits in diesem Starlium das Geschteeht des Tieres leicht unt sicher bestimmen kann. In ihrem Hinteremele hängt meist nocly clie einget rocknete Larvenhant. 1)as Puppenleben des Flohes ist ein anffallend langes. os kann bis zu 30 Tagen

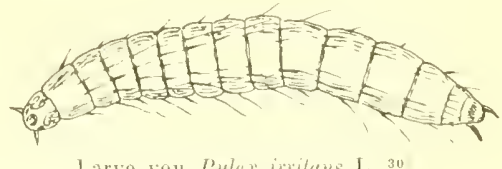

Larve von Pulex imitams L. ${ }^{30} 1$. (Xach (). 'T'ArthEXBERf.) thatern.

Die Puliziden und Nyelopsylliden sind temporäte l'arasiten. Wie clie blutsaugenden Zweiftügler nur währond dor Nahrungsaufnahme ihre Wirte besmehen, *o) verbissen auch die gexättigten Flöhe hänfig ihre Gastgeber. um zur Eialolage zu sehreiten eder nach einger Zeit cin anderes opfer aulzusuchen. Die befruehteten Weibchen der Sarkupsyllielen dagegen werden st a t ionä ro Sehmarotzer: sie bohren sieh in die Hant ihrer Wirte ein und fallen, wenn sie nicht durch Kratzinfektiomen vorher herausitem, erst nach der Eiablage kraftlos mol alegelebt aus ihren Höhlen oder werklen als ejugetrocknete häutige sücke mit der verbrauchten Epidermis alsgestußiser.

I) Körperformen und Funktionen der Psyllomorphe werden durch ihre parasitisehen Gewohnheiten stark beeinlubt. So sehwellen die Sarkopsylliden in (ler Hatut ihrex. Wirte zu unfönzigen Eiersätlien an (Fig. 77 Taf. III, e). Die trägeren T'uliziden, welehe nicht mehr gezwungen sind im Haarlickicht den Nychopsylliklen gleich ravels vorwärts zu gleiten, bekommen eine kïrzere uml gedrungenere ferstalt. So bïbsen die aut Natehtieren und Höhlenbewohnem lebenden Nyehopsylliden iln Augenlicht rim. Viele Fledermauslöhe mol die Sandflöhe vertieren dit Fihiglieit zu springen usw.

\section{Systematik.}

Die Payllomorpha zerfallen in zahlreiche Familien, von denen liver nu lie Xyehopsylliden. die l'uliziden und sarkopsyllielen, in cinigen best mers dhatiteristischen und wiehtigen Gattumgen und Arten besprehen werden sollen 


\section{Nychopsyllidae.}

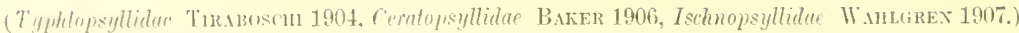

Dic anschlieblich auf Fledermäusen schmarotzenden drten haben am trevesten die urspringlichen Merknale der (hehumg bewahrt. Es sind langgestreekte,

Fig. 71

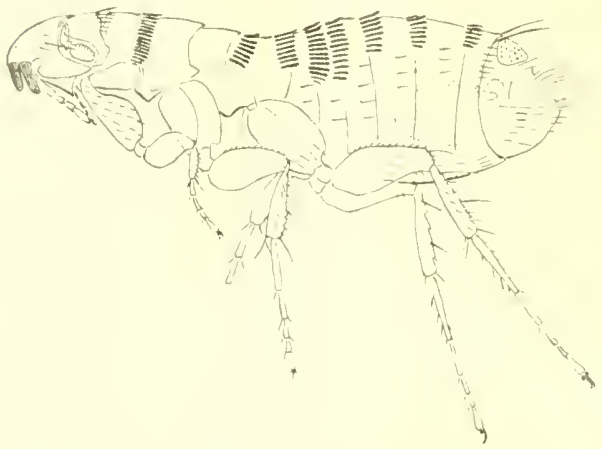

Tiphopsyllus octuctome Thoenexbere, 25/1. (Original. Citmera lucida.)

In den linteren Patiten des Nbdomens liegen vor der durchschimmernden Spermatlecke zwei ausgereifte Eier. stirk zusammengerliülite, zahlreiche Ktenidien tragente. äuberst bewegliche Tiere, die sich sehlangenartig dureh tils Haardickicht ihrer Wirte hincturehwinden. Sprungbene simt bei ihmen noch nicht zur Entwicklung gekommen und w ürden auch zwecklos wein, da sieh der ganze Lebenszylus der Fledermanslöhe auf ihren Wirten ahspielt.

Der lange und sich nach vorn stark verjüngende Kopf der Nychopsylliden besteht ansnahmslos aus zwei Segmenten, deren vorteres amdistalen Encle des L'nterrandes jederseits rin zweizinkiges Kitenidinm trägt ${ }^{1}$ ). Angen fehlen.

Dersehr lange und bewegliche Thorax ist an Hinterrande des lronotums mit cincm wohlentwikelten Kamme geschunuckt.

Solche Ktenidion befinden sich, meist in gröberes Zahl auftretend, auch auf dem Tergiten der Abdominalsegmente.

Die Ein der Xychopsylliden werden in ähnlicher Weise, wie die der Podiculiden an den Haaren der Wirte befertigt.

bie geringe Wehrlaftigkeit der Chiropteren maeht die oft unglaublieh große Zahl von

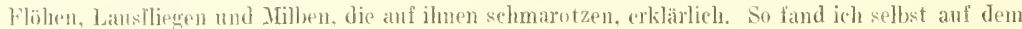
viel witcrstandsfihigeren Maulwurf nech über dreibig Lixemplare des nahe verwandten Ctenophthul-

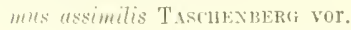

Der in Fig. 71 abgebildete Tychopsyllus (Typhlopsyllus) octectenus ist cinc der guwöhlichsten met typicehsten drten. Er schmarotzt anf l'spertitio murinus.

\section{Pulicidae.}

Körper gertrungen, mel namentlich in seinen vorderen Abschniten, wesentlich kürzer, als ther ter Fledermanshöhe. Augen und Sprmgbeine wohl entwickelt.

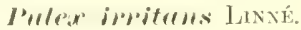

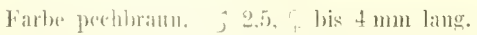

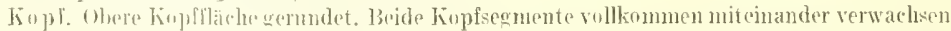
Fühlorgrube von dem hullare des arsten hoplsegmentes teilweise bedeckt. Zweites Fühlerglied mit mehreren langun in dor Richtuns der Antenmenathe verlanfenden Borsten besetzt. Drittes

1) In moruhologiseler and biologiseher llinsicht erinnern die Zinken des liopfkammies der Fledermausilole an die oberen Eckzähne des Wahosses. 


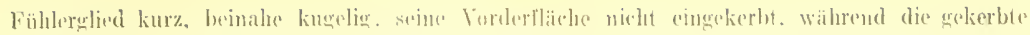

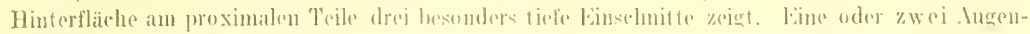

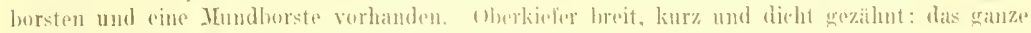

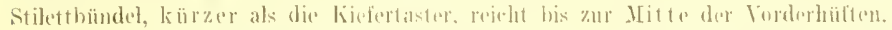

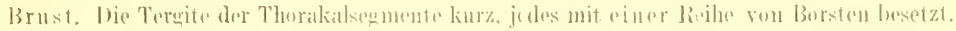

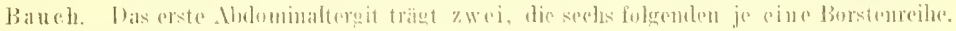

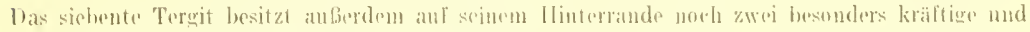
lange Borsten (Antepyguliallorsten). Wie stiemen sind grob.

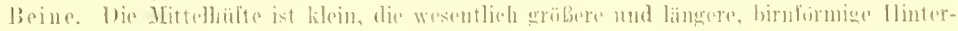

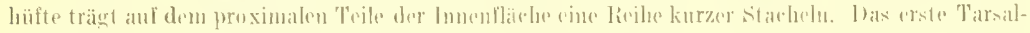
glied dere Vorder-und Wittelbeine ist kürzer als das zwrite.

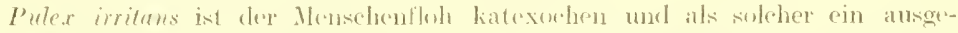
sprochener kosmopolit. Serin Nichtrorkenmen in den Gasen unt in süblen der

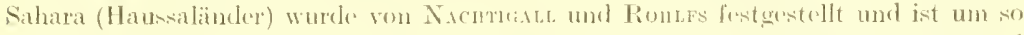
auffallember, als bei der nieht allzugroben lieinlichkeit ihrer liewohner Läuse und Wanzen massenhaft dort angetrotfen worken. Häufig wirl w anch auf Humben, seltener aul Füchsen, lgeln und anderen wilken Tieren grefunden.

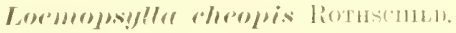

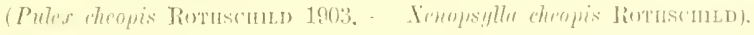

Die Crattung Loemopsylla ist der Gattumg Pulex so ähnlich, la lis sie Rothsemed erst in dahe lons von ihn ahtromete.

Fig. 72.

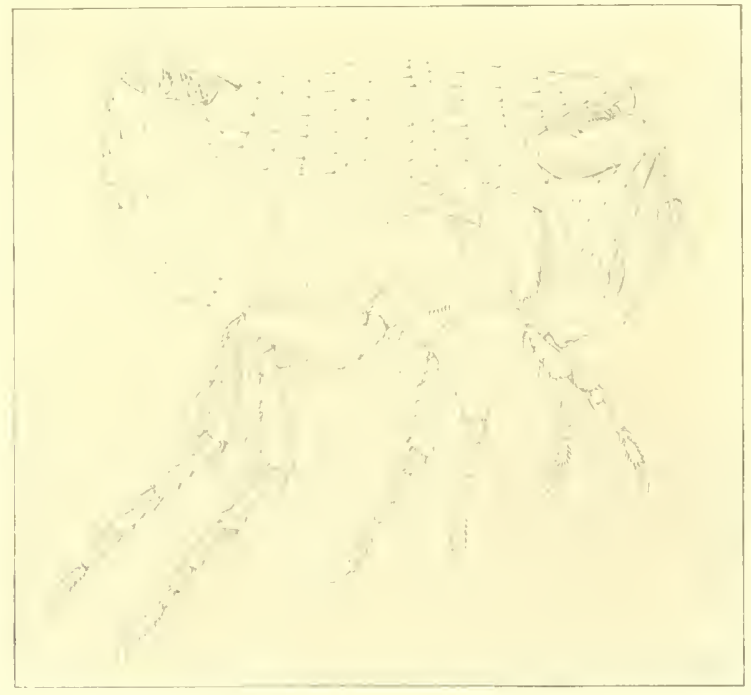

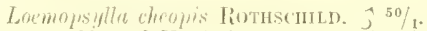

(Naeh K. Jorvax. Aus foldax, K. ant N. C. Romischub, Revision of the non-combed eyed Siphonapteri, l'arasitology Vol. I No. 1, 1908..)

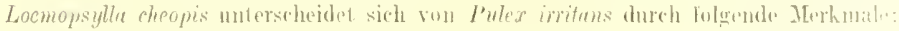

Farbe heller. hörpererobe geringer, j 1.5 , $72,5 \mathrm{~mm}$. 


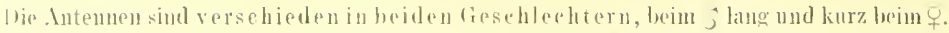

Nur eine, etwas luöher stehende. Augenborste vorhinden. An Ilinterande der Fiillergrube

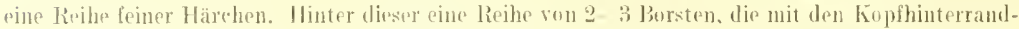

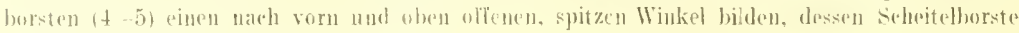
der hinteren-unteren lioplecke aulsitzt.

Oberkiefer, viel langer als bei Pulex, erreichen das distale Ende der Vorderhiufte und iiberragendie kiefertaster um ein beträedetlehes.

libenso sibd die Intepgridialborsten wesentlich lämger und kräftiger.

Loemopsylla cheopis ist der Rattenfloh der warmen Länder. Seine eigentliche Heimat scheint das Xiltal zu soin; von hies aus rerbreitete er sich ïber ganz Atrika und sïdasien. Zu schiff gelangte er dann auch nach Australien und siudamerika. Er ist unter scinen ordunngigenossen fraglos als eler wichtigste Überträgter der P'st auf den Mlensehen anzuschen.

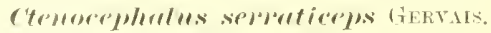

Farbe rotbraun. ô $2,+3 \mathrm{~mm}$ lang.

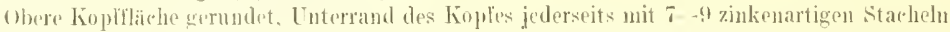
besetzt. Fühlergrube durch eine dimue, den Vorderrand überlagernde Clitinglatte (Kollare) teilweise geschlossen. Fühlerkenle aull ihrre Hinterfläche mit tielen Einsehniten versehen. Augen grob, in der Mitte der Seitenlläehe des Koples gedegen.

Jige. 7is.

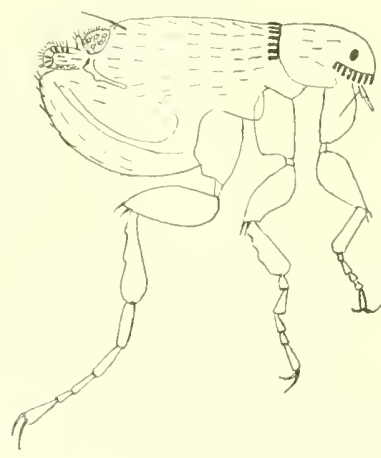

Clenocephalus serraticeps liERTAIs, $\vec{j}$.

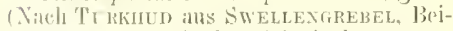
1rike zur kenntuis der Biolugio der enropaiischen liattenflöhe, Areh. lïr sichiflis- und

T'rop.-1fyg. Bd. 16, s. 170, lig. 1.)
Fig. 74 .

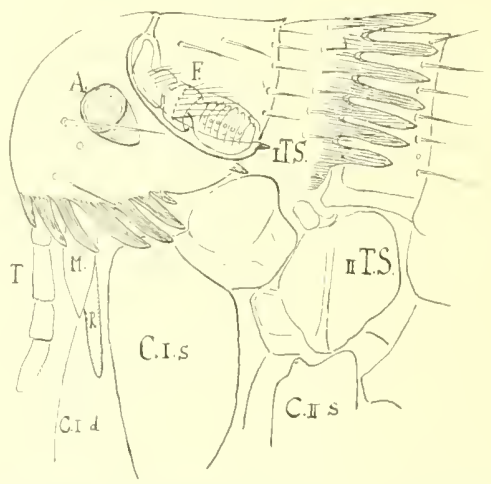

Ctenorephatus serraticeps (iERvars ${ }^{80} / 1$. Kiopf und Vorderbrust. (Original, Camcra laciela.) A. Auge.F. Fühler. T. Taster. M. Maxille. Re. Riüssel. C.I.d. rechte Torderhiifte, C.I.s. Jinke Vorderhiifte. 1.T.S. erstes Thorakaleegment. II.T.K. zweites Thorakalsegment. C.II.s. linke Yittelhülte.

1Hp Brust- und Leibesringe tragen nur dine Borstenseihe (4 a setae), der llinterrand

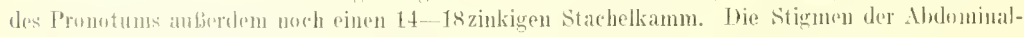

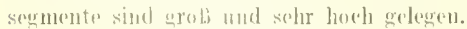

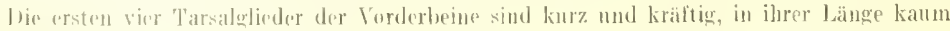
von einander verededen, das bindglied ist so lang, als die drei vorhergehenden zusammen.

Ctenoceghalus serraterps ist der gemeinste Parasit des Haushundes, wird aber anch auf der llanskat\%, den Fuchs, 1ltis und Hasen angetroffen. Er befältt und sticht nicht selten auch den Mlensehen. Da mun von Sixtitortir (Pathologica, 1911. No. 61. S. 2:31) naehgewi(esen wurde, daß durch Ctenocephahes serraticeps 
Leishmaniosen ron Hund anf llund ïbertragen werelen. so ist dep Verdacht,

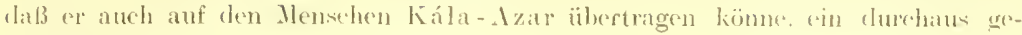
rechtiertigter.

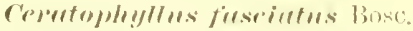

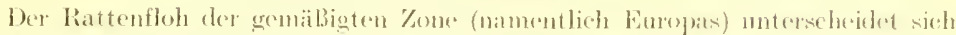

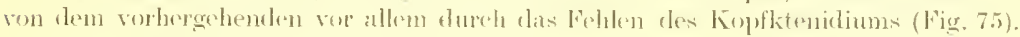

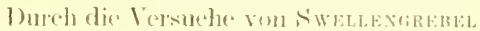
(Arch. 1. Schiffis- u. Trop. - Hyg. 191:2.

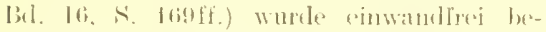
wiesertl, dabs ceratophyllus fescintus häufies anch den Mensehen ledeillt. Dat unn andererreits durch die englisehe Pestlommnission (Reports I!nfi. I: t!mit. XV) experimentel] lextgestellt warte. dalb meben Loemopsylla rheopis. Puler irritens und ctenopsylle mes:weli auch diuch Ceratopheyllus fasciutes die. lest ron Ratte zu Ratte übertragen werklen

Cerutopingllus fusciutus Bosc., j.

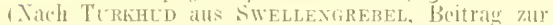
himatnis der Biolugie der europaischen Ratticinflihe: Arelt. f. Schitis- und Trep,-Hrg., Bel. Lis, s. 170, Fig. 4.

Fir Ti.

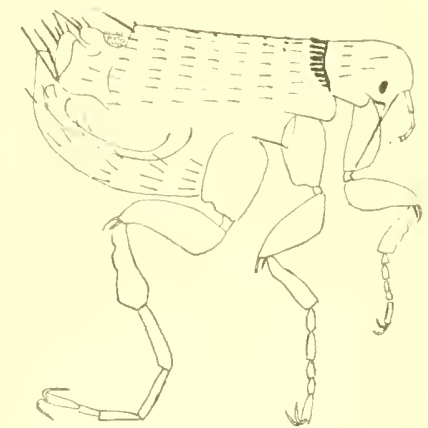

kann. so muls aneh mit der Möglichkeit der P'estiibertragung auf den Henschen durch Ceratophyllus fasciutus gerechnet werden.

\section{Sarcopsyllidae.}

Khone Flöhe, deren befmchtete. Weibehen zur stationiiren l'arasiten geworden als.

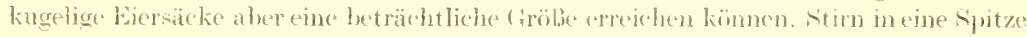
ausgezogen. Augen vorhanden oder fehlend. Thorakakegnente änberst schmal. sprmglerine und Klauen wenig entwiekelt. Ktendien fohlen. Borsten und Hare in nur geringer Anzahl rorhanken.

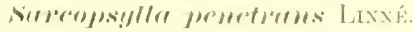

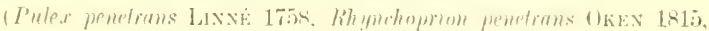

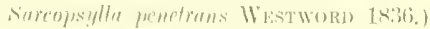

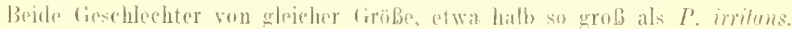

Maxillen klein, Fiefertaster viershiederig. Jandibe]n um ein Viertel der IEaxillartastor

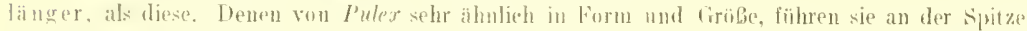

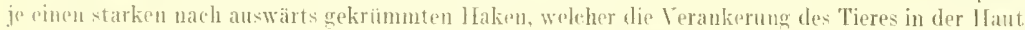
seines IVirtes zu einer sehr festen zu machen geeignet ist. Hif Mindibeln uncehlieben das bajonettförmige Labrum (Labrum-Epipharrnx), wetehes, den Furehenzahne der Schlangen vergleichbar, eine ventralwatsts beinahe gesehlossene Rinne einsehließt (distales Lnde des buetus salivalis commu-

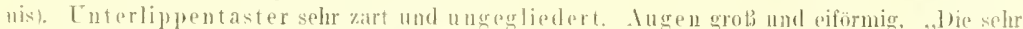

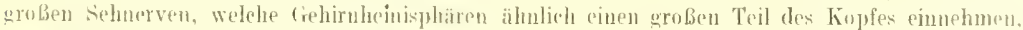

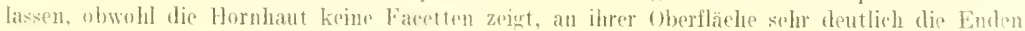

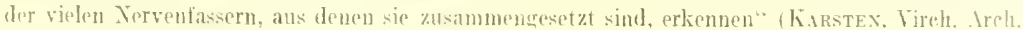

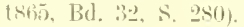

las kollare des Metathorakalsegmentes ist sehr grob und bedeckt als dreiechice, flim rol. artige Chitimplatte fast die ganze Vorderhälfte des Dodomens.

Das zweite, dritte und riete tbdominalstigma fehlt den weiblichen T eren.

Mense, Irandbuch der Trogenkranklieiten, 2. Aufl. I 
Nur die llinterhüfte an der vorderen-nuteren Eeke in einen kräfigen Dorn ausgezogen (im Grogensatze zu dem Vorkommen eines solehen an allen Coxen von Sarcopsylla caecala EvoERLEw). Der krältige Sı henkel des dritten Beinpaares trägt in der Mittellinie seiner An Genfläche

Fig. 76.

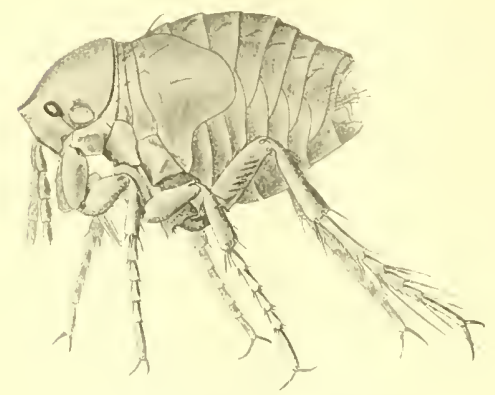

Sarcopsylla penetrans L., ${ }^{50} / 1$.

(Nach Karsten, Beitrag zur kemntmis des Rhynchoprion penetrans, Viich. Arch. 1865, Bd. 32, s. 269ff. Die Ibbildung hat eigentiumliehe Schicksale gehaht; sie wurle zuerst von TAsenexBERG in seiner Honographie ohne Ingabe des Antors reproduziert und gelangte damn über Vloviez in Braun's , Tierische Parasiten des Nenschen". Daß sie auf diesem langen Lebensund Leidenswege nicht vollkommener wurde, sondern viel von ihrem ursprünglichen Glanz und Schimmer einbiabte, jist nur begreiflich. lols hathe deshalb auf das (riginal zurïckgegriffen.) eine Reihe starker Borsten (Fig. 76). Thas erste Tarsalglied der Hinterfube ist anf der vorderen liante dureh starke Borsten kammartig gewimpert.

Der Sandfloh (Nigua, Chique, ('higoe, Chigger) ist im tropischen Amerika beheimatet. Er wurte in Jahre 1873 durch Sehiffe von Brasilien an die Westküste Afrikas verschleppt und hat sich heute ïber den ganzen afrikanischen Kontinent unet seine Inseln verbreitet. In den letzten Jahren wurde aneh iiber sein Auftreten in ('hina, Indien und Persien berichtet.

Namentlich an der Küste und an vielen Flußufern kommt er oft in ungehenrer Menge ror und kam hier zur ausgesprochenen Landplage werden: es sind sehon ganze Expeditionen dureh ihn marsch- und kampfunfähig geworlen.

Eine sehr ansehauliche Schilderung seines biologisehen T'erhattens mol der vielen kleinen Leiden, welehe der Sandfloh den Afrikanern, Eingeborenen wie weißen Ansiedlem, zufügt, gibt Mexse in seiner Rede, Hygienische und medizinisehe Beobachtungen aus dem ('ongogebiete" gehalten auf der 6s. Versammlung Deutseher Naturforscher und Ärzte (1596). Er sagt:

,Sobald man dem Fub auf afrikanische Erde setzt, lallen die tierisehen Parasiten über den Henschen her, von denen auber den Moskitos der Sandfoh (Pulex oder Sareopsylla penetrans) am Congo der mangenehmste ist. Ursprünglich aus Brasilien stammend und zur Zcit des Sklavenhandels eingeschleppt, hat er sich duwh die Karawanen mod die Arbeiter und Suldaten der Expeditionen Jandeinwärts verbreitet and ist bis zu den Stanley-Fällen hin cine Landjlage geworten. Bald wird er Afrika durchquert haben. Die Mämehen und die unbe[ruclueten Weibchen belästigen nur wie gewöhnliehe Flühe. Wenn man in eine längere Zeit unbewohnt gebliebene Negerhütte tritt, so kann man binnen wenigen Mimuten seine BeinkJeider mit ten hungrigen Tierehen tieht besitet finden und die Weibehen von den Hämehen leicht untersedeiden, denn letatre schleppen den verhältnismäbig riesigen Penis von der form einer Fuchsienblute narlı und erscheinen dadureh $2 \mathrm{~mm}$ lang, während der Körper nur etwas über 1 mum mißt. (Taf. 111, a.) BedenkJicher machen sich die befwehteten Weibehen bemerkbar, deren Tätigkeit in viejen Werken ungenau besehricben wiru. Sie bohren sich nicht nur mit dem hople rin, somdern sehlüpfen meistens, einen kleinen Hautriß benützend, z. B. am Nagelfalz der Zehen, an zerkjüteten Siehwielen an Fubballen usw., in die weiehe Zellenlage des Rete Malpighi bis an die Grenge fler Papillarsehicht. Der Kopf ist hierbei naeh innen gerichtet, während der After durch Atmungsstigmata rechts und links flankiert, in der Tautoffnemg streken bleibt. Durch rasehe Proliferation der unzälligen Eier schwillt der l'arasit zur firöfe ciner Erbse an. Wem die Eier in den Boden gelangen, so bedürfen sie der Trockenheit und Wärne zur Reife. Feuchtigkeit tötet die Eier, wie the junge Brut, des- 


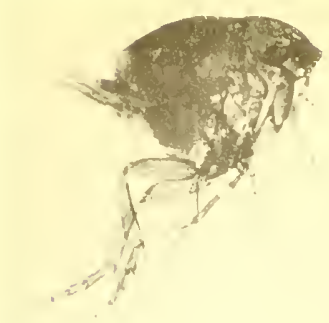

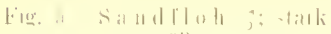

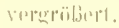

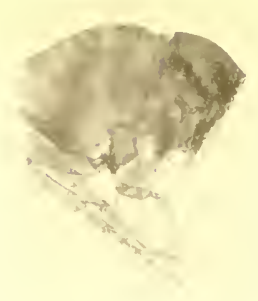

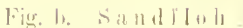
Vereribentuse wis in Fig: :

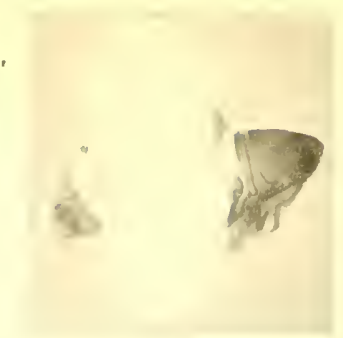

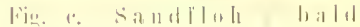

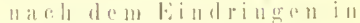

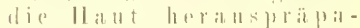

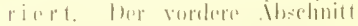
des. Mhlomens ist riel stither all:-

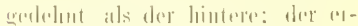
weitorte Msomente ist seheibenliirmig, niclit kugnelig.

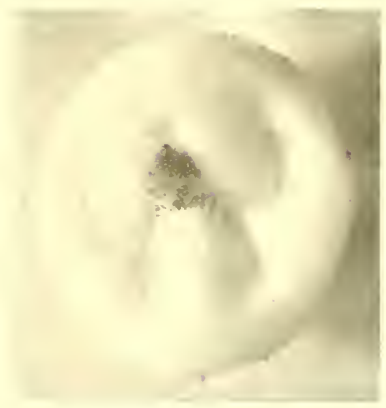

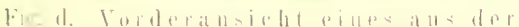

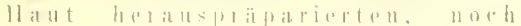

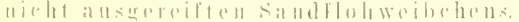

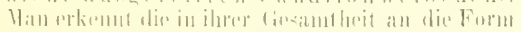

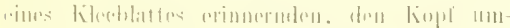

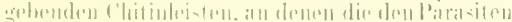
:1)

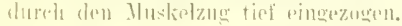

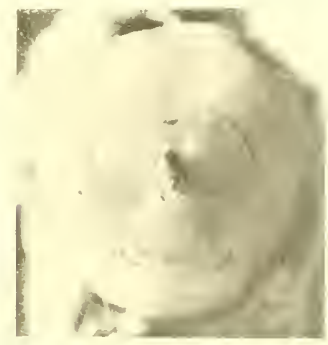

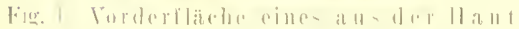

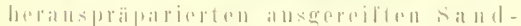

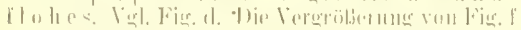

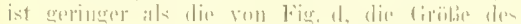

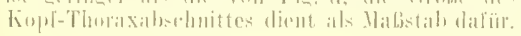

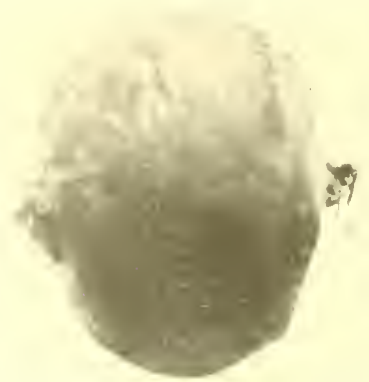

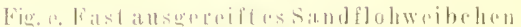

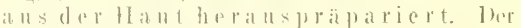
kiond und der the Beine tragende Toradiab-rlunit

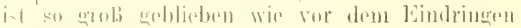

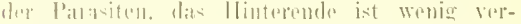

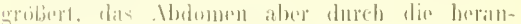

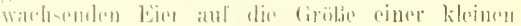
lithas anceselewolln.

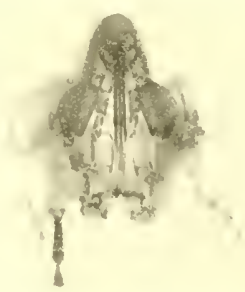

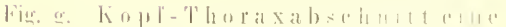

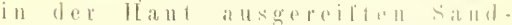

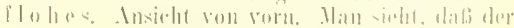

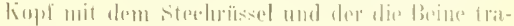

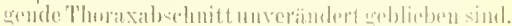



wegen kann man seine Wohnung durch häliges Besprengen des Pubhoderns vor sandlöhen

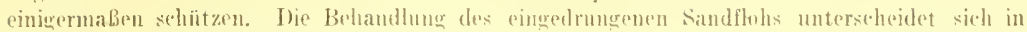
nichts ron der eines anderen fremelköryers oder Abszesses. Wo man feste lederstiefel trägt,

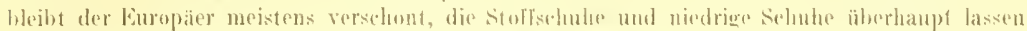
mit den staub anch die sandliöhe durch. Wir hatten, da es keinen schuster gals, nur

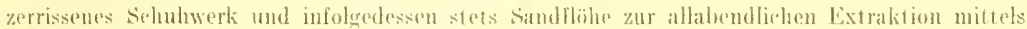

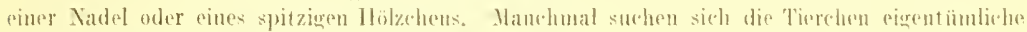

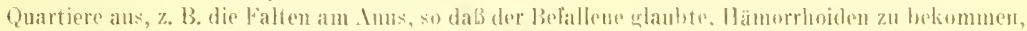
und deswegen meine Hille suchte. The Hunde Jejden sehr von den Samdliohen, bei Papageien sah ich sie kranzförmig die Augenlider umsinmen. Bri Vernachliksigung des dbszesses können

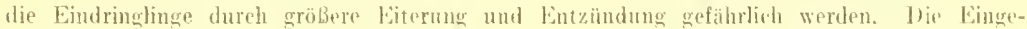
borenen beschiftieren sich deswegen in den alsendlichen llubestunden nit der Entlermung der im Laule des Tages eingedrungenen saudflälue und strenen Lsehe anf die kleinen Wunten. Arbeitswehene Individuen aber unterlieben diese llautpitenge und waren manehmal an Ilanden

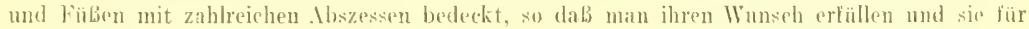
einige Tage arbeitsunfähig erklaren mußte, Als wir eine nen rekrutierte thteihum kaffern bekamen, hedurfte es mehrere Wochen, um diesellexn von sandflöhen zu reinigen und sie mit

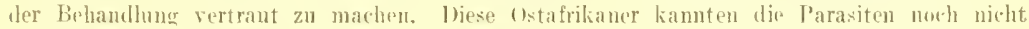
und waren aul dem Yarsehe von der Kïste bis zum stanley leobl uber und äber mit den kleinen beinigern gespickt worken."

The Zahl der cingedrungenen Sandföhe kaun rine sehr grobe spin, es worden schon mehrere llnudert bei einem Menschen beobarhat.

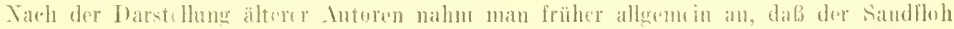

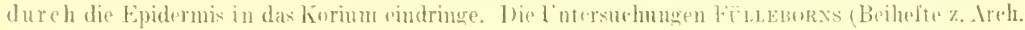

\section{Fing. it.}

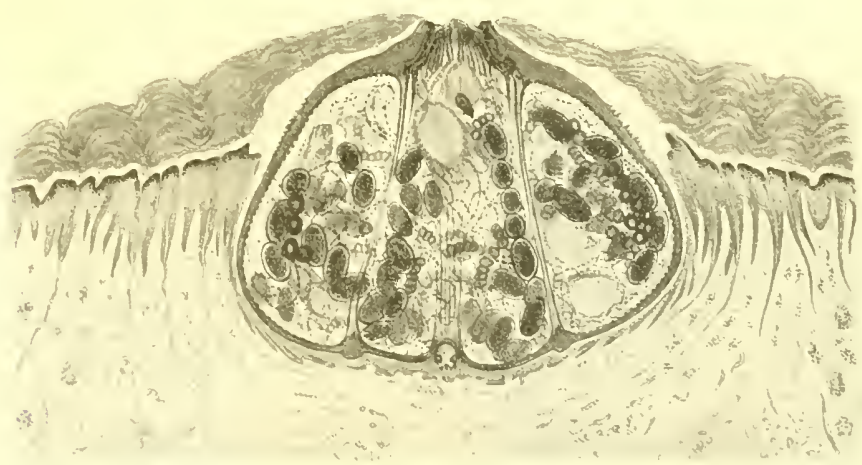

Insgureiltes bandfhohweibuhen indersohlenhaut rines Negers. 10:f. Han sieht, diblj der l'arasit innerhalb des bruchsackartig rorgewoblbten Epithels mol zwar in

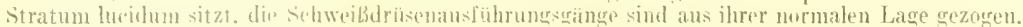
1)as Hinterende des Foles mit den insmimdenden Thacheen befinded sich an der Hantoberlache,

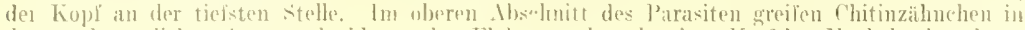

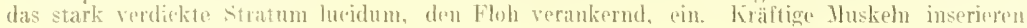

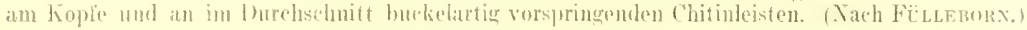

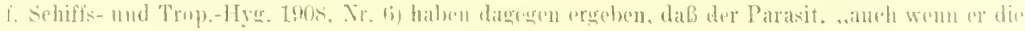

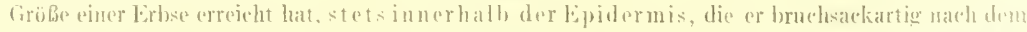

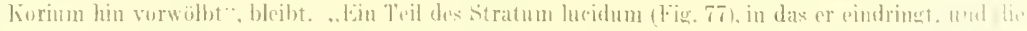

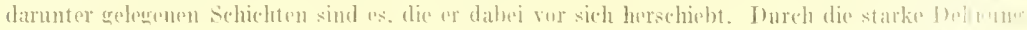

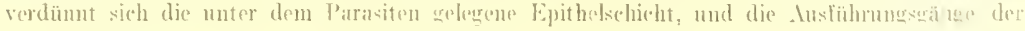




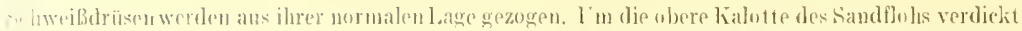

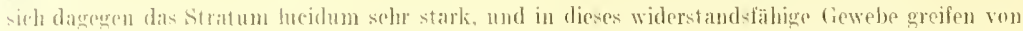
der ('hitinbant des Inselits gebidele Zahurben ein. die den Floh in der llaut fest verankern."

..bas Weibehen selwallt. mathden es in die Haut grolrungen ist, sehmell dureh die heran-

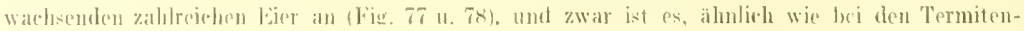

fitis. is.

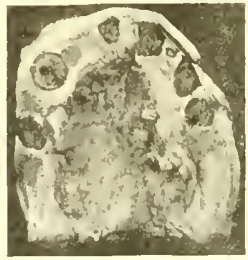

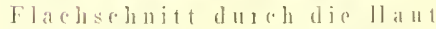
dor groben hehe mit siand-

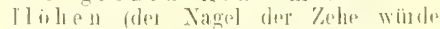
sieh hinter dem Bilde befindent).

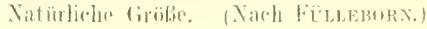

Fig. $7 \mathrm{~s}$.

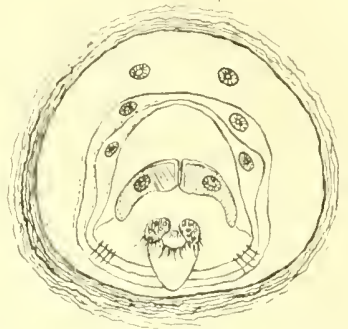

Sirecopsylle peretrues L., $0^{\text {to }} / 1$.

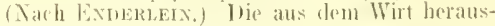
ragende, aus den letzten Nhominalsewenten gebildete Endplatte mit vior Stignemparen. (bol. Fig. 77 und s1.)

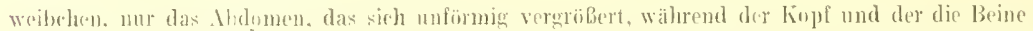

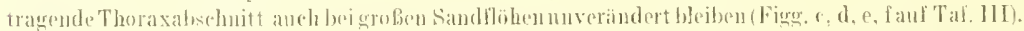

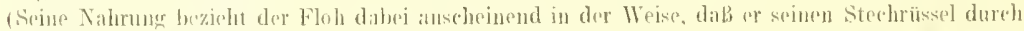

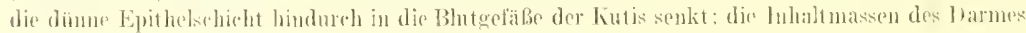

Fing. 80 .

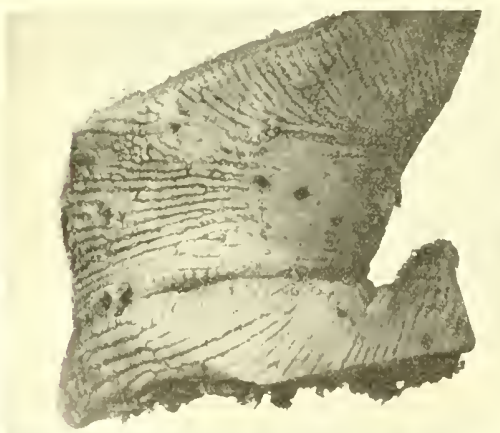

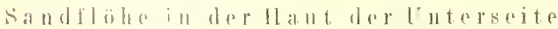

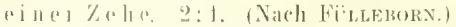

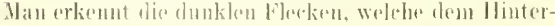

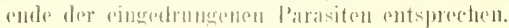

Fig. 81.

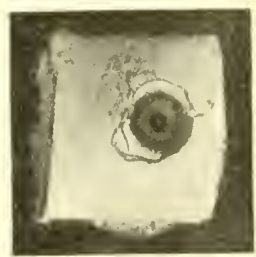

Sandfloh in der Solnenli all t. :2:1. (N. FÜLLEBORN.) las Epithel über dem Sandfloh ist abmazeriert.

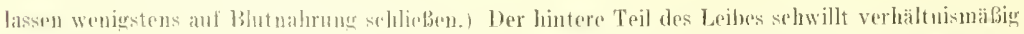

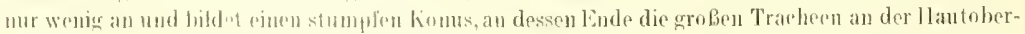
fläghe mimten, da der liloh and buftatmung angewiesen ist (Fig. 77 und 79). MuBerlich markicrt

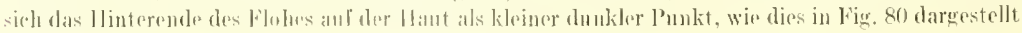

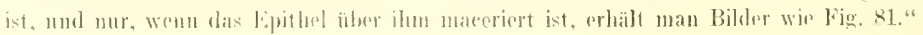




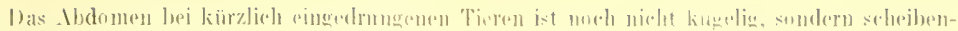

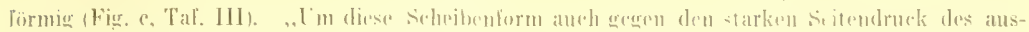

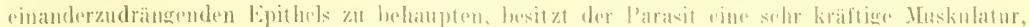

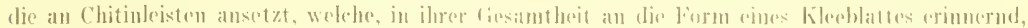

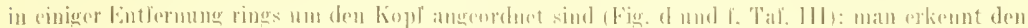

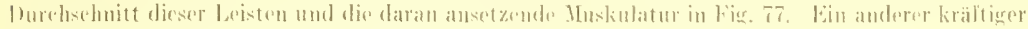

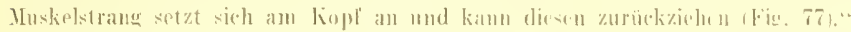

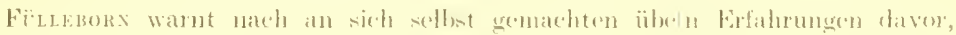

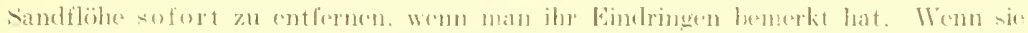

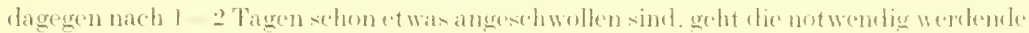

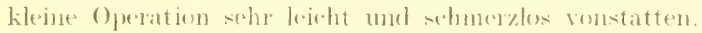

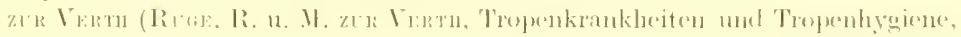

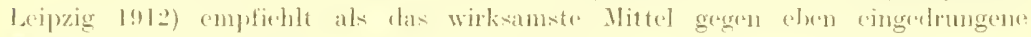

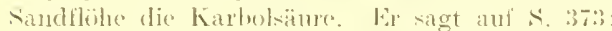

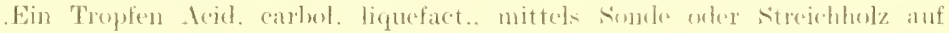

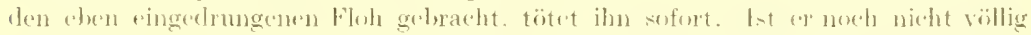

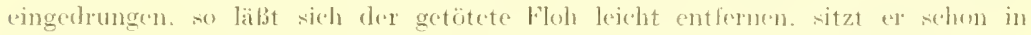

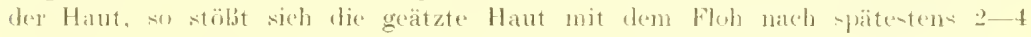

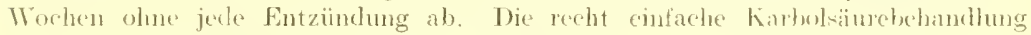
ist nur in shen ersten heiden Tagen anwendbar.

Ist der günstige Zeitpunkt für sie verpalist. so bleibt num die merehanisehe Entfernung öbrig. die leichter ist nach : 4 - 4 s Stumden. als kurz nach dem Eindringen. Sie jint ebensogut ein axeptisch vorzunchmenter Eingritf, wis jeder andere,

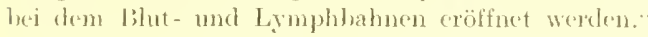

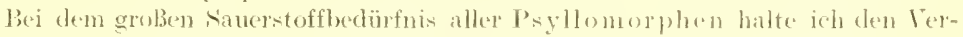
sehhub der stigmen für ein erfolgrerspreshendes Mittel. dies eindringenden und

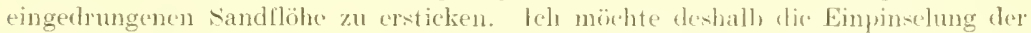

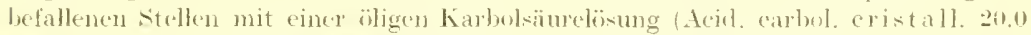

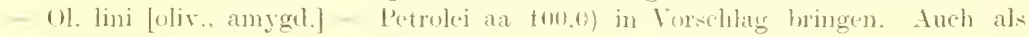
Abwehrmittel dürfte sich das bestreichen der Lieblingsitellen mit deer gleichen Lösung cmplehlen.

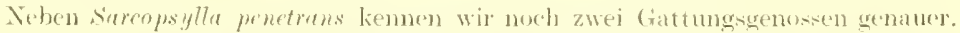

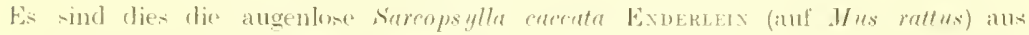

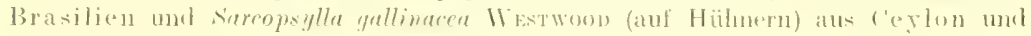

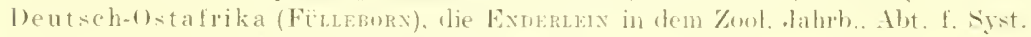

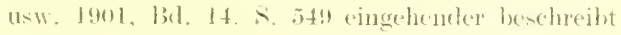

\section{Iuflewahrung, Intersurhung usw.}

Gelïtterte Flöhe lassen sich in der (iefangenschalt bei Zimmertemperatur

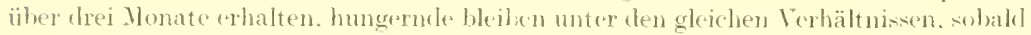
nur die lult feucht gehalten wird. etwa halh so lange am beben.

bei ther bieke ihres ( hitimpanzers welen föhe durch bintrekenen nur wenig verändert und können vor Feuchtigleit gesehützt in diesem \%ustande unbegrenzt

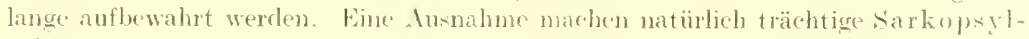

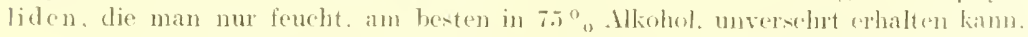

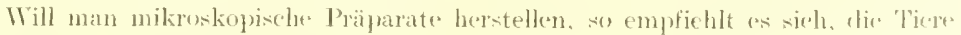
zunächst tür e-in paar Tage in dar gleiche Alkoholgemicch zu legen. damm nut Azete 11 zn

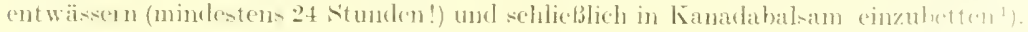

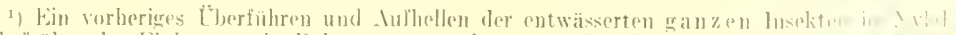

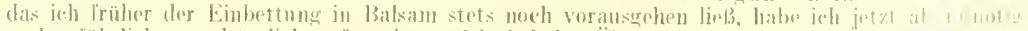

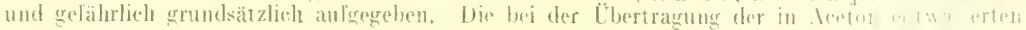


Diss ('hitin wird in Kalilange hinreichend entfärbt und durchsichtig: leider aber werden die Weichteile bei diesem Verfahren vollständig zerstört; vollkommene Entfärhmug bei relativ guter Erlialtung der Weichteile (namentlich der Nerven und Muskeln) crzielt man durch mehrtägige Brhandhung der Flöhe mittels reiner Salpetersäure unter Zusatz von ehlorsaurem Kisli. Sind die Tiere in diesem Gemiseh zu durehsiehtig geworden. so cmufichlt es sich, sie vor dem Einbetten in Bakam mit schwaeher Azetonpikrinsïureösung zu fürbm. Jeghcher Überschuß von Pikrinsäure muß vermieden werden, weil diesclbe anderenfalls in Kanadabalsam anskristallisiert und die Präparate vordirbt.

\section{Feinde, Prophylaxe.}

Außer niederen I'ilzen (Entomophthora) dïrften andere Ingehörige des Pfla nzenreiehes den flöhen wohl kaun etwas anhaben können. Auch ron Tieren droht ihnen wur wenig Gefahr; von allen ihren Wirten wohl gehaßt, sind die meisten dersclben doch alkein auf ein wenig erfolgreiches Kratzen angewiesen und nur die Vierund Zweihänler sind in der Lage, wirksamere Waffen gegen ihre Quälgeister ins Feld zu führen.

Von gasförmigen Vertilgungsmittch sink dic brachbarsten Sch we feldioxyd. Kohlenoxyd und Formaldehyddämpfe. Die Gase werden in den bekannten Apparaten antwickelt und müisen mindestens 12 Stunden in den von Flöhen zu säubernden wohlgeschlossenen Räumen zurückgehalten worden. Die Brut wird am sichersten dureh Reinlichkeit beseitigt : mindestens einmal wöchentlich sinel vor allem die Fubböklen, in deren Ritzen sich die Eicr und Larven rerstecken, mit starkem Seifenwasier, dem man etwas Pefroleum zusetzen kann, zu befenchten. Man läbt das Gemiceh etwa eine halle Stunde lang einwirken und nimmt es damn mit reinem Wasser wieder auf.

Das von Zupitzs als Pulieifugum (mupfohlene Jodoform hat wieh nicht in allen Fällen bewäht (Sweldexgrebel, Areh. f. Sehiff- und Trop.-Hyg. 1912, S. 180 ). Nelkenöl und Tinet. sabadillac halten leider nur für kurze Zeit die Flöhe (und andcre blutsaugende Insekten) fern; auch persisehes Insektenpulver ist ron nur geringer ITirksamkeit.

Es ist eine bekannte Tatsache, daß 1)iekhänter und Huftiere, namentlich Equiden, von Flölen nielt befalden werden. Es liegt dies jedenfalls daran, daß sie von den Ilautansdünstungen dieser Tiere, ihren „Juftstoffen", wie sie Prof. Jüren enphemistisch nennt, abgestofen werden.

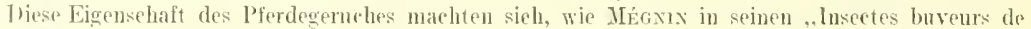
sang" przählt, die franzësiscden Suldaten im krimkriege zunutze. Er berichtet auf seite 76 scines Buches: ,Il faut roire que c'est lodeur de la peau ou de la surur de ces animanx qui fait fuir les P'uees car. lors de la campagne de Crimée, pendant laquedle nos soldats étaient dévorés par les Puces, il leve suffisait de s'envelopper de couvertures de Chevaux qui avaient servi pour "n ître promplement débarrassís."

Nach den Frlahrungen, welehe irh während des deutsch-französisehen lirieges in Frankreich und rin Jahr spüter gedegentlich einer bienstleistnng beim hessisehen llusarenregiment Nr. 14

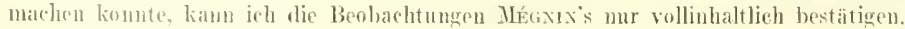

Aurle von versehiedenen deutschen offiziren erluhr ich, dab Reiterkasernen zwar nieht gegen IVanzen geschïtzt sind, aber von Flöhen durhans gemieden werden.

Seit undenkfichen 'ociten ist in china eine ebenso einfaehe als zweekentsprechende Flohfalle in Gebranehe, die aus bambusohr hergestellt wird unel für

()hjekte im Balsam anfänglich entsteluenden šblieren verselwvinden schon in den ersten 24 Stunden

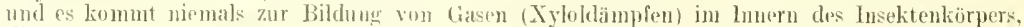

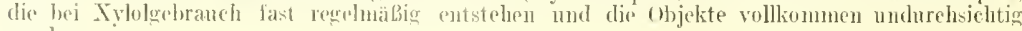
machere. 


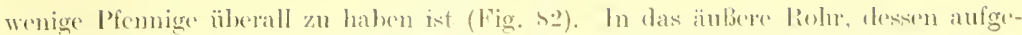

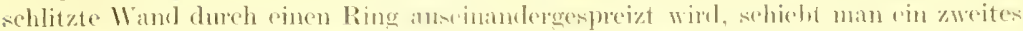

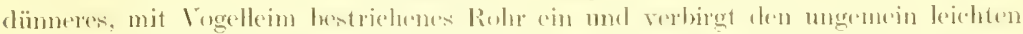

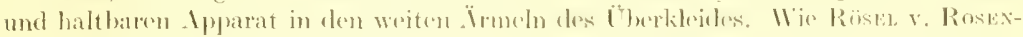

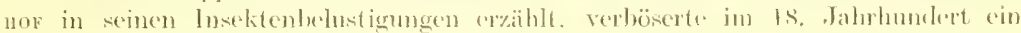

livig. sig.

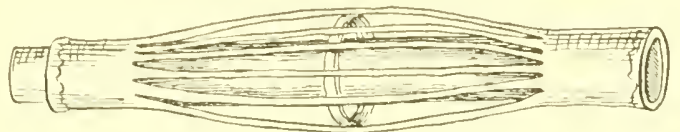

Chinesiophe Flohfalte $1 / 2$ (Original).

Anonymus das ingeniöse (Original. Er setzte an die stelle des Bambus zwej schwere und knsthare Elfenbeingöhren. deren änßere durchlöchert war, deren inneve mit

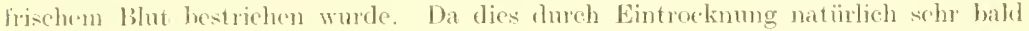
unwirkan wurde. kam die Falle kaum in Aufnalume umd fiel rasch der Vergesonenheit anheim.

\section{Literatur.}

1406 Anvisony Commotee, Reprorts on Plague Juvestigations in Indial. Journ. of Hye., YI, 4. 1907 Dalsolhe, ilid. VII. 3.

1908 Dilsselbr, ibid. V'tll.

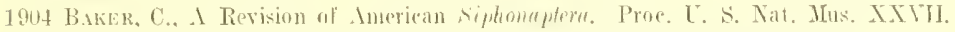

1906 bersethe. The Classifieation of the Ameriean sifhumptem. Bbid. XXIX.

1908 Billet, A., La Peste en Algrie en 1907. Bull. Soe. pathol, pxot. Bu. I.

I835 Borché, Bemerkungen übre die Gattung P'ulex. Nova Arta Lead. Leopold.. Xrin, 1.

1909 coxsent, E., Recherehes sur la Peste en Tunisie. Bull, soe. pathol. exot. Bd. II.

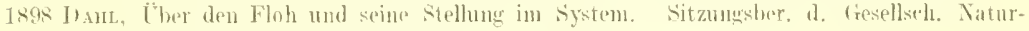
forsch. Fremule zu Birliur, Xr. 10.

1911 1912 DampF, Zur Kenutnis der Aphanipterenfanna Westdentwehłands. Sitzungsher. d. Naturh.-Yer. Rheindand-Westialen. Ibt. E. S. 33 -IJ3. Taf. I- V.

1911 Derselbe, Palueopsylle hldsimu n. sp'., ein Fossiler Floh ans dem baltisehen Bermstein. Xlit 2 Tafoln. Schriften der Physikalisch-(i)konmisehen Gesellsehaft zu Königsberg.

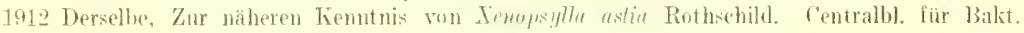
Originale. Bd. 6ō, Ifeft $4 \%$.

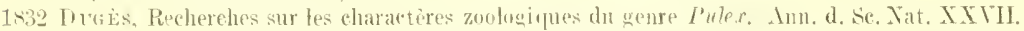

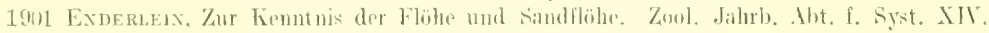

1912 Fox, f.. Some enmmon Siphonaptera of the Plhilippine Jsands. The Plibippine Journal of seience, Bd. 7, See. B. Nr. 2, S. 119

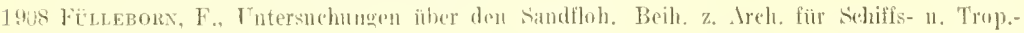
IIve. Boilhelt ts.

1911 G.mbi. L., Lala-Izar e putci, malar. "malatt, d. praes. ealıli, Nr. 10.

1778 de liEer. Nemoires pun servir à lhistoire des lusetes. IIJ.

1899 Jernovs, lie systematische Stellnng der Pulicilen. Zool. Anzeiger XXII.

16ti.) Hooke, Micrographia.

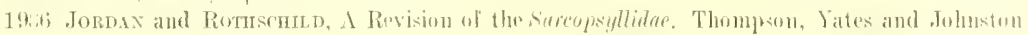
Laboratories Rejert, VII, 1.

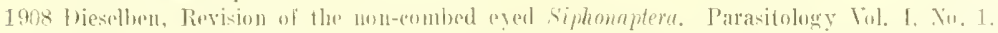

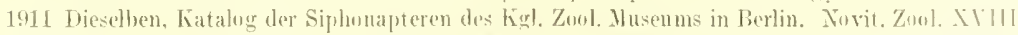

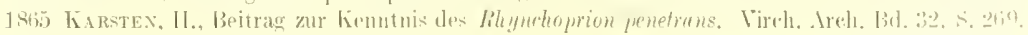
2 Taff.

1859 liolesate, Die Parasiten des Altvaters.

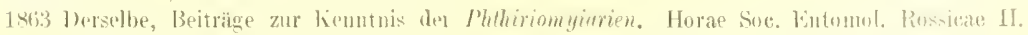




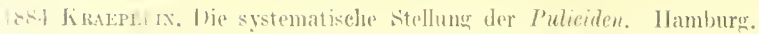

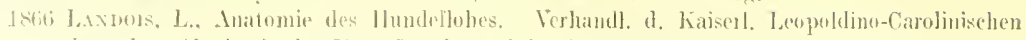
deutsden Akademie der Xaturlurseher. Bet. 33 (1867), 66 seiten und 7 Tal.

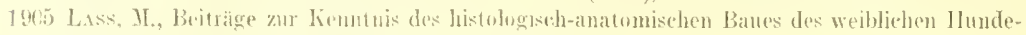

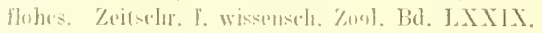

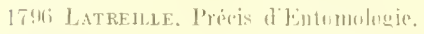

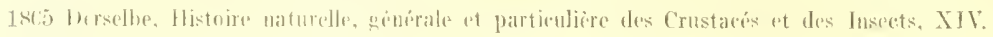

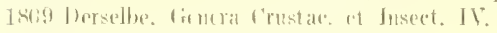

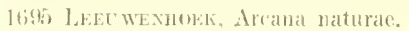

legs thersellse, Epistolae.

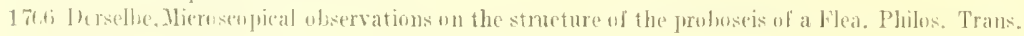
lioy. site. $\mathrm{XXV}$.

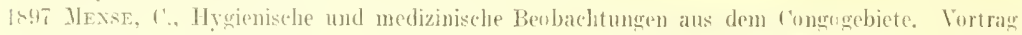
sehalten aud der fis. Versammlnng deutsehen Xaturlorsther und Irzte. Wiener klin. Rundeclian Nir.: 7.

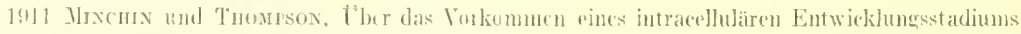

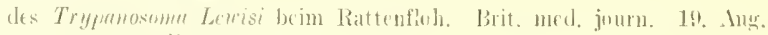

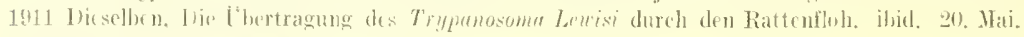

1544 Moscomett. We Prulice.

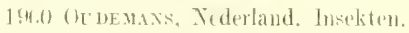

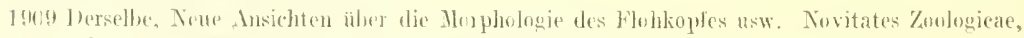
I3el. 16, s. 1:H 158, 2 Tatt.

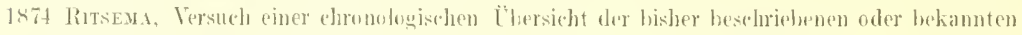
Irten der Gattung l'ulex. Correspondenzhl. des zowl. Ver. Regenshurg.

$17+$ ! Rïsed. v. RosexJor, Insekten-Belustigungen, Il.

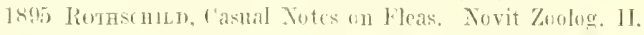

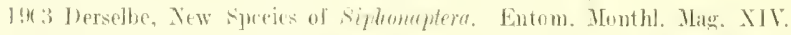

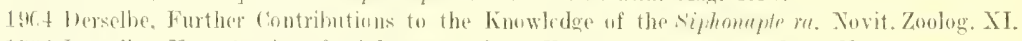

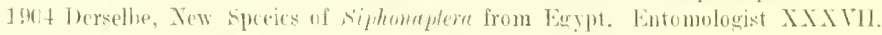

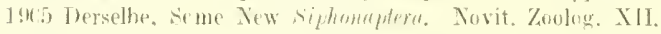

19 (i) Derselbe, I new Egyptian Fleil. Entomologist XXXIX.

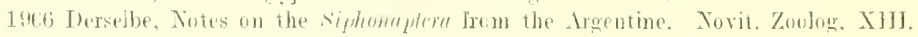

19x, Jerselbe, Note on the species of lleas found on rats. Journ. of Hye. Vi.

19 s Dersellie, riphomphere. Sjöstedt's Kilimandjarn-1Lru-Lxpedition.

1911 Derselbe, some new genera and speries of Siphomeflow. Novit. Zoul. XVIII.

1910 Sintberti. A. Ind I?. Mintetfer, Rattenflihr aus bentich-Ostalrika. Arbeiten aus dem Kaiserl. Ciesuntheitsamte. Bd. 33, H. 3.

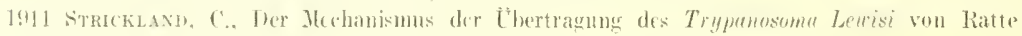
anl Ratte dureh den Rattenllol. Brit. mol. joum. 6. Mai.

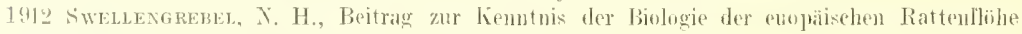

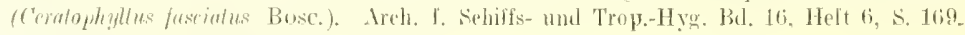

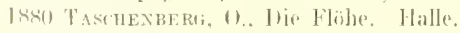

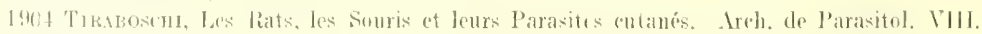

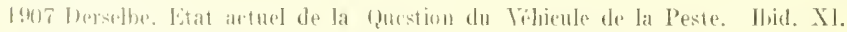

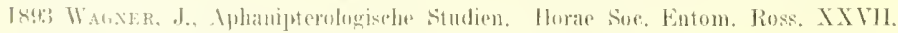

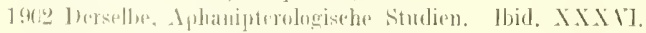

1:10 lersellee, Systrmatisele Ühersieht der Aphanipterenarten. Ibid. XXXIX. 


\section{Die Zwriflügler (Diptera).}

\section{Ilegenteines.}

bie \%weiflügler sind lnsekten mit saugenden und häufig gleichzeitig stechenden Ifundteilen, mit wohlentwickeltem, häutigen, spärlieh geaterten liorderflïgelpare und zwei Sehwingkölbchen. die als homologe Gebilde an Stelle der Hinterflïgel tem Metathorax autsitzen. Die Metamorphose der I)ipteren ist eine vollkommene.

Das gleiehmäßige, alten Angehörigen der orhumg gemeinsame Verhalten der"

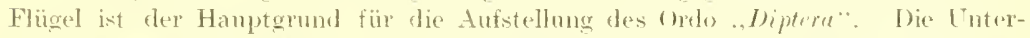
sehiede zwischen den $\mathrm{Xematokeren} \mathrm{mul} \mathrm{Kyklorhaphen} \mathrm{sind} \mathrm{aber} \mathrm{so} \mathrm{große,} \mathrm{tats}$ es fraglich erselheint. ob man sie heute nech als blobe Linterorhungen anffassen kamn. wenn auch zugegeren werden mub. dab die orthorhaphen Brachykeren eine (scheinbare) Brïcke zwischen den beiden groben Aubengruppen der ,Zweiflügler" bilden.

Der Körper der Difteren zerfällt in drei scharf gegeneinander abgesetzte Teile, den Kopt, die Brust (Thorax) und den Bintedeil, (Abdomen). Der Kopf ist in der Hauptrache sitz drer wichtigsten simmorgane. der 'Thorax 'Träger des lokomotorischen Apparates und der Hinterleib Termitler der Atmung.

Der dureh einen kurzen, dïnnen unel sehr beweglichen Hals mit dem Thorax verbundene Kopf ist bei den Mïcken gewöhnlich kugelförmig. bei den Brachykeren hat er meist die Form enes Kugelabsehnittes oder die eines Meniskus. seine dorsale Mittelfläche nemnen wir den seheitel, vor diesem liegt die bis zum Fühleransatz reichende Stirn, die schließlich (von der Fühlerwurzed ab) in den an die Mundteile stolsenden ('lipeus (las Lntergesicht) äbergeht. Die hinter dem sicheitel und den Kinmplexaugen liegenden Partien werden llinterkopf genannt.

Auf dem Sheheitel stehen. und zwar stets in Dreiecksform, bei vielen Zweifligglem einfache Augen (Ozellen), während die zusammengesetzten Augen (Komplexaugen, Fazettenaugen) dic Kopf feitenfläehen einzunehmen pflegen; sie sind im männlichen Geschlechte stets gröber, als bei den Weibchen und können infolgedessten den (bei den immer vorhandenen) Scheitel vollkommen verdrängen, ihre Meelianränfler stolsen dam hart aneinander'.

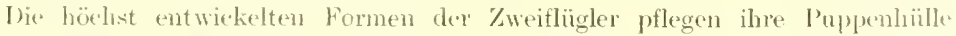

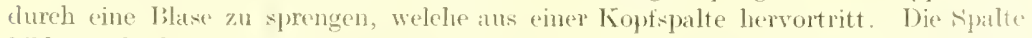
bilket sich durch Auseinamlerweiehen timer präformierten Naht und hat die Form

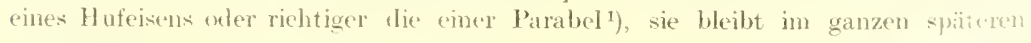

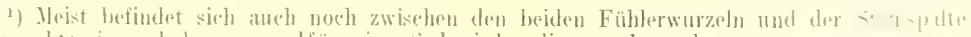
Bogenuaht) eine erbabene mondformige behwiele, thic sog. Lunula. 
Imaginalleben als deutliche Furehe siehtbar. Diese, die ,Stirnspalte", liegt in ihrem mittleren (oberen) Teile (dem Körper des Hufeisens) zwisehen Scheitel und Stirn, ihre beiten Sehenkel befinden sich jederseits zwischen dem vorderen Komplexangenrande und dem C'ntergesicht (vgl. Fig. 150).

Das abgesprengte Stïck der Puppenhaut hat stets die Gestalt einer Kugelmütze (Kalotte) und löst sich in ciner kreisförmigen vorgebildeten Naht von den ïbrigen Teilen der äu Beren l'uppenhülle ab. In diesen Falle ist die Puppe immer cin sog. 'Tönnchen, das in seiner Hiille ans der eigentlichen Puppenhaut und der dariber

Fig. 83 .

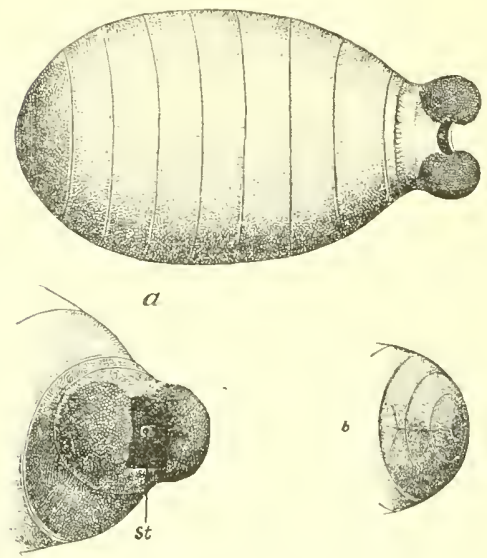

Tönuchenpuppe der Zululandtretse. (Nach Austen.)

a Rückenlbäche der Puppe (\%/1). b Kopfende der Pupue $(6 / 1)$. Die Y-tormige Naht zerreibt heim sehlipfen der Jmago. st Stigma aul dem lnagrübehen der Mlade $(18 / 1)$.
Fig. 81.

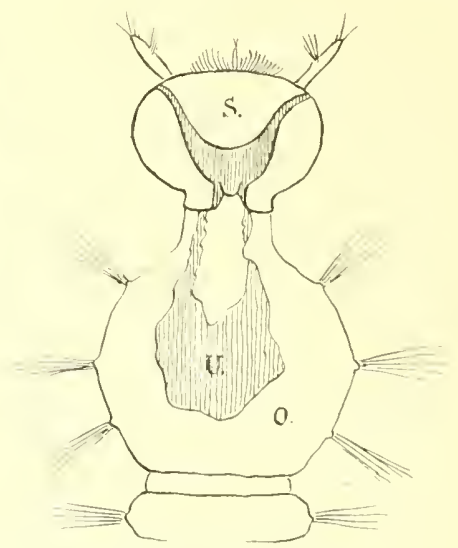

letzte Larvenhant eines Culex, ron oben geselien (Oriminal).

Bogenspalt anf dem Scheitel, (S) Hinterlauptsteil der hoplkapsel ventraler (U) II nd dorsaler (o) Spalt im Hals- und vorderen Thoraxteile.

eingetrockneten mol erhärteten letzten Haut der Larve besteht. Diese kreisfömige, die kephalen Teile der P'uppenhant umlanfende Nabt, gab Braurr die Veranłassung, die höchststehenden Dipteren als Unterordnung Cyclorupha zusammenzutasien.

Brseer stellte dam den Kykloraphen den Rest der Zweiflügler als Orthorha phen gegenüber, da er glanbte, daß die Larven aller Angchörigen dieser zweiten Untrordmung ihre letzte Exuvie durch einen geradlinig verlaufenden dorsalen Längsspalt verlieben; wir werden sehen (Fig. 84), daß dies keineswegs immer der Fall zu sein braucht ${ }^{1}$ ).

l) wohlentwiekelten, verschieden mol mitmer prachtvoll gefärbten Komplexangen sind meist nackt, können aber aneh durch zwischen den einzehen

1) Viel rikhtiger wïrde man die beiken Unterordnungen (wenn man sie uiberhaupt als solehe bestehen Jasson with Civmnochrysahiden und Kryptochrysaliden nennen. Die Mumienjulpuen der (Orthorhajplen (Fymnoehrysaliden) zeigen sich meist unverhült im eigenen Kleide, wiblrend die Tonnehenpuppen der Kyklorhaphen (Kryptochrysaliden) ansnahmslos anber der nieht abgeworfenen auberen Larvenhant auch noch mit der inneren eigentlichen Puppenlant bekleidet sinf. Es ruht also hier die Mumienpuppe (Chrysalis) stets unsiehtbar, umschlossen und verborern, ron dem ans der crlärteten Larrenhant gebildeten Tännehen. 
Fazetten stehende Börstehen behart arscheinen. Die gewöhnlich gleich groben Fazetten sind bei einzehnen Familien (ten 'Tabanidon z. B.) in der oberen umb

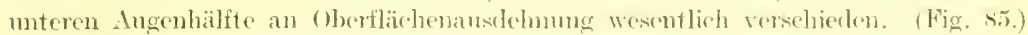

Die Füluler der meisten firmnoelaryaliden sind lang, geibelfümig und aus vielen Gliedern zusammongesotzt, wähend die Fühler aller kryptoelery

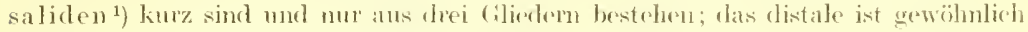
das größte und trägt die sog. Fï̈lulorborste.

bie Ilundteile bilden einen Sang-oler einen siteeh- und sangrïssel,

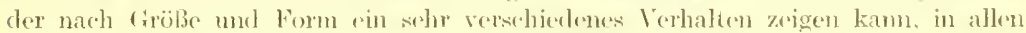

Fir. Kti,

Fig. 85.

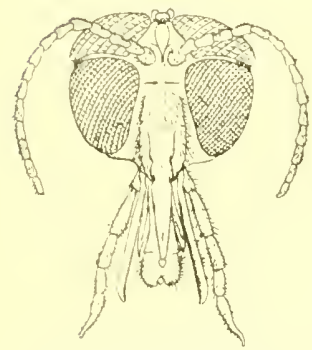

Ropf einer Blepharozeride.

(Naeh Kelloci(i.)

Die oberen homplexangenhälften tragen gröbere Fazetten (hei den Tabomiden gerade mmgekehrt).

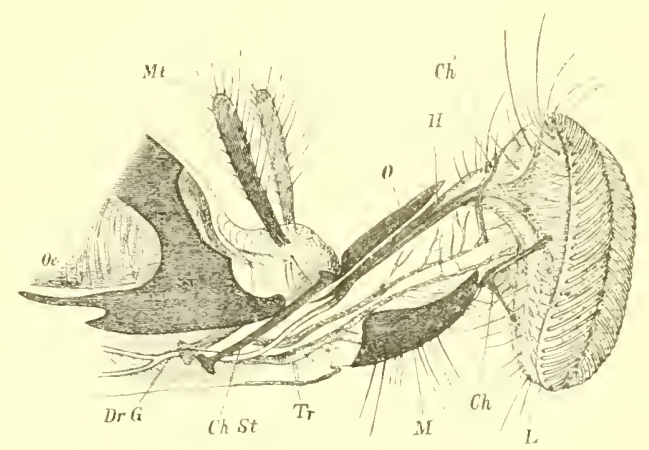

Rüssel einer stubenfliege. (Nach l'Lucs-Grobmex.)

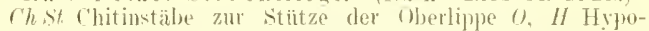
pharynx, L. Luterlippe (Labelten mit den zahlseichen, radiarverlaulenden Sanglurchen, den sogenannten ..Pspudotra-

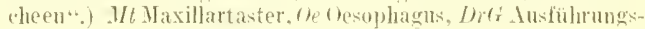

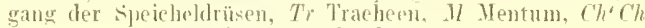
(']itinstützo der labellen.

Fällen aber dureh seinen Baus seinen Zwecken in rollkommenster Weise zu cutsprechen pflegt. (Fig. s6.)

Der äubere und meist allein siehtbare Teil des Rïssels wirl von dem Labium, der L'nterlippe, gebildet unct pflegt als eine längsgespaltene Hohlrime, deren Ränder auf dem Rüsselyücken fast zusammenstoßen. dir anderen Mundwerkzenge seheidenartig einzusehliebon. Dem distalen Eude des Labinms sitzen als hochempfindliche Organe hes Gefühssimnes die Lippentaster (Tabellen) auf, the häufig zugleieh als sehr brauchbare 'T'upfer (Figg. $86,92,93,97$ ) an erster Stelle rle stets flïssigen Nahrungsstoffe der l)ipteren anfzunehmen pflegen. Bei den stechenden Fliegen (Muszicten) sind die Labellen zugleich hochbewegliche 'Träger von verwiekelt gebauten Zahmreihen.

bas Gegenstiick des Labiums ist die Oberlippe, das Labrum (anch Lalbrum-Epipharynx genamt, da seine Hohlrinnenwand direkt in die Mundrfecke überzugehen pflegt); das Labrum legt sich mit seiner (borsalen Fläche fest anf rlen Labiumspalt mul verwandelt somit die ['nterhppe in ein gesehlossenes Rolnr.

Com Borles der Mumlhöhle entspringt eine zungenförmige Chitinholnlnatul. die sich der unteren Innenfläche des Labiums lest anschmiegt; es ist der Hypo-

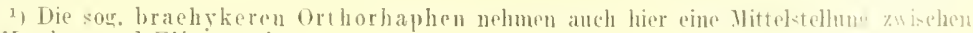
den Mücken und Fliugen ein. 
If aryx (auch Zunge genaunt), ein Nundteil, der bei allen Dijteren wohl entwickelt zu sein pllegt ume die Ansmündung des Duetus salivalis communis einsthliebt ${ }^{1}$ ).

Die tieferstehenten Gymmohrysaliden zeigen fast durchgängig, nament lieh in ihren blut sangenten familien, auch wohlentwickelte, hehspezialisierte ()berkiefer (Aandibeln) unt l'nterkiefer (Maxillen). Sie sind $z$ sägenden umb sehneidenden Workzeugen geworten (Taf. V1]. Fig. W), wolke anberortentlich gorignet erscheinen die Hant ihres Oplier zu durchbohren (Mandibehn) und sich in der gescotzen Wunde zon rerankern (Maxillen).

An der basis des Mundwerkzenghündels. der Rïsselwurzel, befinded sich regehnäBig noel cin zweites Tasterpar, die 1 axillarpalpen. (Fig. 86 .lt.)

Anf den einzelnen Teilen des Kopfes können sieh Haare und Borsten befinden. So sind namentlich die märchtigen Sitim- mol ścheitelborsten (Makrochäten) bei vielen Familien sehr auffallend und von hoher systematiseher Berlentung. Bartantige Behaarung des Untergesichts wird Knebelbart. die auf den Kopfseiten auf-

Fig. 87.

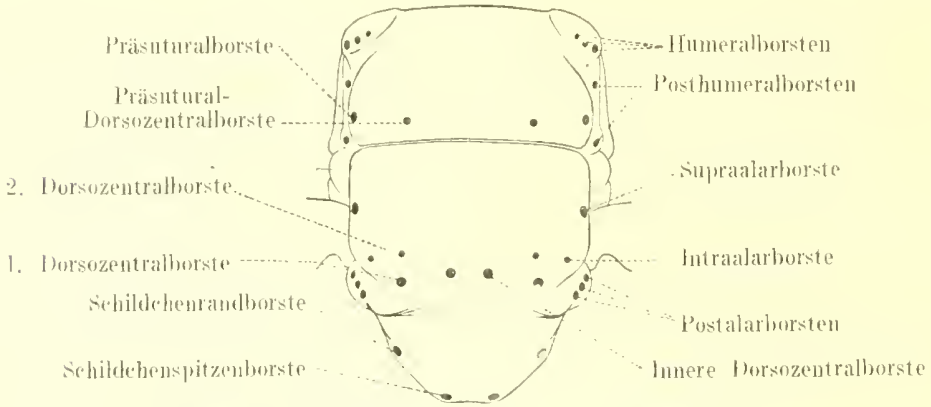

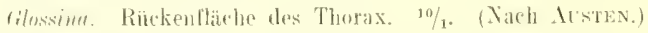

tretende Backenbart genannt. Wimperartige Pö̈stchen, welehe den Angenrand umstehen. leeiben Zilien

Der Therax der Dipteren hat eine Würfel- oder Kastenform, die in den groben (iruppen charakterist isehe Abänderungen erleidet. So ist eler Brustkort) der Nematokeren eme mmgekehrte, abgestutzte Pyamide, der Brustkorb der Tabaniden ein (5)oïl, wähend die eigentlichen Fliegen die Grundform an trenesten bewahrt haben. Merst ist der 'Thorax wesentlich höher als breit, kann aber anch dorso-ventralwärts stark abgeplatted crscheinen (Hippobosziden).

Ino alten Zweiflüglem sim d die trei Thoraxsegmente test miteinander verwathen, nur Jui den am tiefsten stehenden Formen zeigen noch gewisse Nahtfurchen die Gimzen der einzehen Ringe an.

An märchtigsten entwickelt ist das flügeltragende Mittelbruststiok (Hesothorax). wälnent der P'rothorax der an stärksten retuzierte Teil zn sein pflegt.

Die Dorsalfläche des Brustkorbes wird in der Hauptsache von dem Rüekenschilde (Scutum) des Hesothorax eingenommen, der hei vielen Formen durch eine Quernaht in winen vorderen und hinteren Sebild geteilt wint (Fig. S7).

1) Das ganzlicte bohlen des 11 youharyux bei den Psybomorphen, deren speichelgang in labrum verlault, bildet eine uniberbrickbare likult wrischen ihnen und den bipteren. 
Auf den vorkeren beken des Rïekensehildes gewahren wir bej ten meisten

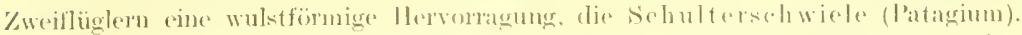

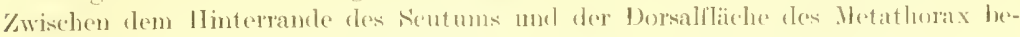

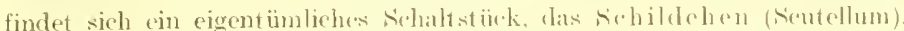

Die Brustseitenflächen werlen von ten fPenten eingenummen, die wir nateh

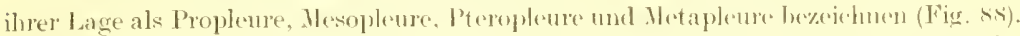

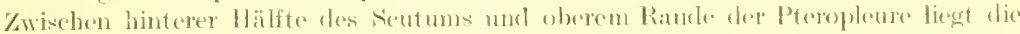

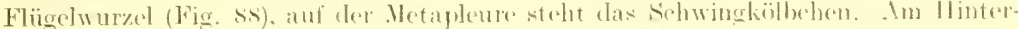

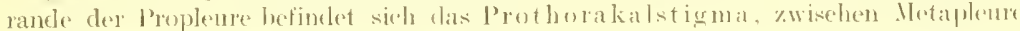
mol Metasterumm dias Wetathorakalstigmat.

Jiv. Sis.

Priisutural. Supraalarberste

Dorsozentralborste: Jutrialarh. Jersozentralborste lutrialarh.

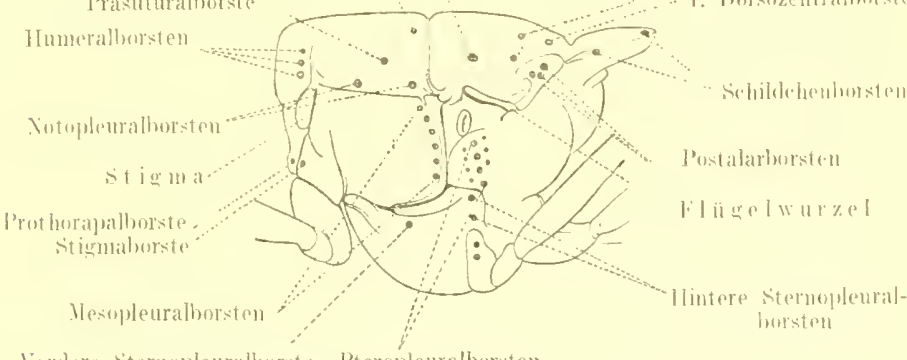

Vordere Sternopleurallorsto Pteropleuralborsten Gilossina. Soritenlache des Thorax, ${ }^{10} / 1$. (Nich Actitex.

Die Lnterfläche des Thorax wird ron dem zwischen ten beiclen ersten Beinparen liegenden thesosternum und dem zwischen zweitem unt drittem beinpare liegenden Metasternum gebildet.

las Abclomen kamn bis zu zehn Ringe erkennen lassen, meist ist ihre Kabl

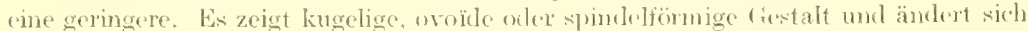

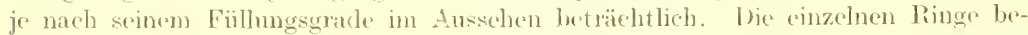
stehen in ihrem Integumente aus einer dorsalen mol einer rentralen Chitinspange. dem Tergite und sternite, die durel eine stark dehnbate. stigmentragende Seitenmembran miteinander in Virbindumg treten. An Leibeseme kïmnen zwei Paare von Ansätzen auftreten, die Iorsal gelegenen Cerci und die am Ende del bauchfläche angehefteten sityli.

Wie der kiopf so ist auch die Brost und der Hinterleih der Dipteren vielfach in ganzer Ausdehnumg oder in einzelnen 'Teilen behast und be borstet. Die Kahl und Stellung der Makrochäten an den heiden Rumpthälften ist abenfalls von grober systemaFig. 84.

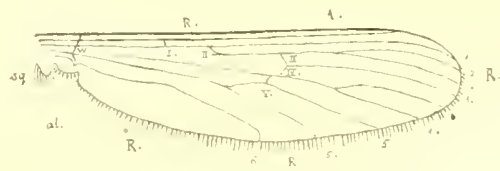

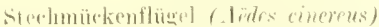
2) 1 (1) (1)iju.

sie. Siquama, al. Mlula, li. Randader. I. Vína

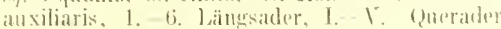
11. Muraligurader. tischer berleutung (Figg. si. ssi). Schuppen treten bei den stechmüeken regelmibig auf und sind in anderen Fanilien eine nur selten beobachtete Erscheinmmg.

Die äuberst zarte. meist glasartig churchsichtige Flügelhaut der I) form ist in regelmaibigen Abständen mit auberorelentlich feinen, spitzenwärts gerichtesten 
Bii stchen bestanden. Sie wird durch ein Srstem von krältigen Chitinöhren gestiitzt und ausgespannt. (In den Am- und Handknoelen der Fledermiiuse, den Rippen rler Samenflïgel von Ahorn usw. liegen analoge Bildmingen ror.)

Das proximale Flügelende nemnen wir die Wrurel, das distale die Flügelspitze, der nach außen gelegene Ramel des Flïgels heißt (nach altem entomologisehem brauche, weil an gespannten mol dadurch in mmatiirliehe stellung gebrachten Flügel oralwärts geriehtet) Vorderand, der Imensanm dementsprechend Hint errand.

Die clie Flïgetscheibe st ützenden hohlen ('hitinstäbe werden gewöhnlieh Adern genannt; sie verlaufen gröltenteils in der Richtung der Hauptachse des Flügels (Längsadem), Verbindngsstäbe von meist schrägem Verlaufe heißen Queradern. (Fig. s!!.) Die kräftigste lä̈ngsader bildet den Vorderrand des Flügets mol führt deshalb den Namen der Yorderandader (Costa). Die folgentlen Längsadern werden meist als erste bis simente bezeichnet, die Queradern treten versehieden an Zahl und sitz auf. und könnes deshalb nu bei den eimzehen Fanilien besprochen werden. Die son den Adern mmgrenzten und eingeschlossenen Flïgelfelder heißen Zellen.

Fig. 90
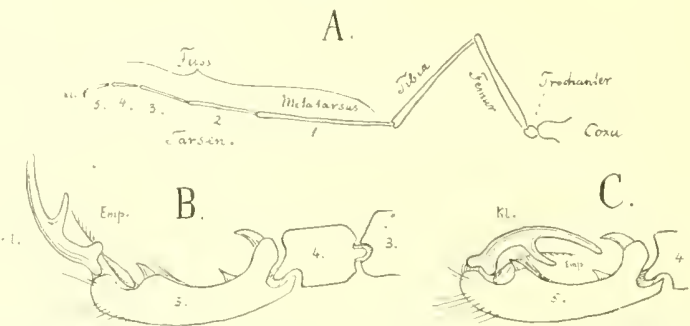

1. Stedunizkenbein. B. 11. (. Ende des Vorderfube's von Culex pipiens of. (Orig.) Kl. Klane, Emp. Emponlium, 5. Fïntes, 4. Viertes Tarsalglied. (C. Ki. Klaue plantarflektiert.)

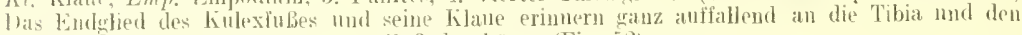
liub der laituse (Fig. 5iz).

Die Flügel kömen in einzehnen Familien (Hippobosziden z. B.) abgeworfen werden, verkïmmern oder ïberhaupt nicht zur Entwieklung gelangen ( Melophagus, Iigrteribit z. 13.).

1) Beine der Zweiflügler setzen sich aus den bekamten Stüeken des InsektenJesines zusammen; sje tragen auf der Fußspitze ein Klauenpar und häufig aneh nelen (inem Empodinm zwei Maftseheiben (Pulvillen). (Fig. 90.)

Ded Geschlechtsdimorphismus ler Dipteren ist selten ein ausgesproehener. 1) Wännchen besitzen in der IRegel gröbere Augen, hänfig einen abweichend gestalteten Hintcrleib mol in seltenen Fällcn (Bibio) eine andere Färbung als die Weibałen. Die Manhbehn fehlen den mämliehen Zveiflüglem stets.

1) ie Entwicklung der Dipteren ist ausnahmslos eine rollkommene. Neist setzen die weiblichem 'Tiere Eier al, könmen aber auch eben geschliiplte (Sarcophaga) oler vollkomman entwickelte (Glossina. Hippoboscidue) Larven gebären, die sich damn ohne weitere Nalurungsantnalnme nach wenigen Stunden verpuppen. Die bei ler Geburt farblosen Eier vieler Arten dunkeh rasch nach und kömnen in kurzer Zeit vollkommen schwal\% werten. Auf clie Wasserfläche abgelegte Eier sind häufig mit kunstvollen Schwinnworrichtungen versehen (Luftkammern der Anopheleseier (Figg. 100, 101), Iinlexhähnchen, Vierseheibe von Corethra usw.). 
Die langestreckten. Wurmartigen Latren sind fublos onler hörhstens mit

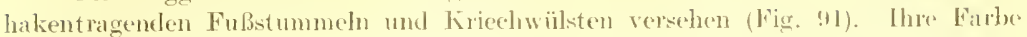

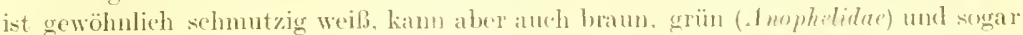

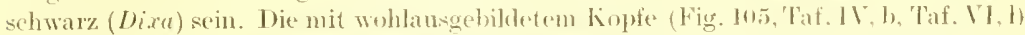

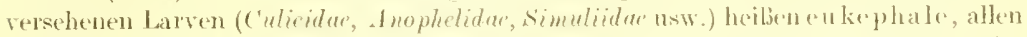

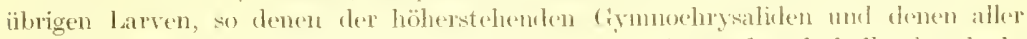
Kryptochrysaliden fohlt rin gut entwiekelter Kopt, sie werden deslall alkephale genamint.

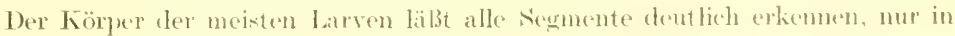
einigen Familien (Sterhmüeken z. B.) sint die drei Thoraxsegnente zn einem St iieke rerwachaen. (Figg. !1, I0.5, Taf. IV, b, T'al. V'I. I.)

Fïix. 91.
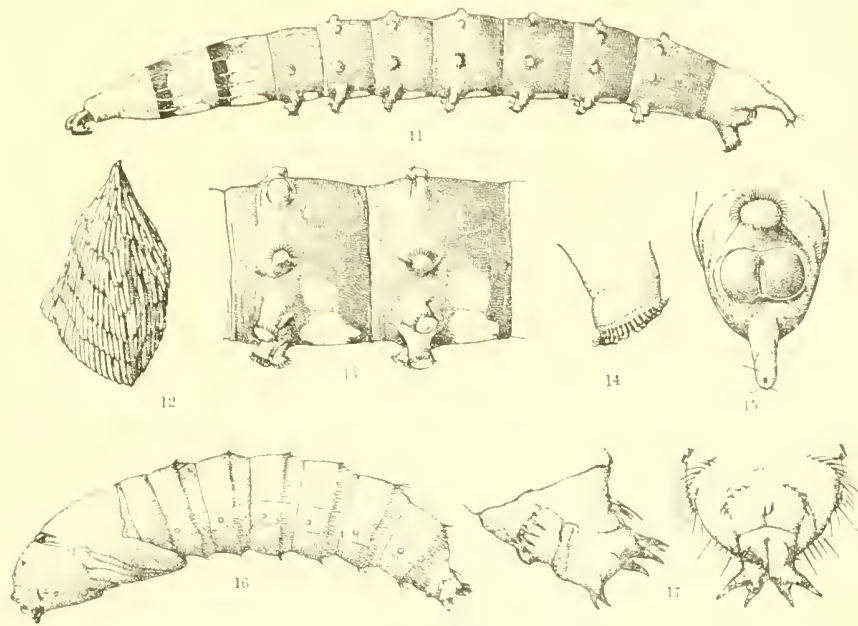

Tabmus Kingi IISTEx.

Aach kixci, Fourth Report-Wellcome Tropical Research Laburatories, Khartum.) 12. Gelege ${ }^{6}, 11$. erwachsene Larve, Seitenansicht $3 \frac{3}{1}, 13$. Seitenansicht des 4. u. 5. Alrdominalsegmentes einer erwachsenen Larve ${ }^{6}{ }_{1}$. 14. Seitenansicht des Inaljsendopodium einer reifen Larve, 15. Analsegment der reifesl Larve voll unten 6/1. 16. Puppe in seitenansicht 3/1, 17. Seitenansicht des Inalsegnentes der Pupje $6 / 1$, Lx. Analsegmint der Puppe von unten 6/1.

Die I)ipterenlarren atmen gewöhnlich durch Stigmen: Kiemen- oder Hatutitmung kommt seltencr ror: "s können aber auch sogar alle drei Atmungsformen bei demselben 'Tiere anftreten. Wie wir dies bei jungen Stechmiickenlarven z. B. namentlich während der. Wintermonate stets zu beobachten in ter lage sinul.

Die Puppen sind, wie schon oben bemerkt, entweder freie Mumienpuppen (Gymnochrysaliden), oder in Larven- und Puppenhaut cingeschlossene 'Tünnchen puppen (firyptochrysalidem). Letztere atmen durch Hinterstigmen (netapnoustisch), während dic Iumienpuppen ihre Atmungsöfnungen oder ihre Kiemen gewöhnlich am Vorderente des körpers tragen.

Die hier gegebene systematische Übersicht schliebt sich im ganzen der lini fischen Einteilung an. 


\section{Ordnung Diptera.}

1. Interordnung. . . . . . . . . Orthorhapha (Gymnochrysaliden).

1. Sektion ............... Nematoecra.

1. Tribus . . . . . . . . . . . . . . Eucephala.

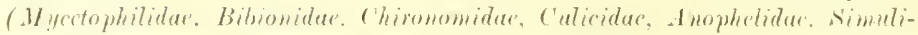
idae. Psigchodidue. I'tyshopteridue.)

2. Tribus . . . . . . . . . . . . Oligonenra. (Cecidom yidur.)

: Tribus. . . . . . . . . . . . . . . . . Polyneura. (Limnobividar. Tipulidae.)

2. Sektion. . . . . . . . . . . . . . . Brachycera.

1. Tribus. . . . . . . . . . . . . . . . Platygenga. (Stratiomyidae |Waffenfliegen]. Tubanidar [Bremsen]. Le ptidae [Schnepfenfliegen]. Asilidue [Raublliegen]. Bombyliidar [Hummelfliegen].)

2. 'Tribus. . . . . . . . . . . . . . ()rthogenga. (Empidar ['Tanzfliegen]. Denlichopodidae [Langbeinfliegen].)

: Tribus . . . . . . . . . . . . . . . . . Acroptera. (Lowrhopteridar.)

๖. Interordmung. . . . . . . . . Cyclorhaphu (Kryptochrysaliden).

1. Sektion . . . . . . . . . . . . . Aschiza ${ }^{1}$.

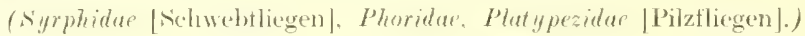

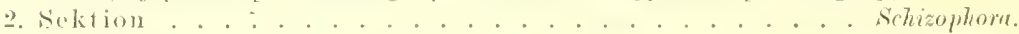

1. Tribus. . . . . . . . . . . . . . . Eumyidae. (Schizometope, Holometopa).

๖. Trilus . . . . . . . . . . . . . . . . . Pupipara. (Hippobscidar [Lanstliegen], Nycteribidue [Fledermausfliegen], Braulidae [Bientenläuse].)

1) (olme Stirnspalte, in (iegensatz zu den .,Spaltenträgern" (Schizophoren). 


\section{Dic Stechmin̈cken.}

Von allen krankheitsïbertragenden Arthropoden nehmen nach dem heutigen Stande unseres Wissens an Wirhtigkeit die Stechmiicken (Schnaken, Gelsen, englisch (inats, spaniseh Mosquitos, französisch Moustiques, italienisch Zanzale) die erste Stelle ein.

Beim Akte des Blutsangens führen die weiblichen Tiere die in ihrem Körper erzengten Keime von pathogenen Protozoen oder die Larven anderer Blut - nud Gewebssaftschmarotzer in dir Gefäbbahnen des Mensehen und der Wirbeltiere ein.

\section{Morphologie.}

Die steehmüeken gehören der moßen Insektenordnumg der Zweiflügler (1)ipteren) an. (S. Stammtafel S. 1.2.)

In der Interordnung der Orthorhaphen (Gymnochrysaliden) und zwar in der großen Abteilung der Sematecer bilden sie eine wohlumgrenzte Grupje und unterseheiden sich durch den Besitz emes den Kopf um ein mehrfaches an länge äbertreffenden steeh- und Sangrïssels, tas Torhandensein von fünf Malpighischen Gefäben und ihr nächtliches Leben von allen ïbrigen Schlankmücken.

Sie zählen zu tlen kleineren Zweiflüglern, da ihre Körpergröße zwischen 3 und $1.5 \mathrm{~mm}$ schwankt; die Mämnchen der gleichen Art sind stets kleiner und zierlicher als die Weibchen.

Ihr Leib wie der aller Insekten zerfällt in drei Hauptalsshuitte: den Kopf. die Brust (Thorax) und den Hinterleib (Abdomen); die beiden ersten Abschnite sind durch einen dünnen, wohlbeweghchen Hals verbunden, während die Brust und (ter Hinterleib direkt aneinanterstußen (s. 'Taf. II, Fig. ll und 'Taf. IV, Fig. h).

Der Körper und seine Anhänge sind in allen ihren 'Teilen mit Schuppen, Haaren und Borsten bedeckt.

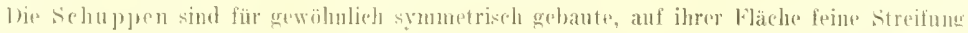

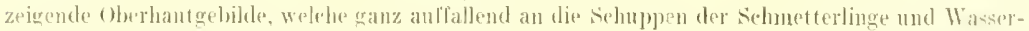

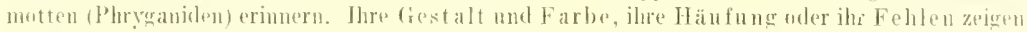

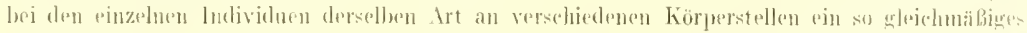

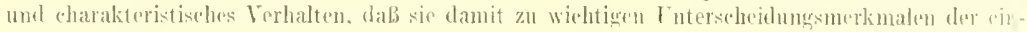
zelnen Gatlumeren und Arten werdent.

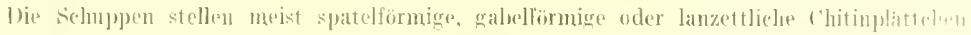

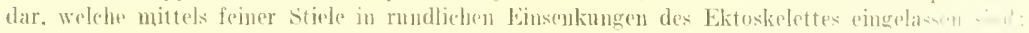

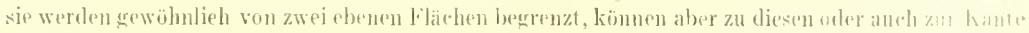
gabogens scin.

II ense. Ilandbuch der Tropenklankheiten, 2. Aufl. I. 
J) Sebuppen, Jatre. Bursten und Dorne stehen niemals senkreeht zur Körperoberfläele, melern sind in gesetzuäbiger Wrise gegen dieselbe geneigt: sie zeigen Sitrömungen, welehe didureh hervorererufen werden, dab sie simtlich so gerichtet sind, dab se der lläcke beim Ausselolïpron die möglielsst geringsten Widerstande entgegensetzen. Von dem Vorderrand des t]esuthorax. der zuerst geboren wird, sind alle selutp]en, Hare und Borsten, welehe

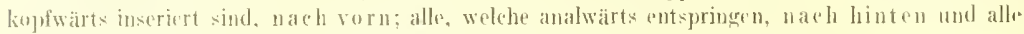
dit. Förperanhänge hedeckenden sehuppen. Haare und Dorne distal gerichtet.

Fiv. 4.

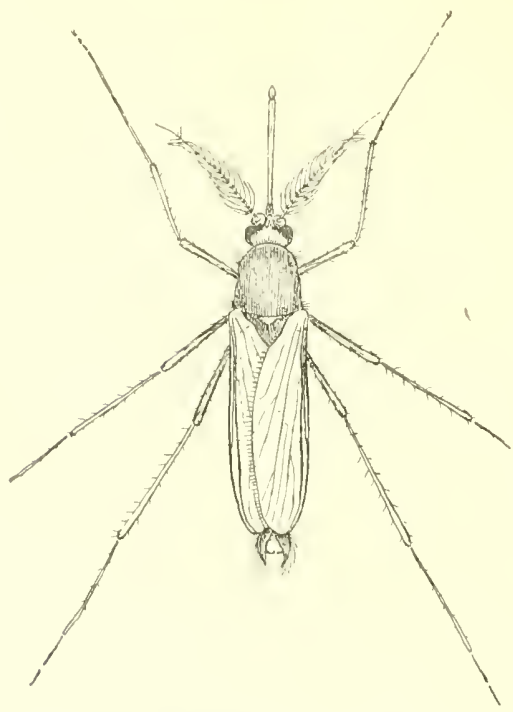

trides cinereus ô. 101. (Orig.)
Fiur. 9.3.

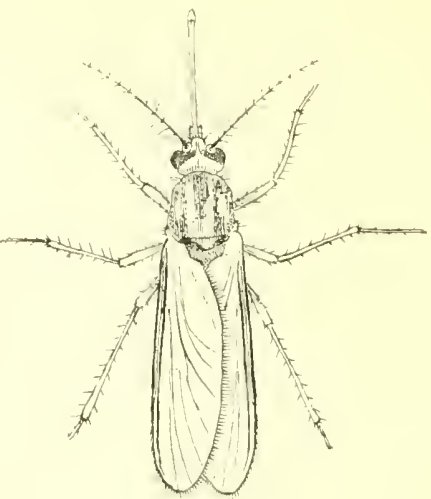

1) je Fühe sind ju beiden lïguren nieht vollständig ansgezciehnet. The Punkte anf dem Riiekenselilile deuten die l'rsprungsstellen starker Borsten (Makroehäten) an.

Der verhältnismäBig kleine liopf der Steehmïeken ist beinahe kugelig (etwas breiter als lang) und wird an den Seiten dureh grobe, halbmondfömige (nach vom ausgeschuttene) metalhisch glänzende Fazettenaugen begrenzt, die sieh ant dex Scheitelfläwhe sehr nähern und auf der Kedlfläche beinahe zusammenstolben. Sie werlen dureh radiär gestellte, augenwärts gebogene Wimpern eingefaßt

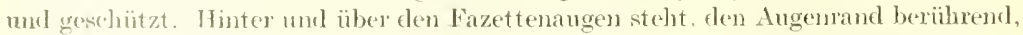
je cin vorkiummertry Ozellus, weleher ans dem Larven- mol Puppenstadium mit herïheromommen wirle.

Das Hinterhaupt ist stark entwickelt uml durch eine vertiefte Pfeilnaht, die sich bis zur Stim trstrekt, in zwei symmetrisehe Hälften geteilt.

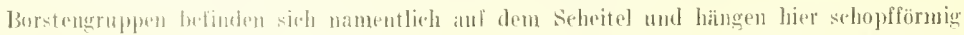

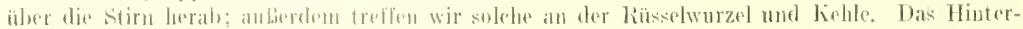

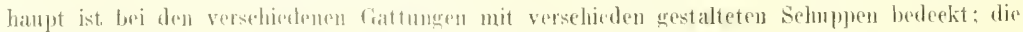

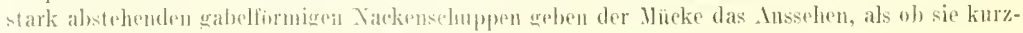

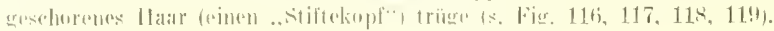




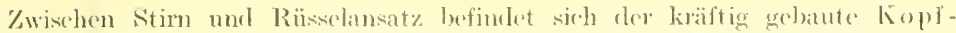
sehild (Clipeus); nasenförmigg ragt dieser Jortsatz aus der dicsichtsfliche hervor.

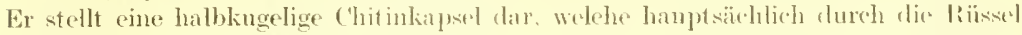

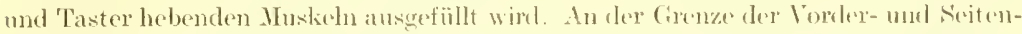

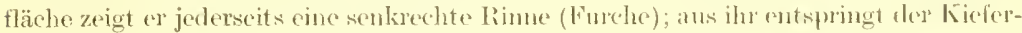
taster (s. Fig. (14).

Yon den Kopfanhängens, fünf an der Kahl, ist der cigentündiclesto der

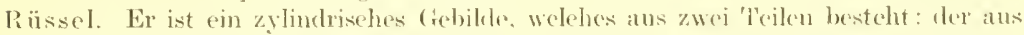
sechs Stiletten zusammengevetzten, hornigen HohInadel uml ihrer muskü̈sen Seheide.

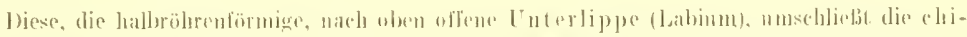

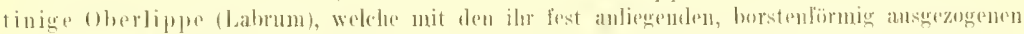

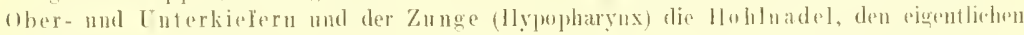

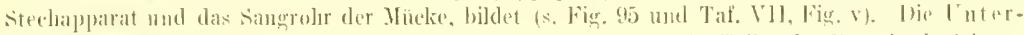

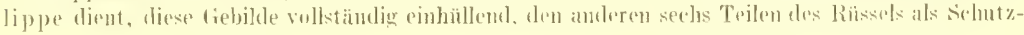

Fig. 4t.
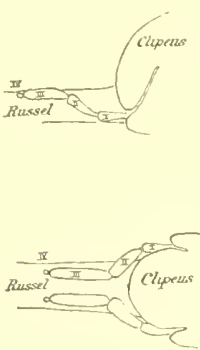

Kinfertaster von dëd. ciner. im Ruhestande, von der seite nud von oben (halbsedematisele). 100 1. (Orig.)
Fig. 95.

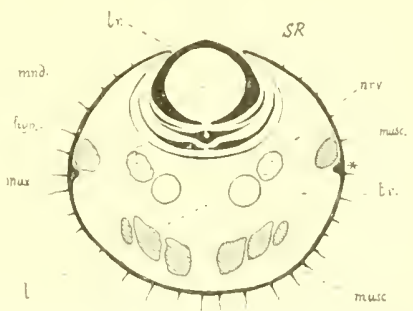

Onersehnitt durchdie Rïsselmittevon l nopheles maculipennis o. 500) 1. (orig.)

li. Labrum, med. Mandibed, hyp. Hypopharyux, mur, Yaxilli, l. Jabium, muse. Juskejn,

fi. Trachee, mo. Nerv, sRe. Saborolir, * 'litinleiste.

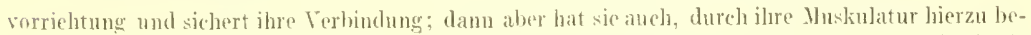
fähigt, dlie Lufgabe. den stiletten die Jïr jeden Fall zweckmäBigste Richtung zu gehen und mittels ihrer am distalen Entle aufsitzenden Taster (Labellen unl, Zängloin") dir passende stelle für den Einstiels zu bestimmen.

An den Rüssel lehnen sich jederseits dic Kiefertaster (Maxillarpalpen) an (s. Fig. 116-119): stabförmige, nervenreiehe Sinnesorgane, die cine für die cinzelnen Familien, [nterfamilien und ( 'attmingen charakteristische Größc und Bildung zeigen (vgl. Ss. 124).

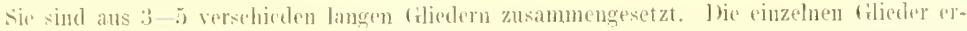

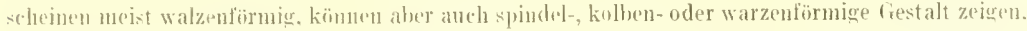

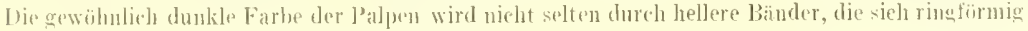

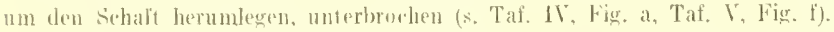

1)ie Taster sind stets mit feinstens. sedor diehtstehenden Härehen beeleckt und tragen anbur-

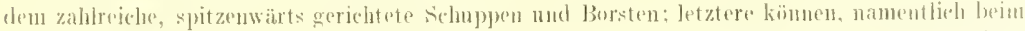

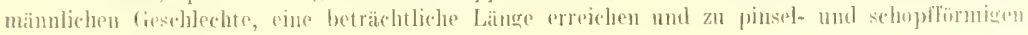
(irupyen zusammentreten (s. Tat. V, Fig. d).

In den Ausschnitten auf der Torderseite der Angen entspringt jederseits ofin Fühler (Antemne); er bietet durch seinen bei beiden Gexchlechtern versohichlenen Bau das einfachste Mittel zu deren Lnterseheilung (s. Fig. 116-11!1). 
1) wh krätige Grundgljed der Fühler, eine runde polsterTümige in der Vitte tief2urable stheibs, ist hei den männlichen Tieren beinahe doppelt so grob, als bei den weiblichen; a unschließt das innere Ohr. Die lolgenden zwölf lilieder der ôò sind meist farhlos, glasartiog durehsehrinent und von flaschenförmiger Gestalt (s. Tar. VIIt, Fig. y). An der bauehigsten Stelke jeden tiliedes entspringen yon zwei halbmontlömigen dunkeln Wükten, weleh" an der oberen und unteren Fühlertlache recht winkelig zusammentreffen, zahlreiehe lange radiär angeordnete Burstemathe. Hic konvexität der Wülste ist gegen die Wurzel des Füblers, die Borstenlaare sind spitzenwärts geriehtet und nehmen aul jeden folgenden Gliede an länge ab. Dje beiden walzenlörmigen Entglieder der mämblehen Intente sind gleiehgrob, jedes etwa fünfual so lang als die voratugehenden l'lasehenfurnigen chlieder; sie weichen im Bau vollständig von diesen ah und ähneln denen der weibliehen Intenne in auffallendster Weise (rgt. Taf. IH, Fig. x mud Taf. Vill, Fig.

lor weibliche Fühler besteht neben der Grundseheibe ats dreizehn walzenförnigen Clichern, die alle etwa gleich lang sint. Ihr Schalt ist donkler gefärbt, das proximale Ende larbhs tnd glasurtig durchseheinend; es trägt sechs lange, wirtelfömig angeordnete Borsten, der sehaft zeigt anf warzigen Erhöhungen heller gefärhte flärchen und an seinem distalen Ende kurze dunkele Borsten (s. Taf. IV, Wig. a).

Der kastenförnige Thorax stellt eine abgestutzte vierseitige Pyramide mit naeh oben geriehteter leicht gewölbter Grundfäche (Rück ('nschild) dar. Er besteht aus drei fest miteunaler verschmolzmen 'Teilen: ler Vorder-, Mittcl- und Hinterbrust. Quenähte, die bei vielen anderen Insekten die Gromzen diescr Teile bezcichnen, fehlen der Rüekenfläehe der Stechmücken vollständig. Zwischen Mittelund Hinterbrust befindet sich, dem Rïckenselild aufgelagert, das quergeriehtete Sehildchen (Seufellum). Die steil abfallente Vorderfläehe des Thorax zeigt jedraseits einen beweglichen seheiben- voler kolbenförnigen Ansatz (Patagium) (s. 'Taf. IV, Fig. (l).

1)r größte 'T'cil der' Thoraxfläche ist mit Schuppen und Haaren bedeckt nnrl trägt häufig auch in charakteristiseher Wreise angcordnete liäftige Borsten (Makrochät(1) (s, Fig. !13).

Die IItelbrust ist der gröbte und bestentwickelte Abschnitt des 'Thorax; von ihr entspringen und zwar an der Grenze des Rückensehildes und der SeitenJächen (Plenren) die llïgel. Nie sind verhältnismäBig sehmal, lang und vieladerig. Dic Flïgrelhaut ist äuberst dium und glasartig durchscheinend; ihro beiden Fläche'n, dic dorsale sowohl als die ventrale, sind mit zahleichen, regelmäbig gestelltw, feincn spitzenwärts gerichtetcn Järehen bewachsen; meistens farblos, kann sie an den Stellen, welche Anhänfung dunkler sehuppen zeigen, ebenfalls dumbel grö̈l)t sein (s. 'Jal. V'II, Fig. g). Die liandadel und die Längsadern sind stets mit Selnupen besetzt.

J) Fe Figgel liegen in Ruhestrllung wagereent den Hinterleibe auf; sie überraxen las Leibesende bei den weibliehen Tieren, bei den ơ ò lassen sie meist den letztcll Abrtominalring frei (s. Fig. 92 1. 9.3).

Jas creäder des stechmïckenflïgels hesteht (s. Figr. 89) aus einer un die ganze leripherie herumbafenden Randader, in welche wio in einen Rahmen die flügrhant cingespannt jst, und

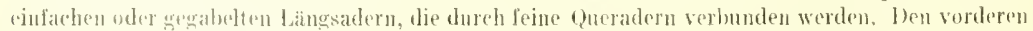
(änberen) Tril der liandater (his zur liugelspitze) bezeichet man gewöhulieh als Vorderrand-

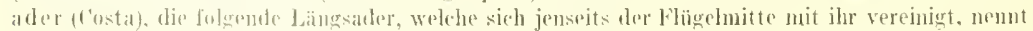
man lliffsader (Toma anxiliaris). Hann fulot die einfache erste Längsader (1). Die zweite.

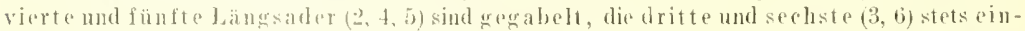

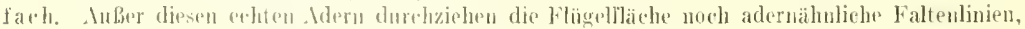

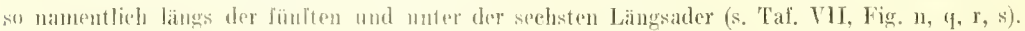

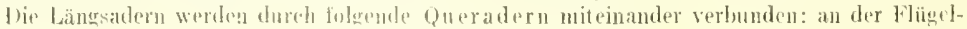
batsis durch die Wurzelyuerader (Wi); die fotgenden fünf Queradern will ieh der Einfachlieit 


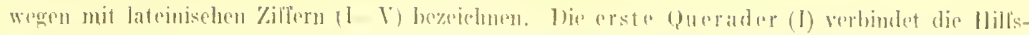
ader mit der ersten laingsader, dic zweite (11) die erste und zweito Längsader, die dritte (III)

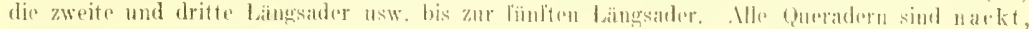

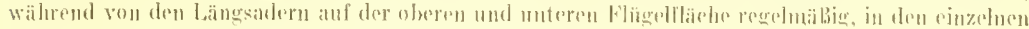

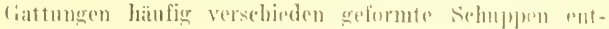
springen. Ebense ist die Randader in ihrem ganzen lere-

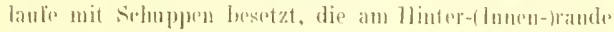

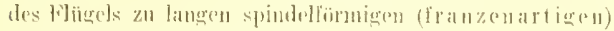
lichildell werden.

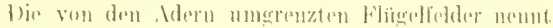

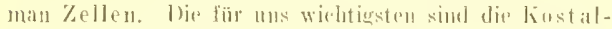

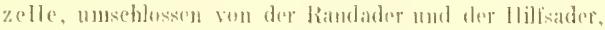
tund die drei trabel\%ollen, die wir vou der zwriten längsaler beginnemd als erste, zweite mul dritte bezеicluen.

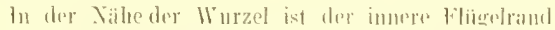

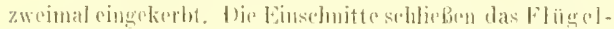
läppelen (Alula) ein, wäluend das pruximak zwischen Jesothorax and dem moximalen Ë̈nchute lingende

Fïg. !li.

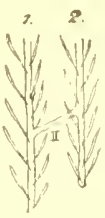

Inopheles

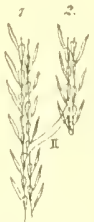

dieles

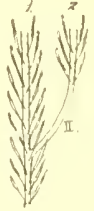

linlex.

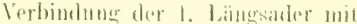

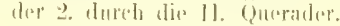
(1)riginal.) laijp)

An Stelle des zweiten Flügelparess (der Hinterflügel) besitzen allo lliptern (in Paar Sehwingköblehen (Halteren), trommelschlïgelförmige Gehihle, wetehe wegen ihres Nervenreichtums als Simesorgane (Gleiehgewichtworgame) angesprochem werden (s. 'Taf. V, Fig. i; 'Taf. VI. Fig. m).

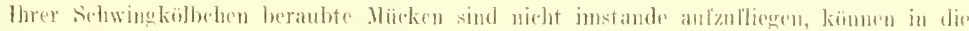

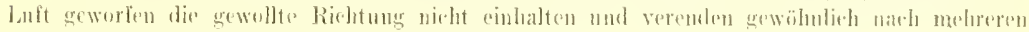
Stunden.

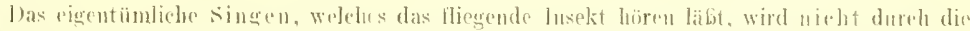

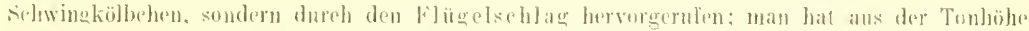

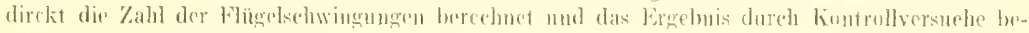
stäjucu können ( MAREY).

Son der sternalen Fuäche der drei Brustringe entspringt je cin Beinpaar.

Die einzelnen Paare nehmen rom ersten zum letzten an länge zu (namentlich ist dies bei den Anophelinten der Fall). Die Beine der Stechmïcken haben mindestens die Körperlänge der Trägerin und kömnen die doppelte Trößc erreichen; sin sind fadenförnig dïnn und leieht vam Körper zu lösem. In ihrer ganzen Ausdelmung sind sie von Schuppen bederkt und tragen anBerlem Borsten und Dorne.

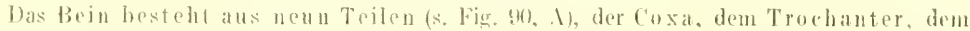
lemur, der Tibia und den fünf Tarsaleliedern, deren proximales — das langste frlied des

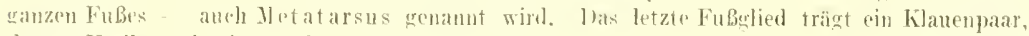
dessen Kral]en mit eincm uder midreren plantarwirts gekrümmten Zälnen besetzt sein kiunnen (s. Fig. (10, BKl.).

Der Ilinterleib der Stechmiicken ist beim of dorsoventralwärts abgeplattert, lein spindelförmig und besteht aus acht Segmenten, die sich bein s vom Thorax bis zum Leibesende stetig verjüngen, beim aber im 3. (4.) Ringe ihren größten Lmfang erreichen (s. Taf. I. Fig. h und Fig. 134). Die äuberen Genitalien sind verhältnismäljig gxoß, namentlich bei den männlichen 'Tieren.

Jeder Hinterleibsring besteht aus einer dorsalen und ventralen chitimplatte, dem The it

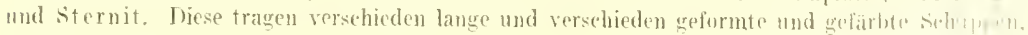

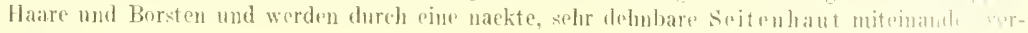
lnumden. 
Wie iuberen lisschlechtsteile der ff werden gebildet ans einem Paare von fienitalw-tern (fonapmplysen), welehe zusammenwirkend bei der Eiablage von hoher Bedeutung sind und deshalh oripositor genamnt werden. Die analogen Tejle der $\hat{j} j$ tragen sehr versehieden

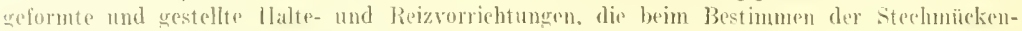
arten gute diagnostische Mubaltspunkte abgeben (s. Fig. 9.99).

\section{Inalomie nud Pliysiologie.}

Die Bewegungen des Rumpfes und seiner Anhänge werden durch quergestreifte Juskeln remitelt. Diese entspingen rom Chitinpanzer (Ektoskelett) oder seinen inneren Fortsätzen (Plnagmen, Apodemen und Apophysen), die in ihrer Gesantheit als Endoskelett bezeielmet werden. Die Eingeweide besitzen erine der 'Tunica propria aufliegende Längs- und Ringfasermuskelsehieht.

Die mäehtigsten Muskehnassen treffen wir in der Brast, namentlich in ihrm mitteren Segmente an. Sie versorgen in der Hauplsarhe die Flüget und im sternalen Nosehnitte anch die Beine (s. Tal. VIII, Fig. $\%$ ).

Das Yervensistem ist wehl entwickelt. Die zentralen Teile (Gehirn und Ganglienkette) bestehen aus dem ()ber- mo Unterschlundganglion, welehe durch eine Doppelbrücke (dic hehlundkommissur) verbumlen werden, und ter Tianchganglienkette, deren 'Thorakalknoten (drei an der Zahl) mitemander verschmolzen sind, während der' abdominate 'Teil aus sechs durch einfache Stränge miteinander verlundene Ganglien besteht.

Motorische und sensible Nerven begeben sieh in ganz ähnlicher Weise wie bei den höheren 'Fieren zur Muskulatur und den Simnesorganen.

Den Nahrungsedhlateh und scine Anhänge imnerviert der Sympathikus.

Die Itmumsorgane der Stechmücke werden ron einem in seinen Endteilen äuferst fein rerzwigten Tracheensystem gelbildet, das alle Organe und Geweloc des Köplers mit Lebensluft zu rersurgen bestimmt ist.

Alit dem bultuese stehen dip. Itemrohre dureh stigmen in Verhindung: versehliefbaren

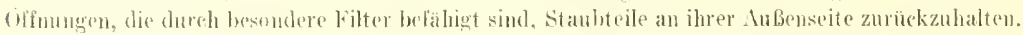

Acht stignenpare liegen bilateralsymmetriseh angeodnet an jeder lörperseite. Uals crste und zugleich gribto stigmenpar helindet sich am vorderen Rande des Hesothorax zwischen

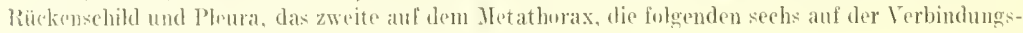
laut des zweiten his sibbentan. Mbdominalsegmentes.

Die Innenwand der Tracheen wirl durch eme zarte (hitinspirale gestïtat. Sie sind deshall, als leingeringelte, luithaltige, arterienartig serzweigte Röhren bis zu ihren teminaten Austäufern muter dam Mikroskent leicht zu arkennem.

J)ir mähtigsten Tracheenstämme hefinden sich in der Brust. Sie Thorakalstigmen

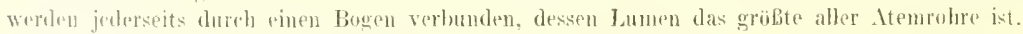

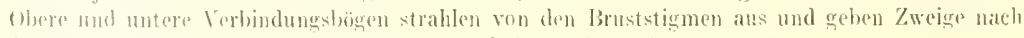
den creanem der Brust, nath dem Koplir und den Beinen ab.

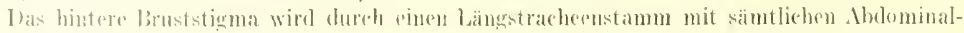

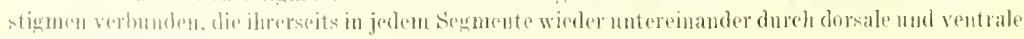
Bögen kimmunizimeren.

Dax Ciefilisystem der Stechmïeken ist wie das aller lusckten nur recht unrollkommen intwiclielt. Es bestcht aus dem großen Rückengefäbe. gewöhnlieh Herz genannt, und seiner Fortsetzung, der sog. Aorta; sie spaltet sich in der Brust in vier Stämme. Lon diesen zicht dirs mittlere Patr von je einem groban Tracheenstamm begleitet dureh den Hals und exdet in noch nieht genau bekannter Weisc in sler Koptlaipscl. während dis ä uberen arteriellen stämme sich nach den Brustseiten beageden. 


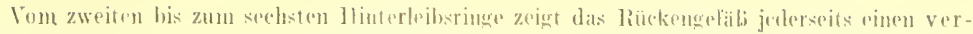

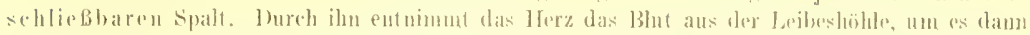

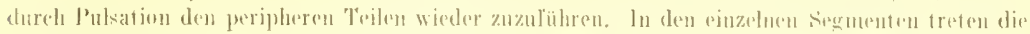

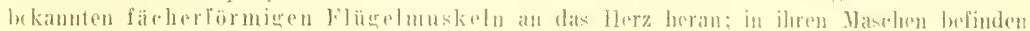
sietr die riesigen Perikardialzallen.

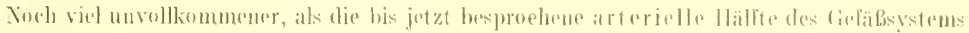

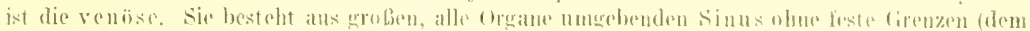
l. ak $1130 \mathrm{~m})$.

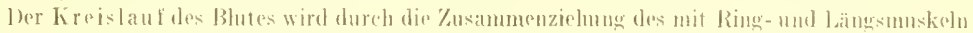

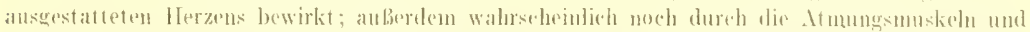

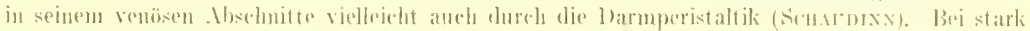

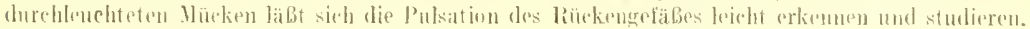
Noclu geeigneter aber sind die Larven tiir derartige Lutersuchongen.

Der Ermährmngsupparal der Stechmëeke ist dex für uns wiehtigste Organkomplex. da hanptsächlich in ihm und seinen Anhängen die Ent wicklung, Vermehrung und Wanderung der pathogenen Parasiten erfolgt.

Fiv. 47.

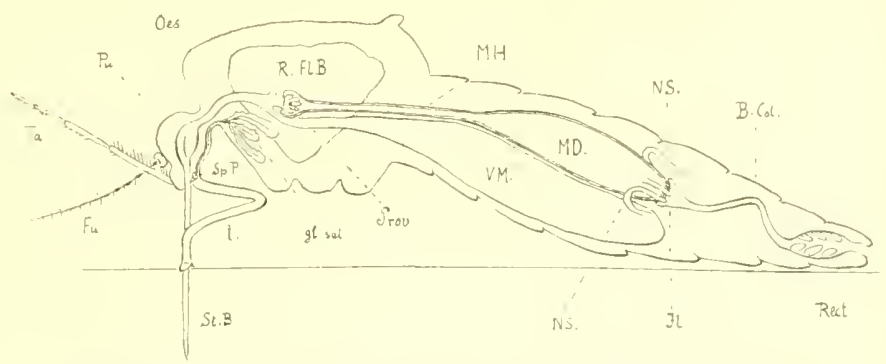

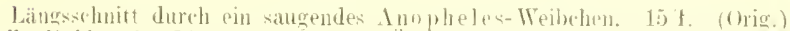

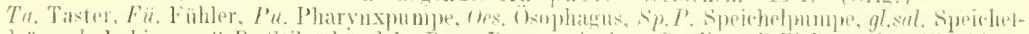

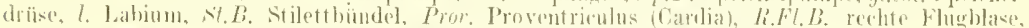

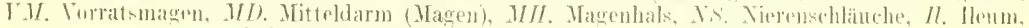
b.Col. Basilische sichlinge des kolon, Rert. Rinktum.

Er zerfälit in drei Haupteile, den Vorder-, Mittel- und Endelarm (․ Fig. 17 ).

Der Vorderarm (Stomadaeum) wird chreh tlen Stechrïssel, die Iundhöhle" (Pharynx) und den Ösophagus gebildet. Iter flaschenförnige IIt teldarm (Mesenteron) beginnt mit einem Kopfabselnitte (Proventriculus): ihm folgt ein climner longenförmiger Halsteil, an welchen sich dann ein erweiterter Abschnitt ansehlielbt. den man gewöhnlich als Magen bezeiehnet. Der Hinterdarm (Proctoraeum). anfänglich trichterfömig (Heum), verengt sich in dem dorwalwärts gebogenen Kolon betrïchtlich, un dann mit rinem ampnllenförmigen Roktum zu encligen.

Von den Darmanhängen münden die beirlen spe-icheldrüsen, die beiden Flugblasen und ter seg. ...haugmagen" (Vorratsmagen wollen wir ihn in folgenden nenuen) in tlen Vordertarm, während die fünf Nierensehläuche (Itaprighischen (refäbc) ithe Exkrete in den Pylorustriehter des Enddarmes entlexpent.

Dats saugrohr des Riissels wirl aussehließlich von der rohrenfömig zul-

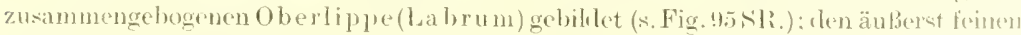

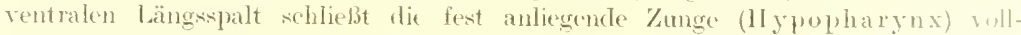
lommen. Tieses schilfblattförmige Gebilde birgt in seinem Inneren ebenfalls anten feinen nach oben offenen Längskanal, welcher das Ende des gemeinsinun . Ius- 
Jïlmmgsganges der Speieheldrïsen darstellt und an der Spitze des Hypopharynx ausmündet (dureh diesen Bau erhält die ,Zunge" die größte Ihnliehkeit mit dem (Giftzahne der Sehlangen). Auf die ventrolaterale Fläehe des Sangrohres legen sich jederseits der Ober- (Mandibel) und Unterkiefer (Maxille).

An der Basis des Hypopharynx befindet sieh in der Rïsselwurzel geborgen dic Speichelpumpe. (s. Fig. 97 Sp.P.), ein starwandiges, kegelförmiges Chitingefäß, welehes proximalwäts von einer clastisehen muskelbewegten Jembran abgesehlossen wird. Dureh sie triti der gemeinsame speiehelgang in den triehterfömigen IIohlram der speichelpmine ein.

Die Speicheldrüsen (s. 'Taf. VIII, Fig. c), relatir große dreilappige Gebilde, liegen den Pleuren des Pro- und Mesothorax an (s. Fig. 97 gi.sal.). Um einen zentralen Gang gruppiert sieh ein einsehichtiges Lager großersaftreicher pyramidenförmiger Zellen. Der mittlert, in seinem Bau von dem oberen und mnteren abweichende Drüsenlappen ist dicker und kürzer. Jeder Lapjen kam sekmeläre Läjpehen tragen; auch werden in seltenen Fällen akzessorisehe Lappen beobachtet.

Am distalen Ende der Drüse vereinigen sich die Ausführungsgänge der rinzelnen Lappen, treten dureh den Hals in die Kopflsapsel ein und rerseimmelzen unter dem proximalen Ende des Pharynx zum gemeinsamen speiehelgang, der dam wie oben besehrieben in die Speichelpmmpe mündet.

Das Saugrohr erweitert sieh nach seinem Eintritt in die Kopfkapsel beträehtlich und bildet (s. Taf. VII. Fig. x) so die Mundhöhle. Naeh ihrem Durehtritt dureh den nervösen Sehlundring abermals weiter geworden, stellt sie die Pharynxpumpe dar.

Es besteht die I'haryxpmmpe aus drei spindelfömigen ('hitinplatten, die an den verdünnten Längsränchern nach innen ungebördełt unt dureh elastische Membranen miteinander verbunden

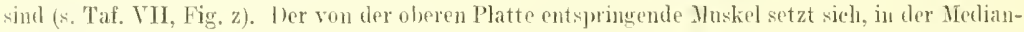

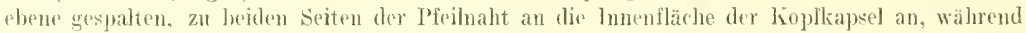
clie bejden ventrolateralen Platten durch einbänchige, nach den seitenteilen der kopflkajsel hinziehende Huskehn bewegt werden. Líraftig entwickelto Ringmuskehn vermögen das Pumporgan am vorderen und hinteren Ende gegen den Vordermund und den Osoblhagus abzusehleben; sie treten, wit wir später bei Bespreehung des Sangaktes sehen werden, alternierend in Wirksamkeit.

Als enges Rohr geht der Ösophagus durch den Hals der Mïcke, unr sich in ller Brust beträehtlieh zu erweitern. Bevor er sieh in den Magenkopf einstiilpt, gibt er chei große Direstikel ab, den in der ventralen Hälfte der lbrust und des Banches (s. Fig. $97 \mathrm{Vm}$., R.F.B.) gelegenen Torratsmagen und die beiden dorsolateralwärts ziehenden Flugblasen, die sieh zwischen der sternodorsalen Muskelgruppe und den l'lemren bejderseits im Thorax ausdehnen und dureh ein muskulöses Ringventil gegen (len Ösophagus abgeschlossen werden können. ${ }^{1}$ )

Sic sind stets lufthaltig, wälnend der für gewöhnlich ebenfalls lufthaltige Vorratsmagen naeh den Mahlzeiten mit Nektar, Fruehtsäften oder Blut gefüllt ist, welche hiri stunden- ja - bei niederer 'T'emperatur - sogar tagelang zurüeligehalten werden kömmen.

Geznekerte wässrige Lackmulöung wirk ron den Mïeken gern genommen. Solange sie im Vorratsmagen verweilt, behalt sie ilure selüne blane Farbe. In den Nitteldarm ibergeführt, röted sie sicl] solort und bleibt anc.l im Enclelarm rot. Erst wemn die blane Farbe der roten vollstianelig gewiehen, hat ker Yorratsmagen die letzten Feste der Zuckerlösung an den Mitteldarm

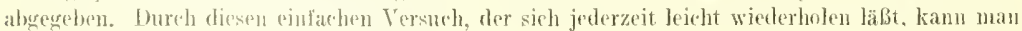

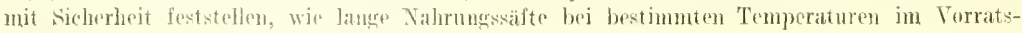
magen verweiles.

1) Ilomologe Bilehueren sind die Sehwimmblaven der Fische, welehe bei den Physostomen moch dureh einen Lubagag mit dem l) armrohre in Verbindung stehen. 
Sind die nährenden Flüssigkeiten von tem mit Lü̈ngs- nnd Ringmuskeln (s. 'Taf. IV Fig. t, n) versehenen und auBerdem dureh die Bauchunesse? unterstiitzten Vorratsmagen nach nom nach an den Ilitteliarm abgegeben worten, so fritt an ihre Stelle wienlerum laft.

Die buft wird zum 'leile verschluekt, wie man bei sehliipfonden') Mäcken aus ter zunchmenden Schwellung des Ablomens mul den liewegumen der l'harynxpumpe durch den noch unpigmentierten ('lipens sehr schön bubachten kann. Sie wird aber später, mol zwar als Kohlensïnre, a uch an ort und sitelle duch einen pflanzliehen Kommensalen, einen Hefepilz (Laveran, Acmandxi), untre gleichzeitiger Erzengung eines Enzyms gebildet, in welehem sonumxx den giftigen, quaddelbildenden Stoff erkamat hat, den die Mürde beim Sterhen in die Munde einflicßen läBt.

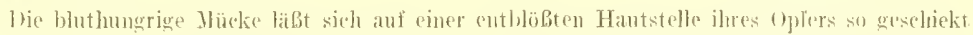

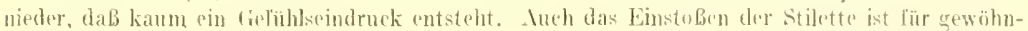
lich nicht schmerzhaft; der schlalende merkt erst am folgenden Horgen durch die jurkinden Qnaddeln, weleh nnangenehme Gäste ihn in der Nacht aufgesucht haben. Häulig sogar (namentlich nach Amphelesstichenf wird Quaddelbikhng überhaupt nieht heobachtet.

Leise tastet nun die Mäicke mit den Labellen des abwärts gekrümmten Riissels die Haut ab und setzt diese und das zwischen ihmen liegende. .Zü̈nglein" dam fest anf die tauglich befundene Stelle.

Jetzt hebt das Tier die 'Taster und fïhrt mit ihnen zitternde liswegungen ans. Die Anopheliclen gehen hierin so weit, daßsie die Palpen mindestens rechtwinkelig gegen the Rüsselichse stellen (s. Fig. 97 Ta).

Nun tritt zunächst die Oberlippe zwischen ten Labellen hervor und drückt sich in die Haut ein, sehnell folgt der Hypopharynx und das Mandibel-mul Maxillenpaar, welehes dureh sägende Bewegungen die ITunde crweitert und dureh Verankerung ein Zurïckweichen des Stilettbündels verhindert.

Jan ist zunatehst gencigt, anzunehmen, dab das Eindringen der Hohluadel dureh Hineinstoben bewirkt werde. Das ist jodenlabls nieht die Hauptsalche. Her Voreang erfolgt vielmehr in der Weise, dab Mandibel und Taxille der einen seite haltmaehen und sich verankern. wiblend

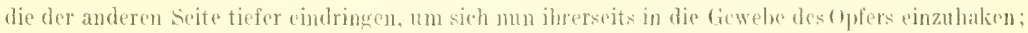
jetzt dringen die freigcwordenum Stilette der ersten site wieder vor usw. Das alternierende dui-

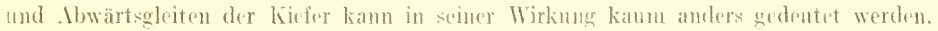

Versueh. Ein Anopheles-f hatte beim Ausschlijplen das vortere Beingaar und das linke Bein des mittleren Paares verluren, sie waren in der Puppenhülle zuriukgeblieben. Xach zwei Tagen wurde das ganz unbehilfliche Tier anf den Handriicken gesetzt. OHne in der Lage zu sein, mittels der Beine seinen Körper eregon die Hant zu ziehen und so den Rüssel einzustoben. gelang

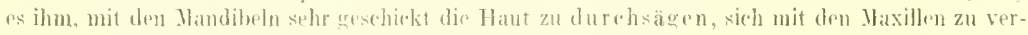

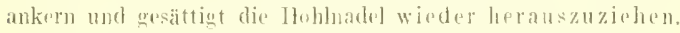

Dic seheide dess Stilettbündels (die L'nterlippe) folgt diesem nicht, sonden entfernt sich bogenförmig (s. Fig. 97 1.) von der ans ihrem dorsalen Spalte heraustretenren Hohtnadel. Beim Weitervorwärtsdringen der Stilette knickt dies Lnterlippe schlieBlich spitzwinkelig ein. $\left.{ }^{2}\right)$

Wenn die Hohlnatel genügend tief eingelrungen ist, preßt die Mïeke zmnächst den Tnhalt der sipeichelpumpe und les Vorratsmagens in die Wunde ihres

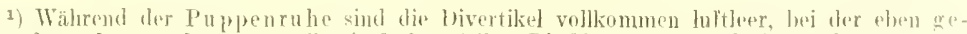

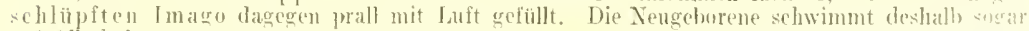
aul thohol.

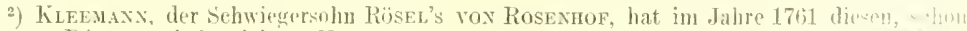

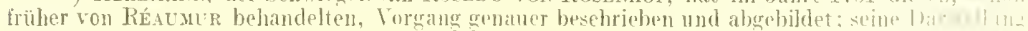
ist bis heute nech nicht übertroffen worden. (Beitr. z. Tatur-oder Insekt.-freseh. B3,. 1, 1:at 15. 
4)fors, um durch Reizung der Gewebe ein lebhafteres Zuströmen des Blutes zu bewirken und seme Gerimnung zu verhindern.

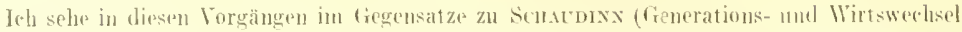
bei Tryposoma und spirowäte, S. Hls) nicht eine Rellexbewegung, sonderu einen Willensakt. bureh Kontrilktion der Bauchmuskulatur ist die Mliteke jederze it imstande, den lubalt tes Vorrats-

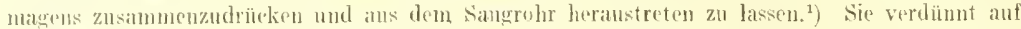
dine Weise, wie ielı häufig beobachtet habe, z. B. ein Tröpleden Nektar wder löst nach Irt der stubenfliegens ein Zuckerkrimehen auf, um das fhïsigg gewordene dann einzuseblürfen.

Nun beginnt das Tier zu saugen; es erweitert dureh die auf Seite 10.4 beschriebenen Hukeln die chitinige Sang- mul Druekpumpe in der Koptkapsel (vgl, auch Taf. VII, Fig.z) und läBt sie später in ihre Ruhelage zur üekfedern. Dureh diexes Vorgehen wird bei alternierendem zweckmäbigem Verschlusse der Ringrentile das Blut ans der Haut angesaugt und in den Ösophagus und Torratsmagen weiter beförlert. Hier wird es flüssig zuriekgehalten und erst bei fortschreitender Verdaunng naeh mol naeh in ten llitteldarm hineingeprebt.

Es kummt ni.ht selten vor, daß auch bei vollkommen gelïlltem Vorratsmagen das Hungergefiihl der gierigen liäcke noch fortbusteht; es fliebt der Vorratsmageu meter diesen Lmständen gewissermaßen über nud erwießt seinen Inhalt in den llitteldarm. Die prall gespannten Banckdeekn aber erlaulsen hier eise gröbere Ansammlung von Fläsigkeit nicht mehr und so sieht man lanm, wilbrent die Dlinke noch einge Zeit weitersangt, das vollkommen unverdaute Blut aus dem After wieder heranstreten.

Dab das Bht im Vorratsmagen nicht koaguliert. beweist lolgenter Versurh. Die oben

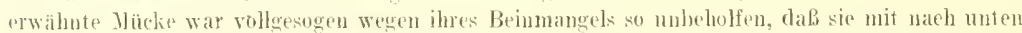

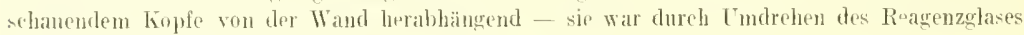
itl diese nngewiohnliche Lage gebracht worten - gar keinen Versuch machte, the typisehe sitzstellung (s. Fig. 114 11. 115) wieder einzunchmen.

l) durchscheinende Serumkuppe, wetche man bald nath der Blutmahtzeit an vorderen Pule des Vorratsmagens zu selen gewohnt ist, erschien nuter diesen Verbältuissen am hinteren Pole. Tach drei stunden wurde das Rádzenzglas nit der Mücke in die ursprïngliehe Lage zurückgebracht und kurze Zeit darauf hatten sich die Blutseloeben in der Flüssigkejt analwärts herabgresenkt, während die sernmkupje sich jetrt an der gewöhuliehen stelle heland.

Während das Epithel des Vorderdarms und Enddarms plattenförmig oder höchstens knbiseh und mit einer (hitinsehicht bedeckt ist, trägt das hohe

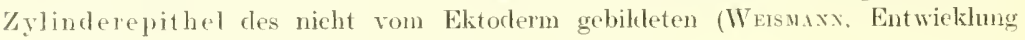
der Dipteren) Mlitteddarmes eine Stäbehensehicht.

In den Kopfteil des Iitteldarnes ist der Endteil des Ösophagus eingestiilpt und stellt hier eine vielfach gefaltete und eingebuchtete Rosette dar. welche durch die gedoppelte (Osophaguswand gebilktet wird (s. Taf. VII, Fig. w). Das Organ rrimert an gewisse Formen ron heerosen (Aktinien). An seiner Wurzed umgreift rin kräftiger Ringmuskel die Basis cles Gebildes und vollendet so den AbsehlnB des Mitteldarmes gegen den Vorderdarm. $\left.{ }^{2}\right)$

Der num folgende zylindrisehe Ilagonhals zoigt die gleiche Struktur wie der Enflabchnit de's Nittelilarms, der sogenannte Magen, und geht ohne siehtbare Grenze in diusen übrr?. Beide bestehen aus einer bintegewebigen Wandschicht, in wolehe längs- uncl quelverlaufenrte Muskelfasern ringebettet sind.

ber Abschlubars Mitteldarmes gegen den Enddarm gleicht der Ösophagne-

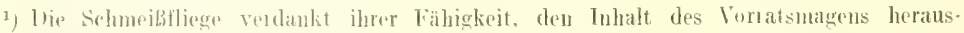
\%upressen, den beinament romitorion!

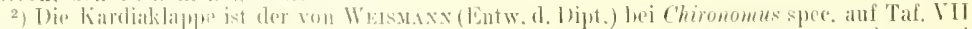

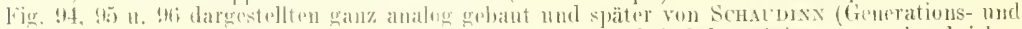

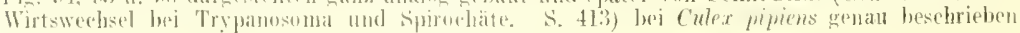
und abgethildet wordent 
klappe; aneh hier ist der vordere in den hinteren . Mbsehnitt invaginiert und das so gebiddete Ventil in seiner Wirknng dureh einen Ringmuskel unterstityt (s. Thal. Vill, Fig. - ).

Der proximale Teildes Enddarmes (I leum) ${ }^{\mathrm{I}}$ ) ist weit und von frichtertömiger Gestalt (s. Fig. 9s.Jl). In seine Mand sind zahlrejehe, regelmäbigr gestellte ('hit innadeln eingelagert, deren spitze ans der Epithetsehicht hervormegen und magenwärts geriehtet sind. (Aleich an seinem Beginne münden die fünl Nierenschläuche in den Enddarmtriahterein. Ohne dentliehe Grenze geht das Ilonm in den längsten und diunsten 'Teil des Euflames, das kolon, iber, wehehes als Basilisehe fehlinge dorsalwärts aufsteigt, $n$ m dam solort wieder herabznlanlen mol in das blasig er'weiterte, diekwandige Rektum rinzmmünden. Der inneren Rekialwand sitzen

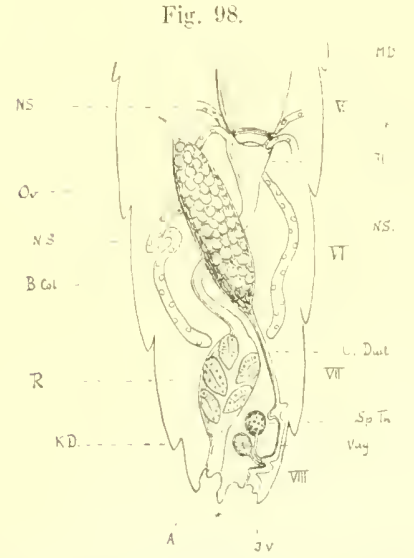

Leibesonde eines junglräulichen Inopholes. 50 1 . (i)rie.)

I. VI. VII. VIII. 5.- \&. Banehring. UI). Magen, Kl. Prlorns, Il. Ilenm, Jit. Nicren-

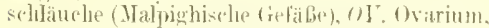

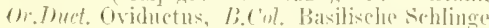
des Kulon. Re. Rektum mit den Roktaldrüson, Sp.Th. Spermatheke, $k l l$. Kitturüse, Tig.

Vagina, 1. Ifter, I.1. Intruïtus vaginat. liig. 99.

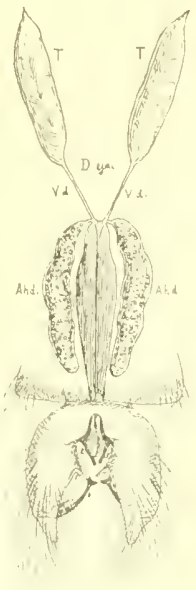

Intere und äubero dieschlechatsteile einer männlichers f'ulizide (adedes). \$0 1. (0rig.)

T. Hoden, l.d. Tas delerens, Hejer. Inetus ejaeulatorius und I'suis. the. Anhangdrüse.

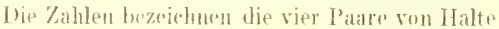
und Reizworrichtungen und geten zueleich die Latge dersellyen zucillated an. J)as erste Paar ist das unterste.

eigentümliehe zapfenfömige, analwïnts gerielıtete Gebilde anf, he sog. Rektaldrüsen (s. Fig. 97, 9 s), deren die männlichen Tiere vier, die wejblichen seehs besitzen. Wieder enge geworden und von cinem krätigen sphinkter umgeben, zieht der Mastdarm zum Ende des aehten Segmentes hin, mu hier naeh auBen zu münden.

liesthlechtsteili. Der Scheideneingang wird ron dem darüberliegenden After dureh eine querstehente häntige klappe (s. Fig. 9s*) getrennt. D) ie lagina rerlänft dem Rektum parallek und liegt dem Sternum des achten Segnentes ummittrhal

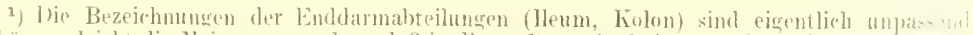

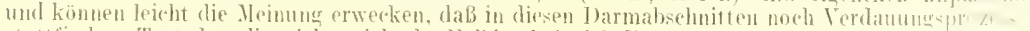

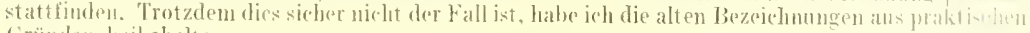
ciründen bribehalten. 
wut (s. Fig. !s). An der Grenze der beiden Endsegmente des Abdomens steigt sie m rechtwinkeliger Knickung dorsalwärts, um bald in den sehr muskulösen OriInetus communis (Uterus) ïbrrugehen. Von diesem ziehen in der ganzen Länge

firis. 100 .
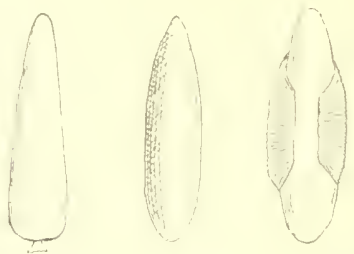

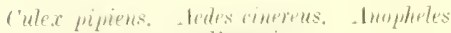
marulimentis.

In stumpten kiude des Culex-Eirs ist der schwimmbeher, welchen das ahgrhobene Exuchorion um den Mlikroperlendul bildet, angrdentet. Das Anopheles-ti zeigt die bekame Iushauchume de' Exochorions an beiden sinitrm. to 1 . (urig.)

Fig. 101. ${ }^{90}{ }_{11}$. (l.
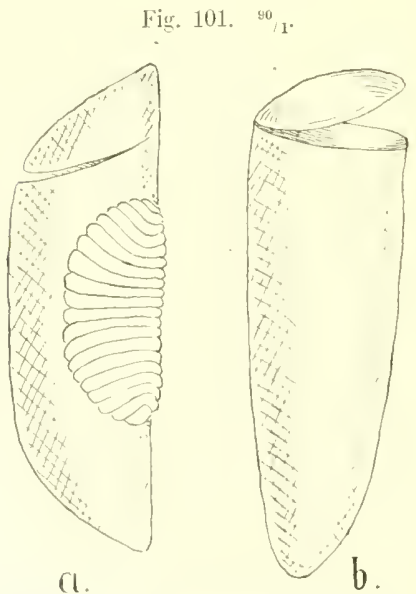

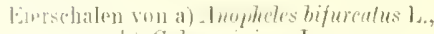
b) Culer pipiens L. (Griginal. ('amera luejula.) des siebenten Segmentes jederseits die Eileiter nach oben und auben zu ten spintlelförmigen Grarien, die bei jungfräulieheı Steehmücken nur wenig länger als die Eileiter sind und in einen spitzen Zipfel auslaufend iber der MitteldarmEnddarmgrenze endigen. Sie fassen den Nahrungskanal zwisehen sich nnd liegen mit ilnen proximalen Enden beträchtlich äber ihm. So kommt es. dals bei hoehwhwangeren Steehmïcken die fast das ganze Abromen fïllenden Eierstöeke den Darm unl seine Anhänge stark nach abwärts und vorwärts drängen.

Nahe dem Scheidenausgange münden die in letzten Segment liegenden Spermathoken und Kittarüsen (rgl. Fig. 9s, s. 707 ) in die lagina.
Figr. 102. 80 .

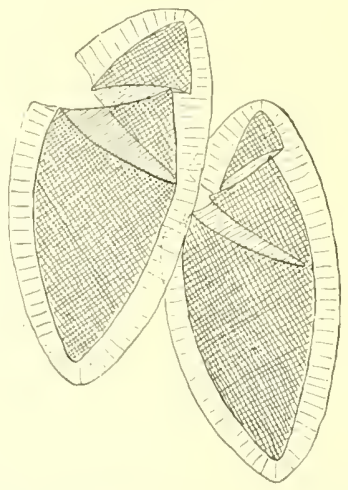

Cyrlophorks nigripes s'TAEtiER. Eicrschalen voul dor schliupfenden Larve durch einen sipuralrib verlassin.

(criciual, Camera lucida.)

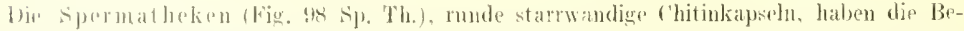
timmung, die Spermatozen wälrend des kuitus anfunetanen und sulange zurüekzuhatten, bis

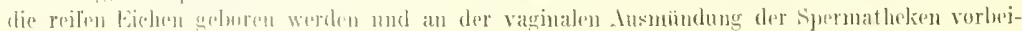

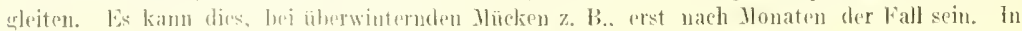

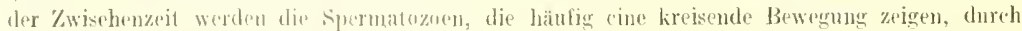

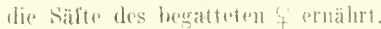

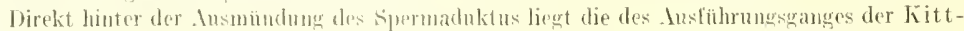

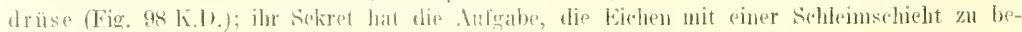




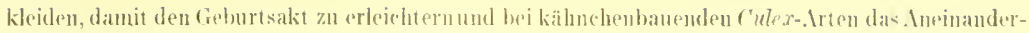
kitten der einzehnen Eichon zu lewirken.

Die inneren fieschledhtsteile der männliehen 'Tiere bestehen ans zwei spindelförmigen, den jungfräuliehen () varien an (tröße etwa glejehkommenden und analog gelagerten Hoden (s. Fig. (09). Die Vasa defarentia vereinigen sich erst im Penis zu einem gemeinsamen (ange, nachem sie kurz vorher dir dusführungsgänge rler beiden Anlangsclrïsen aufgenommen haben.

Alle Organe und Systeme des Körpers werden, soweit sie nicht direkt an den Ekto- oder Endoskelett befestigt sind, dureh ein woitmasehiges Bindegewerbe, don sog. Fettkörpex (s. 'Taf. VIll, Fig. \& B.G.), gestützt und zusammengehalten.

Die Eier (s. Fig. $100-102$ ) der steehmüeken werden anf stehende orler ganz träge fließende Gewässer abgesetzt. Ohne an einem schwimmenden Gegenstande, einem herausragenden Stengel nsw. oder dem Uferrande einen Stützjunkt zu suchen, sitzt die Müeke frei auf der Oberfläehe des Wassers. um clort ihre Eier zu legen.

Sincl solehe Wasserkörper, wie es z. B. bei 'Tümpdn im Sommer häufig vorkommt, ausgetrocknet, so legen die Waddstechnieken ihre Eier auch anf die stets noeh etwas feuchten. vertorften Blätter der 'Tümpelböden ab.

Die im [hrehsehnitte $0,6-0,8 \mathrm{~mm}$ langen und $0,15 \mathrm{~mm}$ an diekster sielle breiten Eier sind

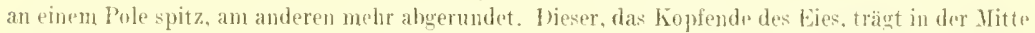

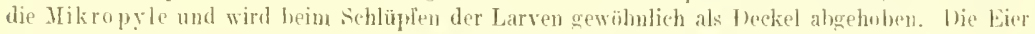

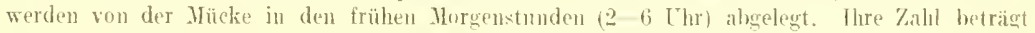
nach den versehiedenen liatungen und Arten etwa 75 bis 350 stück.

Hie meisten Gattungen legen ilare Eier einzeln und unverbunden anf die Wasserflache. wo sie entweder, durch besondere hydrostatisehe Vurriehtungen befahlieg (Anophelident), umhersehwimmen und schlichlich an irgendeinem festen ferenstande Halt gerinnen, oder (dip Eier der meisten Kuliziden) untersinken und im Sehlamme überwintern. Tur wenige Arten der

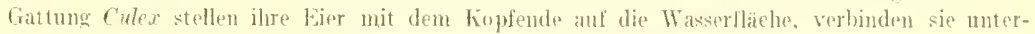
einander mit ciner Kittubstanz und bauen so schwimmende Eierkähnchen.

Die Eier gehen in der für ihre Entwieklung günstigen Jahreszeit je naeh cler Temperatur am 2. bis 5. 'Tage aus.

Larven. Da die Verwandlung der Steehnücken eine vollkommene ist, fehlt ihren fuBlosen Larven jegliche spur rom Flïgelansätzen.

Ihr Körper zerfällt wie der der Hücken in trei seharf gesonklerte Abselmitte, den dentlich umgrenzten Kopf, wie ihn alle cukephalen Müekenlarven zeigen, den aus drei vollkommen verwachsenen Segmenten bestehemten 'Thorax und den nennteiligen Hinterleils (s. Fig. 105, Taf. IV. Fig. b und 'Taf. V'I, Fig. 1).

Die Farbe der Larwon ist gewöhnliel cin helles Bram, kann aber auch beträehtlich dunkeler, ja sogar manehmal ein tiefes sammtschwarz sein. AnophelesLarven sind häufig mit sehr wirkungsvollen \%eichnungen geschmüekt, die aber bei jedem Geschwister versehieden zu sein pllegen: Die Regellosigkeit in der Anordnung der dunkelen Striche und Flecken ist hier geradezn die Regel. Die ausgesprochene grüne Cirundfarle, welehe häufig cinzelne Stücke desselben Creleges zeigen, wird sicherlich wicht durch das mit cinzelligen Algen aufgenommene Chlorophyll bedingt; man sieht sie aueh bei Tieren auftreten, die anssehlieBlich mit dem al)solut farblosen Baliterienrasen gefüttert worden sind. der sich übor Henanfgüssen zu bilden pilegt.

Je rin Gzellus sitzt an den Seiten des Kinpers; ror ihm entwickelt sich noeh im latrvenstadium das zusammengesptzto. Iuge des vollkwmmenen Insektes. Auber den nach surn wit: enden Tastern und Fuhlern boobahten wir an der lonter- und Vorderseite die kreiftier ent wit Mundwerlizenge und das strudelorgan, mittels dessen die Larve ilure aus tieriseluen mu ful, lichen kleinwesen hestehende Xahrung heranwirbelt (s. Taf. VHI. \%. 
Tureh einen dimnen sehr beweglichen $\mathrm{Hals}$ ist der loph mit dem Brmststüeke verbunden.

Die neun singente des. Abdomens verjüngen sieh von vorn nach hinten. ber achte Hinterlejbsring triggt auf seiner Rückenlläche die Stigmen der beiden Haupttracheenstämme. Im liöperende stehen um den .lfer vier spindelförmige Zapfen, die Analdrüsen (Traeheenkiement).

Der Lokomotion der Larve dienen zwej rnderfömige Borstenbündel. (Fig." 105.) Sie stehen in der Vletianebene aul der oberen und unteren Fläehe des neunten Segmentes: cin

Fig. 103. $80 / 1$.

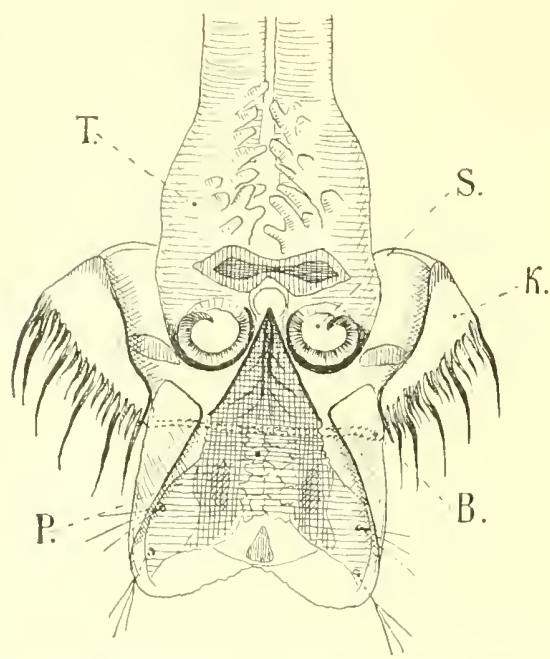

Aropheles meculipentis HFFus, Stigmenhof der ausgewaetsenen Larve. (original. Camera lueidia.) $\therefore$. rechtes Stigma, $K$. reshter Kamm, B. krältige chitinbrücke, welche die bejon distaken Ecken der liamme miteinander verbindet, sie stïtzt und sie in nurmaler Lage hält, $P$. Pelvis: beckenlörmige Chitinschale, die den Boden des Stignenhofes bildet, $T$. linker Ifaupttracheeustamm.
Fig. 104.

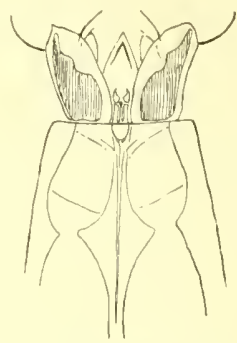

Cule $x$ ammulutus Sehrank. (Original.) Distales Ende des Sipho mit den fünl Yerschlubklappen des Stigma.

größeres ventrales und ein kleineres dorsalwärts schanendes, die in ihrer fresamthejt ein dem Fisehschwanze glejchendes trgan darstellen, während an den Seitenfläehen der acht übrigen $1 \mathrm{~b}$ dominakegmente und der drei (verwachenen) Brustsegmente horizontal gerichtete, kopfwärts an Länge zunehmende Bundel von Tastborsten (Gleichgewiehtsorgane) stehen.

Die wachsente harve (bei der Geburt etwa $1 \mathrm{~mm}$ lang, erreicht sie durchsehnittlieh rine (íöbe von $10 \mathrm{~mm}$ ) wint viermal ihren zu eng gewordenen (hitinpanzer ab und verläBt inn nach der vierten Hänt ung (in tler 2. bis 5. Lebenswoehe) ${ }^{1}$ ) als Puppe (s. Taf. IV, Fig. e).

Die stechmïekenpuppe (s. Fig. I06 und Taf. W, Fig. e) ist der wurmfömigen $\mathrm{J}_{\text {all }} \mathrm{v}$ seh. mähnlieh; sie besteht aus einem großen kugeligen, seitlich zusammengedrïkktem Kopfbruststïek und dem achtgliederigen Abdomen, an dessen Ende zwci seitwärts sehanende Rurlerplatten stehen (Fig. Ho6 u. 107); es wird wie bei den Krabben an die ventrale Fläehe des Kephahthorax angelegt.

Cैber tom Kindhruststücke bemerlien wir die beiden beweglichen Atmungshörner, mittels drom sieh die Nymphe (Puppe) an die Wasserfläehe heftet.

1) Jureh ungünstiee Verhältnisse lamm die Entwicklung der Larven beträehtlieh verzögert werden. So brauchen ïberwinternde Latrven gewöhnheh ebenso riele Nonate, als hier Lebenswochen angergeben sint. 


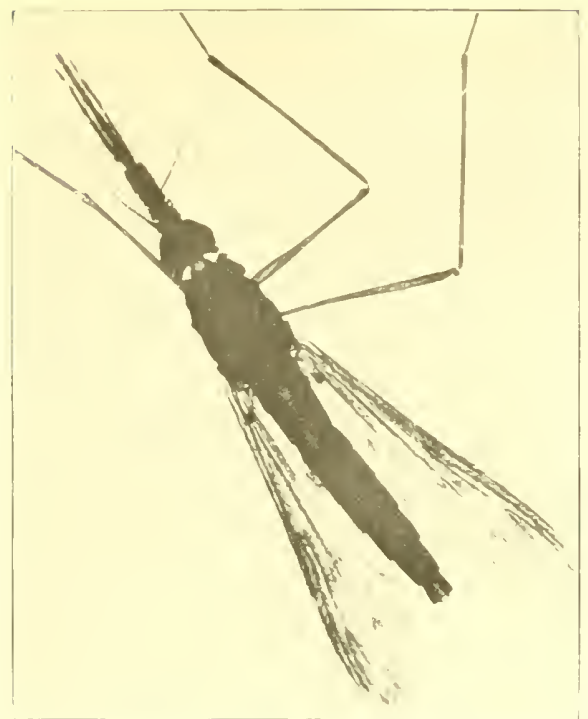

Fig. at. Anophetes Ziemunui, (rnïxв.) f. 121.

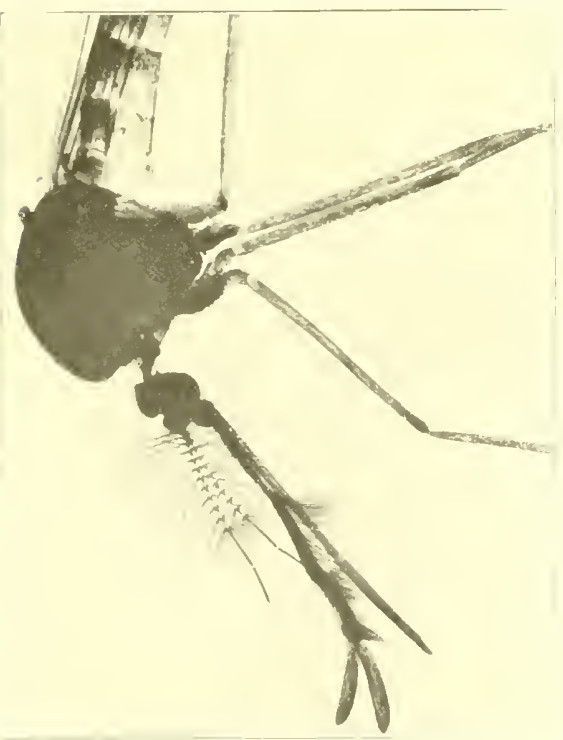

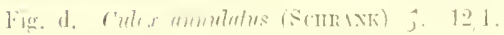

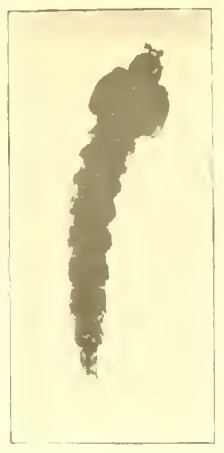

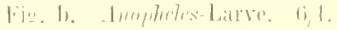

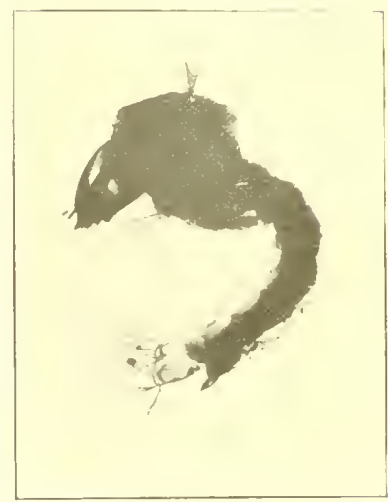

Fig. r. Lnophetrs. Verwantlung der Latre in die Puppre. 91.

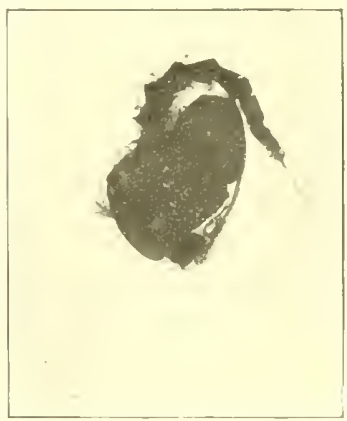

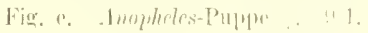



Da eine Nahrungsautuahmo wïhreud der P'uppenruhe nicht stattlindet, fehlt der Puppenhülle eine Mund- und Afterölfumng.

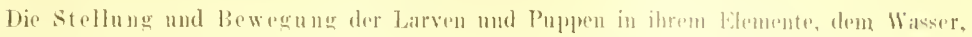

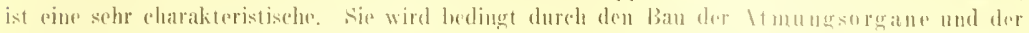
Bewegungewerkzenge der There.

Jlit eincm langen .t mungstortsatze (sipho) (s. Fig. 105, 1' und Tit. l'l. Fig. I) heftet

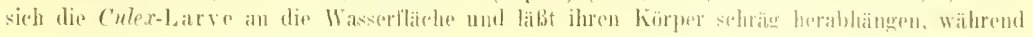

Fig. 165.

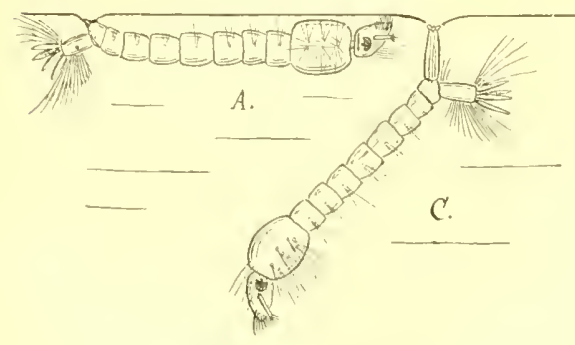

Larve vou tuopleles (.1.) und rulex (1.). Normalhaltung im Ruhestands. (i, 1. (orig.)
Fig. 106.

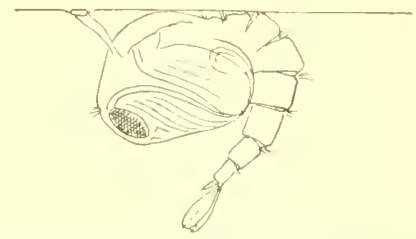

Mnmienpupy emer stechmieke. Normalhaltung im Ruhestande. 10.1. (orig.)

Fị. 107.

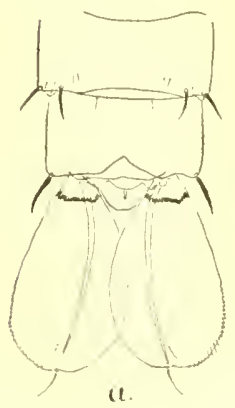

${ }^{25} !_{1}$.

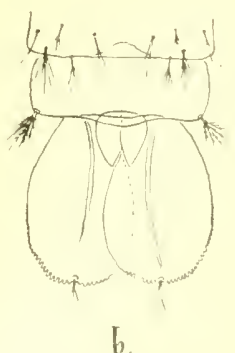

$2 n$ t.

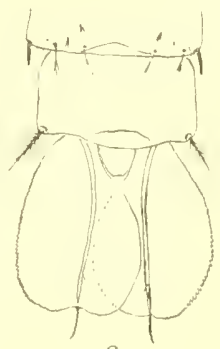

c.

$2 n / 1$.

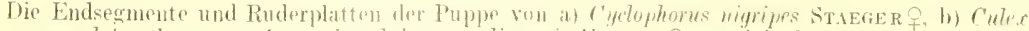

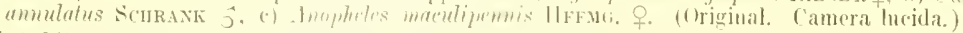

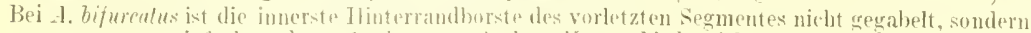

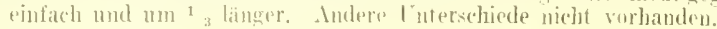

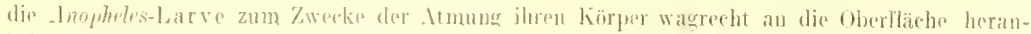
bringen mub (s. Fig. 105.).

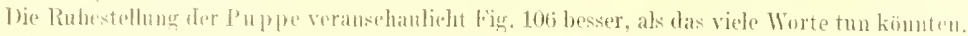

Die Bewergung der latrven wirl dureh seitliehe schlige des Dhdomens wie bei den Fischen

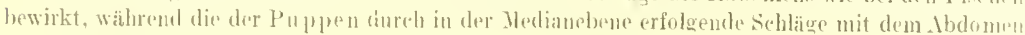
und den stelwanzruderphatten wie hei den hrebsen ausurelost wird.

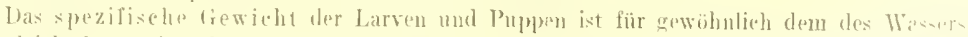
ptwa gleich, kamn atber durch aktive lerengerung der groben Tracheenstämme mitt 1 .

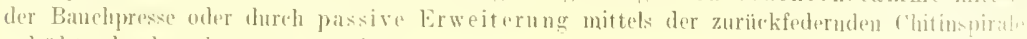
erhicht oder heraheresetzt werten. 
Ynter den gewölnliehen Temperaturverhältnissen der gemäßigten Zone sehlüpt das fertige Insekt 4 - 7 Tage nach der Verpuppung ans.

Auffallend muß es erscheinen, dab dic Stechmïcken, die doch ausgesprochene Dï mmerung:t jere sind. fast niemals abends anssehlïpfen; in den 1 lorgenstunden verlassen sie zumeist die Puppenhülle. Sehon $u$ m llittag tun die's mur noch wenige und reeht selten sieht man in den späteren Xachmittagsstumelen piuse Steehmüeke sehlüplen.

Die Anopheliden stimmen in ihrem Verhalten heim Vorgange des Schlïpfens fast vollknmen mit den Kuliziden überein.

Figr. 108.

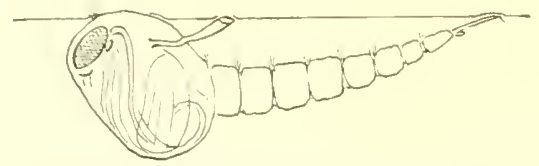

Haltung der Stechmöekenpuppe unmittelbar vor dem Ausschliipfen. ${ }^{10}{ }_{1}$. (Orig..)

Die Puppe beginnt sich in iltrem abdominalen Teile zu streeken, wahrend das liopfbruststiiek zunäehst seine Lage beibehält: die Bewegung erfolgt nieht plötlich und ruckweise, sondern stetig. Tach 10-15 Minuten ist die Strecknng de's Abdomens eine volikommene geworden. Schon vorher hat eine Luft ausseheidung zwisehen Epidernis und Puppenbalg begomnen: die früher braunsehwarze Puppe sieht mun silherweiß ans. Sehlieblieh werden durch einen kräftigen Ruck -

die horizontale Achse. um welche diese Bewegung stattindet. liegt zwischen Jetanotum und prstem Abdominalsegment - dic vorderen Teile des Kephalothorax stark gehobem und mun berïhrt die l'uppe mit den dorsalen Teilen des Pro- und Mesothorax vorn, den stigmen der Atmungshörner in der Jitte und dem Leibesende den Wasserspiegel (vgl. Fig. 108); die vorher stark konvexe Rückenfläche des Tiers ist konkav geworden.

ha die Puppe dureh die betrïbtliche, ans den Imaginalstigmen erfolgende luftauscheidung zwischen äıbere Körperwand und innere IIand der Puppenhïlle wesentlich leichter geworden

Fig. 110 .

Fị. 109 .

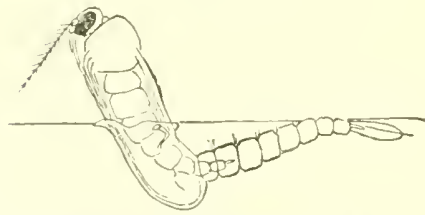

Schthiplende Stechunicke. ${ }^{6}{ }_{1}$. (Original.)

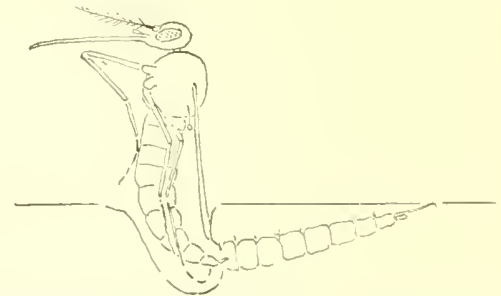

Schlüpfende Steehmücke. $\% / 1$. Späteres Stadium. (Original.)

jst. als das nmgebende Mledium, so muß sie an den Berührungsstellen die Wasseroberfläche an l'wolben (rer]. Fig. 108). Hierdureh wird es der Imago in erster Linie ermëglicht, un benet zt ilhrer IIïlle zı ant:teigen.

Bald roibt mun auch der Puppenbals an der den Wasserspiegel berührenden stelle des liephalot horax genan in der Mittellinie ein, und sofort tritt in den klaffenden Spalt, in die

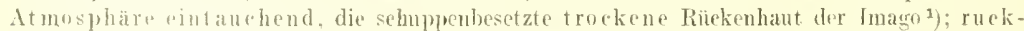
wrise wird um eler Rif erweitert, und naeh etwa zehn- his zwölfmaligem Zurückweichen der Juppenbaut (anf beiden Sciten synchron) steht der Thorax mit seiner ganzen Breite im Spalte ein. Jetzt ersehteint anth das sehildehen, der gezerrte Hals ond das Hinterhaupt des stark abwirts

1) . Lleh dir Stechmücke fügt sich heim sichlüpten dem im ganzen Tierreiche gültigen Gesetze, dab bei der fieburt immer der malsigste Tpil voransgeht; wie beim llensehen der hopf, beim logel tip dickere Hällte des lïes zuerst geberen wird, se erseheint bei der llïcke der Thorax als voransgehender Körperteil iun eben gebilteten I'uppenhiülenspalte. 


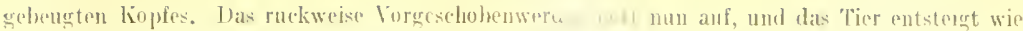

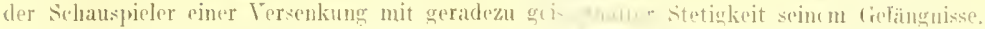

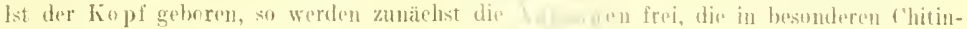

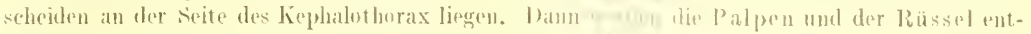

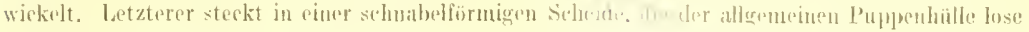
aulliegt.

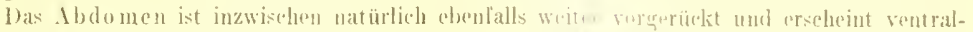

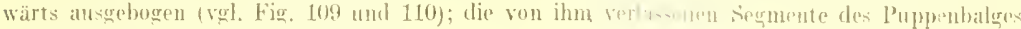
sind strotzenel mit Lult gefüllt.

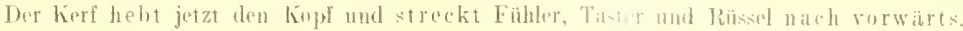

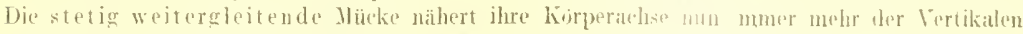
und geht schlieblich sogar atwin über diese hinalus - sie bäumt sich gewissermaßen. Die so putstehende Körpprhaltung, im Verein mit dem Instemmen der Ruderulatten gegen die Wassernhurläiche (vgl. Fir. 110), verhiitet sicher das gefähriche I'berkippen der schlüptenden Imago nach rorn.

hie llücke zieht mun das Vorderbeinpaar ans seinen Sheiden hervor, indem sie zmuächst die Kuiegelenke und dimn auch die FuBgetenke in Ebenen krümmt, die parallel der Vedianebene liegen. ${ }^{1}$ ) sind dir Vurderbeine frei geworden, so werden sir mit den Plantarlichen des Tarsus der ventraten Fläche des Dbdoments anfuesetzt, und es folgen nu ll die. Mittelheine nach. Sind auch diese entwickelt, so werden die beiden vorderen Beinpare gespreizt und, während das Tier seinen lï̈rper nach vurwärts neigt, zu gleicher Zeit mit den letzten zwei bis drei Tarsalgliedern zart anf die Wasseroberflache escetzt. Der Mlickenkörper, der bis dahin mur anf dem luitgelülten P'uppenbalge balanzierte, ist jetzt an Tumf Punkten unterstïtzt, Hut sein dilechenewicht ist somit ein selir stabiles geworden. Es folgen dann schleblich auch die Hinter beine naeh.

samtliche brine werden unabhä ngig ron der Bewegung les stammes entwickelt; sie werden parweise, alternierend und in sehr kleinen Alsätzen aus Fïig. 111.

ihren s.buden hervorgezogen. Is geschieht

dies jedentalls, weil so das Cileichgewidat an wenip twn gestort wird. Würde z. B. das linke Vorderbein whlstänlig herworgezogen, wïlrend das mehe noch in seiner scheide verharte, so miabte

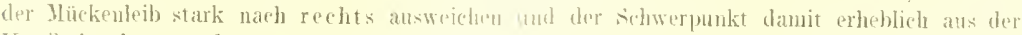
Vertikalen herausedrängt werkn; ein L'mkijpen nath rechts kïnnte in diesem Falle leicht cimtreten.

Zuletzt werden die spitzen der sehon wallerend des schlüpfens vollstindig sich entlaltenden Flügel2) und das Leibesende frei.

Der ganze Vorgang spielt sicls in wenigen llinuten ab.

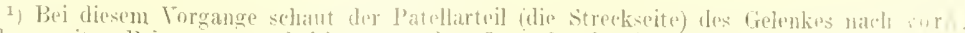

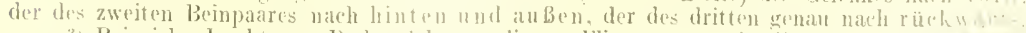

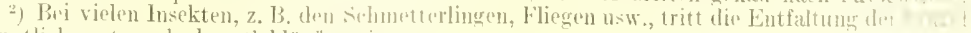
hekanntlich erst nach dem schlüptinn ein. 
1) is tertige lusckt entsteigt im ganzon fast farblos (nur die schuppen werden sehon in

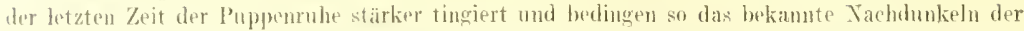
Puppes. Dic übrigen ('hitiuteile dagegen sind sehr hell, der C'lipens und das Stilettbündel sogar rein weib), durehseleinend, mit starkgehlahtem und verlängertem . Mbdomen der sehwimmenden P'nppentiüle, un nach einigen stunden seine blejbende Farbe und form anzmelnmen. bje luft verlabt zun gröBten Teilo wohl per os den Yïckenleib wieder, and unchrfach wird in der ersten Zeit wasserleeller, sulz- und harmsïurereieher Darminhalt entleert.

Hörhst interessunte Resultate ergiht mu das studium der troibenden Krafte beim Vorgange des Aussoblüplens.

Zunächst wirk, wieschon when bemerkt, der sorther dem Mïckenkörper fest anliegende P'up'pen balg durch eine ans den stigmen der Imago ausgeschiedene Luftsedicht abgehoben und ad maximom gedehnt; die vorher dunkle f'uple wird siberglänzend. Der zunehmende Druck in der

Jik. 112

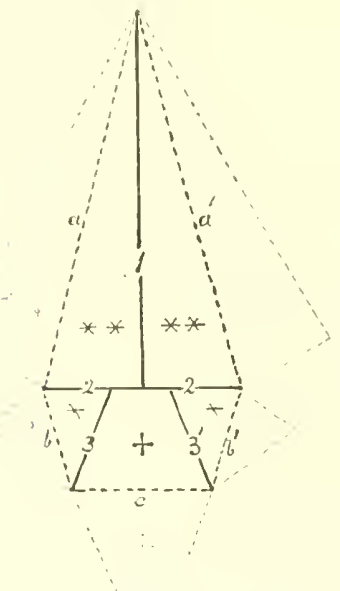

Schematische Darstellung der Entstehmg der Sipalten und Lappen der Puppenhialle. (Orig.) | Läingspalt, 29 Querspalt, 33 und :3' rechter und linker sehräessualt, ** hintero sutemlappen, die mm die tehsen a und a' nach auben umereschlagen

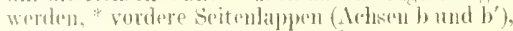
+ Voloderlappen (Achse e).
Firis. 113

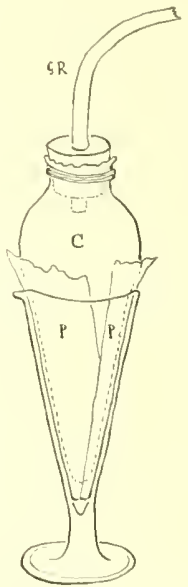

Becherglasversuch, 1/2. (Orig.) C' kinndom, I'P Flicßpapierkencl. (iR Enteres Vierted eines diumen, mögliclist zartwandigen trummischlauches.

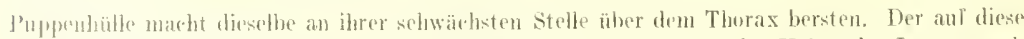
Wuise entstehende laingssyalt erstrekt sich nach rorn his zur Mitte des Halses der Inago, nach

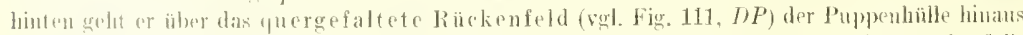

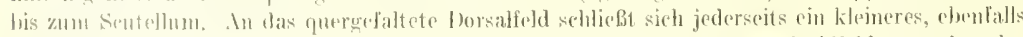
anwelles soitonfold $\{L /$ ', Jig. 111) an. In den beiden Grenzlinien, die diese drei felder voneinander

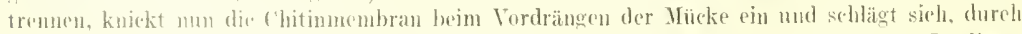

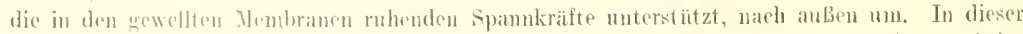

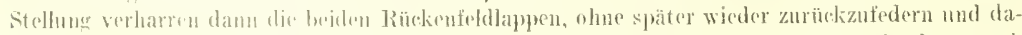

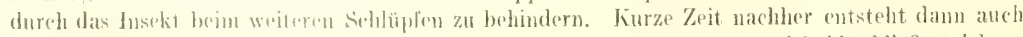

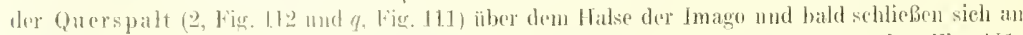

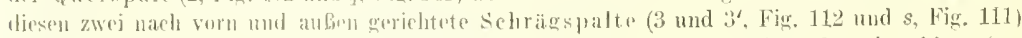

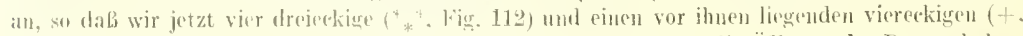

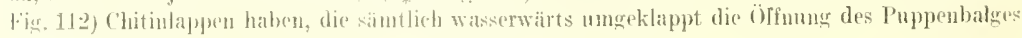




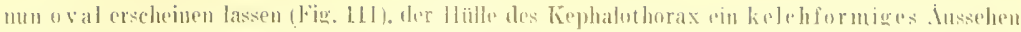

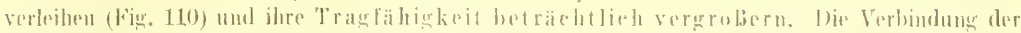

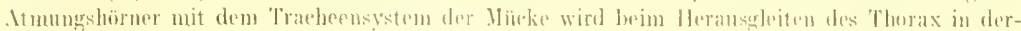

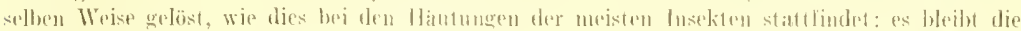

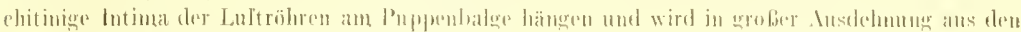
Tracheell harausge zogen.

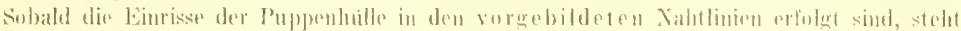

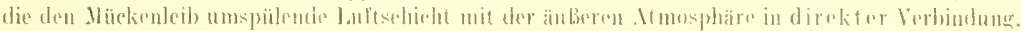

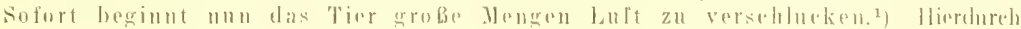

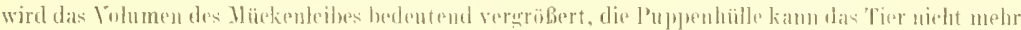

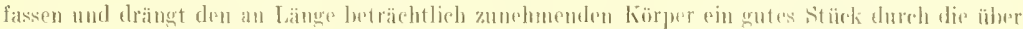

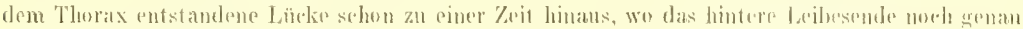

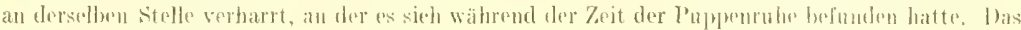

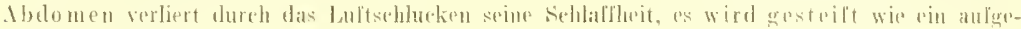
blasenes l)armstürk und nimmt proximalwärts kontimuierlirh an l'mlang zu. l)ie se

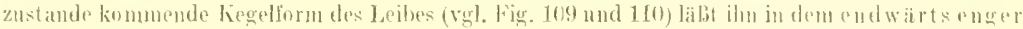

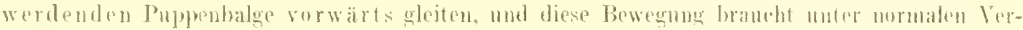

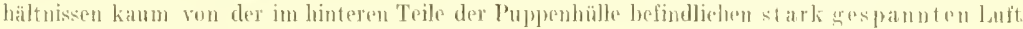
mul der Banchmuskulatur unterstiitzt 7.11 werdem.

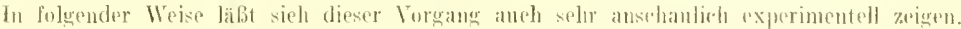
Iran blast ein in ein Becherglas gesteektes Kondern auf und wirl um wahrnehuen, wie dasselbe

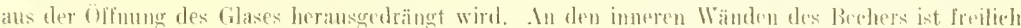

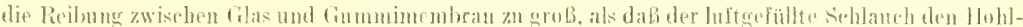

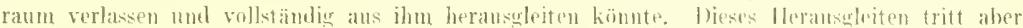
sofort ein. wem wir vorher die hnemwände des Berhers mit ejnem kunisel znsammengedruten

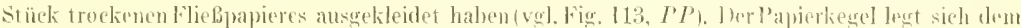

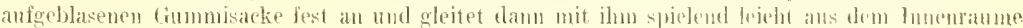
des filases heraus.

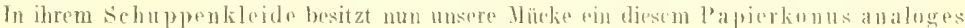

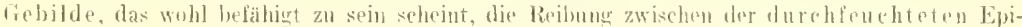
dermis und der lnnenfläche der Puppenbülle prlablich zu verringerm.

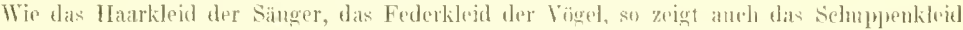

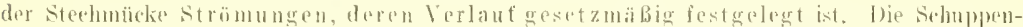

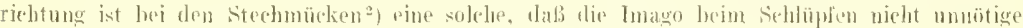

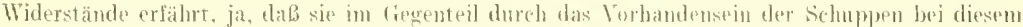

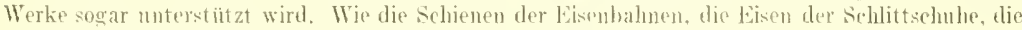

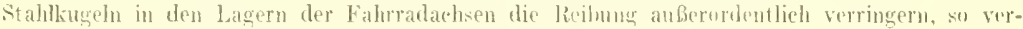

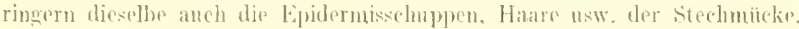

Das spezifisahe Gewieht des Tieres wird durch die Infuahme grober laltmengen betrichtlich

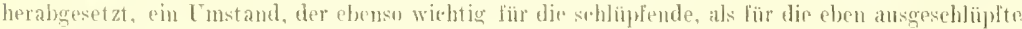
Imagu ist.

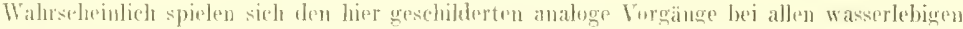

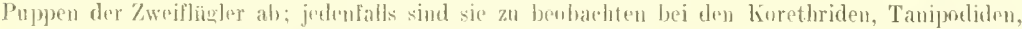

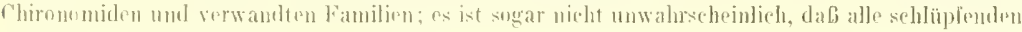
Insekten in ähulither Wpise verfahren.

\section{Biologie.}

Die Stechmücken gehören 7.1 den verbreitetsten Zweiflïglem. Tom Iquator bis über don 71). Breitengrad dor nördlichen und den öt. Breitengrad der südlichen

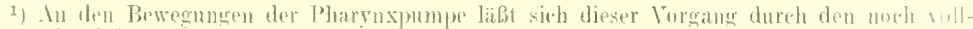
kommen durchichtigen Clipeus unter dem Jikroskop jedesmal genau heuluachten.

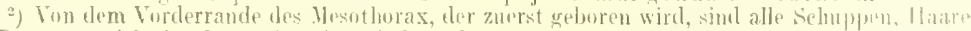

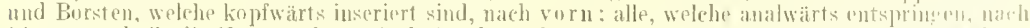

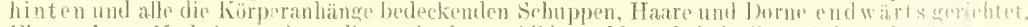

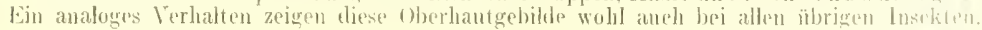


Halbkugel treffen wir sie in allen Welteilen und das ganze Jahr hindurch an. Die Zahl der Gattungen und Arten nimmt gegen die Polarkreise zwar stetig ab, die Individuenzahl aber kann in den höehsten Breiten noch eine ganz ungeheure sein.

IVegen ihres geringen Flugveruögens sind die Tiere mehr oder weniger an ihre Brutstätten gebannt. In ausgedelunten W'̈̈stengebieten, auf regetationslosen, trockenen und windigen Höhen wird die Steehmücke niemals angetroffen werden. Sic bevorzugt fonchte, windgeschützte, mit ITald und Buschwork loestandene Täler, welehe zahlreiche Brutplätze für ihre ersten stände bergen. In ausgedehnten Bergwäkdern und auf Hochebenen jedoch kamn sie sogar in unseren Breiten noch in ganz beträelttichen Höhen vorkommen (bis zu $1000 \mathrm{~m}$ und darüber).

Wenn anch alie Stechmücken durch eigene Flugkraft größere Streeken nicht zurückzulegen vermögen, so kömnen sie doch von geeigneten Luftströmungen getragen

lijg. 114.

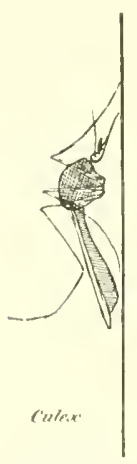

Sitz von Gulex pipirns 우 $111 \mathrm{~d}$ Anowhel's maculipennis o an senkrechter Wand. Nur die beine der rechten Körerlällte sind gezeiehnet. $4 / 1$. (1)rim.) und getrieben, durch Transportmittel jeglicher Art, in Wagen, in Eisenbahnzïgen und Schiffen auf große Entfermungen versehleppt werden. 1)urch eigene Kraft sind sic anch nicht befähigt, sich in höhere Luftschichten zu erheben; der im Freien ant der Erde oder in den mnteren Stoetwerken von Gebäuden Schlafende wird daher an dhesten Gefahr laufen, von den Plagegeistem überfallen zu werden. während Schlafränme in den oberen stockworken einen beträchtlichen Sclutz gewähren.

Die Stermücken sind lichtselieue Dämmerungstiere'); wir werken sie daher an 'Tage nicht wie ihre Terwandten in Sonnenscheine spielend antreffen, sondern aussuhend in Naldesschatten, unter Blättern verborgen. in Höhlen, in domklen Eeken von ställen uncl menschlichen Wohnräumen.

Die Simnosorgane der Stechmücken sime zum Teil wenigstens hoeh entwickelt. 'Trotz der' groben, ihre Fazetten maeh allen Seiten richtenden Augen dïrfte der Gesichtssinn ziemlieh unvollkommen sein. Grassi nimmt an, dab ihr Auge nicht weiter als 70 cu reicht und die 'Tiere nur befähigt, hell und dunkel, unbestimmte Grenzen von mahen Gegenständen und deren Bewegung zu erkemen. Der Gerueh dagegen ist vorzïglich ausgebiket und auch das Gehör ein scharfes; als sitz dieser beiden sime werden die Fïhler angesprochen, wäloend Lippen- umd Kiefertaster die hauptsächlichsten gefühlvermittelnden Organe sind.

Die Beine brancht die Mïcke nur selten zur Fortbewegung. Nie heftet sich Jnittels dorselben in crster linie an senklechten vdex überhängenden Flächen an. Die Körperhaltung wïhrend des sitzens ist eine sehr eharakteristisehe (s. Fig. 114 1. 115). Culex nähert in Ruhestellung das Leibesende der haltbietenden Wand, so dab es beinahe aufzuliegen scheint und kriimmt das letzte Beinpar sehr stark dorsalwärts,

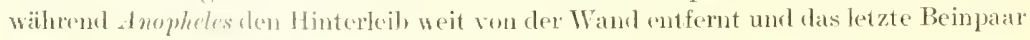

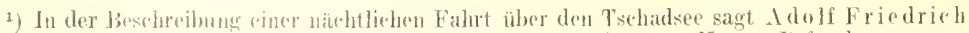
II erzog $z \|$ If

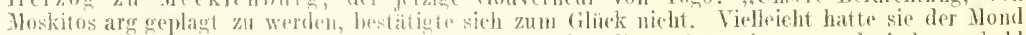
vertroben; denn man mach immer die bilahong, dab diese Plagegeister verschwinden, sobald das licht des Mondes das bunkel der Nacht vertreibt." 
sinlach herabhängen läßt; seene Körperachse ist beinahe sine gerate linge, während ('ulex buekelig und zusammengekaurert tasitzt. Sehon in cines Entlermung von

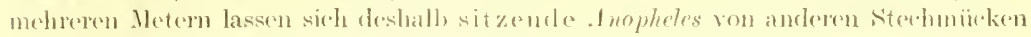
anf den arsten Blick leieht unterseheriden. $\left.{ }^{2}\right)$

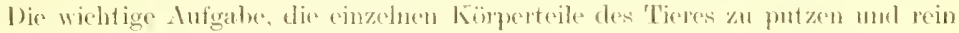
z.11 balten, fällt ebenfats den liconen zot.

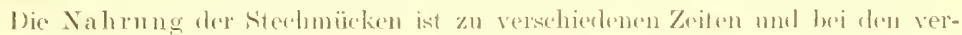
sehiedenen Geselulechtern erine versehiedene. Während die Männehen wohl ansnahmsks Vingetarier sind umd sich von Bläton- unt Fruchtsälten nähren. bratuchen die Wribehen zur Zait der Eierreifung zu ihrer Emährung Plut. ${ }^{2}$ )

Die Jarsen mut puppen entwiekeln sich nur in stehenden oder wanz

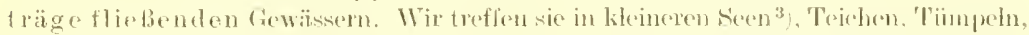

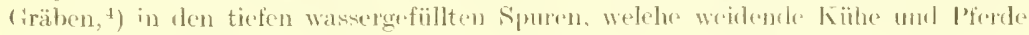

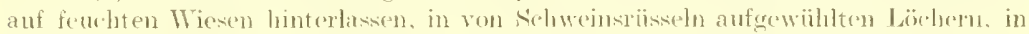
Zistemen. sellst in viels. Mreter tiefen Promene 11 linport of the Welleome Laluratomes at Khartomm, liegentomnen, Dachtranfen, weggeworfenen Konservenbüchsen, in den Blattachsedn der Pahmen, Bromeliazen, den Schläuchen der Sarazenien, den Nepentheskamen und allen nur denkbaren Behiltern, soweit sie geeignet siml. Regen- oder Thersehwemmungswasses zuriukzuhalten und in diesem die zur Ernährung der Lave nötige I'flanzen- und 'Tierwelt entstehen zu lassen. Sichwahe Salzlïsungen (Sole bis zu j ${ }^{3}$ ) und Brackwasser ermöglichen vielen Arten eine rasche und normale Entwicklung. whllrend reines seewasser eine solehe fü gew whnlich ansschließ3t.5) Die Laven liömen selbst in nnseren Breiten unter gewissen Lmständen fle ungünstige Jalneszeit übrelanern. Sir verfallen dann wie die Fische in einen winterschlafähnlichen Zustand, währendessen eine Nahrungsanfnahme nidht stattfindet. Selbst woehenlang andauemden, vollkommenen Abschlub des Wasserkörpers gegon die darüber. lagernde Luftschicht durch eine feste Eisslecke überstehen rlie hant-. kiemen- und darmatmenden Stedmuiickenlarsen sehr gut (Exser.t. Peiträge zur Biologie der Stechmücken. Arch. f. Schiffs- moł Trope-Hyg. 1907. S. 195).

Die stechmïckenlarven sind in erster Linic phytophage Gesehöpfe. versehmähen aber andererseit anch keineswegs an imalisehe Nahrungsstutfe. Letzteres

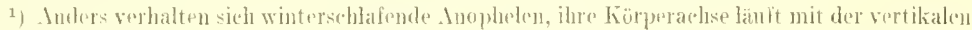
Wantliathe parallel.

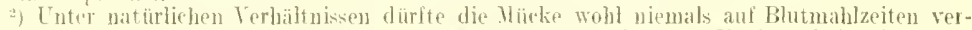
ziehteu. In Laboratoriumsversuche ist es ansualnusweise gedungen, Niucken bei rein vegetabiliseloer liust zur Eiablate zu bringen.

3) Juch in der röhriehthestandenen T ferzone griblerer ströme und seen dionnen larven mol Puphen angetroflen werden, namentlich dann, wem stowimmende Blatter von Wasser-

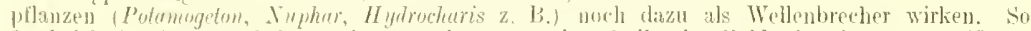
fand ich in lusust 1908 an einer stirk stromendin stolle dor fillda in einem etwa 15 om

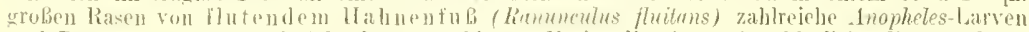

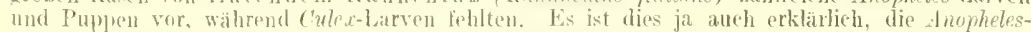

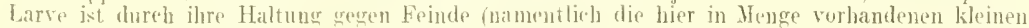
Fisches viel besser geschitzt, als die in den Wassiskirper hineinhängende Culer-Larve, welehe dureh diese Stellung anch nor la dazı drm sitrume eine viel gröbere Angriffsfläche bietet und so

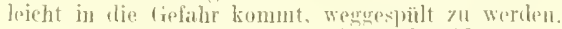

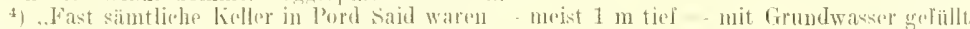

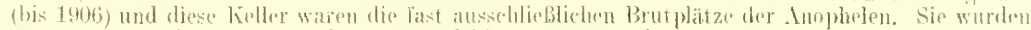

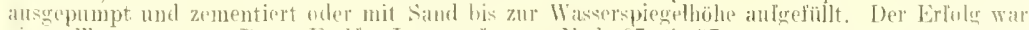
eill vollkommener." Ross. E. 11., Journ. ol trop. Med. 07, s. 17.

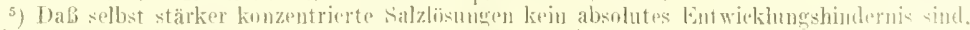

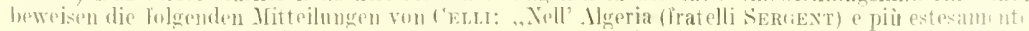

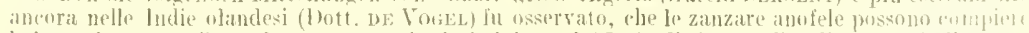

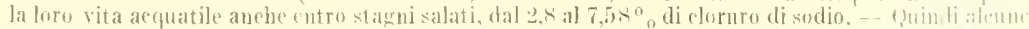

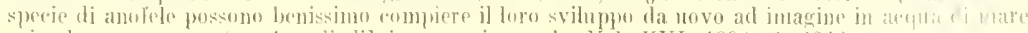

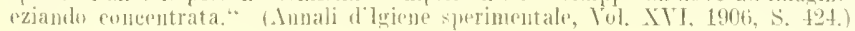


silt mamentlich liir die Larven der Anopheliden, welche am besten bei gemischter Kust gedeihen. Man trift sie häufig an beim l'enagen von auf der Wasserfläche verendeten Insekten (sogar ihrer eigenen Mütter) und kam des öfteren beobachten, (lab sie auch dileme lebende 'Jierchen z. B. Springsehwänze (Lipura fimeturia) mit Hant und Haaren verzehren. Die Stechmückenlarven sind äuberst gefräBige Tiere, ihr Nahıungsstoffe in den Mund beförlernder Strudelapparat steht weder tags noch nachts auch nur cine Minute lang still,

Die Eier vider Arten überstehen niedere "T'emperaturen lange Zeit, sogar EinschlnB in Eis tötet sie nicht. $\left.{ }^{1}\right)$ Monatelanges Verweilen an feuchten Orten ertragen dic hartschaligen Eier vieler Kulizinen. Die Larven und Puppen bleiben in fenchten borken ansgetrockneter Tümpel tagelang am Leben. 'Temperatur'n über 450 töton nach mehreren Stunden die Stechmïcken und ihre Brut.

\section{Sỵstematik.}

Nachdem als erste Hooke, Swamerday und Réacmo die gemeine Stechmïlie (Culex pipirns) beobachtet und ihre Lebensgewolmheiten eingehend studiert hatten. lieferte KLExMxix eine genaucre Beschroibung derselben und ergänzte sie

Fig. 116.

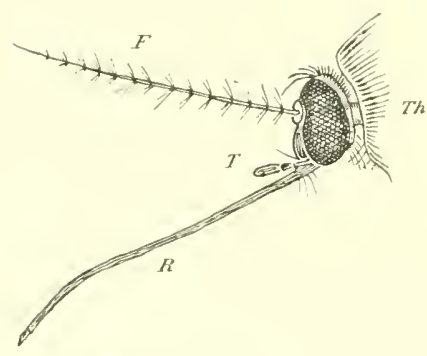

(atler pipiens y. 24/1. (orig.)
Fig. 117.

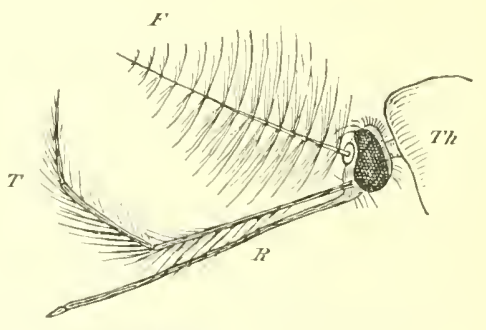

Culex pipiens $\hat{s}$. $24 / 1$. (orig.)

Ii Riulssel, $T$ linkur Taster. $F$ linker Fühler. Th Thorax.

durch stamenswert naturwahre Bilder auf zwei Kinpfertafeln des bekannten Röselseden Mrokes.

Lixwéstellte in tahre 1761 die Gattung ('uler auf und gab die charakterist ischen Mtrkinale von ('ulex pipiens mul bifureatus."2)

Serehzig Jihre später (IsIs) unterseheidet Menex, der Vater der Dipterologic. dic Irei Gattungen culex. Anopheles und Ac̈des.

In dahre Iszz kreïerte Romanat-Destony weitere drei Genera, won denen, Megurhinus dian best eharakterisierte ist.

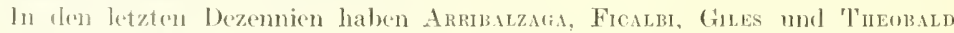
sich grobe. Verdicnste un Beschreibung und Einteilung der Stechmüeken erworben.

") Dic Ein der neisten sitechnückenarten der nörllich gemäBioten kalten Zone überwintern.

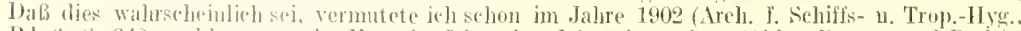

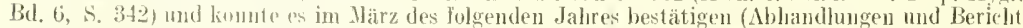

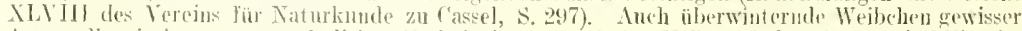
Aren, dis wir in unter gewihnliehen Verhälusisen frostfreien Kellern finden, könen bei Eintritt

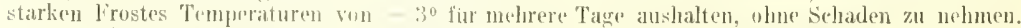

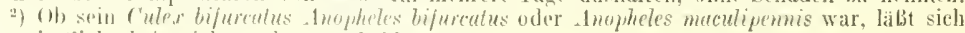

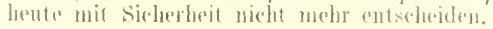


Die alten Gattungen C'ulex. Inopheles. L̈̈des und Megurhinus wurden zu Tnterfamilien erhoben, nene linterfanilien und viele nene fienera kanen hinzu.

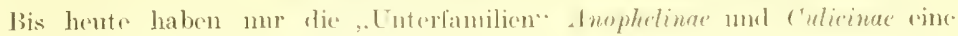
praktisehe Bedentung fiir den dizt ge'womnen.

Eine gendue lienntuis aller stechubekenarten ist vom praktischem liesiehtspunlite aus

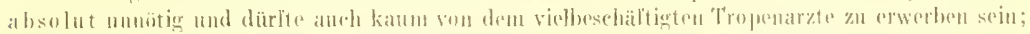

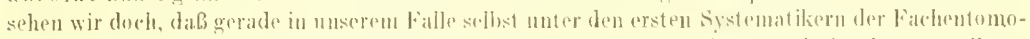

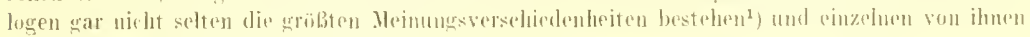
recht anlfallende Irrtïmer widerlaben.

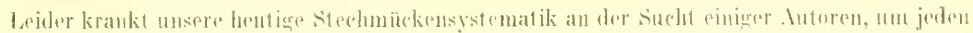

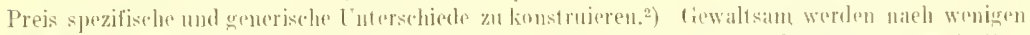

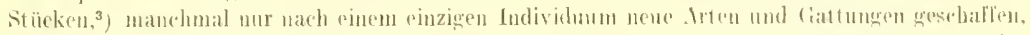

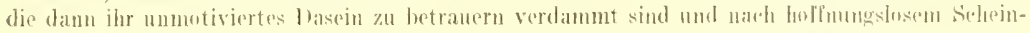

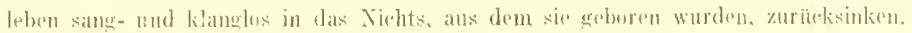

Fig. 118.

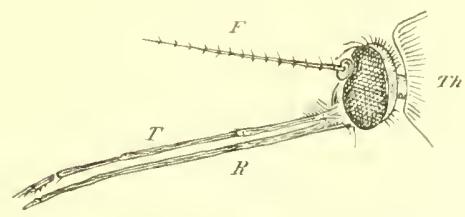

thopheles maculipennis 181 . (orig.)
Fïg. [I!!.

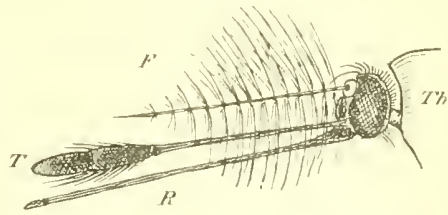

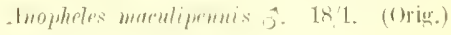

b Rüsel, T linker Taster, $F$ linker Fühler, Th Thorax.

..1l paraît yu à foree d'analỵser un ne perẹit plus exactement la synthòce, et en fouillizıt juscu'aux plus menus détails, un peut perdre la claire vision des earact tres sémeraux sagt mit Recht Obertiür (Étud. de Léplid. comple, Fase. IT, S. 71).

Unser höchstes Gebot sollte hier lauten: Mögliehst vereinfaehen, nicht unnötig komplizieren md die Materie derartig verwirren, dab sehlieblich sogar die Väter ihre eigenen Kinder nicht wieder zu erkennen vermögen.

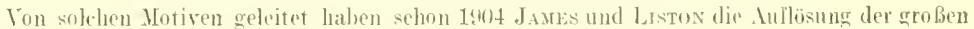
und su an Berordentlich einheitlinhen tiattung thopheles in viele kleine als unpraktiselo und vollkommen verfelilt bezeielnet.

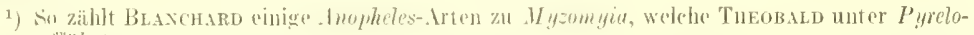
phorus intliihrt.

2) Wir sind auf dem besten Wege, lür jede rinzehne Anophelesart z. B. eine besondere liattung zu errichten. Damil wäre dann freilich aufs einlachste der einwandfreie Beweis dafür gelietert, dah gar keine generischen, sondern nur spezilische Unterschiede zwisehen den einzehen ,nenen diattungen" vorliegen.

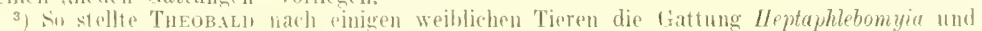

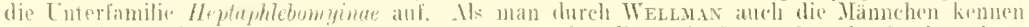

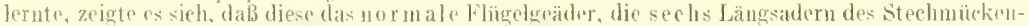

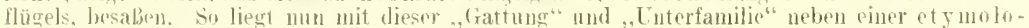
gischern atuch eine entomologische Mlibgeburt vor: oder solte es doch möglieh sein, dab die weiblichen und nännlichen Vertreter dersclben Art versehiedenen Tnterfamilien angedüren kïmnen?

4) Was ihnen natürlich den höchsten Zorn und die grenzenlose Verachtung TuEobatr s zal-

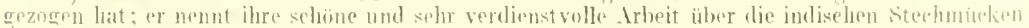
kurzweg ..entonologiseh wertlos". Sie werden sirlı hoflentlich mit den Worten zweier namlatten amerikanisclen Entomologen in bezug auf ihren liritiker getrostet haben: JYaR und LNus urteilen aber THEobatd ,.he is not a trained naturalist, so we are told, and it now al eall that he is incapable of learning". 
Al. besunders erschwerendes Moment für eine reinliche Scheidung knmmt noch hinzu, dab die atchmücken ansgespruthenen saisondimorphismus und grobe Keigung zum Aberrieren zeigen. Su züehtete z. B. Lixoshita aus pinem einzigen Pseudopiclus-Gelege fünt, zwei ver-

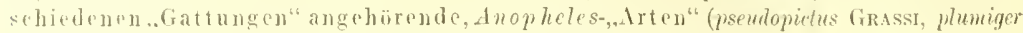

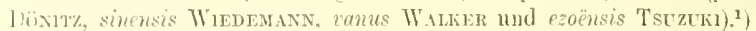

Schon seit einem hahrzehnt laahe ich deshalb den Satz verfochten: Die hente lebiebte Eintrilung der Strchmöicken, die sich zumal bei den versehiedenen Anopheles-, Gattungen" aussclllieblic.] and imaginale und noch dazu recht nebensäehliehe und minderwertige ('haraktere stützt, kann mur als ein vorlänfiger und sehr fragwärdiger Totbeluelf angesuhen werden. Wir werden wst dam in den Beitz cines natürlichen Steclunückensystems gelangen, wem nus die ganze Lehensceschichte der einzehnen Irten bekannt sein wird.

Jian sollte dwhall ruhig allen und jeden systenatischen Kleinkran den kntomologen von lach üherlassen, die sich daran atch fermerhin mit mehr oder weniger Geschick die Zähne ausbeiben mügen, unel sol]te dies $u m$ so medur tun, als jhm vorläufig noch jude praktische bedeutung abgeht.

Line genane Kenntuis aller d nopheles-Arten z. B. würde nur dam unerläbich sein, wenn bestimmte spezies auch wiederum nur bestimmte llabarialormen ühertragen kömten, wenn,

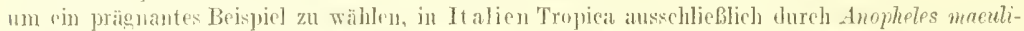
femis, Tertiana nur durch dnopheles superpietus und Quartana nur dureh Anopheles pseudopictus iiburtragen wïrden. Da aher jede dieser drej Arten swohl Tropica, als auch Tertiana und Quartana ühertragen kam, genügt es, wemn im gegebenen Falle der Arzt imstande ist, pinen luopheles von winem Culex zu untrocheiden.

Trichtig wäre es ferner, die einzehnen Spezies zu kemen, wenn gewisse dnopheles Arten als i'herträger für Nalaria nicht in Betraclut kämen, da sie sich nikht nit Plasmodien infizieren könnten. Aber anch dise Annatme mancher Antoren steht auf sehwathen Füßen. Ein großer und weehselnder Prozentsatz der gleichen Juckenart zeigt sielı bei lnfektionsversuchen uit Hämospridien inmun. Jis liegt also sehr nahte, anzunehmest, dab. eine Anopheles-drt, die in diesem .lahre aus irgendwolden uns heute moch unlekannten Gründen keine sichelkeime in ihrem kör]er zur Entwicklung bringt, schon im näehsten bahre unter anderen Terhältnissen zu diner gefährliehen I’lurtränerin der Malarial werden kann. Sn wird z. B. Ahopheles rossi von vieleut für einen zwal

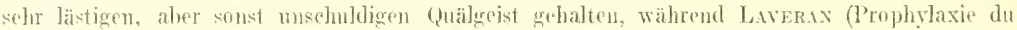
P'aludisme. s. 8(t) gurath ihn und nur ihn allein aus verrufenen balariagehieten Hinterindiens (Annam) zugesandt rirhiclt.

Nuch viel melır bewciken die eventuelle Gefährliehkeit dieser Art die Mitteihngen von DE Toriez und Banks, die gelegentlich des Iinngresses der "Gesellschaft für Tropenmedizin im fernen (baten" gemacht wurden.") Beide Jorseher komnten feststellen, daß in Salzwasser (Meerwasser) zur Entwicklung gelangte Rossimücken in den umliegenden Bezirken die hauptsächliehsten Balariavermittler waren. Noch früher (1902) Jatte Professor kivosma malariainfizierte Anopieles rossi anf Formosa grefunden und Stephexs und Christopiens war es in Nag pur dureh gesehickte Torsuchsanordnung sogar geglückt, diese Mücke im Laboratorinm mit Plasmodien zu infizieren. ${ }^{3}$ )

Ije angeführten Tatsaehen sollten meiner Ansicht genügen, den einwandfreien Beweis zu crJringran, diabes zunathst - und wohl noeh für viele Jahre - das Richtige ist, sich durch die Erwilgung: alle Angehörigen der wroben, wnt als canzes wohleharakterisierten Anophronfanilie könuen sich unter lomständen mit Malariaplasmodien infizieren und diese dann auf den Jenschen übertragan, in der Wahl der prophyaktischen Jafonalumen wuel bei ihrer energicehen Jurchführung leitem zu lassen.

Die Tutersenierle zrischen den, Anophelinen" und allen ribrigen Unterfamilien sind derastig großr mol bedentende, daß wir an ihre Stelle zwei neur Familjen setzen mïsen, dic $A$ nopheliden und die Kolizjden im engeren sinne. ${ }^{4}$ )

1) Ared. l. Sichills- 11. Trop,-Hyg., Bd. 10, S. 626. Siehe anch die Ammulipes-Formen anf Taf. ]X, Fig. 2, $6,7,8,9,10,13$.

2) Medieal liecord, Bel. 77.1910. - Ygl, auch W. T. DE V'oget, Myzomyiu Rossii und Malaria.

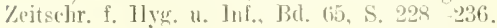

3) Arch. f. Sidhilfs- 1. Trop.-Hrg., Bi]. 10, S. 750.

4) Ja die kiorethriden gar keine steebmücken sind, was jeh in meiner Arbeit "Sind die 
Die Grimde fïr dieses Vorgehen labe ieh in ...Archiv für Schiffs- nnd Tropen-

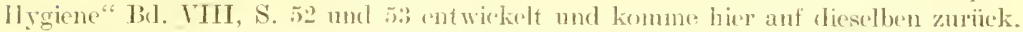
Merkmale:

Es unterscheiden sieh dio Knlizien von den Anophelisen arureh folgende

Inliziden.

\section{Anoplichiden.}

\section{Tier}

in kahnfömigen sehwimmenulen Haufen wler einzeln abgesetzt nund dann meist untersinkend und im Sehlamme, auf rertorften Blättern usw. nngünstige Zeiten ïberlauernd oder in Ifuttroleibe ïberwinternd and tropische Truckenperioden iiberstehend.

\section{Larven}

dureh einen ein Stigma tragenden sipho atmend (Siphonata). Kürper ron der WTasserfläehe herabhängent. Brachykephale Diekköpfe (s. 'Taf. II, Fig. 1).

Ein Staehulfeld auf dem vorletzten Segmente. Intersegmentalseheiben fehlen der Exuric. stets einzeln gelegt mul mit Shelowimmvorrichtung versehen.

Den Winter oler nnginstige '/eiten moist im Mutterleibe äberdanermel.

durch zwei stigmen atmend, die in emer napförmigen Verticfung untre dem Niveau des Körperoberfläehr liegen (Asiphnnata). Körper mit 'Teilen Aler Riickenfläche in horizontaler Lage sieh an den Wasserspiegel anlehnend. Hals gewölnnlich nm $180^{\circ}$ getreht, so dab die untere Kopffläche nach oben sehaut. Doliehokephate Klcinköpfe (s. 'Taf. IT', Fig. b).

Die Larrenhant trägt dorsale, dunkel pigmentierte Intersegmentalseheiben und fächerförmige Haare auf vielen Abdominalsegmenten.

\section{Larven}

Thorax faBförmig, Riickenfläc be gewölbt; ein Thoraxfrontalschnitt zeigt leshalb cinen beinahe kreisfömigen TmriB.
'Thorax dosenfömig, die abgeplattete Rückenfläche trägt in der Meclianlinie einen kielförmigen Grat, an drssen Seitenflächen Längsoruben verlaufen. Anf der Rüekenfläehe des Metathorax häufig ein sternhaar jederseits. auf der des Prothorax (in der Schultexgegrnd) dic Münulungen der Ausfïhrungrgänge ron Talgdrüsen.

\section{Larven}

J) ventrale Kopffläehe

wesentieh holler als die Scheitrlfläehe. wesentlieh dunkler, alsdie Sehcitelfläelur. Erklärt wird dieser Untorsehied durch die typisehe Kopfhaltung der Anophslidenlarron (Drehung um 1so" in ller längsachse). Es trägt so auth clis

Seheitelfläche die schutzfarbe der ventralen Körperfläehe.

I'uliciden eine Familie?" (1905), Areh. f. sehifls- und Trop. Hyg. Bd. 4, s. 4!! nathelsen konnte, wurden sie hier nicht weiter berioteksiehtignt. 
linliziden.

\section{Inophelisten.}

\section{p'nppen}

An den distalen Ecken der Abdominalsegmente stehen meist Jorne.
An den distalen Ecken der Abrlominalsegmente stchen ein- oder mehrfach gefiederte Borsten.

\section{Puppen der 00}

(an den durch die Hülle durchseheinenten kntzborstigen Antennen als solche leieht zu erkemnen).

Palpen als gerade Stäbehon unter ter Palpen zweilach geknickt durch die pupjenhülle sichtbar.

Hiille zu rehen (s. Taf. IV. Fig. (s).

\section{- Imagines}

\section{Längsarhse tles Kürpers}

in der Sagittalebene gebogen, Konvexit ït fast eine gerarle linie bildend (s. Fig. 115). dorsalwärts schanend (s. Fig. 114).

$\begin{aligned} \text { Sehildehen } & \text { (Seutellum) } \\ \text { dreilapplig. } & \text { einfach. }\end{aligned}$

kïrzer

Taster der $q_{f}$

ebersolang

als der Rïissel.

\section{Beine}

etwa Körperlänge besitzend, alle trei wesentlich länger als der Müekenliörper, Pare fast gleich lang. rom ersten bis zum dritten Paare an Länge beträehtlieh zunehmend.

(Die fellende oder vorhantene Krïmmung der Körperaehse und die verschiedene Beinlänge bedingt den so charakteristischen sitz der Anopheliden mul ('mlicislen.)

Vorletztes Glied les Fubes tes erster beinpaares der ôs $111 \mathrm{n}$ ein mehrfaches kiirzer, als das End- ebensolang oder eine Spur länger, als das glied (s. 'Taf. 111, y u. Fig. !n B). Endglied.

Diese Unterschicele bei den of nieht so anftällig, aber vorhanden.

Netatarsus

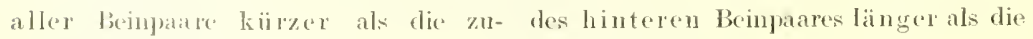
gehörige 'Tiljia. $\quad$ zugehörige 'Tibia.

$$
\text { Endglied des männlichen Vorderfubes trägt }
$$

toin Klanenpanr.

$$
\text { Polsterfömiges Grundglied des Fïhlers }
$$

beschuppt. meistens nackt. 
lïlizisleı.

\section{Alulatramel}

\section{Anopheliden.}

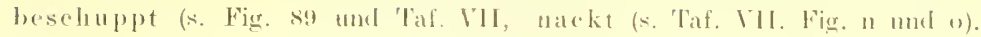
Fig. s).

Die Ausführungsgänge in den speichelfrüsenlaperen zytindriselh. ampullentormig ( $\therefore$ ' Tat. VIIJ, Fig. "1).

Spermat heken

drei (bei Hansonia zwei), ihre ('hitin- eine. Chitikalsel siebformig dureh-

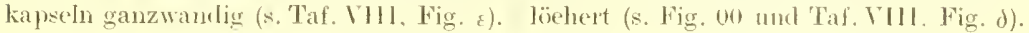

zwei.

$$
\text { Kittlrüsen }
$$

eille.

Dè Flïgel der Anopheliden sind meist gefleckt. die der Kuliziden gewöhnlich farblos und glasartig durehsichtig.

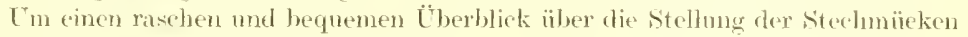
in zoologischen Systeme und ihrer wiehtigsten Glieder untereinander zu ermöglichen, fiige ich hier umstehende Stammitafel an.

Die verbreitetste S'techmïcke ist ('uler pipiens L. (s. Fig. 116,117 mm 'Taf. VII Fig. s), the allbekannte Sehnake, sic ist ein Kosmopolit in wahrsten sinne des Wortes.

Fig. 120.

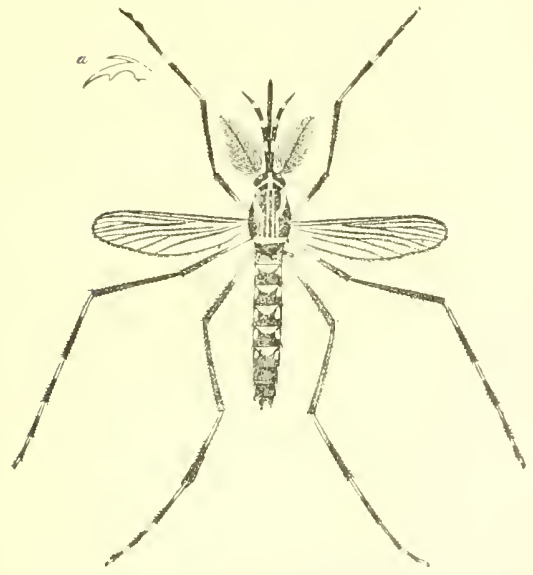

Culex (stegromvia) fasciatus labr. Mïnncheri.
Fig. 121.

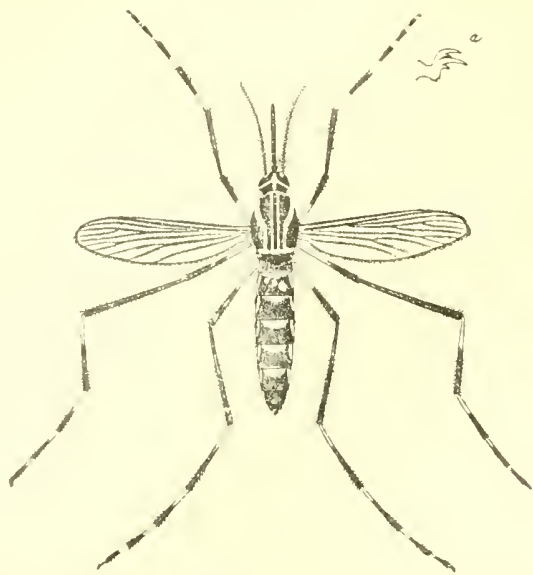

(Tach ('irroll.)

Weibren.

"Kliate des ersten Beinpaires.

Ion anderen f'ulicinae sind sehr repteitet und als Krankheitsüberträter be-

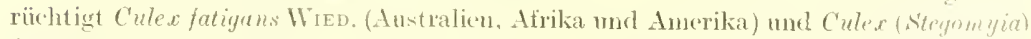
fasciatus Fabr. (Amerika. Afrikit, Asien, spanien, Portugal und süditalien). (Fig. 120, 1:21.) 

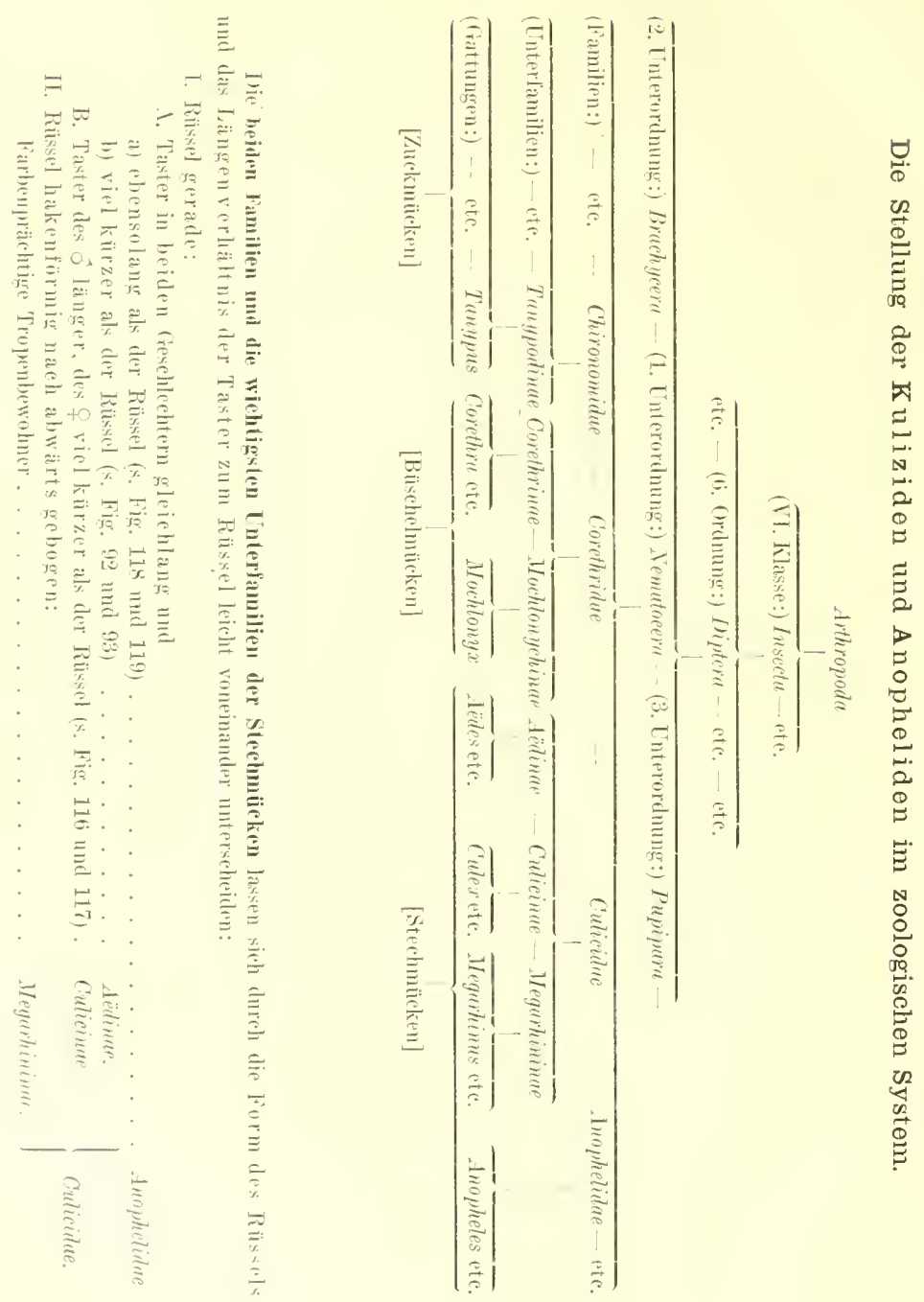


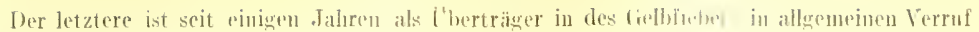

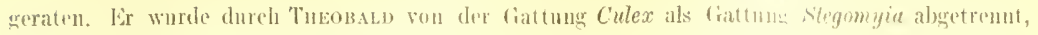
wegen der Virsehiedenheit des lntegurneutes.

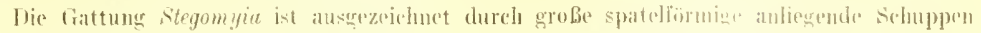

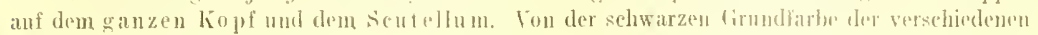

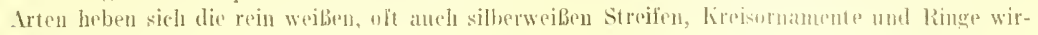
kingsvoll ab.

Fon den Anophedesarton $\left.{ }^{1}\right)$ sind die wichtigsten Anopheles marulipennis Hoffugg, ganz Europa, Nordamevilia, Nortafrika) (s. Fig. 1ts, tlu. 'Tat. T. Fing. H. Taf. III, Fig. 11).

Anopheles (P'yretophorus) costalis LoEW (s. 'Taf. III. Fig. P unt q) ist clie grmeinste afrikanische Art; sie wirt sowohl an der Ost-als an der Westküste iiberalt gefurlen. Im Immeren des sehwarzen Kontinentes herrseht Anopheles (. Hzomyia) funestus GiLes ror. Die häufigsten Asiaten sind Anopheles (. Mzorhymehus) sinensis Wied. (s. Taf. V. Fig. f und i) uml Anopheles (Myzomyiu) rossi (s. 'Taf. V'l. Fig. m) (xiles, während auf dem siidamerikanischen Kontinent und den Antillen Anopheles (Cellia) argyrotursis RoB. Desi. (s. Taf. VIl. Fig. r) die verbreitetste Art ist.

\section{Fang, Infhewahrmug nud Versand.}

Lm Stechmiicken mit Erfolg zu sammeIn, ist es von hoher Berloutung, die abzusuchenden Örthohkeiten richtig auszuwählen und der Jahress- nnd Tageszeit entwpechend die zweekmäbigsten Fangarten anzuwenden.

Wenn es sich nur darum handelte, vollkommen amsges bildete w eiblic he kuliziden zu erbeuten, so wäre die gestellte Aufgabe ja verhältnismäßjig leicht zu lösen, da uns die bluthungrigen Tiere anfliegen und dann nuschwer mit dem Netze veler sitzend und saneend durch f'berdecken mit dem

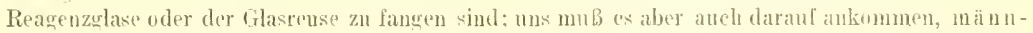

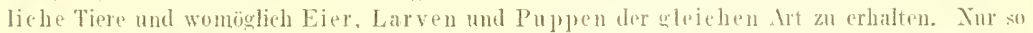

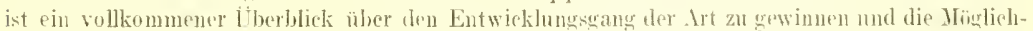
keit gemehen, die notwendigen, systematischen und biologisehen Tatsachen klarzustellen-

Imagines. Die einfaehste Art. Stechüicken zu fangen, besteht darin, dals man die tagsïber traumverloren an den Wänden sitzenden oder in Kellern u. dgl. ihren Vintersehlaf haltenden weiblichen Tire - wem nötig bei kïnsticher Beleuchtung - mit einem zienlich weiten (2 ( 2 im 1)urchmenser) Rougenzglase überdeckt.

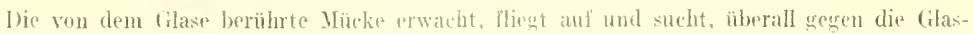
wände anstoßond, den vermeintliehen Answang am Botlen des liohreless. Schnell entfernt man jetzt das Reagenzglas non der Wand und sehilebt die Jüutung nit dern limmen der das Glas haltenden 1land. Eine Wattekngel, gerade grob besnu, die Yündung sicher zu verstoplen, wird mun nebru

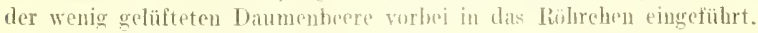

Bei einiger Grechicklichkeit and l'bung lassen sich nacheinander 34 stechmürken anf

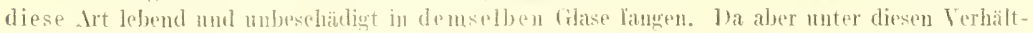
niseen die Tiere später sich leicht gedenseitig vertetzen, verfährt man sichrer und sehonender in

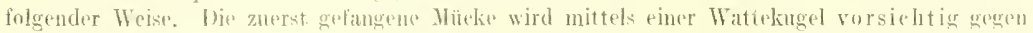
den Buden des Reagenzelases gedrangt und ilu hier gerade noch soviel Raum gelassen, dab sio sith

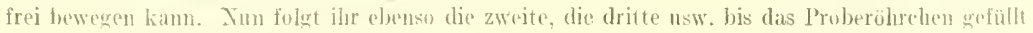

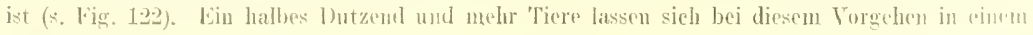

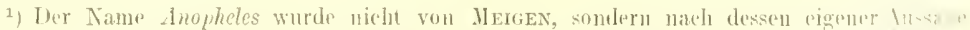

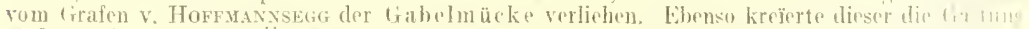

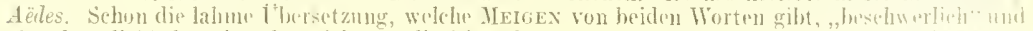

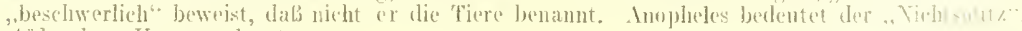
dëdes der "Lnangenehme". 
r.juzigen Röhrehen langen und getrement voneinander unbeschädigt und lebend nach Ifanse bringen, wo sie damn dureh lleranziehen der tiefer eingesto Benen Wattesepten mittels einer ]Jike]natul sufurt bufreit und in ein gröbres frefüb cinsesetzt werken müssen.

In den letzten Jahren habe ich aurh liänfig die von Tocht angegebenen ,flasreusen" be-

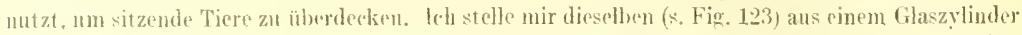

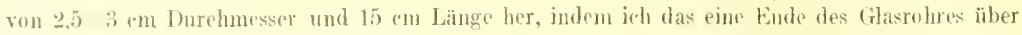

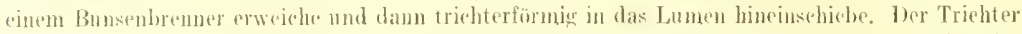
wird durh einen gewöhlichen kork (a) verstïpselt, waihrend das andere dureh eine im Mitteipunkt durchoherte Korkseheibe (b) ahgeschlossen wird, Ein Entweichen der Insekten ver-

Fiti. 12.).

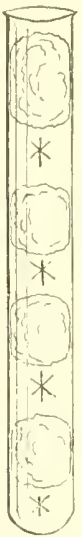

Realgenzg]at: mit gelangenen stechmïlcktrll (*), (O) rig. die dumels Watteliugern crotrentet simi.

fig. 123.

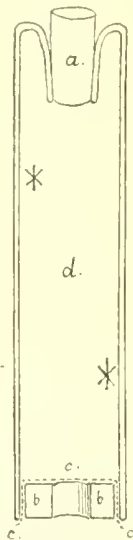

filasruse. a Korkstöjsel, $b$ inuchbohrte kurkicheibe, e Nulllïpprhen. Im Innenramums (d) befiuden sich zwei gefangemp Nürkell (*). (Origr.)
Fig. 124.

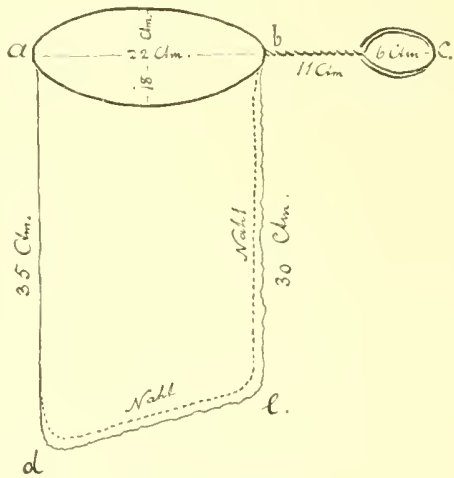

Xetz. (Orig.)

ab Tetzrahmen, be stiel und Handgrili, abde Netzbeutel.

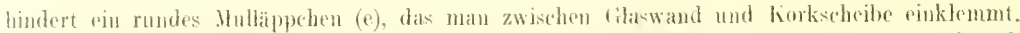

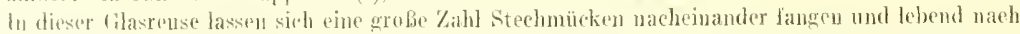
Hause luinger. So schön nnd unbeschädigt als in abgeteilten Reagenzelase bleiben aber die Tiere nicht; auch gelingt es bei lortgesetztem Gebrauche häulig rinigen der sehou cingeschlossenen Mücken, wieder zu entkinmmint.

\section{Kur Ausübung ler Jagd in Freien oder in gesehlossenen Rïunen zur Naeht-} zeit boclicut man sich des Notzes.

1)ats Xetz muls von soleher Gröbe und se gebaut seiu, dab es gebrauehsfertig, bequem

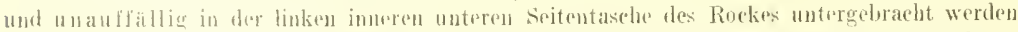

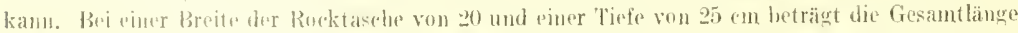

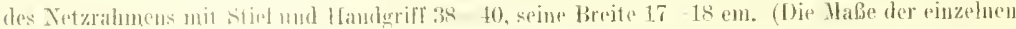

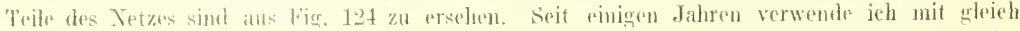

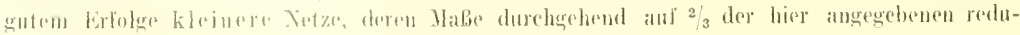
ziturt sint, )

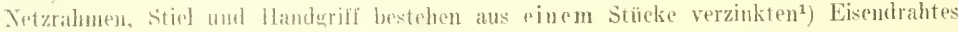

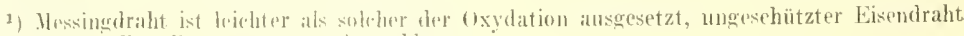

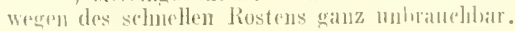



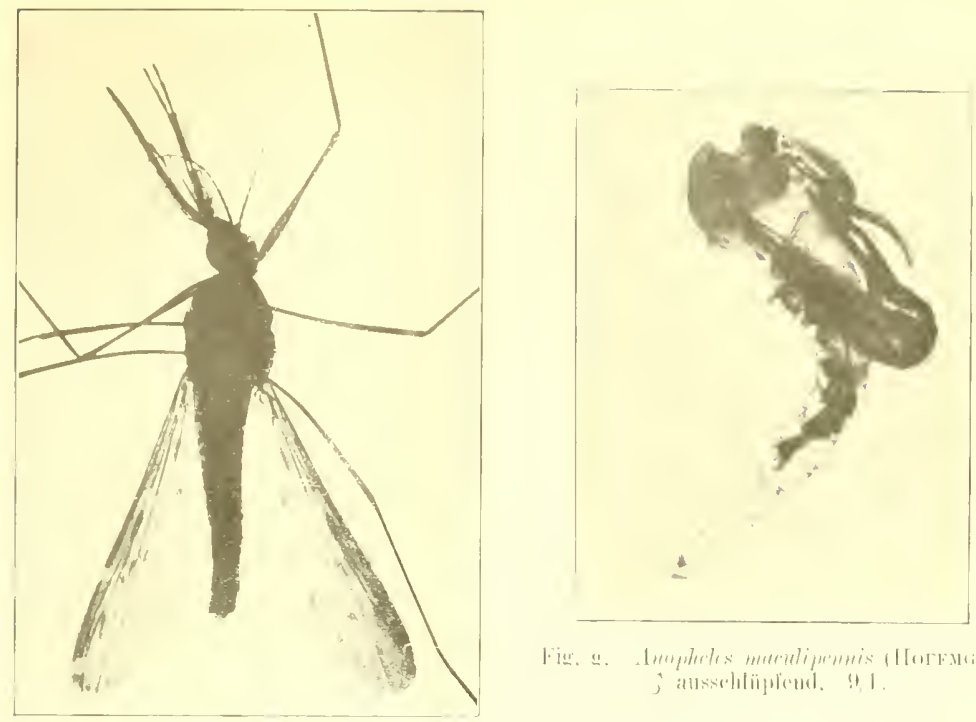

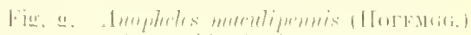

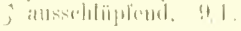

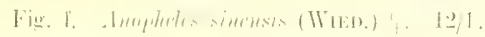

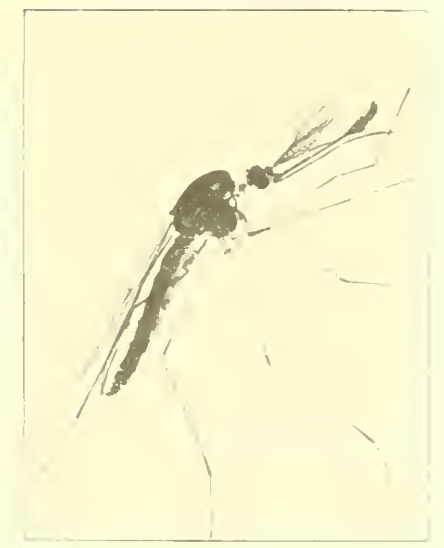

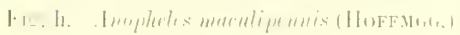
j. if 1 .

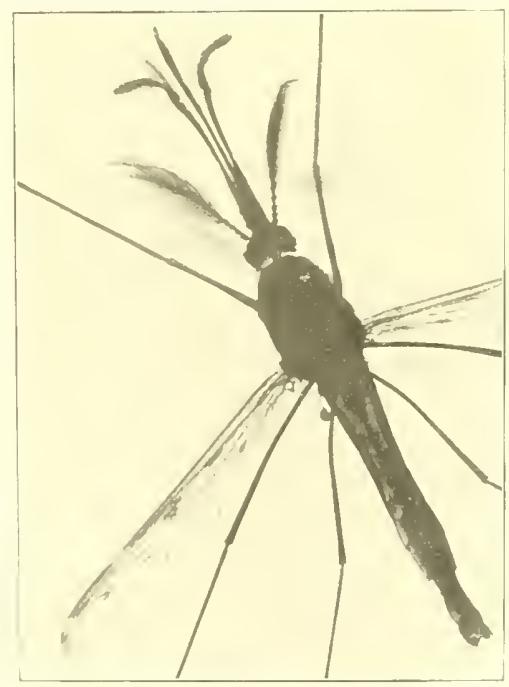

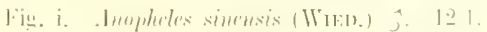





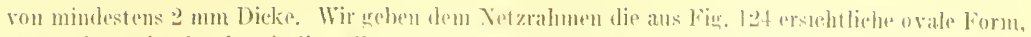
biklen den stiel dureh spiraliges Zas:ammendrehen der beiden Brahtenden und biegten diese ring-

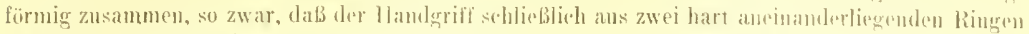

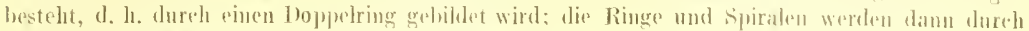
darïberfliegendes Zinn fest mitcintander verlotet. ${ }^{1}$ )

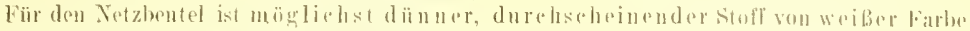

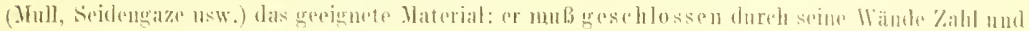

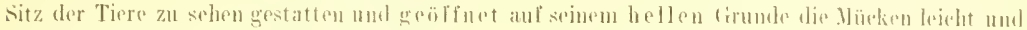

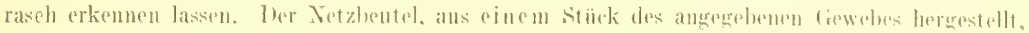

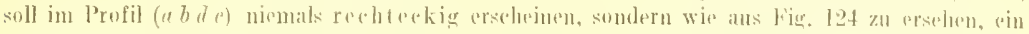

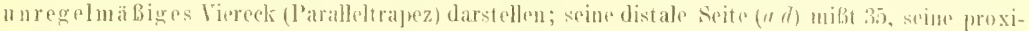

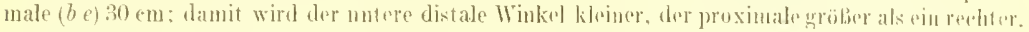

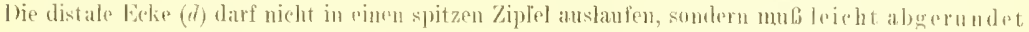

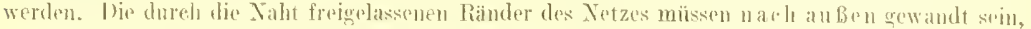
nm die im Innenranme aingeschosisnen Insckten nicht festzuhalten und zu vordecken. Boi so gestalteten Xetzhentel werden wir die Gelangenen stets in demspitzeren (distalen) Zipful antreffen und dureh Drehnng des Netzes um dio längsachse des Pahmens von der Anbenwelt.

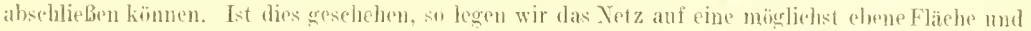
haben nun Zeit, ein Reagenzglas zur lufuahme des Fonges herzuriehten. Sollten sich inzwisehen

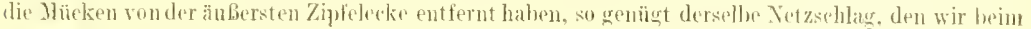
Fangen in Anwendung brachten, um sie wieder an die gewünsehte stelle zurückanführen. Nun hehen wir dits ganze Tetz mit dem laumen und Mitellinger der linken Hand an dem Zipfel d in

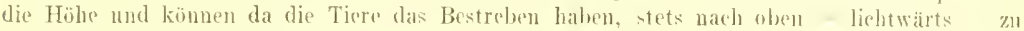
kriechen, es unbesergt offen herablängen lassen. J)ie Reghe liihrt alstam das unversehlussene Reagenzglas - Mïndung nach oben - in den Tetzhented rin, den dureh den dümnen storlt dercht

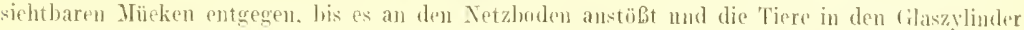
inneinfallen. Mit dem Zeigefinger der Linken wird mu der Xetzstofl gegen die Jlündung des Reagenz-

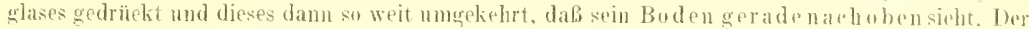
umgestülpte (hinks gemachte) Tetzhentel gestattet jetzt, die Beute geuau zu hetrachten und weiter zu behandeln, wie dies heim einfachen I'berdecken mit dem blaszylinder angesehen murde.

Bei allen Fängen müssen the notwendigen Sammofrermerlis gleich an ort und Stelle gemacht werden. Ian scheibt sie am besten auf die Papierblätter (oktav). mit welehen die emzehen Proberöhrehen wmwickelt werden, um sic vor Bruch möglichst zu sehützen. Es ist wiehtig die Angabe des ()rtes (im Walde, in der Nähe von ITohnungen usw.), seiner geologischen und klimatischen Verhältnisse (Temprratur, Luftemehtigkeit, Wetter), der Jalures- nnd Tageszeit, der Häufigkeit und des Gebahrens der Hïrken, des Namens des Sammlers.

Da die Zueht der Stechmäeken eine verhälnismäbig unfache Sache ist und wir ant keine andere Weise so leicht schöne und vollkommen unverletzte namentlich auch männliche - Tiere erlangen kömm. müissen wir uns, wenn w irgend angängrig, in den liesitz bon P'nppen. Larven mx Eiern zu setzen suchen. de weiter diese Vorstufen des ansgelikleton Lusktes in der Entwicklung vorgesehritten sind, $n$ m so mühedoser unt rascher werden wir bei der Zucht zum Ziele gelangen.

Larcen und Puppen. Das von mir in den letzten , Iahren anssehlieBlieh an-

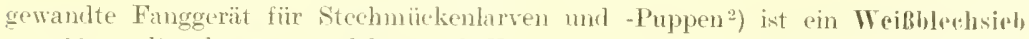
ron $10 \mathrm{~cm}$ Durchmesser. Welches nach Fig. I25 und 126 von jerlem Klempner hergestellt werden kam (Prein etwa 2 Mk.). Die Lörher im Siebboden dïrfen die Dureh-

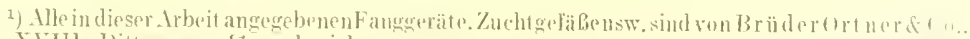
Wien IVIH, llittescasse 11 zll bezieher.

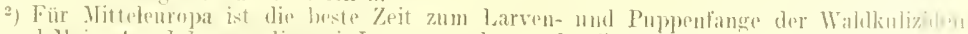
tpril und Mai. Anopheles mexulipemis-Larven werden am häufigsten im Juli und Augus, du wa Culex pipiens vom .Juni bis zum (Mtober angetrollen. 
ninswerübe von je $1 \mathrm{~mm}$ nicht übersehreiten, Der rohrförmige. leicht konisehe Hamlyriff ist inrch den mit der Spitze fest ${ }^{1}$ ) eingestoßenen Spazierstock, wenn nötig, zul virlängern.

Le grelang mir nichs soltem, mit diesem einfachen Ipparat ans reied besetzten Tümpe]n weit äbrer 100 Pujplen mud Larven auf tinen \%og herausufischen.

Hat man den fiag atus dem Wasser gehohen und oberflachlich gemustert, so taucht man den sibloboden wieder ein, läbt durede leichtes Xeigen die Tiere mit einer geringen Menge des

Fig. 12\%.

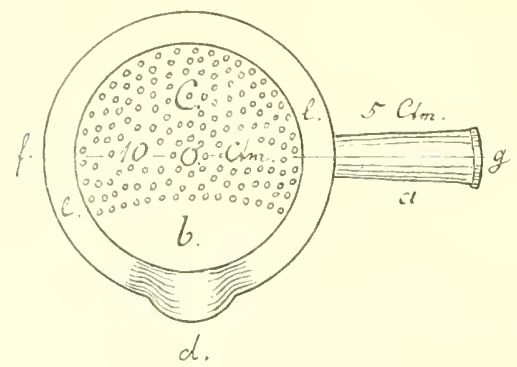

Fig. 126.

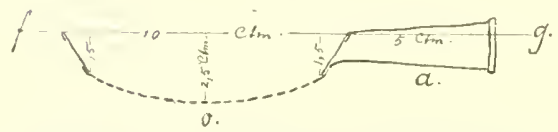

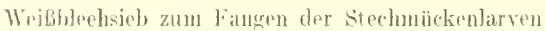
und - Pruppen von when and Vurtikaliclunitt, $f$ bis $g$

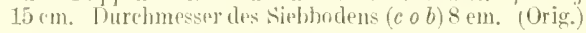

In den letzten Jahren habe ied die siebmaße weit uröber, his zum lopplettell der lier angegebenen Verlıältnisce, gewählt. wiedereingedrungenen Wassers illif dem undurehlässigen Tejle (Fig. 125b) zusammenkommen und giebt sie mun in das bereit gehaltene Transportgefali.

Im besten verwendet man zu diesem Zwecke ein starkwandiges (ilas, welehes nur habb mit Wasser gefüllt, dann aber fest verkurkt werden darl. J)ie von mir gebrauchten viercekigen cijarer fassen bei einer Hohe vou 10 , einer Breite ven 3,5 und einer Yundweite von $2 \mathrm{em} 50 \mathrm{~g}$ Wasser; in den lineingegebenen $25 \mathrm{cem}$ Wassers habe ich, ohme den liurk zu lëftem, stundenlang mehrere Hundert Lializidenlarven und -Puppen setbst bei huher Lufto temperatur mit mir gefülurt und alle lebend nach laause gehracht. ${ }^{2}$ )

bas sin] ist beruem in der linken unteren zubereu seitentasche des Rockes zu tragen; während das Glas mit den gefangenen Larven und Puppen, ditath das Taselentuelı in aufrechterstellung geladten, in der linken oberen seitentasche semen Platz findet, da es an dieser stelle dureda die Bewegungen des kirpers beim Geleen usw. am wenigsteu erseluätert wird.

Lis lälit sich zum Larven- mul Puppenfange natürlich auch ein feinmaschiges Tiillnetz verwenden; cbenso ist der von Scundo-Sehwedt ${ }^{3}$ ) angegebene Apparat. dessen flacher beatel ans einem Gewebe von weiben l'fercheharen besteht, reeht bratuchar.

(1) eine Wascransammlung äberhaupt Stechmückenlarven nud f'uppen enthäl, gerwaht ein geühtes Auge sufort an der leichten Einsenkung (s. Fig. I05) des 11 atsserspjegels, die jodesmal da entstelit. Wo das Tier sich mit seinem Atmungsfortsatze an der Oberfläele anfhängt. Die Larven selbst sinel gewöhulich num damn zu sthen, went sie sith von hellen an Grunde liegenden Gegenständen ablebent).

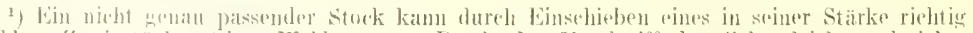

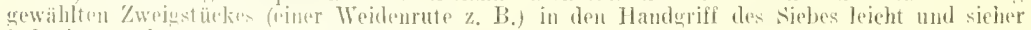
befestigt werdint.

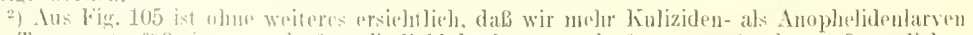

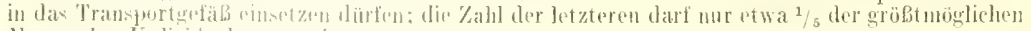

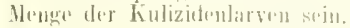

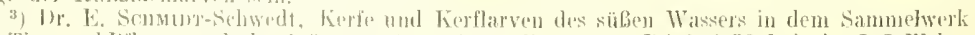

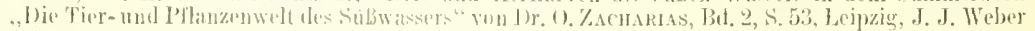
$[x(1)]$.

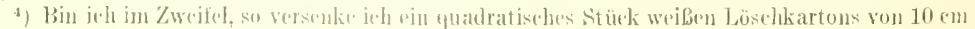

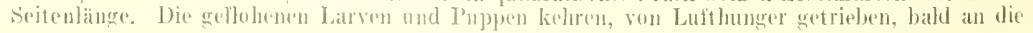




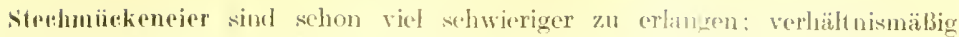
leicht grelingt es noch, die Eierkähnehen von Culex pipitms und culex annulatus aulzutinden. welche als rubflocken- oder mausekotähnliche Gebilde auf rler Wasseroberlläehe von Regentonnen und kleineren Tümpeln in der. Nähte von mensehlichen Wohmungen unherschwimmen (s. Fig. 127b). Die cinzeln getegten Eier von Walelkulizinen, von Anopheles, Lëles usw. dürften für gewölnhlich nur von gefangenen, whlerhaltenen urd blutgenährten weiblishen Tieren iur Zuchtglass zu gewinnen sein.

Bofhandlung der lebenden Tiere. Die Stechmiieken, welche lebend beobachtet, infiziert oter zur Zucht verwentet werden sollen. bringen wir in ein kleines oben mit Inll verschlossenes Vivarimn oler einfach in ein gewöhnliches weibes Zylinderglas, wie es unere Hausfrauen zum Eimmachen von Früchten verwenden:

Fig. 127.

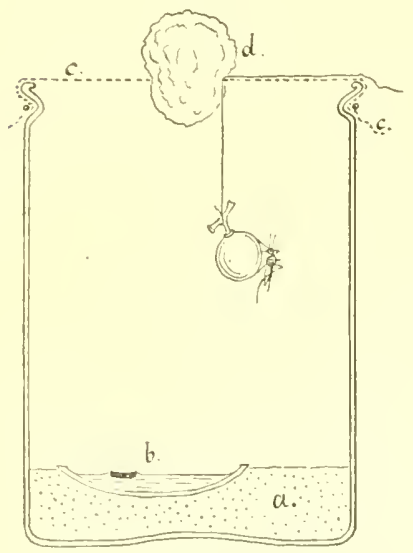

Erklärumg in Texte nachzulespen. (0riginal.)
Fig. 128, 1 .

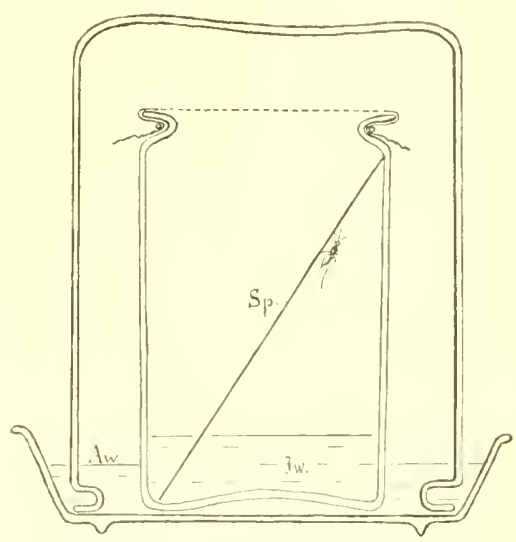

Fenclite Kammer zur Stechmuickenzuclit. (O)riginal.)

A $r$. AuBenwaser, I $u$. Innenwasser, sp. Hulzspin. Ilis Luiftung des Kammerrammes erfolgt dureh de!n Waserring $d u$.

es brauchen cliese Gläser nicht höher als 15 und breiter als 10 cm zu sein. Der boten des GefälBes (Fig. 127) ist mit einer :3 em hohen Schicht feinen Kieses (a) belegt. welche ein tiefes, etwa $6 \mathrm{~cm}$ in Durchmesser haltendes Lhrglas $(b)$ aufnimmt. las zur Hälfte mit gekochtem (sterilem) Wasser gefüllt sein mul3. ${ }^{1}$ ) Die Weibchen benötigen dieser Glasschale, um ihre Eier abzulegen; fetztere müssen dann in ein größeres. Aguarium uberführt werden. Die Iündung des (Xlases verschließt eine Mullseheibe (c), in teren Hitte sich ein 4-5 gen grobes imnles Loeh befindet, das für gewöhnlich durch einen Wattepfropf $(d)$ rersehlossen gehalten wird. Es gestattet diese Öfnnng, die Mücken sicher in clie (tläser einzubringen, ihnen Nahrung zuzuführen unt sie auch leicht mittels eines Reagenzglases wieder herauszufangen.

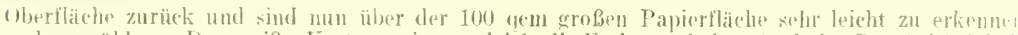
und zu zählen. Der weibe Karton zeigt zugleich die Farbe mol don cirad de! Durehsichtioki des Wissirs.

1) Toch einfacher ist es, die sandsehicht granz wegzulassen mul anl den Boden d w i id

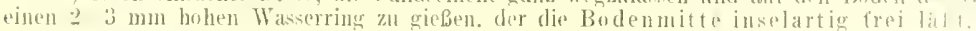

Meuse, Handbuch der Trojenkrankhpiten, 2. Aufl. I. 
Wïhrend es nun low den meisten Sterhmäckenarten gar nicht sehwer hält, in grwahnlichen

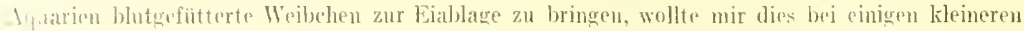
und emplindliehen sjozies bis zum sommer des Jahres 1941 auf keine Wrise gelingen.

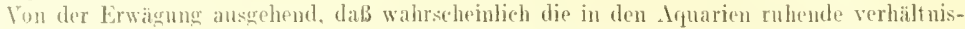

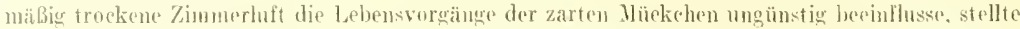
irh die in Fig. 128 abgehildete fenchte Kanmer zusammon. Sie besteht in der Hamptsache aus vinem tiefen Tellev und zwei gewöhnlichon, verschicden wroBen Fruchtghisern.

loh wurde in meiner frwartung nicht getäuscht und hatfe von da ab kaum noch einen Vib-

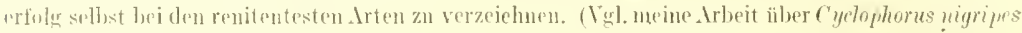
jun Mreh. f. Sehiffs- und Trupen-Hyg. 1912. S. 421ff.)

Puppen. Larven und Eier bringen wir in ein kleines, uben mit Mull verschlossenes mul mit Algen mol sonstigen Wasserpflanzen ${ }^{1}$ ) spärlieh besetztes Iyuarimm, das sute Gelegenheit bietet, die Entwieklung der Tiere an beobachten und sie heranreifen zu lassen. Alle Gefäbe, welche gellïgolte Stechmücken ouler deren Brut enthalten, diirten niemals them direkten Sommonlichte ansgesetzt werden. ${ }^{2}$ )

Nach jahrelangen Versuchen mit allen mögliehen pfanzhehen und tierisehen sitoffen fand ieh die beste I arvennahrung in den ïber Heuanfgüsen bei mimdestens

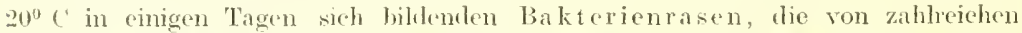
Paramezien aufgesucht mol algeweidet werden. Niodrigo Temperaturen verzögern the Entstehung des Pilzrisens beträchthch, auch tritt dann leicht schärliche schimmelhilınng auf. Dic schwimmente bakterienckeke ibbertrage ich stïckwrise mittel eines ausgeglizhten l'Jatinspatels auf die II asserfläehe der Zuehthehälter.

lionservienum. Die getöteten Stechmücken kömnen wir in getrockneten Zustancle oder in Flissigkeiten ${ }^{3}$ ) anflewahren; jecle der beiden Lónservierungsmethorken hat ihre Totejle und ihre Mängel.

Beim Eintroknon schrumpfen die Leiber und firdmaben der Tiere betrahtheh und nehmen ein mmatürliehes, verkriippeltes Aussehen an, nur die Flügel, Borsten, Hatare, Schuppen usw. bewahren ihe normale Crobe und Form. Intakt aber bleiben vor allem in vollkommener Treue die Pigment-und sogar die sie hiller-(Interferenz-)Farben und in ihnen die wichtigsten diagnostisehen Jlerkmale der Irten.

Die feuchte Auflowahrung dagegen erhält die Form und llaltung der Sterhmücken in tadelloser Weise. Sie crhält auch die in ihren Leibern wohnenden Parasiten und ermöglieht ein späteres Eimbringen in Kanadabalsan odor dats Einbetten in Zelloüchin resp. Paraflin zwecks llerstellumg von sirhinttserien.

Dic zu konscrvierenten 'Tiere mïssen möglichst balı nach der lfomkehr grefïtet werden.

HForzu verwendet man die lonkannten Tötungsgläser, an deren Boden eine Zyankaliumstange liegt, die durch leirht arhätrnden Gipsbrei dort nmsehlossen mol festgehahen wird. Itber der

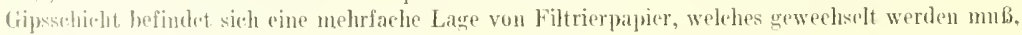
solsatel es feucht arworden uud vergilht ist.

Noch enlarher ist es, die There mittels ather-oder benzingetränkter Kantonstreifen, die man zwischen Waftepropl und Glaswand in dic Proberohrehen rinsehiebt, zn töten.

Sollen div. Mïrken genadelt werlen, so hat dies sofort nach dem Ableben zu geschehr'n, da auch clie scringste Mazeration oder Eintrocknung das Nadeln crheblich o'seliwert

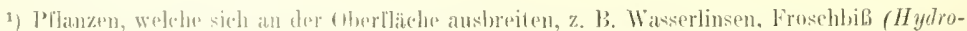
tharis) usw. diartan nicht verwendet warden, da sie die Tirre am Itmen hindru.

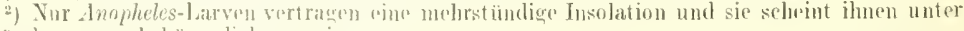
l'mstäulen sogar lowkimmileh zol seint.

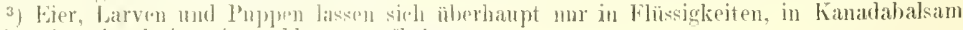

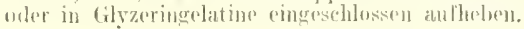




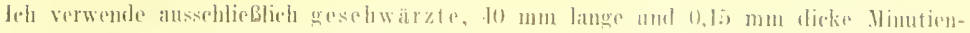

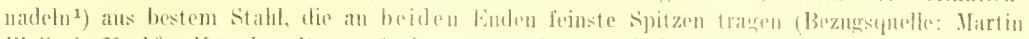

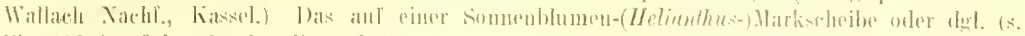

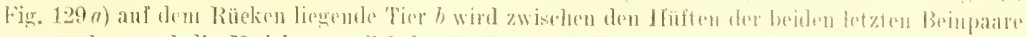

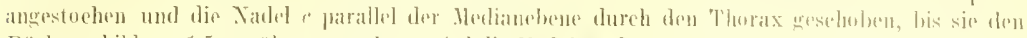

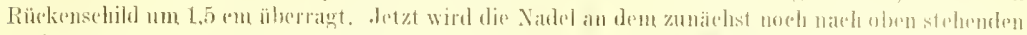

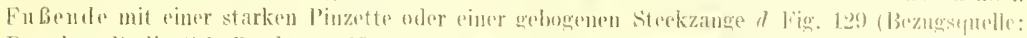

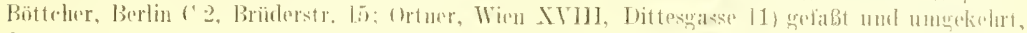

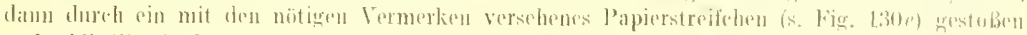

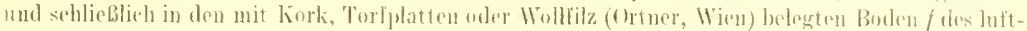

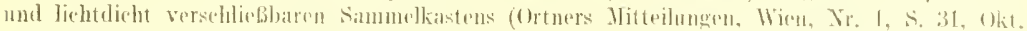

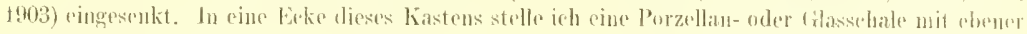

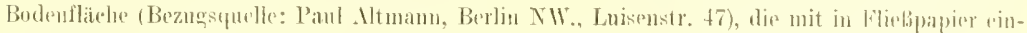

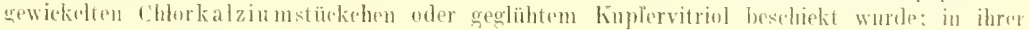

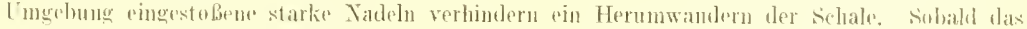

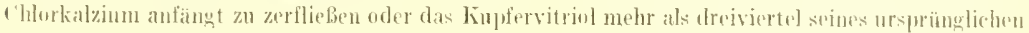

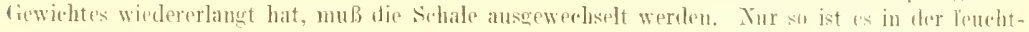

Fio. 129

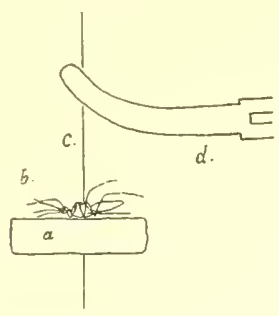

Tadelnder stev-hmückell. (1)rig.). (Indieser stellung werden die Tiere for dem Einbringen in diesammelkästen getrocknet. Diedureh Blaseu oder mit piner Pripariornalel in möglichst naturliche Haltung qebrachten Körperteile bewatren so am besten die gewünschte Lage.)
Fig. 1:30.

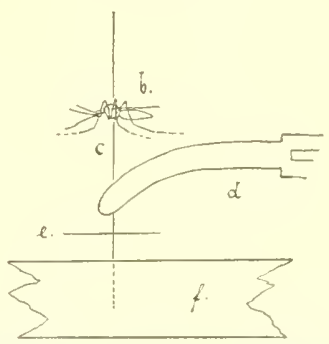

ibretragen der genadelten stechmüekon in den Sammel- oder Vrrsandkasten. (Orig.)

warmen Tropenhut möglich, dio Stüteke vor dem Vischimmeln za bewahren. welches sip anderenfalls in küzester Frist bis zur Inkenntlichknit entstullt. liegen tierische Parasiten empliehlt es sich, ein stuekchen Taphthalin oder einen allwöchentlich zu wechsehnem benzingetränkten Wattebanseh mittels riner Xadef am kastenhoden za ludestimen.

Sinllen die 'Tiere nugenadelt getrocknet worden, so wirl man in den Tropen in folgender Weise vorgrohen:

Luf Filtrierpapier, nicht zu diclıt gelagert, werden die Nläcken in rinem Brütschranks luei

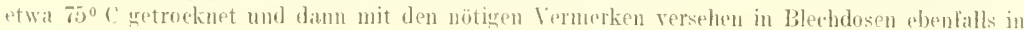

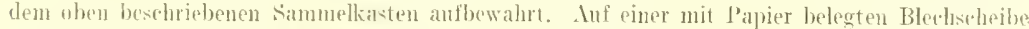

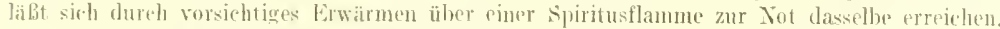

Bei Sonnensehein kommt man leicht zum Ziele, wem man die Tiere in einer gröberen Bleclsdose, deren beckel sehicf und klallend auforestat ist, der Einwirkung der Sommenstrahlen derart

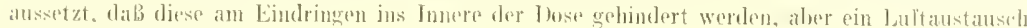
jekerzeit mögliell ist.

Wenn ande nexh immere und ron versehiedenen sejten emplohlem wimi.

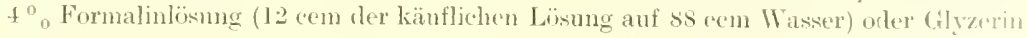

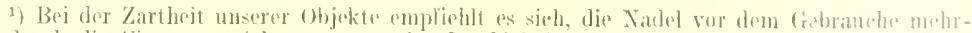

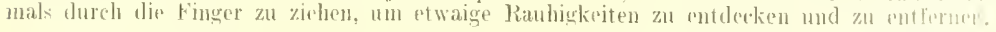


zur fachten kionservierung der geflïgelten Insekten zu verwenden. bin ich clem $75^{\circ}$ o Alkohol bis hente treu geblieben, er ist und bleibt die für unsere Zwecke an besten gecignete Flüssigkeit. Formalinlösung und Alkohol absolutus machen die Nïeken zu hart und brïchig und deshalb füx den Versand ungecignet. Warum Glyz'rin der $75 \%$ Alkohollösung vorzuziehen sei, ist mir unerfindlich. Es ist wiehtig. bei einer größeren Anzahl von 'Tieren die lionserviorungsflüssigkeit in den ersten vier Wochen 2-3mal zu wechseln. Jedes Glas muB clie notwendigen Sammelvermerke tracen.

Die haltbarsten Präparate gewinnen wir durch Einsehhß der Mücken in lanarlabalkam. Sie werden zu dienem Zwecke nach mindestens zweiwöchentlichem

Fig. 131.

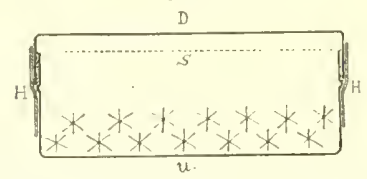

Blechelose mit stechuriicken (*) rïr denl Tropen- und seversand hergerichtet. (1)rig.)
Liegen in $75 \%$ Alliohollösming auf 24 Stunilen in Alkohol absolutus und dam für die gleiche Zeit in Xylol gebraeht. Jetzt sind sie geeignet, von dem im Hohlsehliff des Objektträger's befindlichen 'Tropfen Balsam aufgenommen zu werden; ein Deckglas, an dessen unterer' Fläche ein 'Tropfen Balsam hängt, wird aufgelegt und bildet (lam den besten Schutz für das eingeschlossene Insekt. ${ }^{1}$ )

Es mögen num noch ein par Vorsehriften folgen, die auf das Verpacken und den Versand der konservierten Stücke Bezug haben.

Ich stelle hier zumächst die Grumdsätze für die Tropen-und Seetransport $t^{2}$ auf; sind die klimatisehen V'erhältnisse des betreffenden Landes den deutsehen ähnliche, so wird man beim Verschicken von getroekneten Stechnü̈ken in viel einfacherer Weise vorgehen kömen.

bie wolıl getrockneten Tiere werden lose, möglichst nath Arten und Fängengetremnt, in runde absolut trockene, auf etwa 75-100 (' erwämte Blechdosen (Fig. 131) von 3-5 ('m Deckel-

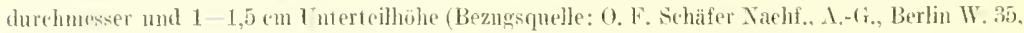
Lützowstr. 107/108: Verein. Graba- und Schregerwerke, MejBen. Sachs.: Intom Reiche, DresdenP'lanen, Preis dee Dense 0,75 bis 1,6 Pig. bei Bezug von mindestens 500 Stück) gelegt: (lann überdeckt man den Unterteil $(U)$ zunächst nit einem Blatte leiusten Seidenprapieres $(S)$, anf wejches die nötigen Sammelvermerke zu schreiben sind. Das Papier soll den Rand der lose nm mindestens 1 rm ïberragen ind beim Sehließen dersethen zwisches beckel $(D)$ und I'nterteil eingeklemmt werden. Die an unteren ldeckelrande heranssehenten Tejle des Papiers werden durch cinen kräftigen Jlesserzug abgetremnt und mit einer P'inzette vollständig entlernt. Die Berührungsstelle vou Deckel

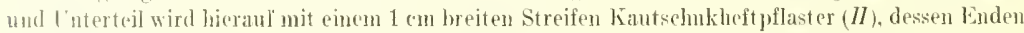
übereinander greilen müssen, ringtormig mmgangen, und so ein sicherer schutzwall gegen eindringends Lulterachtigkeit gesehaffen. Es libt sich cine vollkommen gentigende bichtung auch durch eincon l'araffinring erzielen, den man mittels cines bremnenden J'araflinkerze um die Dose herumzieht. Ringe von Wrachs, Kanadabalsan oder. Asphaltack geben ebenfalls vorzügliche Resultate. Vor dem Versand wird jode Josp in Seidenpapior eingeschlagen und mit gleich groben fest und unbewerlich in jassende Kisten ciugesetzt, die am besten mit verlotbarer Zinkeinlage versehen sind.

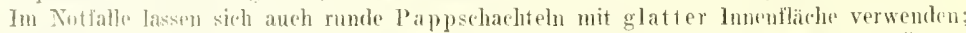

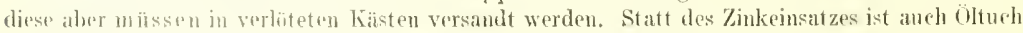

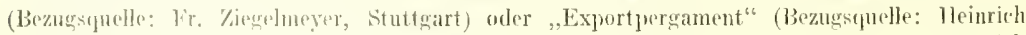

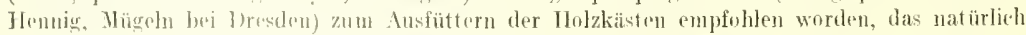
an den lreien Rändern mil einer Tarzliosung u. dol. zu verkleben wäre. Trockene nud erwärmte.

1) In der letztru \%eit habe ich statt des Xylols auch Azeton verwendet: der Stoff löst sicl

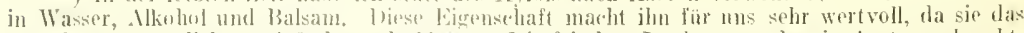

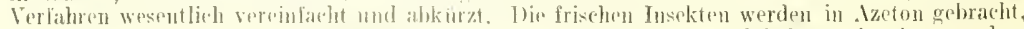

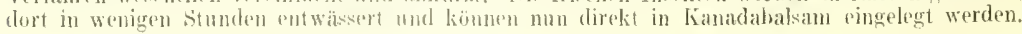




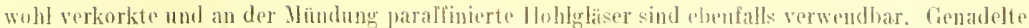
Insekten werden fest in den weichgefütterten (Korkphatten usw.) Boden kileiner kidsten eingestedkt.

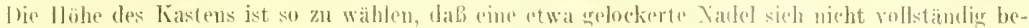

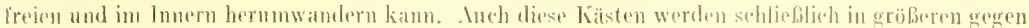
Fenclutigkeit gesclututzten listehen vereinigt.

Spiritusmäcken versende ich seit . Jahren nur nod in zylindrischen (dis-

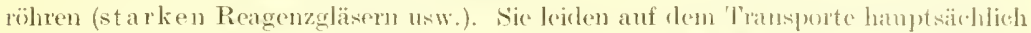

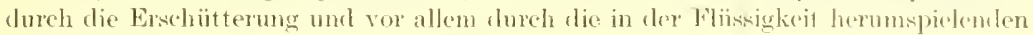
Luftblasen.

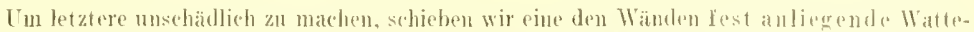
kugel in die Flüssigkeit des mit spiritusmïnen besclickten Reagenzglases so (s. ["ig. 132) hinein,

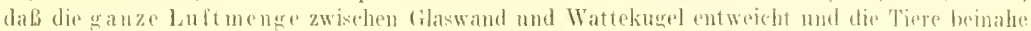

Fì. 132.

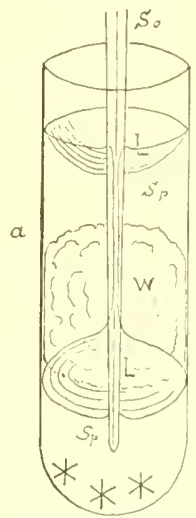

Herauslassen der unter der Wattekugel (w) belindlichen Luftblase ( $L$ ) mittels einer hart in der Giaswand herefoürten Hohlsonde (So). wrlche gleichzejtig die Watte bodenwärts weitersehiebt. Xach dem Heranszichen der sonde ist die in der Wattekugel zurjickblejbende Rinne mit der sondenspitze zuznstuBen. (Orig.)
Fig. 133 .

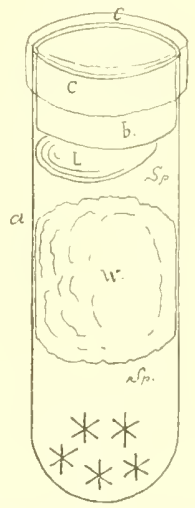

Versandfertieres filastolir (a) mit Stedounichen

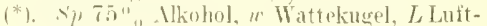
blase, b korkstojpel, (" Parallimkappe. (Orig.)

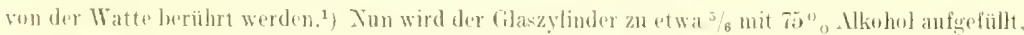
fest verkorkt unel an der. Mündnog in geselomolzenes Paratfin eingetaneht (s. Fig. 133). ${ }^{2}$ ) Eine klein lultblase mub zwishen Stopsed und lotztemgeführter. Wattekugel zuriukbleiben, da anderenlalls bei Wairmezunahme das tilas gesprengt oder mindestens sein Versehub getoekert werden wïrde: sie kann ja auch keinen Schaden auriehten, da in diesem Teile des Glases sich krine Hücken befinden. Jit Sammelvermerken versehen nud einer Wattelage wohl umwickelt werken die Giazer dann in entspredbemben Kistehen fest verpackt.

Eine rinzelne Röhre findet den passendsten schutz in den balkenförmigen, holuzylindriseh

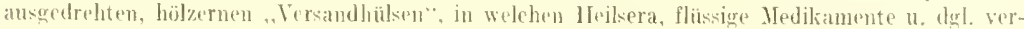
sedickt werden; in jeder Ajothete sind solche leicht crhältlich.

1) Es können natürlich in demselben GatiiBe anch mehrere Arten und fainne, durch weitere Wattekugeln getrennt, untergebracht werden.

3) Dies geschieht am besten erst wach 24 Stunden. Häufig Jiklen sich nämlich in den spoten.

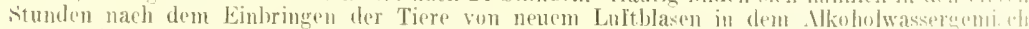
(namentlich wenn dies frisch hergestellt wurde) und müssen damn obenhalls sorarlialtig pntf rnt

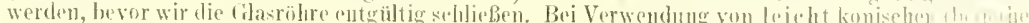
zylindrisehen) liantschukstöjsedn ist der P'aralfinüberzug. entbehrlieh. 
Widerstandsfähige Arten, z. B. Culex (Stegomyia) fasciatus, überstehen ganz cul weite Reisen und sind in watteverstöpselten Gläscrn. deren Innenluft durch getränktes Fließpapier fencht gehalten wurde, mehrfach lebend nach Europa gekommen. Eier in lebendem Zustande zu versenden, macht noch weniger sehwierigliciten; es genügt, dieselben auf einem angefeuchteten Streifen st e rile $n$ Filt rierpapieres verteilt in keimfrei gemachte Glasgefäße einzuschieben und diese gut zu verkorken.

\section{Intersmehung. Infizierumg usw.}

Die Lntersuchmo weiblicher stechmüeken anf Malariajarasiten. Filarialarven ısw. sollte, wemn irgend müglich, an lebendem Materiale vorgenommen werden; sie ist unter diesen T'mständen verhältnismäßig leicht anzustellen, während die Einbettung konservierter Tiere, die Herstelhung entsprechend feiner Sehnitte und deren weitere Behandlung eine sehwierige, zeitranbente und bei nicht tadelloser Konservierung eine molankbare Arbeit ist.

Fiv. 134. (0rig.)

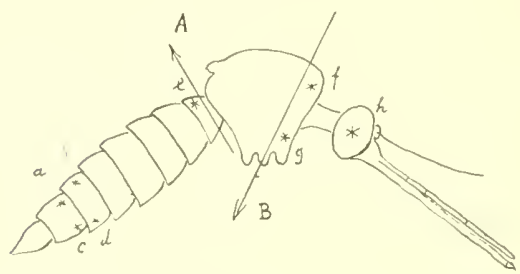

Die mittels Ätherdamptes betäubten Nüicken faßt man an einem Flügel; dhurch leichten Zug werien dic Beine, welehe stets in Hüftgelenke sieh ablösen, entfernt und hieranf dureh etwas stärkeren Zug auch die Flügel beseitigt. Das seiner Extremitäten beraubte Tier legt man auf einen mit $0,5^{\circ}$ Kochsalzlösung befeueliteten Objektträger und trennt mittels eines feinen Messerchens das Abdomen von dem Thorax durch

cinen Sichnitt im arsten Hinterleibsring (Fig. 134. Pfeil A). Hierauf wird die Verbindung zwisehen tem 6. und 7 . Leibesringe vorsiehtig gelöst, indem man gleichzeitig je eine Nadel im Punkte a und $b$ (Fig. 131) einsticht und die Ringe anseinander zerrt; dasselbe gesehieht damn von den Punkten $c$ und d aus. Num sticht man die aus J'unkt d gezogene Nadel in l'unkt e cin, und jotzt folgt cinem leiehten Zuge von Punkt $r$ aus hei nïchternen 'I'ieren unfehlbar Darmkanal und Magen mit den sehlangenförmig gewundenen Malpighisehen Gefäßen. An de’n Eileitern hängend folgen auch die Ovarien. die als traubenförmige Gebilde zu beiden Seiten des Darmkanales liegen. Man gibt num ein par Trojfen $11.5_{0}^{\circ}$ Kochsalzlösung hinzu, nm etwaige Fettröpfchen usw. abzuspülen, überträgt dann die Teile in einen Tropfen $0,5 \%$ Kochsalzlösung. der sieh auf einem reinen Objektträger befindet, und legt vorsichtig ein Deckgläsehen auf. Es lassen sich so die Organe längere Zeit hindureh lebent beobachten. Man sieht sehr sehön die peristaltischen Bewegungen des Magendarmkanales und die Kontraktionen der Eileiter und Orarien. Bei befruchteten Weibchen beobachtet man häufig das Austreten der sehr beweglichen Spermatozoce ans den Spermatheken und an den Magenwänden etwa vorhandene Parasitenrysten.

IIähend man die Baneheingeweide recht wohl mit unbewaffneten Auge herauspräparieren kann, empfielılt es sieh zur Isolierung der Speichedrüsen eine Präparierhape oder noch besser ein Stereomikroskop zn verwenden. Die Hücke ist wie oben angegeben gelagert; wird nun mit einer Präpariemadel der Thorax in seiner Nitte zusammengedrüclst, so tritt der Jlals weit herror. Ein Sehnitt in der Gegend des Pfeiles B trennt ilm mit den vorderen 'Teilen der Brust von dem übrigen 'Thorax. - letzt reilst man von dem Punkte of und / aus das Brusthalsstück bis zu seinem An- 
satze am Kopf auseinander, fixicrt diesen dam durch eine im l'unkte h cingestochent Nacke! und streicht mit der zweiten Nialel die am Boden der Mundhible (Hypopharynx) hängenden Speicheldrïis(n al). Trotz der Kleinheit der (Orgathe gedingt w

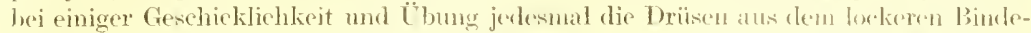
gewebe herauszuheben; sic sind dreilappige, in den vorleren 'Teilen des "lhorax (s. Fig. 97 gl.sal.) liegendr. Gebilde, welche einem Bïndel ungekränselter Stratulien-

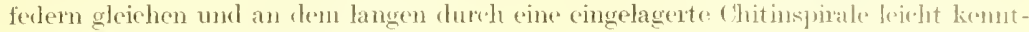
lichen Ausfiihrungsgange hängen.

Ein leiehter Druck auf das Deckglïsehen läßt in die $11,5 \%$ Kochsalzlösumg einen 'l'eil der' etwa vorhandenen sichelkeime, namentlich aus dem mittleren l neilsenlapjen heraustreten, die sich dam in wirbelnder bewegung in dor erwärmten (*35 bis $\left.41^{\circ} \mathrm{C}\right)$ Flïssigkeit verteilen.

Zur Färbung der frischen, kurze Zeit mit " " Formalinlësmug behandelten Paraxiten rerwende ich noben der Romanowskychen (G1Eu:1) anch konzentrierta. wăsserige Itethylenblaulösung.

Hanklelt es sich darum, konservierte Itücken anf Parasiten zu untersuchen. so) muß man sich daran erinnern, daßs die oberhant der Insekten für geschmolzenes Paration, Zelloidin- oder Photoxylinbömeg vollkommen undurehdringlich ist: es gelingt deshalb wohl, die Tiere in solehe Stoffe cinzubetten, nicht aber sie mit denselben zu elurchtränken. Hierzu ist es nötig, die Chitindecke rorher dureh seichte Einsehnitte zur ritzen.

Nun läßt sich leicht das vollkommen entwässcrte Insekt (mehrstündigess Einlegen in Allsohol absolutus oder Azeton) mit geschmolzenem Paraffin oder Zclloüdinlösung durchtränken und in cliese Stoffe einbetten.

Wenn auch the Einschmelzung in Paraffin (lie besten liesultate liefert, so)

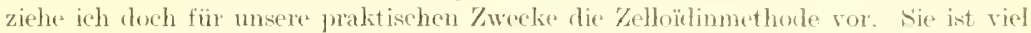
einfaeher. ermöglicht genane Orienticrme mol macht vor allem die Benutzung eines Wämoschrankes umötig. Nan darf auch nicht vergessen, elab bei den reslatis hohen 'Temperaturen, welehe die Einsehmelzung in Paraffin crforclert, die ciewebe beträchtlich sehrumpfen, und so kommt es, daß ein Schnitt ron 7 Mikren l)ieke eines Paraffinpräjarates einem solchen von ot wa lo Mikren cincs Zelloirlinpräparates entspricht.

Im stechnieken zu infizieren. lälst man sie zu gecierneter Zcit das Bhut ron Tarasitenträgern saugen.

1) ausgehungerte Jiocke wird am einfachsten in einem weiten Reagengelase eingeschlossen auf eine passende Hautstelle des Kranken gebracht und hier cinige Zeit ruhig gehalten. In der

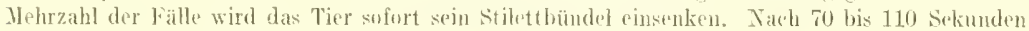

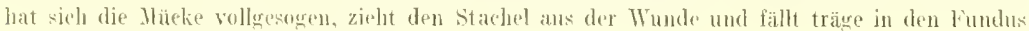
des umgekelurten Röhrehens zurück.

Zum Zwecke der Märkeninfektion sind auch verwehedene Kälige angegeben worden. Durch

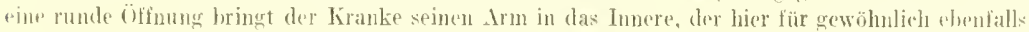
shling von din stedhmürken angenommen wird.

Derartig gefütterte Ilïken müssen dam bei Temperaturen von 25-300 gebalten werden.

Die Entwicklung der larve von Filaria banerofti in der Stechmileke (in diexem Falle dem Zwischenwirt) wirt von Looss in einem der folgenden Bänele dieses Werkes beschrielen werten, so dab ich hier un auf seine loarstellung zu verweisen brauche

Die Infektion des Mensehen mit Filarialarven erfolgt naeh Angabe aller Autoren während dess Stechens der Mücke, aber iber das Wie bestehen noch hente gen is . Meinungsrersehiedenheiten. 
Wemn nach eingen Wochen die in dre Hüeke herangereiften Filarienlarven ans den Nuskehn in das Blut zurïckgwandert sind, verbrejten sie sich im Zölom nach allen Richtungen; sie gelangen (4) ancls in das Labinm, die Stilettbündelscheide, kriechen aus der beim sangakt stark geknickten and unter den gegebenen Verhältnissen leitht berstenden Interlippe herans und dringen dann dureh de Wunde in des Körper des definitiven Wirtes, des Mensehen, ein.

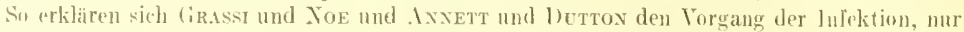

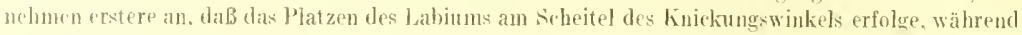
die letzteren die diume Thant an der Basis der Labellen einreißen lassen.

lih sprach seton 6905 (1. Autl. d. Werkes, Bd. 2, S. 76) die Ternutung ans, daß die anf die Ilaut des Mensehen golurathten Würmehen vielleicht auch durch die Haarfollikel in unseren Körpes. gelangen könnten. da dies dured die seloünen Beobachtungen von Looss an Ankylostomum-Larven (s. L. Aull. d. W., Bd. I. S. 130) sehr wahrseheinlich genacht werde. Yleine Insieht wurde später dureh fílLEBoRx experimentell bestätigt.

Die dritte Erkiarung des Infektionsmodus warde von S.mво gegeben. Er nimnt an, daß die Würmchen die O)ophatguswand durchbohren, den lianal Jes Labrum (s. Fig. 95 S.R.) durehkriechen und so in das Blut des Jenselen einwandern.

Tarh den Benbaehtungen von Senumbix findet bekauntlich eine Entleerung des Torratsmageninbaltes vor Beginn des Sangaktes regehmäßig statt; es liegt nun, meine ieh, sehr nahe, anzunehmen, daß die sehon frïler in den Vorratsmagen direkt eingewanderten oder auf de m Wege der Flugblasen aus der Brustmusulatur in den Ösophagus gelangten Filaria-Larven mit Jem ])ivertikelinhalte durch den Sangkanal (s. Fig. 95 S.R.) in die Blntmase des Mensehen linïbersedruiekt werden.

Der Lebenslanf des Plasmodimm ist hente in allen seinen Phasen genan geliamnt. und dïrfte dureh das angefïgte Schena am einfachsten erläutert werden.

\section{Sthema des Zeugungskreises.}

(Generationswechsel mit Wirtswechsel) des Plasmodium praecox (irassi und Feletts nach den Forschungsergebnissen von Gr.ssi und Scmatorx.

1. Eindringen aes Sichelkeimes (Sporozoï) in cine rote Bhtzelle. 2. ansgewachsener Schizont. 3, begimende T'eilung (Sehizogonie). 4, Freiwerden der Merozoïte, die größtenteils über I den Kreislauf der ungeschlechtlichen Vermehrung von nevem leginnen, oder andercrseits sieh in ten Blutkörperehen zu männlichen und weiblichen Geschlechtsformen entwiekeln (5 und 6). In ten Miiekenmagen gelangt, werden die sogenannten Habmonde ( $7^{\text {a }}$ und $7^{\text {h) }}$ ) kugelförmig (Sphären) ( $8^{2}$ und $s^{\prime \prime}$ ). Jic männlichen Parasiten lassen die .,Geißch" (Spermatozoen) aus ihrem Körper anstreten (9). Dic Spermatozocn schreiten alsbald zur Kopulation (10) und der befruelitete weibliche Körper (Copula) nimmt Würmchenform an (11). Solehergestalt. ist or trefähigt in die Epithelzellen der Magensehleimhant einzudringen und kommit untrr ihnen zur Ruhe. mm hier eingekapselt zu werlen. 12, Kenteilung in ter Oozyste. 13 zeigh die sporoblasten vollkommen ausgebildet und auf ihrer Oberfläehe mit

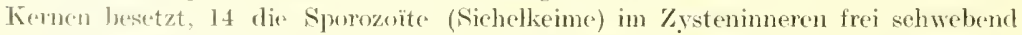
ume sieh berwegend. Der dureh Platzen der Zystenwand freigewordene Siehelkeim (15) gelangt in die leibeshëhle, mit dem Bhutstrom in die Speicheldriise der Gabelmüeke und ans tlieser wiedterum furch Stich in die Ibutmasse des Menschen. Iliermit ist der Kylilus gesehlosicen und begiunt zugleich von neuem.

\section{Projleylaxe, Feimle.}

Die Lampf- mol Vorteiligungsmiltel des Menschen gegen die Stechmücken und ihre Brut sind zahlreich. 


$$
\text { 2. } \frac{1}{c}
$$



Fịt. 135. (1)rig.)

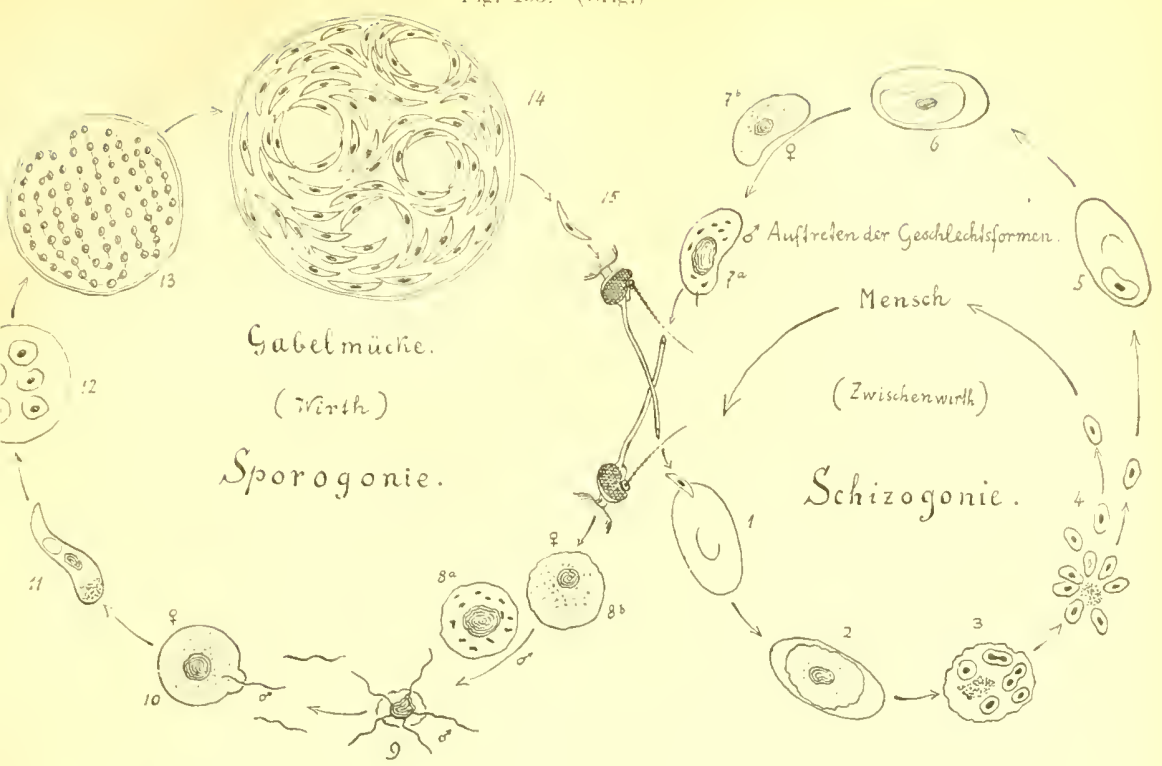

Imago. Höher- und froigelegene Wohnhäuser, welche die Nachbarsehaft der Hïtten von Eingeborenen und die Nähe von Wald, Busch, schattenspendenden Bäumen und Sträuchem mögliehst meiden; helle Wohn- und Schlafräume in den oberen Stoekwerken, deren Fenster und Türen von Somnenuntergang bis Somnenaufgang geschlossen bleiben orler besser noeh lurch Drahtgewebe gegen las Eindringen der Insekten zu sehützen sind, und der Gebrauch von Mosquitonetzen halten uns die Plagegeister vom Leibe.

husäucherung eines gutvershlosspen Raumes mit Pyrethrum- oder Insektenpulver (V'rbrennung von $2 \mathrm{~g}$ auf den Kubikmeter Luftraum) betäubt alle Jicke'll. Tach emer Stunde wird der Raum geöfnet, die aul d'm Boden liegenden llürken werden zusanmengefegt und verhrannt. Schwefel- ( 8 g pro Kubikmeter) und Formalinräuchernmg tötet die insekten, erfordert aber hinterher gründliche Lüftung.

Der mechanisehe sehutz unserer Wohnungen und unserer Person wurde zuerst dureh die Italiener eingeführt ('ELLA) und ansgebildet.

Alle Zugänge zu den inneren Räumen des Wolnhisuses, die Fenster, Türen, Rauchfänge (Schurnsteine) usw, sind mit passenten brahtgeweben derartig zu verschlieben, daß ein Eindringun der stechmücken unmöglich wirl. Nie Jaschenweite des firwebes beträgt am besten einen Villimeter. Weitere Maschen ermöglichen keineren stechmüskenarten ein Durchsehlüpen, währenct angere die Zirkuktions der Luft behindern.

Cngeschätzter Eisendraht wird bald rostig, brüclig und unansehnlich, namontlieh in der Xähe der Küste. Ist man gezwungen ihn denno'h za verwenden, so wird mit Vorteil von cinem ()lfarbenanstrich Gebrauch gemacht.

Varzinkter Eisendraht ist "twats tewerer, dafür aber von beinahe unhegrenzter Halthatrkeit und deswegen das empehtenswerteste Waterial. (Messingewebe in griberer Ausdehnung zu verwenden, rerbietet sich schon durch den hohen Preis.)

Seit einem haben Jahrehnt ist auch eine Bespamung der Fenstereinsatzralumen mit wasserglasimprägniertem Tüll empfoblen und vieffach angewandt worden. 
In überspannten Holzalnmen müssen anf das genaucste in die Fonsteröfunngen eingepaßt wnd die Tḧren durch dopueltr, automatisch wirkende Verschlïse geschützt sein, deren auberer die Eingangspforte ciues anderthalh bis awei Neter tiofen kastenartigen Virbanes versedıliebt. Der Eintretende hat darauf zu arhteu, daß die außere Tür schen gesshlessen ist, wemn er die imnere öfnet.

Tach Somnenuntergang müssen alle Zugänge, Thüron und Fenster ungeschützter Fohmungen festgeschlossen gehalten werden und muB der schlafende sich gegen Müekenstiehe durch gut vearbeitete und gecignet befistigte Moskitonetze schiitzen.

Sinfl wir gezwngen, die Nacht im Freien zu verbringen, so gewähren uns passend um hopf und Hals geschlungene Schleier, weite Handsehuhe von geeignetem Gewebe und famasehen sicheren Schutz gegen Miiekenstiehe. Die Eingeborene'n des tropischen Sïlamerikas (Orinow, Amazonas) graben ihre Leiber nachts in den sand und bedecken das Haupt nit schleierartigen 'Tüehern. 1)as bei

\section{Fir.r. 13 ti.}

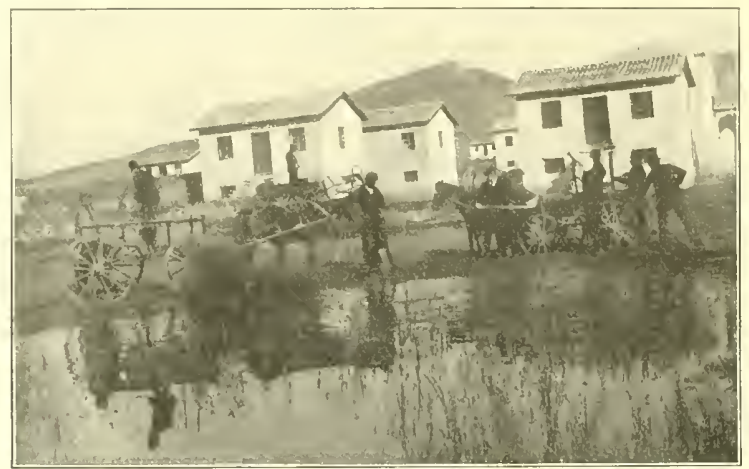

Zuschüttung des Sumples bei Nen-Anedialos.

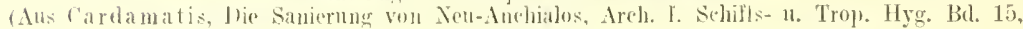
S. $441-4 i+1$.

manchen Naturvölkern ïbliche Benalen und Bestreiehen der Haut sehïtzt anch in gewissem Grade vor Insckten und ist vielleieht ursprïnglieh eine hygienische Habregel gewesen (.11 Exsi).

Die verschielensten Eimeibungen in die Hant wie ätherische (̈), Chininglyzerin (MExse) usw. sind rougesehlagon worden. nm die Mücken abzuschrecken. Bestimnte Ger üehe seheinen uns sicher vor den Angriffen der 'T'iere zu bewahren (Immmität der Arbeitur in den sizilianisehen Schwefolgruben). Aus gleiehem Gesichtspunkte wird auch das Knoblauehessen, Genub von Tellurpräparaten (v. Bassewrz) von versehiedenen Tropenreisenden warm empfohlen. ${ }^{1}$ )

Winterschlaterule Stechniicken in gewölbten Kellern und anderen nicht gerade feucrgefählichen Rämmen werden am besten durch Spiritusfackeln oder durelı Sehwefeldioxyd (schwellige säure) oder Kohlenoxydgas (Nornt und Giemsa)

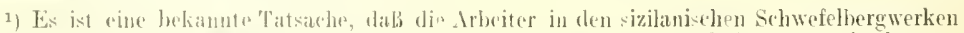

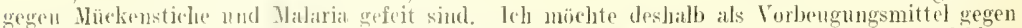

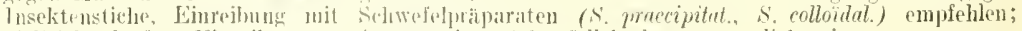
riellejedit dürten linrejbunger nnit wisseriger sedwelilleberlisung nützlich sein. 


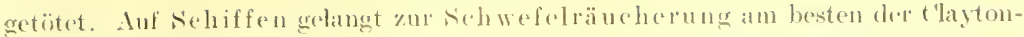
alphatrat zur lerwendung.

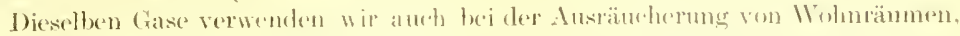
die natürlich möglichst alyudichten simel. Durch vollstindiges Eiuhällen vom

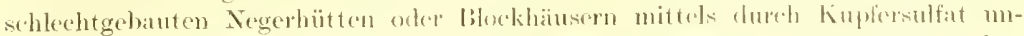

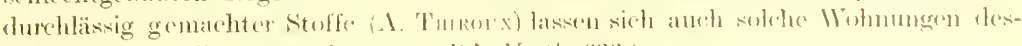
infizieren. (Bull. soe. path. exot.. Bit. I. К. 6333.)

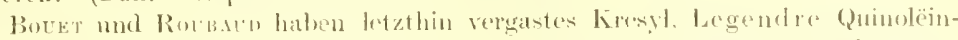
dämpte als hochwirksame Räncherungsmittel empfohlen. (liull. soe. path. exot..

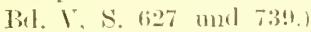

Die brut der Stechmiieken vemichten wir am sichersten durch Assanierung

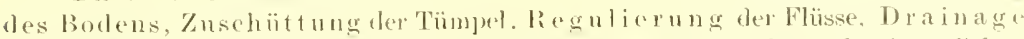

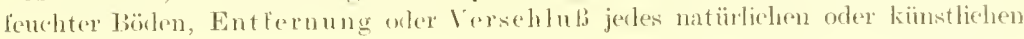

Fiv. $13 i$.

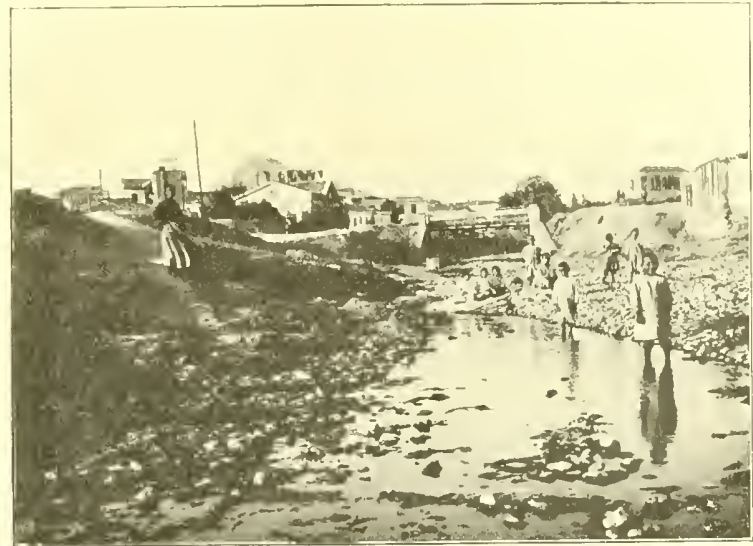

Was bett des llisiss vor der Regulinomer

Behälters ${ }^{1}$ ), in tem sich liegen- oder (Therschwemmungswasser ansammeth kann, Übergießen der Brutstitten mit Petrolemm. Saprol orler ähnlichen Stoffen, um Larven mel Puppen zu ersticken, oder dureh Vergiftung der 'l'ümpel mit gewissen Anilinfarben (Malachitgrin, Larvizid nsw.).

I'm kleinere Wasserfächen mit öligen substanzen zu bedecken, bedient man sieb einer ge-

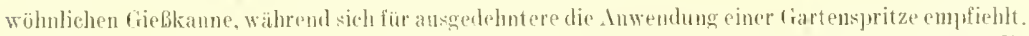
Tha die Bedeckung nur danu wirksam ist, wenn sie die Wasspransammlung vollkommen gegen die Luft abschliebt, düren dip (Bhmengen nicht zu kline sein. Nan rerhet anf einen Quadratmeter mindestens 5 cem Petroleum, dar schon vor volltommenor Verdumstung (spätestens nach 14 Tagent zon erneuern ist. Ein Zusatz von Teer in gheicher Honge verlangsamt dic Torlhüehtigung des Erdöls ganz beträehtlieh, gibt der sichicht gribere Festigkeit und rerhindert so ein Zusammengetriebenwerden derselben durch den Wind.

Jureh Bedeckung mit öliwen Substanzen verdniten wir auch sicher ein w eit e res Bosetztwerden

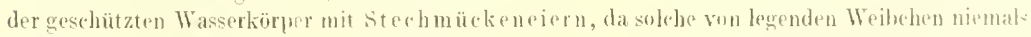
auf die geölte Wasserflaiche ahgesetzt werden.

1) Regenfässer, wasserhaltende Vasen, Kritge usw. sind mindestens a inmal wächentlich zil intleeren. 
Lim Strolımückeneier unselädlich zu machen, scheint mir eine groben Erfolg ver-

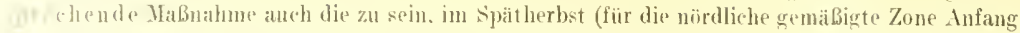
- hovember etwa) oder wihrend der tropiselen Trockenzeiten die schwarzen, vertorften Blätter, whehe den Beden ausgetrockneter Tiimpel bedecken, anszuheben und zu verbrennen. Sollte die Fenervernichtunor der den Tümpeboten hiklenden Pllanzenstofife und der daran klebenden

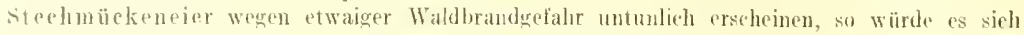
cmpfehten, das aus dem eimgetrockneten Tïmpel zusammengeraffe Lanb und Ifos an benachbarten, höhorgelegenen ()rtenso zu lagern, dabes dureh Wind und Regen nieht wieder zurückgrefïhrt werden könnte. Jie Eier wïrden dann nicht ansgehen, und die Brut mïBte lolghich verkimmen.

Unsere Bundesgenosien in T'ier'- mol P'flanzenroiche sind gliicklicherweise selır verbreitet mol rührig; die Aufgahe des Wensehen ist es nat ürlieh, sie in jerler Weise zn sehüzen und ihre Vermehrung zu begiustigen.

Fier. 138 .

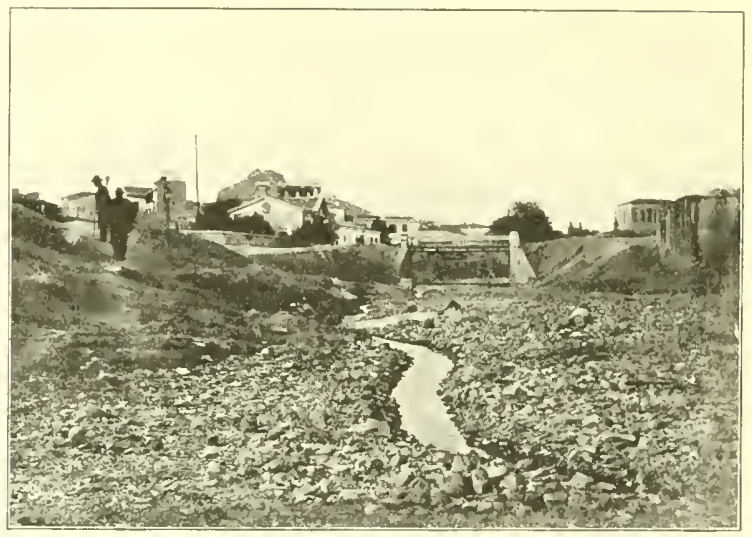

]) as Bett des Ilisses nath der Regnlierung.

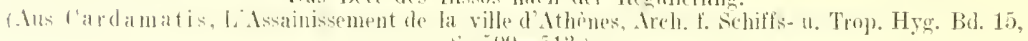
s. :) $19 !$ 51:3.1

Den gefligerftun Strefmithen stellen Spimen (namentlich Wolfspinnen, Lygrosidue). Wanzen (Redueidae), Henschrecken, Libellen, Skorpionsfliegen (Panorpa). Wesuen, Fliegen (dsiliden) und andere Raubinsekten nach. Sir werden refolgt von dem groben Hecre der Amphibien (Laubfösehe) und Reptilien (chamäleon, Eidechsen. Thaumschlangen usw.), von Vögeln und Fledermäusen.

Zahlreidhe Ento- und Ektoparasiten werden von den Stechmücken beherbergt, mathen sie krank und hingen sie zum Absterben. E. l'Erroxato, Turin, stellte

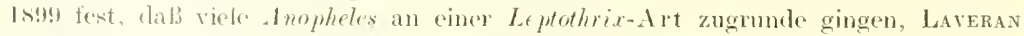
fancl in Amopheles, die ans Rio tinto stammten. eine Hefeart, die den 'Tod der 'liere

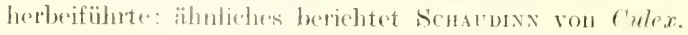

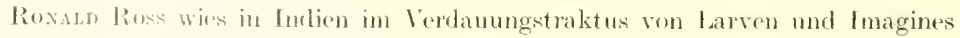
Gregarinen in grolior Anzalil nach.

Dals Hämosporidien mu bis zu einer gewissen Zahl der Müeke ein Weiter-

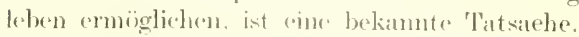

Saugwiirmer wrelen nicht sclten im Zölon der' 'Tiere eingekapselt angetroffen (Martinaxo, Sinoo, Rvcit); sie grhören bei den un Kassel gefangenen Mücken 
zu den häufigeren Befunden. Ebenso findet man dann und wann Gordius-latrven in Stechmücken.

Daß Milben (Gumusus) oft $z$ 1)utzenden sich den Stechmijcken anhiugen und sie ausingen, ist allgemein bekannt.')

Noch viel zahbeicher und ihnen verderblicher sind dic luinds der latrven und Puppeu.

pflanzen. Spoltpilze ror allem vernichten recht häulig the leben. Es geschicht dies nicht allein in unseren Aquarien, somelern wohl ehenso häufig in tan freien Natur.

Von höheren Pflanzen sind es hauptsächlich die raseh wachsenden mul an der Wasserfläche dichte Rasen bikknden (Lemna, ${ }^{2}$ ) Hydrocharis. Izolle ranadensis, 1zolla caroliniana usw.). welche den Tieren das Atmen unmöglich machen uml sie so ersticken.

Fleischfressembe Wasserpllanzen, in erste Line die weitresbreiteten Ltricularien in ihen heimischen und tropisehen Arten stellen Larven und Puppen erfolgreichst nach (s. 'Taf. VI. Fig. k uncl I). Die Tiere werden chrch den Reusenapparat ter Ltricularienblasen (s. Taf. V1, Fig. 1) festgehalten, am Aufsteigen zum Wasserspiegel verhindert, so erstickt, dann pept onisier t und bis anf den (hitinpanzer verspeist. Ein einziges Plänzchen des Wassersehlauches (L'triculariu vulyaris) kann auf diese Weise mehrere hundert Larven unschädlich mathen.

Fïr Siicleuropa nud die warmen länder äherhaupt hat noch eine andere submerse Wasserpflanze nach clieser Richtung hin hohe Bedentung. Es ist lie zu den Sonnentangewächsen gehörende Adrovandiu vesiculosi. deren Blätter die Bildung und Funktion der verwandten Dionaca mucipula (Venusfliegenfalle) zeigen und schlieBlich die Brasilianische Genslisea ornata; ihr schlanchartiges Blatt gleicht einer Aalfalle.

Tiere. Von räuberischen Mitbewohnern des Wassers werden zahlreiche Larven und Puppen vernichtet.

So habe ich mehrfach beobachtet, dab sinßwasserpolypen (Hydru viridis usw.) junge Stechmückenlarven mittels ihrer Fangame ergriffen und dann verzehrten. Sangwümer (Turbellariem) gleiten beim Kriechen an der Wassurfläche (nach Schneckenart) unter Anopheleslarven und saugen sie in kïrzester Frist vollständig ans.

Den Larven von Corethe und Kochlongs fallen viele zum Opfer, ebenso den gefäBigen Ephemerilen- und Libellenlarren.

Die Schwimmkïfer und ihre Brut räumen gehörig unter ihnen auf; eine einzige fast ausgewachsene larve von Acillus sulutus. die von mir in ein Aquarim gesetzt war, verzehrte während einer Nacht sämtliche (iiber 40) Culex-Larven.

Als die schlimmsten und erfolgreichsten Feinde aber zeigen sich clie $\mathbf{W}$ asserwanzen und deren Laven.

Dit sehen wir zunächst die bekannten Wasserläufer (Ilydrodromiri) und

1) Vor kurzen wurde yon lionmax und an anderer stelle aueh voustantox die interessante Beobachtung gentacht, daB kleine Miickchenl, licratopogonarten, den blutgetiillten Magr'n von Stechmïcken anbohren nunl dessen Inlal soweit es ihnen möglich sich sesbst einverleiben. Es handelt sich hier meiner Ansicht naw aber leider nicht um Raubmord, sondern nur um einfachen biebstahl. Sebon im Jahre 1904 bemerkte ich nämlich, ta B vollgesogene Lausfliogen (Melophagus) son hungernden Artgenossen in gleicher Weise behaudelt wnrlen. Trotzlem hier ein viel massigerer und plumperer Stech- und samgapparat benutzt wurde, als ihn die winzisen, meist niclit ejnen Willimeter langen Keratopogoniden besitzen, hejlte die Wunde rexelmäbie arts: die Tiere kounten bei weiterer Blutnahrung noeh wochenlang am Leben erhalten werelen.

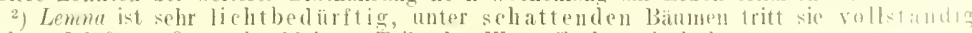
zurïck und läßt größere oder kleinere Teile der Wasserläche unbetecki. 


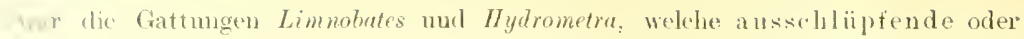
werlegende Steehmücken ïberfallen.

Von den im Wasser lebenden Familien der Nepiden und Notonectiden sind es (le. Wasserskorpion (Nepe rinerea). die Nadelwanze (Ranatra linearis), llie geneine Schwimmwanze (Tuucoris cimicoides), die gestreifte Ruderwanze

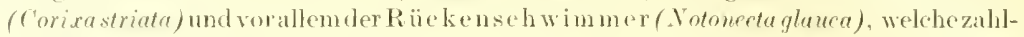
lose Stechmïckenlarven und I'uj'pen hinmorden. Ich habe oft gesehen, dals Ranatra z. B. eine mit dem Rüssel aufgespleBte Larve aussangte, während sieh sehon wieder 7.wei newe Opfer in den unfehllar fassenden und haltenden Fangarmen lirummten.

I ie Fische fïhren einen ebenfalls sehr erfolgreichen Veroichtungskrieg gegen die ersten Stände der Stechmücken. Sie kömnen dies freilich nur dann mit vollkommenem Erfolge tun. Wenn die Wasserbecken hänfig vom untergetauehten Pflanzengewirr befreit und ihre Ränler sclarf abgestochen werden. Es sinel hier die K a rpfenarter) (z. B. Goldtische. Maplochilus pumilus. Haplorhilus Grahami, Fundulus turniopygus) und vor allen der Stichling (Gusterosteus) und Girardinus poecilödes zul nemnen. ${ }^{1}$ )

1) oft gepriesenen Kaulquappen und ihre Eltern, die Frösche, habe ich nie eine Larse verzehren sehen. dagegen öter bemerkt, dab dies Molche und Salamander, unl zwar hauptä̈hlich in ihrem Larvenzustande, tun.

sicherlich sind anch Wasser- und Sehwimmvägel, so namentlich Enten, nicht zu unterschätzende Bundesgenossen des Menschen. .

\section{Erklärung dej Mbillungen anf den Tafeln IV-IX.}

bie Originalnegative, wedehe den lutotypien und den Plotolithographien der Tafedn IV lis V'llf zugrunde liegen, wurten nach meines Ingaben und nach Präparaten mejner Sammlung von den Herren Erost Stephaxi und (ieorg Harsmaxi2), beide in kassel. hergestellt.

Herr StEpHaxi gebrauchte zur Anfertignng der won ilun auf Bromsibergedatineplatten von

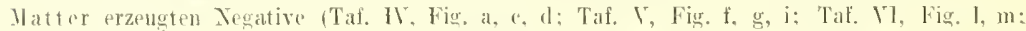

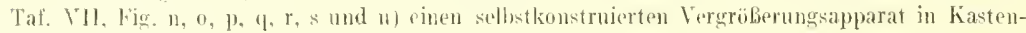
form, dessen objektiv eine Brennweite von 3 cum lesitzt mond ans zwei jlankonvexen, achromatischen linsen hesteht.

Fe kam mur durhallendes diffuses Tayeslicht zur Verwendung.

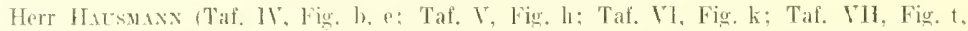

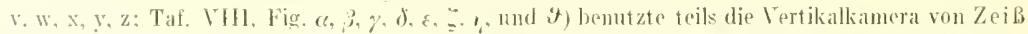
(Xr. 723 des Verzeidhisses mikrosph. Apł., 190:3, 5. Ansg.) mit den Mikreplanaren Serie 1a, Xr. ㄴ

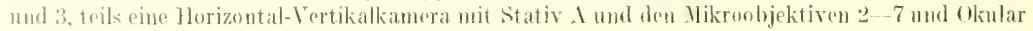
l voll Leit \%.

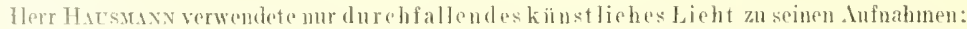
Inerluremner mit Xeusilberretlektor, Pikrinfilter, einfacher achromatischer Kondeusor, Irisblende.

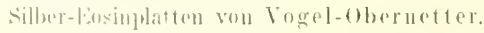

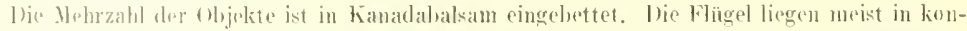

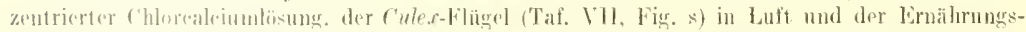

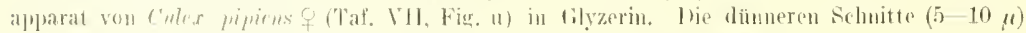
sind mit Eosin und Ilimatoxylin, die dickeren mit Mlaunkarmin gefärbt.

Dir Oripinalplotugramme zu Talel IS wurden von l'rolessor lixosnita unter Leitung

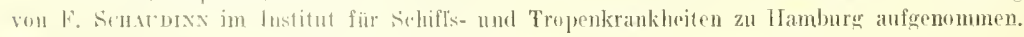

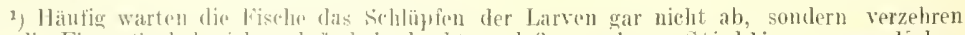

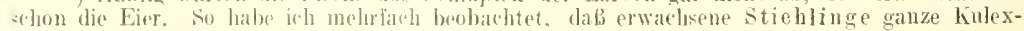
kïlunchen verschlangen.

2) detzt in Giottingen als Mlimbalere der optisehen Anstalt von R. WinkeL. 
Tal. Wl.

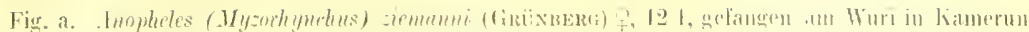

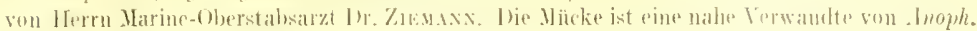
sinensis (Taf. Y. Fig. fi land i).

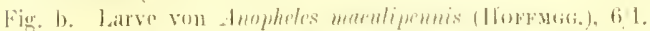

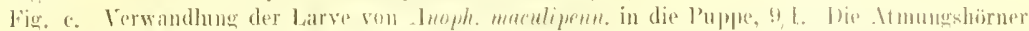

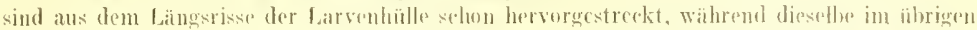

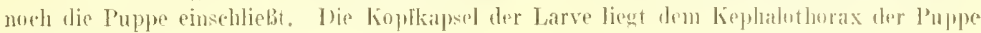
maskenirrig vor.

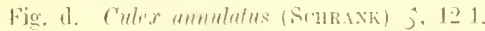

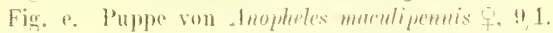

\section{Till. $V$.}

Fig. 1. Anopheles (Myzorhymhus) sinensis (WIE1.) q, 12, 1 .

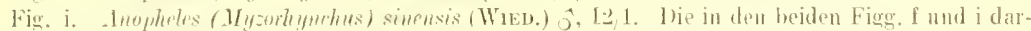
gestellten Viscken verdanke ich dem liebenswiodigen Entegegenkommen des Herrn staluirztes X. Wroe zu Taihoku (Formosa.)

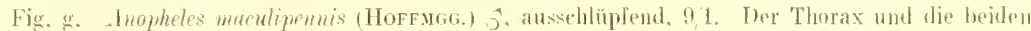
ersten Nbdominalsegmente haben die Puppenhülle schon verlassen, ebenso die Fhägelwurzchn mit den Halteren. Hit distalen Enden der Fühler und Taster sterken noch in ihren Seheiden.

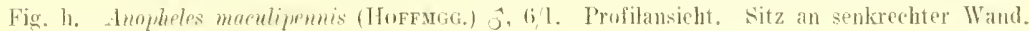
Die Tibia des linken Vorderbeines ist gekniekt.

\section{Taf. T1.}

Fï. k. Blatt von Ctricularia mlyaris mit gelangencus Culer-Larven, 41. In den beielen unteren Blasen auf der linken seite des Bildes befinden sich je zwei Larven.

Fig. I. Einzelne Blase eines Blattes von Ltriculorin vulquris mit gelangener Gulex-Larve starker vergröbert, 12, 1. Das Tier jst an Endsesmente durch den Rensenapparat gefabt. Mit dem Kopfe voran geraten die steflumbekenlarsen mur ansnahmsweise in die Falle: sie werden also jedenfalls von der Pflanze nicht geködert, sundern gelangen beim liebranche des Sehwanzruders zufällig in die Rense. Tede weitere Bewegung der Larse lährt nicht zu ihrer Belreinng, sondern libit sie nur nowh tipfor in tie Blase hineingeraten.

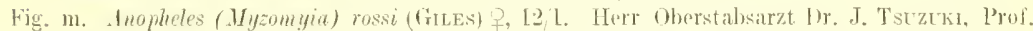
an der Kaiserliehen militiriirztliehen Akademie zu Tokin, hatte die früte, mir im dalıe 1902 eine Anzahl ostasiatischer Anupheliden zu übersenden, unter denen sirh auch die hier daryestellte befand.

Tal. IIl.

Fig. n. Flügel vou Anopheles mentipennis ([Гofrusiti.) j. 12'1.

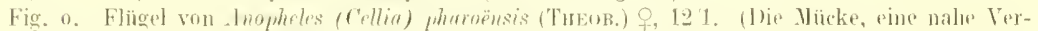
wandte von Aluopheles argyrolursis (Taf. YH, liz. r) wird in ligypten und an der ganzen afrikanischen Nord- und Testliuste häfig angetrolfens.)

Fig. 1. Fhägel von _lnophetes (l'yrotophorze) costulis (LoEw) 9, 1.2/1.

Fig. q. Flügel von duophels costalis (LoEw) f (entschupht) 1.21.

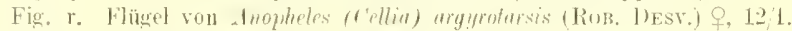

Fig. s. Flügel von Culex pirines (L.) 9.121.

Fig. t. Anopheles costalis (l,oEw) 18 1. Hedianschnit. Th.M. Sterno-dorsale Jusketerupun, des Thorax, I. Vorratsmagen, H. Magen, 1). jung früuliches ovarium.

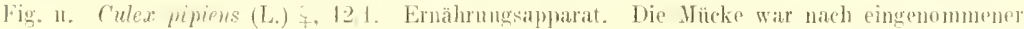
Mahlzeit getötet worden: (ler Vorratsmagen ist mit Zuckersaft gefült, der Mitteldarm (Hacen)

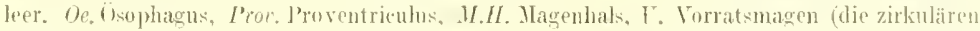
Inskelfaserbiudel an den Einschürungen und den parallelen, an die Breitengrade eines Globus erinmernden Querstreifen deutlich zu erkenuen), U. Magen, T. Pylorustriehter de Ilenm, R. Rektum, I..U. Nierensehläuche.

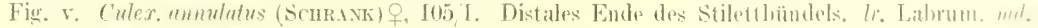
Mandibeh, mx. Jaxillen, hy. Ilypopharynx. 


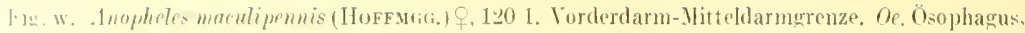
Procentr. (fardia) Proventrieulusmit (isophagusklappe. WH. Magemhals, Jll. Hals des Vorratsmagens. (i.sul. Speichetelrïse.

Fig. x. Culex pimens (L.) ㅇ, 50, 1. Pharyxpmume. Th. Thorax, H. Hals, K. Kopf. Ph.P. Pharynpump. s. speichelpumpe. Cl. Clipsus, fir.F. Basalglied des Fühlers, $F$. Fühler, $T$. Taster, $k$. Rüsscl. Die Theichteile sind dureh lialilauge aus dem ('hitinskelett entlernt.

Fïr. y. Cules pipiens (L.)ô. I05 1. Torderfuß (vgl. Fig. 90, B). hl. Klanerı, Emp. Empodium, 5. Fünltes, 4. Viertes. 3. Drittes Tarsalglied. Die Intertarsalgelenke erlauben nur eine begrenzte horsal- und Fhantarrellexion; es sind spergelenke, wie aus der Figur dentlich zu ersehen

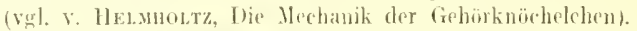

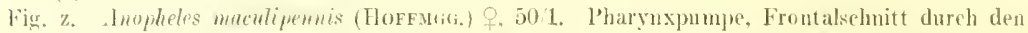
mitteren Teil. 1'rtex Scheitelgegend, IT. Hangengegend der Kopfkapsel, Ph. Pharynxpmpra. o. P.obere Schlundplat te, u.P.I. und u.P.r. linkeundrechteuntere Sehlundplatte, M.r.ph. Yhuseuhu. vertirwharyngeus (der Verticopharyngeus besteht genau genommen aus zw ei ILuskel pa aren, cinem vorderen und einem hinteren, welche durch das corpus callosum cerebri voneinander getremt sind), M.b.ph.s. und M.b. ph.d. Husculus burcoplaryngeus sinister et dexter, rer.('er. weres Schlnudganelion (Crehirn).

\section{Taf. V'lH}

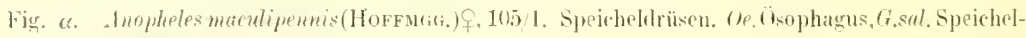
drïsen, 1/use. Brustmuskeh.

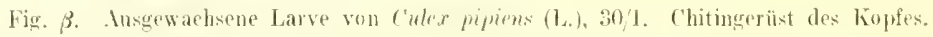

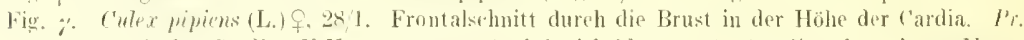

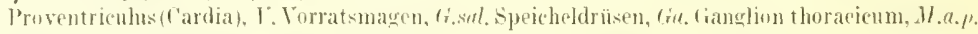
Musculi anteroposteriores, M.st.d. Musculi sternodorsales, BM. Beinmuskulatur, Fl. Flugblasen.

Fig. d. Anopheles matulipennis (Horfmiti.) f, 50/L. Leibesende. El). Enddarm, R. Rektum, IU. quergetrolfene Vasa Malpighi, sp. spermatheke. $K$. Kittdrüse.

Fin. $\varepsilon$. Culex pipums (1.) . 50 1. Leibesende. Ml). Mitteldarm, T. Pylorustrichter, des Ileum. El) Enddarm, RR Rektaldrïsen von der Dorsalwand der Relitalanpulle entepringend.

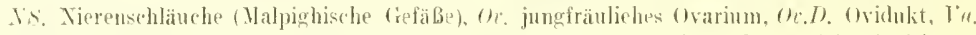

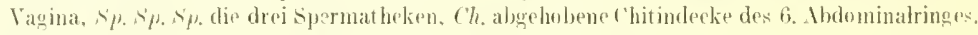
Blr. Bindegewebe, Fl. Längsichnitt dureh den liüges. B. Bein.

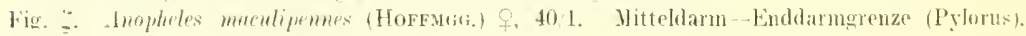

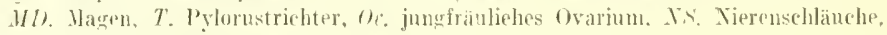

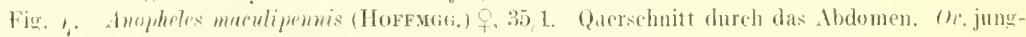
fräuliches () varium, (I). ()vidukt, M/). Mlitteldarm.

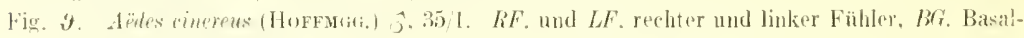

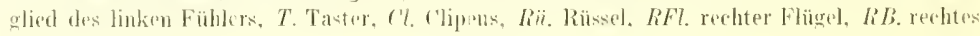
Vorilerbeis.

\section{Taleel 1X.}

lirgrg. 1-13: Flügel der Anophelen $\left({ }^{13,5}, 1\right.$ ).

Fig. 1. Lnopheles sinensis WiEn.

$$
\begin{aligned}
& \therefore \quad . . \quad \text {.. annulipes Win. (dreptor-Form). } \\
& \text {.. } 3 . \quad \text {.. listoni lastox. } \\
& \text {.. } 4 . \quad \text {.. fuliginosus (inLES. } \\
& \text {. i) . }
\end{aligned}
$$

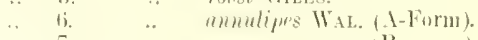

$$
\begin{aligned}
& \text { 7. } \quad \ldots \quad \ldots(B-\ldots) \text {. }
\end{aligned}
$$

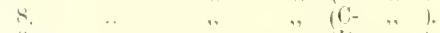

$$
\begin{aligned}
& \begin{array}{lllll}
1 & \text {. } & \text {, } & \text {, (I) } & \text {, }
\end{array}
\end{aligned}
$$

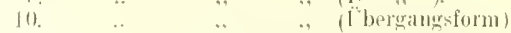

$$
\begin{aligned}
& \text { I1. ‥ listoni tostox (subumbrosa-Form) }
\end{aligned}
$$

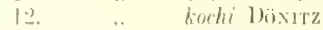

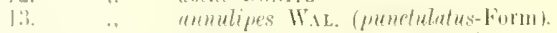

$$
\begin{aligned}
& \text { liner. 14 17: Oerysten der Tropicaparasiten. }
\end{aligned}
$$

lige. 14. is Tage nach (lem blutuahl (Hämatoxylinfarbung soo

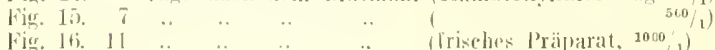

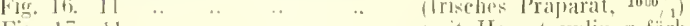

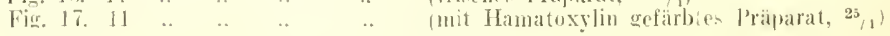


, 

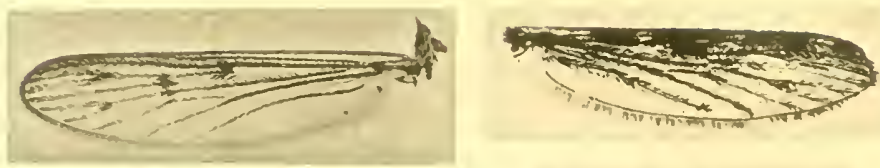

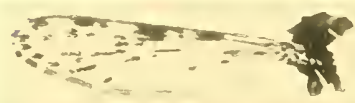

$$
F_{-2}-z_{2}=-1
$$
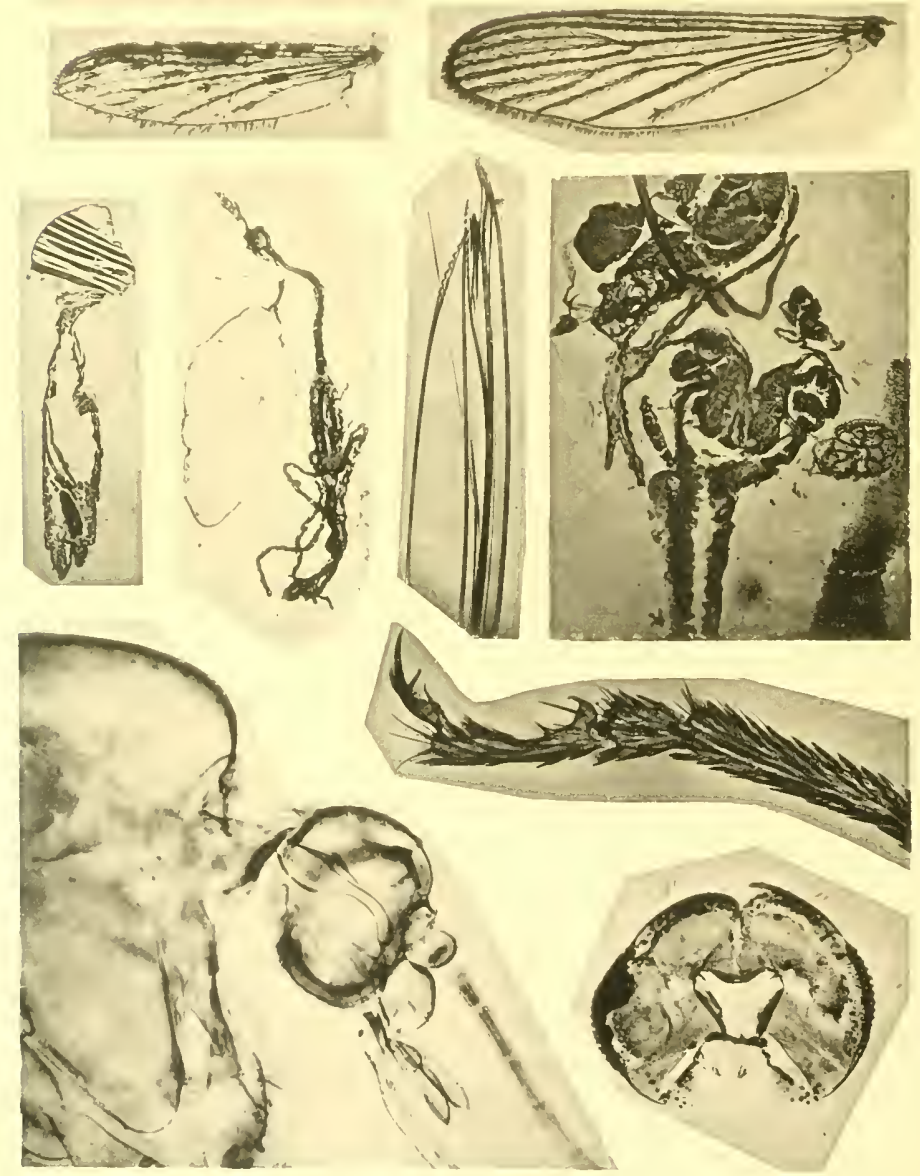

Stechniicken. 

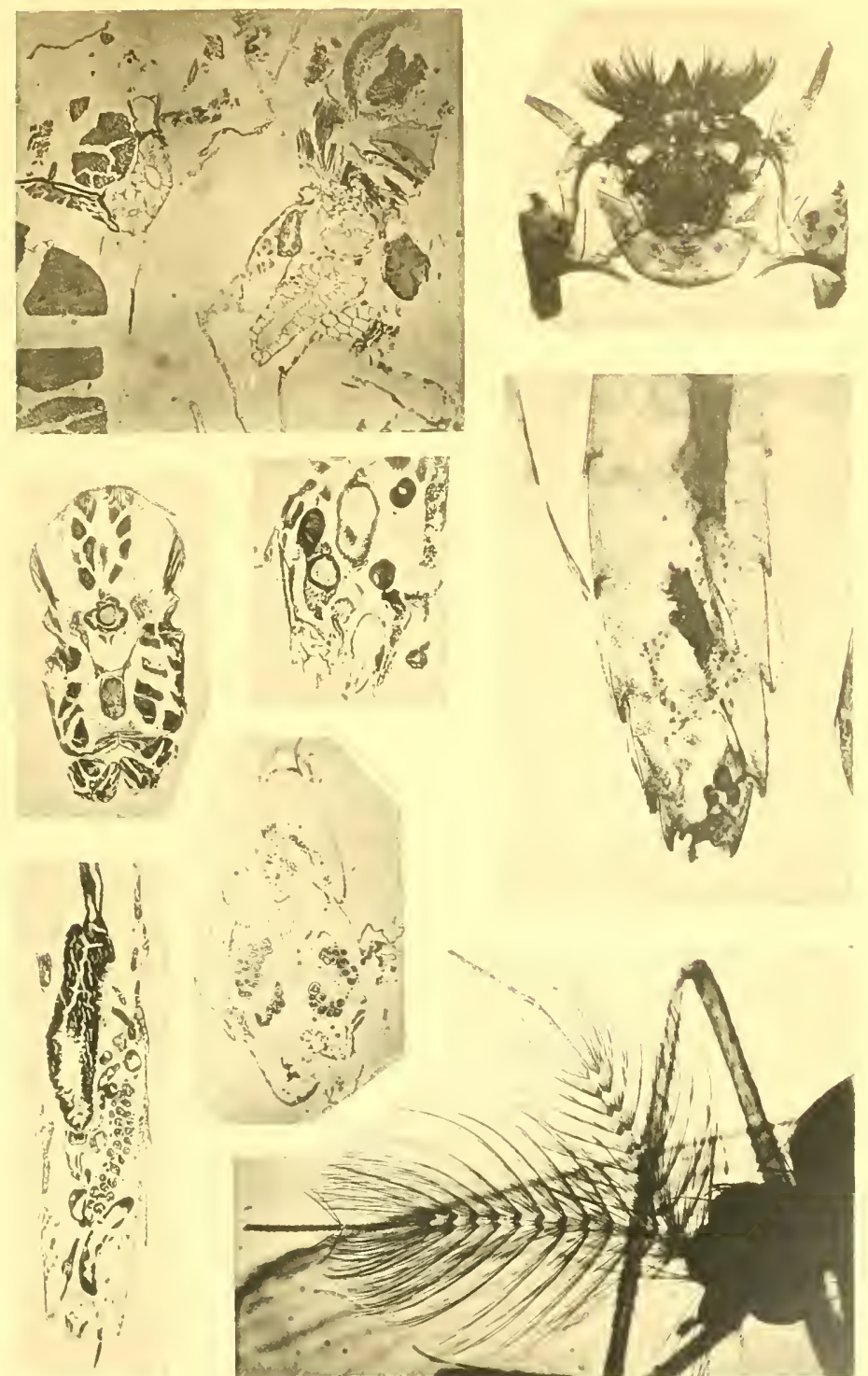



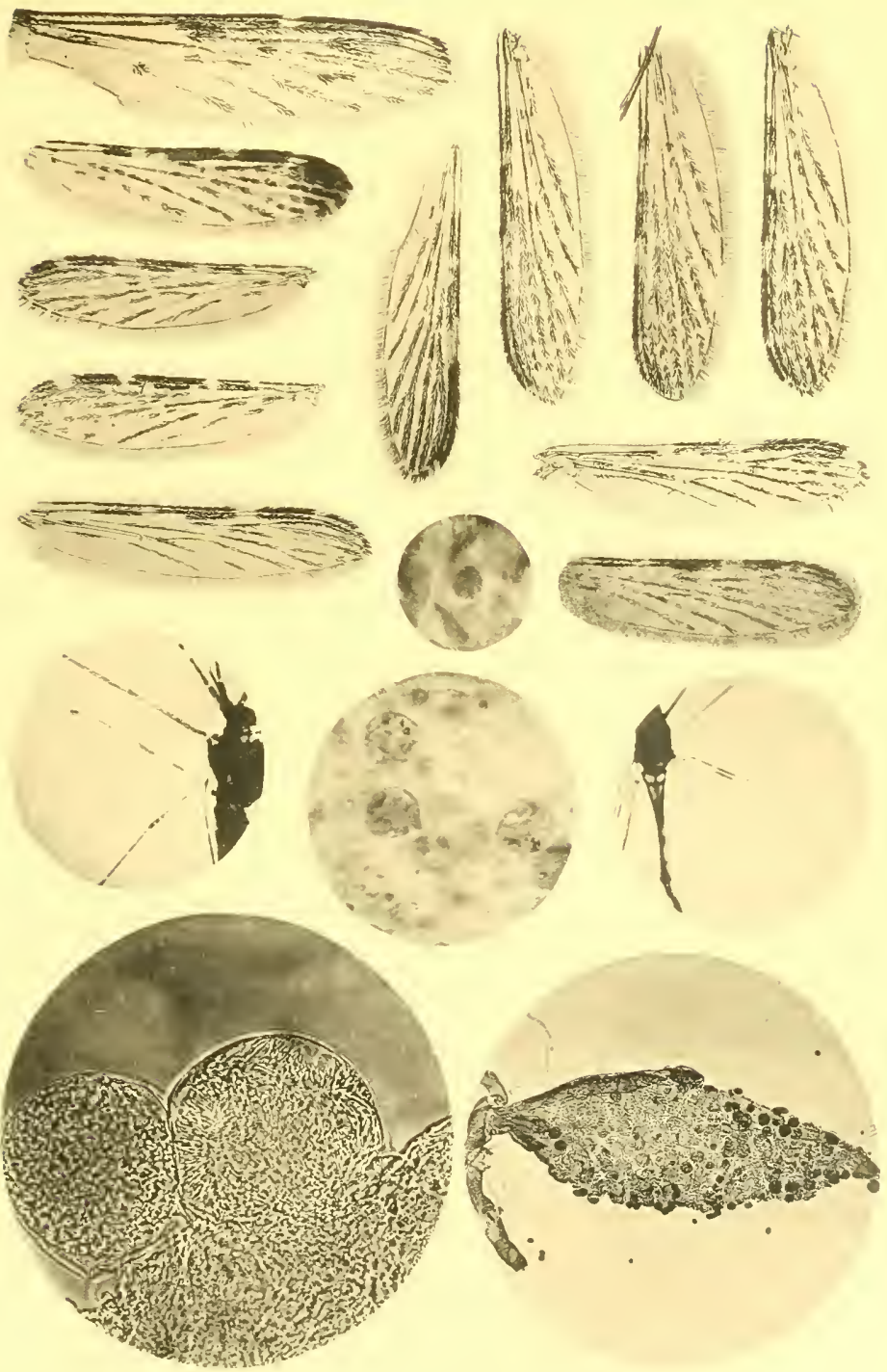

K. Kinoshita 



\section{Literatur.}

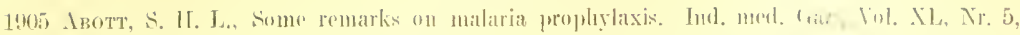
p. 173.

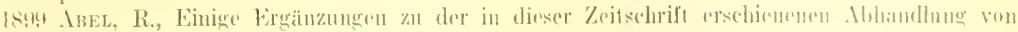

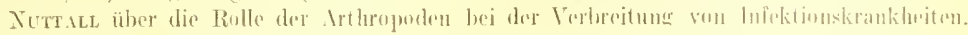
Hyo. Rumblscham, S. 1065 .

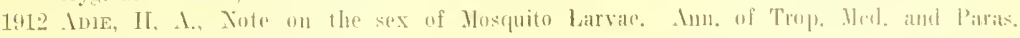
Bil. 6, X. 4. \&. 4ti3- thii.

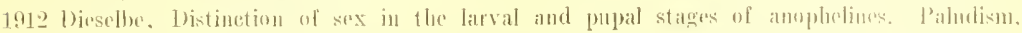
September, Nr. is, s. 41.

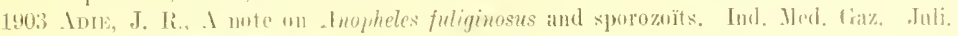

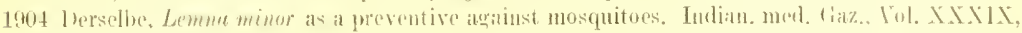
Xr. 6 , 1. 207 .

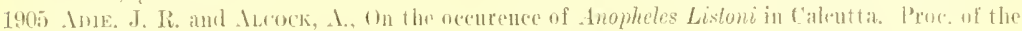
R. soc., sirr. b. Vol, LXXYl; Bisl. sex., p. s19-321.

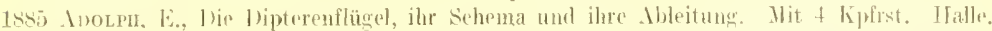

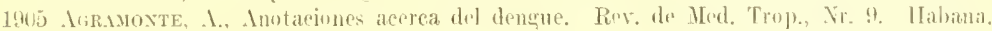

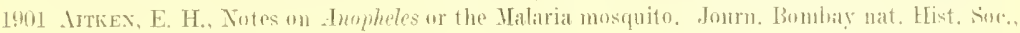
Vol. 13. p. $691-695$.

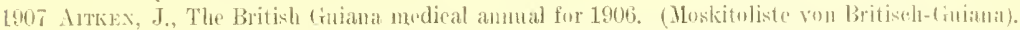

1905 Ilbert, H., Insects: the Role they play in the Transmision ol Dixease. Xew lork Mad. Jomru., Vol. 81, p. $220-2.25$.

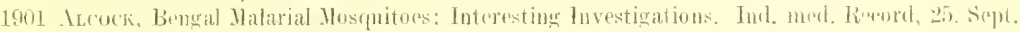

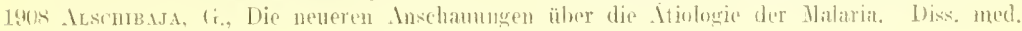
Barlin.

1910 I mosinito-proof steamer. Juturn, of Trop. Mert. Hyg., S. 152.

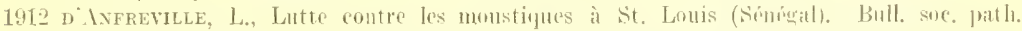
exnt. T. I, 1). 637 .

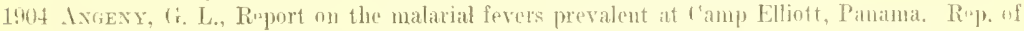
the Surgenu-Cieneral I. S. Navy. Washington. p. 257260.

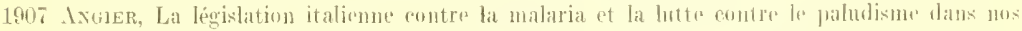
colonies. Amn. d'lirg. at de méd. colom.

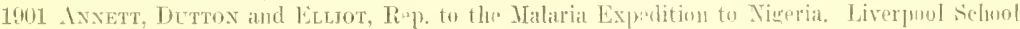
of Trop. Ned. Memoir 11I. Part I und II.

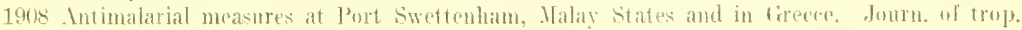
med. and hyg., Vul, XI. Xr. 13. p. $205-20$ - 20.

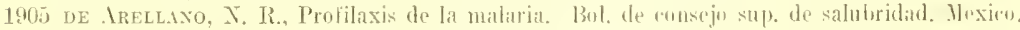
Epuca 3, T. IX, Nr. 12; 1. 371387.

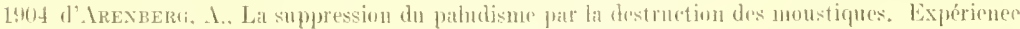

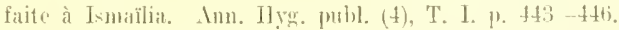

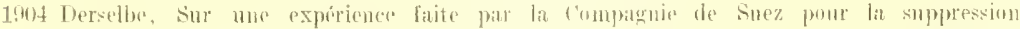

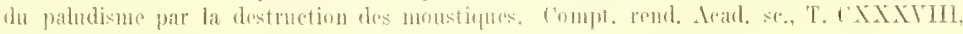
Tr. 11. p. $670-6373$.

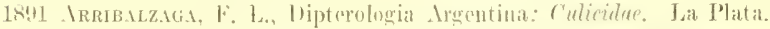

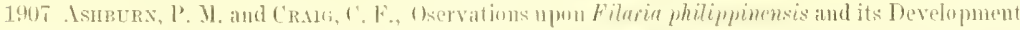

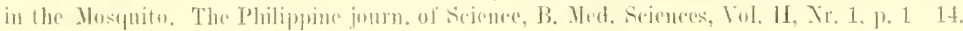
Lit 6 Taf.

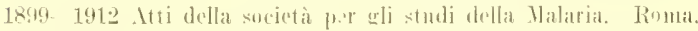

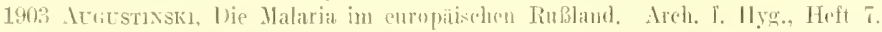

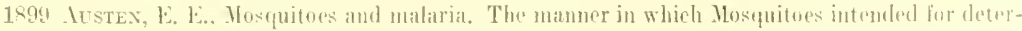
mination slonuld be eollected and preserved. Nature lIX.

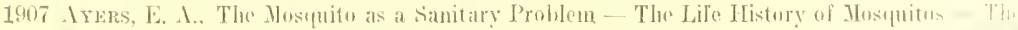

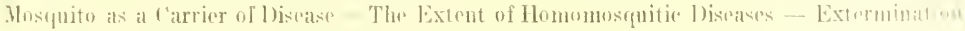

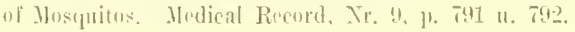


DE, Azevfodo Somré, 1. 1. und ('oxto, H., 1)as Gelbfieber. Tothnagel's spez. Path. U. Ther., Bd. V. Teil 1T, I1. Abt. 312 s. mit t2 Abhildungen und 4 Tafeh in Farbendr.

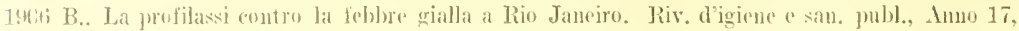
Nr. 2. [1. 33-37.

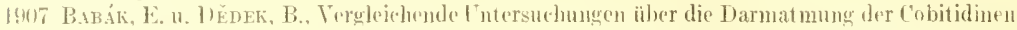
und Butrachtumg äber die Plyylogenese derselbem. Biol. Centralbl. XXYll, Nr. 21, p. 697 biks 703.

1904 Bateler. Fr., XLY. Congresso di medicina interna. Il Policlinieo, Nr. 64.

1905 brethe, Linfezione da malaria. Faz. med. Lombarda, 1. 94.

1902 Bapaloxi, C. G., La malaria in raporto alla eoltivazione del riso nella provincia di Bulognil. Bul]. scienz, med. Bolugna. Marzo.

1902 Jagizo, C.. Coutributo aldo studio della profilassi malarica. Suppl. Riv. metl.

1903 Balfour. Ifosquitoes and Steaners. Jomm. of tropieal mod, Vil. Vt. p. 253.

19tef Balfotr, A., Zweiter Bericht der ,Welleome-Laboratorien" an dem . fiordon Vemorial (ollege" in Khartoum. Vit zahldreiclen sblildungen und farbigen Tafeh. Whartoum. f)epartment of Edueation. Sulan Ciovernment, $255 \mathrm{~s}$. Ref. in beutselie med. Woehenschr. 1907, s. 320.

1907 Derselbe, Herpetomones parasites in fleas. Jouru. of Hrg.. Bd. 61, p. 1952 - 655.

1!no Baxcroft, T. L., (he the metamorphosis of the young lorm of Filarin Benerofti Cobr. (Filuria.

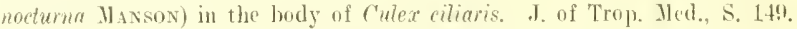

1903 Baxdi, J., Cielblitber und Minsquitos. C'entralbl. f. Bakt., Bil. 35, s. 323.

1904 Derselbe. Studium uher die Xtinlogie d. gell. Jïebers. Zeitsehr. f. Hyg., Bd. 4t. s. 81.

1906 Baxks, C. S., I Xew Genus and species of Culieidae. I Taf. Philipjine Journ. Se., Vol. 1. 1). $779-782$.

1900; Derselbe. A list of Philippine Culicidne with deseriptions of some new species. Pliilipu. Journl. of Seience. T. 1, Nr. 9, p. $97 \%$ - 1005 .

1905 Barbezievx, Le paludisne à Jong Treu (Younan). Amn. d'lỵg. et de méd. col. p. 100.

1904 Barreto, de Barros and Rodrfoues, Travanx touchant lia prophylaxie de la firive jaune. 1901-1903. p. 47. S. Panlo.

1737 Barth, .I. 11., De Cnlice. Ratish.

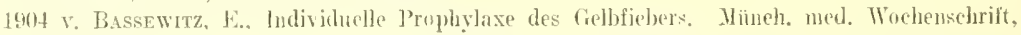
Tr. 29.

1905 Derselbe, Wie schützen wir uns gegm Malaria, Gelbfieher, Filariose nsw. Arch. l. Sehiffsu. Tropenhygine, Bel, 9, H. 5, s. 219.

1900 Bassett-Sinti, 1'. W., Ofservations of Ilosçuitoes. 1 pl. Joum. of trop. med., Vol. 3, 1. $53-54$

19ur larselbe, An analysis on the Reports of the Royal societys Commission on the Prevention uf If diterrancan fever. Irrh. I. Sechiffs- u. Tropen-Hyg., s. 675-680.

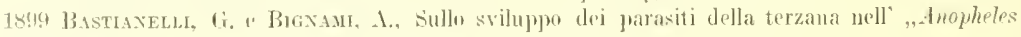
deniger". Annali digiene sperimentale, Tol. IX, Fasce. Ill.

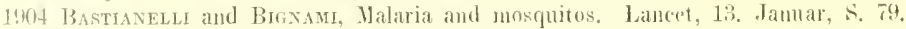

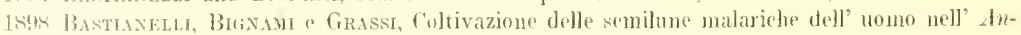
opheles duriger Fabr. Resd. della R. Acad. dei Lineri, V11, 2, S. 11, Romil.

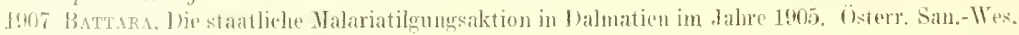
XIX. Wim.

1901 Battesti, f., observations sur fr palualisme en Corse. Bastia.

1902 1)erselbe, ('ummunt on se difind rontre la paludisme? Bastia.

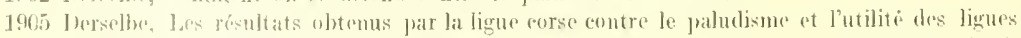

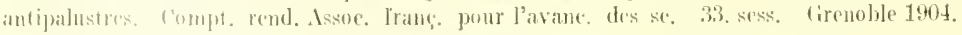
p. 1476 lis Hertion. Paris.

1903 Beld. J., Xote on an muthreak of malaria on loard of ship. Laneet, 20. duni,

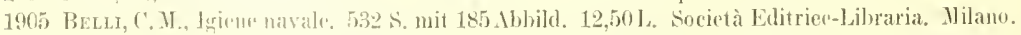

1911 BEATLEY, Report of an investigation into the causes of Malaria in Bombay and the measures necessary for its control, P'rinted at the Goverument central press.

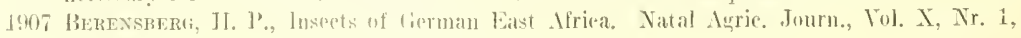
1.. $50-55$. 


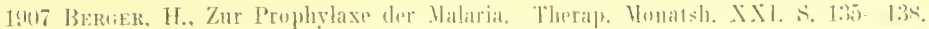

1902 Berkeley, W. X.. laboratory Work with Monquitos. Xiw Vorli.

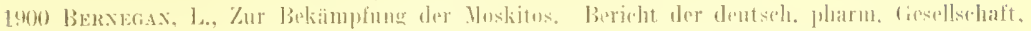
s. 210 .

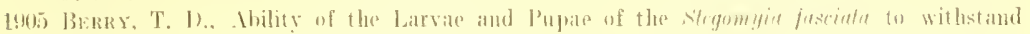

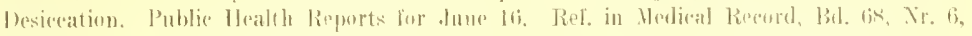
ए. 2024 .

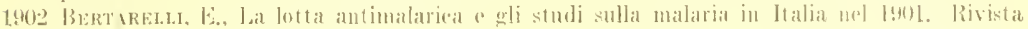
l"igicn. (2 san. jubl., j. $4+4$.

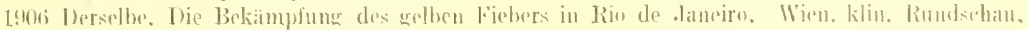

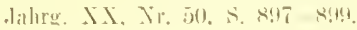

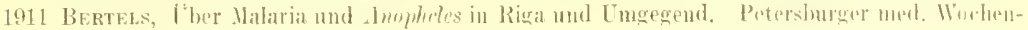
schir., Nr. 20.

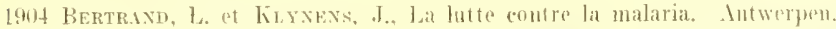

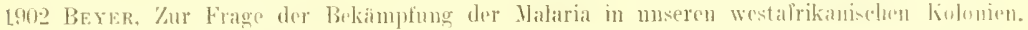
lentsehe mel. Wurhemschr.. S. 47.2.

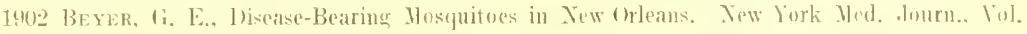
L.XV. Ir. 2.

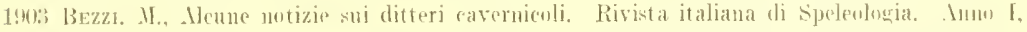
I:asc. Il.

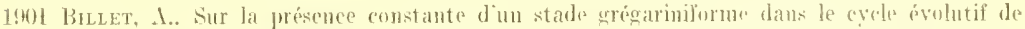

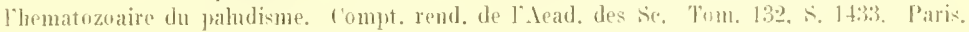

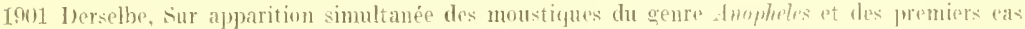
de paludisme dans la region de Constantime. (raz. des hope. Xr. Los.

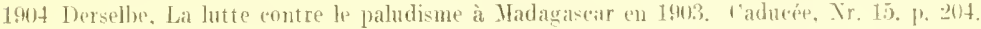

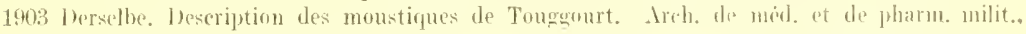
T. XILI, Nr. 1.

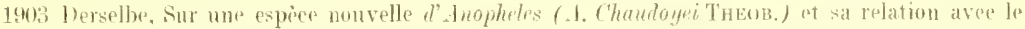
paludisme à Touggourt (Sud-Comstantinois). Compt, rend. de la soe. de biol.. T. 1, T. Mr. 16, 1. 5 (i⿱⺈.

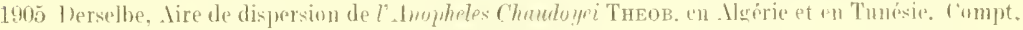

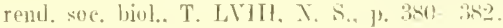

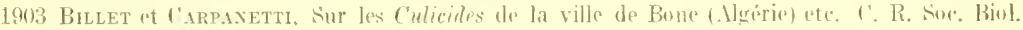
Bi1, 5. 5,1231 .

1902 Binnwood, G. T., some Practieal suggestions lin the P'revention ol Malarial levers. Ind. mid. Rexe, 5. Febr.

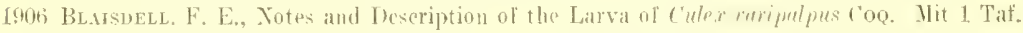
Entom. Jew: Tol. 17, p. 107 - 109.

1900 Blaxemard, R. Transmission de la Filariose par les Houstiques. Mrell. de paras. 111, Nr. 2, S. 280 .

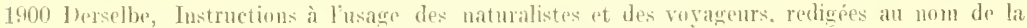

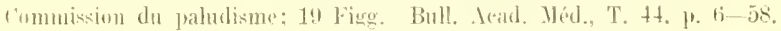

1901 herselhe, Les Moustipues de Paris; leurs mófaits, mesures de preservation. Bubl. Aead. Méd. Paris (3). T. 46, 11. 23:3 24t.

1903 Derselbe, Les moustiques propasateurs de maladirs. La Xature. Ann. 31, I, s. 119; 11, S. 1ti3; III, ‥ 179 .

1905 berselbe. Les Moustiques, histoire naturethe tmidieale. I'aris, k. R. de Rnderal.

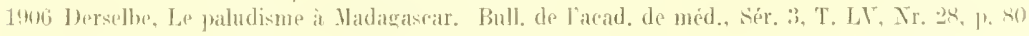
lis ! iti.

1907 Derselbe, Le paludisme à . Vadigasear. Irch, de parasitol., T. XI. Nr. 2, p. 185 -21.4.

1,007 Bleyer, The transmisson of mataria. St. 1,ouls Cour. Med. XXYYT.

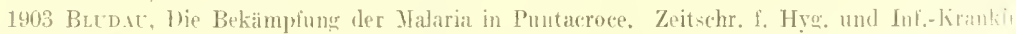
Bil. 43.

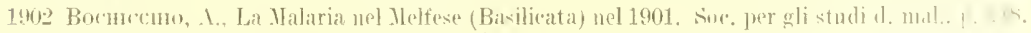

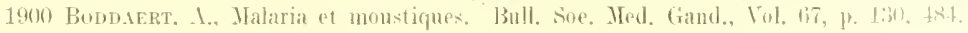

1901 Bumb.rod, I., Imozaes is malaria. 1. med. contemp., Nr. 21. 


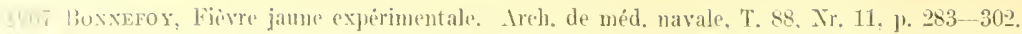

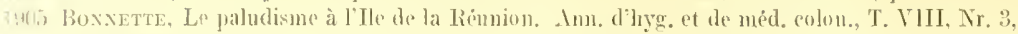
1. 4 . 4335 .

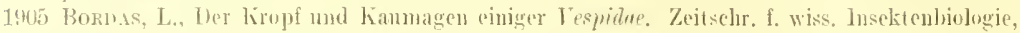
Bel. 1. 17elt \&, 9, 10 mit 12 Figg.

1402 Burbu, . .. Contribuzione alla sistematica dej Culiculi eon spreiale riguardo alla dilfuxione della Malaria nmana, R. d. R. Ire. d. Lincei. Roma, 5. ser., vol. Xl. 2. sem.. fase. 11, p. 318.

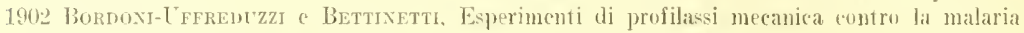
nel fonmune di Milans. Friom. d. R. Soc. Ital. digiene, Ar. 3.

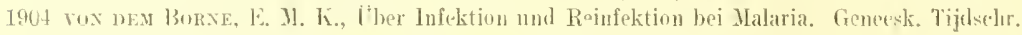
v. Niclerl. Tut., 1). XLAl.

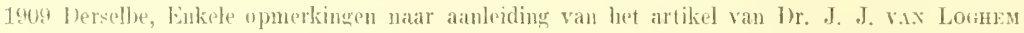
..Het voorkmen van de gele Kuortsmug in Ned. Indiët. Geneesk. Tijdsehr. voor Neder]. Indie. dees 49 , aflevering 6 .

1907 Boste Yr, E... Di un nuwo mezzo di distruzione delle zanzari malariche. Gazz. Osped. Inno 28, Nr. 21, p. 2.2. 2.23.

1905 Botet, La doctrine anophélienne et le malaria en Émyrne (Madagasear). Annal. d’hyg. ef de médecine colon.. Bid. s, p. 38; +10 .

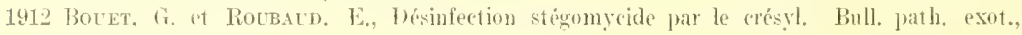
T. I. p. $6,27$.

1910 Boyee, sir Rubert W.. Mosquito or Man? Mit zalileichen Tafeln. London, John Hurray. 1863 Briter, F. M., Momograjuhio der (Vestriclen.

1880 1895 Therselbe und Bergexstam, Die Zweiflügler d. Kais. Unsenns zu Wien. 24 Tal. Wirll.

1903 BraUx, I., Dje tierisehen Parasiten des Jenschen. 3. Aufl. Würzhurg.

1902. Srazzula, F. Di mia zona malarica nel fommune di bulngua. Inn. d'igiene surerim., Vul. Xll. Fiase. 1, 1\%. 537 .

1907 Brexs, Prophylasis of paludie diseases. Amer. Publ. Moalth Iss. Rep. XXXlI.

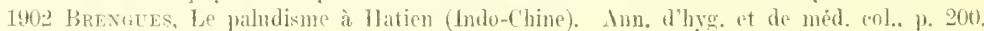

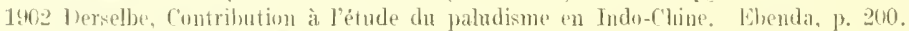

1904 Tho British Jedical Astociation. Section of tropical diseases. Vhiscussion on the Prophylaxis uf Malaria, Brit. Met. Journ., 17. Supt.

1906 Brot ardel-filbert, Nonvean traité de méderine. Bd. TT: Maladies exotiques. 439 s. Paris, Baillìre fils.

1902 Browx, H. H., The prevention of Malaria, Brit. ned. jonrn., Vol. I. p. 121.

1907 BRowx. W. C., Dalaria in Madagascar. Journ. of trop. med., Vol. 10, Nr. 12, p. $206-208$.

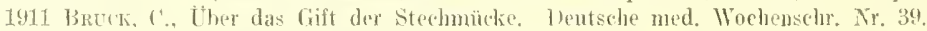

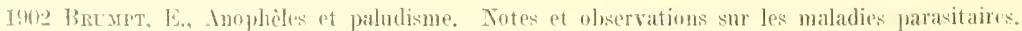
Irch. de l'arasit., T. V. 2. Ser., Tr. 1X. 1) 149.

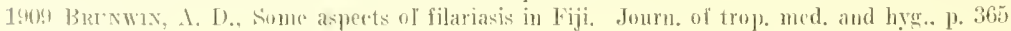
lisis 370 .

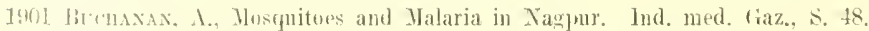

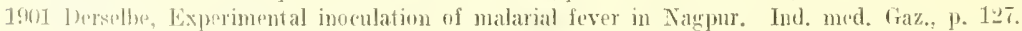

$19(1) 2$ forselhe, Mosinitues and Malaria. Brit. med. Journ., p. 1107.

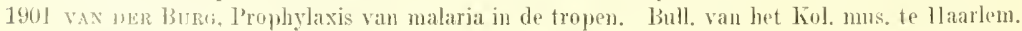

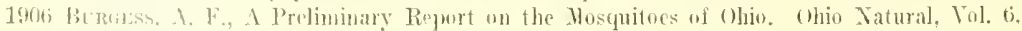
1. 4.38 440,

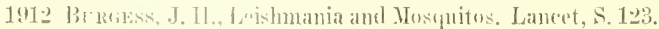

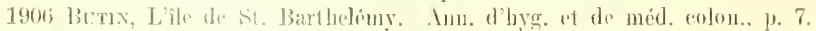

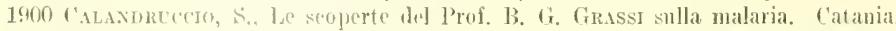

1901 lersellor, Incora le seoperte le] Prof. B. C. Cirassi sulla malaria. Catania.

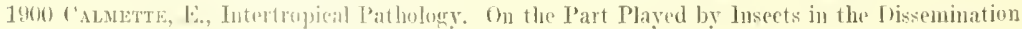
uf the Jistases of Hot (intutries. Journ. of tropl. med., Vol. 2, p. 159-160.

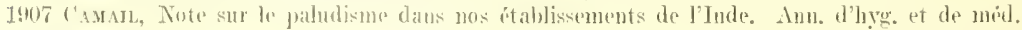
coloul. X.

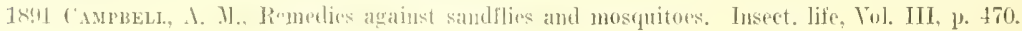




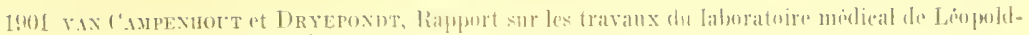
ville en 1900. Soe. d'Études poluniales. Binsulles.

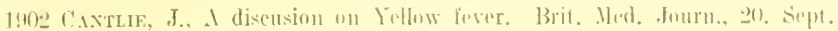

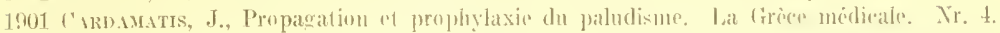

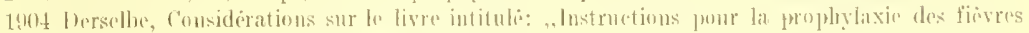
patustres" de M. Comst. Savas. Progres méd.

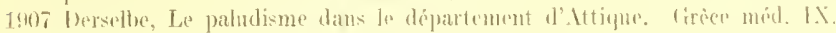

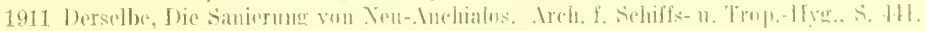

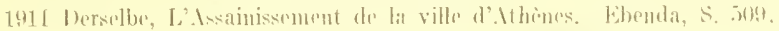

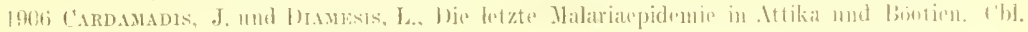
f. Bakt., Abt. I, Bil. Xlll, s. 527.

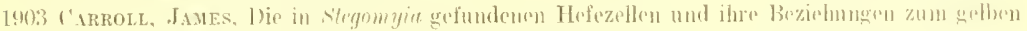

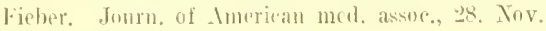

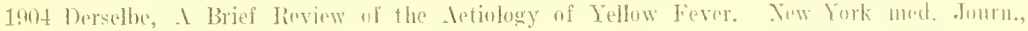
Vol. 79, p. 24111.307.

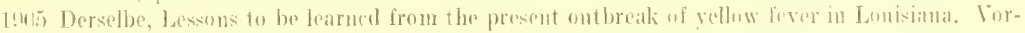
trage in der Imer. Publ. Thalth Assoe., Septenulur.

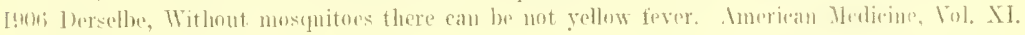
Ir. 11, p. $383-380$.

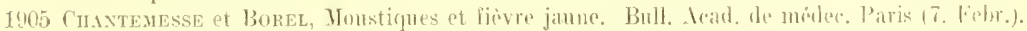

Itrot Carter, H. R., I Tote on the spread of yollow fever in lonses. Wid. Record, 15. Jumi.

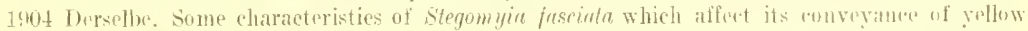
fever. Med. Ree., s. 761 .

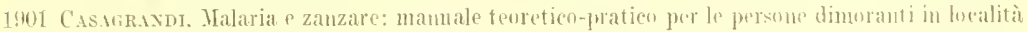
malaricle. Poma.

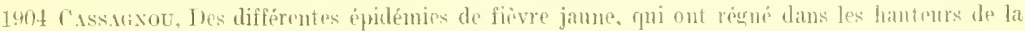

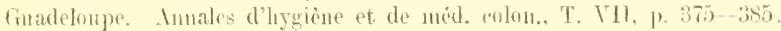

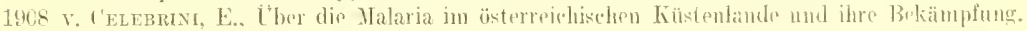
llitt. d. Naturw. Yer. f. Steiermark, Bd. 44, 11. 2, 5. 2L5-218.

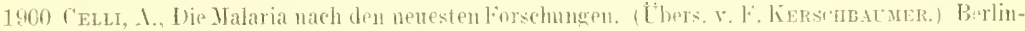
Wie's.

1900 Derselbe, Epidemiolngie und Prophylaxis der Malaria rom neuesten aitiologischen sitandjumkte aus. Berl. klin. Wnehensclir., s. 113.

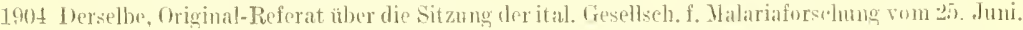
(b). f. Bakt., Referate, Bd. XXXT, s. 379.

1905 Derselhe, Siebenter Jahrobericht der Ital. Ciesellsch. f. Malariaforschmer. Orie.-Rerorat.

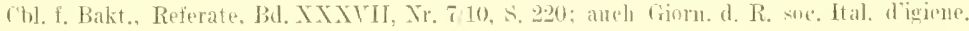
Amno 27, Nr. 11, p. $525-534$.

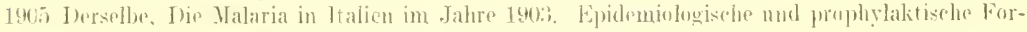
schumgenl. Areh. 1. Hyg. Bil. LII, Heft I.

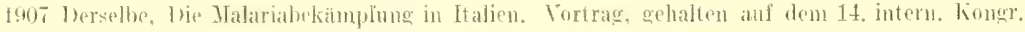
f. IIye. I1. 1) mographie zo Berlin.

1907 Jerselhe, La lotta enutro la malaria in Italia. Rilpp. al 1t. Congr. di Igiene in Berlinn. Inn.

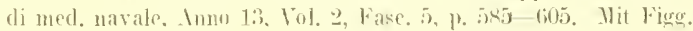

1607 Derselbe, La malaria in Italia durante il 1!the: riwlerche epidemiologiche e prufilattiche. Ann. Lgiene sperim.. Tol. 17. Tr. 8, Fase. 3, p. 433- 182.

1907 berselbe, Neunter Tahreshericht. Ital. Gexellseh. f. Walariaforschmng. sitz. am 3. .Iulj 1907.

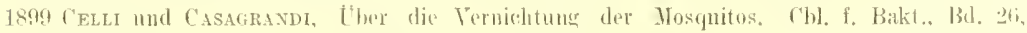
S. 396.

1901 Cell, 1. und Gasperixi, li., Pahdismus ohme Malaria. ('bl. f. Bakt., Bd. XX.., Y.. 1 .

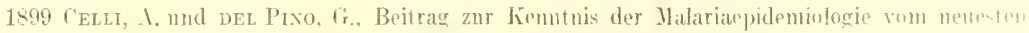
ätiologischen Standpunkte ans. Ctb. f. Bakt.. 1. Ibt., Bd. XXY'T. s. 4s1.

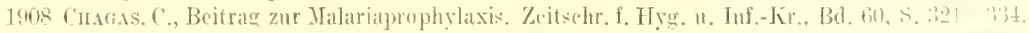

1902 Chaluers, J. 1. A theory to explain bow man and the anopheles originally hee mu in apt with the malarial germ. Journ ul Trop. Yherl., p. 133. 


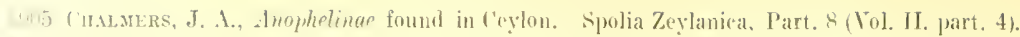

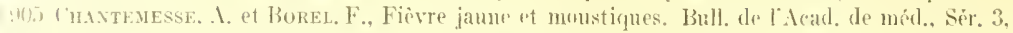

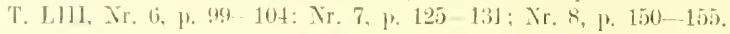

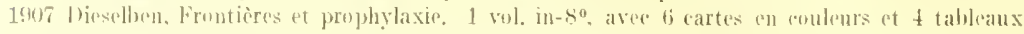
moirs. :313 pages. J'rix: 7 Franos. ([noin, editeur.)

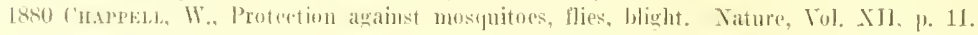

1903 ('Ir.sse, Elforts to abate the mosquito muisance in Brooklyn. Boston med. and surer. Journ., 30. July.

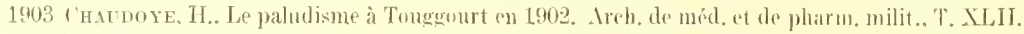
Nr. 1.

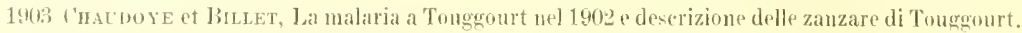
Gionu, med, del Reg. exercito, Nr. 12.

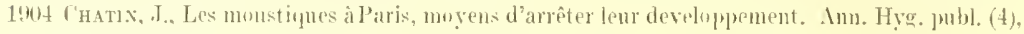
T. 2,1 , 97.

1901 ('hatterjee, B. C.. l'arasites in Anopheles. Ind. Med. fraz., p. 371.

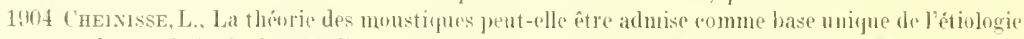
et de prophỵlaxie du paludismo ot de la fiève jaune? Semaine medie. Ann. 24. p. 117-179.

1907 Churo, Etiology of malarial disease. Imeric. Publ. Health Iss. Ru. XXXII.

1901 Christorners. S. R.. The anatomy and histology of the adnlt female mosguito. Rep. to the malaria committee of the Royal Soejety. Lombun.

1904 Derselhe. Second Report of the Anti-Malarial Operations at Mian Nir 1900 1903.2 Talf. Scient. Mem. off. Med. Sanit. Dept. Govern. India. X. S., Nr. 9.

1906 l)erselbe, the the importance of larval characters in the clascification of mosquitoes, $4^{\circ}$. 18 . ('alcutta (fins. P'rint. Olí.).

1900 C'Hristy, C.., Mosquitos and malaria. Iondon and Bombay.

1904 Derselbe, The Etiology of Malaria. The Laneet, Vol. 167, p. $1750-1751$.

1906 Croff, E., Malaria senza anofolismo. Tommasi. Inno 1, Nr. 19, 1. 4ni-483.

1907 CLACDE, Je la contagion du paludisme à distance. c'aducép Ylll.

1903 Claus, Die Malaria in der tiamison Thorn. Dentsehe militärärtl. Zeitschr., s. 270.

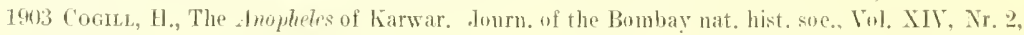
$1 \mathrm{Taf}$.

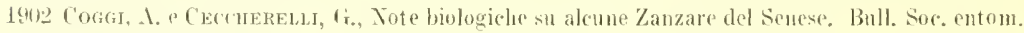
ital. In11. 36 , \%. 49.

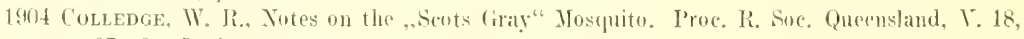
1). 67 - 80), 5 plis.

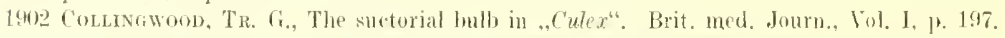

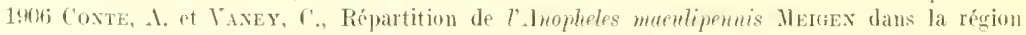

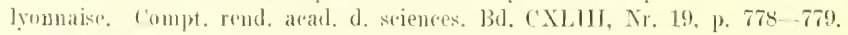

1960) Cook, 1. R., Malarial fever as met with in the Great Lake region of rentral Ifriea. Joarn. of Treple. Med.. Vol. V.

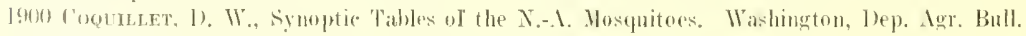
anit . Ibls.

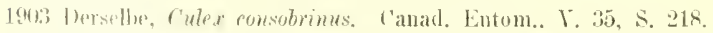

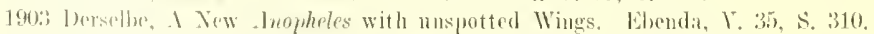

1903 1)ersellye, Four Now sipecies of Culex. Ebenda, V. 35, s. 255.

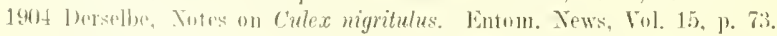

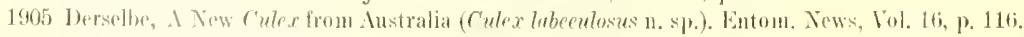

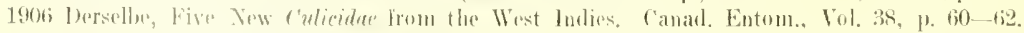

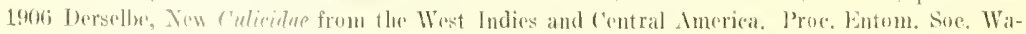
shimgton, litl. 7, ], 18: 186i.

1906 Jersellow, I Xim fulex near cumiei. Entom. Xews, Vul. 17, 1. 109.

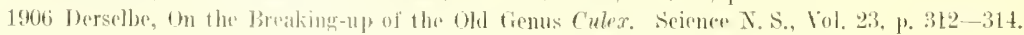

1900 CorNwal, . I. W., The extermination of malaria. Jnd. mod. Faz. Jan.

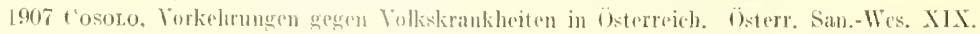

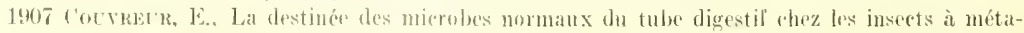
morphoses pendant la nymphuse. Inu. de la Soc. Linéenne de Lyon, T. 1.111, 1. $215-216$. 


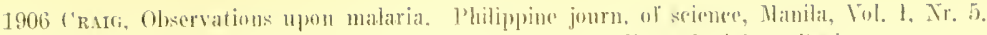

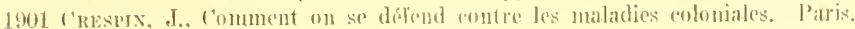

1004 lyerselhe, l'recis du paludisme. T'aris.

1903 I'Resswell, J. E., Malarial lever in the lsthmus of Surz. Interu. Med. Cungr. in Katiro. (kef. in Arch. f. Seh.- 11. Trop.-Hyg., Bel. 7, S. 397.)

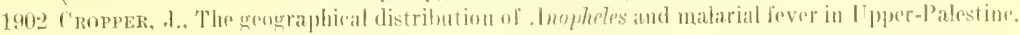
Journ, of liyg.. Vol. H, 1, 47.

1905 lerselbe, The malarial frevers of Jerusalem and their prevention. Journ. of liyg., lot. V, Nr. 4, 1). 460 466.

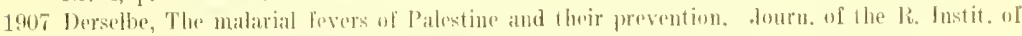

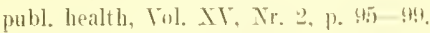

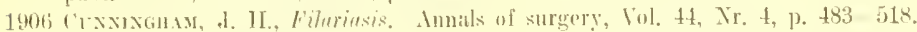

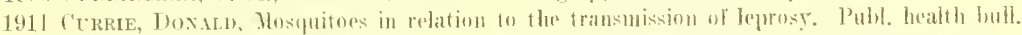
Hashington, $\mathrm{Nr}, 3 !$, s. :3.

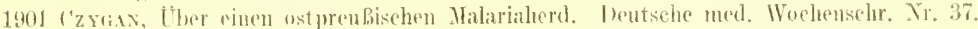

1908 1).hugkex, b. E... Tlu mataria mosquito. Guble leallet series ol the Ameriean Muscum ol Natural History, Nr. 27, Trw Tork.

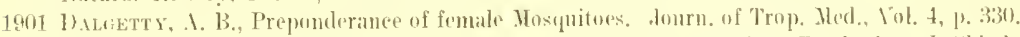

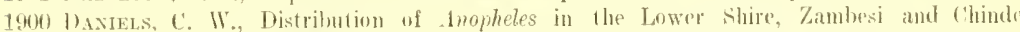
Rivers, Rur. of the Mal. I'omm.

1900 Derselbe, Distribution of Anopheles Brepding (rounds in the British East Mrican Protectorate. Riter. of the Mal. Comm.

1900 berselhe, Hast Nirica. Some Observations on the fommon Anophetes of British ('entrat. Irricil, the Haunts and lJabits of their Larvae dmring dry Season 1899. Rep. of the Mal. ('onme

1900 lerselbe, On the Transmission of Proteosoma to Birds by the Mosquito. R. S. Rep. ta the Mal. Comm. - Journ. of Trop. Med., Bit. 1, S. 338, Bd. 2., s. 24.

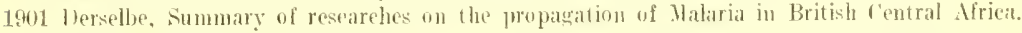
Brit. M[ed. Journ.n 19. 193.

1903 lorselhe, Studies in laboratory work. London.

1905 LE I)Axtec, 1. Précis de Pathologie exoticpue. (Maladies des pays chauds et des pays frojils.) Bordeaux.

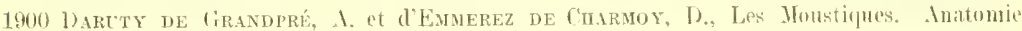
pt Biologie etc. Port Louis.

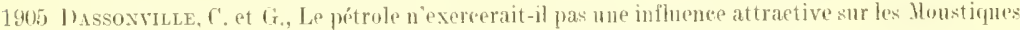
"t sur d'autres [lipteres? r. R. Soe. Biol. Paris, T. 59, 1). $334-335$.

1912 Harrs, Matd L., A note on the anophelines found in Quetta. Paludism, September. Nr. 5, S. fti.

1901 1)ebove, laps Moustiques de Paris. Bull. Acad. Méd. Paris (3), T. 45, p. 474-475. - l)iseuss. p. $475-478,491-492$.

1905 1)Ecorse, Chari et Lac Tehad. Ann. d'hyge et de méd. coton., p. 173.

1908 Delandre, lestruction des mouches et des monstipues par le pormol. Ireh. de méd. et de pharm. milit., p. $297-301$.

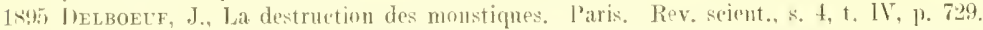

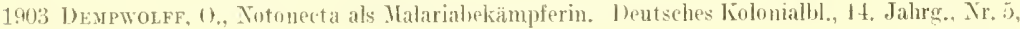
S. 108 .

1964 1)erselbe, Berieht über eine Malaria-Expedition nach Deutseh-Xeuguinea. Zeitschr. f. Hyg. u. Inl.-kirankh., Bd. Xl,

$1 !(16)$ Desfosses, P.., Proteftion méthodique contre le paludisme. La presse médicale, Nr. 4: 1). 335 .

19tof l)erselbe, fanal de Panama ot fievre jaune. Presse méd., 17. Novenber.

18x' Drмmock, fi., Anat. of the mouth-parts and of the sncking-apparatus of some Diptera. Buston. With 4 plates.

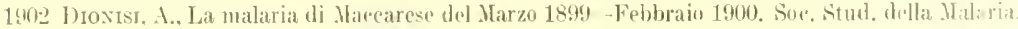
1). 1.

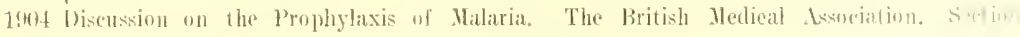
ol tropieal diseases. Brit. Med. Jomrn., 17. Sept. 


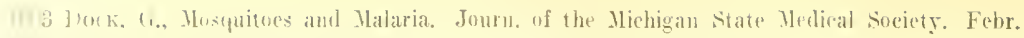

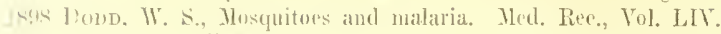

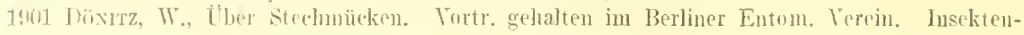
Börse, Nr. 5, s. 34.

1902 Derselbe, Beiträge zur Kémntnis der Anopheles. Ztschr. f. Hyg. ı. Inf., Bd. 41, Nr. 1, s. 15.

1903 leersedbe, Beiträge zur Kemmtnis der Anopheles. Il. Mitteilung. Ebenda. Bd. 43. S. 215.

1902 Tersebe, t'ber Malariamücken in den deutsehen Kolonien. Vortr. wehalt'n auf tem deutsehen Kolonialkongresse zu Berlin.

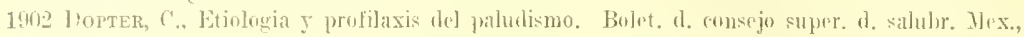
T. VIJI. Nr. 2, p. 83.

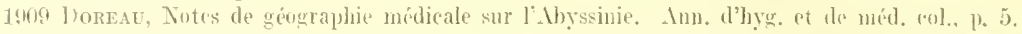

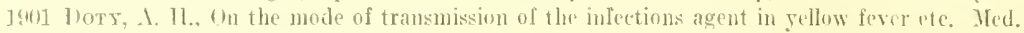
Pec., Xr. 17, si. 649 .

1:05 7)ersclbe. The Tse of Sulphate of Copper alone, and in combination with Lime, for the l)estruction of Mosquito Larvae ete. Yed. Ree. New York, Yol. 67, ]. 90-92.

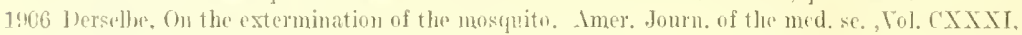
Xr. 2, p. 187-197.

1907 1)eprey, A. B., The Malaria of the East Coast of Trinidad. Jomrn, of tro]'. med.. 1). $299-303$.

1!04 1)upuy, J.. Navires et moustiques. Rev. d'hyg., T. XXYJ, Mr. 4.

1901 T)

1901. Feritam and Mrers, Yellow Fever. Joum. of trop. med.

1903 I) ctтox. E. J., Report of the malaria expedition to the Cambia 1902. Thompson Fates and duluston laboratories report, Vul. V, Nr. 1.

1906 1) utrox et Tond, Rapport sur la prophylaxie de la Malaria dans les principanx postes de l'ṕtat indéprendant di Fongo. Liverpool sidhool of Troj. Med., Mem. XX.

1904 T) yar, Jl. G.. Nutes on the Jlosquitoes of British Columbia. Proe. entom. Sue. Washington. Vol. 6. 11. 37.

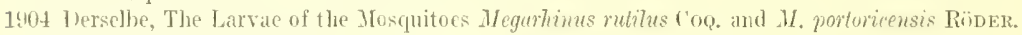
Ebenda. Vol. 6, p. 20.

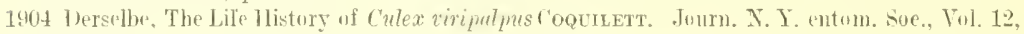
1). 90.

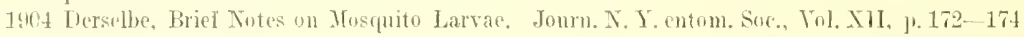
and p. $243-246$.

1905 Jersedbe, Illustrations of the Abdominal Appendages of Certain Mlosifuitocs. Joum. X. Y. rentum, suc., Vol. 13, p. 53-56, 2 j jk.; p. 185-188, 1 pl.

1905 1)ersellhe. A simoptic Table of Nortl Ameriean Nosquito Jarvar. Journ. X. Y. cutom. Soe., Tol, 13, p. $23-26$.

1905 Terselbe, Briff Notes on Mnsipuito Larvae. Journ. X. Y. entom. Soe. Vol. 13, p. 26-29.

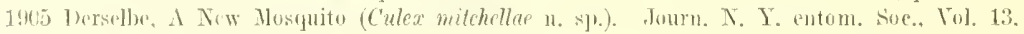
p. 74 .

1905 Terselbe, Remarks on Genitalie Genera in the Culicidae. Proe. entom. Soe. Washington, Vil. 7, p. 42-49, 1 fig.

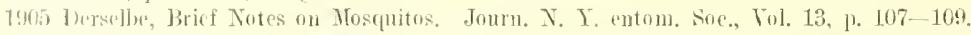

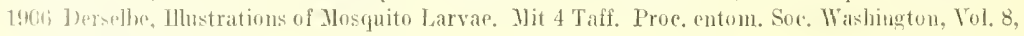
1). 1.5. 21.

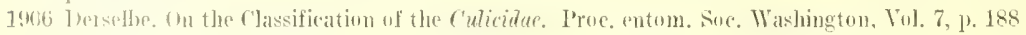
bis 191.

1906 Dersthe, The ("lassilieation of Mlosquitoes. Science X. S., Vol. 23, 1. 233-34.

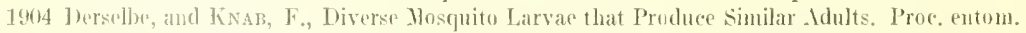
Sere. Waslingtun, Tol, 6 , p. 143-1.44.

1907 Diesciben, Jeseriputions of New Mosquitoes from the Panama Canal Zone. Journ. N. Y. entomol. Soe, Til. XV, p. 245.

1904 l) y'é, L., Sur la répartition des, J nopheles à Madagascar. C. R. Soe. Biol. Paris, T, 56, p. 544.

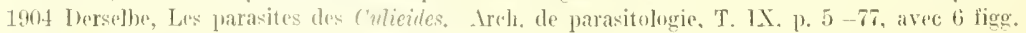
dans de texte.

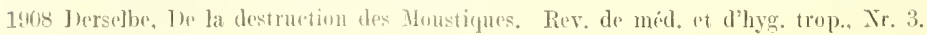




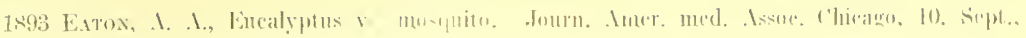
1. 6 is:

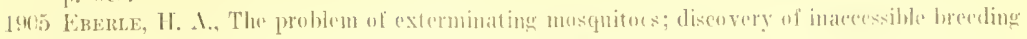

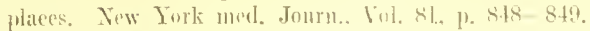

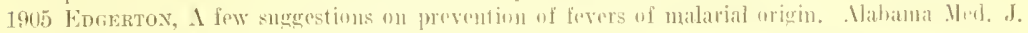
Xill.

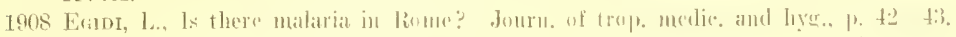

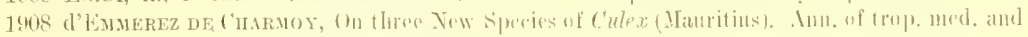

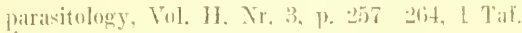

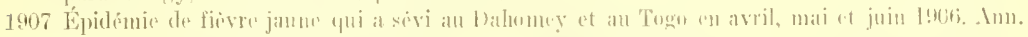

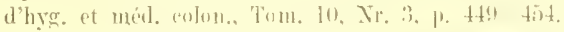

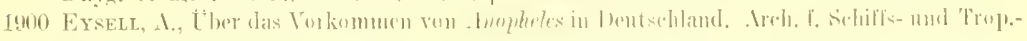
Hyo., Bd, 4. S. :35:3.

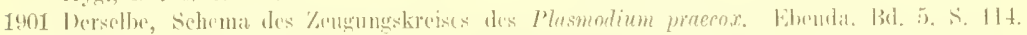

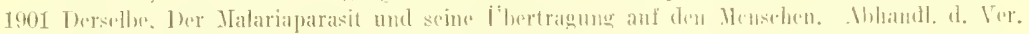
f. Naturk. Kassol t. d. Vereinsjallr $190(1) 191) t$.

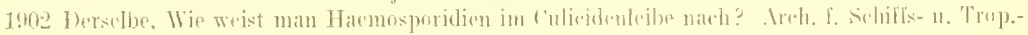
IIYe, Bil. B. S. 160 .

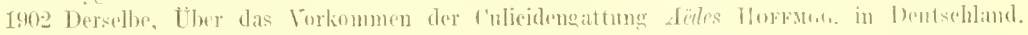
Ebenda, Bil. 6, 5.217.

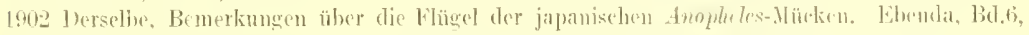
S. 2906 .

1903 Dersellye, dedes cinereus Hoffurt. Ehemeli, Bd. t, s. 333.

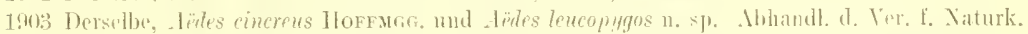
Kitscel f. d. Tereinsjilhr 1902,1909 . s. 285.

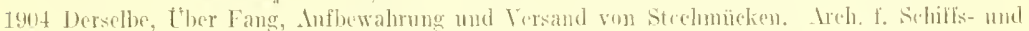

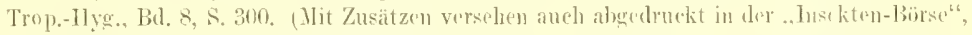
1904, Jahre. XX1, s. 330, 338, 346, 354.)

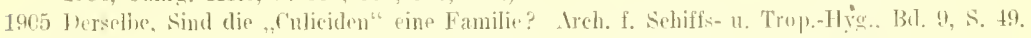

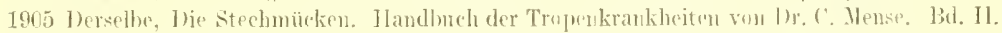

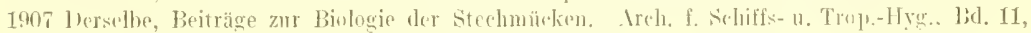
S. $197-211$.

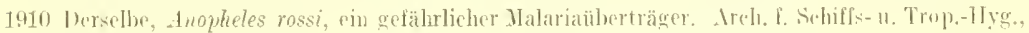
S. $\$ 16$.

1911 Derselbe, Thas Schlipfen der Stechmiekn. Areh. f. Sehiffs- 11. Trup.-Hya., S. 273.

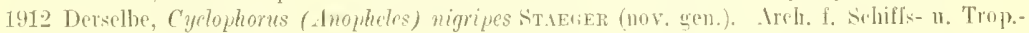
Hvg., \$. $421-431$.

1906 rox Ezoorf, H., Personal experience in preventing spead uf yollow fover. Jouru. Imerie. mid, assue., Vol. XLT'1, Mr. 1. 1\%. 11-14.

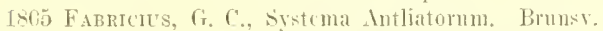

1904 Fas.redo. F., (1) impaludismo. Rio de Janciro.

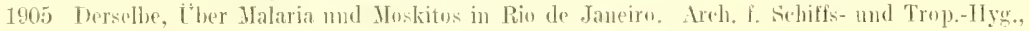
Bd. 9, s. 66 .

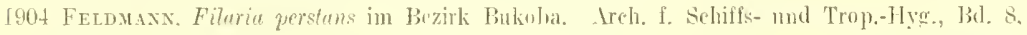
S. 990 .

1904 Fert, E. P., Mosquitos ar Culieidae of Wew-York sitate. Abany. (Bull. T. Y. State Mus.) with 57 plates and 113 ligures.

1905 Derselbe, Culex brittoni 11. sp. Entom. Xtws, Vol. 16, p. 7980.

1901 Fersi und Cano-Brusco, Versuche znr Malariaproplyylaxis. ChI. 1. Bakt.. Nr. 25).

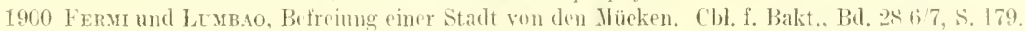

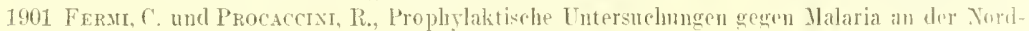
küste von Sardinien. ('bl. f. Balit., Bl. XXIX, Xr. 21.

1900 Ferm und Toxsmi, La profilassi della malaria e la distinzione delle zauzare nell' isuli lull' Limara. Amm. d'ig. sperim. 2.

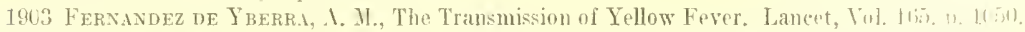

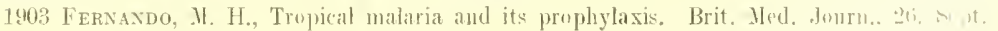




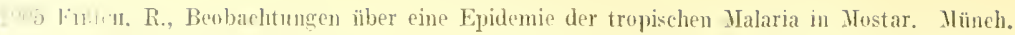
med. Worhensedur, Nr. 8 .

issog Ficatbi, E, Xotizie preventive sulle Zanzare italiane. Siena, Atti Ac. 8o.

1 1896 Irerselbe, Revis, sist. d. Culicidae Europ. c. 4 tar. Firenze.

18es l)erselhe, Venti specie di Zanzare italiane. Boll. d. Soe. entom. ital.

1901 besche. Sopra lia malaria e le zanzare netha salina di cervia a nel territorio di Comacehio. Anu. d’ig. sperim. liake. I.

1905 Fixk, C. H., The mosquito malarial theory and malarial prophylaxis from the latent phase. Journ. of trop. med., Bd. 8, Nr. 11), 11. 25i-258.

1R81 Fingar, C., lil mosquito considerado hipoteticamente eomo agente de transmission de la ficlore amarilla. Halmana.

189f Jerselbe, lnowlation for yellow fever by means of contaminated mosquitoes. Americ. Journ, of med. Se. Siept.

1899 therselbe, Mosquitoes eomidered as transmittors of yellow fever and malaria. Med. Record, Nr. 1490 , S. 737.

1901 Jerselbe, The mosquito-theory of transmission of yellow lever with its new develetpments. Jed. Rer., 19. Ja1.

1901 Derselbe, summary of the progress made in the nineteenth century in the study of the propagation of yellow fever. Ehenda, 9. Febr.

1901 Jersethe, Vellow fewer and its transmission. Journ. of the Amerie. med. Assoc. Nr. 15.

1901 l herselloe, Two different ways in whith yellow fever may be transmitted by the culex mostuito stegomyin turniatu. Wbenda, Nr. 21.

1902. 1)ersethe, Agreement between the history of yellow fever and its transmiscion by the culex mospuito. Ebenda, Mr. 16.

1903 [nrselbe, Finbre amarilla. Rev. med. tru]. Habana, T. 4, p. 121-132.

1906 I)erselbe, Informe general sobre la reciente epidemia de fiebre amarilla. Revista de med trop., Halsana, Nr. 1.

1906 Fisch, Cher Stoffe zur Moskitosicherumg. Arrh. f. Seliffs- ı. Trop.-Hyg. Bd. X. \. 172 bis 175 .

1908 Foley, F. H. et lvenxault, A., Anophélines dans l'ean salée. Bull. soc. path. exot., 1. 172 bis 173.

1902 Fontorsent, M., Le Paludisme en Emyrne (Madagatcar). Craz. méd. de Paris. August.

1906 J)rselbe, La médicine à Madagasear. Arels. de parasitol., T. X. Xr. 2, p. 227-237.

1904 Forel, A., Zur Malariafrage. Nünch. med. W., S. 562.

1907 Fontr, F. Der Kampf gegen die Malaria in der römisehen Campagna. Med. Klin., lahrg. 4, Nr. 1, s. $33-34$.

1011 de Fosser, A. M., Influence des vents dominants sur les larves de Culex at drapheles. Bull. soe. patl. exot., Bd. 4. s̀. 325 .

1911 Frexichisı, G., Leishmania and Vosfuitos. Laneet, p. 1268.

1912 I)erselbe, On the Presence of Leishmenia in the ligestive Tract of Anopheles anculipennis. Amn. of Trup. Hed. and Paras. Bd. 6, 11. 1 B, S- 41- 52 .

L907 linetedexthal, G., Eine Malariaepidemie in Peine (bei Hannover), hauptsäellich bei Kindern heokachtet. Areh. f. Kinderleik., Bd. 47, s. 95-115. 4 Figg.

1906 Jiriedmax, T., Praktische Ergebnisse auf dem (iebiete der Tropenhygine. Die Bekämpfung des Malariatichers. Berl. klin. Wochensclır., Jahrg. XLll\}, S. 236-239.

1962 Fruemrensex, Moskitos auf Schiffen. Deutsch. Kolonialbl., 15. .luni.

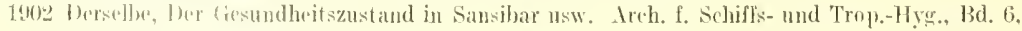
S. 380 .

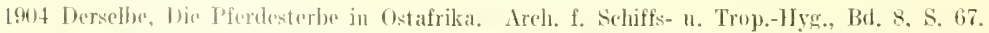

1905 Derselbe, firsundheitshericht aus Zanzibar lür die Monate April his Juni 1904. Areh. f. Achiffsи. Trop).-IIyg., Bd. 9, s., 50.

1905 Frogriats, W. W., Homestic Insects: Monquitoes. Igrie. Gaz. N. S. Wales, Vol, 16, 1 pl., p. 10821087.

15112 Fry, 1. B., Note on Thalaria in Chota-Nagpur. Palndism, September, Mr. 5.

1912 Derselbe, Indigenous fislo and mosquito larve. Paludism, September, Nr. 5. 


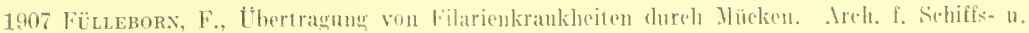
Trop.- 1 rg... S. $635-643$.

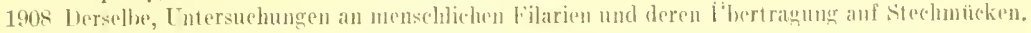
Mlit 7 Doppeltafeln. Ireh. I. Sehiffs- ". Trop.-Tyg., Beih. 9.

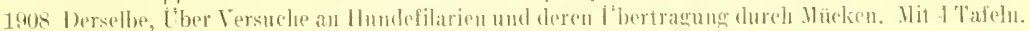
Areh. f. Sehills- u. Tropr.-Ilyg., Beilt. si.

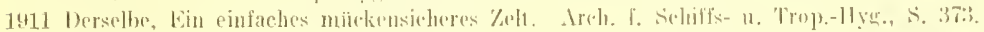

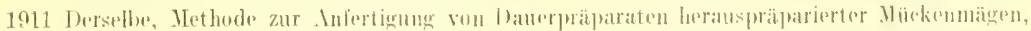

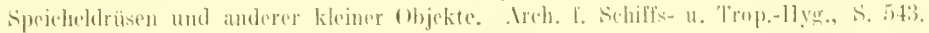

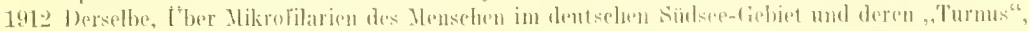
nebst Bemerkungen über die klinischen Manilestationen der tortigen Filariasis. Awh. f. Sellitis- - 1. Trop.-1Tyg., s. 53:3-547.

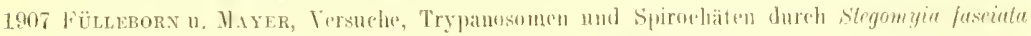

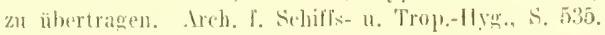

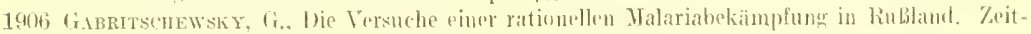
schr. 1. Hyg. u. Inl'., Bid. 54, S. 2-27.

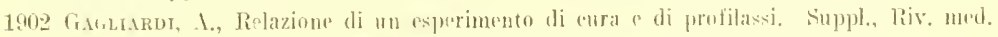

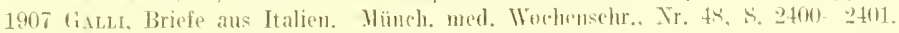

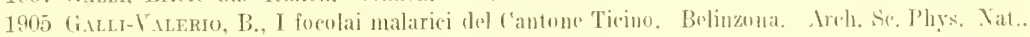
Vol. (4) 19, p. 212 .

1905 Werselbe, Il focolaio malarieo di Sorieo e Gera. Atti della sure italiana per gli studi dellat malaria, Vot. VI, Roma.

1905 Derselise, La lotta contro la malaria in Valtellina. Itti della soe. italtaua per goli stueli della malaria, Yol. VI. Roma.

1906 Derselbe, lie Drahtnetze an Türen und Fenstem som Standpunkte der Hygiene und Pruphylaxis. Therap. Honatsh., Januar.

1907 Derselbe, La protection de l'habitatiou muale contre les mousticues of les momehes an puint de vue de l'hygiene. Compt. rend. des travanx du $2^{\text {me }}$ congress internat. punr l'ansainissement ot salubrité de Thabitation, tesu à Geneve du $t$ an 10 Seput. 1906.

1907 trerselbe, Notes médieales sur la Tunisie. Bull, de la sice, raud. des se. nat., Vol. 43. Tr. 154, p. 201.

1901 Gallo-Yalerio et Narbel, Etudes relatives à la malaria. Lus larves des culex et lnopheles (n) hiver. (bl. f. Bakt., Bd. XXIX, Nr. 29.

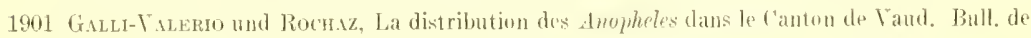
la soe. vaud, d. se. nat. XXXril, Tr. 142.

1904 l)ieselben, L"her Vernichtung der Larven und Nymphen der Culiciden und über einen . 1 pparat zur Potrolëirung der siumple. Therap. Monatsh., Sept.

1905 Diescllben, İber die Wirlung vin . Ispergillus niger und A. gluueus anf die Larven von C'ules und Anoweles, ('b]. f. Bakt. (Oriw.). Bd. 38, S. 174-177. 2 Figr.

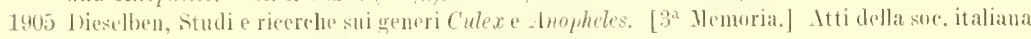
per gli studi della malaria. Tol. Yo, Ruma.

1906 Dieselben, ither die Wirkung von Aspergillus nighr und Leperyillus gluucus anf die Larven von Culex und Anopheles. (2. Mlitteilung.) ('hl. T. Bakt. (Orig.) Bd. XI, 11. 5, S. 630-633.

1906 Dieselben, Manuel pror la Lutte contre les Moustiques. Lamsamm et Paris.

1906 l)ieselben, Studi e ricerche sui generi Culese .Inopheles. (ta memoria.) Atti della soc. itatiana per gli studi della malaria. Vol. VII, Roma.

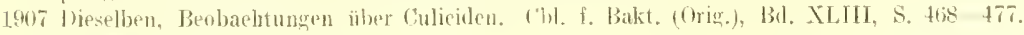
(5. Yärz 1907.)

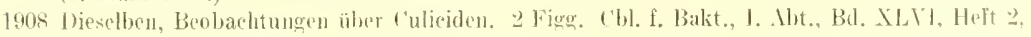
ล. $130-134$.

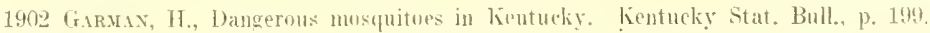

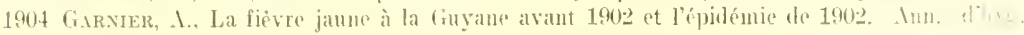
et lle médec. col.. p. 1.

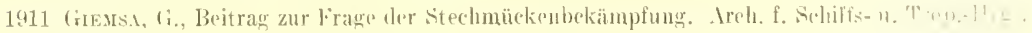
s. 533. 


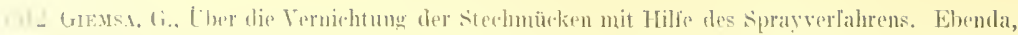
i. $5(i)$.

(!)2 Cillbeas, G., (ontrib), allat epidemiologia e allat profilassi della malaria in allune zone d'Italia meridionale, Liazz, d. osped., 31. Angust.

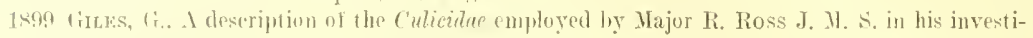
grations on Mataria. J. of trop. Mexi.. S. 62.

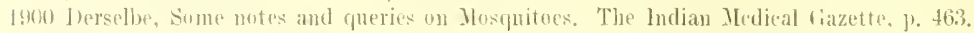

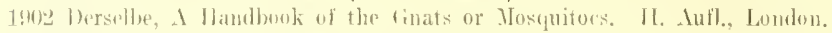

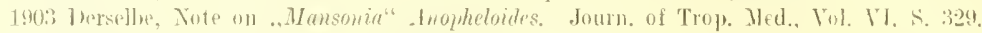

Inot Derselbe, I Revision of the Inophelinae. Landon.

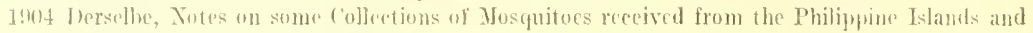
Angola. Jourzo, of Trop. Mad., 1. Mezember.

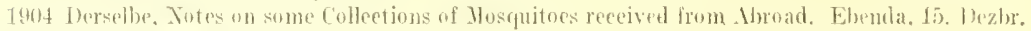
1906; Derselbe, Nosquito Totes. Joum. of trop. Med., Vol. IX, p. 130-132, 1 lig.

1912 Gill, f'. 1., Note on the seasonal peralence of Anophines with special reference to the potentialities of a single breeding place. Paludism, September, Ni. 5.

1902 tirlagecr, R. T., Malaria on the Zambesi and Shire. Brit. med. Journ., Vol. I, p. 624.

1907 Gioliter e Mlassinux, Regolamento rontro la malaria. Salute Puh. XX. Perngia.

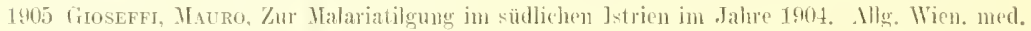
Ztr.. Mr. 24 und 25, S. 292 11. 304.

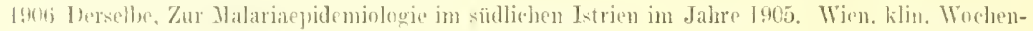
schr., Jahre. NIX, Nr. 46, S. 1373-1376.

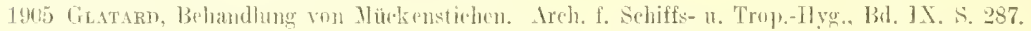

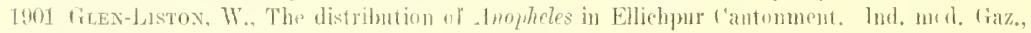
1). 124 .

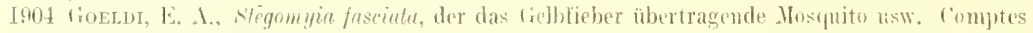
rentus du V fe comer. internat. de Znologie, session de Berue.

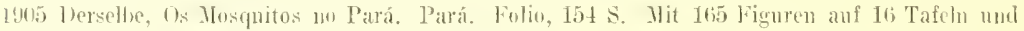
1) pepeitafeln und 5 kolorierten Thepeltafelu.

1907 Gotdrerger, J., Jellow feter. Etiologie, symptoms and diagnosis. Washington, frov. I'rint. (i)t.

1908 Therselbe, La fiehre amarilla, su etiolugia, sintomas y diagnestieo. Bul. del fonseju sup. de salubricia. Jexico. T. 13, Nr. 10, p. 347--367: Nr. 11, p. $383-392$.

1907 Goldschunt, 1)., Disparition de la liève padudéenne à Strassbourg et dans ses environs. Rev, d'hyg. th poliee sinit., T. 24, Nr. 5, j. $417-424$.

1902 Goroas, IT. C., The propagation of yelow lever by Jostuitoes. Tew York med. Joum. LXIT, Nr. 2.

1!102 Derselte, Mosquito work in Ilavima. Ied. Ree, 19. Juli.

$1 ! 102$ Derselbe. Results in Havana during the year 1901 of desinfection lur yellow lever. Laneet, S. 1667.

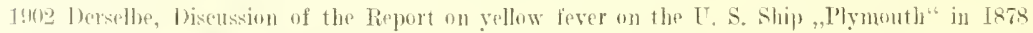
and 1879. Hed. Rere, 4. toet.

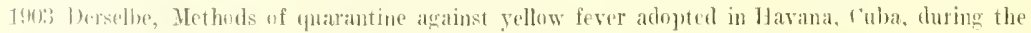

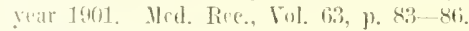

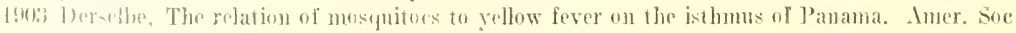
of Trop. Mrot. 8. Tez.

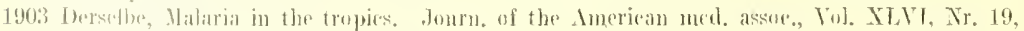
1. 1416 1 1417 .

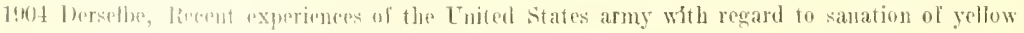

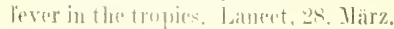

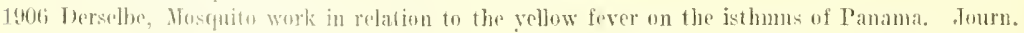

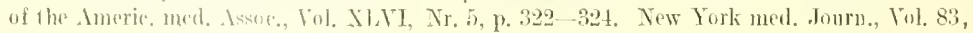
1). 109 .

1907 Dersellow, Hestuito work in relation to yellow fever on the jsthmus of l'anama. The Ameriean society of tropisal medicine.

1908 berselbe, Hethod of sprcald of yellow fever. Hed. Rec., Vol. 73, Nr. 26. 1. 1061-1063. 


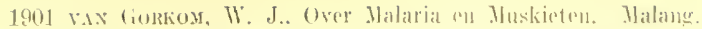

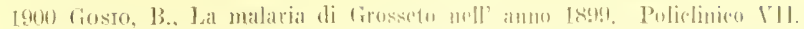

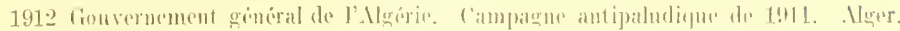

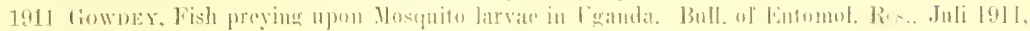
$11,2,1 \% .18 \%$

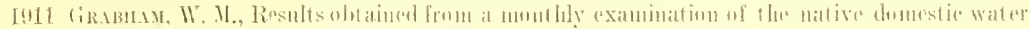

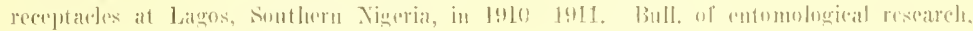
Juli 1911, I1, 2, jr. 1:27- I:3ti.

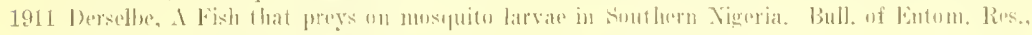
.Juli 1911, I1, 2. 1. 137. 13!!.

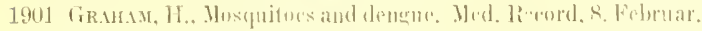

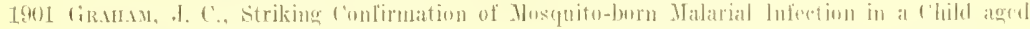
thres werks. Jomro. of trop. mod., Vol. 4, 1). 2.

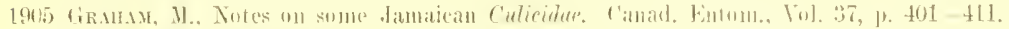

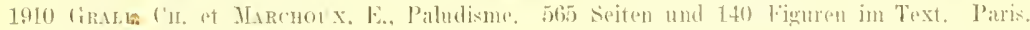
d. 13. Batillicere et tils.

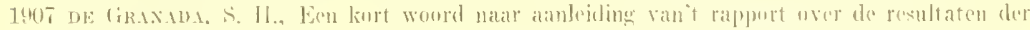

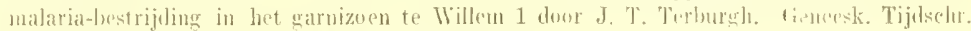
rour Xoderl-1udie, Jeel 47, It'l. 6, p. 755763.

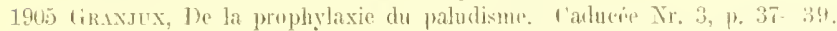

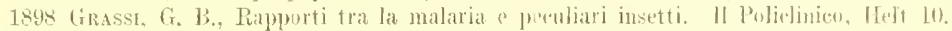

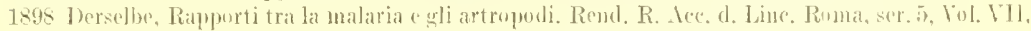
4. lezamber.

1899 Dersellor, Rapjonti tra la malaria e peoliari insetti (Zanzaroni "Zanzare palustri). 11 Puliclinieu, Oet.

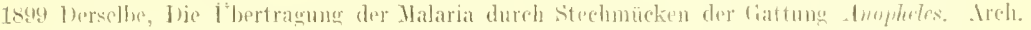
f. Schilfs- u. Trop.-Hyg., Bil, 3, s. 331.

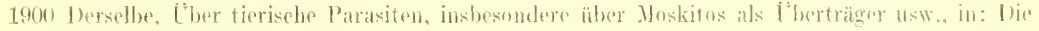
Lmsehau I. Tr. 4k, s. 941.

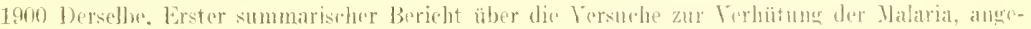
stellt in der Fimend vou Paustum. 1'bl. f. Balit., Bd. 28, 5. 535.

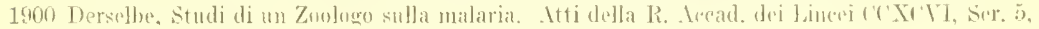
Tis]. Ill, Roma.

1901 Dorselbe, Die Malaria, Studien cines Zuolugen. Irua.

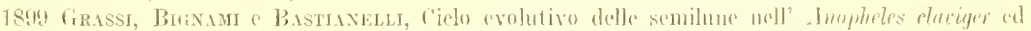
altri studi sulla Malaria. Itti della socontà per yli studi della Malario. Vul. L. Finna.

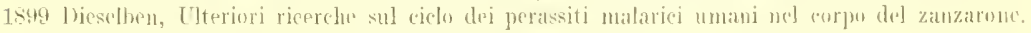
Rendic. della R. Icead. dei Lincei Vill. Tr. 1.

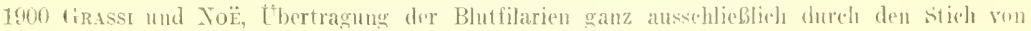
Sitecturiicken. Cb]. f. Bakt., XXTIIl. S. 65\%.

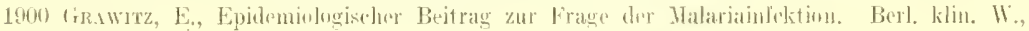
Nr. 24.

1902 Derselbe. Klinisehe Patlunlogie des Blutes. 2. Aull. S. 59t. Berliu.

1900 GiRds, S. G.. Ylat heromes of the mosquitues during the dry seasum. Journ, of Trop. Jeed.. Maly.

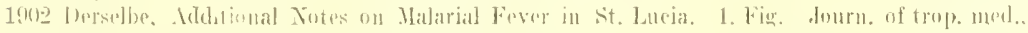
Viil, 5, p. 36i- 3i.

190:3 Irersellw. Romarks on the Panama ('anal and the Introduction of Yollow fever into Asia.

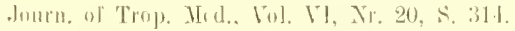

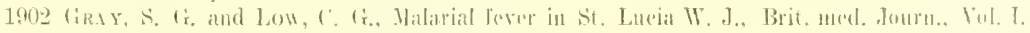
1. 193.

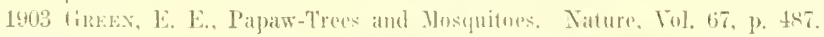

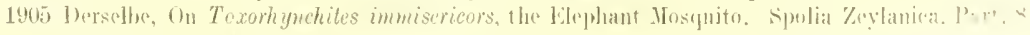
( lial. 1I, Paut. 4), p. 15!', 1 Tiaf.

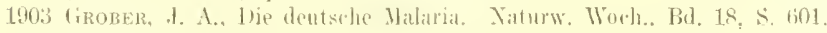

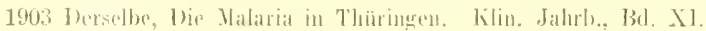




\section{1)r. IDolf Eysell.}

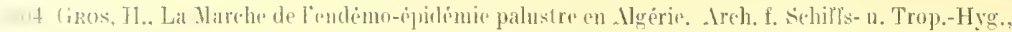
131. 8, s. 5is.

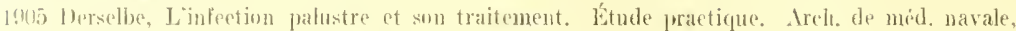
T. LXXXIY, Mr. 7. 13. 33-61.

l(M) Dersetbe Linfection palustre ot som traitement. Étnde practique (suite). Areh. de méd. navale, T. st, Mr. 11 u. 12, 1 Tal.

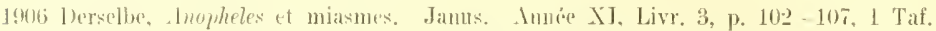

1907 l herselbe', Les metamorphoses do Phopheles algeriensis pendant l'hiver. Bult. méd. d'Algérie. Ref. in Le raducée, Mr. 1s, 1). 246.

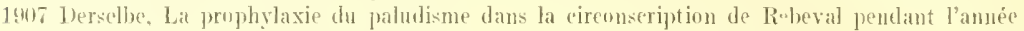

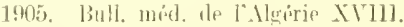

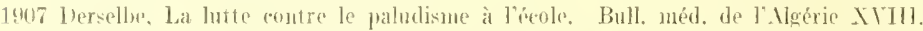

1904 Grossberk, J. A.. Dextription ol a Xew Culex. Canad. Entom. Vol, 36. p. 332.

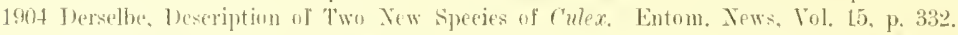

1905 berselbe. Now speries of ('ulicidue. Canad. Entom., Vo1. 37, p. 359 -360. a

1906 Derselbe, Notes on Culor squamiger Coq. with Deseription of a ('loscly-allied species. Ilit 2) Figg. C'anad. Entom., Lol, 38, 1, 129-131.

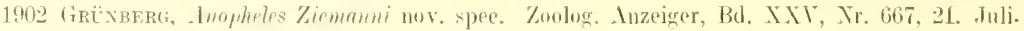

1905 Jerselbe. Zur kenntnis der Culicidenfama vou kamrun und Togo. Zool. Anz., Bd. 29, S. $377-390,8$ Figg.

1906 Dersclhe, Ther zweiflüglige Insektenarten als Schnarotzer bej Mlenschen und Säugeticren. Verl. d. Wentschen Kolonialkungr. 1905, Berlin, S. 60-68.

1!n7 Derselbe, l)ie blutsatuenden Dipteren. Mit 127 .bb. im Text. Jena. (i. Fikeher.

1905 timpex, fieblibhermücken an Bord. Areh. f. Selhiffs- u. Trop.-1lyg., Bd. IX, S. 298.

1900 Ginart, .T., The Recent 1)iscoveries un Paludism. Journ. of trop. med., Tol. 2. p. 300-305.

1900 Herselbe. Les deourert's réentes sur le paludismo'. Bull. d. se. pharmaenl.

1900 Derselbe, Les Noustiques. Imjortance te leur rôle es médecine ef con hyginine. Ann. d'hyg. publ. et de méd. lig.

1902 l)erselbe. Le paladisme daus la Campagne romaine et les récentes exjérienees du Prol. Cirassi. Areh. de paras., T. 5, Mr. 3, p. 401.

1901 Groterds, Experimental vellow lever at tle inoculation station ete. Departmento de Sandad Jlabana, Cuba.

1901. Dersedloc. La fiebre amarilla pxperimental on la estacion de inoculaciones del departemento de sanidad de la llahana. Rer. d. med. trop.. Habana, oct.

1901 Derselbe, Etiologia do la fiebre amarilla. Revista de Nedecina Trenoieal, Habana, Jan.

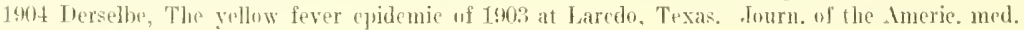
Asociation, 19. Juli.

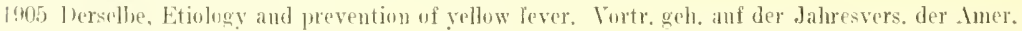

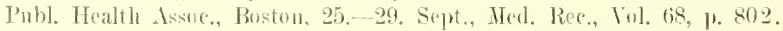

1906 lherselbe, Report on the yellow-fever in Cuba. Trans. of the 2 . internation. Sanitary Convention uf the Imerican Republies. Waklington 1905. p. 217 2.21.

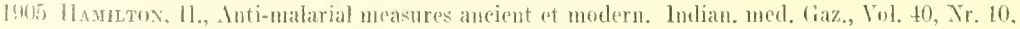
]. $3678 \quad 369$.

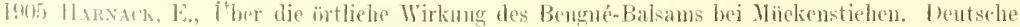
med. Wreduensehr., Yr. th, s. 1932.

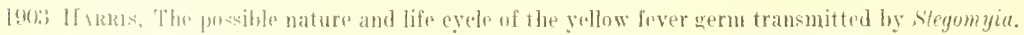
1lol. Rer.. 1. 16it. S. 217 .

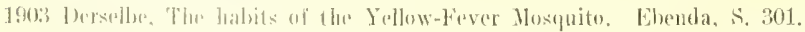

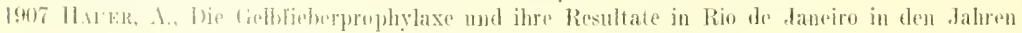

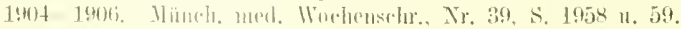

1901 llawar, V.. The Transportations of mosquitos in hagage. Hed. Ree.. 22. Juni.

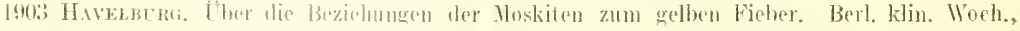
S. 705 und s. 7 .

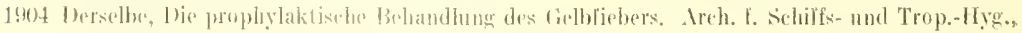
Bd. Vill, $\therefore$. +10 . 


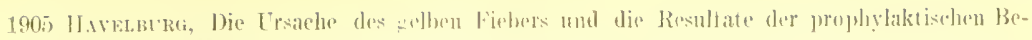
himbllumg desselben. Siamml. kilin. Vortr., Xr. :3000.

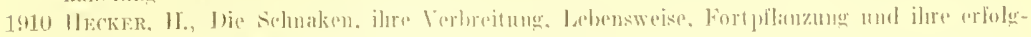

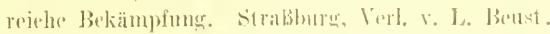

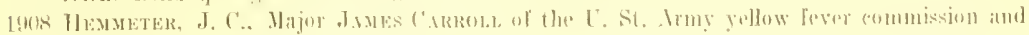

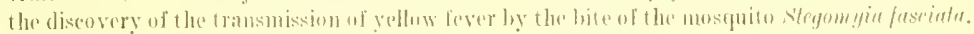

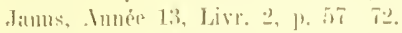

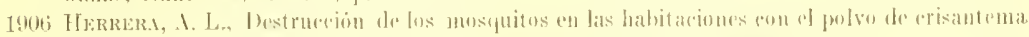

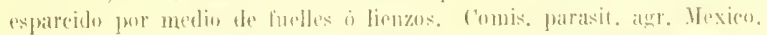

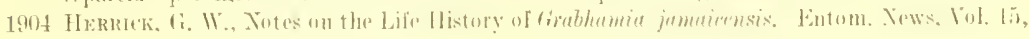
]. 81.

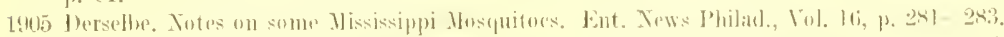

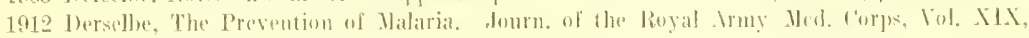
$\mathrm{Nr} .5$.

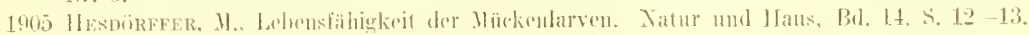

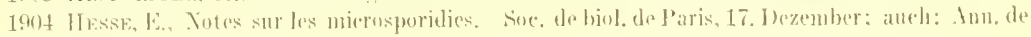

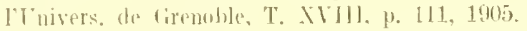

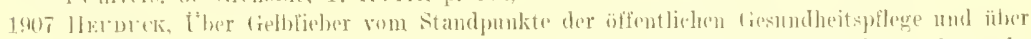

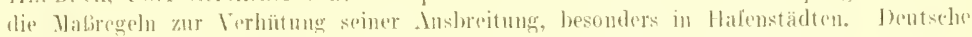
Uledizinal-Ztg., dahre. $28, \mathrm{Xr} .27-31$.

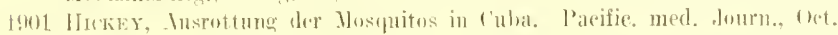

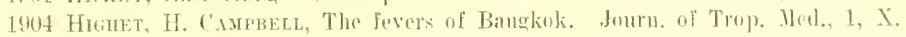

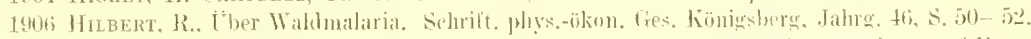

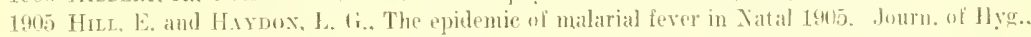
Vol. I. Sr. 4. 1. 467 tit. 1 Tal.

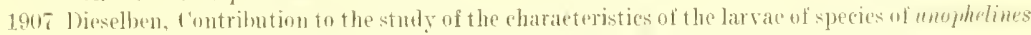
in South-Ifrica. Imnales of the Xatal fiovermment ILusem, Vol. I, part. 2.

1906 Hrxtze, K., Sanitäre Verliziltnisse und Eimichtungen in den Straits Sottlements and fielerated Jalay States (Hinterindien). Arch. I. Schifls- u. Trop.-Hye., Bel. 10, s. 523- 5:36.

1904 Hirsciberg, L. K.. An anopheles Josunito which deres not tramsmit Walaria. Bull. John IJopk. Hospl.. Tol. 15. p. 53.

1902 Hirsubers, L. K. and l)onye, G., The distribution of thopheles in the vicinity of Baltimore. tohns Hopk. Hospe. Bull., [1. tó.

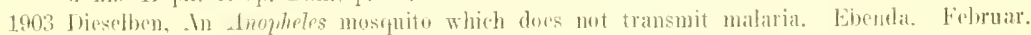

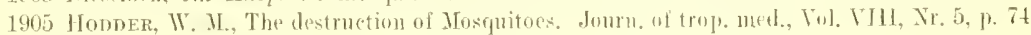
bis 77.

1871 Howid, J., $1 \mathrm{~m}$ Ginats heales, w. pl. London.

1605 Hooke, R.. Jlerographia, p. 185, schem. XXVIl. London.

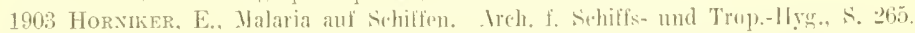

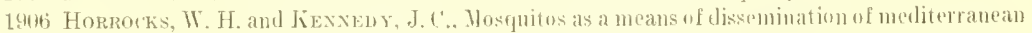
fever. Journ. of the Royal Irmy met. (iorpes, Vol. V1, Nr. 5, 11. 487.

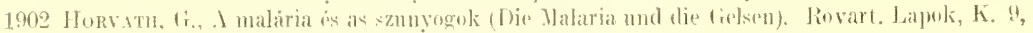
1. 1- 1 . 23.27.

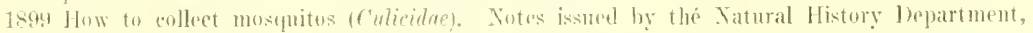
British Jusenm, Journ. ol trou). med., p. 170.

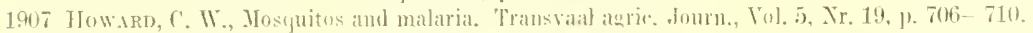
Jit 2 Tail.

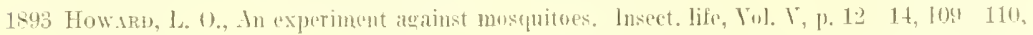
1.99.

1894 Derselbe, Inother mosquito experiment. Elenula, Vol. VI, p. 90- 91.

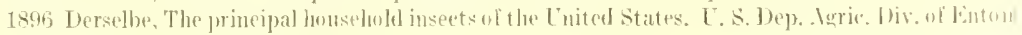
Bull. t, . S. S., Washington.

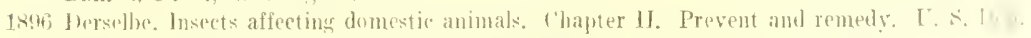

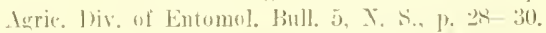

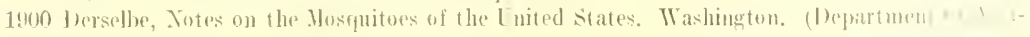
(*)lture.) 


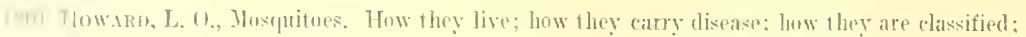

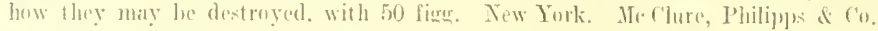

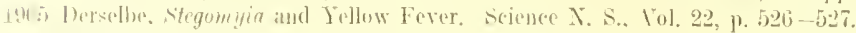

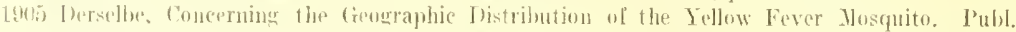

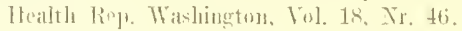

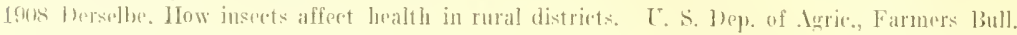
Nr. 1 ins.

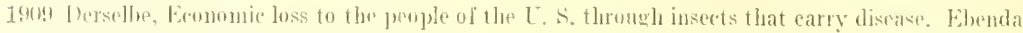
Bur. "f Eutum. - Bull. Nr. is.

1911 berselibe, Some farts abunt Malaria. C. S. Dep. of Agrie. Farmers Bull. 450.

1910 bersellw. Preventive and remedial work against Mosquitoes. L. S. Dep. of Jeric.. Bur. uf Entomanlogy, Bulletin Nr. 88 .

1911 berseller, Romedies and Presentives against Mosquitoes. I. S. Dep. of Igric.. Jarmers Bull. 444 .

1907 Howard, R., Malarial prophylaxis in small lommunitios in British Central . Irriea. London,

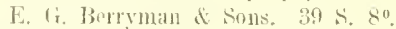

1908 1) remelb. Malarial prophylaxis in sunall communities in British Ifriea. With an introduction

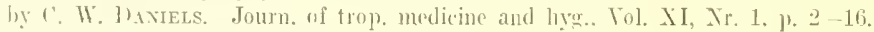

$18 ! 9$ llïBer, Die Sehnakpnplage. Stutterart.

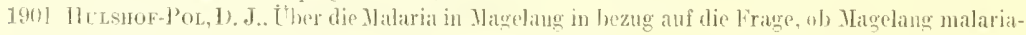

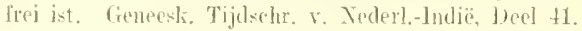

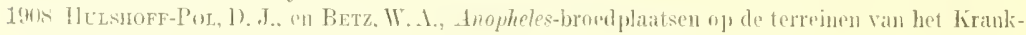

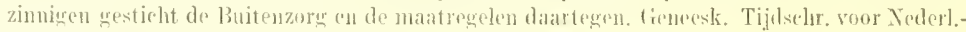
Indie, Toel tr. MI. 2., p. 12t-150.

18.0 Herst, ('. H., The. pupal stage ol' Culex. Haur.hester.

1907 Hessox. A. Enquéte sur le paludisme dans trojs entres de culonisation. Études épidén. at prophỵl. sur le paludisme en Tunisie. Arrdo de l'Inst. Pasteur de Tunis.

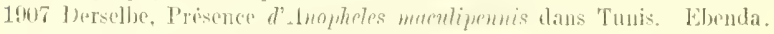

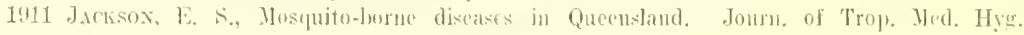
1i. IS.

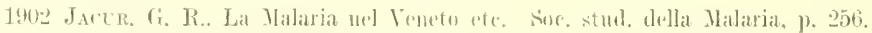

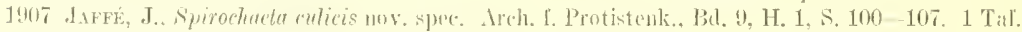
11. ว Fige.

1899 .tues, S. I’.. Mosquitors and malaria. Brit. med. Joum.

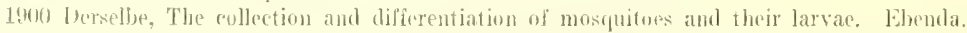

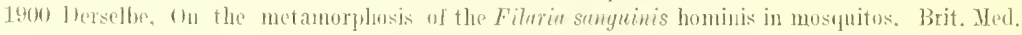
10111.. ऽ. 533 .

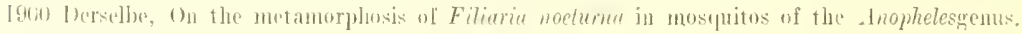
lud. med. Galz. XXl1, s.. 169 11. S. 340.

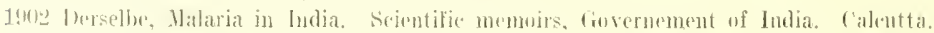

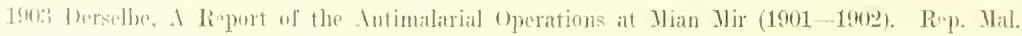

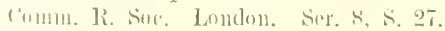

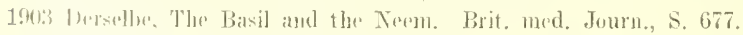

19ut JaMes, S. I'. and 'Herstopuers, S. R., The sucess of mosquito destruction operations. liberula, 17. Singet.

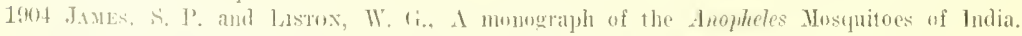

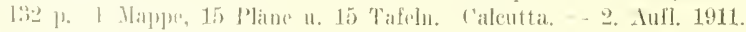

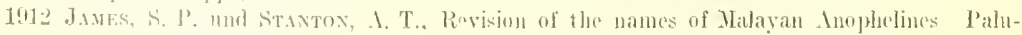
dism, sinplember. Xr. 5 .

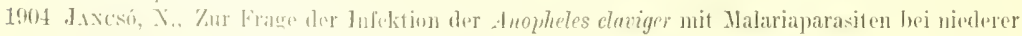

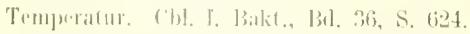

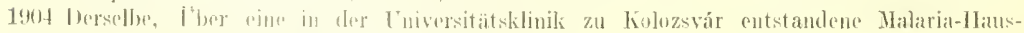

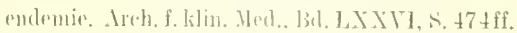

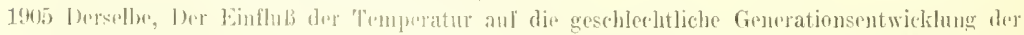

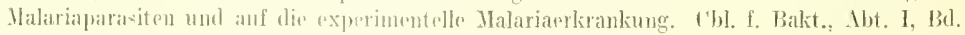
XXX11], S. 650 (iti:). 


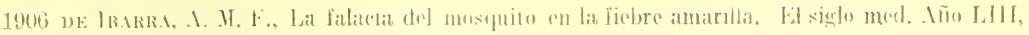
Xr. 2714, H. 3! t?

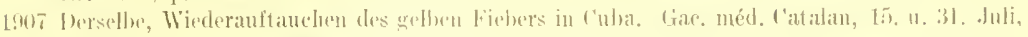

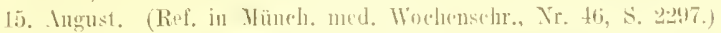

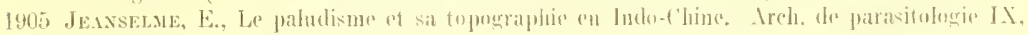
1.

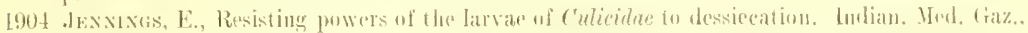
ㄷ. 5 .

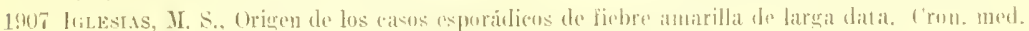
mexienat. X, p. 16 20,

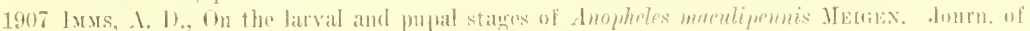
$11 \mathrm{reg}$. Tol. 7 , Jr. 2. p. 291 -318. 2 Tiff. u. 1. Jiug.

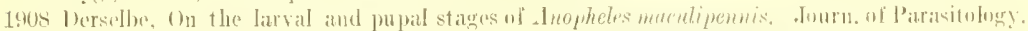

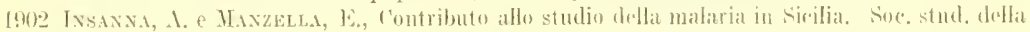
malaria, p. (i11.

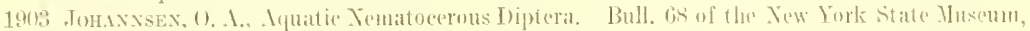
1. 32 . H1. Mbany.

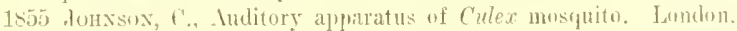

190s Jonxstox, H. II.. Prevention of malaria among the troops at simeapore. Brit. mre. Journ.. Mr. 7. 1). 399-- 401 .

1901 Joxes, Y. 1., Prophylaxis of malariat, Brit. med. Jomun, p. 1,373,

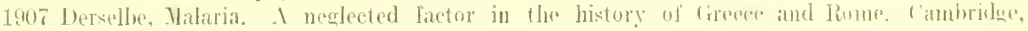
Mar Jillan \& Bowes.

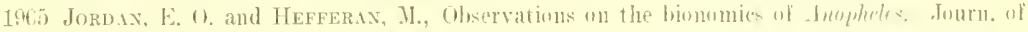
infert. dis., Iol. II, Mr. 1, p. 56 69.

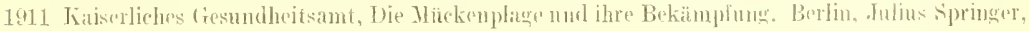
(1),30 $\mathrm{M}$.

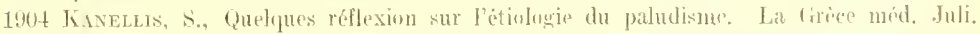

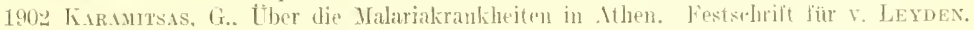

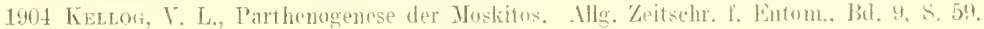

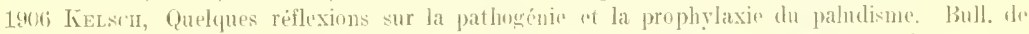

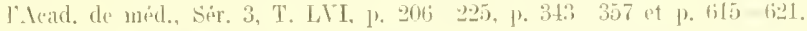

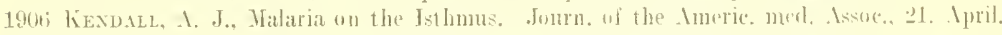

1900 lexxird, $C$. S., Filaria and mosyuitos. Brit. mexl. Journ. S. 75.

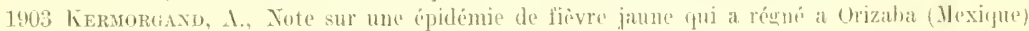
('1) 1902. Ann. d'lyge. et de medec. cololl., p. 42:3.

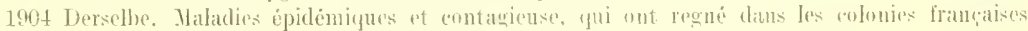

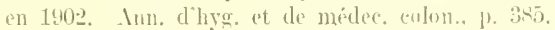

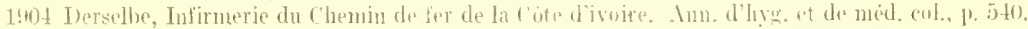

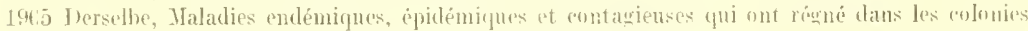

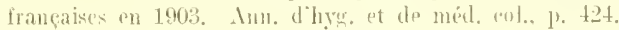

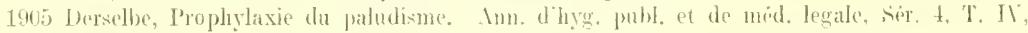
1). $5-29$.

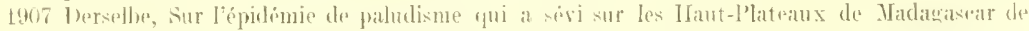
janvier à juillet 1906. Bull. de l'aead. de míd., Sir. 3, T. J,YIT, Nr. 8, p. 291-311.

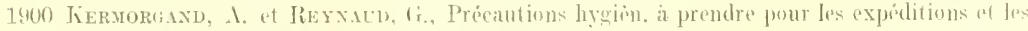
exponrations aux pars chands. Ann. d'hyger. cet de med. colon.

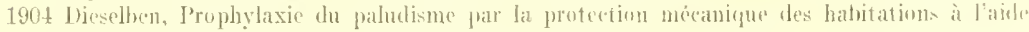
de toiles métalligues. Imn. d'hyg. pt de médec. colon.. p. 3to.

1905 I)ieselben, T'rophylaxie dı paludisme. Khenda, p. 5.

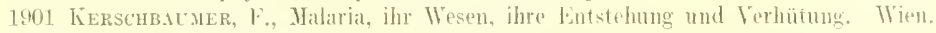

1901 Derswlhe. Memorandum üher die Verhütung der Malaria usw. Wirn.

1902 Derselbe, Die Verhiutung der Malaria. Monatsschrift für Gesundheitspllege. Mr. 1.

1902 liertes\%, Catal. Dipterormu luensque descript. Lijsiae.

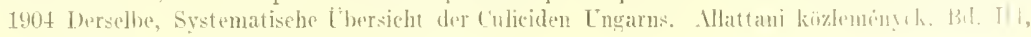
Heft 1. 


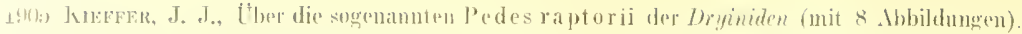

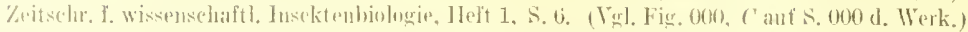

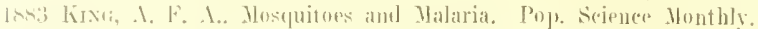

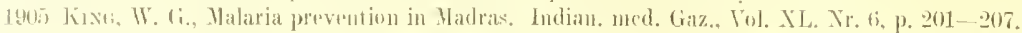

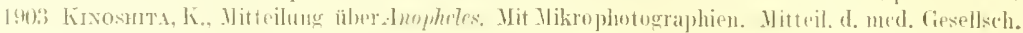

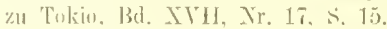

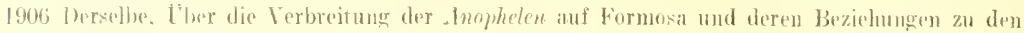

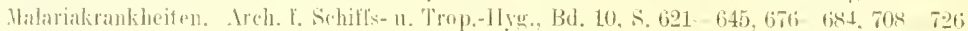
unt $\mathrm{i} 11$ iot. Nit 1 Taf.

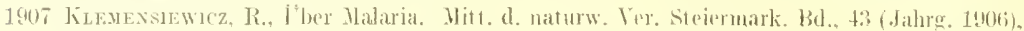
S. 3041317 .

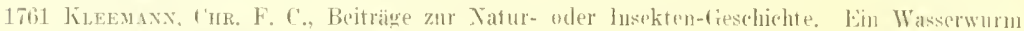
whe FüBe, nebst dessen Verwandungen in einen silnaken. I. S. L25-148, Tab. XV und XVI. Nürnbere.

1904 Kina, F., The Epristomal Appendages of mostuitu Larvale. .Toum. X. T. entom. S., Vo]. 12. 1. $175.1 \mathrm{pl}$.

1904 Wersellse, The Eggrs of Culex territans Walker. Ehenda, Vul. 12, p. 246.

1906 Herselbe, Notes on Deinocerites cancer Theobals. Psyche, Vol. 13, p. 95- 97. 2 pl.

1905 KNy, L., Ủber Emplindung im Pflanzemriche. Naturwiss. Wochenschr., Nr. 25. S. $186 \mathrm{f}$.

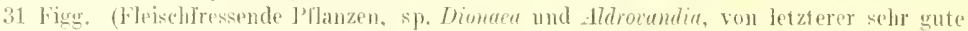
Mbhidungen nach KerNer von MlariLuUn).

1898 Kincir, R., Arztliehe Beobachtungen in den Tropen. Vortrag geh. an "9. Juni in der Mbteilung Berlin-Charbottenlurg der lentsechen Kinfonialgesellsehait.

1849 l)erselbe, Ergebnisse der wissenschattichen Expedition nach Itilien zur Erforschung der Malaria. Jentsehe med. Woch., Nr. 5. S. 69.

1899 Derselbe, Erster Bericht n̈ber die Titimkeit der Valariaexpedition. Fibenda. Nr. 37, S. 601.

1899 berselbe, I†ber die Entwieklung der Jilariaparasiten. Ztsehr. f. Jyg. U. Inf. XXXII, Xr. 1, S. 1 .

1900 Derseblbe, Zweiter, dritter, vierter, fünlter und schlubherjeht ibher die Tätigkeit der Malaria* expedition. Deutseh. med. Wochenschr., Tr. 5. s. s8, Tr. 17, s. 281, Xr. 18, s. 296, Mr. 25 , ก. 397, Nr. 34, S. 341 . Nr. 4 ti, s. 733.

1900 Derselbe, Zusammenlassende birstelhug der Ergebnise der Jabariaexpedition. Ebenda, Mr. 49, s. 7s1, Mr. 50, S. 801 .

1900 Derselbe, Wrgebniswe der vom Dentschen Reiehe ausgesandten Malariaexpedition. Vortrag, gohalten in der Abteilung Berlin-f'harbottenburg der dentschen liolenial-Gesedlsehalt.

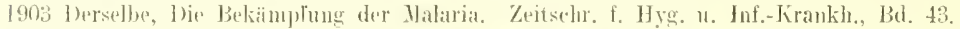

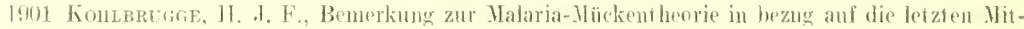

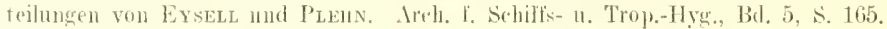

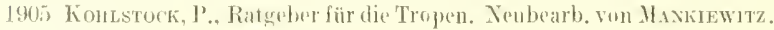

1897 Koub, L., Beiträge zo einer geographischen Pathologie Britisch Ost-Afrikas. 50 s., Leizzig, (i. Fuck.

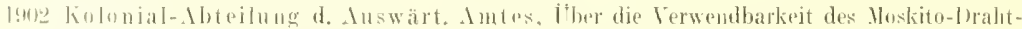

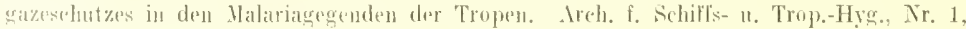
$\therefore 1$.

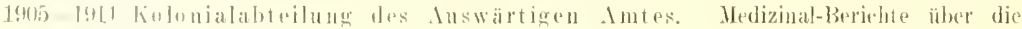

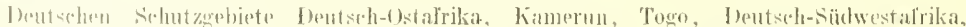

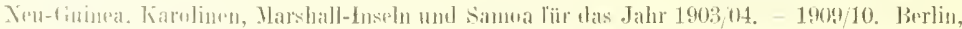
E. S. Uitter is siolnt.

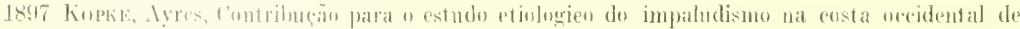
Aricil. Irelta de med. (Xir. 3). lisboa.

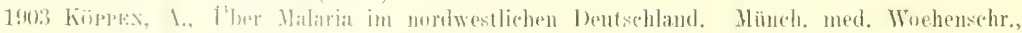
ล. 1071 .

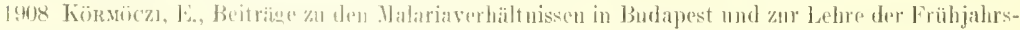

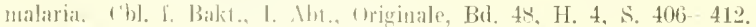

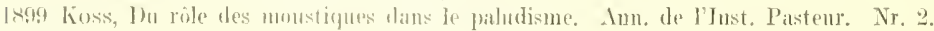

1 184! howalews 


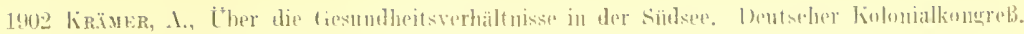

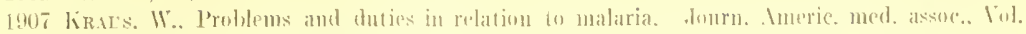
XIX111, Xr. 11, p. 941 913.

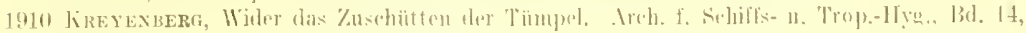
¿. 518 ,

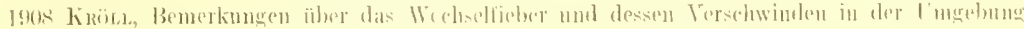

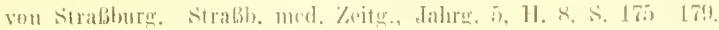

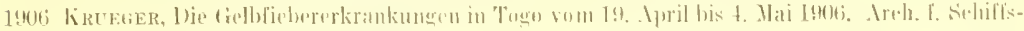

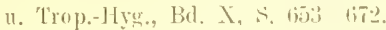

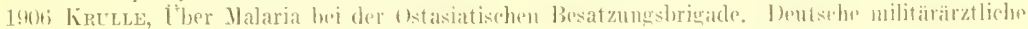
Zeitselirilt, Jahre. XXYV, 11. 1, 今. 1.-7.

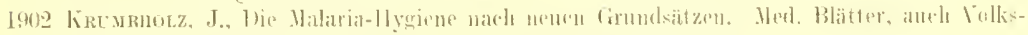

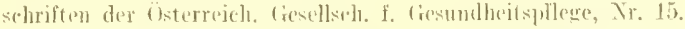

1602 lersellw, ther Kimpf organ die Halaria, loba. J. Satior.

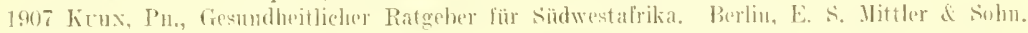

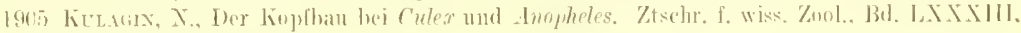
$\therefore$ - 250.395 .3 Tal.

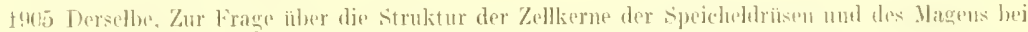
Chironomus. Ztseler, f. wiss. Insketenbiologie, Bd, 1, Hoft 10, S. flis.

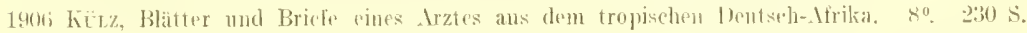
Birlin. IV. Süsstrotet.

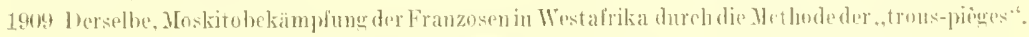
Arch. i. Sichiffs- n. Trup.-Hyer., S. tito lift?.

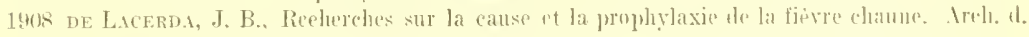
Mus. Taciunal de Pio de Taneiro, Tul. 12. Mr. 1.

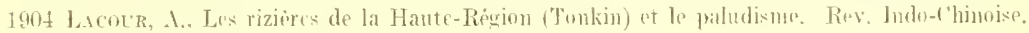
Nouv. Sér., T. NI.

1499 Lampert, K., h)as Lohen der Bimengewisser. Lejuzig.

1888 L.dxghofer, Zur liemituis der Mundteile der Djpteren. Jena.

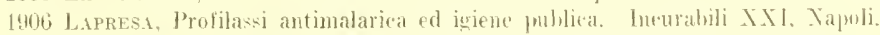

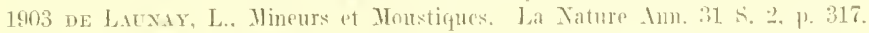

190-2 Latrexre, S. M.. Yosquitus attracted by smends. Brit. med. Jamm.. Vol. I. pr. lit.

1sgs L.tvertx, 1., Traite dn palutisne. l'aris.

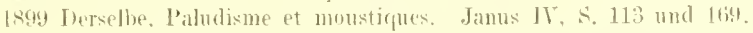

1899 Dersthe. Rapport sur un travail de M, Je 1)r. R. Ross intitule: Note fun I'loistoire du paratste du paludisme "n dehors de liurgan. hum. Bull. Lead. méd.

mon [erselbe, sur une thopheles provenant de Madagasear. Jamus.

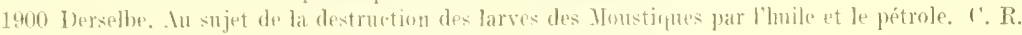
Sinc. Binl. LII.

1900 Jerselbe, Projest d"instruction pour la prophylaxie du paludisme. Bull. Lead. de med. XL1II. 1900 Derselloe, Paludisme et moustifues. Jamus T. S. 269.

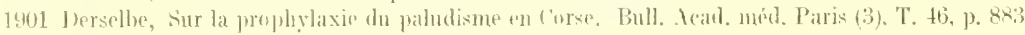
bis 897 .

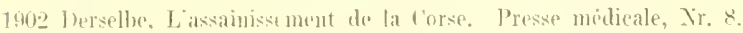

1903 leerselbre. lnopheles et Palutisme. Bull. Inst. Pasteur 1, 1, S. 313.

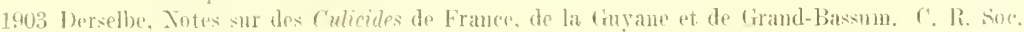

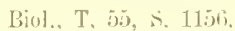

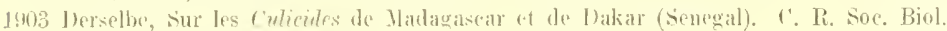
T. 55. 1. 1327.

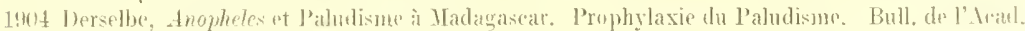
le méd, 4. Ulitober.

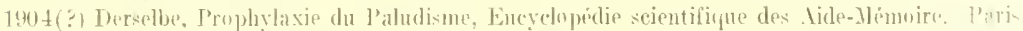

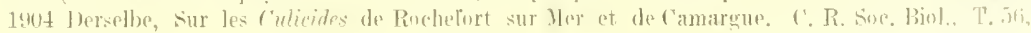
]. 325 .

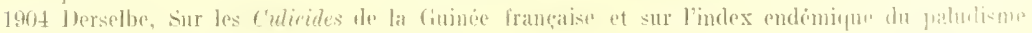
dans cette rẹion. Ebendal, st, 5is. 


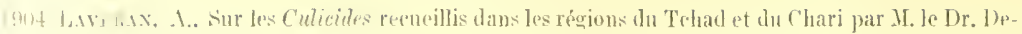

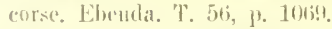

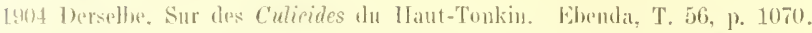

1905 1)ereibe, Paludisme et trypanosmmiase. Paris (Bailliere et fils).

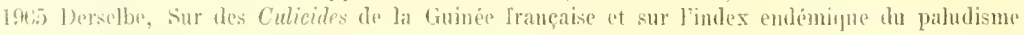
dans cette région, 1' R. Suc. Biol., T. 58, p. 562-564.

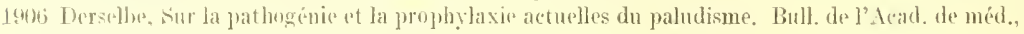
rier. 3, T. U11, Nr. 34, p. $270-282$.

Is.s LANRIE, li.. The mosquito anel the malaria parasite. Lancet, p. 1468.

loge therselthe, be Houstique ef le parasite de la malaria. Presse méd.

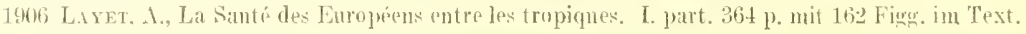
Paris, Felix Nlean.

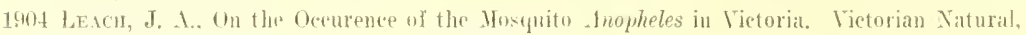
Vil. 21, p. 9.

1912 Leboenf, 1., Recherehes pxpérimentales sur le röle de eertains insectes lématoplages ilans la lèpre. Bull. sor. path. exot. T. T, p. tifis.

1904 Lebredo, MI. Algumas observaciones sobre la anatomia dos Mosquitos. Rer. de med. Truj). Ilabana. Tum. 1, Xr, 1. 4, 5, 6 und 7.

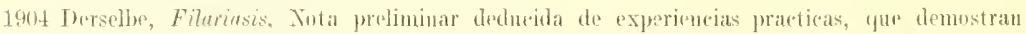

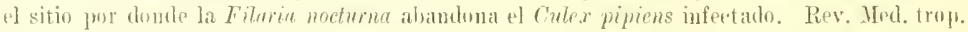
Iabana, T. ¿) p. 171-172.

190.t Leriendre, Tutes sur le paludismo à Pho-lang-thuong (Tonkin). Anual. d'hry. ct de món. (ํ) 1 (1).. T. TII, ]. 354.

1906 l)ersoltue. Notes sur los Moustiques à Phu Lane Thunng (l)elta du Tonkin). Ann. d'hyg. et de méd. eol.. ]. $3 \times 1$.

19t7 lorselbe, Le paludisme an Se-Tehoan. Presse méd., p. T78 779.

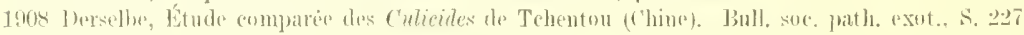
bis 229 .

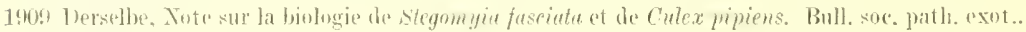
1. $42 \overline{\%}$.

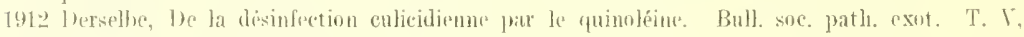
1). 739.

1904 Letier, L., Notes sur les parasites des diptimes piqueures. Sut. de biul. de Paris, 2t. Wezember. Aurh: Aunales de l'Tinivers. de Grenoble. T. XVII, J. 99.

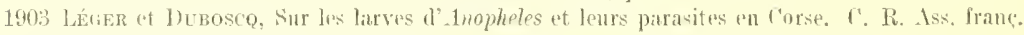

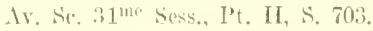

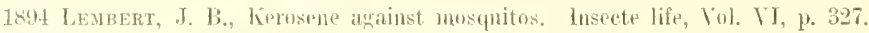

1904 Lexz, 0., Die Malariassanierung der Seefeste Pola. Wirn. kJin. Wuchemschr., Nr. 1 und Xr. 52, 1 kitrte.

1904 LEox, X.. Vortütige Yitteil. über d. Sangriussel dor Anophelinen. Zool. Anz., Bd. 27. 1. 730, 1 liir.

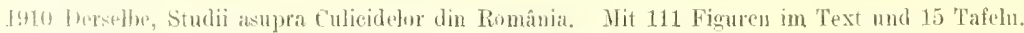
Bukiarist.

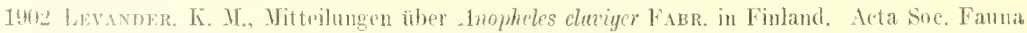

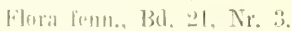

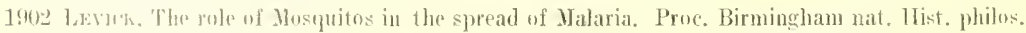
Sive.. I. 11, \$. 699 .

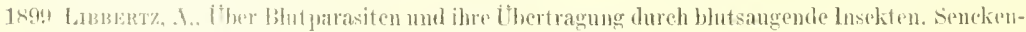
borge. Hatturl. lies.

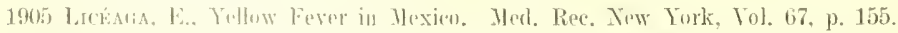

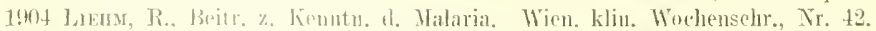

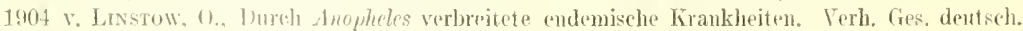
Naturf. und Arzte Vurs, 75, T1. 2, Jhälle 2, P. 450.

1900 haster, l.okD, l'resibential Adress to the Royal society of London.

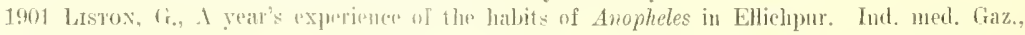
1. $3(i)$ แ1. 411 . 


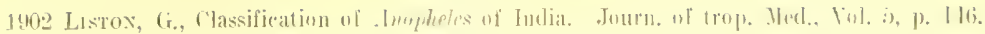

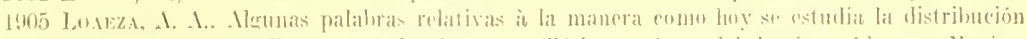

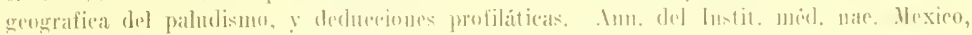
]. Y11, p. -993.300.

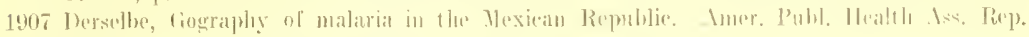
XXXII.

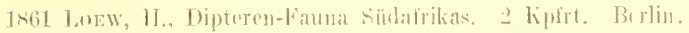

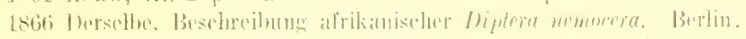

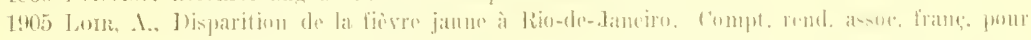

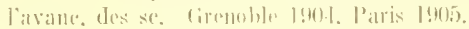

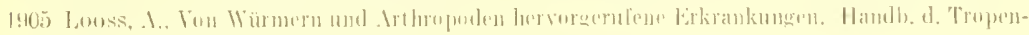
kramklucitur, Bil. 1. S. Ti.

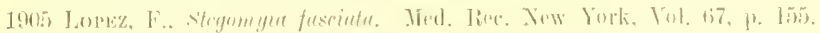

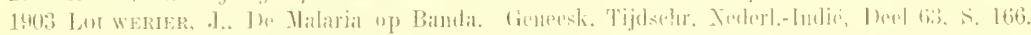

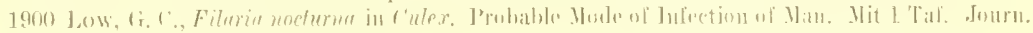
of trip. mal., Vinl. 2, p., 31:3 313.

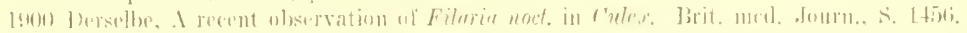

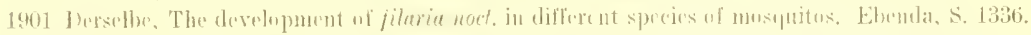

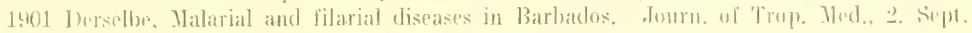

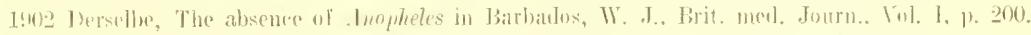

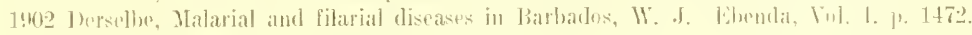

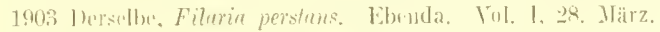

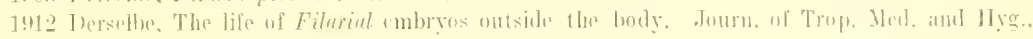
S. 338.

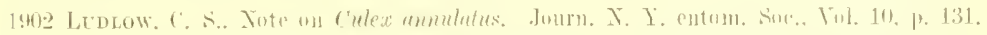

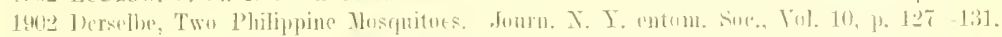

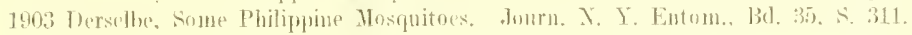

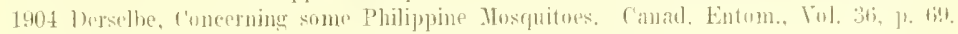

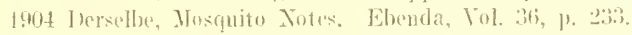

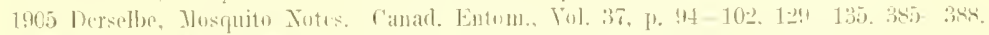

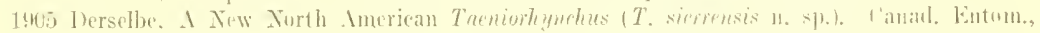
Vol. 37, P. 231 - 232.

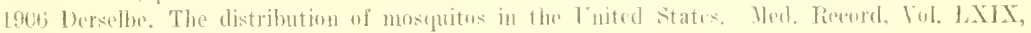
Nr. 3. 1). 95 as.

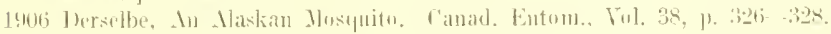

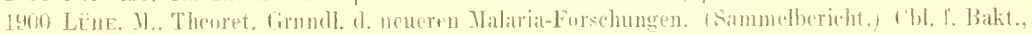
Xr. 6 \%

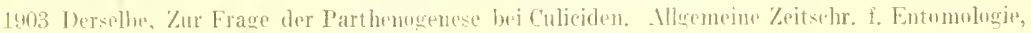
Bd. VIIl, s. 37-?

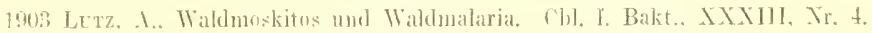

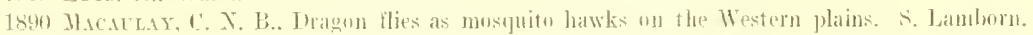

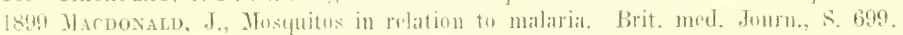

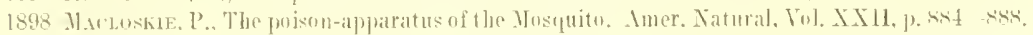
(3. . (b). )

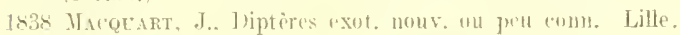

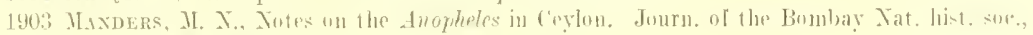
Tol. XIT, Mr. 2, 2 Taf.

1902.- Maxde. J., Die neuesten Forschungen über Malaria. Wilitararat, s. Ibit.

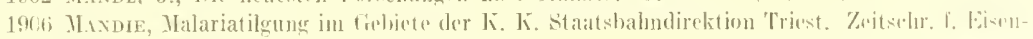
babnhyer., llelt 6.

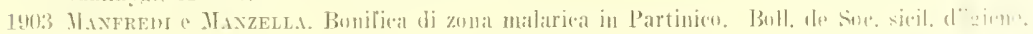
imme $\mathrm{V}$.

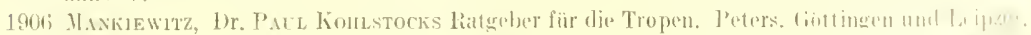

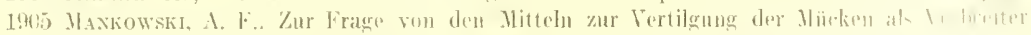

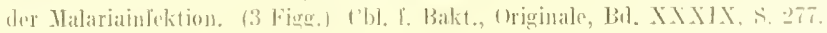




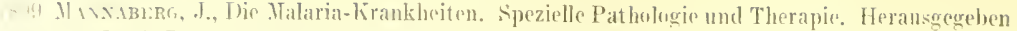
von Prol. Tr. H. Notisatiel. Wien. Afred Hölder.

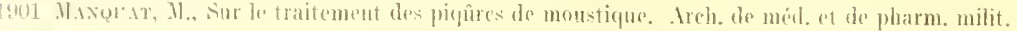
Aprit.

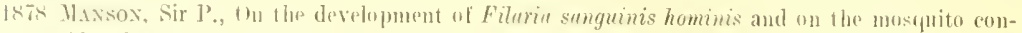
sidered as at murse. Journ. Linn, Seke. London. Zool., Tol. X1Y. Xr. 75, s. 304.

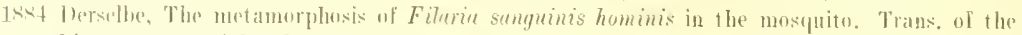
Linuean since, of Londoun.

1896 Derselbe, (In the life history of the malarial germ outside the human body. Lancet, s. 175.5.

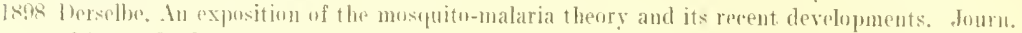
uf Trup. Med.. S. 4.

ls98 Weraclbe, Surgeou-llajor Roxabo Ross's recent investigations on the mosquito-theors.

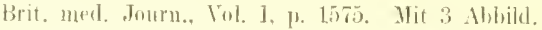

1499 Derselbe, In Filarial promdicity. Brit. Ned. Jeurn., s. (itt.

1400 berselle, Experimental proof of the mosepito-malaria theory. Brit. med. Journ., S. 949 11. 1266 .

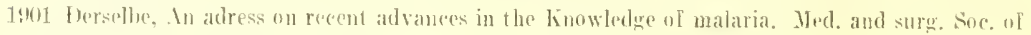
London.

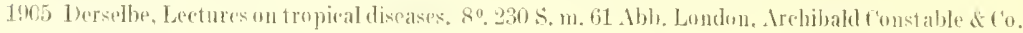
Limited.

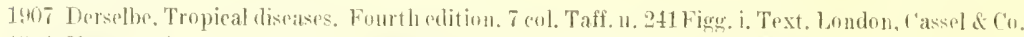

1901 M.wsex, Th., Experimental Malaria. Brit. med. Jonm., Bd. 2, .. T6.

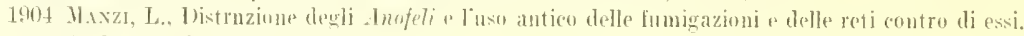
Arch. parasitol., T. $2.5 ., 88$.

1908 Marcial, P., Ctilisation des insectes anxiliaires entomophages dams la lutte eontre les insectes musibles à longriculture. Paris. (75 S., mit Fïgr.)

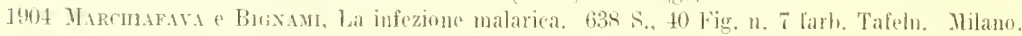

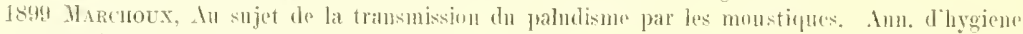
et de medec. colon, p. 22.

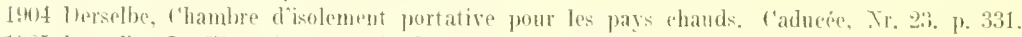

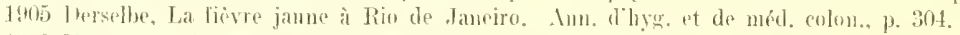

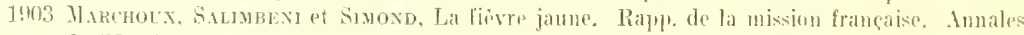
de l'Institut Pasteur, Nov., p. tif5.

1904 Marehocx et simoxb, T'. L., La Tieste jaune. Bull. hust. Pasteur, T. 2. p. 1 et 49.

19n5) fleselben, La transmission héréditaire th virus de la fievere jaune chez lo stegomyin fuscinte. Le faducée. Nr. 17. p. 248. Auch: Compt. rend. lebdom. d. I. Soeiété de liologie.

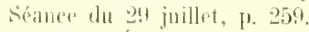

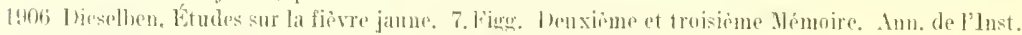

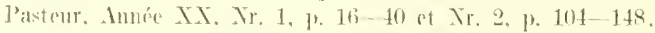

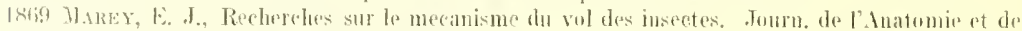

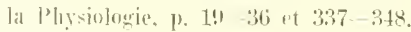

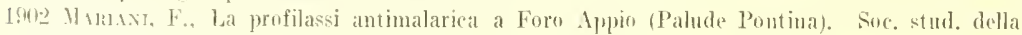
maliaria, p. 891.

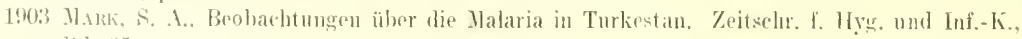
Bil. 35.

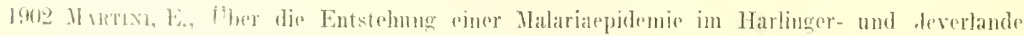

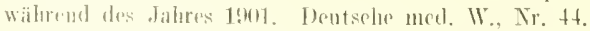

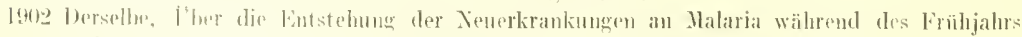

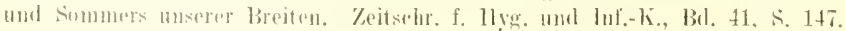

190:3 Dersellue, I'her Vorhitıug abues. Malaria-Ausbruches zu Wilhelmshaven. Zeitschr. İ. Ilyg. u.

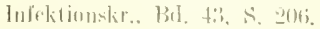

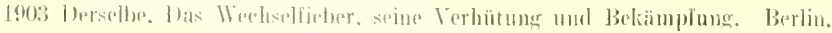

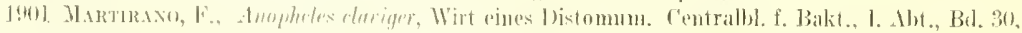
s. $x+! !$

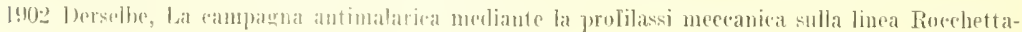
Sianta Venere. Soe. stud. Wella mal., p. 475. 


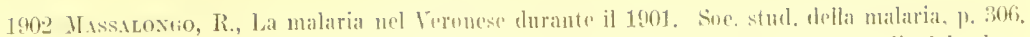

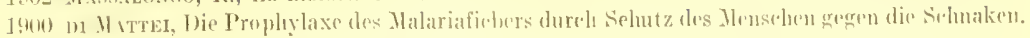
(')i. 1. Bakt., s. 1824.

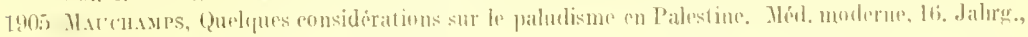
Nir. 24.

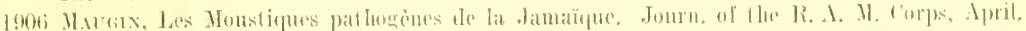

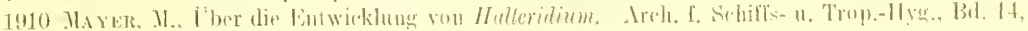
S. $19 ! 9$.

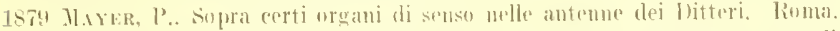

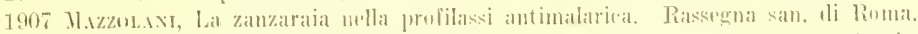

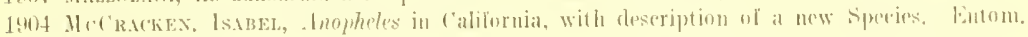
Jiws, Iol. 15, s. 4 .

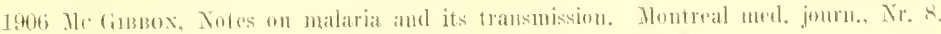

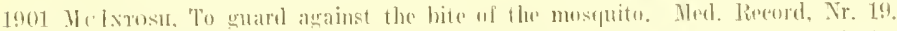

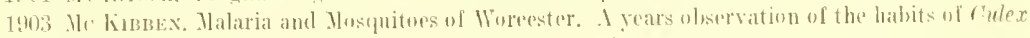
and Inopheles, Boston med. and surg. journ., 17. 1)ez.

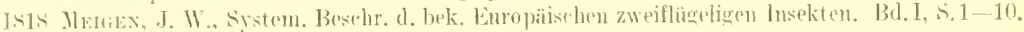

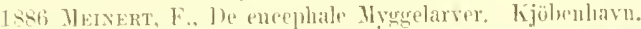

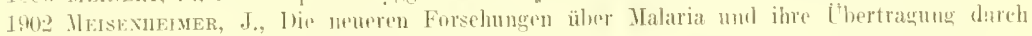
Hospuitus. Taturw. Worehensehr., S. 193.

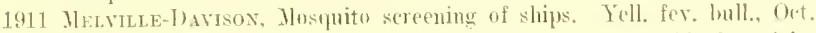

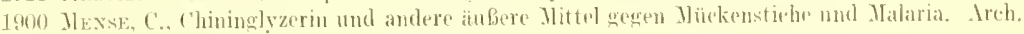
1. Sithilfs- u. Trop.-Hye., Bul. IT, S. 14.

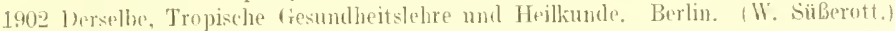

1905 -1904 Derselhe, Handhuch der Tropenkrankipiten. Leipzig. Joh. Ambr. Barth.

1919 Jorselbe, Ile kosmetik im heißen Klma in Jandbueh der Kusmetik vun M. JosEPH, Leipzig, Veit \& Co.

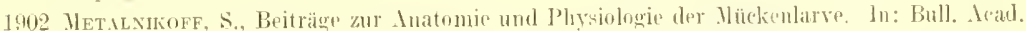
Imp. Sore. Petershures, Ser. 5, Vol. 17, p. 48-58, 2 Tafoln.

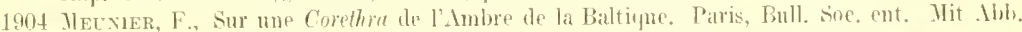

1901 Jeyer, 1. Malariabekampfung in der Campagna Romana. Deutseh. med. W., Mr. t1.

1909 MILxe, 1. 1)., Measures directed towards eradieation ol malarial ferer and other mosifuitoborme dispases in British East Ifrica. Journ. of trop. med. and hyg. 13. 37t-375.

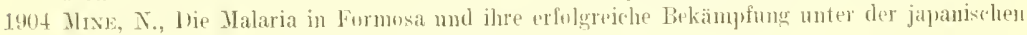
Brsatzung. Arch. 1. Schill:- u. Trop.-H†g., S. 23.

1889 1891 Hrxidzzixi, P., Richerele sul eanale digerente dei lammlinorni fitolage. Nittoil. der Zoolog. Station zu Yeapel. Bol. IX, S. 1-112. 266i-.304 mit 7 Taf.

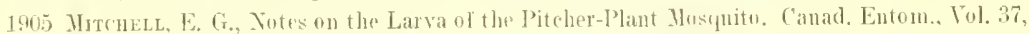
1. 832,1 Fig.

1906 J)ersthe, Mouths Parts of Mosipuito Larvae as Inclieative of Habits. 3 Figg. Psyche, Vol. 13. 1). $11-21$.

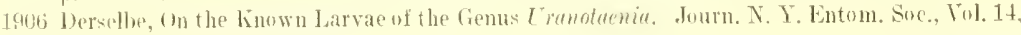
p. 8 - 9.

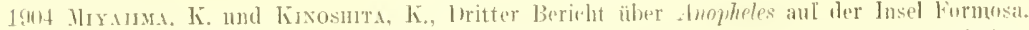
separatabdruek aus den Berieleten über Formosa. 167 seiten mit fi litlogr. Taleln und einer liate.

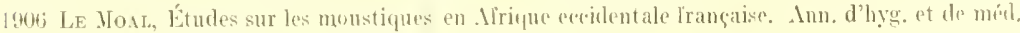

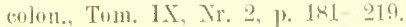

1!ns Molquw, W., Beitray zur Kenntnis der Malaria in Buggarien. Nalaria (Internatimales Irehiv).

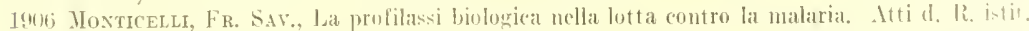

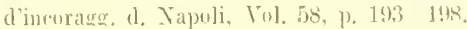

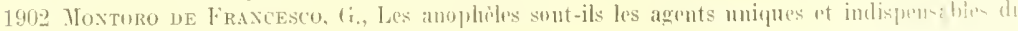
paludisme? Semaine méd., Nr. 20.

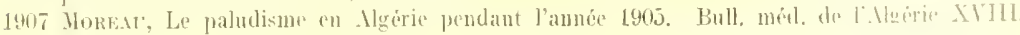


14t5 Morear, J. et Sonne, If., De la répartition du paludisme en Agérie. Arch. de parasitol., T. IX, Mr. 2, p. $2623-265$.

1905 Lieselloen. La lutte contre fe pahudisme en Mgérie. Ibid., p. 272-278.

1904 Mori, A., Prophyglaxis of malaria. dourn. of trop. med, 15. Juli.

1905 Inerselhe, La projhylaxie de la malaria. Bull. gén. de thérapent., T. ('L, Livr, \&, p. 298-31.

1904 Mosxy, E., Jes rechereles réentes sur les eauses of la prophylaxie de la fievre jaune. Anm. Hyg, publ. (4) T. 2. 11. 235, 1 Fir.

1307 Joss, C. F. . ., Malaria in Madagasear. Journ. of trop. med., Wo], 10, Nr. 13, p. 227 - 228.

1907 Jot LD, H., Hesinnito Larvae in tree Hollows. Journ. of trop. med. and hỵg.. Xr. 21, p. 356 his 357.

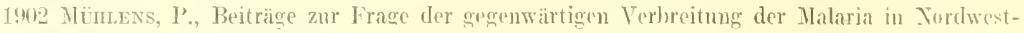
dentsehland. Jeutsclue med. Woehensedr., S. 589.

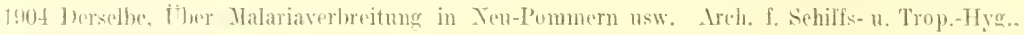
Bd. 8. s. 513 .

19u6; Derselbe, Über Jlalariaerkrankmugen an Bord, inshesondere der dentselen liriegsmarine,

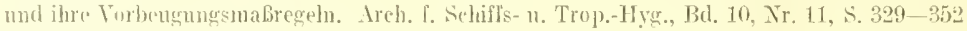
mid Nor, 12, s. $370-343$.

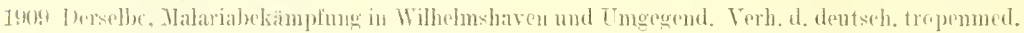
dirsellsch., Beilaeft 6 zum Areh. T. S.chiff- 1 . Trop.-Hyg.

1411 Dersellow, Ein groberer Versuch der Jü̈ekpurertiknng in der Hanthrgisehen Waldgemeinde Wohlshof-ohwstedt. Vurtrag, gehalten auf des Tagung 1911 der Tropemmedizinischen fresollschalt,

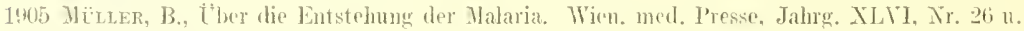
27. 4 Fiser.

I!n3 Yïlues, E. E., Britrag zur Frage der Terhreitnng der Waharia dureh Nüeken. Alls. Wien. med. Ztg., 2. Juni,

1904 Yüller, K.. Die Varbreitung anstedsender Krankhriten chrob die Jïeken. Himmol und Erde, Jahrg. 16, s. 104 - 114.

1904 Mrzo, C., Le Yalattie dei paesi caldi, Joro prolibassi ex jgiene, Mliano, Clr. Hoepli, 560 s. mit 154 Holzsehmitten and 11 Tafeln.

J905 Navarre, I'. J., Les insectes inoculateurs de maladies infectienses. 80. $60 \mathrm{j}$. Lyon. Mit Tal. 11. Figgr.

1907 1) rsellu, La doctrine anophélieme et la prophylaxie practique du palndisme. byon méd. ('VIII.

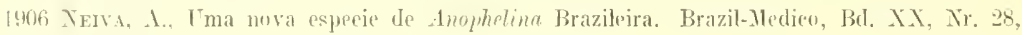
1. 284.

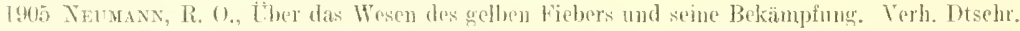

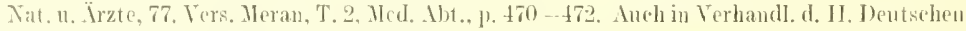
lolonialkongr. am 5. 7. Oktoher 1905.

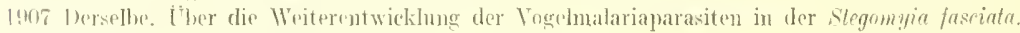

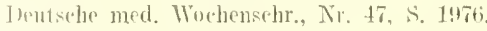

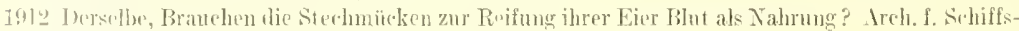

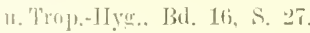

1900 Trwet-Lematre, M., Exposé des Expérienees do P’rof. B. Grassi sur la prophylaxie du pahidisme. Arehe de parasitol.

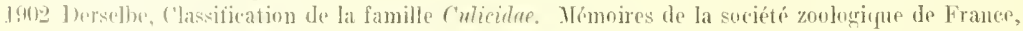
T. XT. 1) 195. Avee un tablan of 12 fig. dans te texte (ref. im Cbl, r. Bakı., Bd. XXXIll, S. $5(12)$.

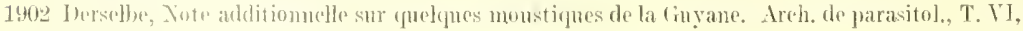
1). 1313 ,

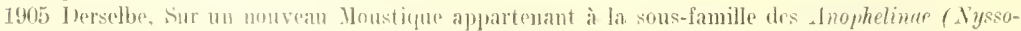

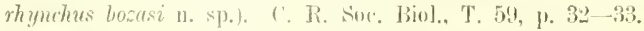

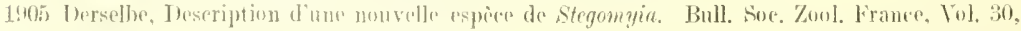
1.. $8-11$.

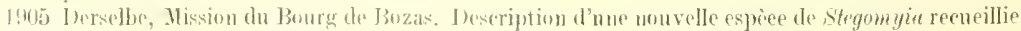




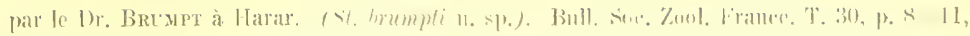
1 ligr.

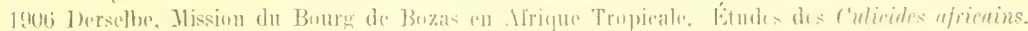

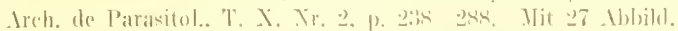

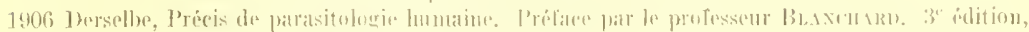

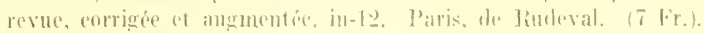

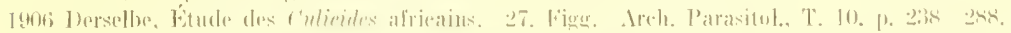

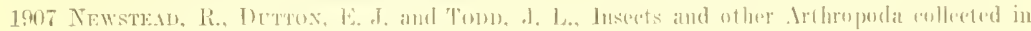

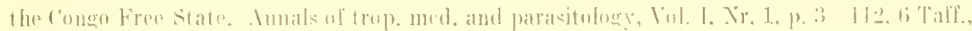
2 kiarten und zahleriche Mhis, in Text.

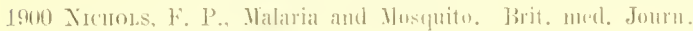

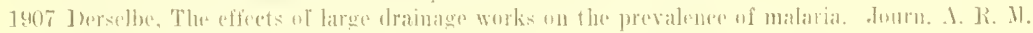
('. VIII, ianduा1.

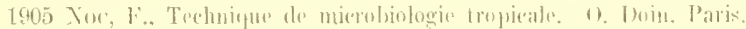

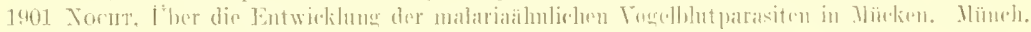
med. Wueli., \&. 907 .

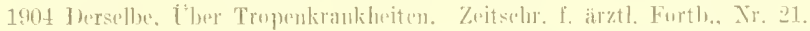

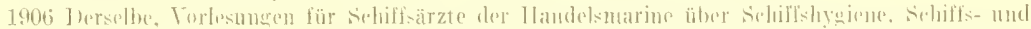

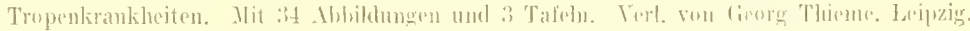

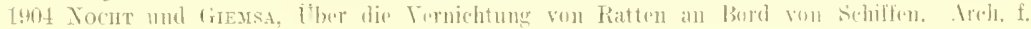
Sehiffs- 11. Tro],$-13 y 2 .$, Bd. TJIl, s. 95.

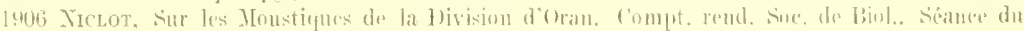
6 janvier, $p .4$.

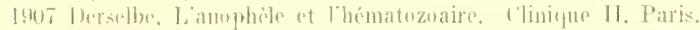

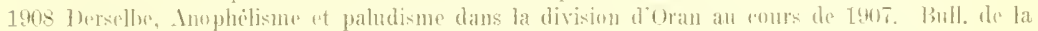

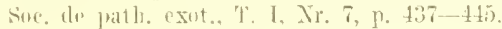

1905 Nory, F. G., Mac Nent, W. T. and Torny, H. N., Mesquitotrypanosones. Tnivers. V. Mleligan, Ann. Arbor, llichigan.

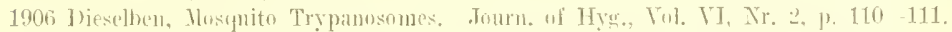

1899 Nottale, (r. H. F., ()n the role of insects, arabuids and myriapols als ('arriers in the spread of bacterjal and parasitic discases of man and animals. Jolns Hopkins IJnspital Rezorts, Bd. B. Xr. 1 1110 ?.

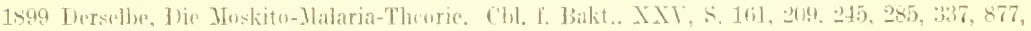
90:3: XXT1, S. $1 \pm 0$.

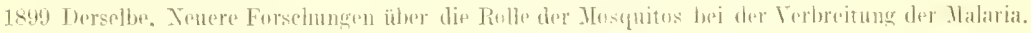
('bl. f'. Bakt.. Bì. 25.

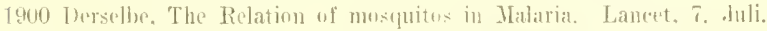

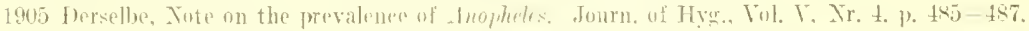

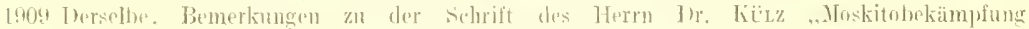

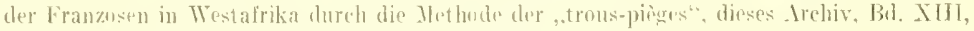

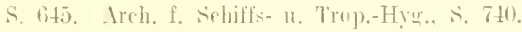

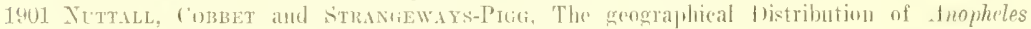
in Relation of the former Distribution uf .gue in England. Journ. of I3yg.. Bel. I, Tr. 1. $\therefore$.

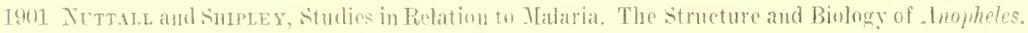

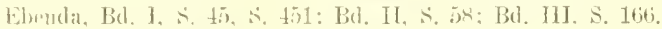

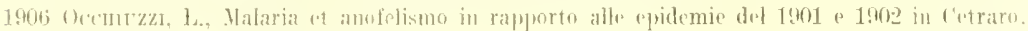
Ineurabili, Fase. 910 (1) 12.

1900 (10 Coxxel, The destruction of mosquitos. Imel. med. Gaz., s. 41 11. 173.

1901 Therselhe, Igue or intermittent fever, its itjologer and cure. Ind. med. Rec.

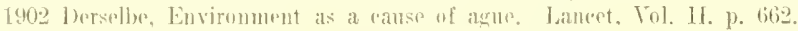

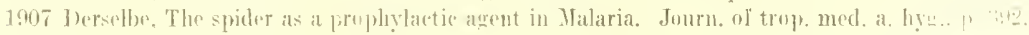

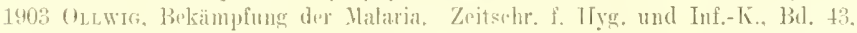

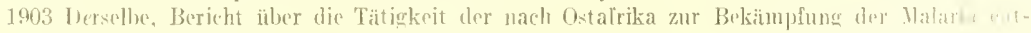
sandten Fxpedition. Zritsehr. f. Hyg., Ha, 15, S. 402.

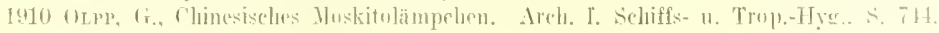




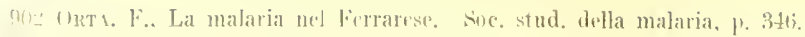

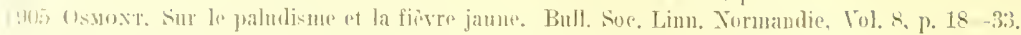

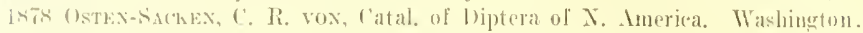

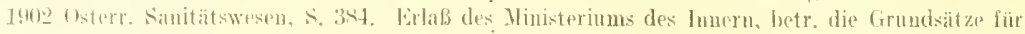
Verhïtung und Bukätmplung des Worhselfiebers.

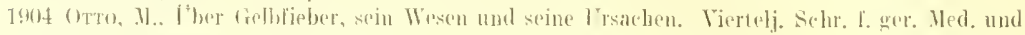

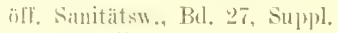

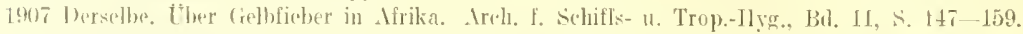

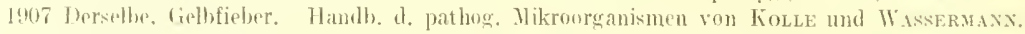

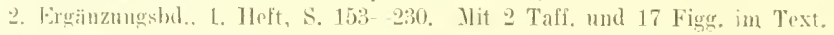

1904 ()тT0, M. und Xecmaxi R. 0., Berieht über die Reise nach Brasilien zum Studium des (iell). tifhers. Mreh. 1. Sehiffs- u. Trop.-Hyg.. Bd. \&, \$. 529.

1:104 lojesthen, Bemerkung zu den Vorshlägen zur individuellen Prophylaxe dos Gelbfinbers auf find der Finday'sehen Kontagionstheorip von 1)r. ERNst vos Bassewitz in Porta Megre. Mïneh. Ned. Mochensehr., Nr. 36 .

1!ł:5 Diesclben. Irsachen und Bekämpfung des Grelbfiebers. Wie L'msehan. 1X. Jahrer. Nr. 8. S. 141 .

1!n Diesplben, Studien über frebfieber in Brasilien. Zeitschr. f. Jyeg. u. Infektionskrankh.. Bu. L1, Helt 3, S. :55-506;.

1902 Ozzaro, 1. 1)., The mosquito and malaria. Brit. Guiana med. Inn., s. 26.

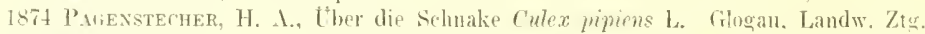

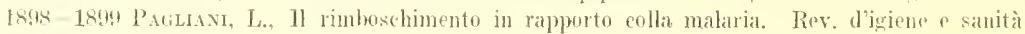
publ.

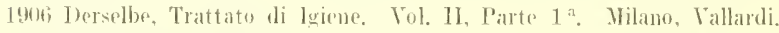

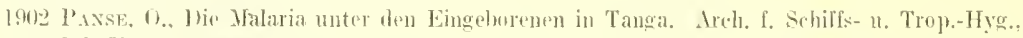
Bd. VI, S. 403.4 .5 .

ISO03 T'ARKER, BeyER and Potmer, A stuly of the ptiology of yellow fever. Rep. of working party Nr. 1, Yellow Fever Institut. Mrashington.

1ent Pasquxu, I fattori otiulogici della malaria. per essere officienti, devone essore elevati a potenze proporzionali. Ramazini 1, Hirenze.

1902 T'atterson, II. S., lestivo-autummal lever in Manlattan island and its environs. Jed. Ree., 6. Sipt.

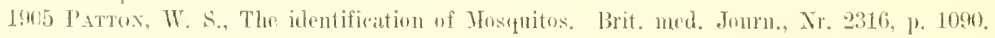

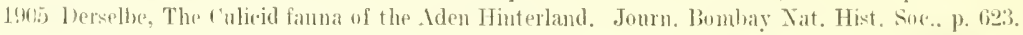

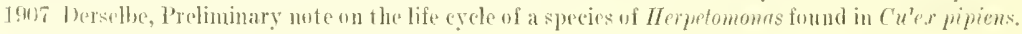
lirit. med. Jonrn. 13. Juli. p. 78.

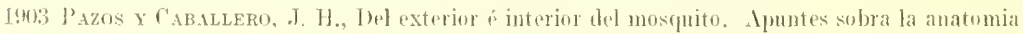
y morfologia. 7 lám. Rev. med. trop. Habana, T. 4. p. $209-218$.

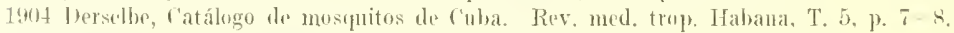

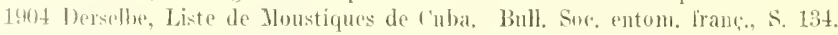

19(); Pranse, F.. Mlospuitors and Malaria, Calentta.

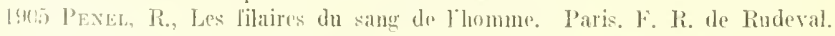

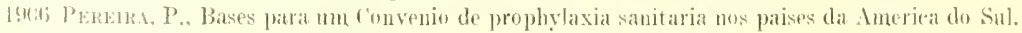
(iazela medival da Bahia, Nr. 10.

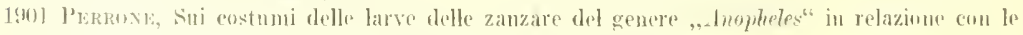

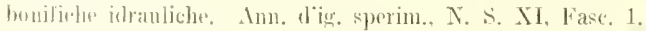

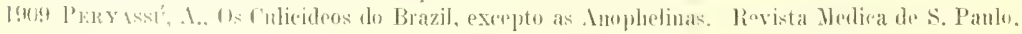
11. I.

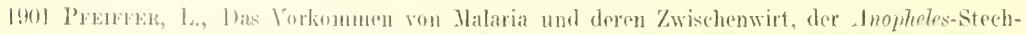

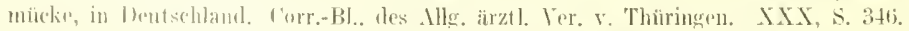

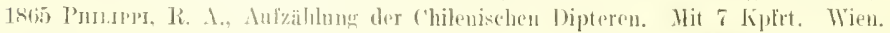

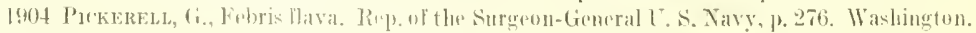

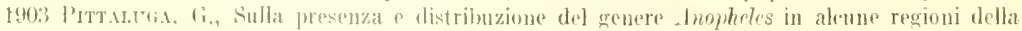

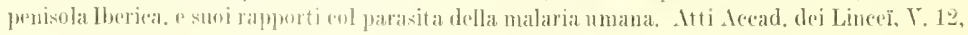
Sim. 1, s. 5.24. 


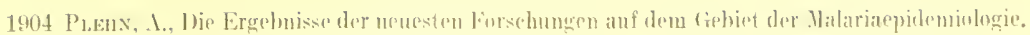
Areh. I. Ityg., Bd. 4i, $\therefore$ I ti.

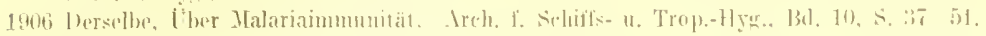

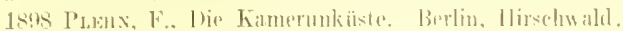

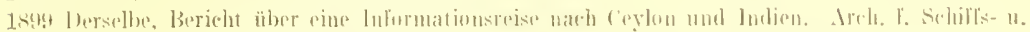

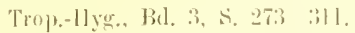

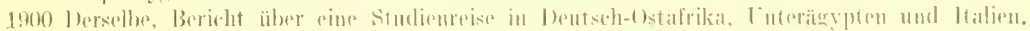

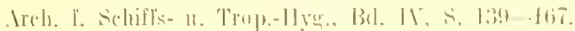

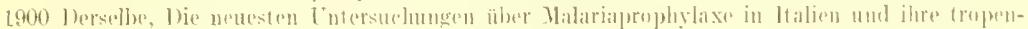

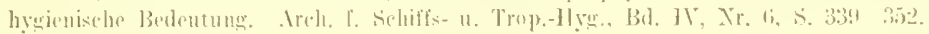

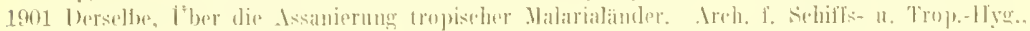

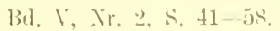

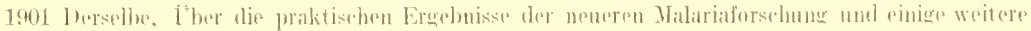

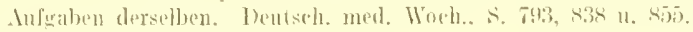

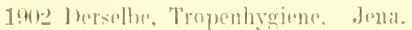

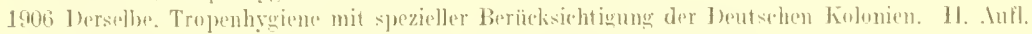
Veubearbeitet von Dr. 1. Pl.fHx. Jena, (ir. Fiseler. 311 s.

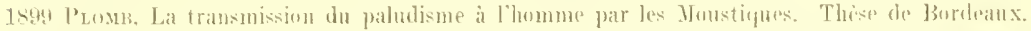

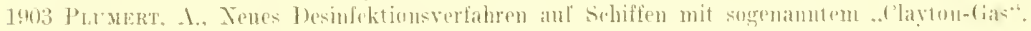
Miteil. ans dem fiebiete des sipewesens. 1[t't 17.

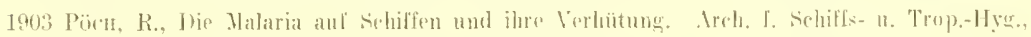
‥ $125-146$.

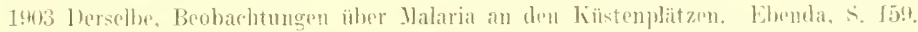

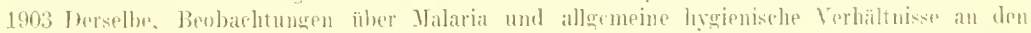

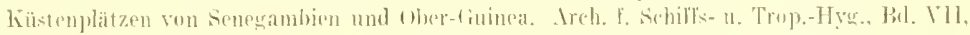
ล. 15:3 $17 \%$.

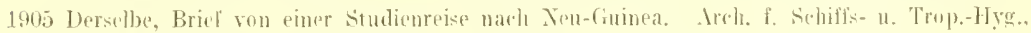
Bd. IX. Heft 10, S. $432-438$.

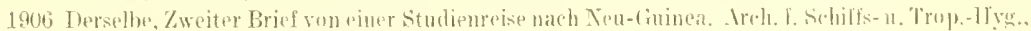

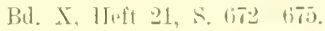

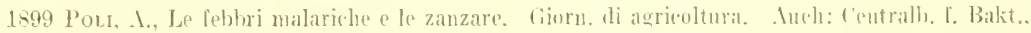
$1900, \mathrm{Bd} .27$.

1904 Poumono, L.. Beitrag zur 'Therapie der Malaria. Vorl. Mitteil, erstattut anf dem XIII. ital. Kongr, l. inn. Med, z.n Padua. Teue Therapie, Nr. 2.

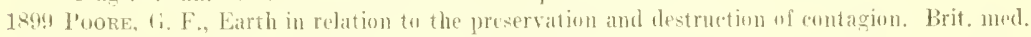
Journ.

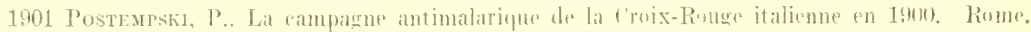

1901 Potancox. H., Contribution it lhistoire naturelle ef médirale des Joustiques. J'aris.

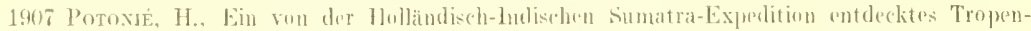

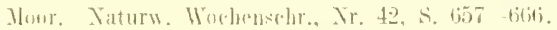

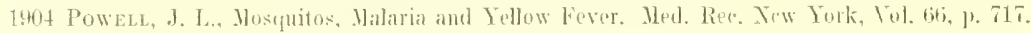

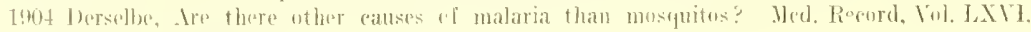
Ar. $21, p, x i s-809$.

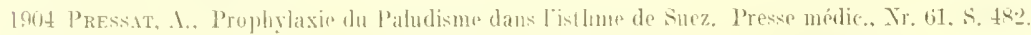

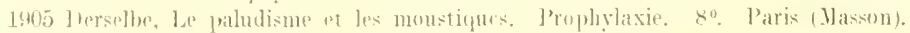

1401 P'revention of malarial lever, And, ned. Ros., 6. Marz.

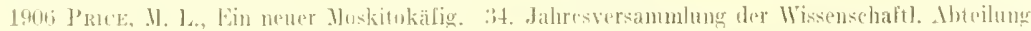

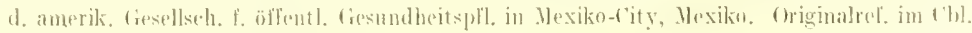

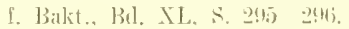

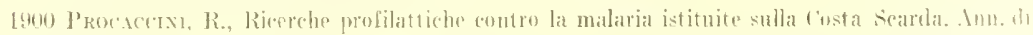
mind, nat.

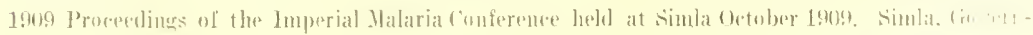
ment Priss.

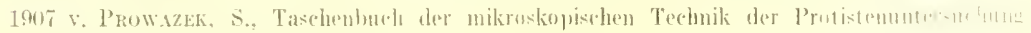
Leipzis, J. 1. Barth, tit; s. 


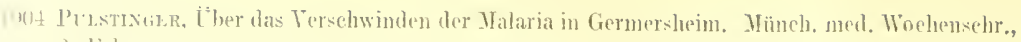
2. Finr.

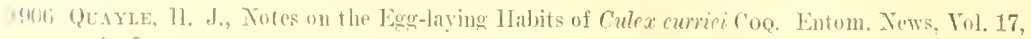
J. $4-5$.

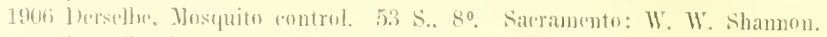

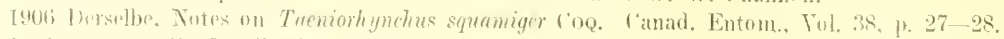

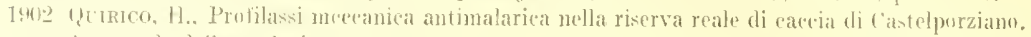
sive. stud. della malaria, p. 38т.

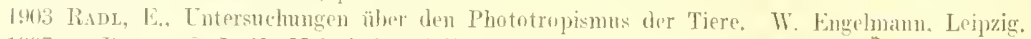
1907 de R.ıDT. O. L. H., Malaria-bestrijding te Willem 1 en Bajoe Biroe volerens het stelsel von 1)r. T. T. Terberan. (ieneesk. Tijdschr. varr Tederl.-Indië, Deel 47. 1fl. 6. 1. $764-775$. 1!us Jerselbe, Antwourd am Th. T. T. Terburge in zake de malaria-bestrijaling te Banjoe-Biroe. lieneesk. Tijulsehr. voror Tredorl.-Indie, Deel 48, Lfl. 4. p. 567-585, 1 Taif.

1!nt RABEs, O., Ither die Atmungsorgane der wasserhewohnenden lnsekten und Insektenlarven. Promethens Jahre. 16, p. $230-235$.

1906 Ridtopoulos, The fight against makria. Ithen.

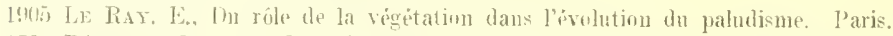

1738 Reatudr, R. A. DE, Némbires pour servir à l'histoire des Instetes Bd, 4. mem. XIII, 1. 573 his 636. planthes $39-44$. Paris.

1:k11 ReED. W.. The propagation of yellow fever hased on recent researches. Now York med. Re., 10. $\operatorname{lng}$.

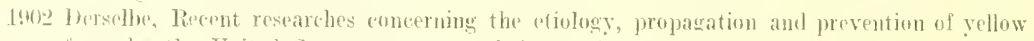
lever by the Inited States army commission. The Jomm. wl Ilyg. Nr. 2.

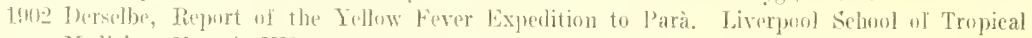
Nivlicine, Hemuir. VII.

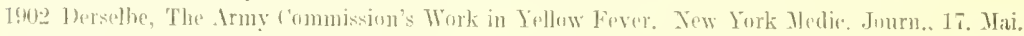

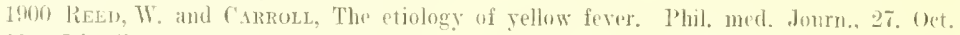

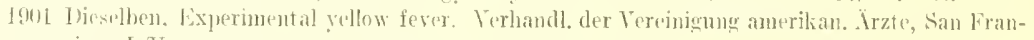
(نision I. 1.

1.401 licselben, "The prevention wl yellow fover. X. Y. med. Rec.. s. 641.

1902 Dieselhen, Die Atiologie les gelben Jiebers, 1'bl. f. Bakt.. R f. XXXI, Xr. 10, S. 299.

1960) Rerd, CARroll, Igranoxte and LAzEAr, Preliminary nuto on the otiolugy of yellow fever. Phil. med, Journ, 27. fhet.

1ynl Rezo, farrol and driramonte, The pathology af yellow fever. Boston med. and surgieal .omrn., Tol. ('ILIV, Tr. 14.

19ue Rass, 1). C., Experimental profof of the malaria-mospuito theory. Brit. mud. Jourm., s. 1054.

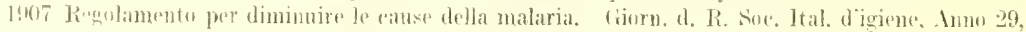
Mr. 5- 8 .

157i) Rencke. Bedeutung des (ielbfiebers Jür den Norden Luropas. IIamburg.

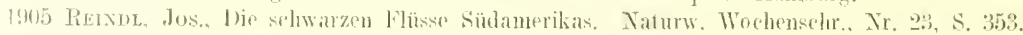

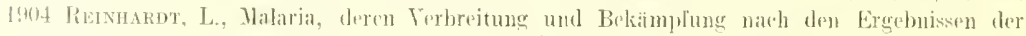

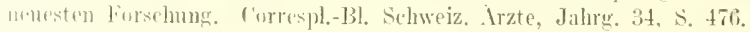

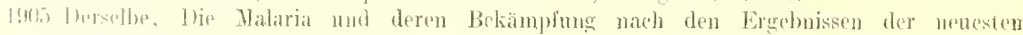

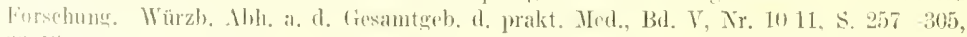
:3.; l.juger.

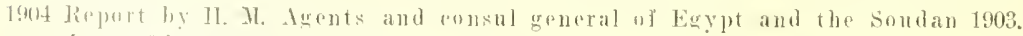

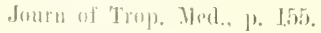

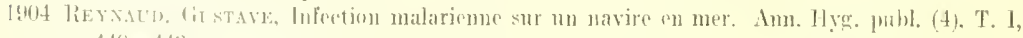
1). $440+4: 3$.

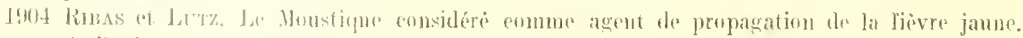
$\therefore$ P'iulu.

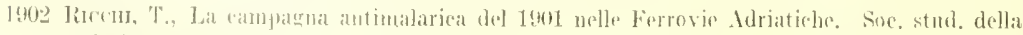
malaria, 1). 53:2.

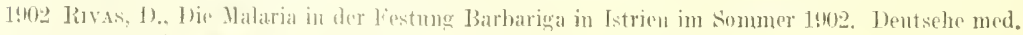
Hochemseler. Xr. $5(1)$

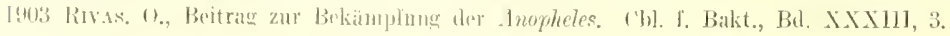




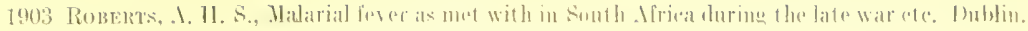
donrm, Tox.

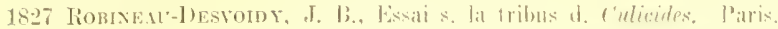

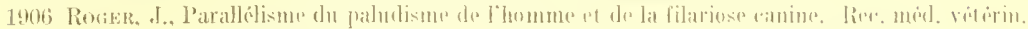
l'aris, T. 83, 1. $119-120$.

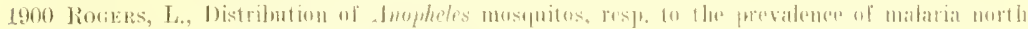

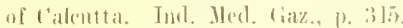

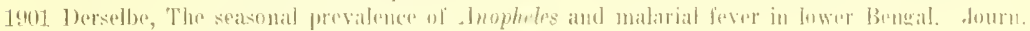
11 Hre., I, Xr. 4, s. 407.

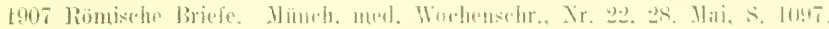

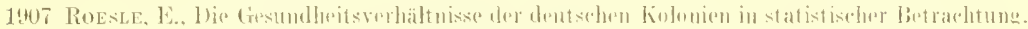

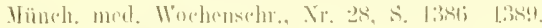

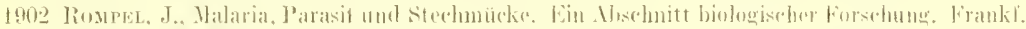

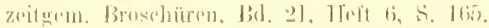

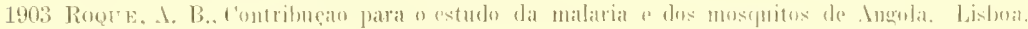

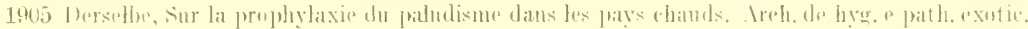
lisialontl.

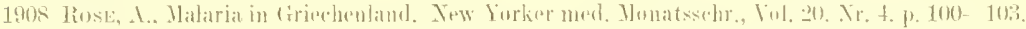

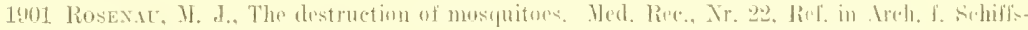
11. Trop, - Hyg., Bit. T, S. 40.

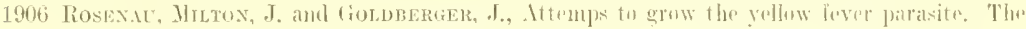

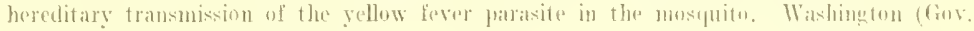
Print. (111.), so, ]. $108-11 \overline{1}$.

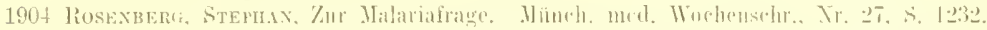

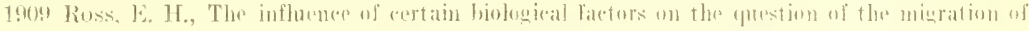

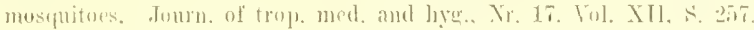

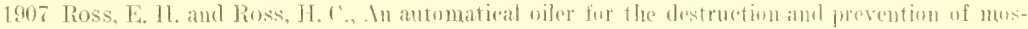

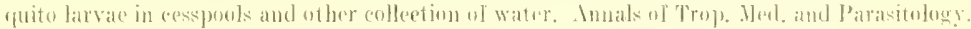
1) $165-160$.

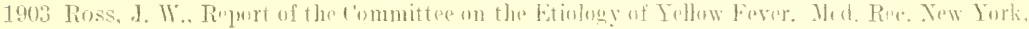
Viul. 64, 1). 793 .

1896 lioss, R., (Ohservations on the malarial parasite within the mospuito. Int. Wul. liaz.

189- 1)ersethe, Pigmented cells in mespuitos. Brit. med. Jimrn., S. 1786.

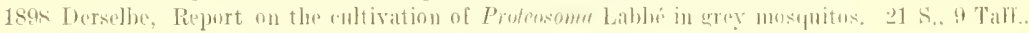
faleutla.

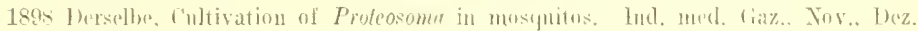

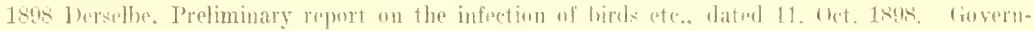
ment Printing. India.

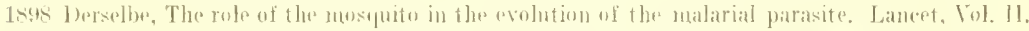
1899 1) 1894 Deralbe, Infection of hirds with Proteosoma ete. Ind. med. liaz.. lan.

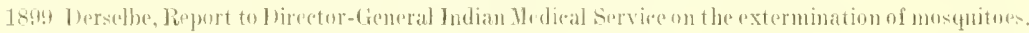
lind. med. Giaz.

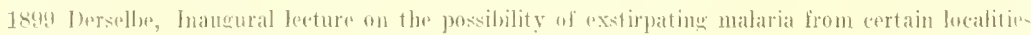
luy a new methel. Brit. med Journ., 1. July.

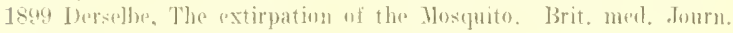

1900) Jerselbe, Malaria et nomstiqus. Revore seimtif., 2:3 Juin.

1900 Dersellse. Malarial fever. Med. Ammal.

1900 berselloe, The extermination of Inopheles ots. Brit. med. Jumrn.

1901 ] nesellon, Letters from Rumw on the new discoverys in malaria. Jiverpoul.

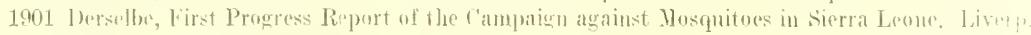
Siclumel of Tropl. Hed., Nem. V. Part. J.

1902 1)erselbe, The war against mosepuitos. Ind. med. Gaz, 1. 35.

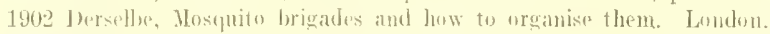

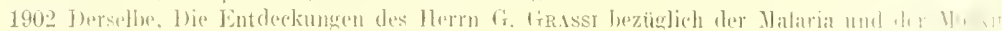
bentsehe med. Wuehemsehr.a Mr. 13. 
no: Ress. R., 'The exstirpation of C'ulex at lsmailia. Laneet, 1, 165, s. 18ti.

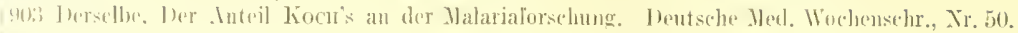

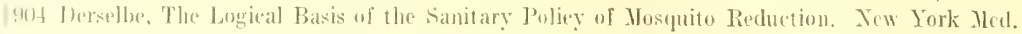
Jomril.. Vil. S(1), p. 761.

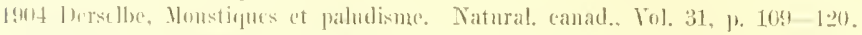

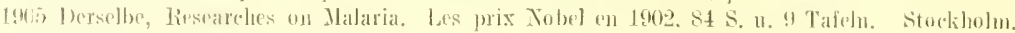

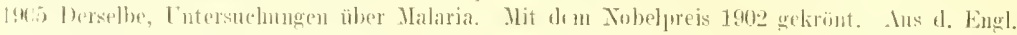

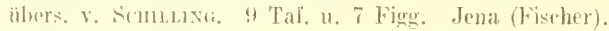

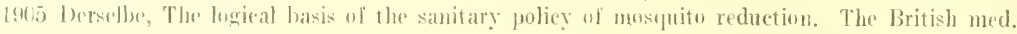
d(11111. נ). 1025

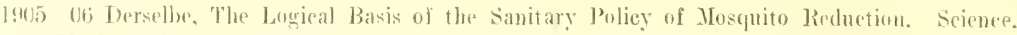

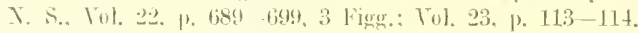

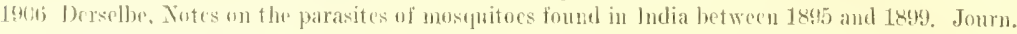
al Hygiene, Meit 2.

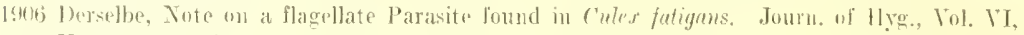
$\mathrm{Tr}, 1,1 \%, 96,-97$.

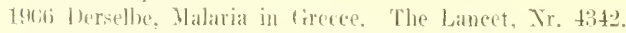

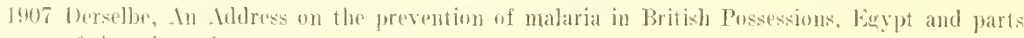
uf America, limonet.

1907 Jorselbe. The public prophylaxis of malaria. System of Medieine. Jaemillan and co., London. usto hersellye, Report on the provention ol Malaria in Mauritius. London.

lyto Derselhe. The Prevention of Malaria. Mit zalureiches Tafeh. London, Iohn Murray.

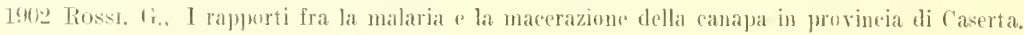
soe. stud. tella malaria, f) f(1)t.

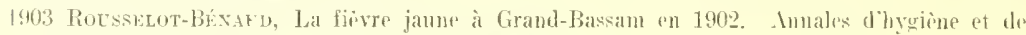
médicine poloniales. T. VJ, Nr. 2. 1). $319-330$.

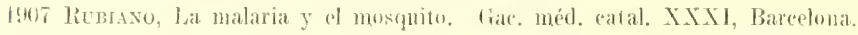

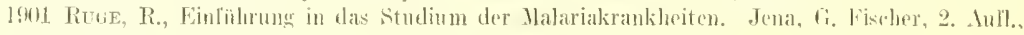
1306 .

teml berselbe, I'ntersuchung über das deutsehe Proteosoma. ('bl. f. Balit., Xr. 5.

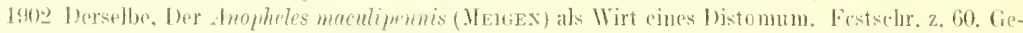
burtstage von RoBlert lioril. Jena.

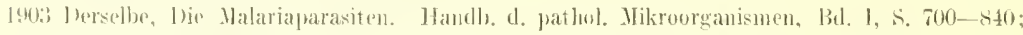

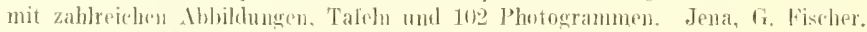

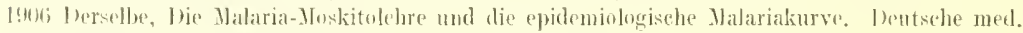
Wodlenselur., Jahre. XXXIl. Tr, 3is, s. 1405 - 1 toti.

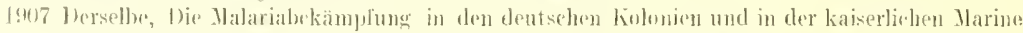

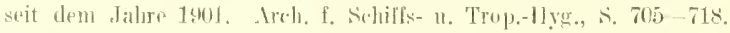

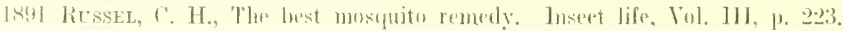

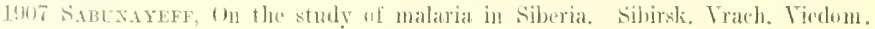

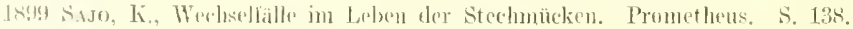

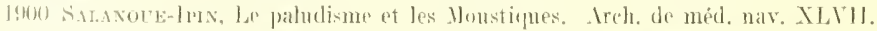

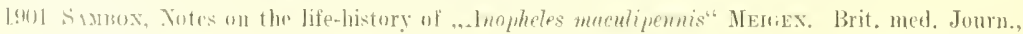
1. $145 \%$.

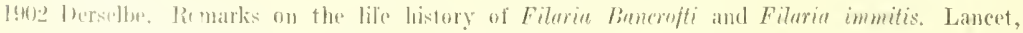

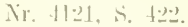

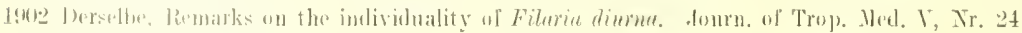

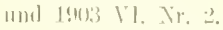

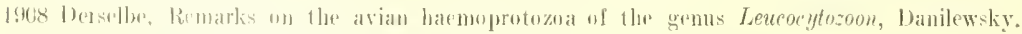

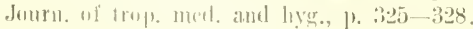

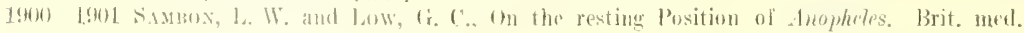
fintrn., p. 1158 .

19(1) Dieselben, Roperts on (wo exporiments of the moskito-malaria-theory ete. Med. and surg. soc, ol londons.

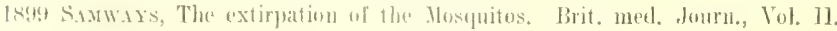




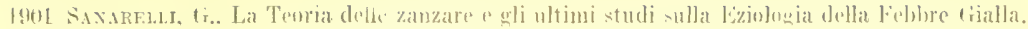
Vlailand.

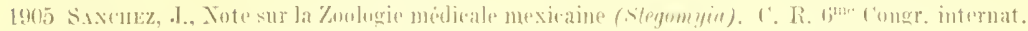
\%oul. Bitrue, p. 69:3 6:45.

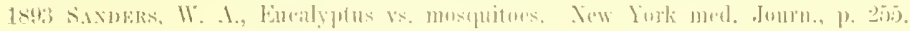

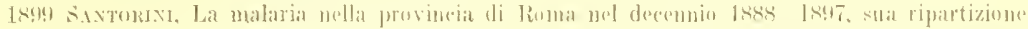

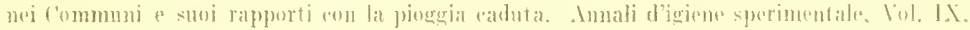
Jleti $3,0.354$.

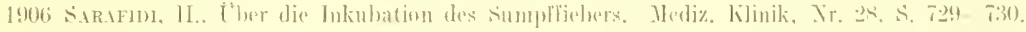

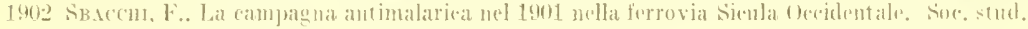
della malaria, ]. (iont.

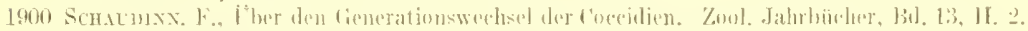

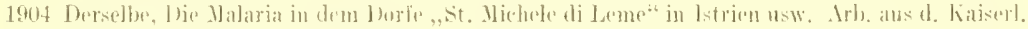
tiesumblhejt:ante. 13i\}. XX1. 11. 3.

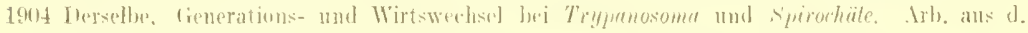
kidiserl. tiesundleitsante. Bd. XX. 11. 3.

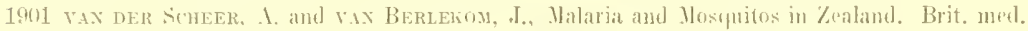
Journ., ]. 20. 200 .

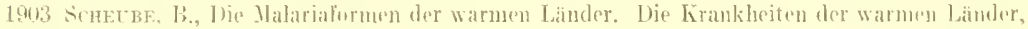
S. 139 .

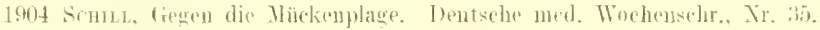

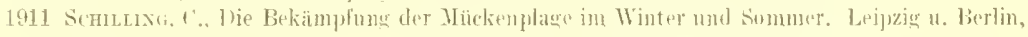
Terubner. 0.50 II.

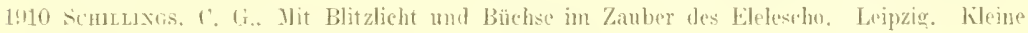
dusgabe. s. 251,254 mud 257.

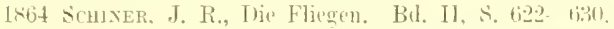

1901 Schuvarm, P.. I recente studi sulla malaria. Malpighi, p. 111.

1902 Therselbe, Padudi, rikaje ed anoleli senza malaria. Whenda, p. 16i!.

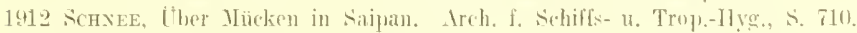

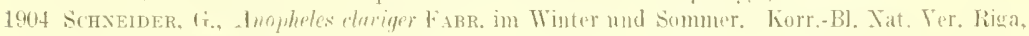
Nr. $47,5.41-45$.

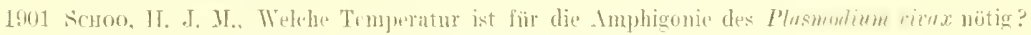
Teterlandsch Tijdschr. varr lieneesk., 1t. Dezember,

1!10.2 berselbe, Wat kan er aan proplyylaxis der malaria in Vederland gedaan worklen? Ebenda, Sr. 17.

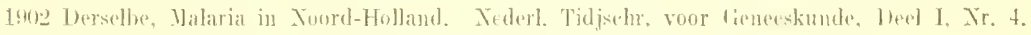
1902 Derselbe, Valaria in Krommonie. Ebenda, Jend I. Xr. 10.

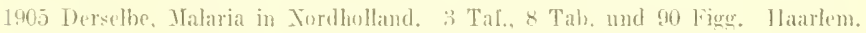

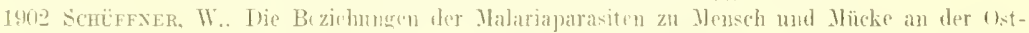

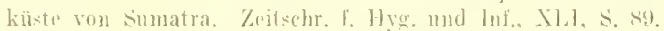

1902 Derselhe, Lber Malariaparasiten im inopheles an der tstkiste von sumatra. Geneesk. Tjjolscbr. v. Tetorl. Ind., I). XIJII.

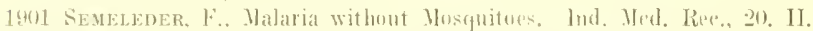

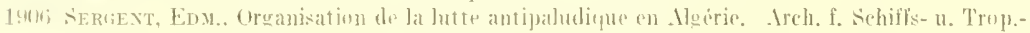
Hyer. Bil. 10. S. 73t 741 .

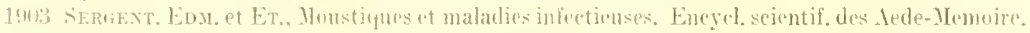
Piris.

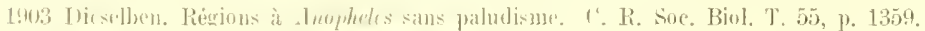

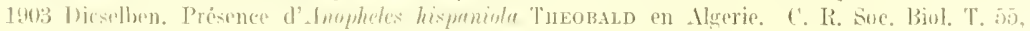
S. $1: 3(i)$.

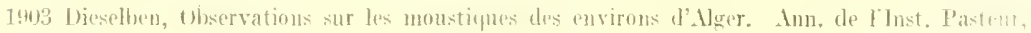
Nr. 1.

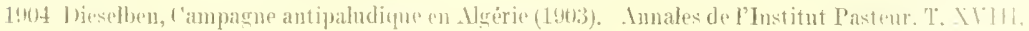
livirier 1904.

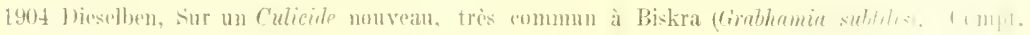
rund. sus. hiol., T. LYIII, Nr. 14, p. $17 \bar{s}-6 \overline{7}$. 


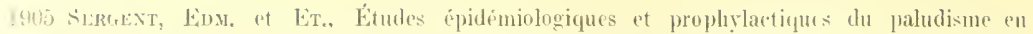
Neérie en 1904. Amm, Inst, I'asteur, T. 19, p. 129-164, 13 figres.

1905 l)ieselben, Inopheles algeriensis et 13 yzomyin hisponiola convonent le paludisme. Compt. rend. soc. Jjol.. T. LIX, Mr. 34, p. 4999500.

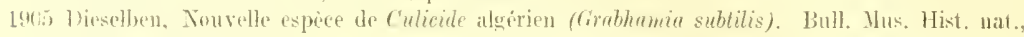
p. $240-2+2,7$ liggr.

1905 l)ieselben, Hémamibes des oisentux et monstiques: .. Generations alternantes" de semaUdx. Compit. remel. de la sere. de biol., Nr. 2.

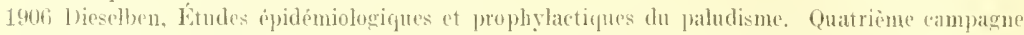

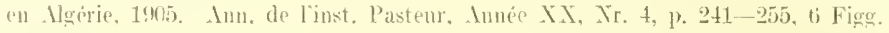

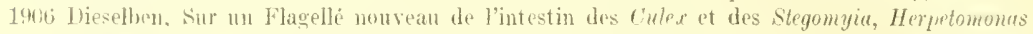
algeriense. Sur un autre Flagello ed sur des Spirochaptes de lintest in des larves de Joustiques.

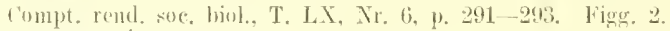

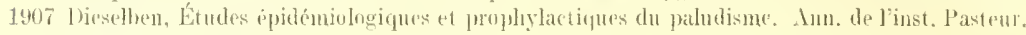
Inué XX1. Tr. 1. p. 28 46 . 2 Jigg.

1907 hieselbrn, Etudes sur les hematozoaires des viseanx. Inu. de J'inst. Pasteur, Innée 21, Xr. 4. 1). $251-2 \mathrm{~s} 0,2 \mathrm{Tafl}$.

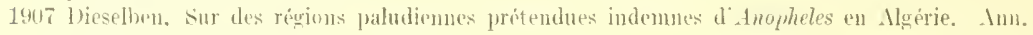
de linst. l'asteur XXl. p. 825.

1908 I)ieselben, Études épidémiulogípues et pophlylactiques du paludisme. (je rampagne en Algérie 1907. Ann. de l'inst. Pasterr, Amée 22, Nr. 5, 11. 390-424, 17 Figur.

1911 Diesclben, Études épidémiologiques pt propleylactiques du paludisne. Teuvieme campague pll Agerie (1910). Ati della Sor. furer gli studi della Malaria, Vol. XII, Ruma.

1912 I jeselben, Paludisme des ojsean (Plasmodium relichm). L'infection peut se faire par simple irottis du thorax du moustique sur la pau. Comptes rendus des scances de la société de Bulugie, Tome IXXXill, p. 36.

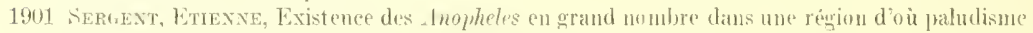
a disparu. Imn. Inst. Pasteur, T. 15, 1. $811-816,1$ Fieg.

1904 Service Sanitaire de St. Panl (Brósil). Travaux touchant la prepleylaxie de la flevre jaune 1901 1803. St. Paulo.

1904 SEwelt, E. T'.. The results of the campaign aganst Malaria in Mlian-Irir. Brit. med. Journ.. 17. Sipt.

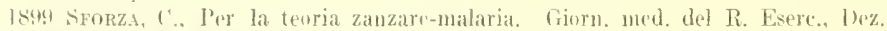

19020 Iterselbe, Mauerato o zanzare nel contado di Bologrna. Riv. igiene e sanita publ., p. 59.

190:3 Shurley, 1. L., I pot of Bilsil. Nature, p. 105.

1902 lerselhe und IILson E., On a pussible stridulating orean in the Mosquito. Trans, royal. soe. of lidinhourgh 4, P. 2, 1. $367-372,1$ Tal.

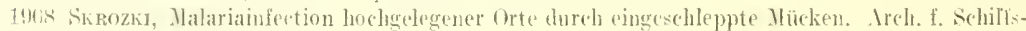
ณ. Trop.-11ye., S. 165.

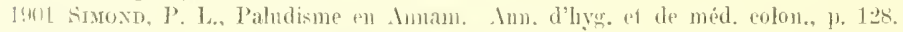

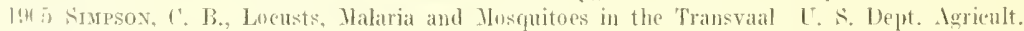
biv. Entom. Bull., Ar. 54, p. $76-77$.

$19(1) 7$ Simpsox, W. T., Inti-malarial Sanitation, Journ. ol frop. med. and hyg., 1. 286--288.

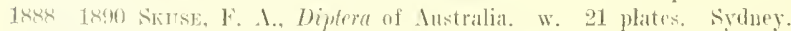

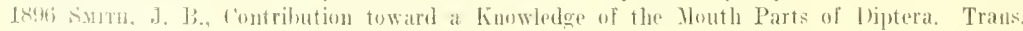
Imer. este Sox., Vol. 17, p. 319 329.

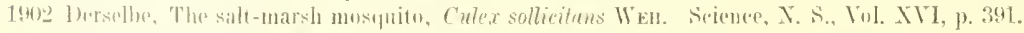

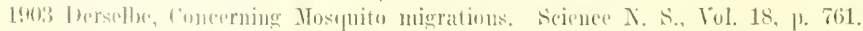

1903 Dersethe, The sanitary aspeot of the mostpito question. Med. News. 7. März.

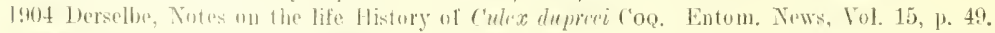

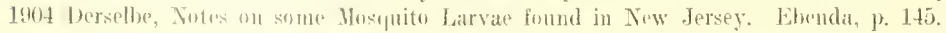

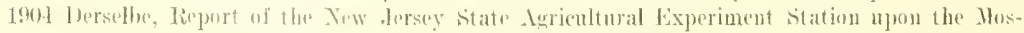
quitoes oecenrine within 1 lo sitate, their hahits, lite history ete. Trenton X. J., Nae Crellish d Quigley.

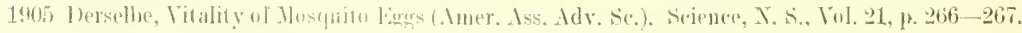

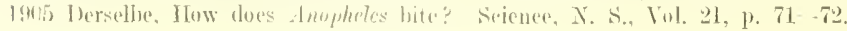




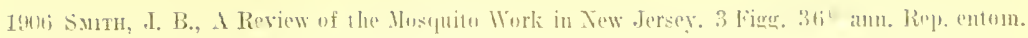
soc. ()utario, p. $34-3 \bar{\tau}$.

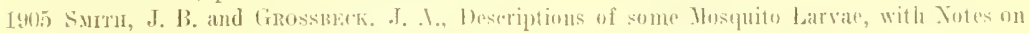
their Tabits. Psyche, liol. 1:2, p. 1:3 1s.

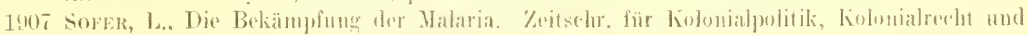

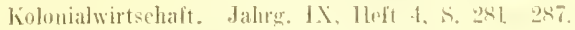

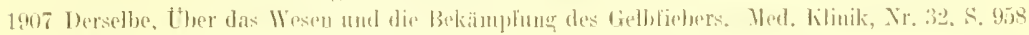
Jis 160 .

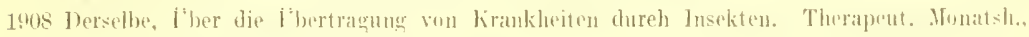
s. $193-197$.

1902 Soper, fi. 1. Mesquito destruetion. Mru. Tews, Mug.

1903 Dersellw, Josquito "xtermination in New Jork cily. Ebenda. 7. Marz.

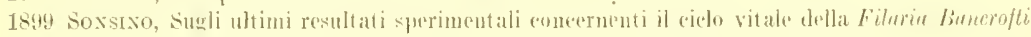
nella zanzara. Cibrn. dello IR. Necat, di Toriuo, T, Fase. le.

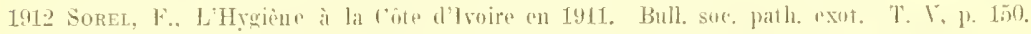

190 - sorefor, E., ()n the transportation of mosquitos hy vessels. Iled. Rece. 5 . Juli.

1902 leaselter, The Hosquitos on heard of Vessels at quarantined ports as factor in the transubsion af yellow fever. Hed. Rec., 16. Aug.

190.2 Derselbe, Hn the eradication of yellow fever in Hatrana. Ehenda, 25. ()et.

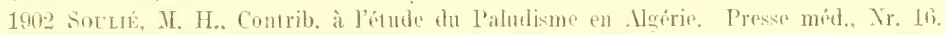

1906 Derselbe, Sur un eas de paludisme eontraté à Jlarseille. Le C'athere, 19. Mai, 11. 131.

1!)1 SPEISER, P., ¿́ber siteehmïleken. Leijuzigr, lnsekt.-Bürse.

1903 Derselbe, Insedten als lirankheitsübertriger. Lntom. Jalntb. 13, ․ 103.

1904 Derselhe, Zur NomenkJatur bhutsaugender Diptoren Imerikas. Insektenbörse, s. 14x.

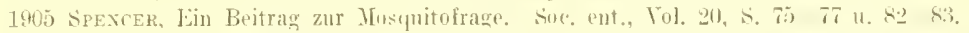

1900 Sptrrier, The Malaria Josquito in East Mriva. Tourn. of trep. mro].. To]. 2, p. 309--310.

1903 statistical reports of the heatth of the Xary. 1894-1s02. Lomelon, Eyre and spottiswoode.

1904 statistisehe santätsberichte der K. u. K. Kriegsmarine 1s93-1973. Wien, Braumuller.

1905 statistische Sanitatsberichte über die Kaserliche Marine his 190304. Berlin, E. S. Nittler \& sohn.

1904 DE Stefixi-Perez, T., Ostervazioni e notizit sui Culicidi siciliani. Natural. sieil. Mnn. 17, 1. 9 e p. 43.

1!nf Stepnexs, J. W., The Anti-Malarial Operation at Mian Mir (Punjal.) Laneet, Vol. 166, 1). 1337.

19ut Derselhe, The Prophylaxis uf Malaria. Ebendit. Vul. 167, j. bill.

1911 Therselbe, Malariabekimplume in Ismailia. Nmo of Trop. Med. and Paras. Be. 5, H. 2.

1!n0 Stephexs and Christophers, Mistribution of . Inopheles in sierra l,ome. Parts 1 and 11. Eberrela.

14(0) Dieselben, The Native ats the Prime Reent in the Malarial Infection uf Europeans. Royal Suciety, Further Rep. 16 the Malaria committer.

1900 bieselinen. On the destruction of Anopheles in Lagos. Rep. to the Mal. Comm.

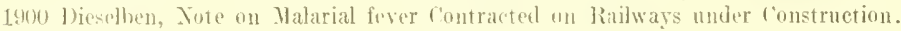

1901 Dinsulden. The Relation of Malarial Eudemicity to species of dnopheles. Ruyal suciefy, Rop. to the Mal. Fomm., Uetober.

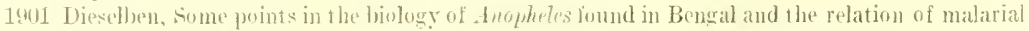
rndemicity 10 species of thopheles. Rep. to the Halaria Committee. Oetober.

140.2 Jieselben, R. S. Rap. to the Malaria commitese. Ser. 6. London.

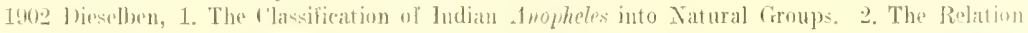
ul spercies of Inopheles to Malariat Endemicity. 3. The Relation of species of Lnopheres qu Malarial Endemicity, Further Report. 4. In Investigation into the Facturs which dete nin "

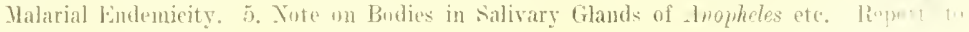
tho Nlalaria Committes. Sieventh series, Lomelon.

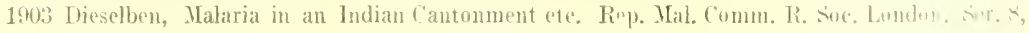
S. 13 แ. 2.2. 


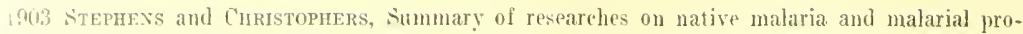
phylaxis. Thompson Lates and Johnston laboratories report, Fol. I. 1.

$1: 404$ bieselben, The practical study of Malaria. Sec. Edit. mit 6 kol. Taleh und zahlreiehen Figuren im Text. London. Williams of Norgate. 3. Aufl., 1908.

18,1 SiterLiNi, E., Mosquitoes in boreal latitudes. Insect life, Vol. 111, p, 403.

1903 Stedber. Mitteilungen aus dem Sanitätswesen von llutseh-Ostafrika. Deutsche med. Woch., Nr. 19 11. 20.

$1 ! 11$ sтетdez, E., Vorkehlag zu einer nenen Methode von Malariabekämpfung. Areh. I. Schiffsแ. Trop.-Hyg.. \$. $121-123$.

1902 Storcesce, lı., Pahdixme en Remmanie. Thèse de Paris.

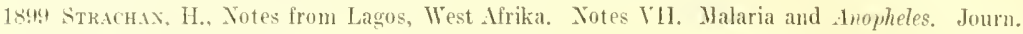
af Trojp. Hed., s. 113.

Ioto- Dorselbe, The Ilosquitos on board of Vesseks at quarantined ports as a factor in the transmission of yellow fever. Med. Ree. 16, YIII.

1902 Derselhe, (in the eradication of yellow fever in Havana. Ebenda, 25. X.

1904 Derselbe, Notes on the Prophylaxis of Halaria. Lancet, Vol. 167, 3. 611.

1904 Jerselbe, Lages, West-Afrika in biscussion on the mrophylaxis of malaria. Brit. med. Journ.. 17. Sept.

1902 Stromeyer, L., Moscputos and malaria. Some objections to the theory. Ind. med. Gaz.. 1). 36 ,

1403 Strunk, Bericht üher den EinfluB der Pflanzen aul die Entwieklung von Moskitos. Deutseh. Kolonialbl., Bd. 14, Nr. 9.

Itor suxder, H., Kann die weiBe Rasse sich in den Tropen akklimatisieren? Zeitschr. f. Kolonialpolitik usw., S. $177-193$.

18ts Sitsta, J., Die Ernährung des Karufen und seiner Teichgenossen. Stettin.

1904 Suzri, K., Lntersuchungen ïber die Malaria übertragenden Stechmïeken "Aropheles" auf der Insel 7tajima in Japan. Mitteil. der Medizin. Gesellseh. zu Tokio, Bu. XVIII, Nr. I.

1735 Swanmerd.m. J., Bijbel der natuure, of historie Jer Insecten, Class, 1II. (1). 1 $14-148$, Tal). XXXl u. XXXII.) Leydae. $\left.{ }^{1}\right)$

1!06 Takin, Three lectures on the preservation of health amongst the personal of the japanese navy and army. The Lancet, p. 1369, 1451, 1520.

1912 TAYLor, F. II., Tescription of Mospuitoes eollected in the Northern Territory during the expedition, 191. Bull. of the Torthern Territory, Bull. Nr. 1a. Dep. of ext. Affairs, Melbourne.

1903 TAyuor, J. R., Observaciones sobra los mosquitos de la Habana. Rev. de med. trop. T. IV, $\therefore 101,145,165$.

1902 TAYloR, L. W., Sanitary work in West Ifrika. Brit. Med. Jomrn., 20. IX.

1902 Ted Tedor, G., fontributo allo studio deHe sostanze zanzarieide. Soc. stud, della malaria, p. 102.

14t); Teneschi, La Ligue contre le Paludime en forse. Amm. d'hyg. ct de méd. colon., p. 416.

19(0), Temple, R. (', ( ) n some administrative measures taken against malaria and consumption in the tropics. Journ. of troj,. med, Fol. VIII, Nr. 15, p. 226-231.

1!105 Terbursh, J. D). I)e makaria-bestrijding in Italie. Cieneesk. tijdschr. voor Nederl.-Indië, l)eel XLY, Ill. 5.

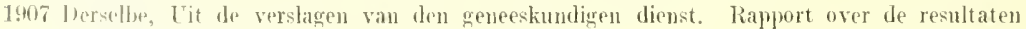
lker Malaria-bestrijding in het garnizoen de Willem 1, 1. 11. 05-1. 1. 07. Geneesk. Tijdsehr. voer Tederl.-Indiö, 1)eel 47. Ifl. 4, p. 435-465.

1900 T'zsti, F'. sulle zanzare della citta di Grosseto, Giorn, d. R. esereito.

1902 Terselbe, Riverele sugli amofele durante Ja campagna antimalarica nella Marremuna Grossestana 1901. Cinrn. umd. R. Esercitu, \%. 337.

1 tog bersethe, Topouratia anofeliea e bonilica idranliea. Ehenda, p. 449.

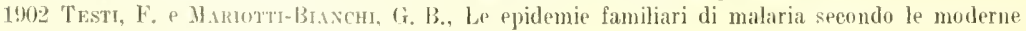

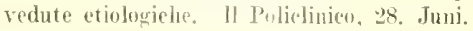

1) Geschrieben wurde das Werk sehon 1679, aber erst nach mancherlei Sehicksalen nach dem Tode des Verfassers von BuERuark lerausgegeben. 


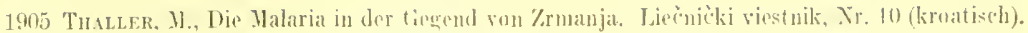

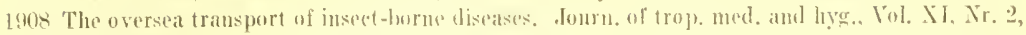
1. $2 \cdot 2-2: 3$.

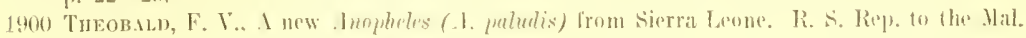
f'ommitt. Inndon.

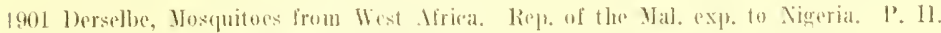

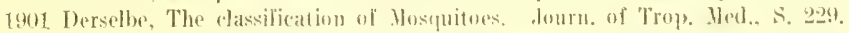

1901 u. 1903 Derselbe. Yommeriph of the C'ulicidue or Hosquitoes, mainly (ompilod from the

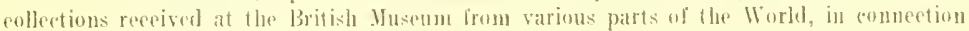
with the investigation in to the eause of .lalaria eondueted by the folonial office and the Royal Soeiety. london. :3 Bïnde.

1902 Derselbe, The ("lasification of the Inophmine. Journ. of trop. Mod, V. 5, p. 181 18.3.

1,903 Derselbe, Deseription of a Now North American ('ulex. C'anad. Entom., V. 35, S. 211.

190.3 berselbe, Report on a collection of Josquitoes lrom equatorial Eatst Ifrica ele. Rep. Sleeping Sickn. Comm., R. Sine. Londun, Nr. 3, s. 33.

1903 Derselhe. Xew Culicidue from the Federated Malay states. Lutomolouist, V. 36, S. 206.

1903 Therselbe, Totes on the C'ulicidae and their Larvie from Peros, Vew-Mexico usw. ('anad. Entom. 13d. 35, s. 311.

14003 Derselbe, Rep. on a colleetion of Josquitoes or Culicidue ete. from trambia and deseriptions of new species. Lomblon.

1904 l)erselbe, New Culcidae from the Federated Halay States. Eutumolougt, Vol. 37, p. 12, 36, $77,111,163,211$.

1905 Derselbe, Genera Culicidomm in Genera Insectorum pull. par l'. Wytsman. Fase. 26. Bruxelles.

1905 Derselbe, I Tew (ienus of Culicidne (Anisorhelemyia). Entomologist, Vol. 36, 1). 52 56.

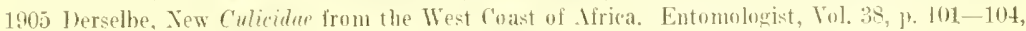
$15 \frac{1}{2}-158$.

1905 Derselbe. I new stegomyia from the Transval (Sleg. simpsoni a. sp.). Entomologist, Vol. 38, p. $224-225$.

1905 Derselbe, I new Ficulbin from Wtest Mriea ( $F$. mignigus n. sp.). Mnu. Mag. Mat. Hist. (7), Vol. 15, 1\%, 199-20).

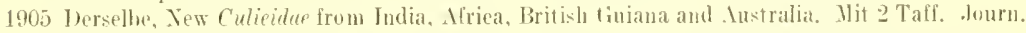
econ. Biol., Tol. I, y. $17-36$.

1905 Derselhe, I Catalogue of the Culicile in the Hungarian Tational Musemm. Mith Descriptions of $\mathrm{New}$ Genera and species. Inu. hist. nat. Mus. nation. Hungar., Fol. 3, p. 61- 120.

1906 Derselbe, I New Hegarminus. Entomologist, Vol, 39, p, 241.

1902 Thiele, I'ber Malaria in der Jeversehen Marseh. Weutsche med. Wochensehr., Nr. 36.

L89g Tmx, li.. The Etiology of Malarial Fever. Jomm. of trop. med., Vol. 2, p. 1- 1), $19-20$.

1900 Derselbe. I note on species of . Wopheles found amonest Hospuitos sent from Shanghai and Java. Brit, med. Jumu. s. 307 .

1912 Turoux. 1., Hestruction des moustiques dans les locaux mal clos. Bull. soc. path. exot. $\mathrm{T} *$ I, p. 633 .

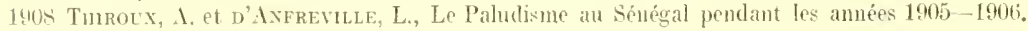
Paris, .I. B. Bailliere et lils.

1 go1 Tuossox. J. C., The prevalence of mosquitoes and Malaria in Hongkong. Jomrn. of Trop. Ved., S. $23-26,38-40$.

1901 lerselbe, Mosquitoes and malarial parasites in Ilongkong. Ebenda. S. 38.

1905 Thospsox, M. T., Mimentary f'anal of the Mesquito. Mit 6 Taff. Proc. Boston Soe. nat. Hist.. Vol. 3.2. p. 145-20.2.

1907 Torresse. J., Les insectes et la transmission des agents pathourenes (. lnopheles et rulex diun la région Jyomnaise). Thése do Lyon.

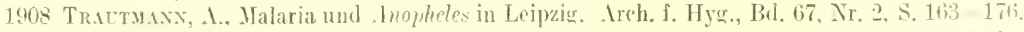

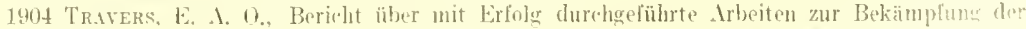
Malaria in Selangor. Ireh. f. Sehilfs- It. Trop.-Myg., Bd. I'IlI, s. 21.3.

1906 lerselbe. A further report on measures taken in 1901 to abolish malaria trom hlane and Port Swotfenham in Selangor, Federated Malay states. Journ. of trop. mel. Vol. 1X, Nr. 13, p. $197-198$. 


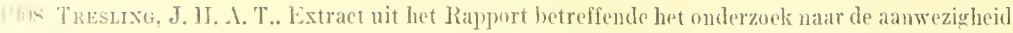
van muskieten en het voorkomen von malaria en andere niet nader gedefinieerde koortsige ziekten ojs. H. M. Wachtsehip en in de gebouwen von den torpedodienst van 1. Juli 1906 tot 30. Jumi 1907 te Soerabaia verricht. Geneesk. Tijdschr. voor Nederl-Indië, leel 48, H. 15. p. $151-193$.

190T Trected, G.. ither das Malariafieber und seine Bekämpfung. Ber, d. naturf. Ges. Freiburg i. Br., 13d. 11. ล. 163 .

1905 Treutleix, A., Malayiseher Reisehriel VII (Schlub). Mïnch. med. Wochensehr., Mr. 51, S. $2511-2513$.

1911 l)erselbe, Verdient die Chimingrophylaxe den Vorzug vor dem mechmischen Malariaschntze in den Trupen? Areh. I. Schills- u. Trop.-Hyg., S. 753-764.

1eks Trillat et Legexdre, Étude sur la toxieité des vapenrs de quelques sulstances chimiques sur les Moustiques. Bull. Soc. path. exot., p. $605-610$.

1906 Trolard, Étiologie du pahdisme. Bull. méd. de l'algérie XYI.

1907 Tromistr., Appunti sulla campagia antimalariea del 1906 mel commune di Strongoli. Salute [m]l). XX.

1902 Tstzuki, J., Uther die Terwendbarkeit des Moskito-Drahtgazesehutzes in den Malariagegenden der Tropen. Areh. 1. Schiffs- n. Trop.-Hyg., Bel. 6. s. 1.

1902 1)erselbe, Malaria und ihre Termittler in Japan. Ebenda, S. 285.

1902 Derselbe, Ther die Ergebnisse meiner Malariaforschmy in Hokkaido. (Cbl. f. Bakt., Abt. 1, B1. 31, S. 763 .

1902 Tंber die Terwendharkeit des Moskito-Dralıtgazesclutzes in den Malariagegenden der Tropen. Zusammengestellt nach dem amtlichen Material der Kolonial-Abteilung des Auswärtigen Intes. Arch. f. Schiff́s- u. Trop.-Hrgo., Bil, 6, Nr. 1, S. 1-9.

1912 Thmer, G.. L'usere Wasserinsekten. S. 119 ff. Leipzig, Quelle \& Meyer.

1904 LlRich, F., Zur Kenntnis der Lufteäeke (,Flugblasen") bei Diomeden exulans und Diomedea fuliginosn. Wiss. Erg. der deutschen Tiefsee-Expedition, Bul. VI\}.

1908 Tinexhutit and Weidanz, Uther dem biologischen Nachweis der Herkinft ron Blut bei blutsaugenden Insekten. Arb. a. d. Kitiserl. Gesundheitsamte, Bd. 28, \&. 595-599.

1905 Lxderwood, H. L., Malarial infeetion in Kurdistan. Ameriean Medicine, Nol. X, Nr. 27, p. $1104-1106$.

1906 Crsix, H.. The Entwicklnng der Stechnücke. Woehensehr. f. Agnar. und Terrarionkunde, Jahrg. 3, ^. $38-39$.

1903 VAgedes, Mrztliche Beobachtungen ans Deutsch-SW-Afrika mit bes. Berieksiehtignng der Infektionskrankheiten und der Kocr'schen Malariabekämpfung. Vierteljahrsschr. f. off. (iesundheitspfl.

1903 Derselbe, Bericht äher die Malariaexpedition in Deutsch-SW.-Afrika, Zeitschr. 1. Hyg. und huf., Bd. 43.

1903 Derselbe, Tie Malaria unserer Kolonien im Lichte der Koch'schen Forschnngen. Festurdur. \%. 60. Creburtst, von R. lioci, S. 177.

1900. Valagussa, F., La campagna antimalarica mediante la jrofilassi meceanica sulla linea Romal'isa durante l'ammo 1901. Soc. stud. della malaria, J. 554.

1613 Talextra, F., I'ber emheimische Malariaerkrankungen. Die Tleilkunde, Heft 7. S. 289. 1967 Talentixo, Ch., La hute eontre les moustiques aux colonies. Presse médicale, 6. Xl.

1904 Valiry-Havaro, The Transportation of mosquitos in bagage. Med. Reend, 2e. Juni.

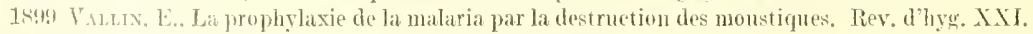
190L Laney, Malaria et inonstiques. Rev, de med. April.

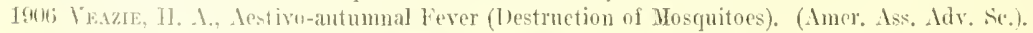
Sicienee, К. S., Vol. 23, p. $407-415$.

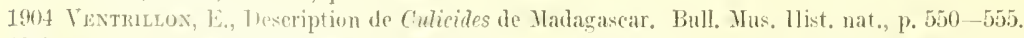

1905 Herselbe, ('ulcides nenveanx de Madagasear. Arch. de parasitol., T. IX, Mr. 4, ]1. 441-450.

1905 berselbe, Vote sur mo nouvelle espere de Monstirute le Magadascar. Anm. Iyg. Métl, colon., 1. $2[7-200$.

1905 Dirselhe, Les Culicides de Iladagascar. Areh. de Parasitologie, 1. Juli.

1905 lorselbe, Note sur une nonvelto espeoe de Moustique de Hadagascar (Stegomyia lumberli). Annal. d'hyg. et de médee. enton., T. VILI. Nr. 2, p. 217. 


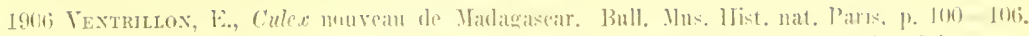

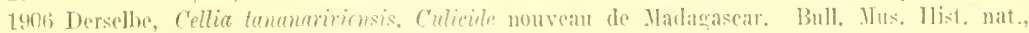
p. $198-20$ - 2 .

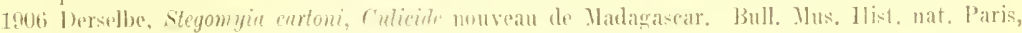
p. $143-1+5$.

1907 Verdex, Les eoneeptions modernes sur la prophylaxie du paludisme. Féchu méd, du nord, XI, Lille.

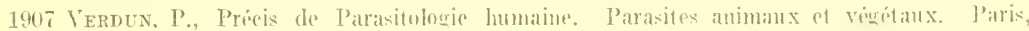
750 p.. 4 Tat.

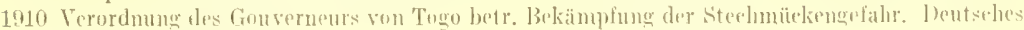
Kolonialb]att. \$. tils.

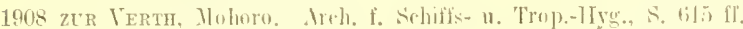

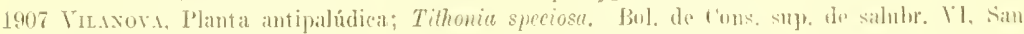
Salvikiur.

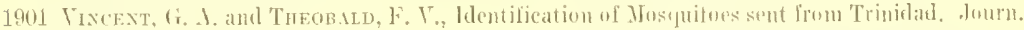
of trop. med., Vol. 4 , 1. 401 .

1905 Vixcext. L. ... Prophylaxie de la fieve jaume. Ireh. de paracit. 'T. IX, Mr. 2, p. 161170.

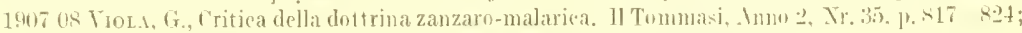
Nr. 36. 1). 841 \$50, Immo 3; Nr. 1, p. 2-4: Tr. 2, p. 25- 3.2.

19ut Vitocx, fr., La lutte contre les moustipurs. Presse médicale. p. tift.

1902 Vivate, R., La malaria in Venezia. Riv, d'igien. e san. puhl., [1. 23t.

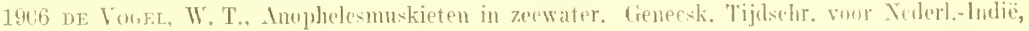
l)eel ILVI, Afl. 2, 1. 6ti- 85.

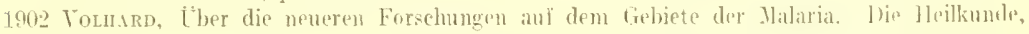
S. 3 sis.

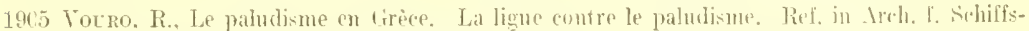
11. Trop.-Hre.. Bil. X. S. 258, 1906

1903 WADDELL, 1. R., Soil nitrifieation v, the incidence of malaria and othel mosquitu lorme diseasts. lancet, p. $15 \mathrm{~s} 9$.

1896 W.ADE, Hibernation of mostuitues. Insect lifi, p. 52 .

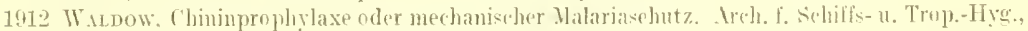
$\therefore 5+\bar{\imath}-5 \overline{5}$.

1851-1850; WiLker, F., Insectu Britumica: Iniptera, e. 30 Tah. ain. London.

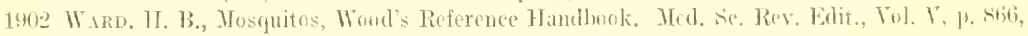
figor.

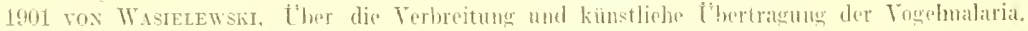
Ireh. 1. Hye., S. 68 .

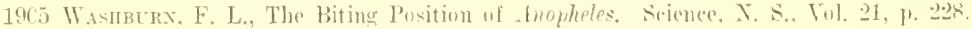

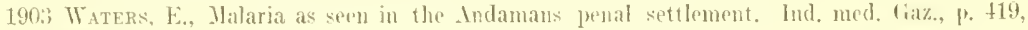
44., $1904,1 \% .7$.

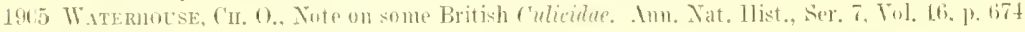
bj: liTit.

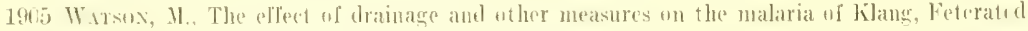
Jalay States. Jomm. ol Trop. Mel., 1. Iynil.

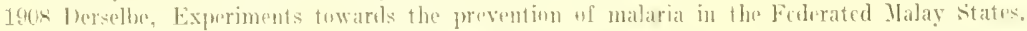
British med. Jomrn., Xr. 2ftil, p. 499 500.

1887 Webster. F. M., Report on Buffalo enats. Washington, Dep. Ier. Bull.

1895 WeED, IT. E, some experience with mequitos. Insect hife, p. 212.

1902 Weeks, ('. H., Gome pratical sugerstions on mosquito extermination ju Tew Jersey. Hed. Yows, 7. Nairz.

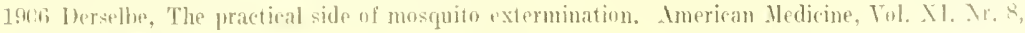
]. $320-324$.

1901 Wegr, J. 1., Persmal protection against mosenitoes. British meslical Jomrnal.

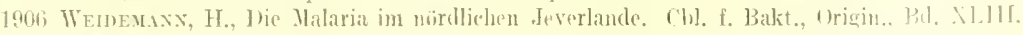
S. 80 s8.

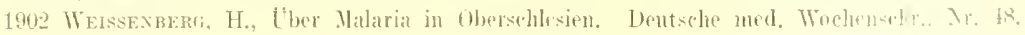


InGt Wersuax, M., The Futwicklung der Dipteren. Leipzig (W. Eingelmanm).

Intic Derselbe, llie Jetamor jhose der C'orthra plumicomis. Ebenda.

[8.28-1830 Wiememax, (). AuBereuropäische zweiflüglige Jusekten. Hamm.

1905 Weqr, F. H., Mosquitoes and Malarial fever. Laneet, Mr. 7, p. 461.

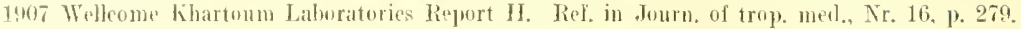

1904 Wellas, I., C., Brief conspectus ol the trop. diseas. common in the Highlands of West Central Africa. Journ. of trop. med., 15. Februar.

1905 Derselbe, Notes on tropical diseases of the Angola Highlands. Tew York Wed. Junrm, and [']iladelphia IIed. Journ.. August und September.

1 1950 Derselbe, Notes on the common mostuitoes of Bihe and Bailundo districts, portuguese West Afrea. Journ. of inlect. dis., Vol. I1, Nr. 4, p. 627-631. 5 Figg.

lnot Derselhe. Rejort on the insanitary Condition of various Tuwns in the Colony of Angola. Tew Tork and Plil. Hed. Journ., 31. March, p. 662.

1906 berselbe, Notes on the commen mosquitoes of Biht and Bailundo districts, Portugnese West Strica. Journ. of infect. dis., Vol. III, 1. I87-190.

1907 lersethe, Uher cinen anflallenden Geschlechtsdimorphismus bei Heptaphlobmya simplex

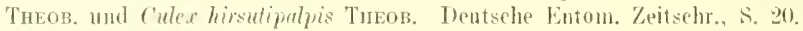

1870 Wexzet, lige Jarsehfieber in ihren ursiehliehen Beziehnngen während des llafenbanes im Jadegebiet von 1858-1869. J'rage. Vierteljahrssehır. f. prakt. Heilkunde, Bil. 4. S. 1.

1904 Wesché, Tlie mouth parts of the Nemocera. With 6 pl. London.

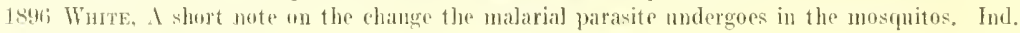
med. Lraz, Nr. B.

1899 Wrllam and Modv, Mosquitos and Malaria. Jamus.

1900 Wixter, sir F. P.. (H) wervations on makaria and mosquitoes in Queensknd and British New (ininea. .T. of 'Trep. Nled., S. 37 - 38.

1912 Wre, K. S. and Mrxett, E. P., Experiments with erude carbolie acid as a larvicide in Britisht Giviana. Journ. of trop. med. and hỵg., p. 358 .

1900 Woldert, A.. A Prelimuary Investigation of the Theory of the inoeulation of Malarial Fever trough the Agency of Mosquitoes. Jumrn, of the Americ. Med. Assoc. Fehruary.

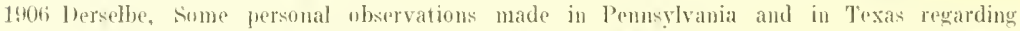
malarial fever and the Inopheles mosquito. American Medicine, VoI. XI, Nr. 12, p. 423-427.

1907 Wolferstax, H.. On Jellow fever in the Climpanze. Brit. med. Journ.. Jan. 19.

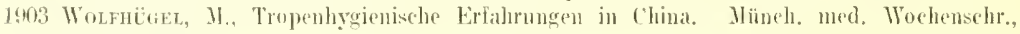
Nir, $47,48,49$.

1876 Woopward. J., (1n the markings of the Bodyseate of the English gnat and the Ameriean mosiquito. w. 2 plates. London.

1902 Writitr, B. L., Malaria: a sunumary of recent progress in the knowledge of its etiology and prephylaxis. Amer. Journ. of med. se., Oet.

1901 Wruint, 1l. .J., The resistance of the larval mosquito to cold. Brit. med. J., 13. April, S. 882.

1877 Wrep, F. I., Y. D., hipt. Neeerlandica. M. 14 eol. TItn. Gravenh.

1908 de Tbarra, 1. M. F., Jellow ferer to ('ubib. Texas med. Joum., Nr. 4.

1909, Yellow Fever al St. Nazaire, France. Journ. "f trop. med. and lyg.. Fol. XII. Nr. 2, 1\%. 27.

1891 \%.rnartas, 0., bie Tier- und Pllanzenwelt des Sibwassers. Leipzig.

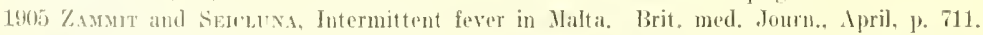

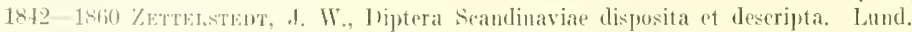

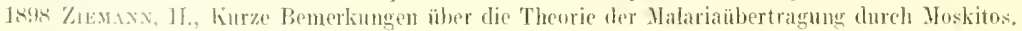
Areh. I. Sechill- 11. Trop.-Hyg., Bel. II, s. 345.

1900 Dersellow, T'ber die Beziehungen der Mosquitos zu den Malariaparasiten. Dentsehe Ded. Woxhenselur., Ni. 25. Aueh in Murn. of Trop. Med., Bel, 3, s. 121.

1900 bersellhe, Zweiter Bericht über Valaria und Mosquitos an der afrik. Westkuste. Ebenda,

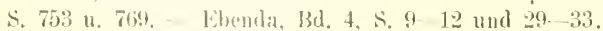

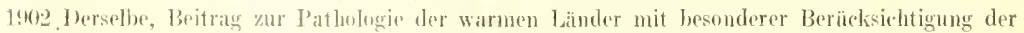
('ap-Terdischen Inseln. Arch. I. Achiffs- u. Tropr-1Iyg., Bd, 6, S. 27t.

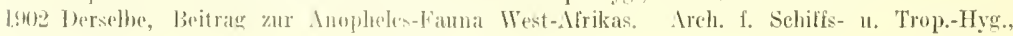
S. 360 . 
1902 Zuenaxx, II., ther Malaria einst und jetzt in den Marselen. Deutsele Medizinalzejtung Nr. 77 11. 88.

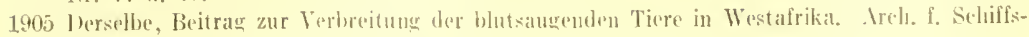
u. Trop.-Hyg., Bd. 9. S. 114.

1905) berselbe, Beitrag zur Trypanosomenfrage. ('bl. R. Bakt.. Heft 3 und 4.

1905 berselbe, Beitrag zur Filarialkrankheit des Mensehen und der Tiere in den Tropen. Dentsehe med. Woehenschr., Xr. 11. s. 4.00-424, 3 l"ig.

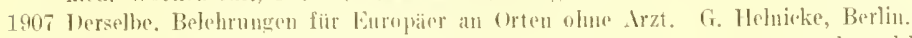

1907 Jerselbe, Jalaria prevention in uncultivated districts. . Tourn. of trop. med. and hyeg. p. 288 bis $2 \times 9$.

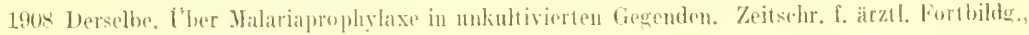
Jahirg. 5, Nr. 5, ऽ. 133 138.

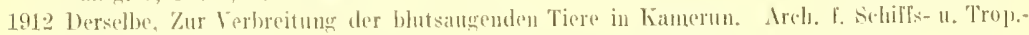
$11 \mathrm{yg} .$, s. $53 \mathrm{~s}-5 \mathrm{~s}$.

1907 Ziexets, Malarial fever in Daghestan. P'ract. Trach. V1, St. Petershurg.

1905 Zuxтz, X. Ther ten Winterschlaf der Tiere. Xaturwissensch. Worhensche., Mr. 30, s. 145. Jena, fi, Fischer.

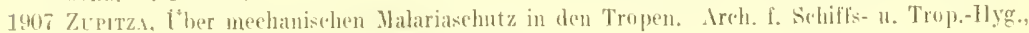
Bd. 11, S. $179-196,225-240$ und $257-272$.

\section{Psychodidae.}

Die wichtige Gattung Phlebotomus wird am Ende dieses Bandes von Dörr und Russ in einer besunderen Arbeit besprochen werden.

\section{Chironomidae (Tendipedidae).}

In der Fanilie der Chironomidem. (Zuckmücken) werlen mehreve L'nterfamilien zusammengefaßt, die so rerschieden an Bildung und lebensweise sind, daß man sie später jedenfalls als selbständige Familien gelten lassen wird. Der Familienverband ist hente ein großer Sammeltopf, der die heterogensten Forusen mmatürlich in sich rereinigt.

\section{Cerectopengoniluere.}

Uns interessieren nur die Keratopogoninen (richtiger Ceratopogonidae), welche in sechs Gattungen blutsaugende Arten aufweisen.

Die Keratopogonen gehören zu den kleinsten Dipteren, da die Mehrzaht der Alten kaum millimeterlang ist, ja sellbst diese (iröße noch nicht eimmal erreicht. Es sind dunkel, gran oder schwarz, gefärbte Mückchen.

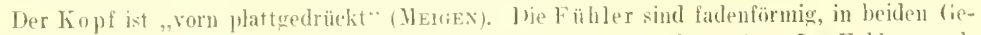
schlechtern 14ghiederig, zart beborstet (q. Fig. 139!) oder pinselartig behaart ( $\hat{0})$. Das Fühlergrundglied ist birnförmig. die folgenden kugelig und die Endglieder stäbchenförmig, distalwärts an Länge zunehmenul; sie lassen sich infolgodessent frat mit einer śpaltpilzkette vergleichen, in der eine liokkenschnur in eine solehe von Bazillen ühergeht (Fig. 139). Jer naels abwärts gerichtete Rüssel hat mindestens die länge des koples. Inie yaxillarpalpen sind in der legel tgliederig.

Thorax grob und gut entwickett, aher nicht kapuzenförmig über dat llinterhaupt sich ans-

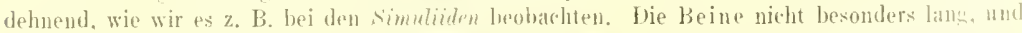

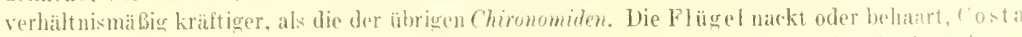

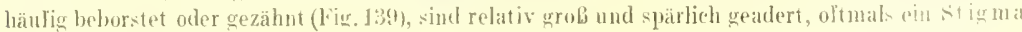
(Ramlmal) tragend. 
Ininterleib zylindrisch, neumringelig. Nur zwej spermatheken vorhandem.

The wurmfïmigen. 13ringeligen Larven bewegen sich schlägelnd und seln geschickt dureh das Wasser. Hönzelne Arten entwickeln sich aurh in faulenden Pflanzenstoffen mo Pilzen. Eine Art (mymecophitus) ist sogar in Aucisennestern angetroffen worden.

1. Die zahlreichsten Vertreter stcllt die Gattung Ceratopogon MEngex (Culicö̈des 1.ATR.), im Ost('n Deutschlands unter dem Namen ,Gnitzen" bekannt, selbst. Die Keratopogonen sind in zahlecichen Arten über die ganze Erde verbreitet,

Fig. 139.

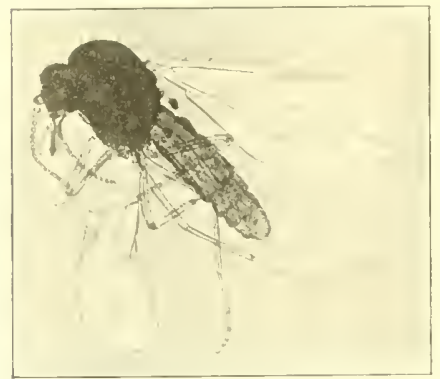

Cerutopogon stigma Heicien. $40 / 1$. (Original.)

Deutsehland allein besitzt deren über zweiliundert.

Tnsere Figur 139 stellt eine der gewöhnlichsten Arten (Crutopoyou st igmu, MEIiEx) dar, die an fenchten Waldrändern im Friihjahr uns massenweis zu ïberfallen pilegt und auf dem Handrücken flink molnerlaufend durch Überdeeken leicht gefangen werden kann. Noeh häufiger wird Cerutoposon pulirolis beobachted, der schon Lrswé (C'ulex pulicaris) bekannt war.

Ton afrikanisehen Arten sind als lästige Blutsauger beschrieben worten

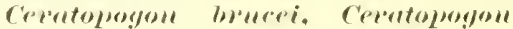

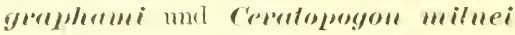
in Ostafrika (Uganda) und Ceroutrjongone hubcrevi in Kamerun.

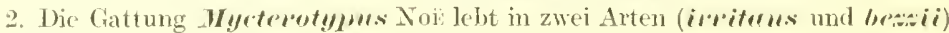
in Italien.

3. Das Cemus Tresestes Townsenu besitzt nur 13 Fühler- und 3 Palpenglieder. Nur cine Art ist aus Sïdamerika mot auf den Antillen bckannt geworden.

4. Im Gegensatz zu der vorigen iibertrifft die Gattung Orewetu Poex die gewöhnliche Gliederzahl der Fühler mo 'Taster um je eines, so daB sie deren 15, bzw. 5 besitzt und zwar in beiden Gesehlechtern. Die beiden bekannten Arten furers und hustilissimu gehören, wie ihre Namen sehon vermuten lassen, zn den lästigsten Blutsaugem auf Kuba mnd an der Nordostküste Südamerikas. Sie liönnen den Aufenthalt am Meeresstrande zeitweilig unmöglich machen.

5. An der Mündung des Amazonas, namentlich in Pará wird als ungebetener

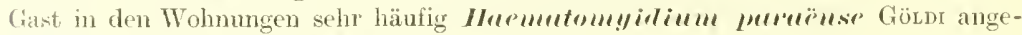
troffen. Die Stiche des Mïckehens sind schmerzhaft und gewöhnlieh von Entzïurlung in der Ungebung gefolgt.

(i. In B sellst die Polargebiete noch, von , Gnitzen" bewohnt werden, beweist

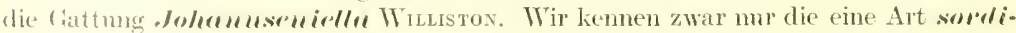
/r/ll. diese aher kommt in so ungeheurer Individuenzahl an der Westküste Grönlands vor und ist so zudringlich, daf sie in den Sommermonaten zu einer wahren Landplitges werten kann.

\section{Literatur.}

1912 forman, I. (1. Yote ons a parasitic fly which infests malaria carrving anopheles in Lower Burma. Paludisun, Nir.

1912 Jutz, A. Beiträge zur Kemutuis der butsaugenden Ceratopogoninen Brasiliens. Mem. do Instit. Oswaldo Cruz. Toms. IY. Fasc. I. IRo de Janeiru-Manguinhos.

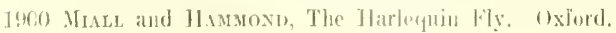


1911 Romerts, R.S., Sambon's new thery nf pellagra and its apjuliealion to eonditions in lieorgia. Journ, of the americ med, assose p. 17t:?.

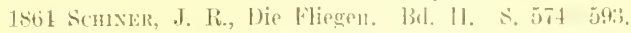

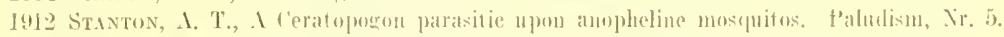

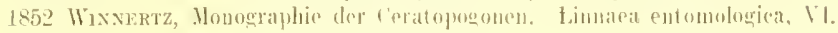

\section{Die Kriebelmücken (Simuliidae) (Simd-flies).}

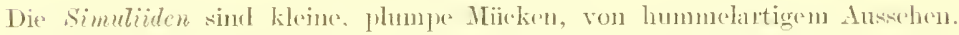
Sie fallen durelı ibren gedrmgenen Körperbau, ihre verhältnismäBig groben mud breiten Flügel, den mäehtigen, stark gewöbten Thorax mel cinen fast nie vermißten Sammetglanz sofort auf. Die Weibchen sind lästige und höehst zudringliche Blutsanger, welehe mit Vorliebe das Gesicht (namentlich die Angen) anfliegen und verschevcht sofort in frechster Weise ihre Angriffe wiederholen; sie kömen im frühjahr und Sommer dureh ibre [therfäle den Besuch gewisser Orte, wie Flußufer, fenchter Wiesen usw. rollkommen nmmöglich machen. So ist die berïchtigtste Angehr̈rige der Familie, die Kolumbaczseher Mïcke, in den ungarischen Ebenen der Schrecken ron Mensehen und Tieren. Jie Kriebelmüeken stechen, wie die Ginitzen, nur an Tage.

Die Farbe der seltener angetrotfenen Männchen ist neist ein Sammetsehwarz, die der Weibehen ein dunkles Grau: helle Flecken und Streifen an den Seiten des Thorax und an den Beinen (hänfig in Pingform) werden bei vielen Arten angetroffen.

Der rerhältuismäBig klcine $K \circ p$ f crscheint in der Richtung der Körperlängsachse zusammengedrïckt und wird, an den unteren Partien der Vorderfläclue des Thorax angeheftet, vom Rïckenschilele kapuzenartig ïberragt.

Die großen, nierenförmigen, im Leben meist sehwarzrot gefärbten \& ugen stoßen bei den Männchen anf der Stim zusammen. Ozellen fehlen. Die Fïhler sind 11 gliederig und verhältnismäßig kurz. Die cinzehnen Glieder, breiter als lang, verschmälem sich endwärts stetig. Die tgliederigen 'Taster sind geißelfömig, das letzte Glied so lang, als die drei vorhergehenden zusammengenommen. Der kuze, krältige Püissel zeigt bei dem weiblichen 'liere sämtliche Mundwerkzenge wohlentwiekelt.

Dex Thorax ist den anfallend groben Flügehn entsprechend mächtig entwickelt, der kuppelfömigg gewölbte Rücken lälst die Mücke, nanentlich bei Seitenansicht, buckelig erscheinen (Figg. 140, 141). Die mittelgroBen beine sind, hauptsäehlich in den Sehenkehn, kräftig gebaut, die Sehienen und Metatarsen zusammengedrüekt und in männlichen Geschlechte breiter, als hei den Weibehen. Ein Klauen- und P'ulvillenpar ist stets vorhanden.

Der klowe Hinterleibsetzt sich ans s segmenten zusammen und ist wesentlich schmaler als der Brustkorb.

Die enkephaten Larven (Fig. 142) werden nur in fliebendem, oft sogar nocls in stark

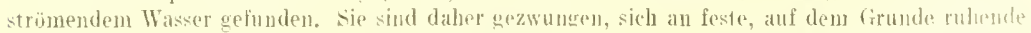
liegenstände oder an Wasserpilanz"n anzuklammern, und haben infolgedessen am hrirperende eine Haftscheibe entwickelt. Die zwäl hörperringe sind ron zylindrisher Gestalt. die treif prsten

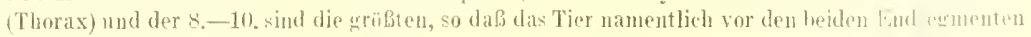
stark verbreitert erseheint (Fig 1+2). 
Der liople zeigt jederseits einen doppelten lugenfleck, die Füller sind dün und geibelförmig. Inurch zwei faicherformige strudelapparate führt die Larve ilıre Nahrung den wohlentwickeften Hundwerkzengen entyegen.

Auf der Bancliliche des ersten Thoraxringes befindet sich ein hakentrauender Fubstummel. Die Simulialarven sind Hautatmer.

Die kurze, gedrungene Pupje (Fig. 14i3) liegt in einem dütenförmigen Kokon, weleher von der Larve gesponnen und gewöhnlich an Wasserpllanzen (honuneulus fluitens z. B.) derartig angeheftet wird, dafs seine lreitere offmung stromabwärts gekehrt erscheint. In dieser schitzenden Hülle

lïg. 140.

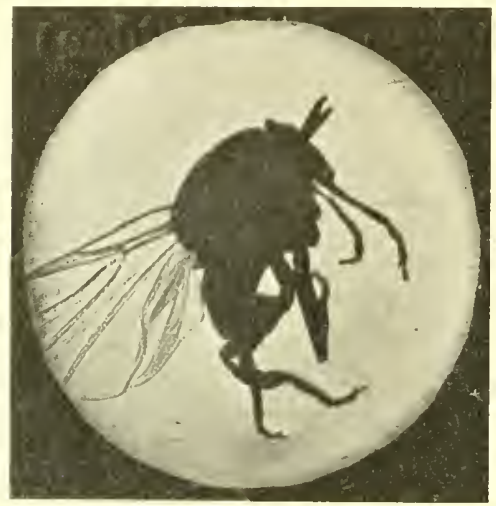

Simuliu reptans LINAÉ. ${ }^{15} / 1$. (Original.)
Fig. 141 .

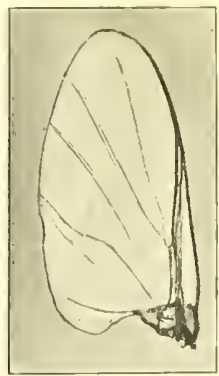

Simulia reptans Lixxé. Flügel. $15 / 1$. (Original.)

rulıt mit kopfwärtsschanenden Häkchenreihen, die an der Bauch- und Rïckenfläche der Hinterleibssegmente entspringen, verankert die Puppe. Thre geweihfömigen Kiemenfäden ragen aus dem Vorderende der hokondiite hervor und werden rom strömenden Wasser umspüt und hin und her gesehamkelt. Das Schlüpton erfolgt in ähnlicher Weise, wie bei den Stechmüelien (l)ehnung der Puppenhiille durch ausgeschiedene Luft). Wa es unter Wasser erfolgt, vollzieht sich der Vorgang in auberordentlich kurzer Zeit, die lefreite llücke steigt rasch zur Wasserfläche leervor und fliegt sojout als. Die lestgehakte P'uppenhülle blejht in Jer Düte zurück.

Die bei uns häufigste Art

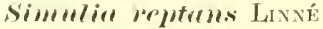

ist cin ausgesprochener Kosmopolit und mag deshall, hier als 'Typus der Familie beschricben werlen.

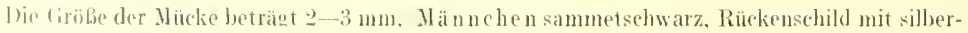
wribem Raude, der an den schultern am hreitesten ist: Pleuren und Sejenfledke and dem 2., 7. und 8 . Hinterleilstinge etrenfalls sillserweibs schimmernd ${ }^{1}$ ). Lntergesicht schmutzigweib. Fühler, "T'aster und Boine dunkelbraun. die Schienen, namentlich in der proximalen Hällte, heller.

the Weibelen sind nicht so kontratteich gefärbt, als dje Vännchen. Inf schwarzgrauem Ciruncle spürlich, gedbwejls belatart, zeigen sie ähnlich gelagerte grauweibe Flecke auf den Thorax und Abdomern. Schwinger nnd fir̈geladeru gellyjich. Beine wesentlich heller, als die der Hänndhen.

Die Kolumbaezscher Mücke jst nur eine Lokalrasse unserer reptans.

$\left.{ }^{2}\right)$ Bei hestimmter Haltung der Würcke treten diese Zeichnungen einerseits stärker hervor mad kömen anderersejts bej veranderter Haltung interbrochen erscheinen. 
In Südasien wird die simmlid imdir, häufig angetroften, in Afrika

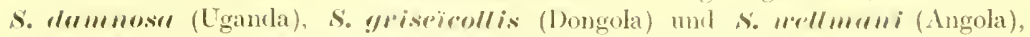
in den lereinigten Staaten s. mereiliomalis. Die grölste Artenzall ist son Siidamerika (Brasilien) bekamt geworken.

Fig. 142.

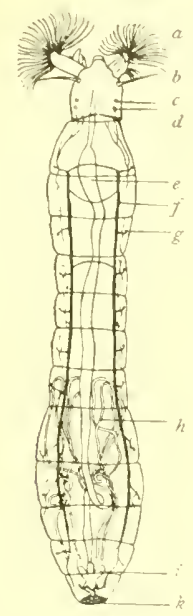

Fir. 113

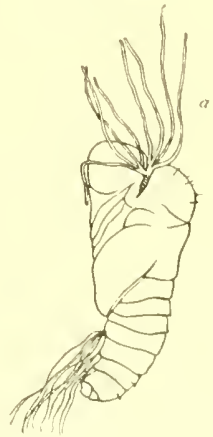

Simulin repture Laxwe. Puppe. (Narh Meinert.)

Erklärung der Figur 142.

Simuliue repturs Lixné. Larre. (Nach Mernert.) a strudelipparat, b Fühler, r. d dugenflecke, e litteldarm, / längstracheenstamm, g Stimmenanlage, h. Vasa malpighia, $i$ Reetum, $k$ Jaftseheibe.

Alle Simuliden zeigen ausnahmslos ihren typischen Habitus und ihre höehst charakteristischen Lebensgewohnheiten, so dal3 eine Verwechslung mit Angehörigen anderer Familien ausgeselılossen erscheint.

Nenerdings erklärt S. mвox nach eingehenden Untersuchungen die l'ellagra fïr aine Intektionskankheit und glaubt in ler Kriebelmäcke die Überträgerin derselben gefunden zu haben.

\section{Literatur.}

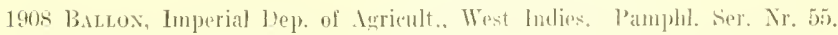

1908 ('hrtsty, Sleeping sickness Repert, Ruyal soriety, Mr. 3, London.

1905 Dammax und Oppermoxs, Simulia ormata als Vermittler der Wild- med Rindersenelo. Deutsehe Tieriirztl. Worhensehr. Mr. $4 t$.

1913 Jexings and Kixti, The Etiology of Tellegra. Journ. of Amerie. Hed. Assoc. 25. Jan. (Ref. Jourm, of trop. I] ed. 191:;, St, i2).

1909 Leos, Simulium columbaczense. ('entralbl. I. l'akt. Bu. 51. S. 6is?.

1910 Letz, A., Zweiter Beitrag zur Konntuis der hrasilianisehen Simulinmarten. (Mlit + Taf.)

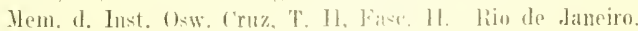

1913 Niles, fi, M., T'ellegra, An ameriean ['roblem. Ref. in Jumru. of trop. med. liyg. S. Bo.

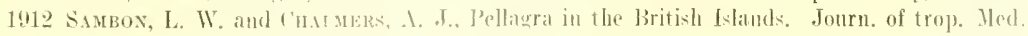
and $1 \mathrm{Jg}$. p. 344 .

Ats Kinder stark strömendrr lilisse und Gebirgsbäche sehließen wir die

den Simulinden direkt an. 
Die Blepharoceridae sind im Gegensatz zu der voraufgehenden Familie außerrontlich langbeinige Gieschöpfe, die sich durch ihr eigenartiges Flïgel-

F.ig. 144.

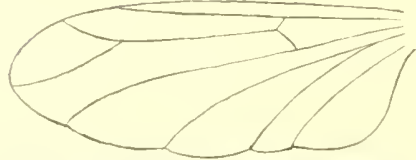

lilïgel son Cumuira torrentium F. IÜLLER. (Nach F. MüLler.) geäder (Fig. 144) und ihre sehr oft dureh einen Quersteg (Fig. 85) getremten Komplexaugen anszcichnen. Ozellen sind vorhanden.

Während wir nur eine Art, Blepharocera fasciata WESTW., besitzen, werden in den 'Tropen in newn Gattungen zahlreiche blutsaugende Arten angetroffen. Berürhtigt ist namentlich die brasilianische Curupira torrentium F. Mültis (Fig. 144).

\section{Tabanidae (Bremsen).}

Da Glossinen in Asien fehlen und anch sonstige Stcehfliegen hier kaum in Frage knmmen, ist die Utbertragung der Surra dureh Bremsen hente wohl als erwiesen anzusehen.

Ton afrikanischen Bremsen werden Haematopota imbrium Wied. (Kapland), Tubanus infestans Mace., Tabanus albifacies Löw (Nordafrika, hauptsächlich Unterägypten) und Tabanus sulanicus C.ralbou angeschuldigt, Trypanosomen zu iibertragen. DaB der letztere dic der Surma verwandte Mborikranklieit vermittelt, wurde vor eingen Jahren in den Welleome tropical research Laboratories zu Khartum sicher festgestellt.

Im Vorratsmagen von Tabamus soeius, einer afrikanischen Bremse, wurde Herpetomonas in den verschiedensten Entwicklungsstadien melufach angetroffen. Ebenso fand Patrox ('The Lif Cycle of a Species of Crithidia Parasitie in the Intestinal 'Tracts of Tabrens hilarius and Tabanus spec. Areh. f. Protistenkunde 1909, S. 333 bis 362) in zwei inflisehen Bremsen einen Flagellaten, eine Crithidia. In allernenester Zeit (On Calabar swellings, Lancet, 4. Jan. 1913, p. 51) gelang es R. 'T. Leiper den Teweis zu crbringen, daß ein Chrysops spee. (wahrsehemlieh dimidiatus v. D. WULP, (ice ,Hangrove-fly") Filaria diurna überträgt, was sehon vor dahren auf Grund geographischer 'Tatsachen von Masson vermutet wurle.

Es ist deshalb sehr wahrseheinlich, daB anch noch andere Blutparasiten im Leibo der Bremsen sich entwiekeln and rermehren und gelegentlich auf ITarmb) iiter übertragen werlen.

1)ie Bremsen, französisch Taons, enghisch Breezes, Horseflies, italicnisch 'T'afani, sind über die ganze Erde verbreitete Steclefliegen, die im weiblichen Gesehlechte ausnahmslos und mit Vorliebe Blutnahrung zu sich nehmen. In zahlreichen (gegen 40) (Gattungen zählen die Tabaniden weit über 2000 bckannte Spezies, und ïbertreffen somit selbst die Stechmücken um ein mehrfaehes an Artenzahl.

\section{lligemeines.}

Als cine in sich al)geschlosiene, wohl eharakterisierte Gruppe gehören die Bremsen zal den brachykeren ${ }^{1}$ ) Gymnochrysaliden (Orthorhaphen).

1) Richtiger würde man sie mesokere (Dipten mesocera) nenen, weil ilıre Fülder in bezng imf Länge und Giliederzalla die Mlitte halten zwischen den Fühlern der ne mokeren und hraehykeren Zieillügler. 
Die 'T a baniden sinel groß3e, kräfig gebaute Fliegen ron so eigenartiger Ciestalt, dab sie mit den uns sonst zumedst interessierenden IInsziden und Pupiparen kaum verwechselt worken kïmnen.

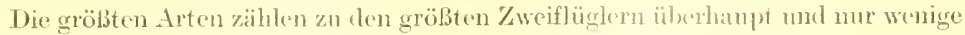
geben in ihren Kö̈permaben bis zu dem der Stubenfliege herunter.

Die elarakteristischsten Körperteile sind cher mächtige, seheihenförmige Köof mot die grobflächigen, vieladerigen, häufig auch schön grfleediten und gezeichneten Fliiged.

\section{Morpholugit.}

Der liäftige, gedrungene Körper oler Bremsen gelst ziemlich in die fireite, schlanke Formen werden seltener angetroffen.

ber kopf, groß und flach, bildet einen auf semer Hinterfläthe ausgehöls] ten Kugelabsehnitt (Meniskus); er ist meist etwas breiter (namentlich im weiblichen (reschlecht) als hoch und ïberragt die vortere Thoraxfläche allreitig. Die schr großen Angen nehmen etwa its der vorderen, konsexen Fläche des Kopfes ein. Sie sind meist sehr eng und gleichmäßig fazettiert, können aber ansnahmsweise, nament lieh im männlichen Geschlechte, an den unteren und hinteren Partien wesent lich größere Fazetten tragen ${ }^{1}$ ). Die Komplexaugen der Bremsen sind narkt oder mehr oder weniger dicht behaart nut leuchten häufig in prachtvollen, namentlich grünen, metalliseh glänzenclen Faxben . Sie werden auberdem gewöhnlich von roten und

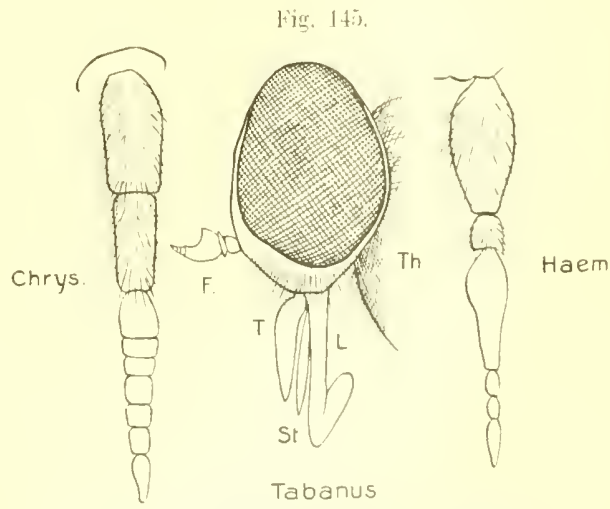

Kopl von Tubanus hovinus L. (Neitenfläche.)

Th. Thorax, L. Lalun, Nt. Stilettbindel, $T$. Taster, $F$. Fühler.

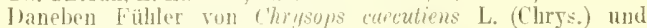
Itematopota plucintis L. (Haem). (Original, Camera hoida.) blanen Streifen und Binden

durchzogen und sind oftmals noch nit wirkungsvoll kontrastierenden bunten Flecken geschnückt. Zwischen den Angen befinctet sich im weiblichen Geschtechte stets eine mohr oder weniger breite, mit kahlen, glänzenden Feldern oder Schwielen bestandene Stimfläche, die bei den MLimmen fehlt, da bei ihnen dic Innenränder dex Augen hart aneinanderstoben. 1) zelle'n sind nur selten vorhanden und auch dann meist zurüekgebikdet.

Stirn und ['ntergesicht in (lex. Reged bestäubt und bartartig behatert.

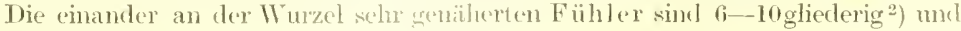

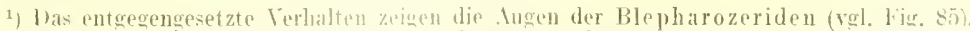

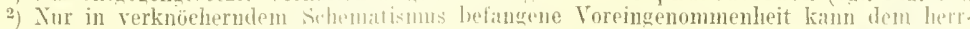

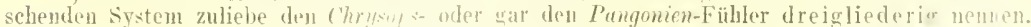

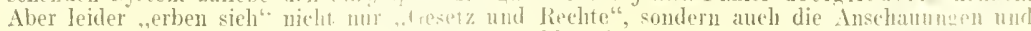

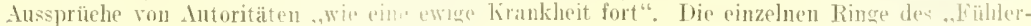
endgliedes" sind gegeneinander hewegbar: wie man hiernach noch von blober, Einsehnürungen" der Fühlersnitze - prectren kann, ist nir unerfindieh. 
In den einzelnen Gattungen verschieden gestaltet (Fig. 145). Sic werden reeht winkelig sur Kopffläehe getragen und schauen deshalb meist gerade nach vorwärts, während 'Taster mol Rüssed abwärts gerichtet sind ${ }^{1}$ ).

Der 'J'horax als Träger und Beweger der mächtigen Flïgel ist groß, breit und gewölht, er hat die Form eines Eies oder eines Wïrfels mit abgeruncteten Eeken. Der Rüekensehild (s. Taf. I, Fig. I) wird dureh eine in ihrer Mitte unterbrochene Quemaht in eine kleinere vordere und eine größere hintere Hälfte geteilt.

Das Schildehen (Seutellum) hat die Form eines Kreisabsehnittes. Alle Fläehen des brustliorbes erscheinen lostäubt und sind mehr oder woniger dieht behaart; die Rïickenfläche ist zudem noch häufig mit längsstrienen gesehmüiekt und an ihron Rändern abweichend gefärbt.

Die Flügel (Taf. $X$ und Figg. 146, 147) sind groß und breit, sie überragen das Leibesente oft ganz beträchtlich. In Ruhestellung werden sie stets halb offen getragen und liegen meist flachförmig dem Abdomen anf. Das Geäder zeigt bei allen Angehörigen der Familie die gleiche, höchst eigenartige Anordnung.

lie Vorderrandader (Vena costalis) ist bei den Tabaniden (ebenso wie bei den Stechmücken) zu einer vollständigen Randader geworden, sie umliuft den ganzen Flïgelsaum und hält so als Ralmen die Fligelscheibe ausgespannt. The Längsadern sind vielfach gegahelt und schlieben wollumgrenzte Flügelfelder ein (Basalzellen, 1)iskoìdalzelle und Randzellen). Zwej wohlentwickelte Läplehen (Mula und Sipuama alaris) und eine grobe Halterenschupe (Squama thoracalis) sind stets vorhanden (figg. 146,147). Die Flügel zeigen, anch wemn sie sonst nur sehwah tingiert erscheinen, hinter dem Ansatz der Hilfsader stets ein deutliches Vorderrandmal (Stigma). Sie sind häufig mit hinden- oder flcckenlörmigen dunklen Zeichnungen geschmückt (Chrysops, Hupmatopota z. B.).

Die Beine sind kräftig gebant, von mittlerer Länge und bei einigen Gattungen stark behaart und beborstet.

In ihren distalen Partien sind die größeren (ilieder meist dunkel gefärbt (Taf, X, Fig. 1). Jie Ilitteltibien tragen an ihrer distalen Innenecke stets einen looplolsporn, welcher bei einer Unterlanilie an derselben stelle der Hintersdienen ehenfalls vorhanden ist. Das Endglied des Fubes trägt ein Klauenpar und drei wollentwickelte llaftläplehen ${ }^{2}$ ).

Das Aldomen der Bremsen sitzt dem 'Thorax breit auf und wird ans 7 sichtlaren Ringen gebildet. Es ist von selur versehiedener Gestalt. Bei nüchtemen 'Tieren stets dorso-rentralwärts komprimiert, erseheint es in Seitenansicht abgeplattet, während die obere mol untere Fläehe einen spindelförmigen, ovalen (T'af. $\mathbf{X}$, Fig. 1) oder kreisrumden ('Taf. $X$, Fig. 3) Umriß zeigen kann. Im letzteren Falle hat der leib cine ansgesprochene Linsenform, während er sonst meist kegelförmig erseheint. Dis Leibesende pflegt je nach den Geschlechtem versehieden gestaltet zu sein: bei then +7 ist es mahr abgermolet, bei den ồ leicht zugespitzt. Die männlichen Begattungswerkzeuge liegen im Abromen verborgen. Dic einzelnen Segmente sind häufig nit Querbinden geschmüekt ('Taf. X, Fig. 3), zeigen andererseits aber auch verschieden geformte Flecken, die häufig auf die Nachbarringe ïbergreilen. Stets ist das Abdomen mehr oder weniger dieht behart.

\section{Inatomie und Plyysiologie.}

Das Muskelsystem der Tabaniden ist vorzüglich entwickelt, namentlich die mächtige Muskulatur des Brustkorlos, dem hervorragenden Flugremögen der bremsen entsprectiencl.

1) Xur die l'angoniinen machen lier eine Ansnahme, sie strecken den langen, nadelförmigen Riissel meist wagereeht nach vorn und hehen ilhe Taster stirker, als dies bei den anderen Gattungen der Fall ist.

2) Das zwischen den eigentlichen Halt]äppehen stchende Empodiun pflegt bei den Tabaniden zu einer dritten llattscheibe ungehildet zo werden. 


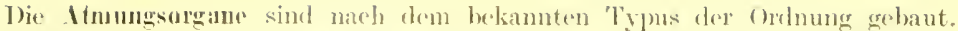

Traetus intestinalis. Die Mundwerkzenge bestehen aus denselben stüeken, welche den Rïssel der stechmücken zusammensetzen; auch don bremsen pllegen in mämnliehen Gesehlechte die Mantibehn zu fohlen. In seiner Form und länge weieht der Rïssel bei den ringehen Gattungen wesentlich ab. Kurz mod gedrungen

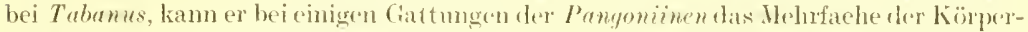
länge errejehen; zwisehen diexen beiden Extremen liegen alle denkbaren C†bergänge.

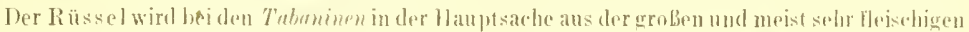
Unterlippe (Labium) mit ihren tewöhnlich gut entwickelten siaugkisscu (Fig. 145), den labellen, gebildet. Thm liegen bei den weiblichen Tieren die kegelförmigen Taster (Maxillarpalpene) anl', während sie bei den llännehen etwis weiter abstehen und kugehg gestaltet und stark boborstet zu sein pifegen. Die stilette sind kurze, sehr krältig gebaute und stark chitinisierte lanzettlormige Ciebilde. Ihin an der Basis verbreiterte oberlippe (Labrum) wird durch the entgegenkommonde Zunge (Ilypopharyna) zum saugrohr, dem dam die mit gesigten Rändern versebenem oherund L'nterkieler seitlich imbliegen.

Bei den langrïsseligen Pangoniznen erimern die Vundteile an den Fï̈sel gewister Hummelfliegen (Bumbylus) und schwärmer. Jit den letzteren haben sie sugar das gemein, dab sie dureh Aufrollen zuriuckgezogen werden können: es liegt in diesm falle aber die dann entstehende spirale

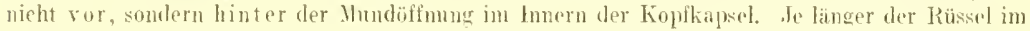
Verhältnis zur Körpergroße wird. um so mehr nimmt or Nadeflorm an, um so dünner und starrer wird die Unterlippe, um so kleiner die Labellen, die schlieblich mur als winziges hinöffehen am Rïsselende sichtbar werden. Seine stilette bekommen dam eine anflallende Alnulichkeit mit den homologen Stiieken des Stechmuelienrüstels.

Die als Saug-und Druekpum pe wirkende Vorrichtung des Schlundkoples ist der Pharyn pumpe der Stechmücken ähnlich gebant nnd gelagert.

Die Tabaniden besitzen emen verhältnismäßig kurzcn $N$ a hrungssehlauch, der sich aus clenselben Abschnitten zusammensetzt, welehe auch die Schlankmücken zeigen. Unter einem sehr crweiterungsfähigen Mitteldarm liegt der Vorratsmagen, mäehtige Speieheldrüsen münden durch den Hypopharynx nach anben. Der Enddarm, in welehen die Tasa malpighii ihre Exkrete einflieBen lasien, ist. kurz und mündet mit dem After am Ende des siebenten Siegmentes aus.

\section{Biologir.}

Die langspindelförmigen, dunkelbramen bis schwarzen Eier werden den von Bremsemmüttern in den Frühlingsmonaten in kegel-oder pilzförmigen ${ }^{1}$ ) Kilumpen an Pflanzenstengel oder an das felsige Ufer ron Flïsisen und Seen befestigt. Jedes Gelege bestcht ans mehreren humlert (30n_tho) Eiern, die schichtenweise (Figg. 91, 1:2) abgesetzt werden. Jeele folgende Schicht der mit ihrer Längsachse horizontal liegenulen Eichen berührt mit den Kopfenden die Schwanzspitzen der früh'r gelegten Ovula. Stets nur wenige Zentimeter über der Oberfläche angebracht werden sie ebensowohl über dem Wasser an Sehilfhalmen oder wenigstens in der Nähe des Wassers, als auch an selbst relativ trockenen Stellen (Heirle) in Walde, auf Wiesen usw. gefunden. Nach einigen (2-1) Woehen sehlüpfen die langgest reekten, walzenförmigen (Fig, 11, 11) Larven, welche je nach den verschiedenen Gattungen mul Arten ihre Entwieklung im Wasser, in feuehtem Boden, dem Mum kernfauler Bäume usw. durchlanten. Ihre Nahrung besteht in animalisehen Stoffen, vor allem werden im gleiehen hitien lebende Kerflarven erbentet und rerspeist.

Die elfringeligen akephalen La r ven (Fig. :1, 11) fer Bremsen sind von schmutrig meißer oder hellgrauer Farbe. Zwei kräftige, cinziehbare Freßspitzen (Mandibchn)

1) Sie erimern in Form nnd sitz ganz anlfallend an gewisse Polyporusarten, z. B. an den gemeinen Zundersehwamm. 
zaren aus dem Vorferende des Tieres hervor. Die mittleren und hinteren Leibesringe sind mit einziehbaren FuBstummeln besetzt, die Hakenkränze tragen und paarig nur auf der Tentralfläche vorhanden sein, aber auch in Mehrzahl auf allen Seiten der Segmente auftreten kömnen. Ein einfaeher Spalt oder ein kurzer am Hintercnde befindlicher Sipho setzt gelogentlich das Traeheensystem der meist hautatmendon Tabanidenlarven mit der AuBenluft in Terbiudung ${ }^{1}$ ).

Naeh mehrmaliger $H$ äutung verwandelt sieh die Larve in eine Mrumienpuppe, die den Puppen der Sehmetterlinge oder noch mehr denen der Tipuliden sehr ähnlich gestaltet ist (Fig. 91, 16). Prothorakalstigmen und sieben Paar Abdominalstigmen sind für den obsolet gewordenen metapneustischen Apparat anfgetreten. Die analen Ränder der Dorsalfächen säntlicher Bauchringe tragen Dornengïrtel. Auf dem Ǩopfende befinden sich Höcker und starke Borsten, während auf den Hinterende häufig kräftige, gruppenweis angeorhete Dorne ${ }^{2}$ ) stehen.

Obwohl auch noch in hohen Breiten 'Tabaniden in Unmassen auftreten können - so sollen die Romntierherden der Lappen schr unter den Überfällen von Hämatopotaschwämmen zu leiden haben - ist die Bremse doeh in erster Linie ein Kind wärmerer Länder: gegen den Gleicher nehmen die Tabaniden an Artenund Individuenzahl stetig zu. Hier finden wir die größten Formen und hier entfalten sie auch die höehste Farbenpracht und bunteste Körper- und Fliigelzeiehmung.

Die Bremsen sind sehr gewaulte und sehnelle Flieger. Nur ansnahmsweise gelingt es z. B. einmal durch einen gesehickten, von unten kommenden Netzschlag einen männliçen Tabanus zu erhaschen, trotzdem er seheinbar angewurzelt in Sommersonnenglaste über einem Waldwege rittelnd schwebt.

AussehlieBlich 'Tagtiere pflegen die Bremsen ihre Opfer mit Torliebe in den heißesten Stunden anfzusuehen. Nur die Weibehen sind äuBerst hartnäckige und aufdringhiche Bhutsauger; ähnlieh wie bei anderen Gymnochrysaliden hängt ihr Bhutdurst mit der Entwicklung der Gesehleehtsprodukte zusammen. Die männlichen Tiere dagegen könuen schon wegen ihres Oberkiefermangels die Hant von Warmblïtern gar nicht durchbohren.

Die Tabaniden entfernen sich trotz ihres herrorragenden Flugvernögens in der Regel nicht weit von ihren brutplätzen, die sieh deshalb meist in der Nähe ihrer Jagdgebiete befinden. Wir treffen die 'Tiere (ror allem die oof) anf somigen Viehweiden, am Waklessaume, in Schneisen, anf rerkehrreiehen LandstraBen und manche Ciattungen vor allem in der Nähe des Wassers, an Flüssen, Teiehen usw. an. Wenn auch meist das Wild md msere Haustiere unter Bremsenstichen zu leiden haben. so wird doeh aneh der. Menseh von den Angehörigen mancher Gattungen in anfdringlinhster Weise verfolgt und unbarmherzig gestoehen. Es sind dies vor allem die IIaemalopota-nul Chrysops-Arten, denen sieh in den Tropen auch noeh die Panyonizen wïrdig anschlie $B\left(n^{3}\right)$.

${ }^{1}$ Im September des Jalıres 1906 fand ich an Rande einer Waldwiese in dem zementierten Butken ciner Vichthäke, die von einer stark fliebenden Quelle gespeist wurde, zahlreiche $4 \mathrm{~cm}$ lange Tabanidcularven. Etra ein Dutzend derselben wurde in ein groberes Terraquarium eingesetzt. ] he Tiere waren trutz ihree (iröbe lejker nicht an Leben zu erhalten und zur Verpupunng zu bringen. Schon an lotgenden Norgen fand ich sie sämtlich eingegangen vor. Tahrungsmangel konnte in der kurzen Zeit den Toul nicht herbeigeliuhrt haben, er nubte also in dem wohl zu warmen (160 (), stehenden und destall, sautratolTarmen Wascer durch brstiekung erfolgt sein.

2) Solche Vorricdunten haben stets den $Z$ week, die P'uppe beim schliajpen in eine zweek-

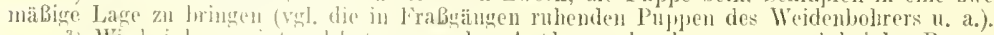

3) Wie boi den meisten butsanganden Arthropoden kann man auch bei den Bremsen die Brobachtung maclen, daf einzolne Tiere und Jenschen auffallend häufig von ibnen befallen werden - sie hahen, sülies Blut" sagl der Volksmund - während andere so gut wie gar nieht unter ihren Angrillen za leiden haben. Dab diese Anzelung oder Abstobung dureh bestimmte 


\section{Sytenatik.}

Die Einteilung der Tabaniden liegt noch setur im argen. so wird Chrysops hente meist zu

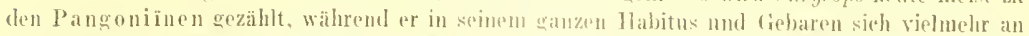
die (ianung Haematopota anschliebt. Ans Zwerkmbibigkeitsorïnten sind wir aber gezwnumen,

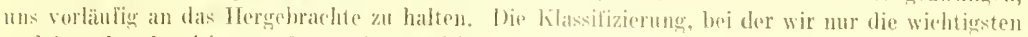
und hestcharakterisierten Genera herücksichtigen, würde dann etwa folgende sein:

\section{Tabanidae.}

Hintershienen mit zwei Endspornen . . . . . . . . . . . . Pengoniz̈nue Hinterschienen ohne Endspomen . . . . . . . . . . . . . Tabaninue

\section{Pangonïnae.}

a) Rïissel kurz.

I. Fühler länger als der Kopfchrchmesser. . . . . . . . C Chrysops

‥ Fühler kürzer als der Kopfolurehmesser . . . . . . . . . Silvius

b) Riissel lang.

1. Rüssel nur wenig länger als ter Kopf .......... Cadicera

2. Rüssel gewöhnlich viel länger, als der Kopf, häufig sogar viel länger als der ganze Köruer . . . . . . . . . . . Pungonia

\section{Tabaninae.}

A. Thorax und Abdomen pelzig behaart unl irisiesend. . . . . . . Lepidoselaga B. Thorax und Abdomen ohme irisierenden Pelz.

a) Augen naekt.

1. Drittes Fühlerglied ohne Zahn ............ Haematopota

2. Drittes Fühlerghied einen wohlentwickelten Zahn tragend. . Tabanus

b) Angen behaart.

1. Mit ozellentragendem Höcker . . . . . . . . . . Therioplectes

2. Ohne einen solchen .. . . . . . . . . . . . Atylotus

Die Tabaninengattung Hexatoma llentiex ist wegen ihrer deutlich 7 gliederigen Fühler, die zugleich die relativ längsten Tabanidenfiuhler itherhaupt sind, besonders interessant, aber hier nicht weiter berüeksichtigt, weil sie in den Tropen nicht vorkommt und nur eine Art zählt: die emropäische Hexaloma petheens Fabricits.

Ei genger ï e he des Wirtes bedingt wird, jst mir sehr wahrecheinlich. Weleh michtige Rolle bestimmte Rieehstofle im Einzelfalle spielen. geht aus den mitgeteilten Beobachtungen bei Flöhen (s. Seite s6) und ste e hm ü :ken (s. Seite 1:38) and das Bestimmteste hervor. Verf. hat ron jeher den zweifelhaften Vorzug gehabt, zn der arstgenamuten Kateworie zu gehören, und ist dieser I'mstand einer der Gründe gewesen, die jhn veranlaßt haben, sich dem stuctinm der himatophagen Irthropoden spezieller zu widmen. 1]* er am Ende der achtziger Jahre des vorigen Jahrhnnderts mit mehreren Kollegen cine Wikgnfahrt am Nordufer des Giardases machte, rief der verstorbene Reiehstagsabgeordnete und Vorsitzende der Hessen-Sassanisiblen Arztekanmer ExDEMaxi den Mitfaluenden, die dureh die Wolken ron steehfliegen unrulige und ängstlich wurden, zil: ,.Regt ench nicht auf, Eysect beansprueht sie sellbstverstandlich alle für sich und hält sie uns so vom Leibe." l)en Vorteil vor anderen haben solche Uenschen aber is de'r Tat, daß sie mit der Zeit eine gewise hmmunitat gegen die beim Stechen eingefulhten physiglogischen cifte, die Eigengiltstoffe der Blutsagger, erwerben: juekende Quadueln brobahtet Verf. schon seit vielen Jahren nicht mehr an seinem kürper. Jias bekannteste Bejspiel dieser

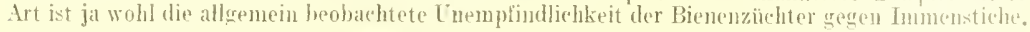




\section{Pangoniïnae.}

\section{Cenus C'hrysops Melgen.}

Die Gattung ist ïber die ganze Erle verbreitet. Wir kemnen heute etwa 170 Arten (MEItiex führt in reinen ,Europäischen zweifliigeligen Insekten" [1sis] deren sehon 11 auf).

Die häufigsten mitteleuropäischen Arten sind Ch. molirtıs HzFari. und (\%. "orentiens L. Letztere, die prächtige, goldäugige ,Blindbremse", so genannt,

Fivis. 146 .

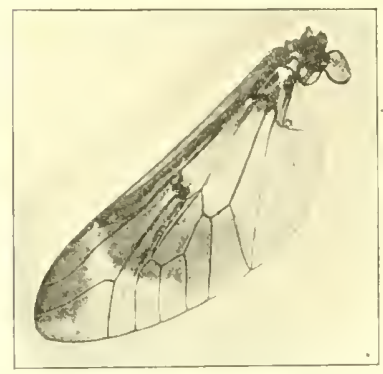

Flïgel von (hrysops checutions $\mathrm{L}$. 6/1. (iriginal.) weil sie während des Sangens gegen jede Gefahr blind ist und in ihrer Gier sich ohne Fluchtversuch ruhig ergreilen läßt, wird bei fenchtwarmem Wetter in lichten Wäjdern besonders zuctringhich und lästig. Ton tropisehen Arten deren Wiedemans 1828 sehon 27 kannte) sind besonders wichtig die Afrikaner Ch, dimillowtıs v. D. WuLP, die Mangrovefliege Kamerums, in deren Speicheldriisen Leiper die Larven von Filaria diuma (lancet 4. I. 1913) fand, C\%. distimetipenllis Alstex, Uganda, C\%. Imwiger Löw, Kapland and Ch. stigmmatiralis Löw, Delagoabai. In Indien, besonders auf Ceylon, kommt $\mathbf{C} \boldsymbol{H}$. lispro. Fibracles als häufigste Art überall in massenhafter Verbreitung vor. Die brasilianischen Vertreter der Gattung $\mathrm{CH}$. mmissus.

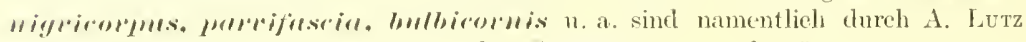
bekannt geworden. Fie Körperlänge der Gattungsgenossen beträgt 7-11 mm.

\section{Genus Silvins Merriex.}

Zwar ebenfalls Kosmopolit, wird sil.rils doeh nirgends häufig gefunden unt überall als relativ gutartig angesprochen. Die bekanntesten europäisehen Arten simel s. rituli Fabr., s. hirtws Lw. und s. algivms Mg. (Südeuropa und Nordafrika). Im Kaplande wird S. dentirernis W1ED, häufiger angetroffen. Silvius ist wesentlich grölier als Chrysops, clie sehönen Fliegen haben eine Länge von $12-14 \mathrm{~mm}$.

\section{Gemus Cadicera Marquart.}

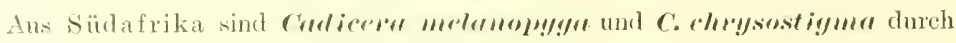
WiEnEMINx besehrieben worden. Länge $1 \mathrm{~S}-21 \mathrm{~mm}$.

\section{Cienus Pangonir Latralle.}

Jic (iattung, über die ganze brte verbreitet, ist die Bremse der warmen Länder. Sie kommt sehon in Südeuropa, vor allem aber im tropisehen Afrika, Asicn mul Inerika vor. Han kemt hente ïber 260 Arten dieser meist großen (einkchl, des Rïsscls messen versehiedene Pingonien $50 \mathrm{~mm}$ und mehr) und sehr robust gebamten Sterhfliege.

Von enropäischen Arten sind die gewöhnlichsten Immgomia murulutu

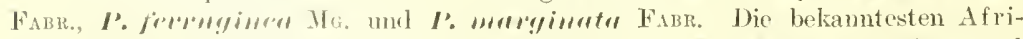

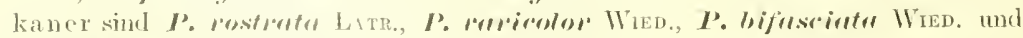
P. "roiromis Wikn. Von hrasilinisehen Pangoniönen fübrt A. Lutz neben

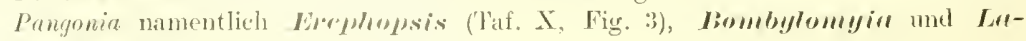

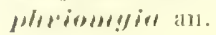




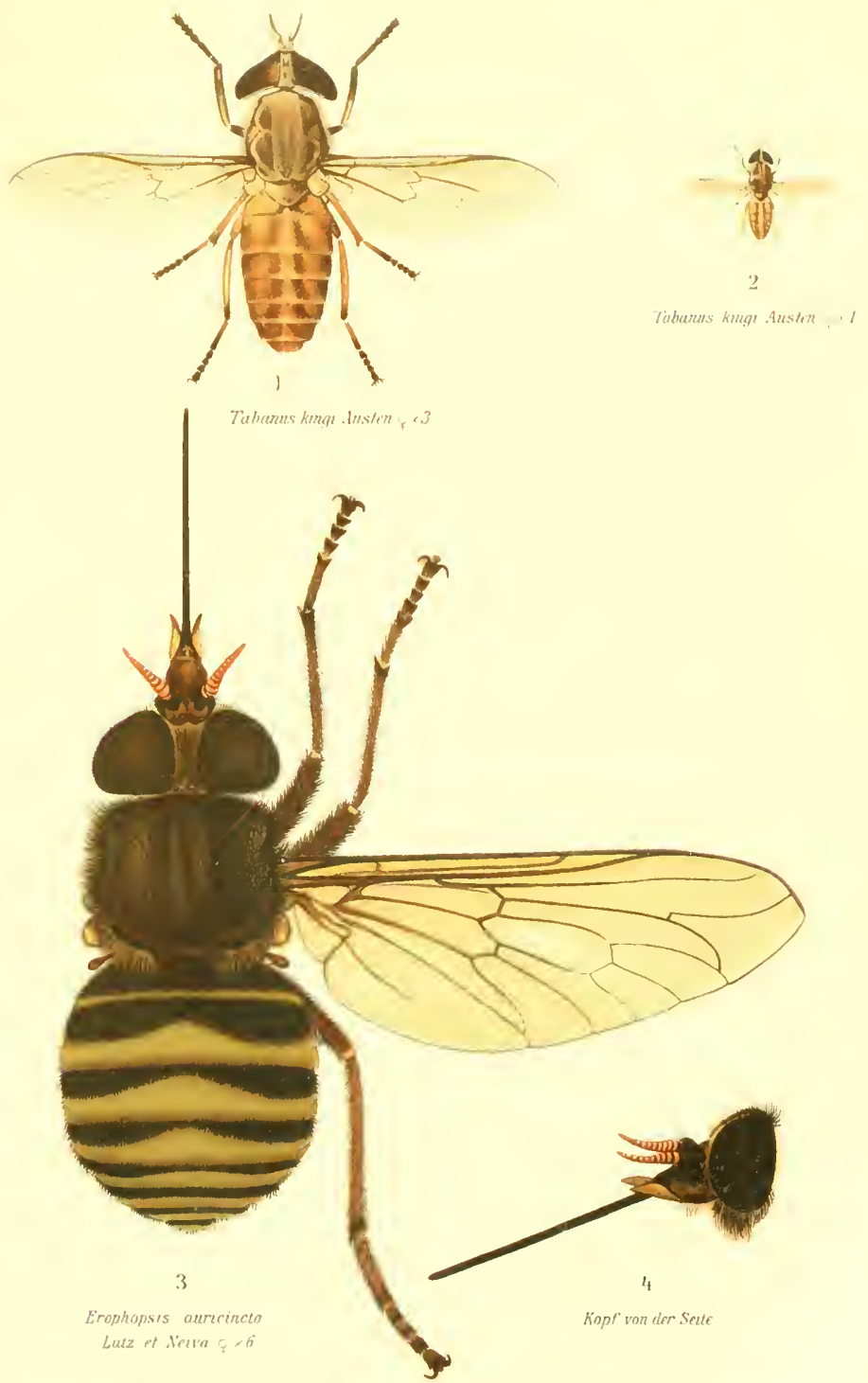





\section{Tabaninae.}

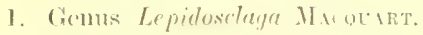

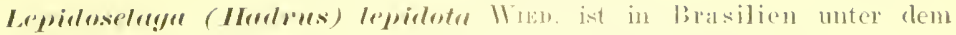
Namen Votúafliege bekant mol wegen ihrer blutgier gefiirelatet.

\section{Genus IItemutopote MLEritix}

Die Gattung zählt etwa 70 Artens. Thre schlanken liörper sincl fast durchgängis

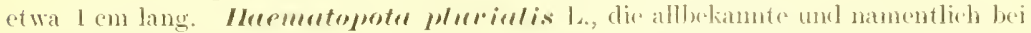
Gewitterseluwiile kaum abzuwehrende, Regenbremse" ist die gemeinste curopäisehe

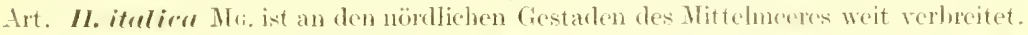

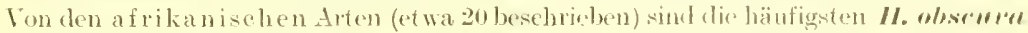

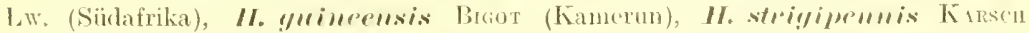

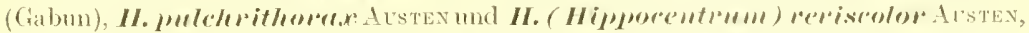
die beirlen letzten Arten verbreitet in Britisdi-Zentralafrika, Tganda und dem Sulan.

\section{Genus Tabanus Lixxé.}

Die Gattung Tabanus ist die artenreichste (gegen lout) der Bremsenfamilie. Die meist selur groljen und kräftigen Fliegen können bis zı 30 mm länge erreichen.

Tabmums beroimes L., der bekamuteste lertreter der Gattung, wird in der ganzen a iten Wrelt angetroften. Häufigere Afrikaner sind $T$. alitueniotus M.res, $T$. edretes Lw., T. sordus Walker.

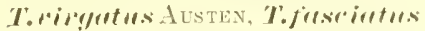
Fabr. und T. liturins. Tnsere Tafel X zeigt eine schöne und in ihrem ganzen Entwicklungszyklus ineobachtete Bremse des Suclans: Tuburus lim!i Aistex (Fig. 91).

Die Genera Therioplertes Fig. 147.

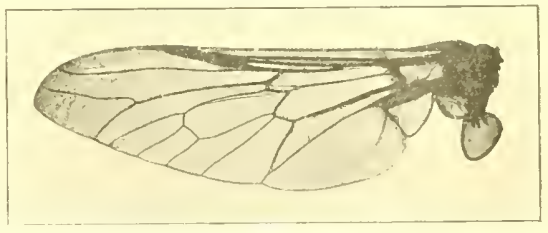

Flïgel von Tubums bocinus L. 3/x. Inf die Thorakalselumpe (am writesten rechts) folgt die sifuana alaris, daun die . Mula mol schlicblich die Flïgelläehe. (triginal.)

\section{\%eller und dyjotuls Ostex-}

Sickex sind bis jetzt nur in Europa gefunden worden , Th. mirems Mi., Th.

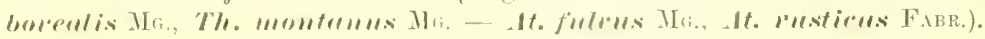

Fang, Infhewahrumg mud ditersuchmm.

Alle Bremsen sind Tagtiore, die in der heibesten Jahres- und 'Tageszeit am sichersten angetroffen werden. Heist suchen sie auch die hellsten stellen des (ielïmles auf; so trifft man dir mämlichen Viehbremsen (Tabumes) fast nur im grellen somenseheine an. Die 'Tabaniden sind mit den Notze schwer zu erbenten, an sichersten fängt man die Weibehen mit dem Netze oder dureh Überdecken dann, wenn sie sich zum Bhtwaugen auf ihren (Ipfern nieclergelassen haben.

Fon der Inflewahrong und dem Versande gilt im allgemeinen für die Tabar niden das bei den Stechmürlien (S. 1:31 1:3:3) Gevagte. Das viel kräftigere Fikto. skelett der Bremsen macht eine gute 'Trockonkonservierung viel leieliter, itls eine solehe bei den Schlankmüeken mögliell ist; sie bewahen ihre Formen in fur inus

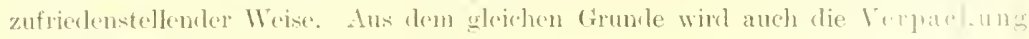
zwecks Versindes eine viel einfachere. 
Zn anatomischen Intersuchungen rerwende man, wenn irgend möglich, eben getötete 'T'iere.

Für dic Anfertigung von mikroskopischen Präparaten, Schnittserien usw. gelten auch für dic 'Tabaniden die bei den Stechmüicken und den früher beschriebenen Ordnungen angegebenen Torschriften.

\section{Prophylaxe. Feinde.}

Unter den Stichen der Tabaniden hat für gewöhnlich der Menselı weit weniger zu leiden, als seine Haustiere und das Wild.

Da die Bremsen niemals in die Wolmungen und Ställe eindringen, lïnnen wir uns gegen sie viel leichter schützen, als gegen die Stechmücken. Durch Vurmeidung ihrer Licblingsaufenthalte, namentlich in der heißesten Zeit des 'Tages, durch Schleier und Einreibung stark riechender Flüssigkeiten oder noch besser solcher Terbindungen, die langsam Riechst offe abspalten: unserer modernen Schwefelpräparate z. B. (Sulfur colloïlale usw.). ${ }^{\mathbf{1}}$ ) in die unbedeckten Stellen der Körperoberfläche werden wir vor ihren t’berfällen bewahrt. Inselstizide (Chrysanthemumextrakt z. B.). die vielfach empfohlen und gerühmt worden sind, nützen in die Haut eingerieben gar nichts: die nicht mit Geschmacksnerven versehenen (das die Geschmackseindrücke vermittelnde Organ der Fliegen, mindestens das der Gymnochrysaliden, liegt in den hinteren Teilen des Pharynx) Stilette gleiten unbehelligt an den imprägnierten Epidermisschichten vorbei, ohne daß die Stechfliege (oder Steehmiucke!) das geringste Unbehagen rerspürt.

Ton den Feinden der 'Tabaniden aus dem 'Tierreiche sind nur Hymenopteren (Grabwespen, Ichneumoniden usw.) und Raubfliegen (Asiliden) bekannt geworden. Daß die Bremsen unter bakteriellen und Protozoeninfektionen zu leiden haben, setze ich als bekannt voraus.

\section{Literatur.}

1916 . Mstex, E. E., Ihnstrations of British blood-sucking flies with notes. London, British Mluseum, it $\therefore$. 1!. 34 Taf. 8 ?

1913 Bequart, J., Tabanides recheillis au congo Belge par la mission ponr l'Étude de la Maladie du Sommeil. I. Pangoniinae. Rev. Zool. africaine. Bel. 2, fase. 2.

1903) Bezzı, MI., Katalog der Padäarktischen Dipteren. Bd. II, s. 45-74. Budapest.

1,TO Bracer, F., Wie Tabamusarten der euroj), mediterr. und sibirisehen Subregionen. Denkschr. d. mat],-11atum. Kl. d. Kais, Mkad. d. Wissenseh, Bd. XIII. Wien.

1912 ('ARTER, H. F., Descriptions of three new Afrean species of the Genus Tabanus. Ann. of Trop. Med. and Par., Series T. N. Bd. 6. H. 4. p. $435 \mathrm{ff}$.

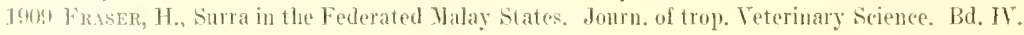
1). 345 .

18.95 7l.1RT, Bull. Tllinois state Lahoratory of Tatural History. Fol. IY.

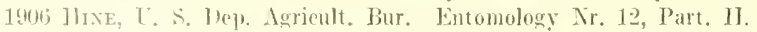

1940) Kertés, 1'.. ('atalogus Tabanidarum orbis terramm universi. Budapest.

1907 L'T2, A. Bemerkıngen ïber die Nomenklatur und Bestimmung der brasilianischen Tabaniden. Centrall,t. 1. Bakt. Lbt. I. Bd. 4t. S. 137-14t.

1911 Wersedbe, Neue Boitriage zur Kemutnis der Pangoninen und ('hrysopinen Brasiliens (Mit 1 Taf.) Ilem. do Instit. ()sw. ('ruz. T. 117. Fase. I. Rio de Janeiro.

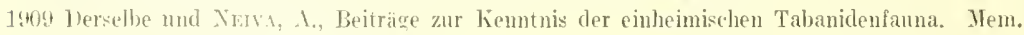
do Inst. (Isw. Iruz. T. I. Fase. I.

1) Sulfur. collöd, 10,0 sipon. virit. 20,0 Ay. destil]. $\quad 70,0$ I]. D. S. rinzmpinseln
Sulfus: collö̈. 10,0

oder Viselin. 90,0

1L. I. nngt.

1). s. einzureilien 


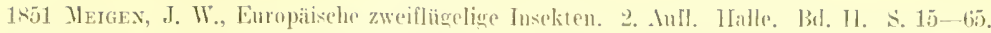

1909 OLd, J. E. S., Contribution to the sudy of 'Tryjanosomiasis and to the geographieal distribution of some blood-suckine insedts. Joum. of troje. Veter. Se. Bd. IV. P. 395.

1909 Pıтtox, Ireh. für Protistenkunle. s. 393.

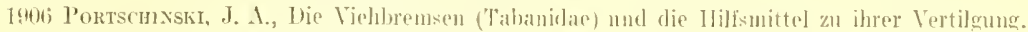
3. Auil. 49 S. 19 Figg. St. Petershure.

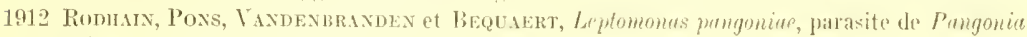
infuscu. Bull. soe. patlı, exot, T. V. p. bot.

1862 Scmuer, J. R., Dip Fliegen. BJ. I. S. $28-44$. Wien.

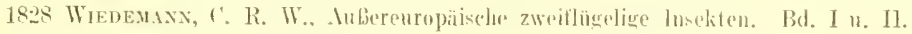

1912 Ziensx, H., Zur Verbreitung der lolutsagenden Tiere in Kamerun. Ird. f. Sehill's- u. Tropenhyge. Bd. 16. S. 53.

Da man sic sehr häufig auf Vichtriften findet, hat man angenommen und belauptet, daß aueh unter den Raubliegen, den

\section{Asiliden}

gewisse Irten gelegentlich bei Gleichwarmen sehmarotzten. Ibiese Behauptung aber laiat einer ernsteren lítik nieht stand. Es soll nicht gelengnet werden, dab man Süugerhlut im Iagen der großen Formen dieser Fanilien gefunden hat; das kann aber dann selır wohl auf dem Lmwege des Bremsenmagens in den Mitteklarm der Raulfliege gelangt sein (vgl. FuBnote 1 anI S. 141).

\section{Die Fliegen (Muscidae).}

Die Musziden gehören der großen Zweiflïglergrnppe der Eumyidae (Huscuriue) an. Die Muskarien, oder Fliegen im engeren sime simb in unzähligen Arten über die ganze Erde verbreitet. Allen gemeinsam ist lie gleiehe Grundform im Bau der Mundwerkzenge und in der Anordnung des Flügelgeäders, alle verlassen sie auch das mittels der stimblase gesprengte Tönnchen dureh eine kreisförmige iffinmg an seinem Vorderende.

Die Musziden sind sehizometope (kalyptere) Eum yiden, deren Wangen scharf ron der vertieften Stim abgesetzt erseheinen und deren Schwinger von emem deutlichen Sehüppehen bedeckt werden.

Neben der Stubenfliege, die als Zwisehenträgerin von Krankheitskeimen fiir uns von so hoher Bedeutung ist, dab L. O. How.ARD vor einigen Jahren den Vorschlag maehte, sie künftighin nur noeh 'Typhusfliege zu nemmen, interessieren uns hier ausschließlieh die hämatophagen Musziden, welehe in allen bekannten (6) Gattungen eine so große Ahnlichkeit mit unserem gemeinen Wadenstecher zeigen, daß man sie in der Familie der Stomoxyidae zusammengefaßt hat.

Als bekannteste und typischste Erseheinung unter allen Iusziden verdient lirer zumäehst die Stubenfliege (Wusca domestica Lixvé) einer kmzen Betrachtung unterzogen zu werlen.

Etwa einen Zentimeter lang ist die

\section{geneme stubenfliege}

in beiden Gesehlechtem änBerlich fast gleich gebildet und gefärbt. Die brim j etwas sehmalere Stirn wird beim z ron einer dreieckigen (Basis analwärts liegend) 
Shwicle eingenommen. Grundfarbe asehgran, Untergesieht gelb, Rückenschild mit vicr shwarzen Striemen, Dolsalfläche des Hinterleibes sehwarz gewürfelt, Banehfläche blaßgelb. Fligel leicht graubraun mit gelblicher Wurzel. ohne Randdom.

Die Stubenfliege ist eme obligate Begleiterin des Menschen. Dic Larven (Maden) entwickch sich im 1) ïnger und in faulenden vegetabilischen und animalischen Stoffen ${ }^{1}$ ).

Der für uns wichtigste Teil des ganzen Flicgenkörpers, der lï̈issel, ist zugleich das Prototyp der Muntwerlizenge aller Eumyiden und soll deshalb hier etwas eingehender behandelt werden.

Aus der .. Unulöffnung" der Fliege ragt eine einziehbare, weichläutige, lingellärmige Verlängrung des kopfes, der soganannte liopfkegel hervor. (lig. 86 links). In seinem Innem bufindet sich die l'harynxpumpe (das sog. Fulerim), ats weleher der Oesophagus (Fig. 86 oc)

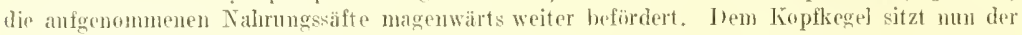
ejgentliche Rässel der Fliege auf. welcher in der Hauptsache aus der dicken, fleiseligen Interbippe mit ihren zu groben Sangkissen umgestalteten Labellen gelibdet wird. Sie triagt eine in das lorsum tief eingeschnittene Rinne, welehe zur Anfnalume der Oberlipje (Labrum) nud des von Speichelgange durehbohrten Hypopharyn (,Zunge") dient. Die Jandibejn sind vollständio verboren gegangen, die Maxillen zu last unkenntlichen Resten

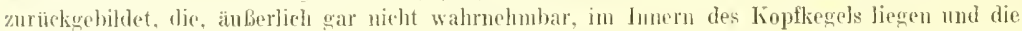
. Tulwahe haben, die Labrumbasis zu stiitzen (Fig. 86 , (Chst). Thre stets eingliederigen Taster (Baxillarpalpen) sind proximalwärts weit alogeriickt und sitzen der Rüekenfläche der Koptlegelspitze aluf.

Alle Teile des Muskariissels fincten wir nun auch in dem Rïssel der Stechfliegan wieder. Siesind zwar ihrer bestimmung nud ihren Leistungen entsprechend abgeändert, aber in den Grundformen und dureh die gegenseitige Lage sofort wieder zu erkemen.

\section{Stomoxyidae.}

Ton allen hämatophagen Gymmoehrysaliden (Orthoraphen) unterscheiden sieh die Stomoxyiden grundsätzlich dathuch, daß sie

1. in beilen Geschkehtern blutsangende Parasiten der Wirbeltiere geworden sind $\left.{ }^{2}\right)$ und

2. dab sie in ganz anderer Weise das Saugrohr in den Körper ilner Opfer einfülıren.

Während nämlich die Steehmücken (sens. lat.) mond die Tabaniden nur mittels ihres stilettbïndels die Hant ihrer Wirte dmrehbohren und auch nur mit diesem in deren Körper eindringen, ihre Unterlippe aber beim siangakte niemals direlst betciligen, durchsägen die blutsangenden Musziden mit den äußerst verwickelt, abet durehaus zweekmäBig gebanten Zahureihen der Labellen die Körperlecke ihror Nahrungsspender und fülıren dowch die so gesetzte Wunde den Riussel als Ganzes in die Blutbahn ihres Opfers cin; es ist also im letzteren Falle das Labinm ein integrierender Bestandteil des saugrohres geworden.

1) Im stinkenden lïter alter (icselww üre, den zersetzten Alsonderungsprodukten entzündeter

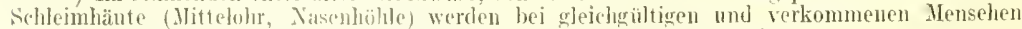
nicht selten peben Larven von Lucilin anch solehe von Musca angetroffen.

2) Die männlichen Tiere diescr liamilie sind deshalb cbenso gefährjiche Krankheitsüberträger, als die Weilucben. 


\section{Genus Stomot!s E. (HEofrem Saint-Hilaire 1754.}

Der bekamnteste und typischste. Virtreter der blutsugenten Musziden ist unser Wadensteeher:

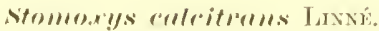

Die in Tiehställen und mensehlichen Wohmräumen des Sommers häufig zu beobachtende Stechfliege hat dine so grobe ilnnlichkeit mit unerer geneinen Stubenfliege, dab sie von den meisten Menschen einfach für eine soldhe grehalten wird. Farbe umel Gröbe sind hilun versehieden, wohl aber bemerlit din sehärferer beobachter sofort Lntersehiede im llabitus und Gebatren von Musca mel stomoxys.

Fig. 1 t8.

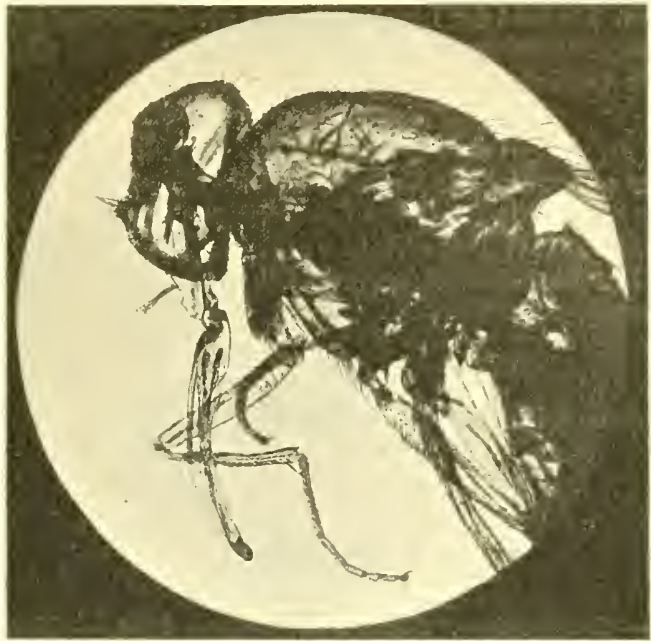

Stomoxys calcitrans Livné. ${ }^{8 / 1}$. (Kalilaugepräparat.) (Original.)

Die steehfliege sitzt viel ruhiger und steter auf dem einmal gewilhlten Platze, als die unruhige, hin und her laufende stubenfliege: sie unterschejdet sich ferner boi genanerem llinsehen ron Museu sufort threh die weit offener getragenen lilügel nud dureb die höchst eharakteristische sitzstellung: withrend die stubenlliege unter diesen Verhälnissen in lnophelenstelhung verharrt, nähert umgekehrt stomoxys das Leibesende der senkrechten Wand und entfernt den kopl weit von derselben. Ferner ist der bei Musea herahbängende, endwärts an Dicke zunehmende samgrüssel mit dem wurzelwärts sich verdickenden, einer Rübe ähnlich greformten, in Ruhelage wagrecht vorwärtsgestreckten ${ }^{1}$ ) stechrüsel von Stomoxys gar nicht \%u verwechseln.

Alle exotisehen stomoxysarten sehen unserem Waclenstecher so ähnlich, daß generische Bestimmungssehwierigkeiten gar nicht existieren. Ton afrikinisehen drten der Gattung sind of wa ein 1)utzend bekannt geworden.

Die Ent wicklungsgänge unserer beiden Fliegen, die namentlich von I) t tox und TODD in Liverpool bei Stomoxys und L. O. Hownd in Washington Jxi Husca genauer verfolgt wurden, sind fast die gleiehen.

1) Während des Saugens senkt auch der Watenstecher seinen Rüm, (wul. Tï. 148). 
I ie $1 \mathrm{~mm}$ langen, roggenkornähnlichen Ejer werden mit Vorliebe an frisehen Pferdemist. at zelegt (stomoxys 50-60, Uusea 120). Die nach wenigen Stunden auskriechenden Larven sinct gellichweibe, kopflose Maten. Hie Körperform ist die eines langansgezogenen Kegels; ans dem zugespitzten Vorderende ragen wohlentwickelte lirebspitzen hervor, während das abgestutzte llintercnele dic stigmenplatten trägt. Die Jaden läuten sich dreimal und erlangen ausgewachsen eine Grïße von 10-12 mm. Dje Puppenbuille, das bekannte dunkelbraune Tönnchen. wird nteh wenigen Tagen von den fertigen Imagines an liopfende gesprengt und verlassen. Die Entwickhngsdaner der Stuhenfliege heträgt durchschnittlich 10, die des Wadensterhers 14-20 Tage.

\section{Propliylaxe.}

Dungstätten und Kehriehtgruben sind mögliehst zu bedecken und dieht abzusehließen; Histhanfen mit P'etroleum zu begießen oder mit gepulvertem, gebranntem Kalk zu bestreuen. Die Zahl der Imagines werden wir durch die allbekannten Fliegenfallen in ihren verschiedensten Formen ${ }^{1}$ ), (burch Gifte (arsenige Säure, Formol) und Räulherungen zu besehränken suchen.

Die weiteren europäisehen Gattungen dex Stomoxyiden (Bererr.mingirn und LIJn'rosio) das afrikanische Gemus Glossimella und die amerikanische (vielleicht auch mediterrane) Hornfliege (Inemutobin sorutu) sind bis hente noch nicht als Krankheitsüberträger verdächtigt worden und dürfen deshalb an dieser Stelle iibergangen werken.

Die bej weitem wichtigste Stechfliegengattung ist

\section{Glossina.}

(Tse-Tse. - Zungenfliege. Glossina Wiedemaxx 1830. - Nemorhina, ,Fadennase" Robineau-Desvoldy 1830.)

Nächst den Steehmücken sind die Glossinen als 'Trypanosomenüberträger die den Tropenart am meisten fesselnden Krankheitsvermittler unter den Arthropoden. Die fattming ist in ihrem Vorkommen ausschließlich auf den schwarzen Kontinent in seimen tropischen Gebieten beschränkt.

Die ersten in Tsetsegegenden vortringenden Europäer (Enghänder) hörten auf die Frage nach dem Xamen muserer Fliege von iliren Basut oführem das Insekt einfach ,tsi" i. e. .Fhege" nennen. Meistens wurde das Wort, um es in der von den Bantuvölkern beliebten Weise stärker hervorzuheben, verdoppelt, also ,tsi-tsi" gesprochen und diese Bezeiehnung ist auch bis heute noth bet museren fuglischen Veftern, ohne tie geringste Ahänderung zu erlejden, in Gebrauch gebiehen (Tsetse, gesproclen: Tsitsi). In Congo français kennt man das Wort gar nieht, hier wird

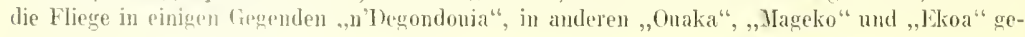
nannt.

1) Für groblere Raume, Stäle usw. wird der im Herbst 1912 in den Handel gebraehte (J. Gesche Nf., Berlin N 37, Schwedterstr. 263) Fliegen-MIassenfänger von Bohm vielfach empfohlen. Iber Apparat ist sut koustruiert, einfach zu handhaben und durehams Feuersjeher, so dab or sich iuch bej strohbedeckung und dergl. in Eingeborenenhütten anwenden jassen würde. 


\section{Alluenteines.}

Die hell- bis dunkelhrauu ${ }^{1}$ ) gefärbten, ,Zungenfliegen" (Glossinem) sinel

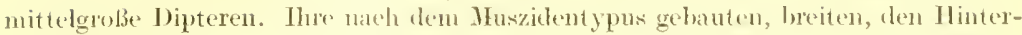
leib stets weit ïberragenden Flïger werlen in linhestellung in Cegensatzo zu Musca und zu den ïbrigen Stomoxyiden geschlossen und dem Abdomen wagerecht

Fig. 149 .
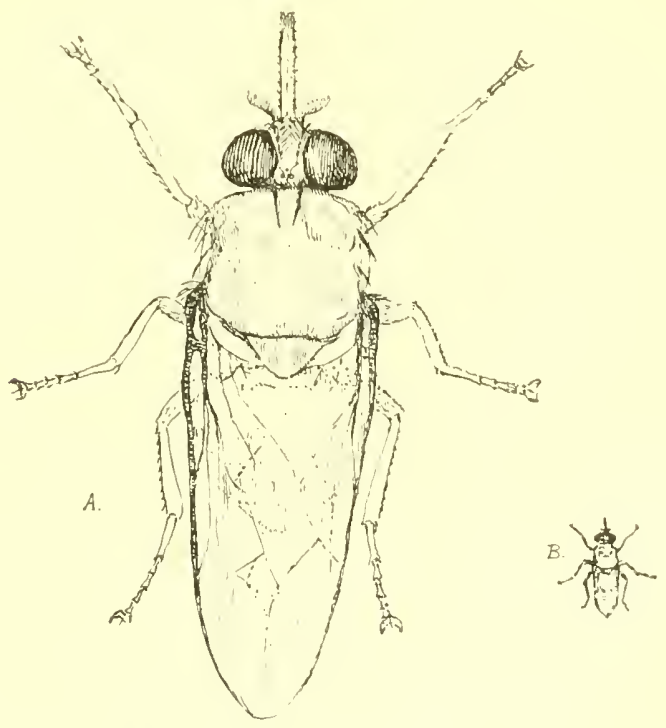

Ruhende Glossina morsitans Westw. (Nach SAxder-Austen.) 1. ${ }^{6} / 1 .-$ B. natürliche Größe.

a ufliegend getragen. Diese Flägelhaltung gibt den Tretsen ein ganz eigenartiges Aussehen (Fig. 149) und gestattet, sie auf den ersten Blick von ihren Verwandten sicher zu unterseheiden, Verwechshungen mit Stomoxys oder gar mit Tabaniden (namentlich Haematopota) können bei jedesmaliger Beachtung dieser habituellen Eigent ̈̈mlichkeit gar nieht vorkonmen.

\section{Morphologie.}

Die krätig gebanten, etwa muskagroßen (9-11 mm) Fliegen ersehenen ilner langen Flïgel wegen größer und sch lanker als die Stubenfliege und der Wadenstecher Alle Körperteile sind mit zablreichen und typisch gestellten Makrochäten besetzt (Figg, 87, 88).

Der Kopf der Tsetse ist ein echter Huszidenkopf und dem aller Stomoxyiden sehr ähnlieh gebaut. Untersehieden wird er von den Köpfen der anderen Faniliengenossen durch die großen, in allen 'Teilen gleichbreiten, rüssellangen 'Tastel' uncl clen verhältnismäßigsehr langen, in semem dist a len D re i viertel gleichnä Big cliunen

1) Die larben der Glossine $n$ sind die denkbar indifferentesten und woll geeiznet, den Fliegen in C celände einen lohen schutz zn gewähren. 
(horstenfümigen) Rüssel, der einem mächtig verkreiterten, zwiebelförmigen Wurzelt tikek (Tulbus) aufsitzt (Fig. 151). In der Ruhelage wirt er genan wie der ron Stomoxys

Fiv. 151.

ling. 150 .

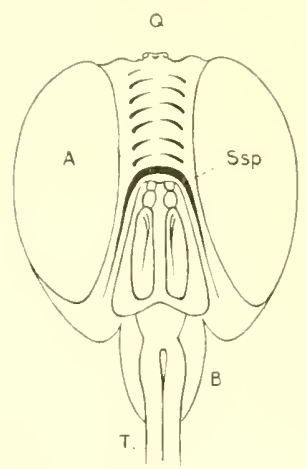

Glossina. Kopf ron sorn.

(Original. (amera lucida.)

Q. Ozellen, A. Ange, Ssp. Stirnspalte, B. Zwiebelfömige Anselswellnng der Rïsselwurzel (Budbus), T. Taster.

lijg. 152.

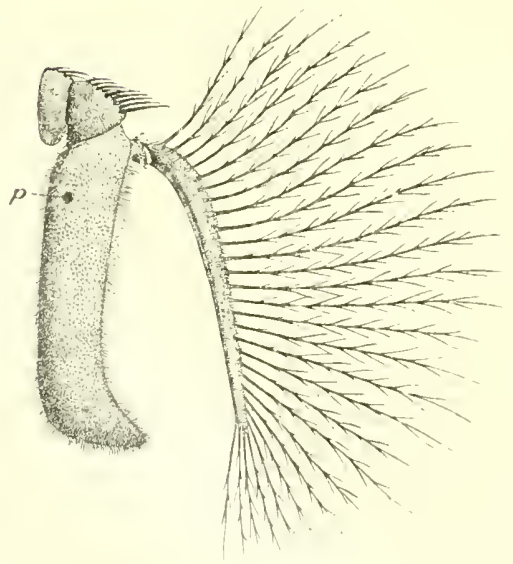

Linker Fühler von Gilussina pallidipes jo. $45 / 1$. (Nitch Misten.) $p$ Öfnung des tieruehsorgans.

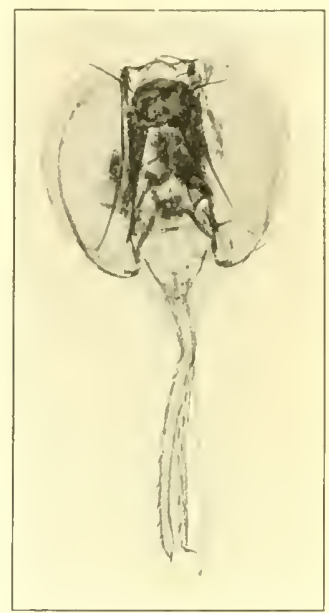

Glossina. Kopf yon vorn. ${ }^{15} / 1$. (Original.) Erklärıng in Fig. 150 gegeben.

(Taster dicht beborstet und bedornt.)

wagereeht naeh vorn gestreekt (Figg. 15!, 1601) und von den medianrimentragenden Palpen eingescheirlet ${ }^{1}$ ).

Der vertikale Kopfolurehmesser (die Höhe) ist wesentlieh gröBer, als der (in der Körperachse liegende) längsdurchmesser. Die Stirn ist in beiden Geschlechtern fast gleich breit (etwa 1 , (ler ganzen Kopfbreite) mnd an ihren Rändem mit oralwärts gerichteten Makrochäten bestanden (Figg. 150, 151). Zwei analwärts schanende Grobborsten stehen an der Scheitel-Hinterkopfsgrenze.

Die bramen Komplexaugen sind fast gerarle nach auswärts gerichtet: ihre Fazetten sehr klein und sämtlich gleich groß. Die Augenhöhe ïbertrifft die Augenbreite um das Doppelte. Ozellen stets vorhanden. Die sehr aufällige Stirnspalte

1) Beim Stechen und während des Singens hebt Glossina die Taster genau so, wie dies fruher bei Anopheles (s. 105) beschrieben warde. 
(Fig. 150) stelst beinahe senkrecht; zwischen ihren mittleren teilen und der oherkante der Fïlulergrube befindet sich eine deutliche Lunulat. Der Cinterrand der Fühlergrube geht, wie bei allen sehizonotopen, ohne sichtbare Grenze in die Tordertäche des cingedrückten Clipens ïber, der als muscheltimmige rläehe sieh bis zum Mundrande erstreekt. An ihren Seiten wird die so entatandene „fiesichts-

Fig. 153.

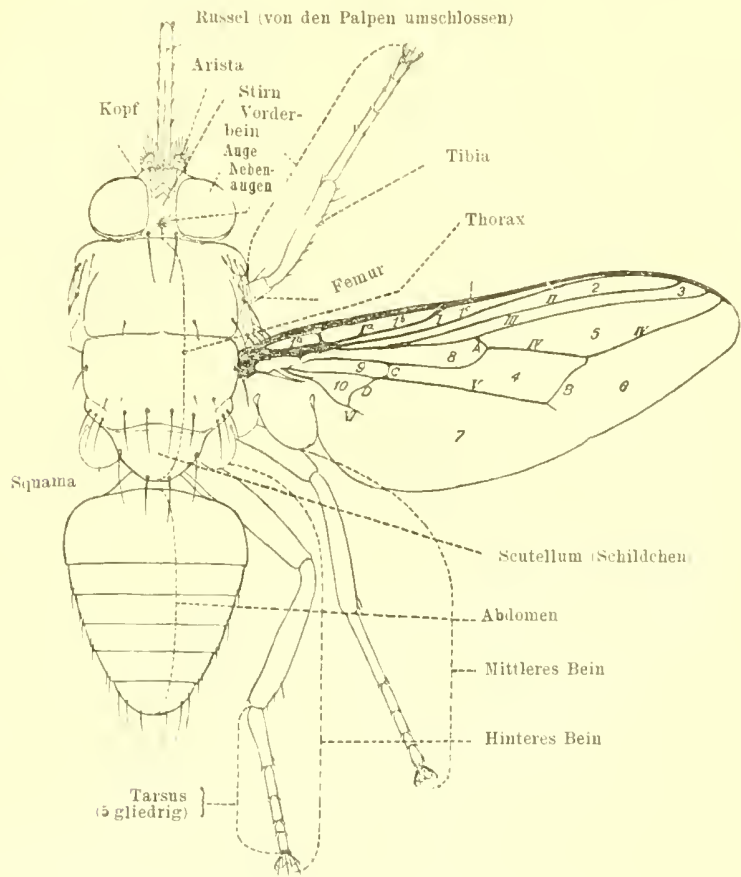

sichesna und Bezeichnmng der äuBeren Gliederung vou Ginssina. Nach A usten.

Längsadèn.

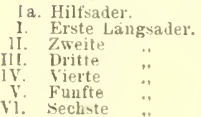

tdern und Zellen der Flugel Queradern.

A. Vorlere Querades.

B. Hintere

C. Vordere Wurzelipuerader.

D. Hintere
Zellen.

1a, Ib, 1c. Erste, zweite. dritte Kostalz+lle.

2. Vorderraudzelle

(Marginalzelle)

3. Nebenrandzelle (Sub-

marginalzelle.

Diseoidalzelle.

6. 7. Erste zwoite, dritte

Hintertandzelle.

8. Vordere Basalzelle.

9 . Hintere Basalzelle.

10. Analzelle.

grube" von einer vorspringenden Leiste, der ,Vibrissenleiste" begrenzt, sn gentunt. weil ron ihr regelmäBig Makrochäten (Vibrissen) entspringen die, wenn an d tr nzteren Ecke der Leiste in gröberer Zahl und kräftigerer Entwieklung vorhancton, linebelbart genamnt werden. Fon allen Teilen des Mundrandes selbet ant-pingen chenfalls Nakrochäten. Die dreigliederigen Füluler (Fig, 152) setzen sich ants den beiclen 
kilinen fruudglictern und dem dremal so langen bananen- oder erbsenschotenformigen Enclgliede zusammen. Letzteres trägt eine, auf seiner oberen dorsalen Ecke entspringende, zweigliederige Fühlerborste. Thre nur auf der Dorsalfläehe stehenden Fiederhärchen zeigen auch noeh sekundäre Fiederung (Fig. 152).

Der Thorax ist etwas länger als breit. Rüekensehild quadratiseh, an deu Eeken abgerundet, lurh eine deutliehe Quemaht in zwei gleiche Hälften geteilt. Die Flügel licgen den Abdomen anf. Die vierte Längsader zeigt zwei scharfe Kunkkungen an den Verlondungsstellen mit der vorderen und hinteren Qucrader. Dieses Verhalten und die Kürze der hinteren Wurzelquerader bedingen die cigentümliche Form der Diskoidalzelle (Fig. 153, 4): sie gleicht einem Beile ${ }^{1}$ ), während die Diskoilalzelle der übrigen Stomoxyiden einem langgezogenen riereck (einem einzehnen Fächerglicile orler einem Propellerflügel) ähnlich sieht. Das distale Endstïek der vierten Längsader verläuft wie eine Fortsetzung der hinteren Querader mol mündet als ,Spitzenquerader" vor der Flïgelspitze in die Riandader ein. Die Beine der Zungenfliegen sind ziemlieh lang und namentlieh in den Schenkeln kräftig gebaut. Der aus fünf Tarsalgliedern bestehende FuB trägt ein Klanen- und Pulvillenpar, welche in männlichen Geschleeht besser entwiekclt zu sein pflegen. Die Vorder- und Hinterbeine sind an ihrer oberen mo nuteren Femm- und Tibiakante mit ciner lieihe kammerartig gestellter, kräftiger Borsten besetzt, während die Mittelfenrora an den gleichen Stellen fast naekt erseheinen (Figg. 161-163).

Das eifömige Abdomen besteht aus sieben Segmenten. Die Männchen haben ein stark entwickeltes Hypopygium, welches als halbkugeliges, längsgeschlitztes Gebilde dem Sternit des Endringes antliegt (Fig. 154).

\section{Anatomie und Physiologie.}

Das Zentralnervensystem zeigt die für alle Eumyiden gleiehe Ausbildung und Anordnung der großen Ganglien. Das Hirn mit den mächtigen Angenganglien

Fig. 154 .

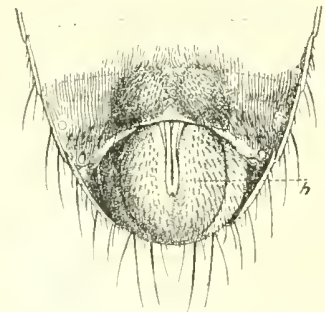

Ilypopyoium ron dilosina morsifues WESTW. 12/1. (Nafh IUSTEN.)
Fig, 155 ,

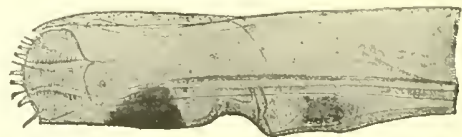

Innenfläche des reehten Labellums. ${ }^{100} / 1$. (Naeh Stritimann.)

Ian sieht die Sügeplatten und ilıre im Innern des Labiums verlaufenden Chitinsehnen und die bei der Verankerung gebrauelten hakenförnigen Chitinzälme.

ist wohlentwickolt, die cinzelnen Teile der Banehganglienkette sind zu einem gewaltigen Brustnervenknoten versehmolzen.

1) Die Form der Taster, die Form des Rüssels, die eigentümliche Anordnnng der Rüsse\}muskulatur, die Form des fingelgeäders, der männliehe Geschlechtsapparat in allen seinen Teilen (s. S. 220) und die Tupiparität rüeken die Glossinen so weit von den anderen Gattungen der Stomoxyiden ab, dilb man sie später wahrseheinlieh als selbständige Familie neben ihmen gelten lassen wird. 
Das fünflammerige Herz liegt in dem vorderen oberen $A$ bschnitte des $A$ hdomens.

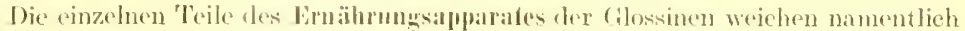
in ihren oralen Partien von denen der bisher betrachteten hämatophagen loipteren ab. Lei keinem derselben hat die den Hinptbestandteil des Sangrohrs biletende Unterlipe eine so gleidhmïbige Breitenauslelnumg, mit anderen Worten, bei licinem bilket sie unter Zuhilfenalme ter Oberlipue cin vollkommen zylindrisehes Rohr. Die fundamentalsten Unterschieds aber zeigen die Labelien mit ilnen drei starken sägephaten mol Widerhaken zu jeder Seite. Durch zwei mäbhtige im Bulbus liegende Nuskelpare, deren ("hitinselnnen im Labiuminnern verlanfen, kömen diese glasharten (icbikle vorgestoben und sägeartig bewegt, verankert und nach dem Gebrauch wioder ins Imnere des Labellenknöjfehens zu rïekegezogen werden. In einer tiefen Rinne der ungemein stark ehitinisierten imneren lamelle des Labiums, die mit ter ehenfalls sehr festen äuberen Lamelle dureh eine dehnbare, elastische Membran verbunten ist, liegt der eine Chitinröhre bildente $\mathrm{H}$ y popharynx. Wie bei allen Zweifliiglem stellt er auch bei Glossinu den Endabschnitt desgemeinsamen Speichelganges dar und reieht bei den Zungenfliegen beinahe bis zur Rïisselspitze (Fig. 156b).

Der Riusselwurzel fast aufsitzend, nur dureh ein ganz kurzes Rolı mit dem Lippenkanal (Püisselsaugrohr) verbunden, schließt sich dam die Saugpumpe, das Fulerum (Fig. 156l), an ${ }^{1}$ ). Aus iln führt ein gebogener Ösophagus, den nervösen Schlundring durchsetzend in den Proventriculus (Figg. I57, $158 \mathrm{pr}$.) Fig. 156 .

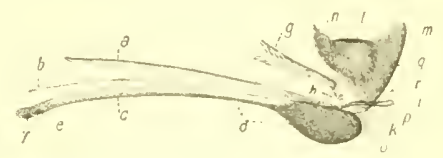

Rüssel unt Fulermm von trlussina. 15/1. (Nach Haxsex.)

"Labruu, b llypopharynx, e Lahimm, d Wurzelabsehnitt des Labimis, e Endabschnitt des Labiums, f Labellen, g Wurzel des linken kiefertasters, h vordere Kopliegelwand, $i$ linke Labrumstütze, $k$ hintere hopl'kegelwand, $l$ Pharynspunpe (Fulermm), m. oberer Fulerumfortsatz, n. T'eil tes Epistoms, o Sehaltrohr zwischen Pharynxpumpe und Lippensangrohr, p speichelpumpe, "Erweiterer der Speichelpumpe, $r$ Tuctus salivalis. und den mächtigen Vorratsmagen

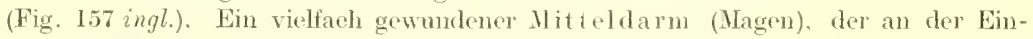
mindungsstelle der beiten gegabelten Nierensehläuche (Vasa Malpighii, Fig. $157 \mathrm{~m}$.) in den gleichfalls gewundenen Enddarm mit seiner Rektalampulle und den ‘urch kräftige liingmuskeln gesehlossenen After ïbergeht.

Die Geschlechtsorgane des ó bestehen in der Hauptsache aus zwei dünnen, milehweiBun Schläuchen, die in ihren Ursprungsteilen knäuelartig aufgerollt erseheinen und so die Hoden biklen. Jas V as deferens der rechten und hinken Seite nündet mit den Ansführungsgängen der beiden sehlauchförmigen Anhangsdrüken an derselben stelle in den Anfangsteil des Duetus ejaculatorius. Der hakenförmigg gekrïmmte l'enis wird auf scinen AuBenseiten ron je zwei kräftigen Klammerhaken thankiert. Der weibliche Genitalapparat entfernt sich in der Ausbildung von dem seiner Familiengenossen, der Pupiparität der Zungenfliegen entspreehent. außerorkentlich weit und zeigt eine ganz auffällige Konvergenz zu den weiblichtn Geschleehtsteilen der Lansfliegen. Ntatt des ronst gewöhnliehen jederseits aus zahbreichen Eiscluänchen bostehenden Ovarialröhrenfäehers der übrigen sito-

1) Die Pharyoxumpe lient bei den Fumviden ziemlich weit vom Fiehirn entfurnt in den

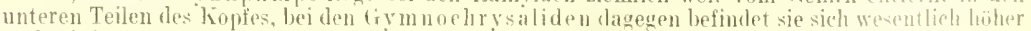

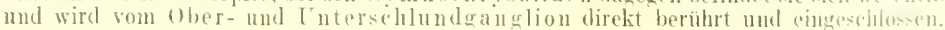


noxydan (und Musziden ïberhaupt) finden wir bei Glossina jederseits nur eine Eirölne. In iln gelangen, anf der einex nnd der anderen Körperseite altemierend,

Fìg. $15 \%$.

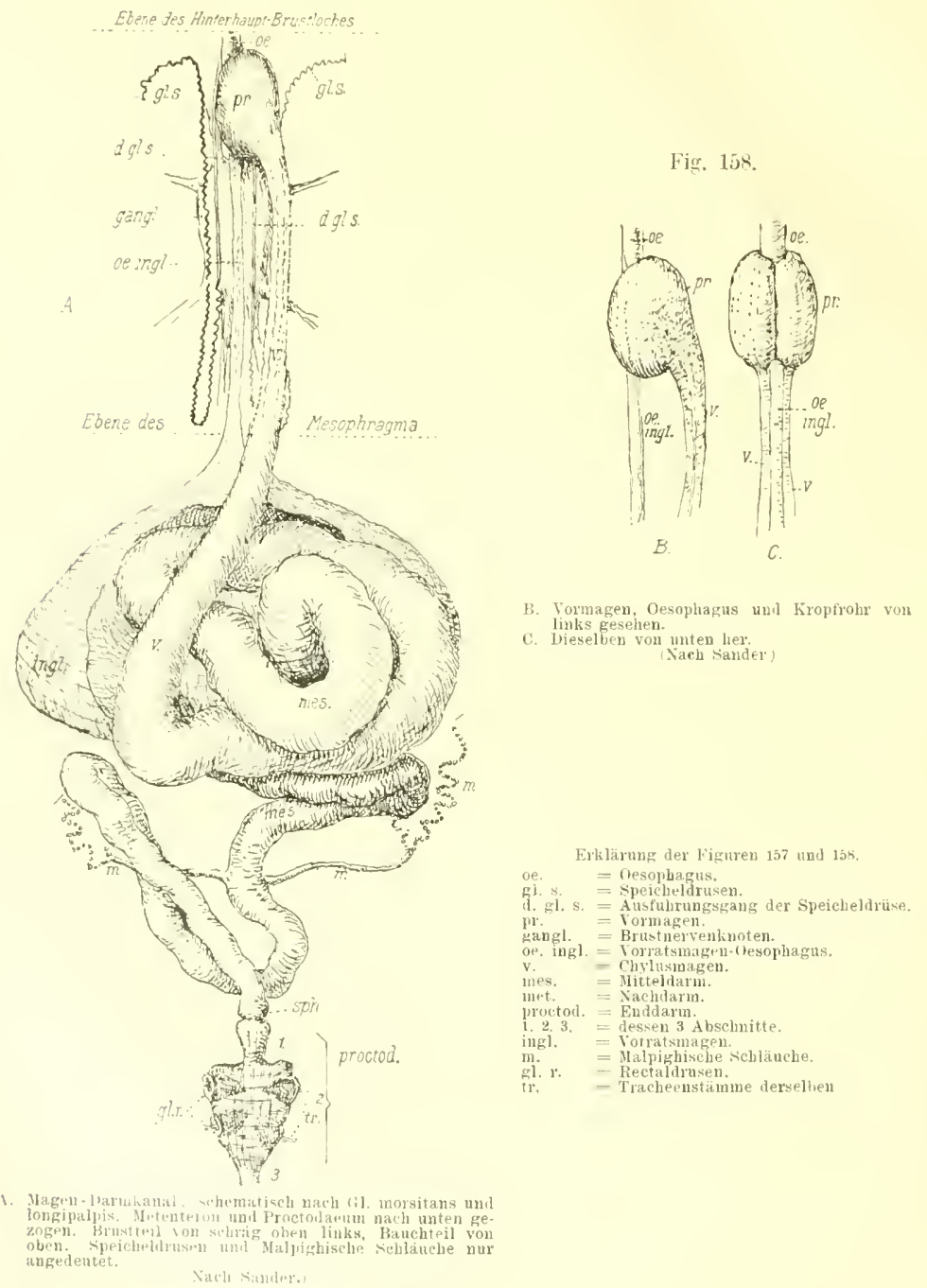

riv lier sehon sehe grob werdenden Eichen zur Entwickhng. Ansgereift werden sie durch cinen gemeinsamen, in des. Vittedtinie liegenden ovidukt in den saekförnigen Uterus weiter befördert. (Die linhältnisse sind bei den H ippobosziden die gleiehen, 
ich danf deshalb wohl atuf Fig. 164 verweisen.) Etwas weiter unter- und außerhalb (distal) ron der Eintrittsstelle des Ovidulstes in den Uterus liegen tie: Ënden ter Ausfiilnungsgänge der beiden spermatheken und zwisehen diesen die gemeinsame, papillenförmige Ansmündung der netzförmig verzweigten beiden fuhangs(Irisson (der sog. Milchdrüsen). Durch wine sehr erweitermosfähige Seheide wird die Gebärmutter ventralwärts vour. Ifter mit der Aubenwelt in Verlundung gebratlt. Kräftige, beim Geburtsakte in Wirkung tretende Muskeln setzen sich an den Ctems und flie Vagina an. In die Gebärmutter eingetreten, verläßt die junge Larve sofort die Eihaut. Ihre Längsachse länft der groben Körperachse der lluttex parallel (Fig. 164), ihr vorderes und hinteres Körperende sind gleichsimnig denen rles Inttertieres gelagert. So befindet sich die Mundöffnung der Larve an der Mlifehchïsenpapille, während der metapmenstische (wahrscheinlich während des Lterinlebens nicht in Funktion tretende) Stigmenapplarat analwiirts gewandt ist. Eine Afteröhnug besitzt die Glossinenlarve nicht; wie bei den Zecken während des ganzen Lebens (vgl. S. 14). so findet bei ihr lis zur Erlangung der Gesehlef htsreile eine Defäkation nicht statt. Nach zwei bis drei Woehen wird die 7 - $8 \mathrm{~mm}$ lange, milchweiße (nur das stigmentragende Hinterente ist dunkel gefürbt) Lav've geloren. Sie sncht ohne weitere Nahrung ${ }^{1}$ ) aufzumehmen sofort eine passende Puppenwiege (meist im Ioolen) nnd ist sehon nach 1 - 2 Stunden ein dunkelbraumes, festes, $6-7$ mm langes 'Tönnchen geworden. Die P'uppentruhe ist cine antfallent lange, wic pllegt 1 - Nonate zu danern.

\section{Biologie.}

bie folgenden biologisehen Daten beziehen sich hauptsiuchlich anf Cilosince pulpalis, als die fïr nns wichtigste Art unter ihren battungsgenosinnen.

Wem anch zugegeben werlen muli, dab durch den Litrawanenverkehr anf den groben Handelsstraben Glossinen versehleppt werden kömen, so muB man andereriseits floch annehmen, daß tie Tsetse sich sehon lange vor dem Auftreten der Tehlafkrankheit in alken den Landstrichen befunden hat, in welchen sie anch heute rorkommt und natürlich jetzt aufmerksamer beobachtet wird, da sie sich so unangenehm benerklich macht.

AHe Glossmenarten rerlangen in arster Linie die Möglichkeit, sich vor den sengencten Strahlen der tropisehen Mittagssonne schützen zu können; sie bevorzugen deshall, sehilfreiche Flub-orler Seenfer und mit Buschwerk oder lichtem Wakdbestande bewachemes Gelände, das sich nicht mehr als höchstens 1 ?oo m inber dem Meeresspiegel erheht. Sie sind ron gewissen okologisehen Bedingungen in hohem Ma Be alhängig, es zeigt deshalb ihr Wohngebiet manchmal eine scharfe Begrenzung gegen

1) Dir paradoxe Erstheinung, dab die von der Hutter his dahin umsehlossene und eben geehorenc larve nat ülich viel kleiner, ak ihre krzengerin ist und doeh ohne weitere Nahrungsanfnahme

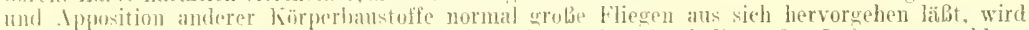
durch dio starke lonzentration der kiorperabte und for allem dureh die groben Luftmengen erklärt,

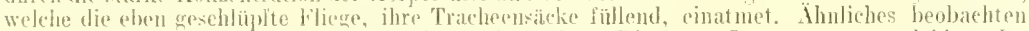
wir ja atele sonst bei der lintwicklung der. Irthropolen. Die junge Larve vou wasserlebigen Insckton z. B. nimnt nath den. Aussehlizyfon in wenigen Sekunden die dopjelte Gröbe des Innenranmes der lischale an. Dies kann nan hesonders sehön an den sehr durchsichtigen reifen foret hral-

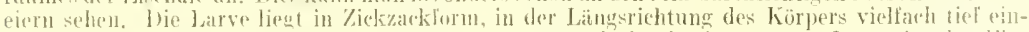
geknickt, derartio in der lischale, dab ilire ventrale Fläehe der konvexen Langseito des lijes

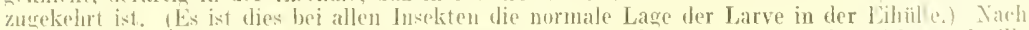
dem Verlassen des thorions, welches in diesem fialle durch einen luängsspalt erfolyt, schwillt

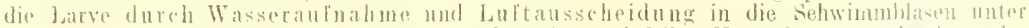

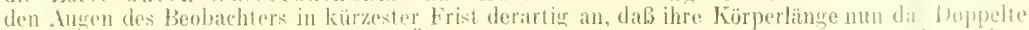

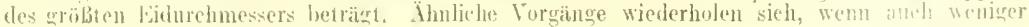
auffiillig, nach jeder folgenden lläutung. 
scheinbar ebenso gïnstige Nachbargebiete, und so kommen nieht selten sieh lang hinzichende, verhältnismäßig schmale glossinenbesetzte Striche, dic sog. ,Fliegengriirtel", zustande. Währent nun die einen (Gloss, morsitans) ansgedehmte Gras. landschaften in ziemlicher Entfermung von Flüissen und Seen bevorzugen, andere (Gloss. fusca) rerhältnismäßig trockenes Hügelland lieben, ist (ilossina palpalis an das Wasser gebunden. Man findet sie ansschlieBlich am Uter von Flüssen und Scen (aber niemals am Meeresstrande) und trifft schon in einer Entfermung von 1 Kilometer rom Ufer keine Palpalis mehr an. Kahle, felsige oder aut weite Strecken nur mit Steppengras oder Papyrus bestandene Ufer werden von der Zungenfliege gemieden; es wird aber auch nicht jede beliebige Holzart gleichmäßig häufig aufgesucht. So beriehtet Roвert Kocir, daßB es vor allem der in Wasser wachsencte

Jijg. 159.

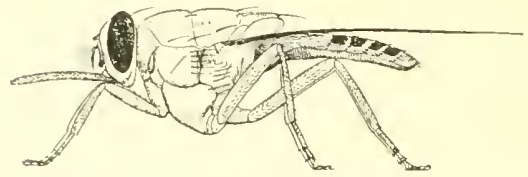

Crlossina morsitens Westw. 울, nüchtern ${ }^{4} / 1$. (Nach Auster.)

Fig. 160.

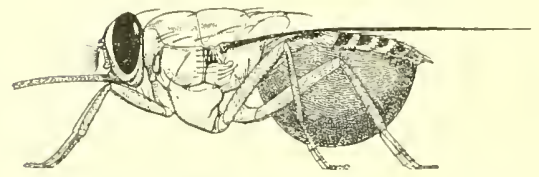

Glossina morsituns WESTw. 우 vollgesogen ${ }^{4} / 1$. (Nach Auster.)

Ambaschbusch (Aeschynomene claphroxylon) ist, welcher im Viktoriascegebiete von mserer Glossine bevorzugt wird.

Alle Zungenfliegen sind 'Tagtiere. Während aber Glossina fusca hauptsächlich in den Morgen- und Abendstunden sticht (F. STuntMANx), hat sich Glossina palpalis lie heißeste Zeit des 'Tages zu ihren Jagdansflügen ausgesucht, sic erseheint nicht ror $9^{\text {th }}$ a. $m$. und wird schon $4^{\text {h }} \mathrm{l}$. m. meist nieht mehr gesehen. An Regentagen werden Ghossinen überhaupt nicht jagend angetroffen. Bei den ölsologisehen Eigentiumlichkeiten von Palpalis sind es natürlich hauptsächlich die im Wasser oder an seinen Utfern besehäftigten Fiseher und Arbeiter, die wasserholenden Frawen und das zur 'Tränk eilende Großwild, welehe von der Stechfliege befallen werden. Ton den Hanstieren werden in erster linie Equiden angegriffen, dann die Rinder und Kamele mul zuletzt erst das Kleinvieh. Peptilien, Krokodile und große Eidechsen (so der Taran), und rogar Fische, wenn beim Sehwimmen unter der Wasserfläche Förperteile von ihnen in die Luft ragen, werden von Glossinen verfolgt und gezehntet. In höchst gewandtem, lantlosem Fluge maht die Fliege ihrem Opfer, setzt sich kaum fühlbar auf die erwählte Körperfläehe und wird erst rlureh ihren wenig schmerzhaften Stich bemerkt. Verseheneht kehrt sie mit. Bremsenfreehbeit immer wieder zuriick, bis sie schließhich ihren Zweek doch erreicht. Die dunkle Haut des Negrers loekt sie viel mehr, als die helle des Ariers. Aueh dunkle Stoffe oller dunkle'Jeile von Kleidungsstiicken werden mit Vorliebe aufgesucht, reinweibe oder wonigstens hellfarbige Anzüge geben deshalb cinen hohen Sehutz gegen Gilossinen als.

Unter allen Trmständen meidet, wenn es irgend angeht, die Fliege direkte Insolation. Sclbst fuir clit' kurze Zeitspanne von meist nicht 100 Sekunden, die währenct ihrer Blutmahlzeit verstreicht, sucht sie besehattete Körperstellen anf. Mit Vorliebe pflegt sie sich deshalb unter der Hutkrempe ihres Wirtes anzusetzen. Der Stich ist, wie xchon oben bemerkt, für tie meisten Mensehen wenig sehmerzhaft; er wird kaum 
mehr, als der eines Moskitos rmpfunden und rufi für gewöhnhirh auch keine weitcre Reaktion in der Comgebung des stichlanales hervor. In seine Wohnräume verfolgt die 'I'setse den Menschen nirmals.

Die Vemehrumg der Fliege findet hamptsächlieh in den feuchten f'eriorlen des Jahres statt. In Gebjeten. die nach dieser Richtung hin keine (nnterschiede zeigren, kam sie das ganze Jahr lindureh (wie R. Kocu von den Seseinseln berichtet) erfolgen. Bei der relativ langen Entwelslungsdauer der Larven kömen anch unter günstigsten Verhältnissen von einem Muttertiere jährlich nur 24 Lirren geboren werden. In Wirklichkeit wird diese Zahl wohl uiemals errejeht und R. Korn nimmt wegen der großen Iläufigkeit der Fliege an den Stellen, wo sie überhaupt vorkommt, deshalb wohl mit Recht an, daik die Fliege sehr langlebig ist und nur wenig getähtliehe Foinde besitzt.

\section{Systemalik.}

Tm die Bestimmung der einzelnen Arten und ilne Abgrenzung gegeneinander hat sirh in erster linie E. E. Atstex verdient gemacht. Er teilt die bis heute bekannt gewordenen acht

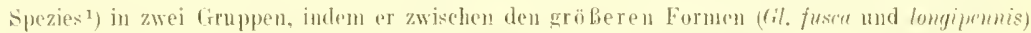

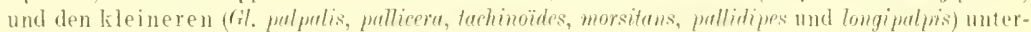
scheidet. Seine Artenbestimmungstabelle ist die folgende:

1. Hintertarsen dunkel, oder wenigstens alle ihre Glieder stärker oder sehwächer dunkel gefärbt (heim von Glossina tachinoüdes sind die Wurzehälfte des ersten Gliedes und die folgenden zwei Glieder nmmittelhar an ter Wurzel gewönlich hell)

Hintertasen nicht völlig dunkel; nur die letzten beiden Glieder dunkel,

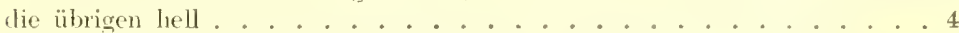

2. Die Grundfarbe des Hinterleibes ockergelb oder lerlerfarben, mit unterbrochenen, dunkelbramen Querbänderm und scharf abgesetzten, hellen Hinterändern der Segmente; sehr auffäliges cruadratisches oder rechteekiges helles Feld in der Mitte des zweiten Segmentes; kleine Art, nieht über s nm lang (ohne Rüssel gemessen), j̀ beträchtlich kleiner . . . . . . . tachinoüdes Wrestw.

Hinterleib nicht so gezeichnet, sehr lunkel; die Hinterränder der Segmente wemn lichter, damn nur in äuberst schmaler Ausdehnung und aschgrau; ein helles, gewöhnlich dreieckiges Feld in dor Hitte des zweiten Segmentes, scine Spitze nach hinten gerichtet uni durch einen aschgrauen Wittelstreifen fortgenetzt: größere Arten . . . . . . . . . . . . . . . . . 3

3. Drittes Fühlerglied dunkelbraun bis schwarz... . palpalis Row. Dest.

Drittes Fühlerglied hellorange oder loderfarben . . . palliccra Bus.

4. Große Arten: Länge wengstens $11 \mathrm{~mm}$, Flügelspannweite (von Flügelspitze zu Fhügelspitze gemessen, während die Nïgel reehtwinkelig rom Körper abstehen) wenigstens $25 \mathrm{~mm}$. . . . . . . . . . . . . . . 7

Fleinere Arten: Länge selten bis $11 \mathrm{~mm}$, oft beträchtlieh geringer. Flügelspannweite höchstens : . . . . . . . . . . . . . . . 5

5. Die letzten beiden Gireder der Vorder- und Mitteltarsen mit seharf abgesetzt dunkelbraunen odej schwarzen spritzen. . . . . . . . . . . (;

Die letzten bejclen Glieder der Vorder- und Mitteltarsen ohne schart abgesetzt dunkelbrame oder sehwarze Spitzen; Vorder- und Mitteltarsez] vollständig geth, orler hördistens die letzten beiken Glieder der ersteren mit hellbraumen spitzern

1) bie letzthin von ihm norh hinzugefügten Arten werden von der Mebrzahl der Eutomologen wolh als solehe nicht anerkamt und nur als Varietäten und Lokalrassen betrachtet werkles.

Mense, Handbuch der Tropenkrankheiten, 2. Autl. I. 
(6. In allgemeinen deutlich größer; Kopf breiter; Stirn dunkler und sehmäler in beiden Gesehlechtern, die Seiten beim ơ parallel; Hinterleibsbänder tiefer herabgehend, die Hinteränder der Segmente nur in schmaler Ausdehnung hell lassend; Hypopygium kleiner, dunkler und stärker behaart; Hinterleibsande des $\hat{o}$ an den Seiten dieht mit kurzen, sehwarzen Haaren besetzt: Borsten anl 6. Segment feiner und weniger in die Augen fallend . longipalpis W'ied.

(iewöhnlich kleiner; Kopf schmaler, Stirn blasser und breiter", Augen in beiden Gesehtechtern deutlich gegen den seheited konvergierend. Hinterleilssbänler weniger tief herahgehend, die blasseu Hinterränder der Ringe deshalb breiter; Hyıpygium größer, blasser, etwas mehr oral im Umriß, mit wenigeren mel feineren Haaren besetzt; Spitze des Hinterleibes beim ô an den Seiten unbehaart; Borsten cles 6. Ringes beim ô lisäftiger und ansehnlicher morsituns $\mathrm{WTST}^{\top} \mathrm{TW}$.

7. Rïekensehild des 'Thorax mit vier seharf begrenzten, kleinen, dunkelbrannen, ovalen Flecken, die in der Form eines Parallelogramms angeordnet sind, zwei vor, zwei hinter der Quernaht: der Bulbus der Rüsselwurzel an der Spitze braun . . . . . . . . . . . . . . longipennis Conts

Rüickenschild ohue solche Flecke, doch mit mehr oder weniger ansgesprochenen Längsstreifen; Bublons der Rüiscelwurzel nieht braun an der

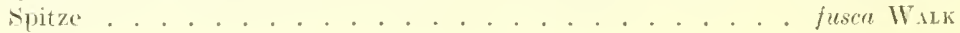

Wirwollen hier nur die drei wichtigsten Arten der Zungenfliegen näher betrachten: Glossina palpalis, die T̈berträgerin des Trypanosoma gambiense, Glossina morsitans (die eigentliche 'Tsetse), die Vernittlerin mörderischer 'Tiersenehen und einer' bestimmten Form ron Sidulafkrankheit und Glossina fusca, die gemeinste Spezies Deutsehostafrikas und größte Vertreterin der Gattung.

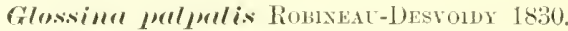

bünge \& $-9,5 \mathrm{~mm}$. Cirundlarbe dunkelloram, Kopf: lesicht gelblich. Fühler schwarz, Lingebung des zweiten Antemengelenkes gelblich. Taster schwarz mit hellhraner Wurzel. Rüssel

Fig. 161

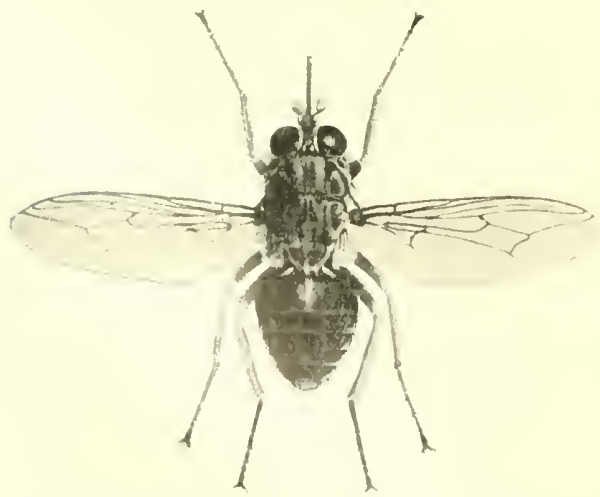

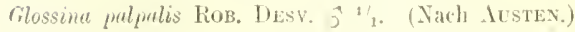

bellbranu, Bulbus schwarzbrano. Stirn braun. Hinterkopf aschgran. Thorax bläulichgrau mit lranner Rückenzeichnung (vel. lije. 161). Schildchen aschgran mit gelblicher spitze. Flügel bräunlich, Achwinger weib. Beine granbraun. Viertes und liunftes Tarsalglied des Forder- und llittellubes schwarz. Die Fübe des hinteren Beinuares vollkommen schwarz.

Jidomen dunkelbram. Erstes Segment und ein drejeckiges Vittelleld ant dem Tergite des zweiten Ringes rothram oder asehgran. Die hintere Spitze dieses Dreieckes setzt sich als schwach angedeuteter. unbestimmt begrenzter Mittelstreifen bis anf den fünten Leibesring fort. Die analen Eckwinkel des zweiten bis 


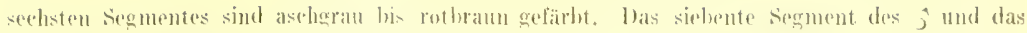
11 y.

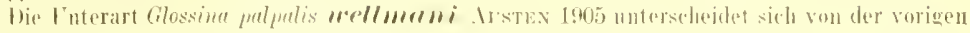

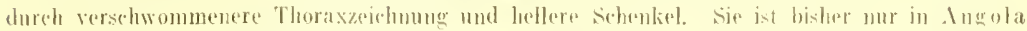
Quefunden worklen.

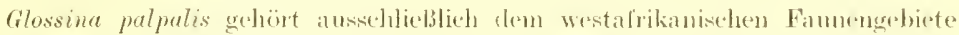
an. Sir wirl rom Senegat bis zur Kongomüntung mul in seinem ganzen Stromgebiete gefunden. In Usten geht sie ïber den Vietoria-Nyansa nicht hinans.

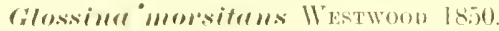

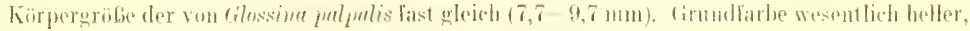
als the der vorigen. Kopf mul Ifinterleih lederbram, Brast aschgran.

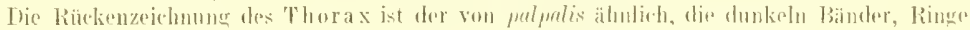

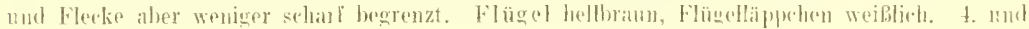
i. Tarsalghed der vorderen beinpaitre an der sjitze schwarz. lije beiden Eindolieder der hinteren Fübe chrchaus schwarz.

Der zweite Ibolominalring zeigh jedersejts einen werwaschencn braunen Fleck (wol. Fig. 16:2), der 3, bis 6. dunkelbrame Bänder, die in der littellinie unterbrochen sind, nieht bis zur den Banch seitentiohen reichen und nur die gribere, proximalp Segmentfläche pinmehmen.

Die Unterschiede zwisehen Glossina morsitans und

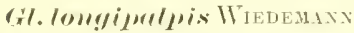
sind so geringe, daß man die beiden in Zukmuft kaum als selbständige Arten nebeneinander bestehen lissien Fï. Iti2.

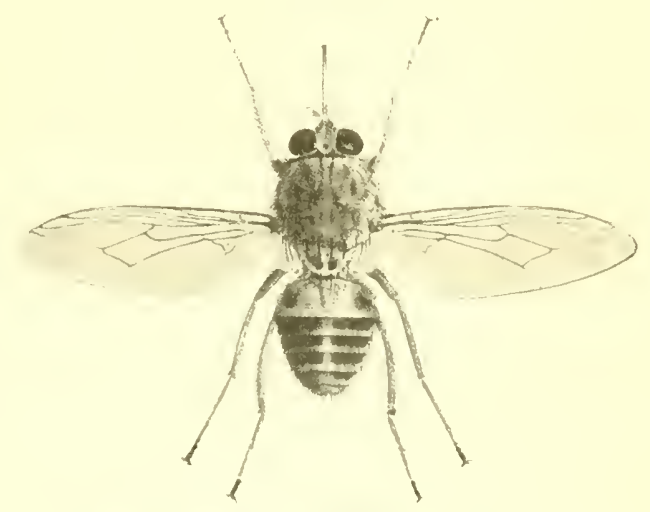
wirl, um so mehr, da sie Glowine morsituns Westw. '1. (Narh Itsten.) auch biolongich sich vollkommen gleich verhalten: bejde iibertragen Nagana, beje bevorzugen in Gegensatze zu Gil. palpalis trockenes, mit Busch oder lichtem Walde bestankenes Cielindle.

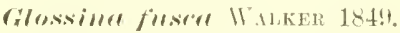

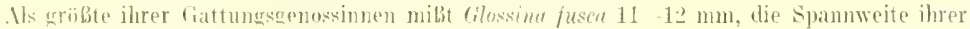
Flïgel kamm in weiblichen (ipchlechte bis zul 30 mun betragen.

Sie ist noch heller gelärht als Mlorsitans nud zeigt in allen hörperteilen die gleiche lellbraune Cirundfarbe. Rürkenzeichnung des Thorax last vollständig verwasehen. Sentellum hellbraun, mit zwei groben verwachenen dunkleren Fleckest. Flägel lebluran mit dunkelbramem

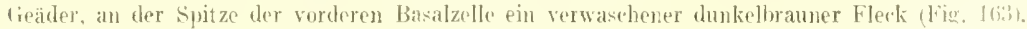

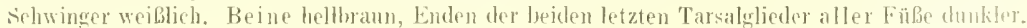

ron allen Zungenfliegen ist fusce die weitest verbreitete, sie lsommt sowhl im der West-als Ostküste des Kontinents vor und ist wie sehon oben hemrikt, die hiufigste Glossine Dentsch-f)stafrikas. Feucht wames Buschland liebt sir wr allem. Sie iiberträgt ebenfalls Nagana. 
Fing. 1 tis.

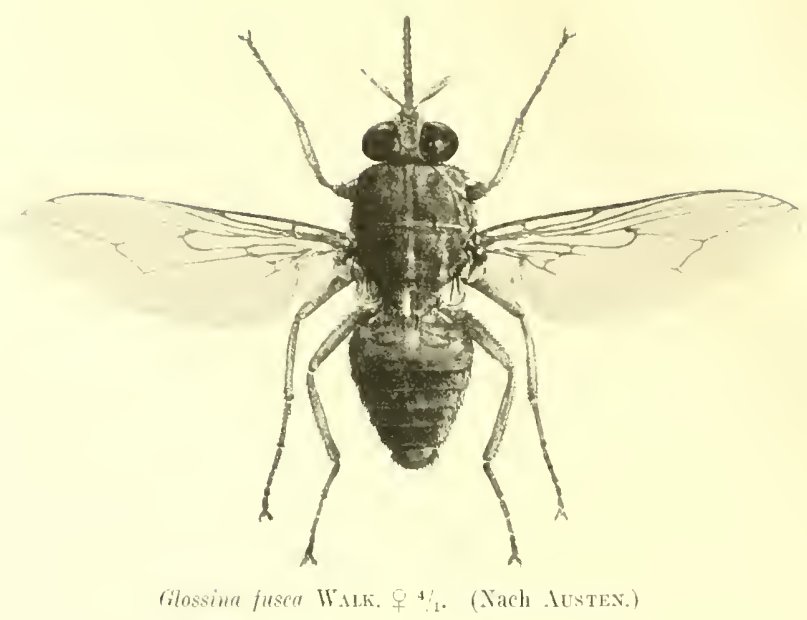

Fang. Inflewahrung, Versand.

Die Glowinen werden am sichersten auf ihren Opfern durch einen geschickten Netzschlag gefangen, oder in taniger Frühe vom vorïberfahrenden boote aus halberstart und träge mnter ihrem Blattsitze mit kler Hand ergriffen. In bezug auf Untersuchung, Konservierung, Verpackung und Versand gilt für die Zungenfliegen alles, was S. 195 und 196 für die Bremsen ampfohlen wurle.

\section{Propliylaxe, Feinde.}

Die persönliche Prophylaxe läßt sich nach denselben Grundsätzen in die Wege leiten, die wir bei den Tabaniden in Torschlag gebracht haben (s. S. 196).

Ton großen Mliteln, die Glossinen zu bekämpfen und womöglieh auszurotten, haben wir bis heute nur ein, aber glücklicherweise ein sehr wirksamcs Mittel: wir nehmen ibnen die Möghichkeit, während der Mittagssomenglut im Schatten zu verdauen und auszuruhen. Das bewirken wir dureh Abholzung des schutzhietenden Gebüsehes an den Stellen, die wir fliegenfrei machen wollen. Gerarle bei der Gebundenheit von Glossina palpalis an relativ schmale Uferstreifen gelingt uns dics bei der Hauptüberträgerin der menschlichen Trypanose glüeklieherweise noch am leichtesten.

bei solehen Abholzungen ist es nieht nötig, die zwischen dem Buschwerk stehenden grolsen Bäume mit zu entfernen, es genügt, wie STEvnec am Moriflusse feststellen konnte, vollkommen, nur das [nterholz und etwaige tief herabhängende Äste abzuschlagen. Das radikalste Hittel bleibt ja immer eine vollkommene Rodung und Ersctzung des Bestandes durch Grasflächen, die dann beweidet werden können. ,Das Sehilf ist mit großen Buschmessem verhältnismäßig leicht. abzuhauen, aber "s wächst raseh wiecker nach. Ein dreimaliges Nieclerschlagen genïgt jedoch, un ein Wieclerwachsen des loolues zu verhindern." "An selor steilen Küsten mit viel Steingerëll kommt es vor, daB die Glossina palpatis auch, nach dem Abholzen nicht versehwindet, weil sie in dem Steingeröl auch naeh 
Niederschlagen des Busehwerk noeh genügend schatten findet: (STrinst.). Solehe sehwer zı samierenden Gegenden mïssen gespert mol dir beriblkermng womöglieh aus dem versenehten Gebiet entfernt werden. DaB an F'luB ̈̈bergängen Abholzungen floppelt gründlich vorgenommes werten und alle bananenha ine usw. in den Ortsehaften entfernt werden müsien, ist selbstrerständlich.

Die Anwendung cines besonderen Leimes, um Glossinen \%u fangen (('LEV) wird you manchen Bobbachtem empfohlen, wäbrems sich die Mehrzahl der Afrikaner diesem Verfahren gegenüber ablehnenul verhïlt. bigegen jst die Anrsenbampe heute wohl von allen Beteiligten für den Glosisnon- und stechmückenfang als unbranchbar erkamet worden (Nocut, Beih. Nr. 4, 1912, S. 150).

Die Grïnde für de'n Milberfolg liegen ja anch auf cles Iland: Glossine ist ein obligates Tagtier und deshalb durch einen Scheinwerfer nicht aus ihrer nächtlichen Ruhe zu bringen. Die śtechmücken sind zwar Dämmerungs- und Nachttiere, aber in Gegensatz zu den meisten Nachttieren so liehtsehen, dals sje wohl aus dem Lichtkegel fliehen, abes nicht in ihn hineinfliegen. Die positiven Ergebnisse, welche in Deutschland mit dem Apparate gewonnen wurden, kam Verf. nicht für unanfechthar halten: Kinliziden und (hiromomiden sind selwo ron „Entomologen:" miteinander verwechselt worlen.

Wie schon oben bemerkt, haben die Glossinen nur wennige leinde in Pflanzennul Tierreiche. Aneh bei ihnen werden ja unter [mständen bakterielle Infelitionen den Tod oftmals ror dem natïrliehen Lebensende herbeifïhren, wir kennen aber bis jetzt solehe Entophyten nieht.

Das bei den Inseliten so vielfach gefährelete Larvenstadium ïhorsteht Glossina im Hutterleibe, und entgeht damit sehr vielen Gefahren, die sonst gerade auf die Dipteremmaden lanern. Die kritisehe Zeit von der Gebmt bis zur Verpuplung weiß die Larve so viel wie möglieh abzukürzen: sie sucht sofort eine geschützte Puppenwiege anf und umgibt sieh in kurzer Zeit mit dem festen Punzer cler 'Tönnehenwände.

Dab Hühner und andere scharrenden Vögel (llexse) hänfig Larven und Puppen rernichten, ist sehr wahrscheinlich. Sie wie alle in Afrika gliicklieherweise sehr häufigen Insektenrögel (Zikм.хx) sind zur Withilfe heranzuzichen und sorghichst zur schonen.

Die fertigen Fliegen sollen meh Leвoecf ror allem ron einer groben, schwarzen Wespe (Bembex sp.) ergriffen, grelähmt und ihren Larven zugetragen werden ${ }^{\mathrm{1}}$ ). Daß spinnen, namentlich Angehörige der L'jsauridenfamilie (Dolomedes z. B.), die obligate bewohner ron FluButem sind, Dipteren und Neuropteren auflauem. wurle von Roubsud am französischen Kongo häufig beobachtet. Derselbe Forscher bemerkte des öteren, daß Ameisen (Pheidole megacephala) sich witend an Glossinen klammern, sich in sie verbeitben und vou ihnen nicht ablassen, bis der 'Tod der Fliege cingetreten ist. Viellejeht beteiligen sich auch Raub- mul Laufkäfer an Glossinenfange; so komte wielerm Rocbatd feststellen, dab während der Regenzeit an den Orten, an welchen viele Zungenfliegen vorkommen, C'icindela interrupta F.1Bricit's massenweise anftrat.

\section{Literatur.}

1912 Ixpersox, J. F. and Frost, W. H.. Lie F'hertragumg der Poliomyelitis duret die Stall-

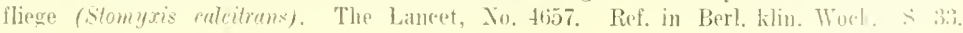
1913.

$\left.{ }^{1}\right)$ Vou Bembex bidentala berichtet F.rore, dab sie sehr oft auf Tahaniden lited mathe. Ebenso soll Bembex oculatu häulig Wadenstecher erbeuten (Bouvier). 
1903 Atstex, E. E., A Monograph of the tsetse-flies based on the Collection in the British Museum, London,

19ut Derselbe, Supplenentary Lotes on the Tsetse-Flies. British Medical Journ. 17. Sept.

1905 Derselbe, The distribution of the Tsetse-Flies. Rep. of the Sleeping Sickn. Commission.

1:Hir Bezzx, M., Die Gattungen der blutsangenden Musciden. Zeitsehr. f. Hymenopt. und Dipterologiè. Bd. 5. S. $413-416$.

1š5 Bugot, J. M. F., Genre Glossina. Ann. d. I. Soe. Entom. d. France, 6. Ser. Bd. 5. s. 121 $-124$.

1912 Boyet, G, et RoubatD, E. Expériences diverses de transmission des Trypanosomes par les ylossines, Bul]. soc. jath. exit. T. T. p. 204.

1:W8 Botffard, G., Du rôle comparé des Cỉossines et des Stomoxes dans l'étiologie de la surrar. Bull. soe. patl. exot. Bd, 1. S. $333-336$.

1912 lerselhe, Quelques considérations dordre prophylactique concermant le Trypanosumu cazalboui. Bull. soc, path. exot. T. V. p. 380 . (lbertragung dureh stomoxys.)

1901 Botrier, E. L., Les habitudes te Bembex. Anuée psychologicue 1900. Paris.

19 (Molver, Giard et Laveran. Instructions pour les reeherehes à effectuer au Congo Irançai. jar la miscion française de la maladie du sommeil.

1881 Bradshaw, B. F., The Tsetre-Fly. Transactions of the Sonth African Plil. Soc. Bd. 2. ล. $51-55$.

18.9 BRt 6 , 1), Furtler Report on Tsetse fly Disease or Nagana in Zulnland. London, Harrisson and sons.

1903 Werselbe, Appendix to Further Report on the Tsetse fly Disease in Zulnland, London.

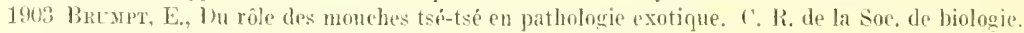
T. H. 1. 14. 140.

1903 Therselbe, Maladie dı sommeil et monche tsétsé. r. R. Soe. de Biologie, 27. Juin.

1904 trerselbe. Sur une nouvelle espece de monehe tsé-tsé, la Grossina decorsei n. sp. provenant de I'Afrique centrale. r. R. de la soc. de biologie. T. LTl. p. 628.

1904 Jerselbe, 1 propos de lia Chossina decorsei. Ebenda, 19. November. s. 432.

1906 l)erselbe, Role parthogène et mode de transmission du Trypanosoma inopinatum Eo. et Et. Sergext. Whenda, Bd. 61. S. 1046.

1903 Castellaxi, A., On the Diseovery of a species of Trypanosoma in the rerebrospinal fluid of Cases of Sleeping Sickness. Prof. iny. Soc. s. 501-508.

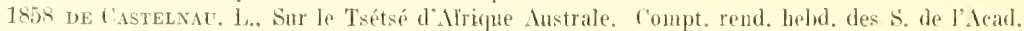
des Sc. Bd. 46. S. $98 t-986$.

1908 (nolookowsis, N., Zur Frage über die Fortpflanzung und Entwicklungsweise der viviparen Fliegen. Arb. d. Kais. Fesellkcl. d. Naturf. zu St. Petersburg. Sitzungsheriehte. s. 106 -108 .

1508 Derselbe, ther den weiblichen Creschlechtsapparat einiger viviparen Fliegen. Zool. Anzeisen. Bd. 33. 18. August.

1825 Torfotr. L., Recherches anatomiques sur l'Hippobosque des chevanx. Amm. Soe. nat. \%uol. YT.

18th bersellie, Études anatomiques ot phỵiologiques sur les insectes diptires de la famille des Pupipares. Eloenda 111.

1901 JALssek, Viviprrität und Parasitismus. Zool. Anz. Bd. 27. S. 761-767.

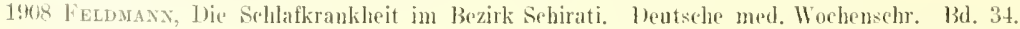
$\mathrm{Nr}, 13$.

1.905 Fraxes, (', Sobre as glossinas da Mriea oriental existentes no Musen de Lisboa. Journ. d. Sci. math., jhyss, et nat. 2. ser. Bd. TII. No. 27.

1912 Fräxki, L., Zur Biologie der Recurrenswirochäten. (Stomoxys) Virch. Arch. Ba. 209. H. 1 .

1894 Giard, 1., ('onvergemen ef poecilogonie chez les insectes. Bull. soc. ent. Fr. (10. Jaumar.)

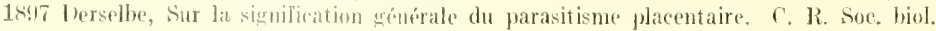

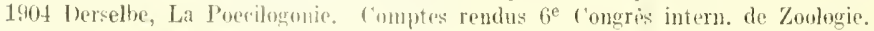

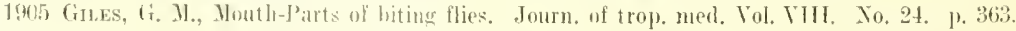

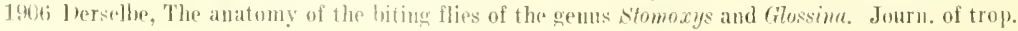
med. No. 7. ]. 94 -10:2. No. 10. 1\% 153-156. 


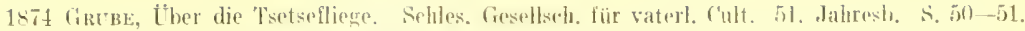

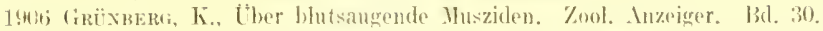

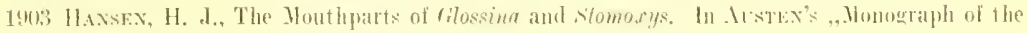
Tsetse-Flies".

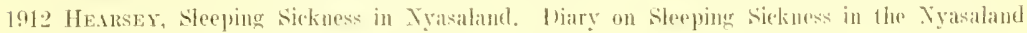
Pretectorate. Part. Xill.

19nt Holmerax, l'ber vivijare Gnsekten, Zool. Jahrb., Mht. lür Systematik, 19.

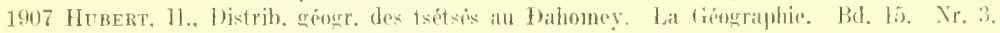

1912 hixinorx, $A$. and Yorke, W.. A Further Report on the Transmision of Ihuman Trypanusomes by Glossinu morsiturs Westw. Ann. of Trop. Hed. and Palas. Be. 1;. II. 2. S. 269 286.

1912 Dieselben, Trrpanosones jnfecting fame and J homestic stock in the luangwa lalley, Xorth Eastem Rhodesia. Ann. of Trop. Yed, and l'arasitology, Serims T. 1]. Bd. 6. No. 3.1. S. 301.

1912 Theselben, Trypanosomes obtained by Fending Wild filossinn moviturs on llonkeys in the Lnangwa Valley, Northern lihodesia. Ann. of Trop. Hed. and Jaras. Bit. 6. H. 3. A. \$. 317 -324 .

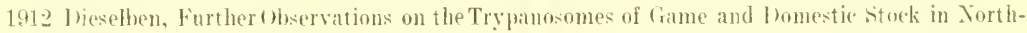
bastern Rhodesia. Ann. of Trop. Hed, and Paras. Bel. 6. It. 4. S. 483-494.

191. Jiesellen, Trypanosomiasis in Game in Cortl-Eastern Rhodesia. Annals of Trop. Ited.

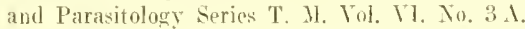

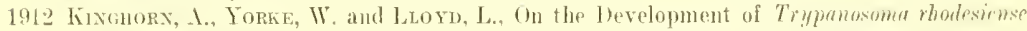
in Glossina morsitums. Inm. of Trop. Med. and Paras. Bd. 1. Il. t. s. $495-503$.

18 in Kirk, J., On the ,.Tsetse" Fly of Tropieal Africa, Gilosinu morsituns Westwoon). Journ. of the Linnean Soc. Bd. \&. S. $119-15 \%$.

1909 Kuerne, Positive Infektionswersuche mit $T$. Imurei durch Glossima pulpalis. Deutsebe med. Wochenselir. Tr. 11.

1905 kосн, R. Vorläufige Mitteilungen üher die Ergebnisse einer Forsclungrseise narch ostafrika. beutsehe med. Worhenschr. Nr. 47. S. 1865. (Entwickhng der Trypanosomen in der Tsetse).

1909 hoch, Beck und Libene, Bericht über die Tätigkeit der zur Erforschung der Sehlafkrankheit im Jahre 190607 nach Ostalrika entsandten Kommission. Wit 5 Tateh und zahlreichen Bhildungen im Text. Irbeiten aus tem Kaiserlichen fesundheitsante Bd. 31. H. 1.

1912 Locr, Bericht über die Fangveruche mit 'leve's Tsetseleim. Areh. f. Schilfs-und Tropenhyg. H. 11.

1883 Jirnepelix, K., Zur Anatomie und Physiologie des Rüisels von Musen. Zeitsehr. l. wissenselr. Zool. Bd. 39. S. 683-719. Mlit 2 Tafeh.

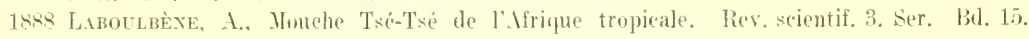
เ. 700 .

1905 Laverax. A., Contribution à l"étude de la répartition des mouches tsét sés clans l'onest africain francais et dans l'état indépendant du congn. C. R. Ac. Sciences. Bd. 141.

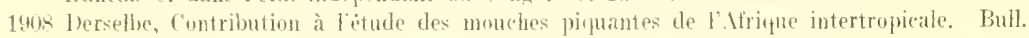
soe. patth. exot.

145. Lecckart, R., Dje Fortpflanzung und Entwickhng der Pupjparen nach Beobachtungen an Melophagus orimus. Wha. d. Xaturf. Cresellseh. in Halle. Bd. 4.

1857 Livingstoxe, D., Miwionary Travels and Researches in South Africa (Tondon: John Murray). S. $79,80-83,487-488,571$.

18,90-1891 Low xe, B., Anatomy, Physiology, Horphology and bevelopment of the Blow lly (Culliphoru orylhrocephulu). London.

1835 Mhrovart, J., Histoire naturelle des insectes. Dipteres. Bd. 2. S. 244-245. Tal. 16. Fï. 1s.

1843 Derselhe, Dipteres exotique nouveanx ou peu comms. Bd. 2.

1904 DE MeIJere, J. C. H., Teue und bekannte südasiatische Dipteren. Bijdrag. tot de Biorkunde.

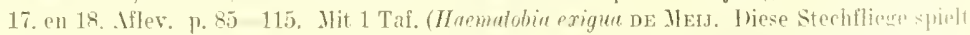
in ()stjava zusammen mit der weit verbeeiteten und allbekannten stomoxys eutrith me $h$. die Hatuptrolle bei der l'bertragung der surra-kiankheit. speiser).

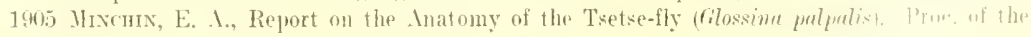
roy. Soc. Ser.-B. V. 76. To. 512.

1906 Derselbe, The Breeding habits of the Tsetse-fly. Nature. Bd. It. 


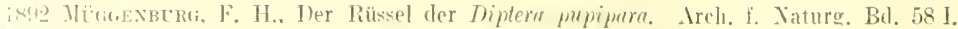

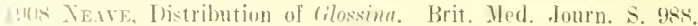

I\&i1 Newnix, E., The Tsetse. The Entomologist. Bd. 5. S. 289-290.

1912 Xewste.n, R., I Tew Tsetse-Fly from British East liriea. Inn. of Trop. Ned. and Paras. Bd. (1) H. 1 3. S. 129.

1907 Newstad, Dettox and Toud, Insects and other Arthropoda collected in the Congo Free State, being the seventh Interim Report of the Expedition of the Liverpool School of Tropical medicine to the l'ongo 1903-05. Ann. of Trop. Yed. and Parasitology. Bd. 1, No. 1.

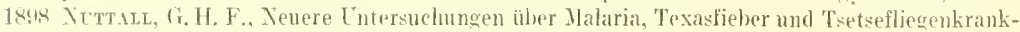
heit. Hyg. Rundschaut. Bd. 8. \&. 108t-1103.

190k Pattox and Stricklaxd, A critical review of the relation of Blood-Sucking invertebrates to the Life eycles of the Trypanosomes of vertebrates. Parasitology. Bu. 1. No. 4.

1813 Pratт, H. S., Beiträge zur Kenntnis der Pujpjaren (Melonhagus ovinus-Larve). Areh.f. Naturg. Bd. 59.

1896 Derselbe. The anatomy of the lemale genital tract of the Pupijarae as olserved in Melophagus arimss. Zeitschr. f. wissenselt. Zool. Bd. 5. S. 66.

1734-1742 DE Réatour, R. A. F., Jémoires pour servir à l'histoire naturelle et à l'anatomie des insectes. Bd. 4, 10e mém.: ,.Des moncles vivipares à deux ailes."

1830 Rorinest-Destoid Y, Exai sur les llyodaires. Bd. 2. S. 389-390.

1912 Rodiux, Poss, Thinerbrandex of Bequent, Trypanoses amimales au Bas-Katanga, rajport avec les glossines. Bull. soe. path, exot. T. T. p. 45, 281, 608.

1912 Irieselhen, Essais de transmission du Trypanosomu gumbiense par la filossimu morsiturs. Bull. soc. patl., exot. T. T. J. $763-770$.

1907 Ross, Pir, heport on experiments carried out to ascertain wheter other species of cilossina besides fil. pulyulis, an carry the human Trypanosome from infected to non infected monkeys. East Africa protectorate. Aple. 11.

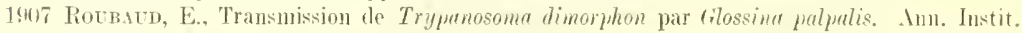
Pasteur, XXI.

1908 Derselbe, Sur la reproduction ot les variations du developpement daus la Cilossinu pulpulis. fompt. rend. .le. des sciences. Bel. 116.

1908 berselbe, Contribution à la biologie de flossinu palqualis. Bull. Soc. path. exot. Bul. 1.

1908 therselhe, Infection naturelle de la trompe des glossines. Bull. Soc. path. exot. Bd. 1. S. 564 -568 .

1909 Lerselhe, Reclerehes liologiques sur les conditions de viviparité et de vie larvaire de cilossinu pulpulis. Compt, rend. Ae. sciences. Bd. 148. S. 195-197.

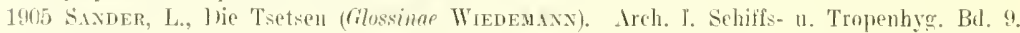

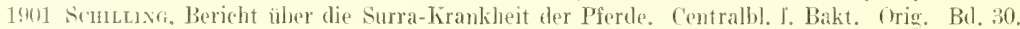
S. $545-551$.

19(1)= Jerscllse, Bericht üher die Surra-Krankheit der Pferde und Rinder im Schutzgebiet Togo. ('entralbl. i. Bakt. ()rig. Bd. 31. Tr. 10.

1stio Simner, J. R., Inie Tsetse-Fljege. Aus ther Natur, Bd. th. S. 783-784.

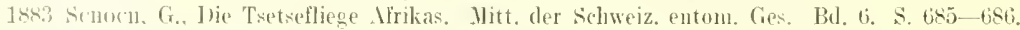

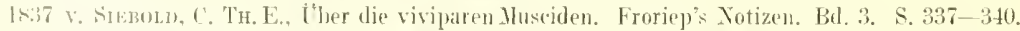

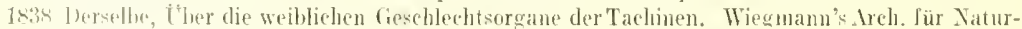
geschichlite. Bal. Ir.

18.96) Sisurn, J. B., Yotes an the Structure and History of Hacmatobin serrala. Psyehe. Bil. 5. S. $343-347$. Nit 6 F Figuren.

1872 Staxizy, II, M.. Ilow I found Livingstone (London). \&. 87-91, 213, 330, 354.

19616 stephens, J. W. and Xenstean, R., The anatomy of the proboscis of biting Flies, liv. Sh. uft trop. med. Ilem. 18.

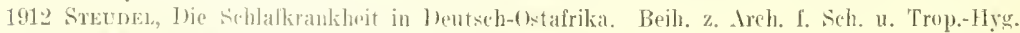
Nr. 4, s. 16 - 1]1. Wit 6 liguren im Text.

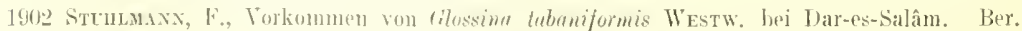

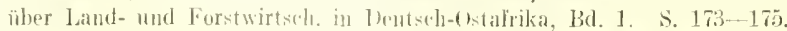

1962 [herselbe, Xutizen übar die Tsetsefliege (Glossina morsitans Westw.) und die dureh sie über- 
tragene surrakrankheit in lentsch-(kstafrika. Ber. uher Land- nul forstwirtsch. in

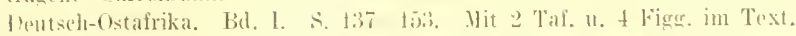

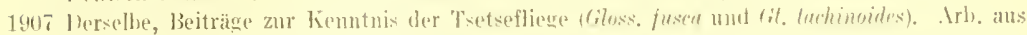
d. Kais. Gesundheitsamte. 13d. 24t.

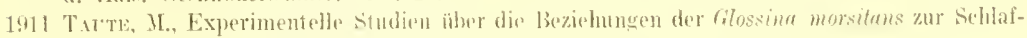
kramkheit. Zeitsehr. f. 11y. H. Infektimlskr. 11. 3.

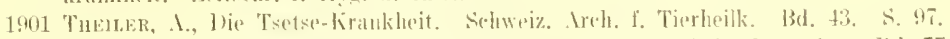

1906 Truboci. F. The internal. anatomy of stomorys. Proce of the Roy. Sor. Ba. 77.

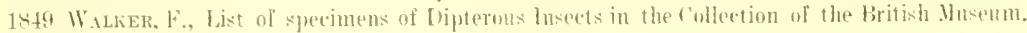
bid. 3. s. 6 is2.

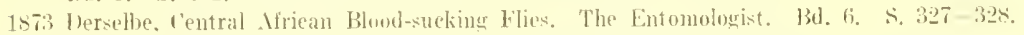

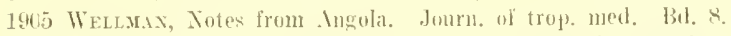

1850 WEstroon, J. O., Obsorvations on the Dustrmetive speries of bipterous luserts known in Cirica under the Names of the T'setse, Zimb and Tsaltsalya, and on their supposed ronnexim with the Fourth Plague of Exgpt. P'roceedings of the Zool. Soce, of London. Bal. 18. S. 25850 . Taf. XIX.

1430 Wrenem.xx, C. R. W. Aubereuropäische zweiflüglige Insekten. Bd. 2. .. 253. Taf. X. Fig. 10.

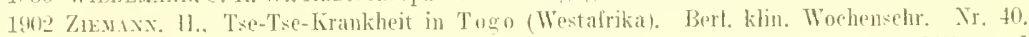

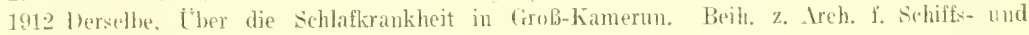
Trop,-Hyg. Mr. 4, S. 112-140. Hit einer Karte.

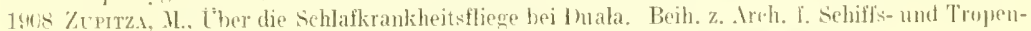

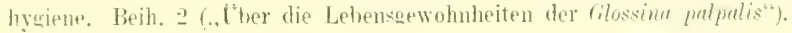

\section{Die Lausfliegen (Pupipara).}

(Eproboscidea LEAch 1817. - Coriaceae 11 ElGEX IS1S. - Hippoboscidae et Nycteribidae SCHINER 1\$64.)

DaB die Pupiparen befähigt sind, beim Saugakte pathogene Protozoen zu ïbertragen, ist mehrfach nachgewiesen worten. So überträgt Hippobosca rufipes (Süilafrika) das Trypanosoma theiteri, Meloplatgus orinus Crithidien, Lynchia maura einen Taubenhämoproteus mol die Nykteribien höchstwahrsebeinlich verschiedene Blutparasiten rler Fledermäuse.

Die Lansfliegen (Pupiparen) sind wie die Eumyiden eehte Kryptochrysaliden (Zrkloraphen) und gleichen flen Muskarien in manchen Beziehungen, zeigen aber andererseits so viele fundanentale Abweichungen in ihrer Organisation und ihrem biologischen Verhalten, dals man sie früher obne jedes Bedenken als dritte große Zweiflïglergruppe (Subotlo) den Mïcken und Fliegen gegenüberstellte.

3ie durch die Pnpiparität gezogene und den alten Lutoren unïbersteigbar seheinende Cirenze gegen die übrigen lijuteren ist mit der gewonnenen Einsieht in die Entwieklung und Fortpflanzung der Glossine nefallen. Die Pupiparit ä ${ }^{1}$ ) hat damit in ihrer systematisehen Bedeutung zwar auberordentlich viel verloren, aber immerhin muB doeh betont werden, daßsie bei du Lansfliegen die Regel, während sie hei den Mluskarien nur in einer einzigen Gattung als Ausualume fest gestellt ist.

1) Man müßte ja in unserem Falle eigentlich von Larviparität sprechen, da dic Lansfliegen ebenso wie die Gilossinen nicht Pujpen, sondern mur erwaebsene Larven gebaten. 
Die Pupiparen sind olne Ausnahme Ektoparasiten (ler Sänger und Vögel ${ }^{1}$ ). Iltre schmarotzende Lebensweise hat im Bau der Lausfliegen tiefgehende Teränderungen hervorgerufen. Wie bei den meisten Ektoparasiten aus dem Stamme der Arthropoden erseheint aneh bei den Pupiparen der Körper dorso-ventral stark abgeplattet ${ }^{2}$ ).

Der Kopf sitzt breit und fast unbeweglich der muschelförmig ausgehöhlten vorderen 'Thoraxfläehe auf. Die sehr kleinen Fiih ler liegen (aus dem bei den Psyllomorphen - S. 71 - angeführten Grunde) in tiefen, hart ror den Augen und in der Nähe des Mundes befindliehen Gruben, auffallend weit von der stets selır deutlichen Stirnspalte entfernt. Die Augen (Komplexaugen und Ozellen) und die Flügel verkümmern in eiuzehen Gattungen und fehlen bei anderen sogar vollständig; dagegen werden die Beine hesonders kräftig und ihre Klauen dureh Bezahmung vorzïglieh geeignet, die Haarsehäfte oder Federkiele ihrer Wirte zu umgreifen und festzuhalten. Wie bei den Flöhen, entwickeln sich auch bei den Lausfliegen aus Reihen kräftiger Borsten anf dem Thorax und Ahdomen ${ }^{3}$ ) mäehtige Stachelliämme (Ktenidien) (Fig. 169).

\section{llorphologie.}

Die Lausfliegen sind mittelgroße, dïster gefärbte (braune Färbung vorherrsehend) Dipteren. Ihr laus- oder spinnenförmiger Körper ist mit zahlreiehen Haaren und Borsten besetzt. Seine beiden vorderen Absehnitte sind durch einen harten, lederartigen (Coriaeeae) Panzer geschützt; das bein Saugen und während der 'Trächtigkeit sich stark vergrößernde Abdomen dagegen ist mit einer weichen, änBerst dolnbaren Chitinhaut überzogen.

Der stets plattgelrückte Kopf erscheint von oben gesehen rundlich oder elliptiseh; in letzterem Falle steht seine längste Aehse meist quer'), der Kopf ist also breiter als lang und häutig an den Seiten noch eekig ausgezogen (Figg. 16Ł_166). Die Stirn ist sehr breit, vorn bogenförmig begrenzt und an den Seiten mit starken Borsten besetzt. Bogennaht stets sehr fleutlieh.

Der Thorax ist breit und ebenfalls stark abgeplattet. Die Coxae der sehr kräftigen, stark behaarten und beborsteten, häufig auch bedornten Beine entfernen sieh weit ron der Merlianlinie (Figg. 164-166). Die sehr breiten Tarsen tragen mächtige Krallen, an deren Basis sich meist ein kräftiger, opponierender Zahn befindet. Die Flügel sind bei vielen Hippobosziden und Strebliden (wenigstens im ò Gesehleeht und zu gewisren Lehenszeiten) gut entwiekelt und mindestens im vorderen basalen Drittel der Fläche durch kräftiges Geäder gestützt (Figg. $167,168)$.

Jas sackförmige Abdomen dor nüchternen 'Ticre erseheint ebenfalls abgeplattet, kann aber hei stärkerer Füllung des Mitteldarms oder des Uterus vollkommen kugelig werden.

1) Nur boulu schmarotzt anf Hymenopteren und weicht aneh in ihrer EntwiekJung von den Hippobosziden, Strebliden nind Nykteribiiden ab: sie gebiert nach Leuckart nicht erwachene Jarven, sondern legt ihre Eier in die Wabenzellen ihrer Wirte ab.

${ }^{2}$ bie P'syllomorphen zeigen ja ebenfalls diese gegen äubere Gewalten sehüzende und die Fortbeweguns in liar- und Federkleide des Wirtes sehr erleiehternde Abplattung des Körpers, bei ihnen abor ist sie ju Gegensatze zu den Zeeken, Läusen, Wanzen, dem Bieberkäfer (Platypsyllus rastoris) nsw. in seitlicher Richtung erlolgt. treterl.

3) Bei den Stroblicln kimmen solehe Stachelkämme aneh am Hinterende des Kopfes auf-

") Die Nykteribien machen cine Insnahme. Bei ihnen liegt der in der Ruhelage messerklingenatig un $180^{\circ}$ \%urückgeschlag'ne längsovale hopf in einer dorsalen Längsrinne cles Rüekenschilkles (Fig. 169). 


\section{Inatomic und Physiologie.}

Die Muskulatur der l'upiparen ist eine selır kräftige: namentlich sind os die Muskeln der Beine, les Thorax (Fig. 16t) und des Cterus, die dureh bosonders gute Entwieklung auffallen. Das Nerrensystem ist im Ban dem der Musziden älmolieh.

lïg. 164.

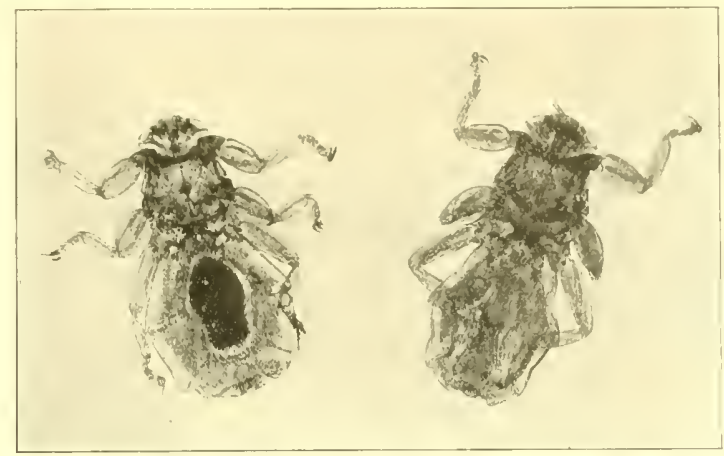

Lipoptena cervi L. $\%$. (Original.)

Links träehtiges Weibehen Rechts Weibchen kurze Zeit uach eler Gehurt einer ausgetragenen Iarve.

Dic Verdanumgsorgane erinnern ebenfalls an die der Muskarien. zeigen aber andererseits doch auch wierter prinzipielle Verschichlenheiten von diesen. bei einzeluen Gattungen ist dex Kopfkegel gut ansgebildet (Hippobosziden), während er bei anderen (Strebliden und Nykteribirden) nur soln rudimentär oder kanm angedentet erseleint. Das Sangrohr brsteht bei den Lausfliegen ebenson wir bei den Stomoxyiden aus der Cuterlippe mit ihren sehmeitenden Labellen, den durchbolirten Hypopharynx mel der den Saugkanal schließrenden Oberlippe. Eingescheidet wird der Rüssel (Fig. 165) bei ten Hippobosziden ron den mäelitig antwickelten, halhrohrförmigen 'Tastern (Maxillarpalpen). Durch einen langen häutigen Kanal steht das stare liusselsaugrolı mit der ganz im Hinterkopfraume liegenden Pharynxpumpe (Fig. 165) in Verbindung. Sie unterseheiklet sich dureh ihre mohr der Saugpumpe der Müeken gleichenre Form und inre Lage
Fiig. 165 .

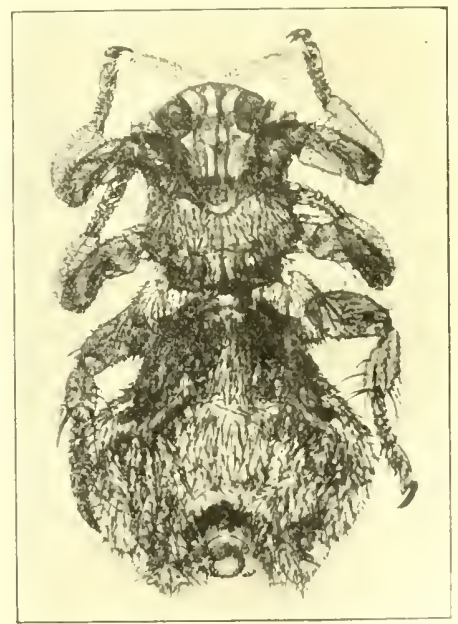

Melophugus arinus L. $f^{14}{ }_{1}$. (1) minal. Palpen und Pharrnxpumpe elouflieh zu sehen. Rituel itber der linken Palpe durrle zwei schmale streilen von lather Palpenlänge leichlit anmedentot. 
10 atfilligstex Weise ron dem Fulerum der Musziten. Einen Vorratsmagen mestzen die Pupiparen nicht.

Am weitesten enternen sich die Lausfliegen von allen ibrigen Dipteren durch den Bau les männljehen und weiblichen Geschleehtsapparates. Es

Fiø. 166.

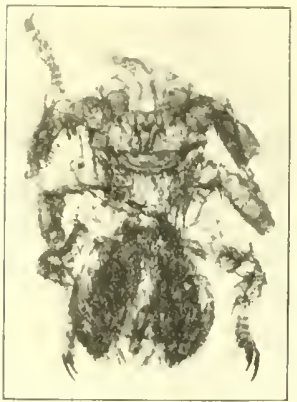

Melophugus ocinus L. ô $\hat{o}^{14} / 1$. (Oriminal.) finden sich zwar vielfaeh Anklänge an den der Glossinen, während andererseits die Gesehleehtsorgane der itbrigen Stomoxyiden gar keine Ahnlichkeit mit denen der Pupiparen besitzen und auch ron denen der Zungenfliegen sich grundsätzlich unterscheiden.

lie männlielıen Geschlechtsteile von Mrophugus, Himpobosea und omithomyia wurden schon in der ersten Hälfte des vorigen Jahrhuiderts von $L$, l)upour in mustergiiltiger Weise lresturieben. Die Hoden sind vou ovaler Form und bestehen aus melreren zylindrischen, zu cinem losen kinäuel aufgewickelter Schläuchen. Die Vasa deferentia vereingen sich nach kurzem Verlaufe zum gemeinsaneu l)uctus ejaculatorius, der daun selır bald die Austiilnungsgänge der stimmgabelförnigen, geralle ver. laufenden Inhangsdrüsen aufnimmt. In weiteren Verlaufe umkreist der Duetus ejaculatorius den Ifter an dessen Hinterseite und nuindet natls vorn umbiegend in den oralwärts gewandten (Fị. 166), krätigen, stark clitinisierten Penis').

Die weiblichen Gesehlechtsorgane der Lausfliegen und die Entwicklung ihrer ersten Stände gleiehen so vollkommen domen der Glossinen, da B ich einfach auf die S. 205 - 207 gegehene Besehreibung derselben verweisen kann.

\section{Biologir.}

Die Pupiparen sind die emzigen Dipteren, die den größten 'Teil ihres Lebens als stationäre Parasiten auf ihren Wirten verbringen. Die über die ganze Erde verbreiteten Lausfliegen sehmarotzen meist auf Gleichwarmen: die Hippobosziden in erster Linie auf den großen Säugem (Equiden, Boviden, Kamelen uкW.), die Melophagen auf Sehafen und Ziegen, die Ornithomyien, Lynehien usw. auf Tögeln. Die Strebliden und Nykteribijden sind ausshließlich Hedermausparasiten. Als einzige Ausnahme wire Braula anf Hymenopteren, zmmeist auf der Honigbiene, gefundent.

Für gewöhnlich halten sieh die Lausfliegen im Haar- und Federkleide ihrer Winte versteckt und verbergen sich hervorgeholt sofort wieder unter dem sehiitzenden ('ewirre. Sie bewegen sich bei dieser Gelegenheit in eigentümlicher Weise krabbehul, inclem sie nach Art mancher Spinnen mit Vorliebe seitwärts answeichen. So ist es verstärdlich, dab man - namentlich dann, wenn es sieh um flïgellose Arten handelte lange Zeit dazu hranehte, die P'upiparen ïberhaupt an die richtige Stelle im System \%u bringen: man zählts sie frïher eben cinfach zu den Läusen.

1) Die $\mathrm{Hoden}$ Won Glosina sind fest gewiekelte linäuel von wesentlich geringerer Gröbe (nicht halb so srob), dio mit einem niclit in die runde llodenmassc einbezogenen Endfaden beginnen.

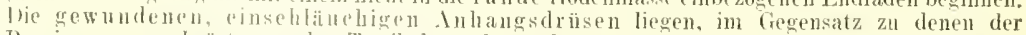
Pupiparen, walwäts von din Textikeln und minden iber (vor) ilmen in den Inetus ejaculatorius ein. Shmorys besitzt wie die meisten Wusziden solide, kıgelige Hoden, kaum sichthare. Inlangsdrisin und vinen gerade verlaufenden l)uctus ejaculatorius, der ohne thon Ilter zu nmgrben direkt in den rïckwäts sehauenden Penis einnumdet. 
Die geflügelten Hippobosziden fliegen im Spätsommer häufig auch den Mensehen an und suchen sich bej flieser Gelegenheit mögliehst rasch im Barte ihres Trïgers zu verstecken.

Die Überwinterung erfolgt meistens anf dem Wirtsticre oder im Pulyenzustande in der geschützten, mögliehst frostfrei ansgewäblten Wiege.

\section{Systrmatik.}

Die systematischen Beziehungen der P'upiparen wrolen hauptsächlich von

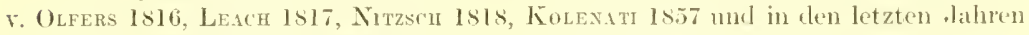
ron S'PEIsER studiert und festgelegt.

Sie zerfallen in fünf Familien mit zahlreichen Gattungen mod Arten.

Die' wichtigsten sind:

1. Rüssel in einer von den Palpen gebildeten Scheide liegend. Hiproboscidae

2. Rüssel ungedeclit.

a) Flügel vorhanden. Fledemmausparasiten . . . . . . Streblidue

b) Flïgel fehlen.

a) Augen vorhanden. Kopf klein, längsoval, in der Ruhestellung auf dem Thoraxrücken liegend. Fledermausparasiten . . Tycteribidae

९) Angen fehlen. Krallen klein. Bienenparasiten ... . Braulidue

Nur ein paar typisehe Formen können wir hicr etwas eingehender betrachten. Niben Melophagus ist wohl die bekannteste Hippoboszide, die Pferdedausfliege,

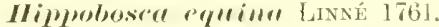

Die brame Fliege ist durchschnittlich $8 \mathrm{~mm}$ lang. Der statk abgeflachte, rundliche liopt liegt der vorderen Thoraxfläehe breit und fest auf. I je peelubramen liomplexaugen sind groli. Ozellen fellen. Die braunen Fühler liegen in einer tiefen Grube mul tragen eine lange, narkte Borste. l)ie breite, hellgefärbte Stirn zeigt eine dunkelloraune Mittelstrieme. Thorax glänzend dunkelbrann mit rostgebben weibumrandeten schultern und geblichen Flecken an llinterrande des seutums. Scutellum gelb mit dunklen Pändern. Flügel brännlicl, dunkelbraun geadert. Halteren schwarz, Beine gelbbrann, die mittleren Sehenkel und schienen mit einem dunketbraunen Ringe, die hinteren mit gleichgefärbtem Doppelringe. Die schwarzen, änßerst krätigen Tirallen schließen gelbliehe Haltläppchen ein. Ablomen braun mit granbramer Behaarung.

Die in der ganzen alten Welt vorkommende Fliege wird hauptsächlich auf Pferden und Rindrieh gefunden.

Die übrigen bekamnten Arten sind meist Afrikaner. Tnter ihnen ist die

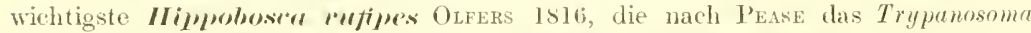

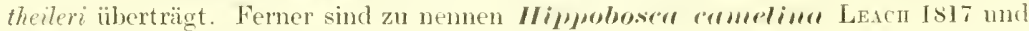

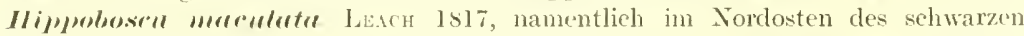
Kontinents rorkommend (Babfole, Fourth Report, S. 351). Mipmobosed struthionis JAXSEN ISs9 wird wahrscheinlich irrtümlicherweise dieser Gattung zugezählt.

Genus Melophagus Latreille 1804.

Die einzige europaische Art ist

Welophuyus m-imls Lixsé 1761.

die allbekannte Schafla us. Die $5 \mathrm{~mm}$ lange, braune, stark behaarte Fliege selunarotzt ausschließlich auf Schafen mol Ziegen; in den Weichen der Lämmer wird ste físt ausnahmslos angetrotten. 
Kopll tuerowal mit deutlichen AuBenecken (Figg. 165, 16ii), dem kaum gröberen Thorax at anlixgend. Die sebr kurzen, knopflimmigen, von zahlreichen Borsten hestandenen Füller Jngen in tiefen Gruben an den seiten des breiten Entergesichts, direkt vor den kleinen, schmalen Kinnplexaugen. Ozellen fehlen. Die seln breite stirn ist an jhren Aubenrändern beborstet. hidstel hurstenfömig, von ten Tastern eingeseheidet. Thorax glänzend rostbraun. Das kleine scutellum trigt eine Borstenreihe. Flügel nud sohwinger fehlen vollkommon. Beine äulerst kriftig, mit langen Hatren, Borsten und J)ornen bexetzt. Der breite FuB besteht anss vier sehr lumzen (irundgliedern und einen wesentlich größeren Endgliecle (es ist fast so lang als seine Vorganger zusammengenommeu). Die sehwarzbramen Kirallen sind auflallend grob und tragen an ter Basis je eine Tebenkralle. Pulvillen und Empodium vorhanden. Das sacklörmige, nach hinten sich verbreiternde I h domen trägt auf seiner vorderen Rïclienfläche zwej rundliche, dunke]uchähte ('hitimplatten (Fig. 165). Da es in den öbrigen Teilen vollkommen weichhäntig ist, sieht man häulig die barmkontenta wut den Lomib des grariden Eterus durch die Baueledecken linfurehichimmern.

Wтвренахx führt (in seinen, auBerenropäischen zweiflügligen Insekten " anf S. 613-614) noch drei weitere Arten an: Melophu!gus moselli PaLcts ans

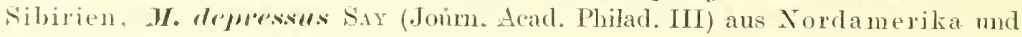

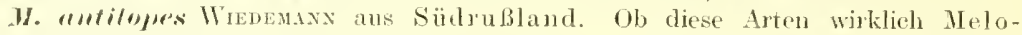
phagen sind, oder ob sie dem folgenden Genus zuzuzählen, welehes zu Wresenıxx's Zeiten von Mengex mit dem Genus Melophayus zusammengeworfen wurle (,, Melophurgus creve*), läbt sich heute nieht mehr entschejden.

\section{Genus Lipoptena Nitzsen 1818.}

\section{Lifoptemet ereri Lixwe: 1761.}

Die braune, der schaflaus ähnliche, 6 mm lange Flicge lebt auf Hirschen und Rehen. Sie ist in Europa weit verbreitet und anch in siidafrika gefunden worken (Figg. 164, 167).

Fig. 167.

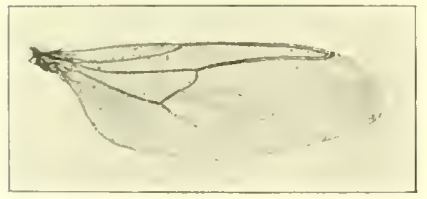

Lipoptene cervi L., rilügel, s/1. (Original.)
Fig. 168.

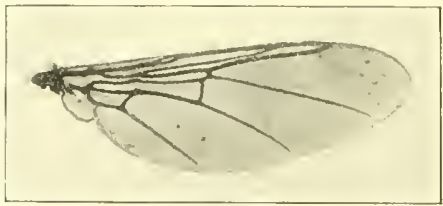

(mithom yie aviculeria L., Flügel, ${ }^{8} / 1$. (Original.)

Komplexangen wröber als bei Veloghngus, (Ozellen stark zurïkgebildet. ThoraxgräBer als der hupli. Sentellum uicht hall, so breit als der Rïedsenschild. Die groben Flügel werden ren den sehuarotzendin Fliegen bis auf kurze Wurzelstummel abgeworfen. Der Hinterleib ist in seincon vorderen Teilen mit fester, dunkler gefübter Chitindecke ïberzogen. Die Tergite der hinteren bautelsegmeste sind schwath angedentet, die zngehorigen sternite gar nicht ausgehililet.

Die ïbrigen zu den Jippobosziden zählenden Gattungen sehmarotzen nur anf Vägeln. Die bekanntesten europäischen Vertreter sind Orvithomyin arirul,ria

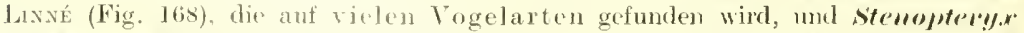
hirmmlinis Jsxxe, die nur auf Schwalben rorkommt. Aus Nordafrika sind

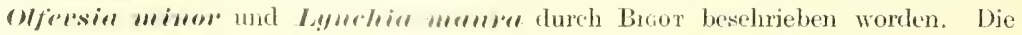
letztere überträgt, wie schon oben bemeskt, einen Blutparasiten auf 'Tauben. 


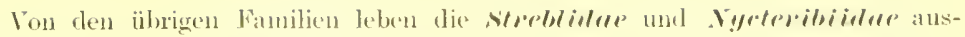
tchlieblich auf Fledermäusen. Die crsteren kïnen noch gut alusgebildete Flügel sagen, die letzteren dagegen sind stets f'lügellos. Die auf tropisehen ('hirop teren sehmarotzenden Arten erreichen häulig ene recht bedeutende Gröbe (Fig. 16!).

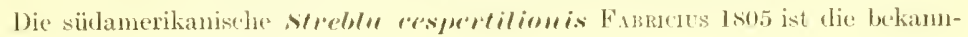
teste Angehörige ihres Fannilic.

\section{Fig. 16?}

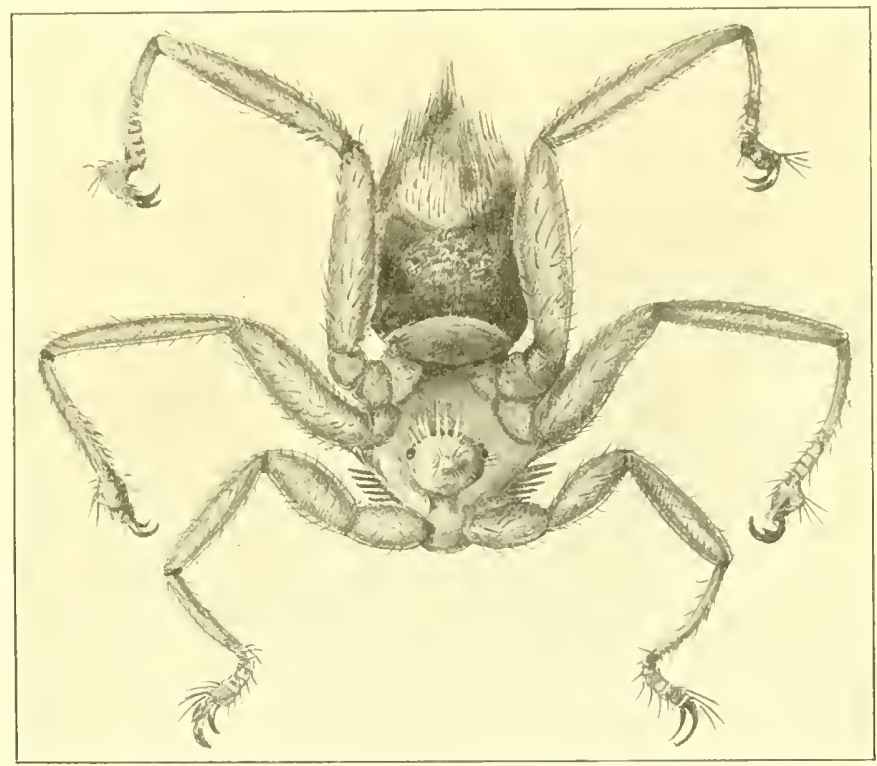

Cycloportin horsfieldi ne Merjere. ${ }^{15}{ }_{1}$. (Original.)

Die Prothorakalktenidien zwisthen erstem und zweitem Beinpale gut erkennbar.

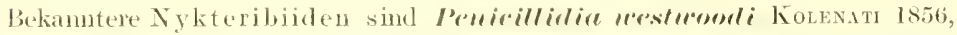

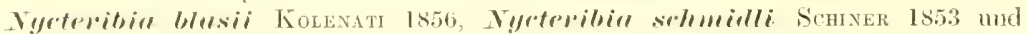

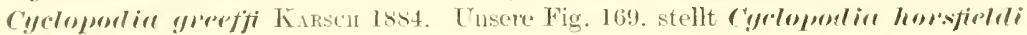
De Mejure (lar $\left.{ }^{1}\right)$. Das aus Java stammente Tier wude auf einem weiblichen Pteropus spec. gefunden.

Man möchte fast sagen als Kuriosun bleiben damn noch die Romulidur äbrig. Sie werden durch die einzige Art Burould refere Nitzsen Isls vertreten. Die nur einen Millmeter langen, milbenartig aussehenden Tiere wurden bis jetzt ansschlichlich auf der Honigbiene getunden.

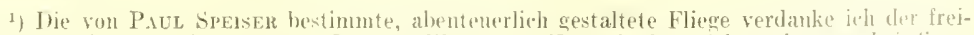

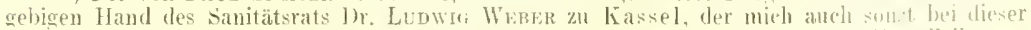

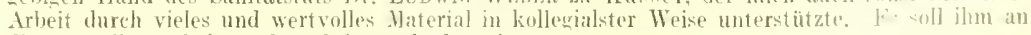
dieser stelle noch besonders dafiar gedankt stin. 


\section{Fang, Iufhewalırung usw.}

Die an ihren Wirten aufzusuchenden oder mit dem Netz erbeuteten Lansfliegen werden am besten in $75 \%$ Alkohol konserviert, weil getroeknete Exemplare dureh die starke Einschrumpfung des Abdomens ein unnatürliches Aussehen annehmen. Für anatomische Untersuchmgen und die Herstellung mikroskopiseher Präparatc. gelten alle die bei den voraufgehenden Familien und Ordnungen gegebenen Vorschriften.

\section{Literatur.}

191:3 Atstex, E. E., Notes on Hippohoseidae. Ann. Xat. Hist. ser. 7. Bd. 12, s. $255-266$.

1911 B.uffour, A., Fourth Report of the Wellcome trop. res. Lab., Lhartum. S. 351 (Hiprobosext cumetina. H. maculuta, Lynchia exomata).

1885 Bit;ot, J., Famille des Anomalocerati. Anm. soe. ent, de France. Ser. 6. Bd. 5. S. 225-24t6.

1825 Drfour, L., Reeherches anatomiques sur l'Hippobosque des chevaux. Ann. scienc. nat, Bd. 6 .

1831 Derselbe, Deseription et figures de la Xyetéribie du vespertilion et observations sur les stigmates des Insectes pupipares. Ebenda. Bd. 22. S. 372-384.

1845 Inerselbe, Études anatoniques et physiologiques sur les Insectes diptères de la Famille des pupipares. Ehenda. Ser. 3. Bd. 3. S. 49-95.

185 tj Kolex.1t1, F. A., Jle Parasiten der Chiropteren. Brünn.

1 sil4 Latreille, Hist. nat. Inseet. Crust. Bd. 14. S. 402 (Jelophagus).

1817 LEAch, W. E., On the Genera and Species of Eproboscideous Insects and on the arrangement of the Oestraceous Insects. Edinbourgh.

15.58 Letrkart, R., bie Fortpflanzung und Entwiekilung der Pıpiparen. Tach Beobachtungen an Melophugus orimes. Abh. d. Naturf. Ges. zu Halle. Bd. t.

1909 Massoxat, E., Contribution à l'átude des Pupipares. Annales de l'Ĺniversité de Lyon. I. Sciences, Hédecine, Fase. 28.

1892 Müriexberg, F. H., Der Rüssel der Diptera mpipam. Areh. I. Naturgesch. Bd. 58.

$1 \mathrm{R} 16 \mathrm{f}$. OLfers, J., De vegetativis ef animatis corporibus in corpore animato reperiundis. Dis:. inaug. Gättinges.

$18 \times 6$ Neutuls, G. H., biptera marehica. Eproboseidea. S. 34t-348.

1909 l'ease, H. T., Trypanosoma theileri Liverax and Galziente (Hipqobosen mufipes). dourn. of trop. Veter. Se. Bd. IV. p. 532.

1893 Pratt. H. S., Beiträge zur Kemntnis der Pupiparen (Melophugus oxinus-Larve). Arch. f. Naturg. 59.

1899 ]'RtT, H. S., The Anatomy of the Femal Genital of the Pupipara as observed in Melopinums orimes. Zeitsehr. 1. wiss. Zool. Bd. 6it.

$1734-1742$ de REAume, R. A. F, Hémoires pour servir à l'histoire naturelie et à lanatomie des insectes. Bd, 4, 100 mém.: .,Des mouches vivipares à deux ailes".

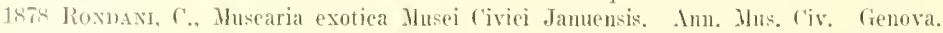

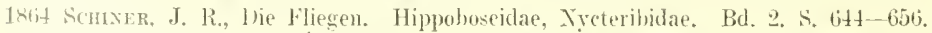

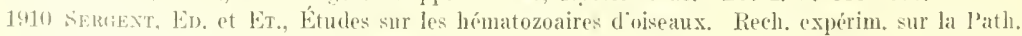
Alerienne. 1902-1909 (Lymchia mauru).

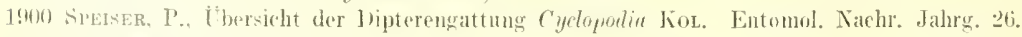
S. $289-293$.

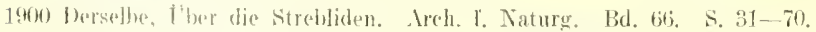

1901 Werselthe, I'ber die Xyertoiden. Ebenda. Bd. 67. s. 11-78.

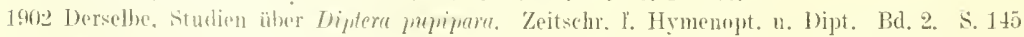
$-180$.

1902: Derselbe, Bespredinng einiger Gattungen and Arten der Diptera pupipara. Termeszet. Fuzeter. Bd. 25. ऽ. 327.

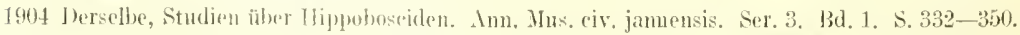

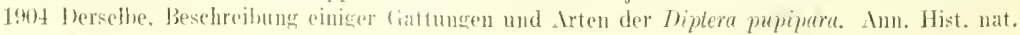
Mus, nation. Hungar. Bd. 2. ¿. 3\$6b-345. 


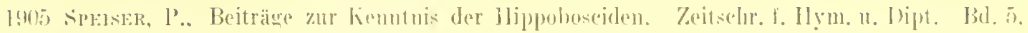
$\therefore 34 \vec{\imath}-3(i)$.

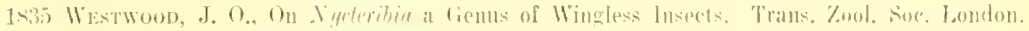
Bu. 1. S. $275-244$.

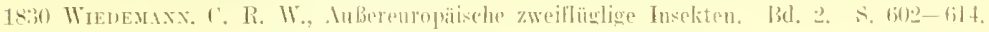

\section{B. Die Krankheitserreger unter den Gliederfïisslern.}

Alle bisher anfgeführten Arthropoden ïbertragen nicht allein pathogene Kéme auf Menseden und Tiere, sondern machen diese, anch wenn sie selbst nicht intiziert sind, mit den beim Sangakte stets einfließenden Eigengiften bis zu einem gewissen Grade krank. Meist sind die dem stiche folgenden pathologischen Erseheinungen rein örtlicher Natur und rasch rorïbergehents: es liommt zu leichter Rötung und Schwellung, zu kleinen Blutaustritten und Quaddeln, die nach einigen Stunden oder Tagen wieder spurlos verschwinden. Bei der verhältnismäligen Kleinheit des Angreifers ist dies ja anch sehr begreiflich ${ }^{1}$ ). Frobere Arthropoden (Tlornissen z. B.) dagegen können, namentlich wemn sie in Hehrzahl einen HInschen angreifen, schwere Allgemeinaffektionen und den Tod herbeiführen.

IIemn wir sehen, dals moter solehen Verhältmissen sogar msere großen llanstiere (bei Jferden mehrtach beolbachtet) zugmmele gehen, so kann es nicht wundernehmen, daß in den Trojen mit ihren weit größeren und giftigeren Fomen nicht selten namentheh Kinder den Stichen von Hymenopteren, Skorpionen²), den Bixen won Giftspimnen und skolopendren ertiegen.

Aus dem Angeführten ergibt sich schon, daß in der Mehrzahl der Fälle von den lswankmachenden Arthroporlen (so auch ton den mit Nexselharen ausgerïsteten Schmeterlingsraupen) das (fift nicht bei der Nahrungsaufnahmo, sondern zum Zweeke der Verteirligung in ten Körper des wirklichen orker vermeintlichen Gegner's eingeftihnt wird.

Andere Gliederfübler wierterum schädtigen den Menschen oder seine Haustiere als stationäre Parasiten: die cinen verbringen ihn ganzes Leben auf orler in dem Nahrungspender (Arachnoïleen, Pedikuliden usw.), die anderen wenigstens einen 'Teil tesselben. So durchlaufen viele Zweifl ïgler ihr Larvenstarlimm in der Haut, den Leibeshöhlen ofler den Darmkanal von Alenschen und Tieren, während die Weibchen von sarcopsylla nach der Begattung in der Hant ihrer Wirte schmarotzen.

1) Wem sie Ireitieh in zahllewer Mlenge ihre (1pfer befallen, sind sellst winzige Insektan, wic

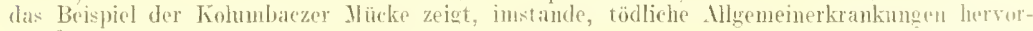
zurulen.

2) In den Vereinierten staten werden hente systematisch viele ('hinesenkinder, wo

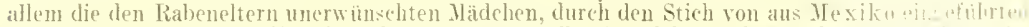
skorpionen getötet. Es soll sich ein schwngroller Handel mit diesem liehensutfolsen lin-

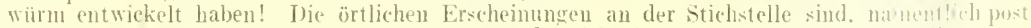
morten, so wenig auflallende, dab die Todesursache nicht festgestehlt werden kinn: ..dir anmen Finder sterben an Krimpfen".

Mens:. Handluch der. Tropenkrankheiten, 2. Aut. I. 


\section{Crustacea.}

lhas ganze Heer der Krebse kommt als Krankheitserreger kanm in Betracht, denn die bei manchen Menschen nach KrebsgenuB auftretende Trtic aria und et waige Quetschwnden, welche dureh die mächtigen Scheren großer Podophthalmata gelegenthich gesetzt werden, sind wohl das einzige von ihnen angerichtete Unheil.

tinter den

\section{Spinnenticren (Arachmö̈lea)}

dagegen befindet sich in der Mehrzahl der Ordnungen eine größere Anzahl von Sehädlingen. Gleich die erste Ordnung

\section{Linguatulida, 'Zungenwüıme⿰}

besteht nur aus höchst lästigen und vielfach auch gefährlichen Sehmarotzern.

Wie schon der Name sagt, besitzen clie Tiere Wurmähnlichlieit und zwar eine so große, daß es vicler Jahrzehnte bedurfte, bis ihre Organisation und flamit ihre Zugehörigkeit zu den spinnentieren erkannt (LEUeKaRT) wurde. In frühester Jugenel nämlich haben sie ausgesprochene Milbencharaktere und exinnem entschieden namentlich an Demodex follieulorum, werden aber in weiteren Verlaufe ihres Lebens durch ihre parasitischen Gewohnheiten (wie wir das ja bei vielen niederen Krebsen auch beobachteten) fast bis zur Unkemntlichkeit verändert.

Der Körper der erwaehsenen Lingnatuliden ist langgestreekt, wmonförmig (Figg. 170, 172), abgeplattet orler walzenförmig und mehr weniger deutlich geringelt; die drei Hauptabschnitte sind (wie bei den Milben) vollkommen miteinander verschmolzen. Am rorderen Leibesende befindet sich die eiförmige Mundöffnmm, an deren seiten je zwei eimzichbare Chitinkrallen liegen. Der den Körper in gerader Richtung elurchlaufende Darmkanal mündet am Hinterende des Tieres aus. Das Zentralnervensystem besteht in der Hauptsache aus einem Schlundringe; höhere Sinnesorgane, ein Gefäßsystem und Tracheen fehlen vollkommen.

Die Geschleehtsöfnung der um rieles kleineren Männchen liegt anf der Bauchfläche und ist sehr weit nach vorn gerïckt, während lie ebenfalls ventral liegende Vulva sieh in ter Nähe des Afters befimlet. Die Zungenwümmer legen ovale Eier, welche ron je einer Gallert kugel ungeben in froschlaichartigen Klumpen ofer schnüren (ähnlieh dem Laiche ter Kröten) abgesetzt werden. Die winzige Larve gelangt über emen Zwischenwirt schlieblich an ihren endlichen Bestimmungsort, die Nasenhöhlen von Säugern (Linguatula) oder die Lungen von Reptilien (Porecephulus).

Cienus Linguatula Frömuen 1789.

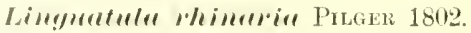

(Synonyme: Tarmia thinuria Prber 1802. - Polystoma taenioüdes RudolpiI

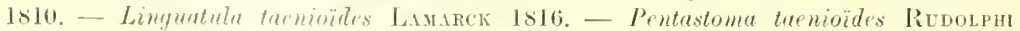
1s19. - Als Larve auch Pentustoma denticulatmm Rudolpm oder Linguatula serratu. Frönucio genamnt.)

Die erwathenen 'Tiere sind ron geblich weiker Farbe. $\hat{s} 18-20 \mathrm{~mm}$ lang: vorn 3-4, hinten $1,5 \mathrm{~mm}$ breit; - s0- $130 \mathrm{~mm}$ lang, vorn $8-10$, hinten $2 \mathrm{~mm}$ breit. 
Der langgestreckte, dorsovemral stark abgeplattete Körper setzt sich ans et wa so

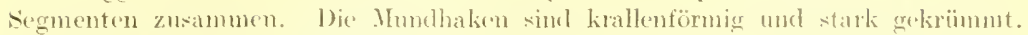

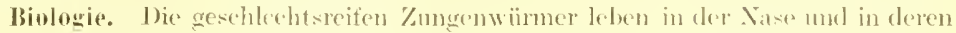
Nebenhöhken (namentich den stimhöhlen) ron Kanisen (Hund, Fuchs, Wolf);

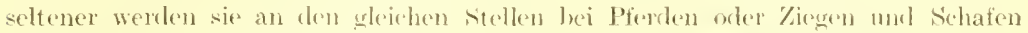

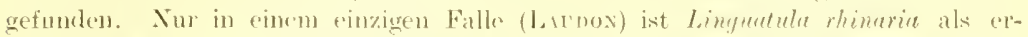
wachenes 'Tier in der Nase rines ostpreubixchen Reservisten nacherewiesen worden,

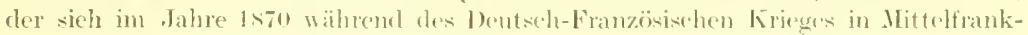
reich, wo Limgutula hesonders häıfig vorkommt. infiziert hatte.

Fig. 170.

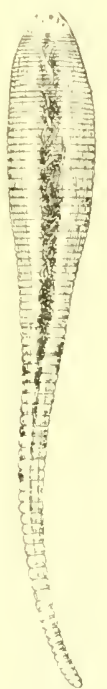

Fig. 171.

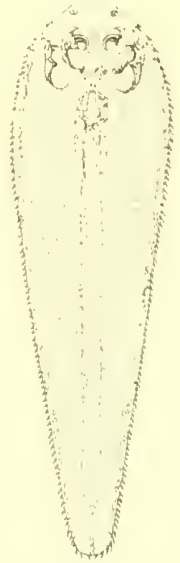

Litrse son Linquefule thimerin. 15. (Pentustsume dinelirulatum.)

(Xach Leiveist.)

Limgutulu thimeria 2. '1.

(Nach Brirx.)

Die /ungenwïmer erzengen eiterige, mit Geschwïrbliklung einhergehende Schleimhautentzündungen unel hänfiges Nasenbluten.

Die eifömigen Ovula sind $90 " \|$ lang unr $70 \mu$ breit. Mit dem Nasenschleim gelangen sie meist durch Niesen ins Freie, z. B. anf Gras und werden dam ron pflanzenfressenden säugem mit der Nahrung verschlmgen; gelegentlich infiziert sich awch eimmal ein Mensch, so namentlich im Cirase lagernde und essende Hirten. In den Magen gelangt schlüpfen :lic sehon bci der Geburt vollkommen entwiekelten 120 " langen Larven alsbahl. Ihr eiförmiger Körper länft in einen gleiehlangen Schwanz aus und trägt neben rudimentären Mundwerkzengen an jecler Seite zwei stummelförmige Extremitäten. Gerade auf diesem Entwicklungszustande ist die Milhenähnliehkeit der Zungenwïmer eine grobe. Die Tierchen dringen in die Blut- und Lrmphbahnen des Darmes ein uml gelangen fortgeschwemmt in die Lrmphlrüisn des Gekröses, in die Lungen und in die Leber. Hier werden sir eingekapscit und treten nach mehrmaliger Häutung $5-6$. Innate alt geworden in das zwe ite Lidrenstadium ein. Sie haben inzwischen eine länge von etwa 5 mm crreicht und gleivhen bis auf die ctwas gedrungenere Gestalt den (rwachsenen Tieren (Fig. 171). Die 
hörjeringe, welehe lrei den fertigen Zungenwümern glatt und unbedornt erseleinen, tragen hei den Larven je eine Reihe analwärts gerichteter, dichtstehender Domen anf ihrem Ilinterrankle. Anf diesen Stadinm angelangt sprengen manche Larven die \%ystenwände und gelangen je nach ihrem sitze in den Peritonealsaek oder in die Pleurahöhle und die Lungen. Daduch, da B sie in die Bronchien geraten, können bei Herbivoren dureh aktive Wandermng der Larve in die Nasenböhle Selbstintektionen mit ausgereiften Zungenwïmen 'ntstehen. Die Kaniden infizieren sich unter gewöhnliehen Verhälnissen dureh den Genuß larvenhaltiger Eingeweicle (hauptsächlich der beher und Lunge) von Hasen, Kaninchen usw. Die Larven werden dann dmeh Verdanung ron ihren Zysten befreit und wandem auf dem Wege des Öophagus mol des Rachens in die Nasenhöhle ihrer definitiven Wirte ein. 1lier angelangt wirft das 'Tier die dornige Larvenhaut ab und damit ist die Imago fertig; nach etwa einem halben. Jahre ist sie vollständig ansgewachsen und verbleibt nun viele In Inate, ja selbst jahrelang in dem inr zusagenden Schlupfwinkel unerkannt und unbehelligt am Leben.

Diagnose und Therapie. Die Diagnose ist nur bei endliehem, meist durch Niesen erfolgenden Abgange des altersschwachen Parasiten oder dureh Nachweis der Eiehen in dem eiterigen Nasensehleime zu stellen. Steht sie ferst. so wären Nasenspühngen mit desinfizierenden Flüssigkeiten (Kaliumpermanganicumlösung z. B.) older (hloroformwasser zu versuchen, und wem diese in Stich lassen, die Stimole' Oberkieferhöhle zu eröfnen. Gegen die Jarsen (das sog. Pentastomum denticulatum), wetche ziemlich häufig namentlich im Osten Dentsehlands und in Österreieh bei Obduktionen gefmolen werlen (bis zn $5 \%$ ) sind wir natürlich machtlos. Neist verkalken die Tiere schließlich in ihren Zysten und werden ähnlich wie Trichinen als mseluldige (orpora aliena, unerkannt währent des Lebens, rom 'Träger weiter beherbergt. In anderen Fälen aber können wandernde Larven in die groben Sürperhöhlen vorgedrungen selbst tödlieh verlaufende Peritonitilen und Pleuritiken lervorrufen.

\section{Gemus Porocephalus II meont 1sil.

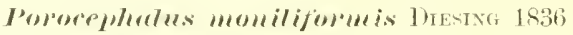 \\ (Sinonym: I'entastomum constrictum BuLnaz-v. Siebolv 1s.jl)}

und

\section{I'mocephalus armillutus WrMAX 1848 \\ (Sirnonym: Pentestomum polyzomum HarLer)}

sind nach looss identisch. Sie schmarotzen beide in den Lungen und der Nasenhöhle grolber atrikaniseher Sehlangen (Boa constrictor, Boa imperator, Python sebae, Python regius. P'ython molurus, Python reticulatus, Bitis nasicornis, Bitis arietans, Bitis

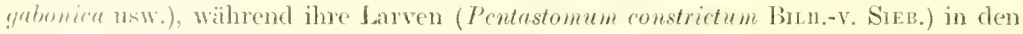
inneren (trganer: klemer sänger und auch gelegentlich beim Menschen gefunden werten. (Das Veripeisen von Riesemschlangen ist bei manchen Stämmen Westafrikas nichts T'ngewrihnliches und so eine Infektion erklärlieh.)ํ)

Simbon, ler anch in Porocephalus moniliformis und Porocephalus armillatus zwei verschichene Arten sicht, heschreibt in Nr. 7 des Ioum. of trop. Aled. Hyg.

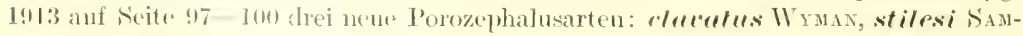

3) Sinzox, der sich in den lotzien Jalıren eingehend mit den Linguatuliden beschaftigt lat, nummt an, dab die tier von I'trocruhulus in das Badewasser der Schlangen übergelsen und

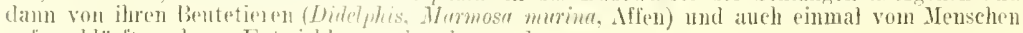
anfyeschliirft und zur Entwicklung gehracht werden. 


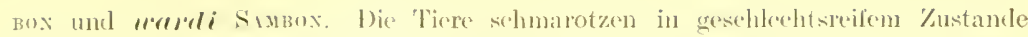
sämtlieh in großen Schlangen und Eideehsen ron siid- und Mithlamerika, sind etwas kleiner, als die Afrikaner und viel wmmïhnlieher als diese.

Von Linguatula untorscheidet sieh Porocrphalus banptsächlich threh seinen drehrunden Körper, die eigentünliche form mel Anordmung der weniger zilhlreichen Segmente (vgl. Fig. 17o), dir besser cntwickelten sensitiven Papillen

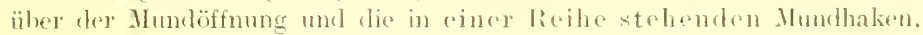

Fị. 17:.

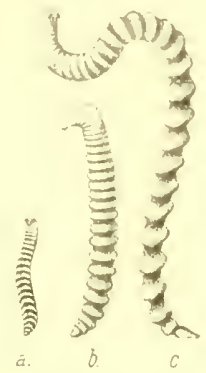

Fi… 173.

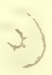

Porocephalus moniliformis. 1 . 1. Latre (= Pentasfomum ennstrictum) aus der Leber voll ('oreopithecus wlboguturis (sudan). b. e. nuntmabliche reschlechtsformen ans der Lunge von I'ython sebue, b. jünger. r. erwachsen. (Tach Looss.)

Penlastomem inonstrichem. ${ }^{1}$. Aus der Lelow des Menschen. then enzystiert, unten frei. (Xach Bil.hizz-ฯ. Siebold.)

Biologin. Über die Entwicklung ron P'oroceplualus ist noch wenig bekannt, sie dürte sich aber wohl ganz ebenso abspielen, wie the von Limuatulu. Beim Mensehen sind bisher nur Larven und zwar in denselben Organen und an denselben Körperstellen gefunden worden, welche auch für unseren Zungenwum in Betracht kommen. Die enzystierten Larven werden meist zusammengerollt gefunten (Fig. 173-I78) und erzengen in dieser Lage vor allem in der Leber kreisförmige, leicht erhabene (,,moniliformis") (iesehwiilste. Die von ihnen hervorgerufenen krankhaften Erseheinungen (..Porocephaliasis") gleichen den von Limguntula bedingten vollkommen, nur pflegen weit heftigere Bronehitiden und nicht selten auch lobuläre Premmonien naeh dem Eindringen der Larven in die kleineren luftröhren einzutreten. Siedeh sich Larven in der Nähe des Gehimes oder seiner Häute an, so kömnen sie Meningitirlen und Geisteskrankheiten veranlassen (Ribrier, Wravow). Gesehleehtsreife Formen in der Nasenhöhle sind bis jetzt beim Menseluen noeh nicht gefunden worden ${ }^{1}$ ).

Während man bisher annahm, daß Porozephaluslarven selbst in Kíamerun, wo sie doch hauptsächlich gefunden $\pi u r d e n$, zu den seltener vorkommenden Krankheitserregern gehören (S.M воx konnte allex in allem nur 16 einsehlägige Beobachtungen

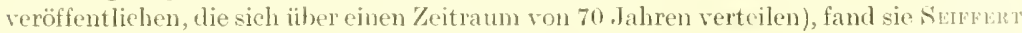
bei 2Is Obduktionen ron fabigen Bahnarbeitern in Kamerun allein 17 mal und

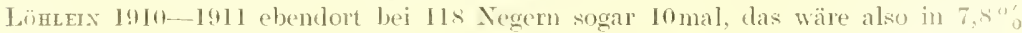
und über $S^{\circ}{ }_{0}$ aller sezierten beichen. Iffen scheinen noch viel häufiger an L'oro-

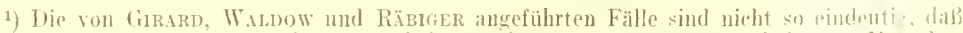

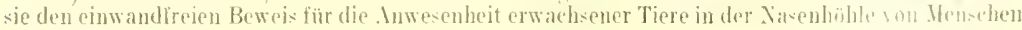
erbringen könnten. 
zephalianis zu leiden; so fanden Brodex und Rodhas unter :3 Tieren $9\left(29^{\circ}{ }_{0}\right)$ mit Porozephaluslarven behaftet.

Fig. $17 t$.

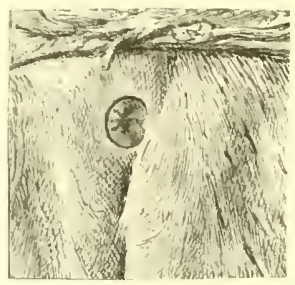

Porozephaluslarse in natiurlichen situs anf der Leher. ${ }^{1 / 1}$.

Fig. 176 .

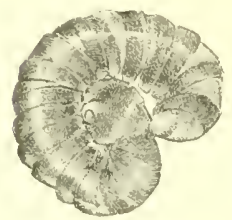

Porozephaluslarve aus ihrer Kapsel heranspräpariert. ${ }^{4}{ }_{1}$.
Fig, 175.

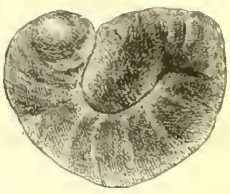

Porozephaluslarve mit ihrer bindegewelsigen kajsel. ${ }^{4} ! 1$.

Fig. 17T.

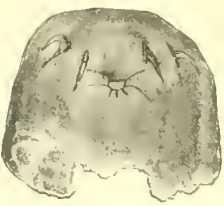

Porozeplatuskopf son der Unterseite. ${ }^{10}{ }_{1}$. (Fig. $174-177$ nach FülleBorx.)

Fig. 178.

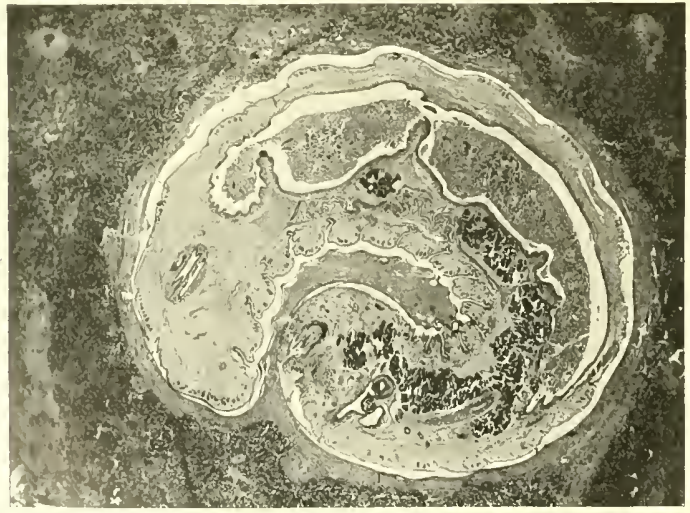

kingekapiete Porozephalustarve in der Leber. (Nach Limberv.)

LönLerx. der alle hishes publizierten Wälle (in: Beiheft a des Areh. f. Sehiffsund 'Tropenhyg. 1912) in lietracht zieht und kritiwch beleuchtet, lommt zu dem Resultat, daß3 lxim, "Clberblicken des gesanten bisherigen Beobachtungsmaterials 
sich zunächst ergibt, dab die Einwanderung unt Ansiedelung der Larven von Porocephalus armillatus in den menschlichen Organismus als für diesen harmlose Vorgänge anzusehen sind, daß eine zweite. Wanderung in sinne von Looss selten beobachtet wird, und endlich, daß keine der bisher mitgeteilten Beobachtungen von angeblicher töllicher Porozephaliasis - in Petracht kommen erustfich nur die Fälle von

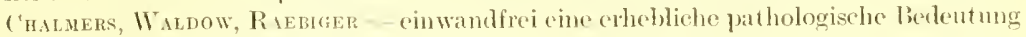
der auf ter zweiten Wanulerung begriffenen Larven beweist".

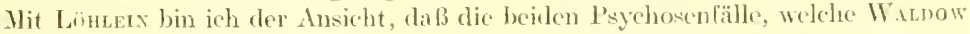
an einem 25jährigen Kamemmeger und RAEmGER an einem jungen Bakwirmame beobachteten, kanm als die Folgen von Porozephaliasis angeselen werten kömm, halte es aber nicht für numöglich, daß jüngste Porozephaluslarven in ähnlicher Weise wie wir es ja nicht selten bei Zystizcrken beobachten, in das Schädelimnere cingeschwemmt werden und sich dann im Gehim und seinen Hänten ansierleh. Hier kömen sie ähnliche pathologische Verändermugen, wie die Bandwmmlarven, hervorrufen und nach schwerer Erkrankung den tödlichen Ausgang herbeiführen.

Die Tlerapie kann nur eine symptomatische sein. Prophylaktiseh sind in erster Linie Abkochungen oder Filtrierung des Trinkwassers zu cmpfehlen.

\section{Literatur.}

1865 Mtriex. W. On the ocenrence of Pentrstoma constrictum in the luman hoty as a cause of painful disease and death. Seience and pract. of medicine, 4. Aufl. London.

1849 vax Bexedex, P. J., Rech. sur l'organisation et le développement des Lingnatiles. Noniv. Hem. Ar. Belg. Bd. 23.

1852 Brunsz, Th., Ein Beitrag zur Helminthographia mumana. Zeitsehr. 1. wissenseh. Zool. Bil. 4. S. 65 .

1856 Derselbe, l'ber Pentastomum constrictum. Ebenda. Bd. 7. S. 329.

1858 Derselbe, Uhersicht über die in Agypten beobachteten Eingeweidewiumer. Zeituchr. der Gesellsch. der Ärzte. Wien. S. 447.

1890 Blxichard, R., Traitẻ de Zoologie médicale. Paris. II. S. 2̌ís.

1909 Brodex et RoDhax, Contribution à létude de Prrocephalus mmiliformis. Ann. ol trop. Hed. and Paras. Nr. 4. ¿. 303.

1899 Chrluers, A case of Pentastoma constrictum. The Lancet, 24. Tuni.

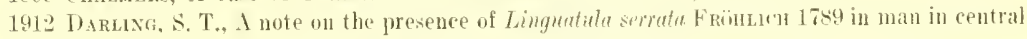
America. Bull. soe, path. exot. Bd. 5. S. 118.

1835 Diesixa, C. M., Versuch einer Monographlie der Gattung Pentustomu. Am. d. Wien. Mus. I. s. 1.

1908 Fithebors, F., Porocephalus (Pentastomm ) aus den Organen eines westafrikanisehen Negers. Arel. f. Schiffs- u. Tropenhỵg. S. 169 .

1896 Ginsro, 1., Sur le Pentastomum constrictum. parasite du foie des nẻgres. C. R. suc. biol. Paris. 111.

1906 hiew1Et DE Joxge, Nadere inlichtingen over de F'orocephulus moniliformis. Fieneesk. Tijuschr. r. Tederl. Ind. Bd. 46. S. 524.

$190 t$ Lorin, .I., Zur Kenntnis des Parasitismus der P'entastomen. Arb. a. d. path. Inst. Berlin.

1912 Derselbe. T'her den Parasitismus der Linguatulu rhinariu PiLien (Pentastomum taenioüdes) im Vergleich zu dem der tropischen Porozephalen. Beih. 4, Arch. f. Sch.- u. Tropenlyge. S. 95 .

1913 KïL, L., himmerumer Sektionsmaterial. Arch. f. Schiffs- 1. Tropenhyg. Bd. 17. A, 273-2-283.

1 sgr Kutugix, X., Zur Xaturgeschiehte des Pentastomum denticulatum. Centrabl. 1. Bakt. I. Bd. 24. s. 489 .

1906 L.texider, H., L'ber I'ntastomum dentirulatum beim Henschen. (entrabbl. 1. Bakt. I. Bit. 40. 今. 730 .

187s Lumox, Ein kasuistiselrer Beitrag zur Mtinlogie des Nasenblutens. Berl. klin. Wou hemschr. Bu. 15. S. 730 . 


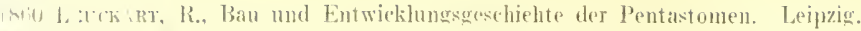

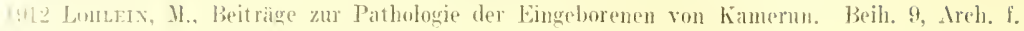

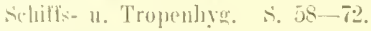

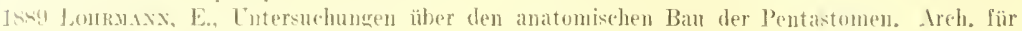
Xaturgesch. Bd. 55. \&. 303.

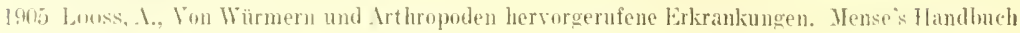
d. Tropenk. 1. Antl. Bid. 1. s. 198.

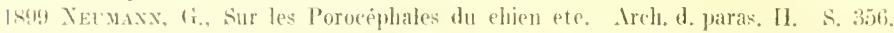

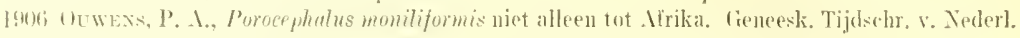
Ind. Bd. 46. \&. 123 .

1St7 PRrXER, Krankleiten des orients. Erbangen. S. $24 !$.

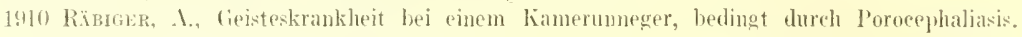
Irch, f. Schiff:- u. Tropenhyg. S. 170.

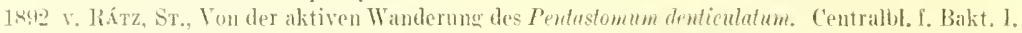
Bil. 12. ค. 320 .

1utiq Simbox, L. Wr., Remarks on Hrs. Brovex and Rownds's paper on ,Poroeephalus moniliformis." Journ. of trop. Yled. S. 79.

1912 berselthe, Porocephaliasis in man. Jomrn. trop. med. lyg. Bd. 15. S. 321-327, 371-374.

1913 herselhe, Jasselhe, Ehenda. Bd. 16. S. 97-100.

1852 Schubart, T. 1). Entwickhung des Pentustomum tumioüdes. Zeitschr. f. wiscensch. Zool. Bd. 4. S. 116 .

1910 s'empert, H., Lin Beitrag zur Kemntnis des Ponocephalus monitifomis. Areh. f. Schiffs11. Tropenhyg. S. 101 .

14as sinpley, I. E., In attempt to revise the family linguatulidae. Ireh, de Paras. I. S. 52.

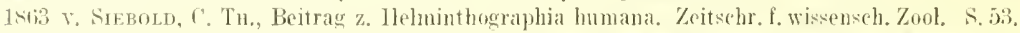

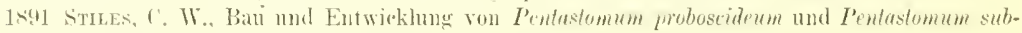
rylindrieun. Zeitschr. f. wissenseh. Zool. Bd. 52. \$. 85.

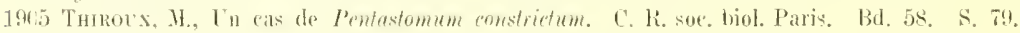

1457 Vincnow. R., Helminthologisehe Totizen. Areh. f. path. Inat. Bd. 11. S. 81.

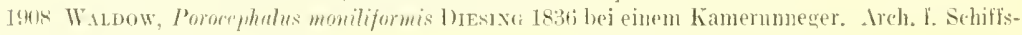
11. Tropenhye. S. 321 .

$18 t i 3$ Went, Gber ein Pentaston einer Löwin. sitzungsber. der Kais. Mkid. d. Wisenseh. Wien. Bd. 48 .

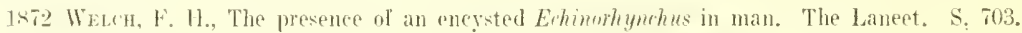

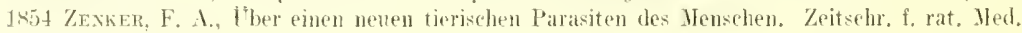
Bal. 5. S. 212 .

\section{Die Milben (Acarina).}

\section{Sarcoptidae. ${ }^{1}$ )}

Die schon linge als Erreger typischer Hantkrankheiten in Vermf geratenen Krätz- unel lïüulemilben dürfen hier wohl als allbekannte Erseheinmengenbergangen werden. Elwnso brauchen wir uns bei den

\section{Demodicidae,}

den Haarlolgmilben (I), moder folliculorum) nicht länger anfuhalten.

1) Jlexise beobachlete am hongo eine todliche Ohrmilbenkrankheit der Ziegen. Der lireger ist eine sarkoptide: Pormotes commenis var. caprat liüstenherg. 


\section{Trombidiidae.}

Als sehr lästigen und in den 'Tropen häufig recht mangenehme Dermatitilen erzeugenden Itilben begegnen wir dam Angehörigen der Familie der Trombidiiden.

Alle hier in Betracht kommenden formen sehmarotzen nur als lanven anf

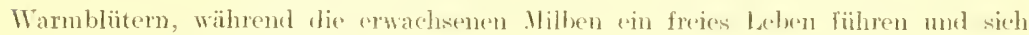
ron I'flanzenst often nähren.

Da ist es zunächst mnsir

\section{Leptus antumumblis.}

die Larve von Trombidium holosericeum, der allbedannten blutroten Sammt milbe, weleher das sog. "Herbsterythem", eine mit lästigem Jueken rerbundene Hauterkiankung herrorruft, die bei Kindem und schwächlichen Personen mit Fieher verbunden sein kamn. Es werden in erster Iinie Entearbeiter von der Krankheit befallen. sie kann aber auch selbst in Städten auftreten, weun sich bei den Wohmungen Gärten mit Strauehwerk (namentlich Staehelbeersträuchem) befinden. Die Ilibe bohrt ihre Mundwerkzenge tief in die Haut des Wirtes ein und verhart an der gewählten Stelle mehrere Tage, mu Blut zu saugen. In der Umgeloung des stichkanals bildet sich raseh eine reaktive Entzündung aus, die in einer etwa linsengroßen Quaddel ihren siehtbaren Ausdruek findet.

Prophylaxe und Therapie. Befallene Felder und Gärten sind naeh Möglichkeit zu meiden. Die festsitzenden Larren, welehe als winzige rote Pünktehen im Zentrum der Papel zu sehen sind, werden durch öleinreibungen erstickt nod kömen dam im wamen Bade durch Seifenwasehnngen lejcht entfornt werden. Aueh Alkohol, Benzin, Perubalsam und Schwefelsalben sind gegen die lästigen Sehmarotzer emptohlen worden.

Von den hierher gehörigen tropisehen Milbenlarven sind wir dureh RiLeY (1573) auf die in Mittel-und s'üdamerika rorkommenden Arten Leptus amerirouls und Leptus irriturs aufmerksam gemaeht worden, eine mexikanisehe Art, das Trombilium tlolsuhumte, wurde sehon 1867 von Lemme besehrieben. Die in Guyna Pou d'agouti genamnte Milbenlarve und die in Nougranada vorkommente Niaibi diüften ebenfalls hierher zu zählen sein. Nahrscheinlich wirl anch die ron Demprobf (Areh, f. Sehiffs- und Tropenhyg. Bil. 2) unter dem Namen "Busehmueker" beschriebene Hautaffektion dureh eine Trombidium-harve hervorgezufen.

Eine gewisse Berühmtheit hat eine andere Trombiliide, die

\section{Akamushi- oder Kedanimilbe}

erlangt: trotzdem gehört sie sowohl in bezug auf ihre Erseheinumg und Entwicklung. als auch in bezug auf die ihr zugeschriebene schädliehkeit zu den problematischen Existenzen.

Von der kleinen, im Durchichnitt $0,25 \mathrm{~mm}$ langen und $0,17 \mathrm{~mm}$ breiten, rötlichen Dilbenlarve kemt man die Geschlechtsformen noch nieht. Das seehsbeinige 'Tier trägt dichtstebende, lange Haare auf allen Körperteilen. Die 'Taster setzen sieh aus drei Gliedem zusammen, die Beine sollen fünfgliederig sein. Anf jeder so'hultur befindet sieh in der Höhe der Mittelhüfte cin Ozcllus. Die oft reproduzierte I arstellung des Tieres ron Tanaka verrät sich sehon flureh den Klanendreizack anj ton FuBendgliedern als Phantasiegebilde mel wurle deshalb hier nicht wich iglogeben,

Bisz und Kawhin, die im Jahre ist9 als erste das in ganz bestimmton, örtlich sehr beschränkten Gebieten an der Westküste von Hondo, der jalnaniwhen 
Hiluptinsel, rorkmmende : Übersehwemmungsfieber" beschicben, lengneten shom die ätiologisehe Berleutung unserer Milbe. Die meisten Forseher, welehe später den Crsachen der Krankheit naehgingen, kamen zu dem gleiehen Ergebuis, während Taxks nach wie vor in einem von der Kedanimilbe eingeimpften Gifte die ('ausa morbi erblickt.

\title{
Das japanische Fluß- oder Überschwemmungsfieber.
}

\author{
(Kka mushi-, Shima mushi-, Kedani-1 oder Inselkrankhejt.)
}

Da: l'bersehwemmungsieber ist eine akute, endemische, nicht kontagiöse Infektionskrankheit von typischem fieberhaftem Verlaufe, die mit umschriebener Ilautnekrose beginnt, zu schmerzhafter Lymphlirüsensehwellung nut später zu einem eigenartigen Hantansschlage fülırt. Jit diesem ist das 4-7 Tage dauernde Höhestadium der Krankheit erreicht. Die bis zu 40,5 angestiegene Kürperwärme kehrt in den normal verlaufenden, mittelschweren Fällen am Ende der zweitess Woche in wenigen Tagen zur physiologisehen Hïhe zuriek und die kranken erholen sich dann gewöilmbich raseh.

Die Krankheit jst bis jetzt nur in Japan²) beobachtet worden und zwar auf einem ganz kieinen Verbreitungsgebiete an der Westkïste der japanischen Hauptinsel Xippon oder Hondo. Es handelt sich um die im Frühling jeden Jahres iiberschwemmten Täler der Fhüsse: Om onogaw a und Ninasegawa im Akitabezirke und des Shinanogawa, Lkagawa, Uwonumagawa und H a jadegaw a im Nugatahezirke. Sie tritt in diesen Tälerm aber nieht in dem ganzen C'berschwemmungsgehiete auf, sondern wieder nur an bestimmten sich gleich bleibenden stelfen. In den benachbarten Flußtälern, in denen zur sebben Zeit ebenso bedentende t’berschwemmungen jährlich eintreten (und die kedanimilbe auch vorkommt), jst die kirankheit niemals heobachtet worderis.

Sind die libusse in ihre Betten zurüekgetreten, so wird das Inundationsgehet mit Hanf und Gistride bestellt; auch viele Jaubeerbiume stehen zwischen den Getreidefeklern und lieferu das Futter für die in den henachbarten Ortschaften massenhaft gehaltenen Seidenraupen. In den ersteu Monaten nach der l’berschwemmung ist das Betreten der Niedenngen ganz ungefahrlich, erst in der zweiten Hälfte des Juli tritt die Kedanikrankheit auf und pflegt his zum Oktober anzuhalten. I ie in Frage kommenden Gebiete werden damn, wenn nur irgend möglieh, gemieden und anssehlicblich von Entearbeitern betreten, die von den allerärmsten und notloidenden Volksschichten gestellt werdeı.

Jas [ै] herschwemmungsfieber ist vor mehr als tausend Jahren schon bekannt gewesen, wie sich aus chinesisehen Iufzeichnungen heweisen läb. Anch die iltere japanisehe literatur tut der Krankheit mehrfach Erwähnung. PaLm (1878) war der erste Europäer, der sic beschrieb. Jie grundlegenden L'ntersuehungen fühten im Jahre 1879 BAELz und Kawakan zusammen aus. Im Jithre 1908 wurde sie dann noch eimmal von AsHBURN und C'RAIt eingehend bearbeitet.

Sinmplomatologie. Prodromalersłheinungen können die Krankheit ankündigen, werden aher in den mejsten biallen vermibt. Wemm sie vorkommen, so bestehen sie in unlrestimmten Störungrol des Allgemeinbefindens, Eingenommenheit des hopfes. Verstimmtsein, Appetitlosigkeit usw. und fflegen 2-3 Tage zu danem. Das Ĺberschwemmungsfieber beginnt in der Mebralil der Fille an 5. oder 6. Tage nach der stattgehabten Infektion mit starkem, mit Hitzegefühl al)werhselndem liösteln, heftigen Kopfsehmerzen, Klopfen in den Schläfen und vollkommener Appetitlosigkeit. Siarkes schwächegefühl mo grobe Hinfälligkeit zwingen den hranken sich niederzuleyent.

tileich im Anfange (an 1. oder 2. Krankheitstage) entwickelt sich entzündliche und reeht schmerzlafte hymphdrüsensehwellung an einer bestimmten Körperregion (Leiste, Achselhöhle, Ilals usw.) nud es wird dann im Bereiche dieser Drïsen als charakteristisches nut nie fehtendes

1) Aka mushi beflentet, ,rote Milhe": Shima mushi ,Inselmilbe", Kedani ,Haarlaus".

2) AsHztrx und ('R.sIt beubachtetent anf den Philippinen eine dem Überschwemmungsfieber ithnliehe hrankheit; ols sie wirklich mit ihm itentiseh ist, werden lernere Untersuchungen ergeben müssen. 


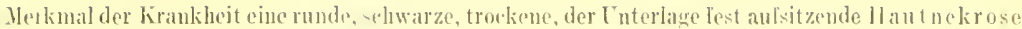

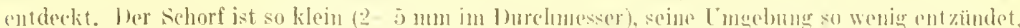
daß der Kranke an dieser Eindrittsotelle des Virns nicht den guringsten schuer\% emufindel

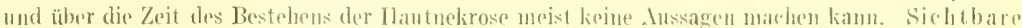

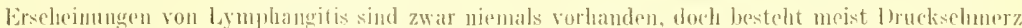
an den zwisehen sehorl und Drüsen gedegenen Partien. In den folgenden Taten werden neben

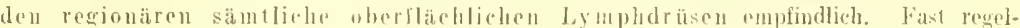
mäbig besteht dabej eine auf dem Bubus stibler als aul den lidern entwickelte honjunktivitis:

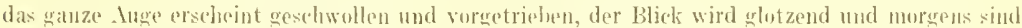

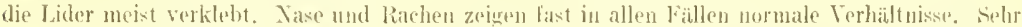
häufig aber hesteht Bronchitis und hartnäckige Verstopfung. lhe Milz ist stets mäBig vergribert, der I'rin vermindert und mandmal riweibhaltig. Nirht selten wird auch öbro llarndrang geklagt.

Die Temperatur sehwankt in den ersten Tagen zwikchen 38,5 und $39,50^{\circ} \mathrm{C}$. Der verhaltnismäbig wenig beschlenuigte I’uls zeigt bei Männern eine Schlagzall von 80 , bej Franen von 100 oder ctwas darüber. In den folgenden Tagen steigert sich das lieher und schon am 5. his. 6. Tage betrigt die houperwärme fast immer $40^{\circ}$ und mehr. Selten kommen Remissionen vor. l)ie Pulsfrequen\% bleibt auch in diesen Krankheitsstadium eine verhältnismaigig niedrige.

Im 6. bis 7 . Tage tritt unter weiterer Temperatursteigerung eiu maliulöses und papuläses Exanthem anf. Der Ausschlag erseheint zunïhst im fresicht (an den Schlifen und Wangen). Die dunkelroten an Masernflecken erinuernden hirsekorn-bis maiskorngruben Papeln konfluieren hüufig. Das Exanthem tritt damn auch an deu Vorderarmen, Lnterschenkeln und am liumpfe auf; an den Oberarmen und Schenkeh pflegt es nie mit solcher lontlichkeit zum Aushruche z.n konmen. Die Jundschleimhant beibt in den meisten Fällen frei. Teben den Flecken und Papeln und gleichzeitig mit ihnen treten am linmule und an den Vorderarmen zahlreiche, hirsekorngrobe. dunke]rote meist von je einem Härehen bestandene Isnötehen aut. Der nieht juckende Anssehlag ist in den cinzehen Fallen ungleich stark entwickelt. Er besteht durchsehnittlich 4 his: 7 Tage (in ganz leichten Fällen sogar manchmal mur einen Tag) und seine I auer fällt mit dem Höbestadium der hrankheit zusammen. I)as Fieber jit jetzt liontinuierhich, die Temperatur $40^{\circ}, 40,5^{\circ}$ (selten $41^{\circ}$ ), wihrend die Frequenz des vollen aber sunst regehmäBigen l'nlses zwisehen 80 und 100 schwankit.

Am Ende der zweiten Woche begimnt das Fieber nachznlassen, nanentlich zeigen die Abendtemperaturen an jedem folgenden Tage eine geringere Höhe und unter stetiger Bessermug des Allgemeinbefindens ist nach eingen Tagen die normale körperwärme wicder erreicht. The Drḯenschwellung versehwindet. Der Appetit stellt sich ein, die Harmenge wächst, die stuhlverstopfung läbt nach und meist tritt anflallend rasch die vollstandige liesundung an. Vie lirankheitsdaner beträgt im Mırchschnitt drei Wochen.

Leichtere Fälle kïmen viel raseher ablaufen. Ine Allgemeinerscheinungen treten derart zurïck und das Fieber ist hïnfig so unbedentend, dab die Kranken gar nieht betthägerigr werden. ther stets sind auch hier dip Hautnekrose und die schmerzhalten Drüenschwellungen als $11 n-$ fehlbares Zeichen der Jirankheit vorhandest.

Die schweren Formen pllegen bei günstigem Ausgange nicht unter vier Wochen zu danern. Sie gefährden das Leben des liranken weniger durch die Höhe des lijehers als durch die häufin hinzutretenden Lomplikationen: Parntitis, Damblutungen, Pneumonic und schwere Tervensymptome (maniakalische .ufälle usw.). Inter komatösen Erscheinugen gehen dam die lirankeu meist an Herzceluwäche zugnunde.

Jie Hortalitätsziffer wirl von den einzelnen dutoren merkwirdig verschieden angegehen.

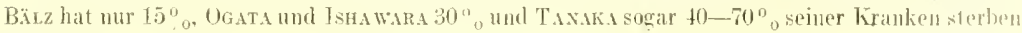
selien,

Jenschen jeden Alters und feschlechts werden vou der Krankheit gheich häufig betitlenl,

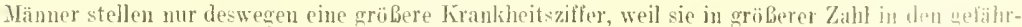
deten Gebieten beschaftigt werden. Die Prognose jst aucl je nach dem Lebensalter whe verschiedest. Jugendliche und im besten llamesalter stehente lndividuen liefern mur pine Mbrtalitaits-

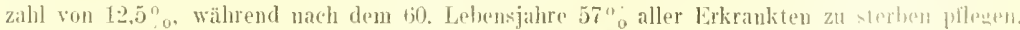
Bei schwangeren ist Abortus mit tödhehem Ausgange häulig. Hureh itherstelyen der lirankileit 
wat zirar liene Immunitat erworben, die folcenden Infalle pflegen aber so leieht zu sein, daß 16. uicht mehr gefürehtet wesden.

I'her die pathologiche Inatomic der liedanikrankheit wissen wir his hente noeh sehr

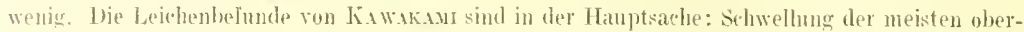
flächlichen Lymplddrïen, stark gerötote und geschwollene Bronchialschleimlant. Erwejchung des Horzmuskels, vergriiberte Wilz bei lcichter Entzündung ilırer Kapsel. In der Xähe tar Heozökalklappe zeigt die lounndarmschleimhat stark gerötete, leicht erlabene Partien. Dals Peritoneum ist stellenweise lethaft gerötet und die Hesenterialdrüsen gesehwollen.

Itiologin. Das Flubfieher ist eine Infektionskrankleit, die flurch ein in beschränktem Crade transpurtahles Virus animatım hervorgerufen wird (BäLz). Man hat früher in Japan die Ledanimilhe als ilıren amsehlieblichen Erreger angennmmen. Es ist richtig, dab gerade in der kritischen Zeit die Wibbe massenhaft in den gedachten Flußtalern sorkommt (so erscheinen die Oly-

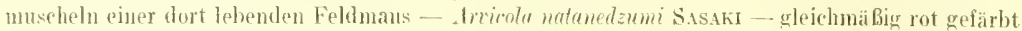
durch die zahlreichen winzigen Schmarotzer), aher schon Bäuz stellte fest, dab Herschen selbst bei starkem Milbenhefalle vielfach von der lirankheit verschont bleihen.

sio ist es heute eigentlieh nur noch Tsxsks, weleher in den Eigengiltes der Akamushimilhe die Krankleitsursale in ähnlicher Wreise erblickt, wie (GoELDI ${ }^{1}$ ) in den Eigengiften von

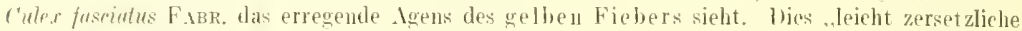
trilt" soll bei den Bliben un zu grwissen Zeiten und in einem bestimmten hehensalter erzeugt. werden. Dabes sich lifer mu nichts mehr, als cine auf recht schwaehen Fiußen stehende Hypothese handelt, geht schon ans dem L'mstande hervor, daß sieh die Kedanimilbe in den ebenfalls überschwemmen Xachbartälem in głeich grober Anzahl befindet, abor hier niemals Flubfieher auftritt. Viel wahrseheinlicher ist es, dab die Milbe nur in der Rolle des Zwisehenträgers der die Jírankheit rrzeugenden tierischen oder pllanzliehen Parasiten anftritt. oder überhaupt gar keine Rolle bei der Lthertragung des Flubfiebers spielt. Ogata sieht einen Fadempilz als Trsache an.

Kontagiös ist die Krankheit nicht: eine f'bestragung von Menseh anf Jenseh findet niemals statt. In seltenen Fällen wird mit dem geernteten llanf oder Kon, mit den heimgelorachten Maulbeerzweigen nsw. das Virns versehlepjt, und es kömnen damn Personen rokranken, welche niemals das Inundationsgebiet betreten haben. Nicht alse in den gefährdeten strichen beschäftigten Arbeiter erkranken und ebenso zeigen sich die meisten Tierarten immun gegen das krankheitsqift (mur bei Affen ist es Mrajus gelungen, Flubfieher durch Einimpfung kranken Blutes zu frzelugen.

I'roplụlaxe. Zunäelsst sind während der Monate .Juli bis ()ktoher die in Frage kommenden (ielsete wenn irgend möglich zu meiden. Die Terwendung von schwefelsallonn nsw. wäre zu versuchen. Als aussichtsvollstes Mittel aher dürfte sich die intensivere kultivierung des Getietes und seine Austrocknung durch Bepflanzung mit stark wasserbedürtigen Bümmen, wie Euculyptus

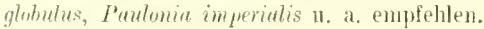

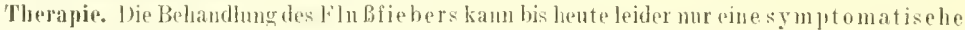
sein. (regen hohes lieber sind Antipyretika (Antipyrin, Chinin, Natrium salyrylieum) anzuwenden, dorh mo man sich daran erinnern, dab der dajaner anf diese Hittel wesentlich stäker reagiert

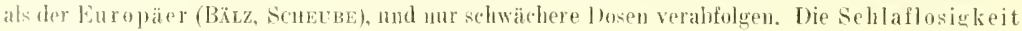
wul die Bronehitis sind mit narkotischen, die Verstopfung dureh Abfïlermittel und Linlïnfe zu hokämpfen.

Nahe verwandt mit den Trombidiiden, zählen die

\section{Tetranychidae}

zwei Schädling zu den ihrigen. Es sind dies der "uropäische

Trtormyohus tolurills Linné 1758,

dic ledamnte, , Spinnmille" welche auf der Hant des Menschen Papeh zu erzengen vermag, die sich ohne weitcre Behandlung bald wieder verlieren, und der siidamerikanische

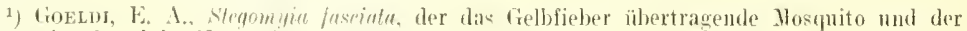

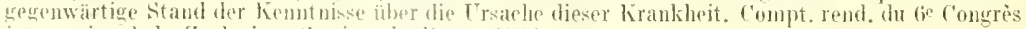
intermational de \%oologile. Sescion the berne 1904. 


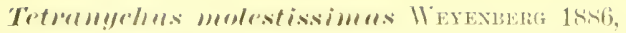

weleher namentlich in Argentinien und Lruguay auf Panthinm mucrocurpum

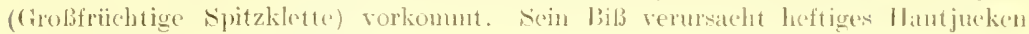
und nieht selten auch Ficher.

\section{Tarsonemidae.}

Seit zwei Jahrzehnten ist

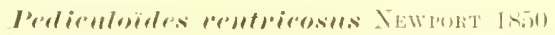

der Familic der 'Tarsonemiden zugebörig, in den Vereinigten Staten in einen recht üblen Ruf gekommen. Die Milbe, wethe früher nur auf fotreicleschäsllingen schmarotzte mel deshalh dem Landwirte ein sehr gem gesehener Helfer war, fing. wie Sknxer beobachtete, in der Jitte dere neurziger dahre dex r. I. an, jedenfalls mit Bettstroh in die Häuser gelangt, anf den Menschen übermgehen urd bei ihm als stationärer l'arasit ausgedehnte papulöse und sogar pustulise Exantheme hervorzurufen.

Pediculödes schmarotzt nur als erwachsenes Tier, und zwar sind es vor allem die befruchteten Weibehen, die sich in die Iant des Menschen einbolnen. Wie sehr kleine Milbe (o $0.12 \mathrm{~mm}$ lang $m$ d $0,08 \mathrm{~mm}$ kreit, $70,2 \mathrm{~mm}$ lang $u n d 0,07 \mathrm{~mm}$ breit) schwilt bei der Eierreifung in ganz analoger Weise, we dies bei sureopsylla cler Fall, zu ciner verhältnismälBig sth. groben hugel an. der die winzig erscheinembe vorkere. Köperhälfte des 'Tieres autsitzt.

Therapie. Oleinreibungen, Wasehungen mit Alkohel, Hher und Benzin. Schwefelsalben töten in kurzer Zeit den Parasiten; die durch ihn hervorgerufenen reaktiven Erscheinungen pflegen dam rasch zuriiekzugehen.

Zu den 'Tarsonemiden gehört auch

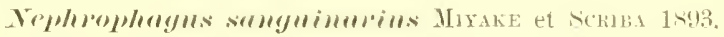

der von den beiden Autoren bei einem an $W$ ä mat ur ie levelenden Japaner wähend mehrerer Tage in dem spontan oder mit kem syülkatheter entherten Trin gefunden whie. Die Tiere waren stets abgestorben und ist deshall nicht mit sicherheit zu sagen, ob sic die Zystitis veranlabt haben. Vielleicht waren sie jedesmal schon rorber in den verwendeten Katheter geknchen oder befimten sich in den gebrauchten Cetäben. Bei der Kleinheit der 'Tieres (70 11$)$ ist ein C̈bersehen immerhin möglich und größte Forsicht und C̈berlegung in solchen Fällen am Platze. che man die Funde als Krankheitserreger anschuldigt.

Als lästices Schmarestzer aus der Familie der

\section{Eupodidae}

ist durch Mosiez

\section{Tyglenes molestus Moxiez 1s,}

beschrieben worden. Die Milben wurlen mit ciner Sendung ron Peruguano in eine-n bedgischen Garten emgeschleppt und erschienen dann regchnäligig in der wärneren Jahreszeit wieder. Sie kamen masienhaft ant Sträuchem und anch im Grasts vor. Stets befielen sie Menschen und Tiere (auch Vögel) und belästigten sie in sthlinmen Weise. Beim Eintritt des crsten Frostes hörte die l'lage fïr das laufende , fallu jerlermal wiecler aut.

Von den

\section{Gamasidae}

den namentlich auf Katern schmarotzenden Milben, gehen 


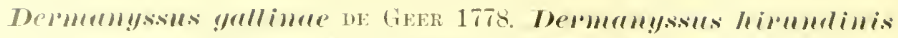

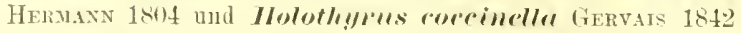

selegentlieh auf den Mensehen ïber und erzengen juekende Hautausschläge.

Die letztgenannte, recht große $(5 \mathrm{~mm})$ Art lebt auf der Insel Mauritjus an griberen Vögeln. Fon dem Hansgeflügel werden namentlich Gänse und Enten befallen und gehen nicht selten an den Folgen des Bisses zugrunde. Auf der Haut des Menschen arzengt die Milbe heftiges Bremen und Sehwellungen; sie siedelt sieh gelegentlich auch in der Mundhöhle ron Kinderu an und ruft damn nicht umbedenkliche Erscheinumgen hervor.

sichtieBlich stellt die Familie der

\section{Tyroglyphidae}

noch eine Anzahl bemerkenswerter Schmarotzer, so die Gattumg

\section{Ty'ogl!y)hus.}

selbst, die in zwei Arten in dysenterischen Stïhlen gefunden wurle (rgl. die bei Vephroplergus, s. 237 , gemachten Bemerkungen).

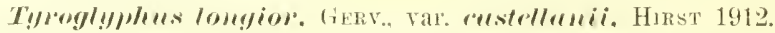

Anf den in Fig. 179 abgebildeten Schädling hat CAsteldixi am Ende des rorigen Jahres (Joum, of Trop. Med., Bd, 15, S. 374) a ufmerksm gemaeht. Die Hilbe erzeugt

Fig. 179.

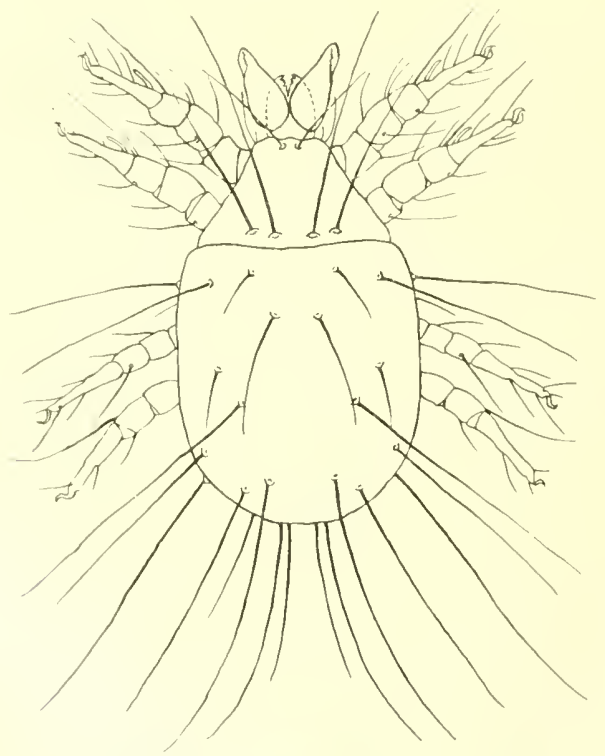

Tyroglywhe longion, var, custellmii, vergrobert. (Nach Hısst.)

die unter dem Namen Copra-iteh in Ceylon bekannte Hautkrankheit bei Arbeitern, die nit der Verpackung von Kokosmubkernen besehäftigt sind. 
Femer velursachen

\section{Glyreiflurylls}

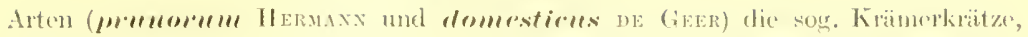
welche nieht selten bei luhabern und betiensteten ron sipezereigeschälten beobachtet wirl.

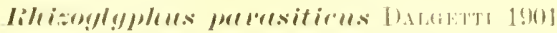

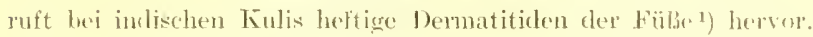

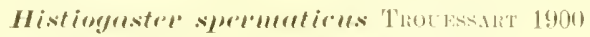

wurde in dem Hoden cines Indiers eingekapselt gefunden.

\section{Literatur.}

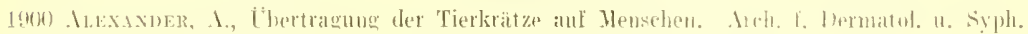
Bd, 52. \&. 145.

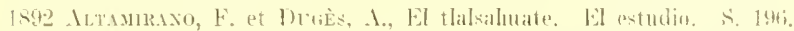

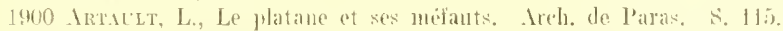

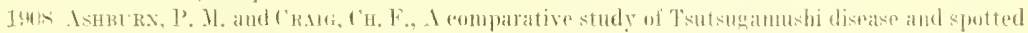
or tick fever of Youtana. Philipp. Jomrn. of Se. Bd. 3. No. 1.

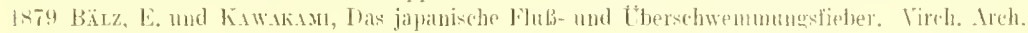
bil. Ts.

1604 Baxks, X., I Treatise (n) the Acarma. Smithsonian Institnte.

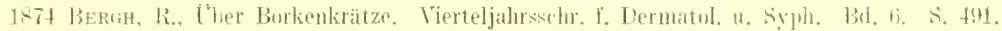

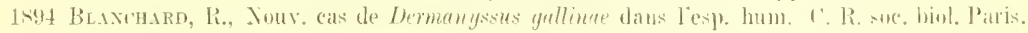
S. 460 .

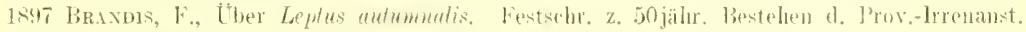
Xictlehen. s. 417.

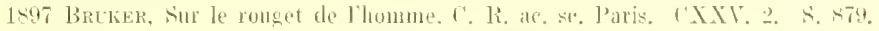

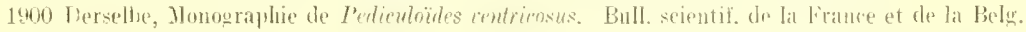
XXXT, 1. 365.

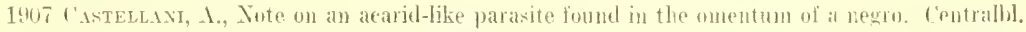
1. Bakt. Orig. Bd. 43. \&. 37 ?․

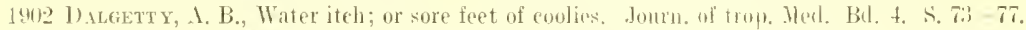

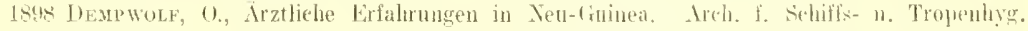
S. 279 lif.

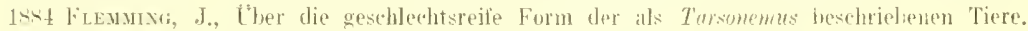
Zeitschr. 1. d. gesamt. Naturw. Halle. S. ti2.

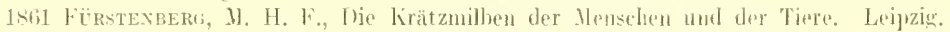

1909 lievoelst, 1., Le paravite de lontacariase des cheves du congo. Areh. f. Srhiffs- und Tropenlrygiente. Xo. 5.

1stil tirtor, llerbsterytheme. Mlly. Wien. med. Zto. S. 19.

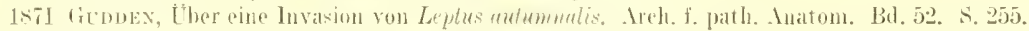

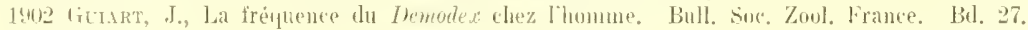
S. 128.

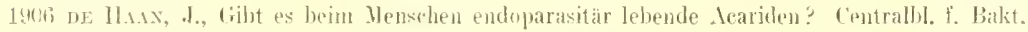
Bul. 40. \&. 693 .

19:1:3 vis der Harst, Mijten in urine. l'hamae. Weekbl. Xo. 6.

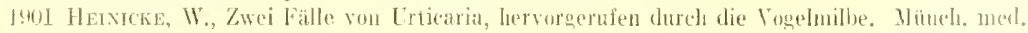
Wordenselir. Nr. 53.

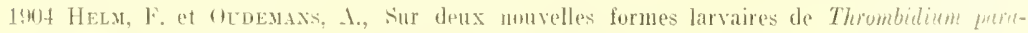

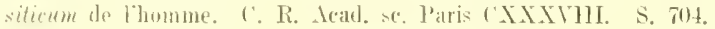

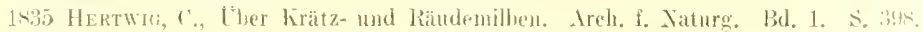

1) lice fiührer ebenfalls als Milbenkrankheit angesprochene Ground-jteh (Lsan) wird jetet wohl allgemein als Folge eindringender d]kylustoma-Larven angesehen. 


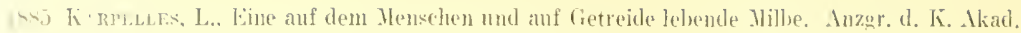
(t. Wiss. Wien. Xx11. \&. 160 .

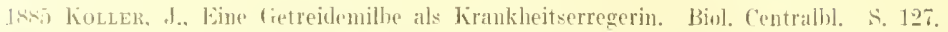

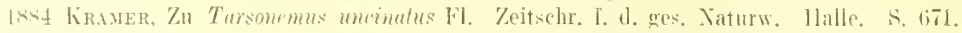

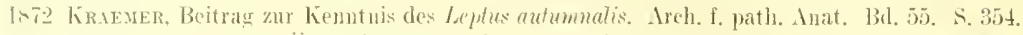

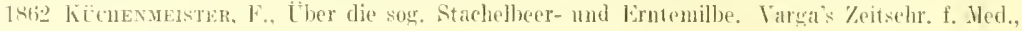
('hir. u. treburtsh. X. F. 1. . . 289.

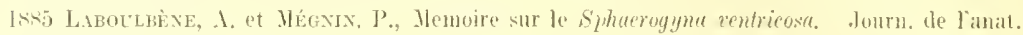
XXI, \&. 21.

1htir Lemare, Import. en Franee du thalsahnate. C. R. Ac. se. Paris LXY. S. 215.

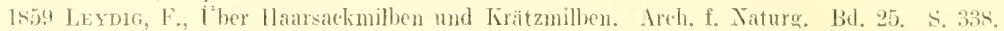

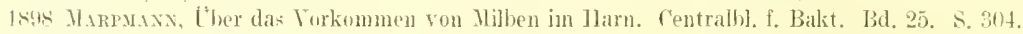

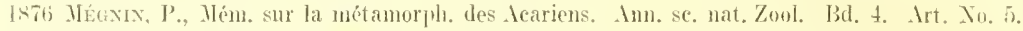
lerselbe, Les Aeariens parasites. Enerel. seientil. des aide-mém. P'uris.

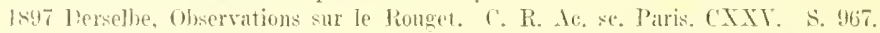

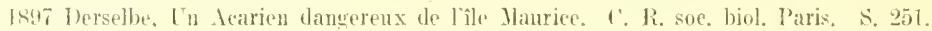

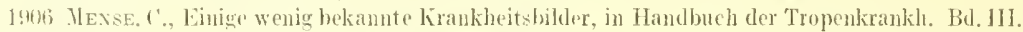

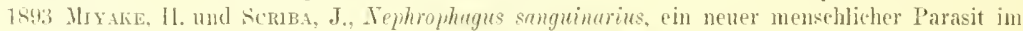
Lrngenitalipparal. Mitteil. a, d. med. Fakultait d. K. Japan. Lniv, 17l. S. 1.

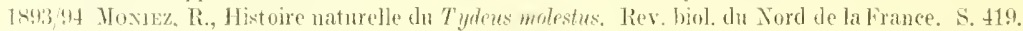

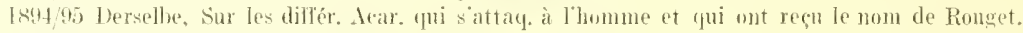
Res. hist. du Nord de la Franee. Bd. 7 . s. sol.

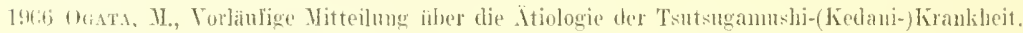
Dentshe ned. Wochensehr. \&. 1828 u. ¿. 1868.

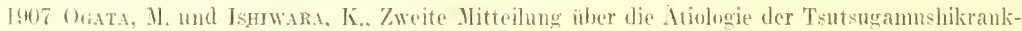
hroit. Deutsche med. Wuchensehr. S. 1331.

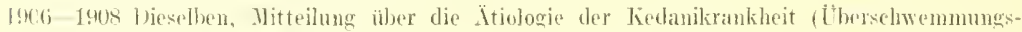

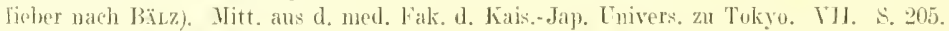

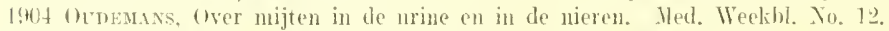

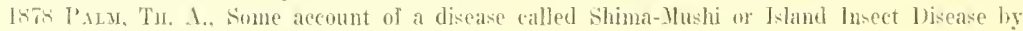
the native of Japan. Elinly. met. Journ. st. 128.

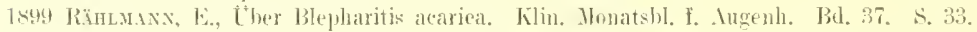

IST.3 Riley, 4. V., The mexican thigger or tlalsahuate. Jusert life. S. 211.

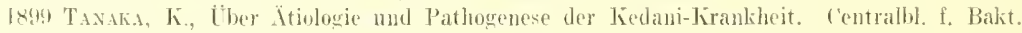
Bd. 26. . . 432.

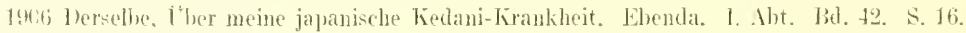

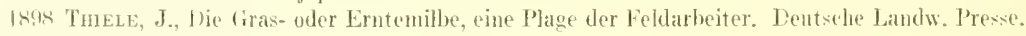
Nir. as. S. 1016.

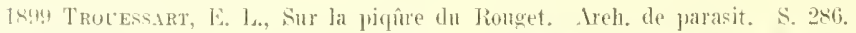

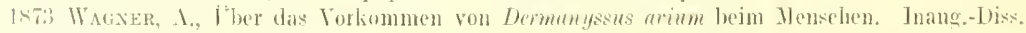
Ciseifswald.

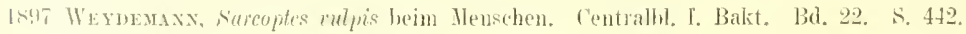

Wron wir nun hier die Milben verlassen, gelangen wir im System anfsteigend zu dor Ordnung der Araehnödeen, die wohl die bokanntesten Vertreter der ganzen Klatse in sich voreingert, zu den dravezda, den echten spinnen.

Die

\section{Spinnen (Arancïden)}

sind in allen Gattmogen mach demselben Grundjun gebaute Arthropoden mod deshalb leicht zu crkemende 'Tiere. Der stets mit dein Thorax zum Kephalothorax verlundene Kopf trïgt zwei Paare von Mundwerkzengen: die Oberkiefer, meist

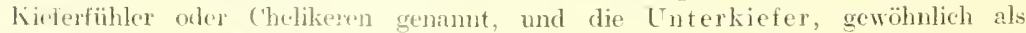
kiefortaster oder l'edipalpen bezeichnet. 
Vom Kephalothorax wirl das mgengliederte, gewöhnlich kugedig erseheinemule

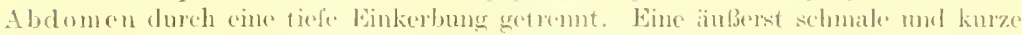
Brucke (man nemnt deshalh den Hinterteily gestielt) verbinded die heiden wroben

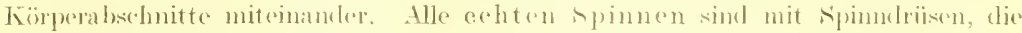

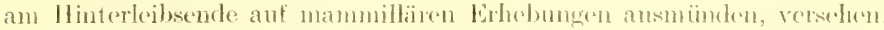

bie vergifteten Waflen the draneïlen siul die klauentörmigen, thureh krältige Inskeh gegeneinander bewegten Chelikerenhaken. sie kïmmen in cine mediane

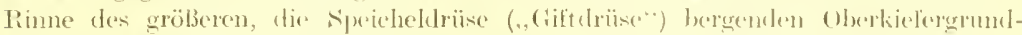
gliedes messerklingenartigr zurückgeschlagen werden. In dir:s'n ('helikorenkrallen verlänft nun wie im Zahne der Vipern der Gittkanal und mïndet in der Nähe der

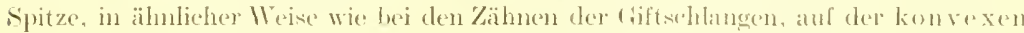

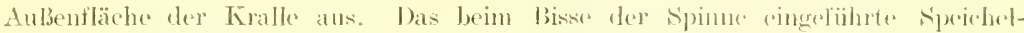
drürenseket crfüllt den doppelten Zweck, das bentroticr rasch zu töton (bei kleineren Insekten erfolgt der. Eintritt des 'Torles fast momentan, grölbere schlägt die spinne nach schlangenart erst an und nähert sich ilmen nach einigen Sekunden von neuem) und seine lleichteile zn verfüssigen und zu prptunisieren. Die verdauenden Eigenschaften des speichels sind so grolie, dab nach kurzer Zeit von riner

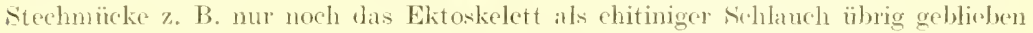
int. in lem die Apodemen und gröberen 'Tracheren deutlieh zu (rikennen sind ${ }^{1}$ ).

Alle spimen sind äußerst giftige $\left.{ }^{2}\right)$ Bestien; dic neisten aber liönnen glïcklicherweise dem Menschen und gröBertn Tieren gegeniiber , ihr 'Tilent nicht verwerten", da ihre Inndwerkzeuge zu schwach und kurz sind und die Giftmenge eine verhältnismäbig viel zn geringe ist. Einige Arten aber sind wegen ilurer Gröbe, der 'Tü̈htigkeit ihrer Iraffen und der ganz nngewönlieh gittigen Beschaffenheit ihres Npeichels anch dem Mlenschen und besomlers zarthäutigen und mo ein mehrfaches hinter dem Körpergewicht Erwachener zurïckbleibenden kleineren Kindern gefählich. Es ist möglich mod mehfrach mit Erfolg ausgeführt worken, Nängeticre gegen spinnengift aktiv zu immunisieren.

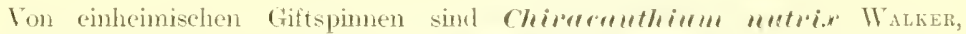

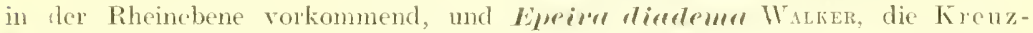
spinne, zu erwähnen. Der Biß beider erzengt heftiges Bremen in der Nähe der Applikationsstelle des Giftes, ruft aber Allgemeinerscheimmgen boim Menschen nicht lerror.

Getahrlieher schon sind ron den Lykosiden dic italicnische Tarantel:

1) Ich halse diese Eigentümlichkeit des spimmoiftes neratezm zum Sehnellskelettieren kleiner Insekten in Anwendung gezogen. Eine Špringspinne (Epiblemum scenicum z. B.) stürzt sich sofort auf einen ihr dargebotenen C'ub pipuch, dor wegen seines nicht allzu stark gelärbten Ektoskelettes sich besonders gut fïr dieven Tersuch eignet, und schlägt ilme (helikerenhaken in senen Thorax. Inter den Angen des Beobarhters schwillt zunäclsst die llüeke beträehtlich an, um dann, wenu die spinne zu saugen anfängt, plötzlich wie ein gep)latzter (iummiballon zusammenzufillen. Ton neurem preßt nun die spimne den speichel in deu Laib ihrer Beute, der sieh wiederum in einen prall sespannten schlanch verwandelt. In dieser Weise wiederholt sich der Vorgang mehrmals

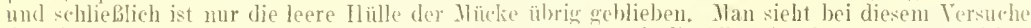
dentlich das Fortschreiten des Verelaungsvorganeres: soweit die Albmminsulstanzen peptonisiert sind, wird der Mä̈kenkörper glasartig durehscheinend, wälırend er darüber hinaus opals erscheint. In den späteren Plhasen des P'rozesses treten zumleich zahlreiche (iasblasen im Imern des bontetieres auf; ob sie durch die spinne eingeprebt werden oder sich bei der Terflissigung der Whedula Io biklen. hahe ich nicht feststellen könuen.

2) Yach Kobert (Beitrige zur Kenntnis der Giltspimnen, s. 183-18t) erwibt die lintersuchnng des Giftes von Epeiru dindemu WaLk, unserer bekannten Kreuzspinne, dit hemerkens-

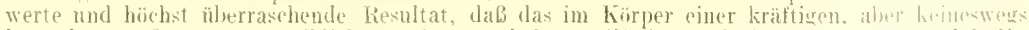

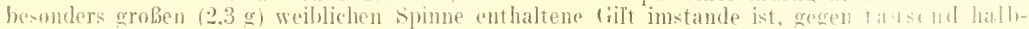
wïrhsige Katzen zu tüten, wenn es direkt in die Blutbahn der Tiere gebacht wirt.

yt nse. Handhuch der Tropenkrankbeiten, z. Aut, I. 
Thromtula rlmliue Rossi (Synonyme: Lycosa tarantula Lrsxé, Tarantula (uscritentris) und die russische "Tarantel":

\section{Trochosh singoremsis LaxMAxx,}

vicles aber von dem, was in früheren dahrhmelerten über die verderblichen Folgen des Tarantelbisses gefabelt wurde, ist stark ïbertrieben: in der Hauptsache treten auch nach den durch diese ansehnlichen spinnen gesetzten Verletzungen unr örtliche Ersheinungen aut.

Entscheden gefährlich aber sind die in südeuropa, in ter Kirgisensteppe und in Thurkestan vorkommenden Arten der Gattung Lathrodectes (Theridiidae). ber italienische

\section{Latheorlevers trederim guttutus Fabricios}

ist in seinem Vatcrlande allgemein unter dem Namen Malmignat to bekannt und mit Recht selrr gefürchtet.

Die nur ! mm lange Spinne hat querovale rote Fleeken anf dem schwarz gefärbten Abdomen, während die noch kleinere, $5 \mathrm{~mm}$ lange griechische Malmignatte an den gtcichen Stellen weiße Flecken zeigt.

Der Biß des Malmignatto rult nach Fruxcesco Marwocem, der im lahre 1786 dem „ragno rosso" (, rote Spinne") nach genauer Beobachtung mustergültig beschrieb, örtich merkwündigerweise auffallendere Erscheinungen, ,als der Stich cines Flohes oder C'ulex" nicht hervor, es treten aber sofort heftige Sthmerzen in den Extremitäten und in tex Nierengegend aut, bald stellt sich auch Parese der Beine, Priapismus, allgemenine Krämpte und Ohmmachten ein. Der Pnls wird lilein und in vielen Fällen besteht Isehurie. Die änBerst umbugen Kranken schreien und werden dyspnoisch. 'Trotz dieser höchst bedrohlichen Erscheinmeng konnte Marnoechi allen seines (30) Kranken das leben retten.

Die russische Art, der unter dem Vulgärnamen, Kara-Kurt" (schwarzer" Wolf) bekannte

\section{Luthrodectes Embus s. lugulmis Korn}

ist von tietschwarzer Farbe in allen Teilen des Körpers und miBt 15-1s mm.

Die weit kräftigere und gefährlichere spime tritt zuzeiten in grofer Anzahl in den südrussischen Steppen auf und nicht selten fallen Iensehen und

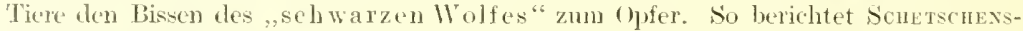
vowiscu (Petersb. med. Wochensehr. 1870, S. 54), daß im Sommer 1869 allein im nördlichen Tejle der Kirgisensteple: 48 Menschen von Karakurten gebissen wurden $(z+)$; temer alagen ron 173 gebisschen Kamelen 57 , von 21 s l'ferden 36 und von 116 stïk Rindvieh 14. Von den 507 gebissenen Tieren verendeten also 107, d. H. der fünfte 'J'eil (mehr als $20_{0}^{\circ}$ ). Die Krankheitsersebeinungen sind denen, die nach Malmignattobisten auftreten, ähnlich, nur erholen sich die Patienten niemals so risch, als nach diesen, namentlich blejbt in den meisten Fällen eine monatelang anhaltende Körperschwäche zurüek.

Merkwiirligerweise stehen die Folgen des Bisses der tropischen

\section{Riesenspinnen ${ }^{1}$ ) (Mygaliden)}

in ausgesprochenem Mlbverhältnisse zu der Gröbe der Tiere: keiner von den wenigen mitgeteilten 'I'velesfiillen kann mit sicherheit allein auf den Biß von Vogelspinnen zuriiekgeführt werden.

1) Vor mir liegt die $7 \mathrm{~mm}$ lange ('Jelikerenklaue einer mittelgroben Vogelspinne. Tiert ron so-90 mun Förperlänge, deren ' Jelikerenklaue dam 13-16 mm messen, sind nichts Un- 
Die bekamntesten anurikanisehen Arten sint die Vogelspimmen:

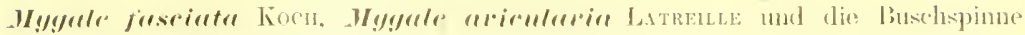

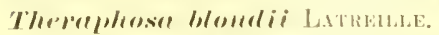

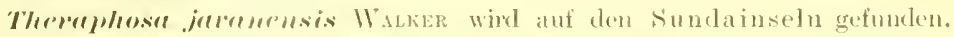
Mygule irfereice Korn wirt in Nortafrika, namentlich Iggpten, angetroften

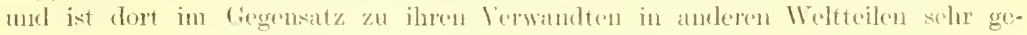
fürehtcet.

\section{Die Walzenspinnen (Solifigare).}

Die oft mit den Spinnen zusammengwworfenen Walzenspinnen bilden eine eigene brinung. Ihr hörper ist riel gestreckter, als der der Alanez̈len und unterscheidet sich ron dem zweiteiligen Leibe der echten spinnen vor allen dadureh, dals (r mit einem wohlahgesetzten Kopfe beginnt, dex sclerenförmige Mundgliedmaßen trägt. Fpimadrisen fehlen.

Die WaIzenspinnen kommen mit etwa 200 bekaunten Arten auf cleei Familien verteilt in den tropischen und subtropischen Gebieten der ganzen Whelt ror. Sie sind zwar liöchst temperamentrolle, mutige und bissige kleine liestien, die selbst mit skorpionen fertig werden, aber, wemn auch rielfach gefïrhtet, in Emangelung ron Giftelrüsen für den Menschen ganz mgetährliche Gesehöpfe. Die bekannteste

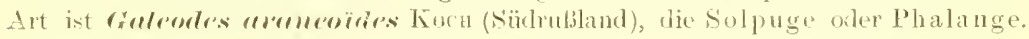

\section{Literatur.}

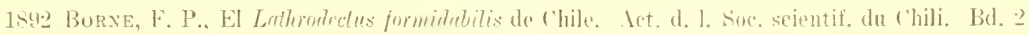
(deux, anm.).

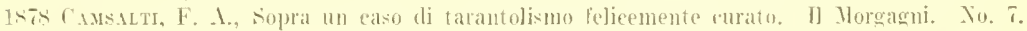

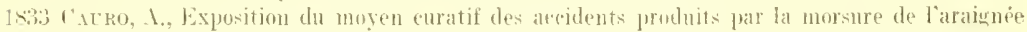
tredecimgutata ou théridion malmignatte du dipartement de lia corse. Thise de laris.

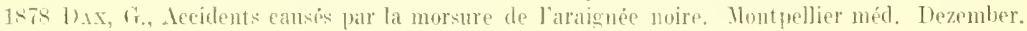

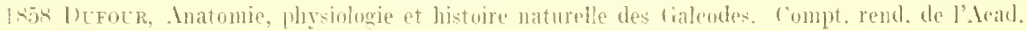
des se. Bd. tis.

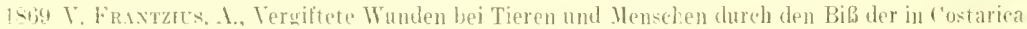

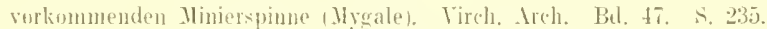

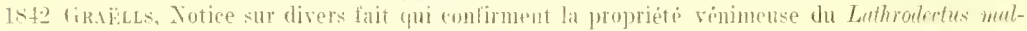
migmetus. Amn. d. 1. Sioc. pentem. d. France. S. 205.

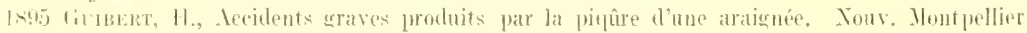
mét. Xo. 6.

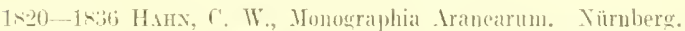

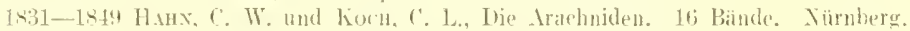

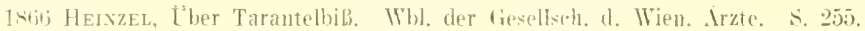

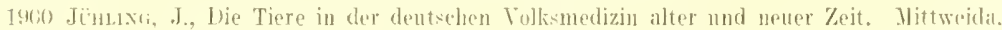

1901 Kовект, J., leiträge zur Lemntnis der Gilitspinnen. Stuttgart, Ferd. Enke.

1901 Jerseltee, ther (iiftspinmen. Wiens. med. Wochensehr. Mr. 38.

1902 Jorsedbe. Gibt es für Menschen gefährliche Spinnen? Ebenda. Mr. 15.

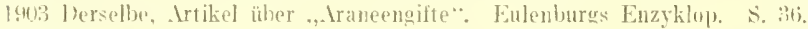

gewölnliches. Ans diesen Waben ergibt sieh zugleich, dab die vergilteten Walfen der suimen

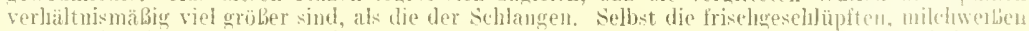
Jungen der Vugelsjinnen, welehe in dem kngeligen, "twa enteneigroben Eierkok n noch längere Zeit veremigt bleiben, habens sclon die tröbe son mittleren Frenzspinnen. 


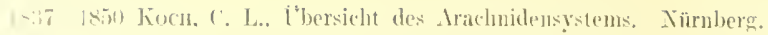

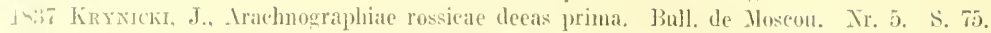

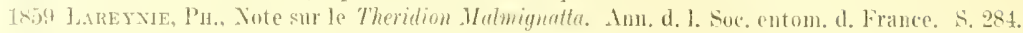

1.ris Llizert, Bau und Leloen der spinnen. Berlin.

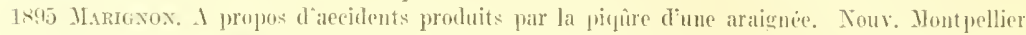
mid. No. 17 .

17 ef MLnsoccu, F., Jemoria sopra il ragno ros:o di Volterra (abgedruckt in: Itti dell' Academia di Fisiocritici di siena, 1800).

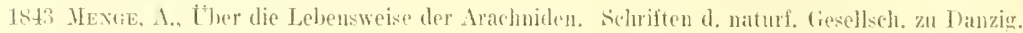
Bd. 4.

1stit berselhe, l'reubische spinnen. Danzig.

1839 Ruliex, 1., Reclerehes, observations et experiences sur le Theridion marmignatte de Volteria et sur bes eflets de la morsure. Am. d. sciences nat. see. série. Bd. 11. S. o.

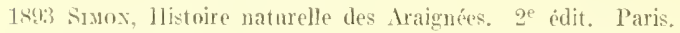

1904 Spruber, W. X., Beobachtungen ïher Erkrankungen, hervorgenten durch den BiB der schwarzen Spinne. Zeitschr. f. Kramkenpfl. S. 297.

19ng Taschenberg, 0., Die giltigen Tiere. Stuttgart.

179. Tots. L.. Menoria fisico-mediea sopra il Falangio, o ragno venefico dell' agro Volterrano. Atti d'Arademia dei Fisiocritici di siena. Bd. 7.

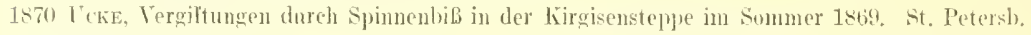
med. Ztselir. \$. 54.

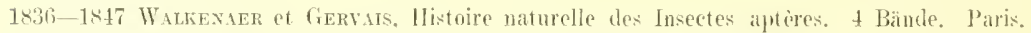
187t) Wrighr, The Katipo, ar poison spider of Tew Zexland. Hed. Tim. and Gaiz. \$. 570.

188 Zaxigilli, A., Il tarantolismo nei snoi confini. Il Raccogl. med.

You den Krankheitseregern aus rer Klasse der Arachnö̈den bjeiben ms num noch die Skorpione ïbrig, dexen Körperformen wohl allgemein bekamnt scin dürften. In ihres äußeren Erscheinmng erimen die Skorpione an die höehst entwickelten Krustazeenformen, die stieläugigen Krebse. Von unserem Flußkrebse

Fig. 180 .

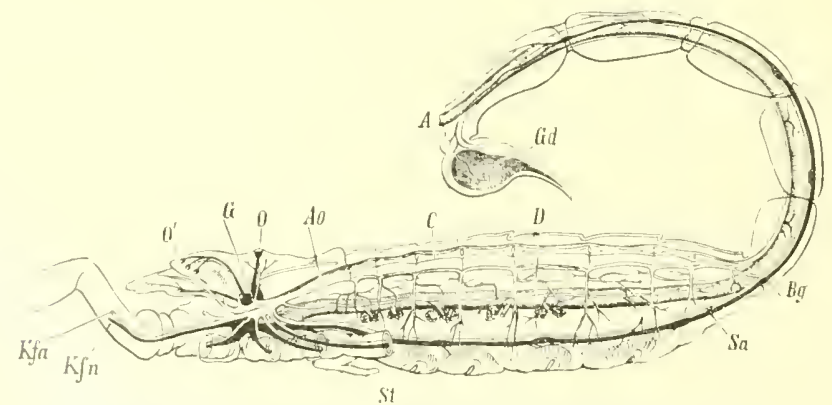

Medianschinitt dureh den hörper eines skorpions. (Nach Nawport.)

(" Herz, Ao Aorta, ") Mittelauge, ") Seitenauge der einen Sceite. I) Darmkanal mit den Leber-

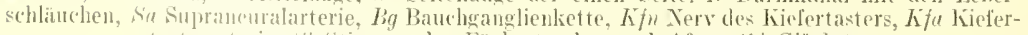
tasterarterie, St stigmen der Fächertracheen, 1 After, fid Gilderise.

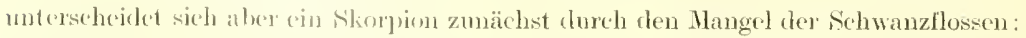
sein Körperend, ist nicht fätherlörmig verbreitert, sondern fundet in dem spitzen, lakenfömig gekrimmten Giftstached scinen Abschluß. Bei näherem Zusehen ge-

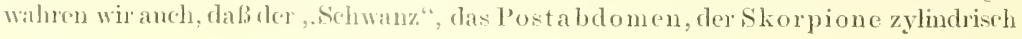




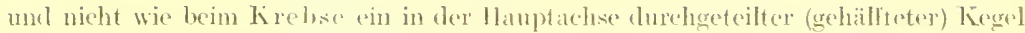
ist. Das siebenglieterige l'räablomen ist mit dem scherentragenden lóple verschmolzen und zeigt aluf der lentralflache des ersten segmentes muter der fie-

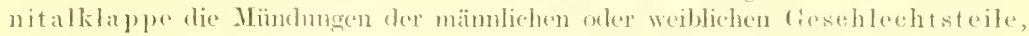
das zweite Segment trägt die eigentümlehen kammförmigens Anhänge, wekhe als modifizierte Gliednaben angesperchen werders. An den glejehen stellen des

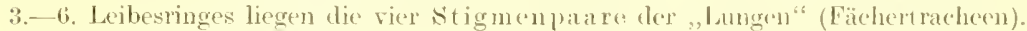
Der Darmkanal besteht aus einem engen gerade verhafenten liohre, das hinter dem vorletzten Ringe des sechsgliederigen l'ostablomens ausmündet (Fiv. Iso).

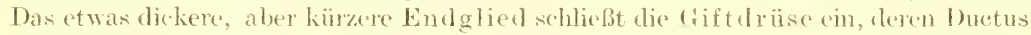
gleich über der Spitze de's stachels ausmïndet ${ }^{1}$ ).

Die Skorpione sinel lebendig gebärende Nachttiere der wamen Länder. Ihre IBeute, die hauptsächlich in spimnen und Insekten bestrht, ergreifen sie mit den Scheren mol töten sie dann durch einem stich mit ihrem dittstachel.

Die Ordnung der

\section{Scorpionidea}

zerfält in mehrere Familien, deren withtigste die Androctonidat (Buthidue), Toleyonidae mol Pandinidae (Scorpionidate) sind.

Als bekimiteste Arten der Alten Welt mögen hicr aufgetihht werden Isuthus aritumus (Mittehmeerländer, Arabien), IButhus quimgurstrimtus (Vorder-

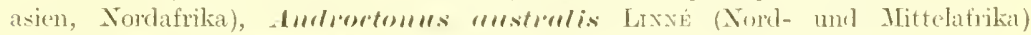

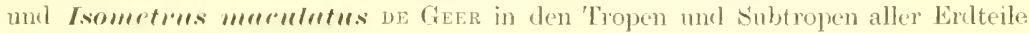
vorkomment.

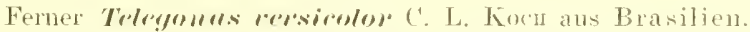

Auf die größten Arten stoßen wir in der Familie der Pandiniden. Der in

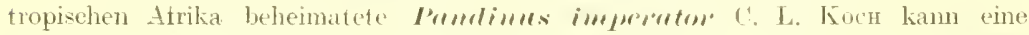
Länge von $18 \mathrm{~cm}$ erreichen. Kleiner ist der in Nordafrika angetroffene srompio

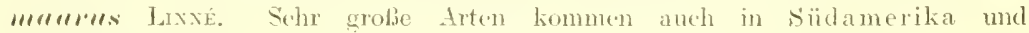
Mexiko verr.

Pathologie und Therapie. Wenn anch die Gefährlichkeit des Skorpionstiches früher stark übertrieben wurde, so sind doch in zahlreichen Fälen tübliche Verletzmngen des Denschen nachgewiesen worlen. Las Gift dex Skorpione scheint

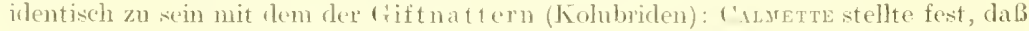
das Serum eines gegen Kobragift immmixierten Pferdes Mäuse und Hecrsehweinchen gegen das Gift von scorpio afrimuss sehützt. Auch im übrigen ist der skomplonstich genau wie ein schlangenhils zu behandelu.

\section{Literatur.}

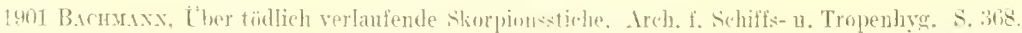

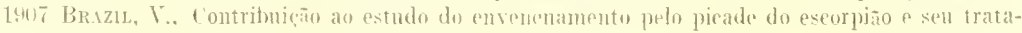
mentu. Rev. med, de s. P'anlo. No. 1!.

1) Bei seomiu ist zwischen stachel und Endsegnent ein Gelenk nieht vorbanden. Der stachel ist ein integrierender Bestandteil des festen lntrumentes des letzteu Banchinges. Die Bewenumg beim Einschlagen der Klaue verlänt deshah nicht in durch ein scharnieruelenk festgelewter bilm, Tie bei den sipinnen oder f'hilopoden. sondern ist eine viel freiere. Dementsprechend ist damu

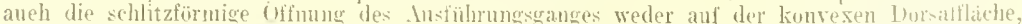

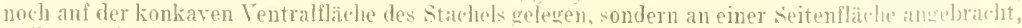
weil so auf alle Fälle ein möglichst freier Abllub des fiftes gesichert wirt. Ihit sichlangen, spinnen und skolopendren ziehen bein Einsehlagen ibrer Watfen deren dur-hbohrte, konvexe Fläche jedesnal ron der Wand des Wundkanales a b, und erlejchteri sn dem (iifte den Iustritt. 
Ints; Dalaxie. Des pigures par les scorpions d’Afrique. Ree de mém. de méd. mil. S. 136.

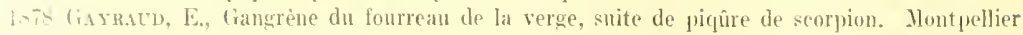
méd. April.

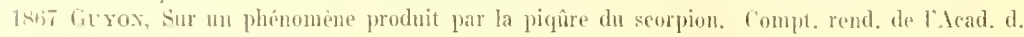
Sc. Bil. 6it. S. 1001.

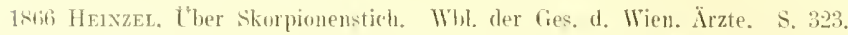

1870) Jotseret, Esai sur le venin du seorpion. (ompt. rend. de l'Aead. des sciences. Bd. 7I. S. 407. 1883.3 Toreux-Liffere. J., Appareil vénimeux et venin du scorpion. Thèse de Taris.

1869 Loxpox, Ein Fall von Verletzung demrh Skorpionenstich. Wien. med. Pr. Xr. 6.

1871 Posada-traxio, A., Note sur les scorpions de la Colombie. Arch. de méd. nav. S. 213.

\section{Die Tausendfüsser (Myriapoda).}

In der Ordnung der Chilopoden (LippenfüBler) finden wir verschiedene Gifttiere. Sehon unser kleiner Lithobius fonfiratus LINAÉ zeigt dureh seine beiden viergliederigen Kieferfüße, dic je eine durehbohrte, mit einer Giftrü̈se in Verbindung stehende Endklaue tragen, dab er ein wolılbewaffneter Räuber ist.

Fig. 181.

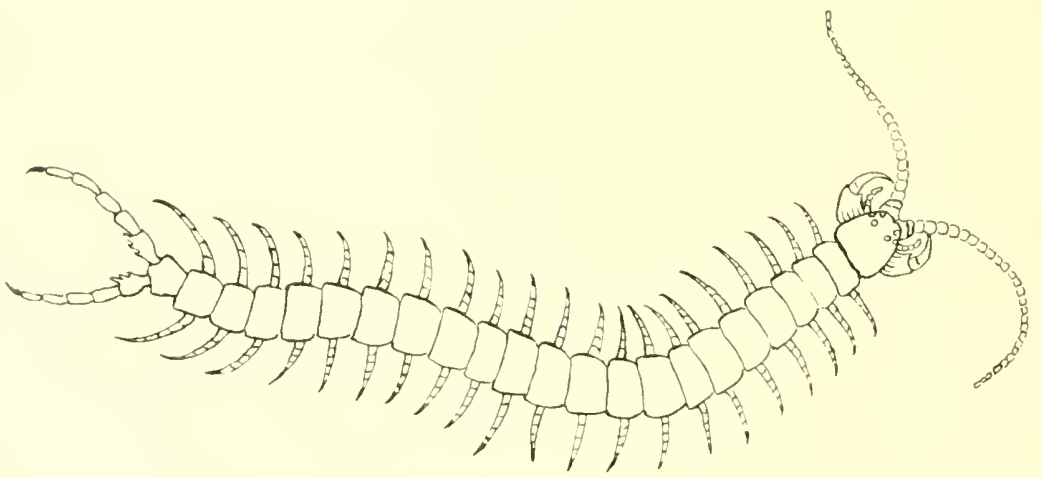

Scolopendru giganten. $2 / 3$. (Original.)

Die Chilopoden sind wie die Skorpione, mit flenen sie sieh ganz gewöhnlich in die gleichen Fichlupfwinkel teilen. Nachttiere. 'Tagsüber ruhen sie unter Steinen, unter der Moostreke des Waldhodens, unter Bamwurzehn und größeren vom Holzkörper abgehohenen Rindenstücken alter Bäume.

Scolopemblor rimgulutr ist die einzige europäisehe Art, sie wird in den westliehen Mittrlmeerländern angetroffen. Srolopremellor grganter (Fig. 181) lebt in Sïdasien (Indion und Indoehina), Scoloperudeu heros im äquatorialen

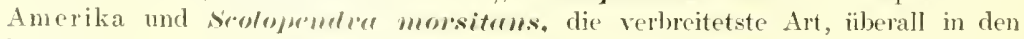
Tropen.

Die großen trepischen Sliolopendren, die eine länge von $20 \mathrm{~cm}$ und darüber errichen, können scllsst dem Jenschen gefährlieh werden. Die Bibstellen der Tiere 
machen sich als zwei kleine blutig unterlaufene Punkte bemerklich, sind lö̈ufig aber ïberhaupt nicht nachzuweisen. Neben örtlichen Erscheinungen, die sich bis zu Gangrän steigern können, wird regelmäBig lejelites Fieber beobachted. Wis kann 7. Erbrechen, Pulsbesehlennigung, Delirien und Kränpten kommen, die bei Kinelern gelegentheh auch einmal ten Exitus herbeiführen. Besonders gefährlich sinel die bisse der ,Zangenasseln" damm, wem die Mundehleimhant oder die Zunge verdetzt wird. Es kam dies bei der Gewohnheit der 'Tiere, sieh in Höhlen zu reskriechen tann leicht vorkommen, wenn Menschen mit offenem Munde zu sehlafen pflegen: es tritt in solehen Fällen zu den aufgetührten symptomen noch die durch rasche Intumeszenz der vertetzten Teile bedingte Gefalur der Erstiekung hinzu.

Die Behandlmng besteht in Waschungen und Cmschlägen mit verdünntem Liq. Anmon, eaust. (1:10), kalten Umschlïgen mul bei starken Schmerzen mul heftiger Erregung in der Darreichung von Narkotizis.

\section{Literatur.}

1s- Bacheller. L.., La scolopendre et sa jiçûre. Thèse de Paris.

1912 (LeldxD, B., Injuries and Diseases of Man in Austrilia attributable to Animals except lusects. The Iustralasian Ifed. Ciaz. 21 September.

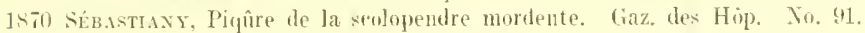

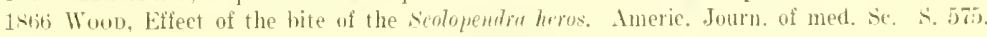

Unter dem zahllosen Heere der

\section{Insekten}

kommen in fast allen ( Mrdnungen Gift tie re vor. AuBer den in der ersten Abteilung dieses Bandes behandelten Siphunkulaten, Hemipteren, Psyllomorphen und Dipteren. stcllen die Käfer (Coleoptera), Schmetterlinge (Lepidoptera) und die Hautflïgler (Hymenoptera) eine ganze Anzahl ron Schädlingen, welche die Aufmerkwankeit des Tropenarztes zu fesseh geeignet sind.

\section{Coleoptera.}

Das in verschiedenen Familien vorkommende Käfergift seheint in allen Fällen Kantharidin zn sein. Von den enropäischen Arten sondern der ölkäfer (Heloë) und the spanische Fliege (Lytta tesicutoria) einen seharfen, stark reizenden Sift ab.

Der in Südasien, hauptsäehlich aul den Sundainseln lebende $7 \mathrm{~mm}$ lange Prrederus peregrimus Furrotes (eme staphylinide) mft mit der Haut in Berïhrung gebracht Rötung, schwellung und starkes Brennen hervor: es kimn sogar zu Blasen- und Krustenbildung kommen ${ }^{1}$ ).

Ein anderer Kurzflügler ist nach Bartecs die Ursache der auf den Marschallinseln hänfig rorkommenden 'Toddykrankheit. Die 'Tiere tallen beim Nisethen in größerer Zahl in den Palnensaft, welehen die Eingeborenen in Kolsosnubschalen im Freien gären lassen, ertrinken und werden von der alkoholischen Flü<isheit

1) Viele paläarktische Staphyliniden (.,kurzfligler") geben, wenn sie heim . Intlirgen in des Konjunktivalsack geraten, zu heftigem Brennen und lejchter Bindehautentzüutung leranlassung. 
"uscezongens. Quälender Hamdrang und blutige Stühle sind die Folge des Gemmsres bon remmeinigtem Tooldy (Palmwein).

\section{Lepidoptera.}

Nur in Larvenzustande kommen in theser Ordnung Gifttiere vor. Solche ".. Nesselriupen", wie sie lileyer (Bleyer, J., A. ('., Ein Beitrag zum Studimm Brasilianischer Neswelrampen. Arch. f. Sehiffs- und Tropenhyg. Bu. 13, 1909, s. 73-s3. Xit 2 Tafehn) sehr bezeichmend nemnt, kennen wir ja auch aus dentsehen Wäldern. Die Bärenranen und ror allem die Larven des Prozessionsspinners sind wegen der durch ihe Gifthate hervorgerufenen Dermatitiken und Entzïndungen der Atmungsorgane berïchtigt ${ }^{1}$ ).

In bezug auf Artenzahl und Giftigkeit viel beachtenswertere Nesselraupen loben in den Tropen; nanentlich aus Siid amerika (Brasilien) sind eine ganze Anzalıl solcher Sehmetterlingslarven bekannt geworden.

Sie erzengen Quaddehn, ausgedehntere Schwelhungen und Schmerzen an der Berührungsstelle mu in deren Tmgebung. Neuralgische Schmerzen der ganzen Extremität, starke Schwellnng der benachbarten Lymphdrïsen und Gebrauchsunfähigkeit gesclln sich dazu and kömnen sehlaflose Näehte berlingen. In den folgenden Tagen klingen dam die Erscheimmgen langsam ab.

\section{Hymenoptera.}

Nur die staclelbewehrten (alkuleaten) Hautflïgler werden unter Umstänten zu Krankheitserregern für. Mensehen und 'Tiere. Im Gegensatze zu den frïher hetrachteten stechenden Arthropoden (mit Ausnahme der skorpionideen, die in (lieser broichung eine vollkommen eigenartige Stellung eimnehmen), deren vergiftete Waffen sämtlich integrierende Bestandteile des Nahrungsschlanches sink, stchen die stilette der Hymenopteren mit dem Genitalapparate in Verbindung: es sind modifizierte Legeröhen und kommen wie diese natïrlich nur den weiblichen Tieren zn. Dementsprechend sind die giftabsondenden Organe im einen Falle die Speicheldrüsen, in anderen die Anhangsdrüsen der Geschlechtsteile. Die Gifturüsen der akuleaten Hantflïgler sind mindestens in zwei Paaren

1) In der ,Revue médieale de la suise romande" 1908 , p. 632 veroffentlieht CunrLes du Eors rinen Artikel über die church die Raupe des Prozessionsspinners (C'nethocampa processimu Lixve hervorgenfene Dermatitis. Differentialdiagnostisch kommt mur Lrticaria und vicllecht Prurigo in Betracht. Von Trtiearia läbt sie sieh, anch wemn in der Animmese nichts run Ralupenberïlrung erwälnt wird, dadurch unterscheiden, dab sie stets ihrem Anfang an einer nubedeckten stelle des Körpers nimmt und von hier aus sich weiter ausbreitet. I)je Affektion tritt mur im Frühling anf. Vou den Beohachtungen, die ou Boss nutteilt, ist namentlich die folgende deshalb hemerkenswert, weil sie beweist, dab die Entstehng der Dermatitis nicht immer die Folge einer digekten) Berübrung der Raupen zul sein braucht, Jr hatte auf einem Waldspaziergange zwej Zïge von Ranuen gelunden und dieseblon mit sich nacd Hanse genommen. Jeden Zurg hatte or in ein besonders vorgehaltenes listchen kriechen lassen. Zn llause angekommen leerte er die

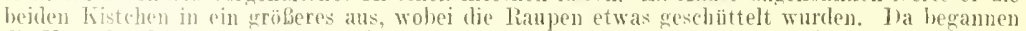
die Lunstedenden rerst in ter Nase, dam im Gesicht und auf den Händen ein Prickeln zon verspüren, fingen an sich zu liratzon und hatten samtlieh nach einer Stunde ilıre vermatitjs, freilich in sehr verschiedenem Malbe. Fine Lntersuchung der Raupe zeigt, dab dieselbe zweierlei Haare besitzt,

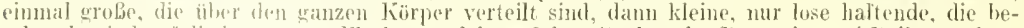
schränkt sind anf die brannoten Flecken, welche anf den Rï̈cken der Raupe in zwei lecihen stehen.

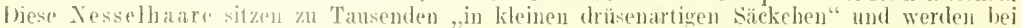
stäkeren bewegungen des Tieres herausceschleudert. Oh) sir dje Hautentzündung mechanisch oder wemisch bewirken, vermag sur bos nicht zu entscheiden, ev hält aber das letztere für wahrscheinlich, da die Jlaare von scit zurei Honaten toten Raupen sich wirkungslos zeigten und anch die Raupennester mur in frischen Zustante als gefährlich gelten.

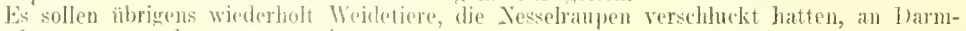

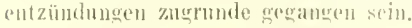


vorhanden, daren eines rine saure, deren anderes eine allalisehe, wasiserhelle

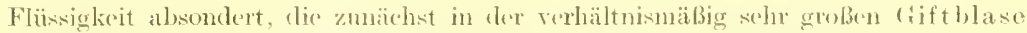
angesanmelt und erst beim sitiehe ausgeprebt wirk. Häufig pllegt noch ein clrittes Inisenparr limzuzutreten.

Die Hymenopteren hatehen ilnen Stachel in erster linie als sehr wirkatme Waffe, aber glüeklieherweise dem Mensehen und gröberen 'Tieren gegeniiber immer nur in der Notwehr. Manele Gattumgen pflegen auch ilure Bentetiere mit dem

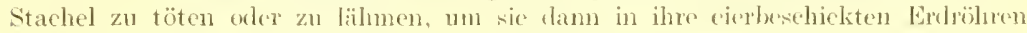
als Nahrung für die schliipfende Brut zu tragen.

Sehon bei uns sind die Hornissen und anch die kleineren Wespent) mit Recht gefürchtete Tiere. Die groben Wespenarten der 'Tropen sind geradezu beriichtigt.

Hior wäle auch noch der flïgellosen Spinnenam oisen (.Mutillı) zu gedenken, wolche mit ihrem außerordentlich langen Stachel recht empfindlich verletzen können. Namentlieh eine zyprisehe Art (,Nphalangi") ist in den letzten Jahren zu trauriger Berühmtheit dadureh gelangt, daß sie mit dem beschmutzten Stachel läufig Milzbrandbazillen auf Menschen und Tiere überträgt (Willdssox, Bitit. ned. Joum. 1900, S. 558).

Pathologie und Therapie. Die liftwirkung der Hymenopteren ist eine rehr große, die Stiche zweier Bienen genügen, eine erwachsene Maus zu töten. CaLmerte stellte fest, daß es leicht gelingt, Mänse gegen Dosen des Gifters zu implen, an welehen Kontrolltiere unfehlbar zugrumde gehen. Beim Henschen und gröberen Tieren treten in den meisten Fällen nur Lokalerscheinungen auf; sie beschränken sich gewöhnlich anf öhematöse, lebhatt brennente Schwelhungen in der Umgebung des sticlikanales.

Anch gegen Hymenopterenstiche wirl meist verdiinnte Ammonialiösung gebratcht. Calyetre, auf dessen Abhandlung in Bd. II rerwiesen sei, rühmt Waschungen und Aufschläge mit $2 \%$ warmer (hlorkalklösung.

\section{Fliegenlarven.}

Die wurmförmigen kopf- und fuBlosen Larven (Maden) der kryptoehrysaliden Zweiflügler atmen (metapneustisch) dureh mehrere stigmen, welche zwei dem Hinterende aufliegende Chitinplatten durchbohren. ${ }^{2}$ ) Die Maden sind umpigmentiert mol an der Mundöffnung mit zwei FreBspitzen ausgeriistet.

Die Larven verschiedener Fliegenarten, vor allem solehe der warmen Lämler, entwiekeln sieh nieht selten in Körper von Mensehen und Säugetieren. Sie können unter solchen Verhältnissen bedenkliehe Störungen verursachen. Die durch Anwesenheit schmarotzenter Larven hervorgerufene Krankheit wurcle ron Hope Myiasis genannt und die medizinisebe Wissenschaft nahm dam diese heute noch gebräuchliche Bezeichmong an. Man unterscheidet in etwas gelsünstelter Weise zwischen II yasis externa und Myiasis interna je nach dem Sitze der Sehmarotzer (Ilitut, Gehörgänge, Nase, Vulva ofler Verdaungsorgane).

1) In Kineutlingen (Lothringen) versehhsckte ein Arbeiter beim Biertrinkes eine IIespe. die ilum im schlunde einen stich versetzte, der den Tod des Nannes durch Ersticking hurbeiliahrte (Zeitungsmitteilung vom 26. Angust 1912).

2) Nach der ersten Häutung treten noch zwei likeine, in der Nïhe des Vordorentes liegende stigmen linzu. 


\section{Muscidae.}

Die durch Muszidenlarven hervorgerufenen Erkrankungen schildert Looss (Mense`s Tropenkrankheiten. 1. Auflage, Bd. 1, S. 205-207) in so trelfender Weise, daß ich seine Worte hier einfach anfiihren will:

\section{Myiasis muscida.}

,In denjenigen Fällen ron Myiasis museida, in denen es sich um normalerweise parasitisch lebende Larven handelt, entsprechen die symptome denen bei Myiasis oestrosa.

Unter den gelegentlich den Mensehen befallenden, von putreszenten Stoffen sich nährenden Muszidenarten kommen in der alten Welt in erster Linie Angehörige der Gattung Sarcophaya MEIG. (magnifica, wohlfahrti, carnaria L.), in zweiter Linie Husca-Arten (vomitoria L., domestica L.) und einige andere Formen (Fanna canicularis $11 \mathrm{E}$ G. usw.), in Amerika Arten der Gattung Lucitia (macellaria Fabr., nobilis MeIg.) in Betracht. Die Eier der ron putreszenten Stoffen lebenden Fliegen werden immer in größerer Zahl gleichzeitig, und nie a uf die gesunde Hant, sondern an eiternde, oder mit eitrigen, mehr oder minder stark riechenden Ausflïssen bedeckte Stellen abgelegt. Besonders gefährdet sind regungslos (schlafend orler aueh betrunken) im Freien liegende J'ersonen. Die Larven nähren sich zunächst von den eiterigen Ausflüssen, dringen aber, wenn diese ihnen nicht mehr genügen, in the gesunden Gewebe vor, wobei sie rïcksichtslos alles zerstören, was ihnen in den Weg kommt. Bei offen liegenden Wunden wird der Schaden selten groß, da sie von außen jederzeit erreichbar bleiben und entfernt werden können. Positive Gefahr ist dagegen vorhanden, wenn sie in Körperhöhlen eindringen; sie können sieh von der Nase aus in die Stirn-, die Augen- und selbst in die Schädelhöhle, vom änßeren Gehörgang aus in das Mittelohr und ebenfalls in die Schätlelhöhle, vom Hunde, der Nase oder auch dem Ohre aus in die Rachenhöhle durehfressen. Die dahei auftretenden Symptome sind charakteristisch durch die Schnelligkeit, mit der sic an Intensität zumehmen und hestehen in heftigen, von Fieber, Schwindelanfällen, Sehlaflosigkeit begleiteten, bohrenden und stechenden Schmerzen und mehr oder minder ausgedehnter Schwellung der L'mgebung der befallenen Stellen, die im Rachen zu sehweren Schluckbesehwerten Anlaß geben kann; aus den äuBeren Öffnungen entleert sich eine blutig eiterige, iibelrichende Fliissigkeit. In normal verlanfenden Fällen gehen die Symptome nach 10-I4 Tagen wieder zurück; die Larven haben ihre Reife erreicht, verlassen ihren Wohnsitz, um sich zu verpuppen und es erfolgt Heilung unter Bildung einer mehr oder minder ausgerlehnten Narbe. Relativ oft aber treten vorher septisehe Komplikationen ein und daun ist die. Prognose eine sehr mnginstige, der Tod ein häufiger Ausgang.

Die Eicr oder anch bereits größere Larven der oben in zweiter Linie genamnten Fliegenarten werlen nicht selten mit angegangenem Fleische, Käse, Vegetabilien und dergleichen frrehrt und gelangen in den Magen. In vielen Fällen werden sie daselbst getötct und crscheinen später halb verdaut in den Fäces; in anderen Fällen (anscheincul hauptsächlich, wemn sie als Eier eingeführt werden; indessen diurfte dabei anch der momentane Zustant des Magens eine Rolle spielen) vermögen sie sich am Lehen zu erhalten, und dam Jringen sie durch ihren Parasitismus ebenfalls meln' orler minder stïmiscles, nieht selten von Fieber begleitete Symptome: heftige, vom Hagen in die [mgehung ausstrahlende Schmerzen, blutige Diarrhöen und Erbrechen 
hervor. Dieselben sehwimlen wieder, wenn die Larven ihre lieife erreieht haben und anf natiorlielsen Wexe abgehen."

\section{Muscinae.}

(iemus . Iuscu.

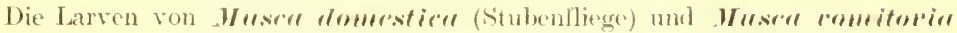
(Schmeißfliege) (Fig. 1n̈̈) werlen nicht selton im stinkenden Eiter rernachlässigter

Fig. 18.?.

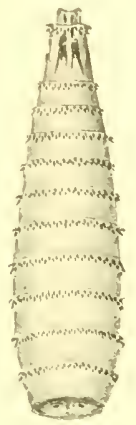

Larve von Muser vomitoria. $3 / 1$.

(Nach Looss.)
Fị̣. 1Ni3.

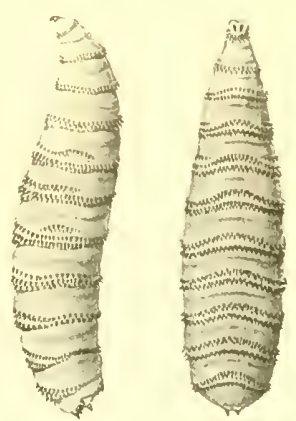

Larve von Lacilin meellurin. 'i. (Tach R. BuAxchard.) Links von der seite, rechts yom Bauche gesehen.

Otorthöen gefunden. Ausspritzungen mit Chloroformwasser bringen die Parasiten rasch zum Absterben und befördern sie dam prompt ans dem Gehörgang und Wittelohr.

\section{Calliphorinae.}

Genus Calliphorr.

Crollibhora erythocephro-Larven sind an denselben Stellen, wie die vorigen, und aueh in alten Geschwïren angetroffen worden.

Genus Chrysomyix.

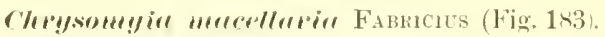

(Synonyme: Lucilia macelluria RoB,-1)Est. - Lucilia hominivorax Cogueres Calliphora infestans PHILPP - Compsomyia mbrifrons MACocart — Somomyia montevidensis Bi(u)

in Nord- und Südamerika häufig, legt ihre Eier ebenfalls auf Geschwïre oder in Körperhöhlen ab. Ex sind mehrfaeh Todesfälle mitgeteilt worten, die durch Meningitiden herbeigefüht waren, welche von der Nase oder dem Ohr her eingertrungene Chrysomyia-Larren ausgelöst hatten.

Genus Lucilia Robineal-Desvoidy 1830.

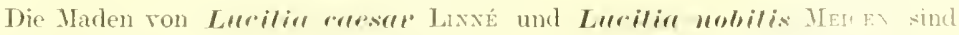
bei Ohreneiterungen mehrfaeh im äußeren Gehögange gefunden worden.

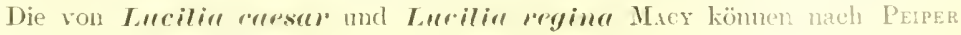
Myasis interna hervorrufen. 
Iie larve vom

Genus Cordylobia Grüxberg.

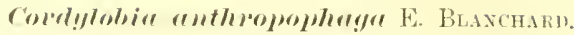

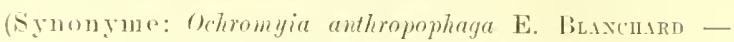
('ordylobic grïnberyi Diisitz),

den schon lange bekamnten, . Ter de cayor" konnte Füllesors (Beih. 6, Areh. f. Sch.- 1 . 'Tr.-Hyg. 190s) in Jahre lsos in Alt-Jangenburg an Nyassasee zu wierlerholten Malen in seiner eigenen Haut bobachten; , die barven waren

liig. 184.

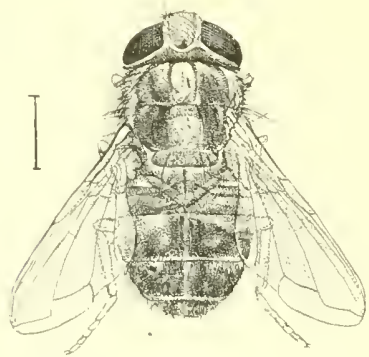

Complybuia anthropoptriga. $4 / 1$.

(Nach Fülleborx.)
Fig. 185.

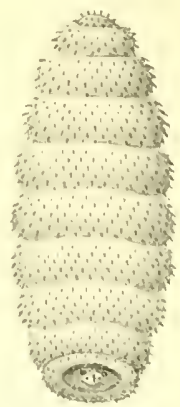

Comlylolica anthropoythage. 3/1 Larve.

(Naldi R. Blanchardo.)

Fig. 18.

Fic. 1sis.

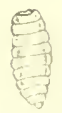

Linve von Cordylobin anthiopopleatye, erwachen. 1/1.

(Xileh lï̈lleborX.)

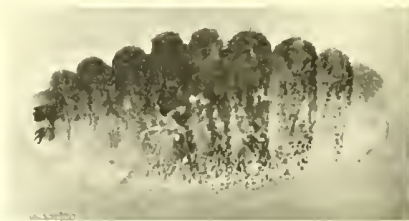

ad Natur.

Larve von Cordylobie mithropophage. Junges Tier. 9/1. (Nath Fïlleborx.)

auch bei anderen Europäem keine Seltenheit, und elsenso litten die Affen und Humle an riese'r Plagere.

Die crste livinuntsehaft machte FüLLEBons gleieh mit sieben CordylobinLarsen, deren bier jedenfalls von derselben Fliege algesetzt waren um die gheiehzeitig, nur geringe , fohnerzen verursachend, in die llaut seiner Arme, Hüfen und lirnst cindrangen. , hn den nä̈lhsten 'Tagen nahnen die Beschwerden zu und bestanden in bohrendem, aler mur anlallsweise auftretenden Schmerzen, wähend in der Zwischenzeit nichts verspiirt wurke. Dabei verhichten sich die Larven nieht gleich, sondern an cinem 'Tage machte die cine, an emem anderen Tage eine andere stärkere Beschwerden, während die äbrigen zur gleichen Zeit kaum empfunlen worden." 


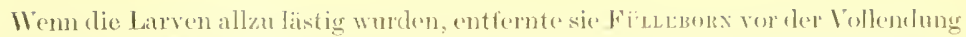

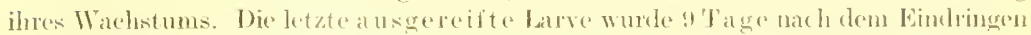

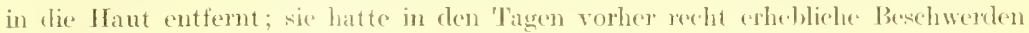
vertursacht.

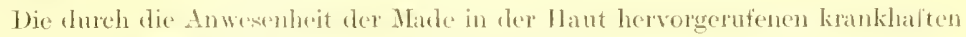

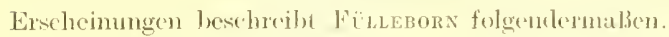

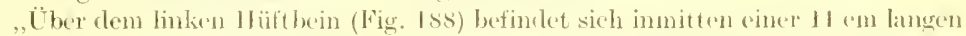

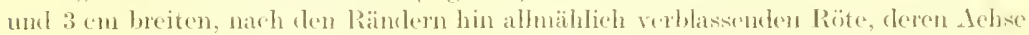
dorsoventralwärts geriehtet ist, eine 2 ('m lange und 1 am breite lnfiltration. I)ie Infiltation bildet einen von ventralwärts nach dorsalwärts allmählich bis etwa

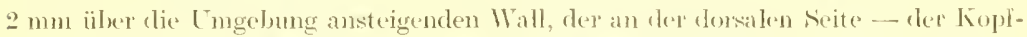
scite der Larre — steil ablällt. Aus diesen lufiltrate helst sieh der Absehnit, weleher

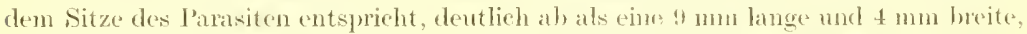
wurstförmige, bläulich vertärbte. Stelle. an der man die L'msisse des Made erlennen kann. Das weibliche Hinterende der Larre ist nicht von der Haut bedeekt, sondern tritt frei zutage in einem tiefen, länglichen ( $11 \mathrm{~mm}: 4 \mathrm{~mm}$ ) grangelblich belegten Geschwiir, das ron infiltrierten Rändern umgeben ist; bei Berührung zieht sich die Made zuriick.

Nach Expression der 1:2 $\mathrm{mm}$ langen und $5,5 \mathrm{~mm}$ breiten Larve entleert sich ans der Wurcle reichlich seröse, blutige Flïssigkeit, und die stelle, an der der Parasit gesessen. ist als deutliche limme in dem umgebenden Infiltrate fühlbar.

Die Heilung des Geschwärs nahm

Fig. 158.

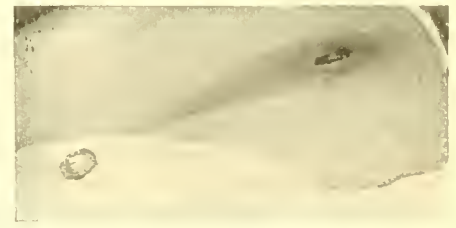

Durch die Larve von Comblobin anthropophage (rzeugte l)asselbeule an der llülte.

(9) Tage nachdem das Eindringen der Larve bemerkt war, aufwenommen.)

(Xach Fülleborx.) ohne Behandlung 2-3 Wochen in Anspruch. Die Narbe ist aber noch jetzt, nach I0 Jahren, als eine et wa 1 am grotbe weißliche Stelle sieht bar.

Die Expression der Larven gelang stets leicht. Wrom man mit eincm s'kalpellstiel oder dergleichen lirätig auf den vorderen Absehnitt des Hautwalles, in dem die Larve liegt, drückt, sf) springt sie ans dem kleinen Geschwiir, in welchem sich ihr Hinterende befindet, heraus. Rationell wäre es auch, die Larve durch em aut die Geschwürsöffnmmg gelegtes Pflaster zu ersticken, wic dies bei Dermatobia-Dasschbenlen angeraten wird. Skrodzi, welehes an des Kïste vou Deutsch-Ostafrika mit Dasselbeulen zu tum hatte, bei denen die Entfernung der Larven schwieriges. was, wandte dies lerfahren recht erfolgreich an."

Del Infektionsmodus ist noch nieht genan bekannt. Die Eier forlex lebendgeborenen Marden?) werlen wahrscheinlich von den auberordentlich beweglichen Fliegen blitzantig schnell an den mbedeckten Hautstellen des zukünftigen Wirtes abgelegt. Die jungen Larven brauchen sich nicht gerade an ihrem Gehurtsorte cinzubohren, sondern können weiter kriechend gevignetere Hautstellen (so die Genitalien und ihre Ungebumg) anfsuchen. Denkbar wäre ja anch, da B beim Baden des zukiunftigen Wirtes die Fliege ihre Brut direkt an den Bestimmungsort oder auf die alygelegte Wäsche brächte. Ein Ankriechen der anf die Erde abgesetzten Larven, wetches ron verschiedenen Autoren für mügtich gehalten wird, ist mir nach lieobachtungren bei audesen Arten sehr unwahrseheinlich, die Fliegenmütter bringen ihre Vach kommen immer in die möglichste Nähe des für sie tauglichen Nahrungrdepots. 


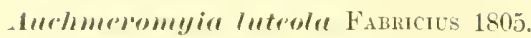

Die Made dieser. Fliege, im tropsischen Afrika unter dem Vulgärmamen des Congo floor-maggot" lekannt, hält sich tagsüber im FuBboden ron Negerbütten ant. Naehts kriecht sie aus dem lockeren Grunde hervor und saugt Blut aus der Itaut der auf dem Erdboden sehlafenden Insassen. Die $10 \mathrm{~mm}$ lange, dunkelbraune Puppe entlälst nach 2-3 Wochen die Imago.

\section{Sarcophagidae.}

Genera: Sacropherga Meigex, Sarcophila Roxdant, Cynomyia RobrneaU-Desvoudy.

Die Maden vieler Sarcophagiden sind in Geschwären und in Darnkanal des Mensclien angetroffen worden.

Die wichtigsten Arten sind:

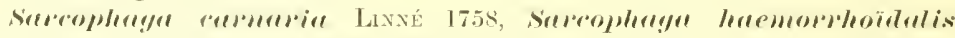

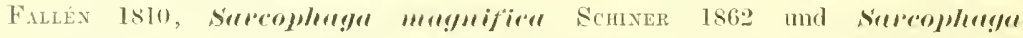

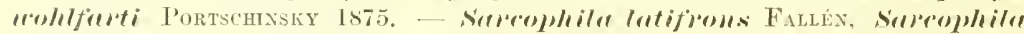

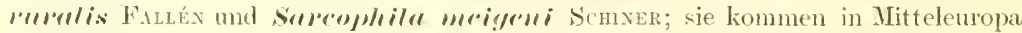
äberall häufig vor. - Auch die Maden von Cymommin mortmor"um Livxé 1761 sind mehraeh in Geschwüren gefunden worden.

\section{Anthomyidae.}

In diese Fanilie gehört unsere kleine Stubenfliege, Fummin armimoloris Laxié 1761. Thre Maden sind von Bloxis meyer im Tractus intestinalis und ron ('Herril in der Harnblase angetroffen worden.

\section{Oestridae.}

Dentrch: Biesfliegen, Dasselfliegen, Französiseh: Oestres, Cuticoles, Engliseh: Ciulfies, Botflies, Bull-bees.

Von den dxei Oestridengattungen Gastrophilus, IIypoderma und Dermatobiu schmarotzt die erste beim Mensehen nieht ${ }^{1}$ ). Während Gastrophilus- und IIypodermaArten amch in der alten Welt beobachtete Schädlinge sind, ist das Vorkommen von Dermatobin auf Amerika beschränkt.

bie Wirlitigsten Vertreter der Gattung

$$
\text { Hypoderma LATREHLE 18:5 }
$$

sinel bovis de (ieler, Jiana lirauer und lincala de Vilders.

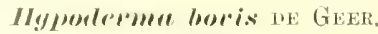

Die Haten rem /1ypoderme bovis (Fig. 189) sind mehrfach in der Haut des Menschen gefunden worden. Sie können an der Eintritsstelle in die Kutis verharen,

1) Dab Gastrophiluscarven die .Hatmanwiore" seien, welehe die ereeping disease

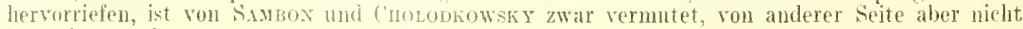
bestitigr wordess. 
wandem aber meist iilue zientich grobe strecken weiter, unterwege dat und dort längere Zeit verweilenel und Abszese hersorrufend. Namentlich hinder werden von der Fliege aufgesucht und mit Eiem besetzt. Diese dlyiasisexterna ist haupt-

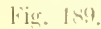

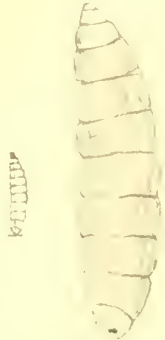

II ypoderme bocis-Larve aus der Hant eines Kindes. Links natïrliche Gröbe. (Nach Niritz.) lïir. 190).

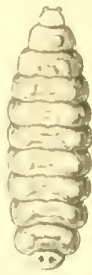

()estridenlarve aus ter llaut des lenseben im tropischen Mrikiil. ${ }^{3},{ }^{\prime}$.

(Nach R. BL.inghad.)

sächlich in skandinarien häufiger beobachtes worden; so komnte Hörris schon im bahe lotig äber 17 eigene und 5 fremde Fälle berichten.

Die Larve von

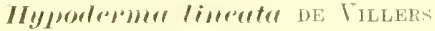

ist der Erreger $\left.{ }^{1}\right)$ der , Kriechkrankheit '('recping disease), welche in ihrem Verlaufe grobe thnliehkeit nit den eben beschriebenen durch Hypoderma bovis hervorgerufenen Veränderungen in der Hant zeigt und häufig aurh mit ihr zusammen-

Fir. 191

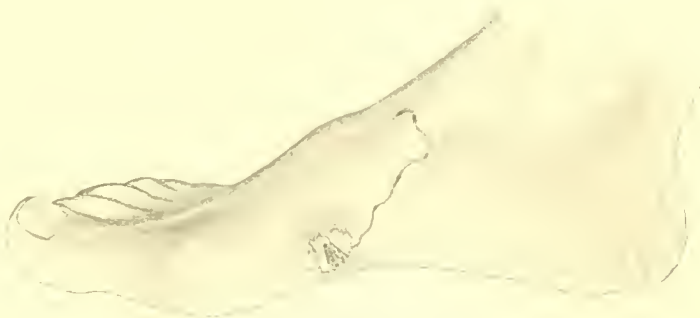

Hautmanlwurf, an der Küse von Liberia erworben.

- Im Ende des l'arasitengangr.s die durch Exzision eines Hantstückes entstandene Winde.) Zeichmug mach einer Photographie. (Nach Füllebors.)

geworfen und verweehselt worken ist (Fig. 191). Die Made erzengt wandermul dicht.

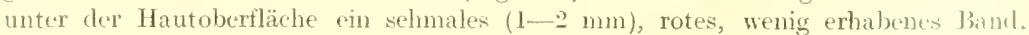
sie rückt an manchen Tagen mehrere Zentimeter ${ }^{2}$ ) vor, während sie an anderen

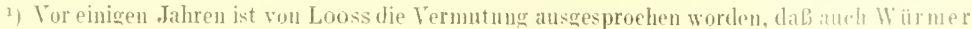
(Ankilostonalarven) ('reeping disease hervorrufen könnten.

2) CRoker (1)iseaces of the skin 1893) beobarhete bei einem zweijahriman Maidelen ein

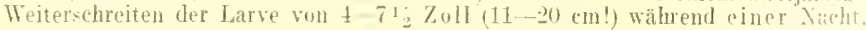


aul einer stelle verhart und den Kanal nur ,bläschenartig" (Fíleborx) erweitert. I) jew wilige sitz der Larve kam füs gewöhnlich von den Patienten genau angegeben wriden. Meist befindet sie sich natürlich am fortselureitenden Ende des Ganges, wo sie auch ,manchmal durch Glasdruck als dunkler Punkt sichtbar gemacht werlen kann" (SEEFFERT). An allen Stellen des Körpers, rereinzelt sogar unter der Mundschleimhant und der Konjunktiva, ist die Larve angetroffen worden. Die Erscheinungen ler Erkrankung beschränken sich auf Juckes und Brennen, zu Abszeßbildung kommt es nicht. Die Kriechkrankheit kommt besonders hänfig in RuBland vor, wird aber auch in den Tropen vielfach beobachtet. Thre Dauer ist eine whr verschiedene, sie brancht nur wenige Tage zu bestehen, kann sich abor auch über elahre (?) $\left.)^{1}\right)$ erstrecken.

Dic Jhehandlung ler ,Creeping disease:" muB in erster linie eine chirurgische sein. Inzision üher der vom Kranken als Larvensitz bezeichneten Stelle und Heraushelen des Schmarotzers sind zunächst zu versuchen. Läßt dieses Vorgeben im Stich, so kann man ein Stüek Hant mit der Lanve exzidieren. Wird blutige Operation rorweigert, so wäre die Abtötung des l'arasiten wit glühencler Nadel oder durch Subliutaninjelition von Kokainlösung oder Chloroform in Anwendung zu bringen.

\section{Genus Dermatobin Brater 1860.}

Die Gattung wird nur in der neuen Welt angetroffen ${ }^{2}$ ). Bekannt ist bis jetzt mur die Art

\section{Dermatobie ryanimentris Macodart 1843.}

(Synonyme: Destrus Guildingii Hope, Cuterebra noxialis Goudot, Cuterebra cyanirentris Micocdrt, Dermatobia noxialis Brater.)

Sie kommt in den wämeren Gebieten Amerikas von Brasilien Jis in den süclen der V'ereinigten Staten vor. Thre Larve wird in Mexiko, "Ter mayocuil", in Columbia "Nuche", in Venezuela, ,Zaneudo", in Cayenne "Ver macaque" und in Brasilien, Bicho" genannt.

Die schöne, zienlich grolse Fliege (im Durchschnitt $15 \mathrm{~mm}$ lang) ist lebhaft getärbt: das gelbe Gesicht und der dunkelgraue 'Thorax stechen wirkungsvoll von dem stahlblauen, in seinen proximalen Segmenten weiBlieh gefärbten Hinterleibe ab. T) je Flïgel und beine erseheinen gelbbram.

Ihre Eier legt Dermatobia auf die Haut ron Säugetieren (namentlich Hausticren) und auch auf den Menschen ab; Kopf und Rumpf sind hier die berorzugten Körperstellen. Die Larven (Fig. 192) können $30 \mathrm{~mm}$ lang werden, sie sind von weißlicher Farbe und häufig lienlenförmig gestaltet. Die vorderen Segmente tragen proximale Dornengürtel, die Mundöffumg ist mit zwei starken FreBspitzen ausgestattet. Die Larven, welche 2-3 Monate zu ilher vollkommenen Entwicklung Jauchen, liegen in Jasselbeulen, tie manchmal, namentlich wemn mehrere Haken in einer sehmuotzen, hiihnercigrol werden können. In der furunkelähnlichen Geschwulst befinder sich stets eine (wenn mehrere Larven in derselben Benle leben je eine für jerke) kleine öffnung, in welcher die Stigmenplatten des Tieress sichtbar werden. Wem bassclbeulen an den Extremitäten vorkommen, so liegen sie immer anf deren Streckeitr. meist wird wie selon oben bement der Rumpe befallen.

Wie die pathologischen Erzengnisse aller kutikolen Oestridenlarven, so rufen anch die Dematohiabulen nu verhältnismäBig geringe Besehwerden herror. Sie bestehen in Jucken und zeitweise anftretenden bohrenden Schmerzen, die sich ge-

1) Wabrscheinlich handelt es sich hier um mehrfache Teninfektionen.

2) Drrmalobia lieniar liols ans Arika trägt ihren Gattungsnamen wohl zu Inreeht. 
wöhnlich zur Nachtzeit betriehtlich steigern. Die-benachbarten Lymphdrüsen schwellen regetmäBig an. I'hlegmonen, Erysipel oder gar Tretanus werken nie dureh die Larven verankBt, sonkem siml nur als Folgen ron Sckundärintektionen aufzutiasien.

Die Diagnose aller Fomen von My iasis eler Haut macht bei berijeksichtigung der angelïhrten Erseheinungen gar keine sehwierigkeiten. Anters stelit dio Sacho bei Myiasis der Kärperhöhlen oder dos Tractus intestinalis. Hier ist spiegeluntersuchung am Platze und versuchsweise dusspritzungen mit ('hloroformwasser in Anwendung zu bringen. Bei Myiasis interna wirl man nach Darreichung von Abe ührm it teln aul etwa abgehende Iacken zu achten haben. Torherige Inspektion der GefälBe und die sofortige Untersuchung des Stuhles sehïtzen ror sonst leicht mögliehen Irrtümern (rgh. auch Tephropleagus S. $2: 37)^{1}$ ).

Die Therapie der Hautmyiasis hat in mögliehst rascher Entlernung der Larsen zu bcstehen. die am besten vor der Extraktion oder Expression durch Erstiekung (Verschlub der Stigmen durch eine auf clic

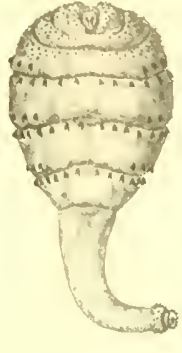

Fir. 192. Disselbeule geklebte Heftpflasterscheibe) getötet werden. Gegen Höhlenmyiasis sind dieselben Hittel, wekhe auf Seite 220 gegen Lingutula rhinaria empfohlen wurden, in Anwendung zu bringen. Bei Myiasis interna sind Magenausspülungen unel Purgantien angezeigt.

Die prophylatischen Maßnahmen sinch nicht immer leicht zu treffen. Mensehen, die an Gesehwüren, eiterigen Entzündungen der Nasenhöhle oder des Mittetohrs leiden, menstruierende oder mit Fhor behaftete Frauen duinten in den Tropen und während der wärmeren Jahreszeit auch in flex genäbigten Zone nicht im Freien oder bei geöffneten Fenstem shlaten. Alle Speisen müssen in sicher verschließbaren Flicgenschränken oder unter Drahtglocken aufbewaht und ror der Mahlzeit genau auf etwa vorhandene Maden untersucht werden.

\section{lionservierung unt Zucht der Larven.}

Aufzubewahrente Flegenmacken werden an einfachsten in $75 \%$ Alkohol eingesetzt. Die Formen erhalten sich noeh besser, wenn man die 'Tiere in das koehend gemachte Alkoholgemiseh einträgt.

Ist man in der Lage, reife Larren zu bekommen, so ist die Aufzucht der. Fliegen eine sehr einfache. Die Maden verwandeh sich in Behältem, auf deren Boden

$\left.{ }^{2}\right)$ Es ist in den letaten Jahren vielfach Brauch weworden, ein jedes im Stuht onfunder Insekt nsw. mindestens als einen Gelegenheitssehmarotzer zu betrachten, ten Fund zu beschreiben und sorgfiltig zu buchen. Ich halte das für einen vißbranch des Setzers und für eine P'apier-

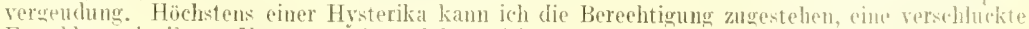
Froschlarse in ihrem Maren zu einem lebengelährdenden Ravbtiere amswachsen zan laken. 
utwas fenchte mol feucht zu erhaltende Erde lagert, willig in Puppen, die dam weh winger Zeit das fertige Insekt entlassen. Ton Looss ist der Vorsehlag gemaelnt. norten, jüngere Oetridenlarven in die Haut ron Wiederkäuern einzupflanzen und chrt anseifon zu lasien. Umreile Sareophagiden-, Musziden- und Anthomyjonlarren sind schon vich leichter zu behandeh; hier genügt es meist, ihnen ein Stück fauknden Fleisches ofler die Leiehe eines kleinen Vogels oder Säugers vorzusetzen. Das Larvenfutter mub aber, nu leidige lrrtüner zu remeilen, gegen das Eindringen anderer saprophager Dipteren durch sieher deckende Drahtgloeken u. lgl. gresehützt werden.

\section{Literatur.}

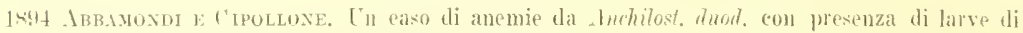

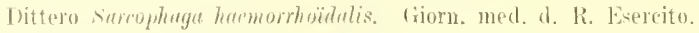

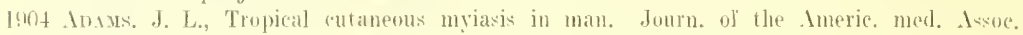
$\therefore .47 \%$

In!k Irvold, Smiti, Maberly, In uıknown larval jarasite. The Laneet. April.

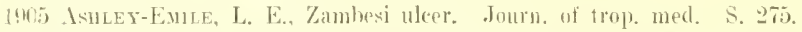

1907 Iestex, E. l... Cordylobia anthropephaga, a parasitic allican Ily. Proceed. Ent. Soc. S. 111.

link lersethe, The 'Tumbu-fly. Journ. of the Roy. Army med. Corpes. S. 18.

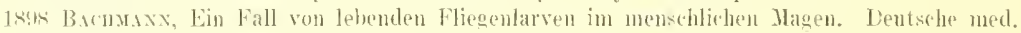
Wrehensehr. \&. 193.

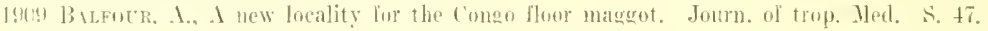

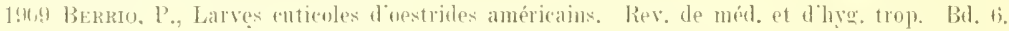
$\therefore 194$.

1540) Blaxchard, R. Traite de Zook. med. P. II. Paris. S. 502, 517, 521.

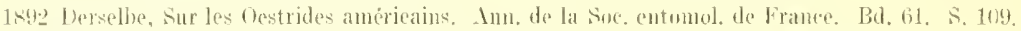

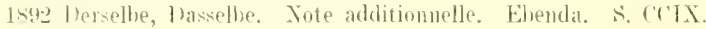

$180:$ Derselhe, Note sur des larves de lermatobia provenant de Brésil. Ebenda LaT.

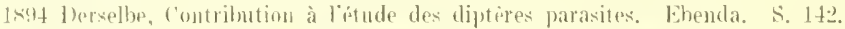

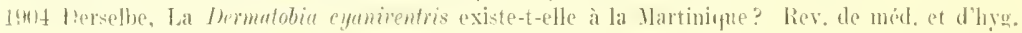
trop. I. S. 20 t.

1!ng Bumixsop, A. P., Ohervations on Tumbu-fly disease. Journ. of the Roy. Army. Med. forps. S. 11i.

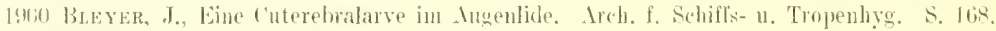

195: Mrerethe, Tratado de Myiasis. Curityba-Paraná.

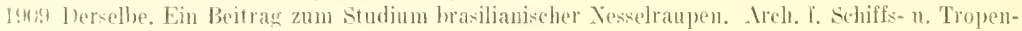
hyeine. Bd. 13. S. 73-83. Mlit 2 Taleh.

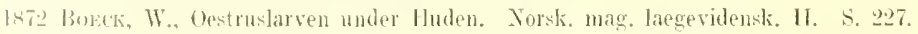

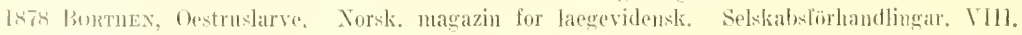
ล. 1 1:39.

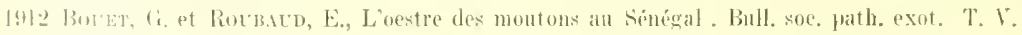
1. $7: 3: 3$.

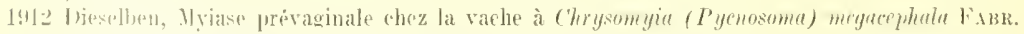

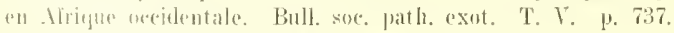

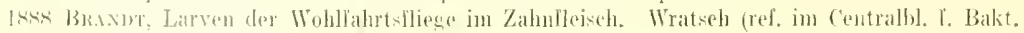
Bil. 5. S. (ith).

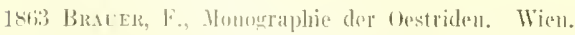

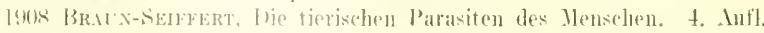

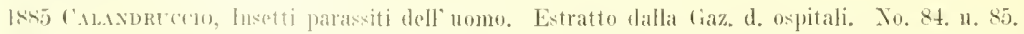

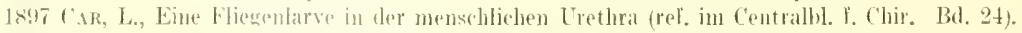

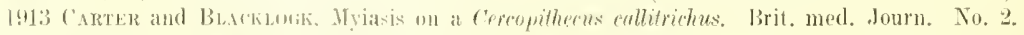

1811 funcuster, fases of hematemesis, connected with the discharge of larvae. Edinb. med. and surg. Journ. Vol. 111. p. 24k. 


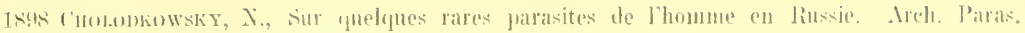
$\therefore 354$

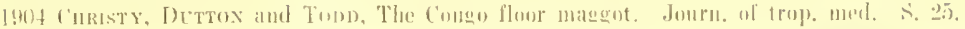

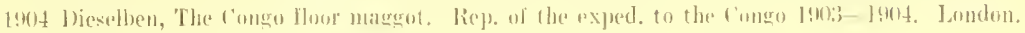
$\therefore 4$. 49

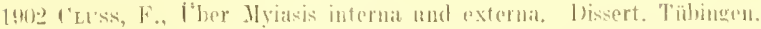

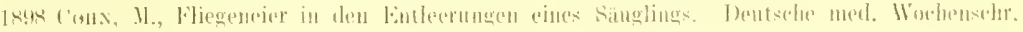
$\therefore$. 191 .

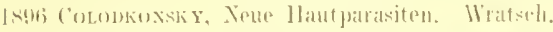

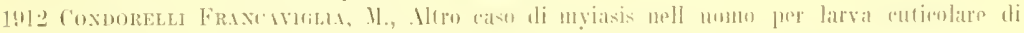

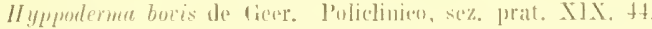

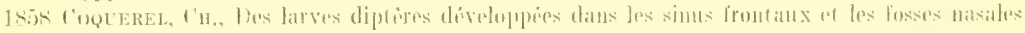

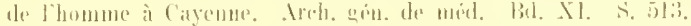

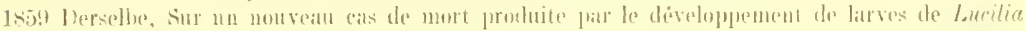

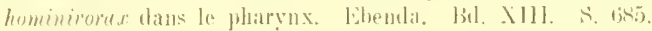

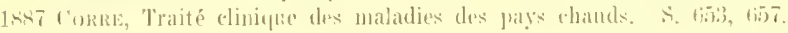

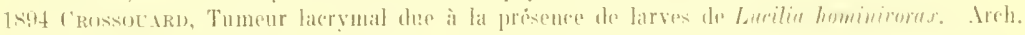

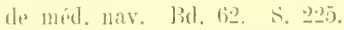

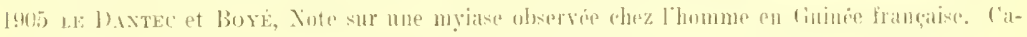
durepe. S. ?.

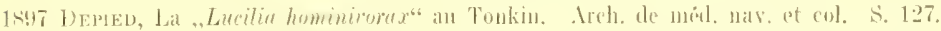

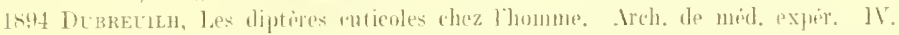

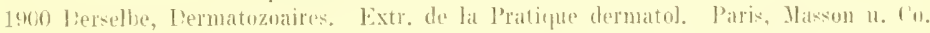

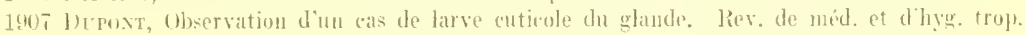
$\therefore 17$.

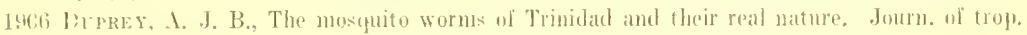
med. S. 2.2.

15:17 Folker, H. II., The gusano worm and its treatment. Ued. Rerert. S. 50).

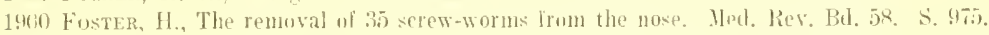

1s68 v. Fraxtzics, L̉ber das Vorkommen von Fiegenlarven in der Xasenhöhle von Tropenhewohnern. Tirch. Arh. Bal. 43. S. 6.

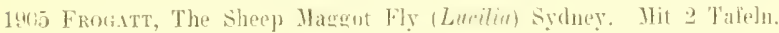

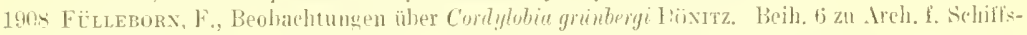
11. Tropenhyr.

1902 lisx. Tn. F. W. Beel-worm in the orbital cavity. Jonrn. of trop. med. S. 114.

1905 Cieboesst, L., Contrihution à l'atude de's larves cuticoles des Muscides alricains. Mred. Paras. Bd. . . ล. 568 .

1kti Cierh.ırd, Magenkatarrh durch lebende Dijteren. Jenaishe Zeitochr. S. 454.

1845 (incouts, Annales des sciences naturelles. \&. 22:1lf.

1908 Cirly, St., C. Screwworm in St. Lncia. Brit, med. Journ. No. 2204.

155:3 lirtob, ther das Vorkommen ron Sarcophagamiden in den dugen und in der Nase von

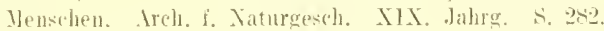

1stio J Jerselhe, Beschreibung einer Oestridenlarve aus der Hant des Mensehen. Arch. f. Naturesech. 26. Jahrs. \$. 9.

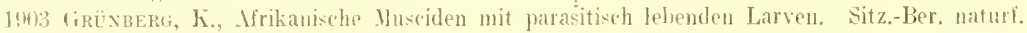
Fremo. Xr. 9. S. 400.

Istos ditcket, ther Fliegenlarven im menselitichen Organismus. ('entrabbl. l. Chir. 25. Jahrg. S. 181 .

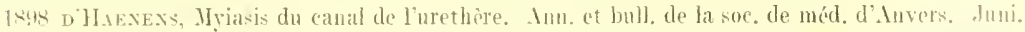

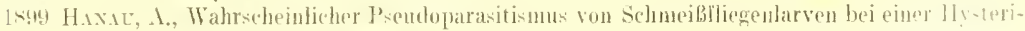
schen. Mrelt. Paras. S. 2:3 27.

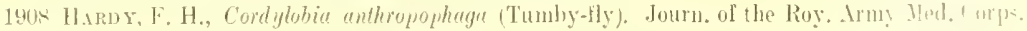
Bit. 11. S. 113 .

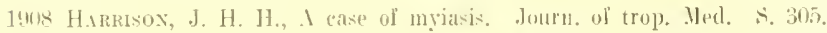

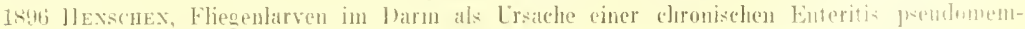
brandeea. Wien. klin. Rundkch. s. 563. 


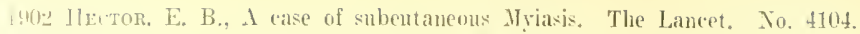

1902 Hexxeberg, Essigfliegen (I)rosoptilu fenestrulis und funebris). Jit Figuren.

1899 Herzog, M., A ease of Oestrus hominis. Mled. News. S. 268.

1,69 Ilïgr. Over Oestruslarvens Jorekomst under Alemneskets Hud or de derved bevirliede patlulogiske Fenomener. Tork Magazin f. Loegevidensk. R. II. Bd. 23. S. $489-50)$.

1899 Hliber, Bibliographie der kinischen Entomologie. Heft 3.

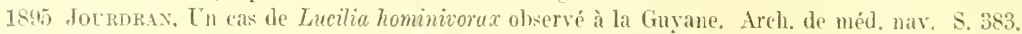

1905) Kiyser, B., Ther Fliegenlarvenbeschädigung des Anges, Kin. Monatshl. f. Augwhl. Bd. 43.

1900 KLyt, F. T., I ease of ,heef-worm" (Dermatobia noxialis) in the orbit. Brit. med. Journ. S. 316 .

1897 lionb, (4., Beitrïge zu einer geographischen Pathologie Britisch-Ostafrikas. Gieben s. 2s.

1897 lioneras, Ilypoderma bovis und ihre jüngsten Larsen. Centralb). f. Bakt. Bd. 23. $\therefore$ S. 888 .

1886 liracse, Ĺber einen liall von Reflexepilepsie infolge von Fliegenlarven. Deutsche med. Wochenschr. S. 291.

1898 Kumberc, Ein Fall von Dermatomyiasis linearis migrans. Trateh, Nr. 2 (Ref, in Centralbl. f. ('hir. 1898. Mr. 20).

1898 Kusvezow, Myasis narium e larvis muscae sarcophagae. Protok. d. Onsk. med. Geselsch. Nr. 3.

1897 Laller, Étude sur la myase du tube digestiv chez l'homme. Thèse. Paris.

1912 Leboeff, A., Dissenination du Bucille de Honsen par la Mouche domestique. Bull, soc. path. exot. T. I. \%. 860 .

184.t Lexolr et Railliet, Jouche et Ver de Cayor. Arch. rétér. S. 207.

1898 LEox, X., Quedques cas de myiase observé en Rounanie et leur traitement par les paysans. Arels. Paras. S. 314.

1902 Lindsay. J. W., Mriasis - The Lucilin marllaria - The Screw worm. Journ. of trop. med. S. 220 .

Isn5 Looss, A., Von Wiumen und Arthropoden hervorgerufene Erkrankungen. Jense's Handh. d. Tropenkrankleiten. 1. Aull. Bd. 1 S. 202.

1893 me Magamies, P., Subsidio an estudo das myiasis. Rio de Janeiro (Ref. im Centrabl. l. Bakt. Bd. 14. S. 370$)$.

1870 Muld.qu, the la Lucilia hominiwarar. Thèse. Montpellier.

1898 MLıfi, Sopra un caso di myiaxis intestinalis. Rif. med. No. 167 (Ref. im Centralhi. f, imere Hed. Mr. 51).

1.68 Manisewicz, T'her das Vorkommen von Fliegenlarren in der Yasenhühle. Virch. Arch. Bd, 44 . S. 375 .

1909 Hariet, J. D., Dermatobia noxiulis-hnfektion. Hed. Record.

1887 Mns, L'her Herm Hr. Josepur's Beohachtungen parasitisch lebender Hypodermenlarven am Menschen. Iheutsche med. Zeitg. S. 785 und Entgegmung Dr. JosepH's. Eluenda. S. 1053.

1908 Mouchet et D) ré, Contribution à l'ätude des larves cuticoles d'oestrides américains. Rev. (he méd. et d'liyg. trop. Bd. 5. S. 262.

1897 Xikez, Ein Fall ron Myisais dermatosa oestrosa. Dentsche med. Wochenschr. S. 6z9.

$141^{2} \mathrm{Nox}, \mathrm{H}$., Remarques et observations sur le rôle des moustiques dans la propagation de la lèpre. Bull. soc. path. exot. T. V. p. 78 .

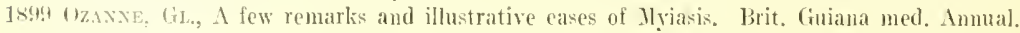
今. 4 .

1898 P’.XTet, d., le Thrixion Halidayanum Roxp. Essai monographique sur les caractères ex-

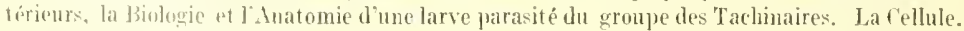
Bid. 15 .

1909 Derselbe, sur l'unilination du nombre des segments dans les larves de Muscides. ('. R. Ac. tes sicjences.

1695 l’ascal, Parasites des luses nasales. Arch. de méd. et plarm. mil. No. 10.

1890 Pasquale, sulla presenza di larve di Ditteri nell' intestino di alaui febbricitanti di Massaua. Rijurn. intern. delle se. med, XIl, S. 781.

1507 PE PER, Zur Symptomatologie der tierischen Parasiten. Deutsche med. Worhenschr. Mr. 48. 


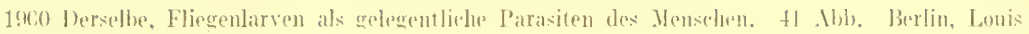
Marcus.

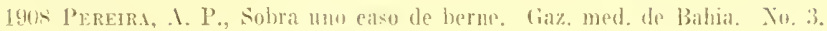

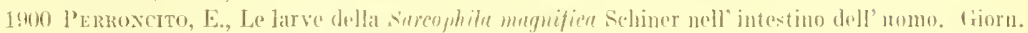
R. lee. med. Torino. S. 52.).

1912 Pieter, H., In eas de myase vulvo-vaginale. Rer. de llid. at d'Hye.trop. Bu.9. S.17it 17.

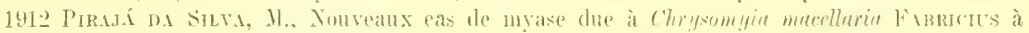
Bahia. Arch. de Parasitulugie. Bd. 15. s. 425-430. Mit 2- Textfigg. 11. 1 Tall.

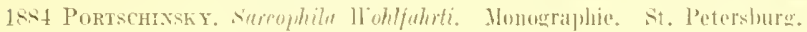

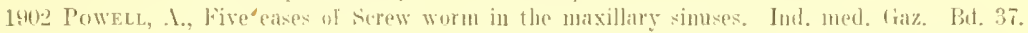
$\therefore 7$.

1882 Provot, cuntribution a liatude des larves de lipteres trouvies dans le corpe do l'homme. Theice. l'aris.

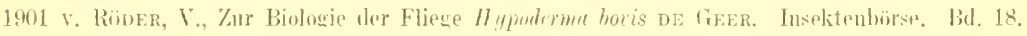
S. 107 .

191.2 Rorbacd, E., Etudes hiologịnes sur les Anchméromyies. Bull. Sur. path. exut. Bu. 5, ล. $128-130$.

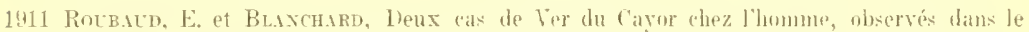
Haute-Sassancira (Cote d'lvoire). Bull. soc, path. exnt. 'T. IY. p. (ist.

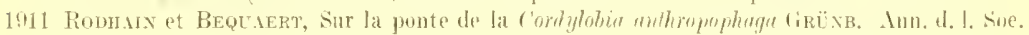
Entom. d. Belgirfue. Bd. 55. Yo. 7.

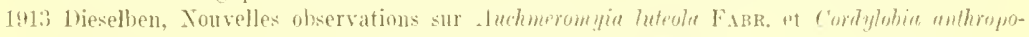

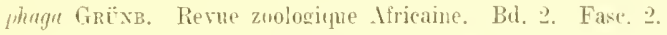

Iso Rocx, Traité pratique des maladies des pays ehands. JII. S. 579.

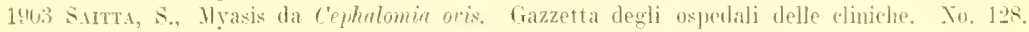
1s45 s.umsox, t'ber eine neue Hautkrankhejt. Wratseh.

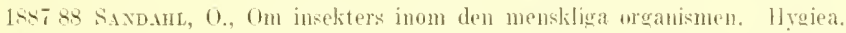

1862 Schemer, S. H., Vergleichende Inatomie der testridenlaven. Wit 3 Tafeln. Wien.

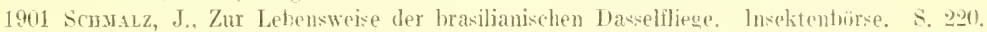

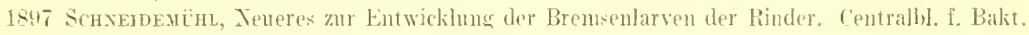
13. Paras. Bd, 22. S. 152 .

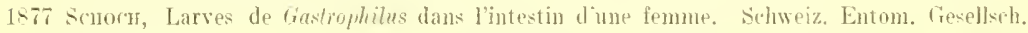
S. 275.

1890 sextror. Über lebende Fliegenmaden im Yagen und in der Mundlülle. Ber\}. dilin. Wuchenschrift. Nr. 9.

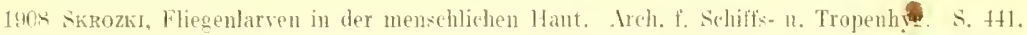

1905 sur, J. I. R.. Ie Tliegenziekte in Cordoba (Argentimië). Nedert. Tijdsehr. r. Crencesk.

1966 Derselhe, Jie lihegenkrankheit und ihre Behandlung. Dentsehe med. Woehenselrr. s. Ti3.

196 sum, F., Tumbu-1ly disease in sierra Leone. Journ. of the Roy. Irmy Med. Corps. \$. 14.

18 s. sичтн. J., Dipterous larvae in the human alimentary eanal. Ind. med. liaz. Bd. 34. S. 370.

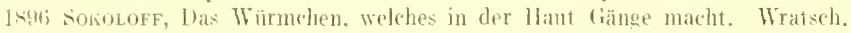

190 ĭ Splexdore, A. Contribuiçaos para o estndo das myiasis. Rev. med. de S. Paulo. Xo. 19.

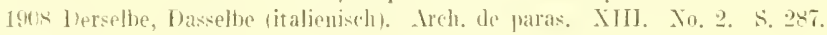

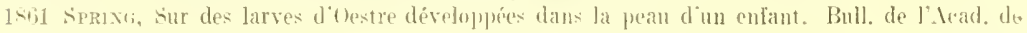
Belgique. IV. S. 172.

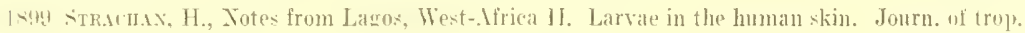
med. S. :os.

I!1!0 swas, J. I., A report on two eases of external Myiasis. Journ of trop. med. s. 1.

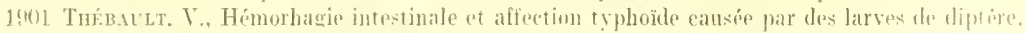

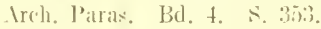

las? Vïlket, fall von Gestrus hominis. Berl. klin. Worhenschr. Mr. 14.

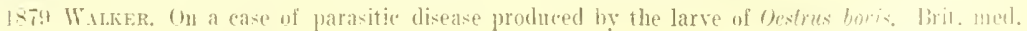
Journ. II. \&. (4)-2.

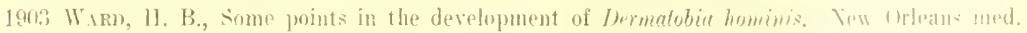
and surg. lourn. Bd. bij. (1et. 
184, WLber. Recherches sur la monche anthropophage du Mexique (Lucilia hominimomx). Ree. de mèm. de mid. milit. S. 158 .

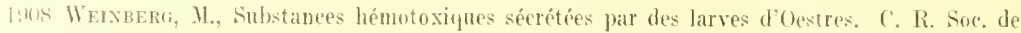
hiologie.

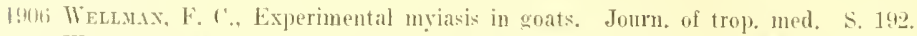

1 1897 Wruss, llyiasis dermatosa oestrosi. Deutsche med. Woeh. S. 524.

18.2 Wixge, E., (lestruslarver udtagne fra Memesker. Norsk. mag. laegevidensk. II. s. 8.2.

1770 Hohlfant, le vermibus per nares excretis. Nova acta phys. med. Arad. ('aes. Leopull. Varolin. T. W. Normbergac.

1904 Yocxie. (i. H., The treatment of mviasis, Brit, med. Journ. S. 360.

1907 Gotxt and Srober, Inman myiais from the Serew worm fly, Journ, of the Americe. med. Assoe, Bd. 49. No. 23. 


\title{
Die Phlebotomen.
}

\author{
Von \\ R. Doerr und V. liuss,
}

Wien.

Die blutsaugenden Phlebotomen scheinen in der Ätiolugie der infektiösen Krankheiten warmer Kimata eino bedeutsame Rolle zu spielen. die sich gegenwärtig freilich noch nicht in ihrem wahren Uufange nit Sicherheit absehätzen läBt. L'nsere positiven Kenntnisse reichen nur so weit, raß bestimmte l'hlebotomenspezies ein epidemiseb autretendes Dreitagefieber iibertragen (DoerR); die Angaben mehrerer Autoren, nach welchen sie auch als die Verbreiter der Aleppo-Beule unel der Pellagra anzusehen wären, tragen einstweilen den (harakter von Vermutungen, die sich mehr auf epidemiologische Momente stützen und experimentell zn wenig fundiert sind, um zu allgemeinerer Beachtung und Anerkemmmg zu gelangen. Jedenfalls simd aber die vorliegenden Tatsachen und Hypothesen geeignet, das Interesse des Tropenarztes fïr diese winzigen Zweiflügler zu erwecken: dazu komnit noeh, laßs the I'hlebotomen niclıt nur als Krankheitsüberträger, sondern auch als blobe hämatophage Insekten betrachtet eine Bedentung besitzen. In zahlreichen warmen und heilsen Gegenden

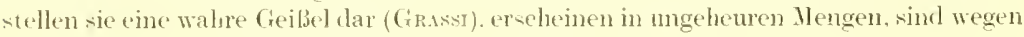
ihrer Kleinheit schwerer abzuwehren als andere Hosquitos und erregen dureh ihre Stiche nieist riel intensivere Schncrzen und stärkere Hantreaktionen (dlie sogar in (Jzeration übergehen können) als Kuliziren ader Anophelen.

Diese Verhälnisse rechtfertigen ein genaneres Eingehen in die Morphologie unt Physologie dieser Dipteren; da die Phlebotomen in vielen Beziehungen, hesonders aber dureh ihre Entwicklungsgeschichte weit ron anderen krankheitsiibertragenden stechmücken abwejehon, ersehien es zwecknälig, ihrer Besprechung einen besonteren Absehnitt zu withen.

\section{Systematik.}

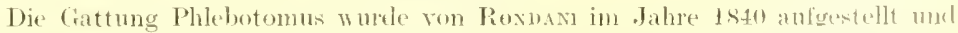
in cler Folge von allen Entomologen anerkannt; ihre Stellung im zoologir hen ststen ist aus dem folgenden, mach den Angaben von Axixpdue lionstruicter sthema zu intnelimen: 
R. Hoterk und Y. Russ.

Ordnung: Diptera

Tinterorhmung: Tematorera

Familie: Psychodidae

Subfamilien: Phlchotominae

Psychodinae

Gattungen: Phlebotomus. Temopalpus, Sycorex

Triehomyia, Eatoniser, Diplonema.

He Psychodideen sind kleine Tematozeren unit relativ großen Fhïgehn, welehe dieht mit Haaren oder schuppen bedeekt erseheinen. Die Flügel zeigen an ber der vorderen Rand- und der Hilfsaler (vena costalis und subeostalis) noctn wenigstens 6 Längsadern; die Queradern sind gering an Zalnl, sehr zart, oft nahezu unsichtbar und fehlen im distalen Teile der Fligel.

Bei der Subfamilie der Phtebotominue gabelt sich die 2. Längsader in 20 oler 3 Aste, welche in hetriehtlicher Entferuung von dem Punkte entspringen, an welehem sieh der Hauptstamm der 2. mit der 3. Längsader verbindet. Das Weibchen besitzt keinen hornigen Ovipositor; das än Bere Genitale des Mämchens besteht aus wenigstens ? Paar Anhingen, welche das eigentliche Kopulationsorgan umgehen.

Bei den Psychoulinae sind stets a Aste der 2. Länusader vorhanden; der oberste ist stärker ausgeprägt als die 2 unteren und vereingt sich mit dem Mittelast an einem Punkte, welcher der Basis des Fligels wäher liegt als der spitze. Die Weibehen haben einen hornigen. ans 2 Klappen hestehenden Legapparat (Ovipositor); das äufere (ienitale der Mämehen weist mor 2 Paare von Inhiangen anf.

Das Genus Phlebotomus erseheint dadureh charalsterisiert, daß die Mundteile zum Steehen und Saugen eingeriehtet sind. Die Palpen haben fünf Segmente, die langen, fadenförnigen Antenmen gew ̈̈hnlich sechzehn. Die Flügel sind sehmal, stark behaart, enthehren aber mit Ausmahme der hasalen Teile der Sehuppen; die zweite Längsacter gabolt sich zweimal (also in drei $\ddot{A s t e}$ ), die (queradern liegen nahe am basalen Viertel des Flügcls. Der Körper ist mit Haaren bekleidet, der [ntersehied der Gesehlechter dentlieh aungeprägt. Dic Larve zeigt die Form einer Raupe, besitzt zwei paar haudaborsten, "rehe seln lang sind, und hat keine wahen Beine. Die Nymphe gehört zu den l'upae (1)teetae, und ist daran leieht zu erkennen. daB die ahgestreifte Larvenhaut mit den charakteristisehen Kaudaborsten stets an den letzten zwei Abdominalsegmenten der Priple haften blejbt (Newste.n, Axxindize).

Zum Genus Phlcbotomus zählen bisher" folgende Arten, bei denen auch der Verloreitungsbezirk (Fundort) angegehen ist:

1. Phlebotomus papatasii Sicopou (Südeuropa, Nordindien, Java),

2. P. mimutes Roxdaxi (Sǘteuropa, Malta),

3. P. mescettii Grassi (Italien).

4. I'. nigerrimus Xewstend (Malta),

5. I'. perniciosus Newstean (Malta),

6. I'. Cifmliformis Heuxire (fossile. Spezies im Bernstein der Ostsee),

7. I'. wrotor ('vorillet (Maryland),

$\therefore$ P. rmatus (ootidlet (Ginatemala).

9. P. dubractui Xiver-Limare (Sudan),

11. P. himulayemis Axxinde (nicederer Himalaya),

11. P. maluburicus Axispdes (Travaneore, südindien),

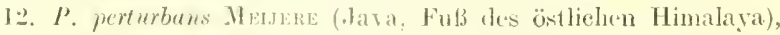

lis. 1'. babu Axxaxdate (Julische Tiefelmene, 


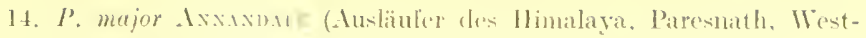
Bengaleni),

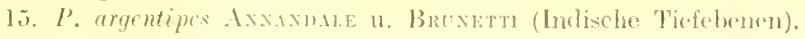

Alle Anteren, wolehen es gelang, das eingangs erwähnte Dreitagefieber (Pappatacifieber) durch Phlebot(nnentiche vom Kranken auf den geenurlen Mlenschen zn übertragen, geben übereinstimmend an, dals bej ihren Experimenten anssehlieblich

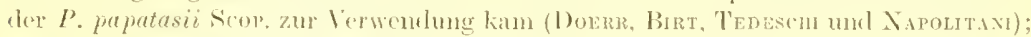
es ist daher auch nur für diene spezies bewiesen, dals sie als Wirt orler Zw wischenträger eine's mensehenpatlogenen Virus fungieren kann, Narh bekamten . Inalugien (Rerifung vou Malariaplasmedien in zahtreichen Anophedeneprezie- wäre es aber natürlich sehr wohl möglich, dab anch andere I'hlebotomanarten das Papplatacifieher oder doch malie verwandte infektiöse Fielorformen verbreiten.

Newstead bezweifelt übrigens, ob die İbertragungsversnehe wirklich nur mit $P$. puputusii ansegfuhrt wurden. so hatte z. B. Bıт, der anf Malta experimentierte, berichtet, dab anf der Insel

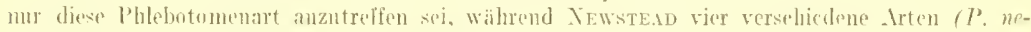

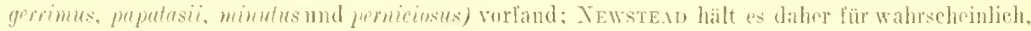
dab bei diesen und anderen Infektomsiersuchen anch andere spezios mitbonutzt worden, um so

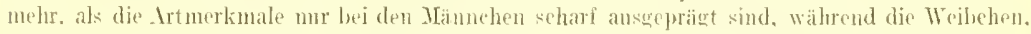
welche allein Blut sangen, nur wenig voneinander differicren und in Barst sehwer zu untersheiden sind. Xewstead ist geneigt, hesonders den $P$. permiriosus als einen zweiten Zwischentriger des l'alpatacifielers zu betrachten, wenn auth direkte Beweise für these Annahme nicht vorliegen.

Vom rein medizinisehen Standjunkte verdient also der Phlebotomus pupatasii Siveod - wenigstens vorläutig - clie meiste Beachtung; da diese spezies übrigens anch in hiologiseher Hinsicht am besten bekannt ist, so soll sie zunäthst gew isserma ben als Paraligna ansführlicher beschrieben werden, um so meln als lie Angahen über die Lebensgewohnheiten der Imago, äber Eicr. Larven. l'upes, Prutpläze usw. nit geringen Abweichungen anch für zahireiche andere Ihlebotomenarten golten. Im Inhange findet mon die differentialeliagnostichen ('hatraktere einiger wichtigerer Siezies überwichtlich zusammengestellt.

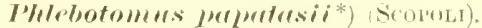

[Diese Bezeichnung stammt vou Gin.sss. - Synonyma aus der äteren Literatur: Bibin papatasii (Scopoes), Cyniphes molestus (('osti), Hemasson minutus (LoFw)?.

a) Ïubere Morphologie der lmago.

Das geflügelte Insckt (rgl. die Tafel 11. Fig. 1-3) erreicht eine Länge von

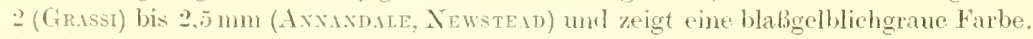
Der ( hitimpanzer (Ektoskelett) ist gelblich uncl so zart, dab der ganze Körper einen bei Dipteren ganz ungewönlichen Grad von Transparenz anfweist, was sowohl bei der Betrachtung mit frejem Ange als besonders unter dem Mikruskop auffällt. Bei Weihchen, welehe Blut gesogen haben, erseheint das Ablomen hellot, wem die Verdaunng fortscheitet, dunkelrot, schlieflich dunkelbraun bis schwarz.

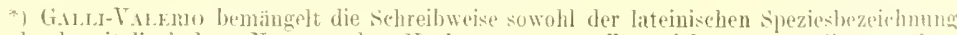
als anch des italienisehen Namens der Hïcke; crstere sollte nieht, ,papatasii", sontern

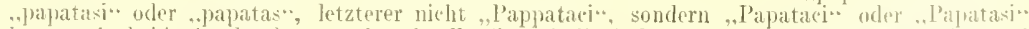
lauten, da beide Indrücke von dem landbänigen italienisehen, „papatas" (papa = é fribu und

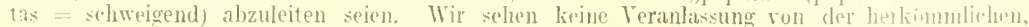

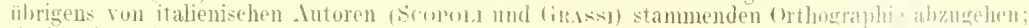

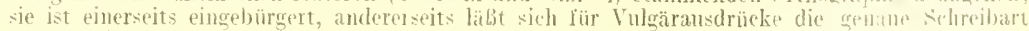
kaum fixieren. 
Yein richtiges Bild von dem wahren Ausseleen der winzigen Blücke gewinnt man, wemn man

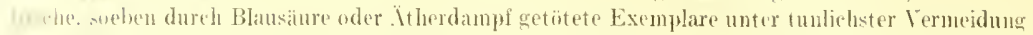
falcr beribung auf einem Objekttriger bringt und dieselben im aulfallenden Lichte unter dem

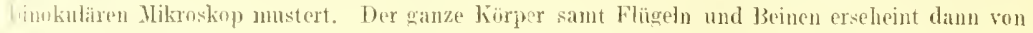
"inem dichten Haarpelz bekleidet, der seidenartig glänzt und eine fahle, ockergelbe Farhe besitzt. In durchfallenden Liehte sind die Haare lichtoran; streift man den Haarbesatz von verschiedenen kiriperstellen ab und untersucht man bei stärkerer Vergröberung, so sieht man, daß sieh derselbe aus stäkcren Dornen und Borsten, aus hleinen, zarten Haren und ans Schuppen zusummensptzt, welelı letztere entweder kurz, breit, spatellömig und lingsgestreift sind wje die selujpen der schmet terlinge oder schmale, Iange, ladenfiirmige, bisweilen gekrummte chitingebilde darstellen (Vig. 16, Tal. 12).

Der Kopf ist länglich, sitzt dem Thorax direkt auf mol biklet mit letzterem einen rechten Winkel; hetrachtet man daher clie Mücke von der dorsalen Fläche,

Fig. 1.

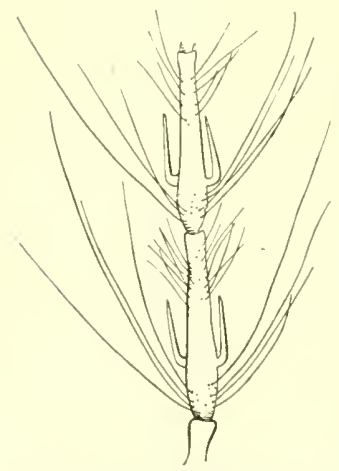

5. und 6. Antenuensegment (3.) und 4. der rieibed). Kopie nach Newsteas. Jian sieht die reclitwinkelig abgebogenes Torne, sowie die proximalen längrorens mol die distalem kistzeren Ilaare der 2 lieibetglieder.

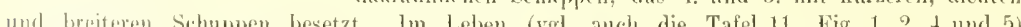
(vgl. anch die Tafel 11, Fig. 1. 2, 4 und 5 crscheinen die Palpen im felenke zwikehen dem 3. und 4, oft auch noch zwisetren dem 4 . und 5 .

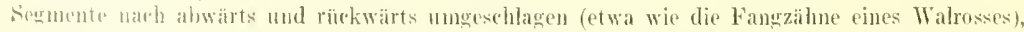

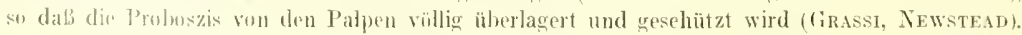

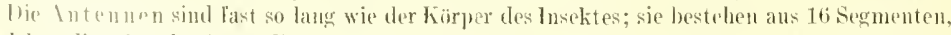

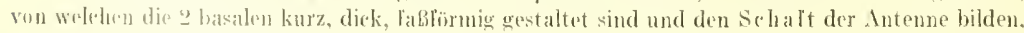
während dir 11 teminalen, sedank-zylindrisehen die Geibet darstellen. Das proximalste cilied

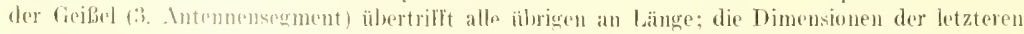
nehmen gegen die S.pitze zu allmähtich ab. In der Basis zeigt jedes fieibedglied "ine Anschwellung,

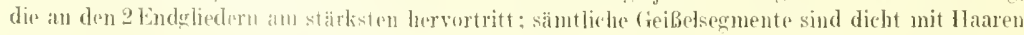
besetzt, welche an der Basis lianger sind als an distalen bude. Das t. his 15. Segment der Anteme (2). bis 1.3. Segment der lieibel) trägrt je 2 starke Dorne, welede bald nath ilyem Abgange von der

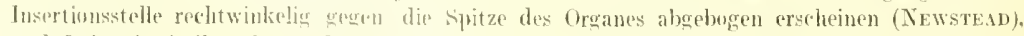

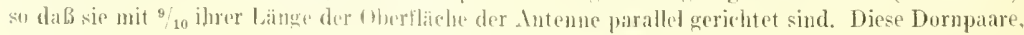

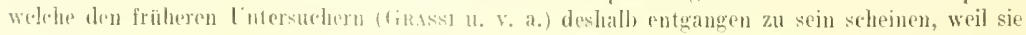


hei der mikroskopischen Borachitung der dorsovental orientierten Anteme unsichthar beiben,

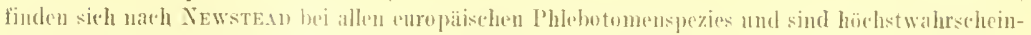
lich für das Gemus Phleholomus in hohem cirale charakteristisch.

Die rïsselfömige l'roboszis ist, vom dem lrsprung der l'alpen an gemessen, nahezu so lang wie der hopf (inklusive elipens). Nie setzt sich aus folgenden bentandteilen zusammen:

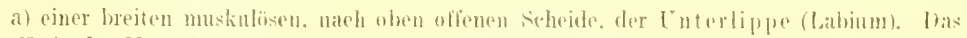

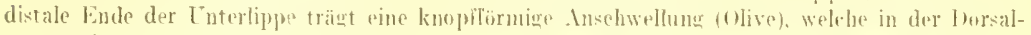
ansicht drei Teile zejgt: einen medjanen, unpaaren (das .Ziinglein") und zwei laterale (labellen oder semioliven), regl. Talel 11, Fig. 4 unel 5:

b) ans einer änberst harten IJohlnadel, welehe in der dorsalen Himne der Unterlippe schleilt und ein Bündel von b chitinösen, stilettartigen fortsiitzen darstellt. Wieses sind:

(e) der Epipharynx (oherlipy, Lahrum), eine langliche sifhede, deren spitze sich plötzlich rejjingt und beim Weibehen an den Rändern mit starken dornartigen Fortsaitzen hewallnet ist,

Fir. :.
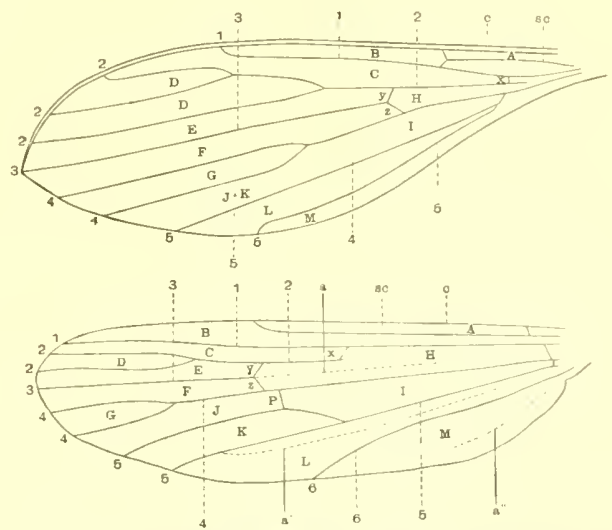

Aderschema des Flügels von Phlebotoms (obrit und (ulex (unten) nach Theobuld

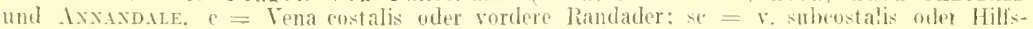
ader; $1-6=1$. bis 6 . V. Iongitulinalis oder Längsader: $y=$ iiberzahlige, $z=$ mittere Guerader: $P=$ hintere Querader: $A=$ Kostalzelle, $B=$ subkostalzelle. $C=$ Rand-oder Marginalzelle. $\mathrm{D}=$ erste, $\mathrm{E}=$ zweite submarginalzelle, $\mathrm{F}=$ erste, $\mathrm{f}=$ zweite, $\mathrm{J}=$ dritte Hinterzelle, $\mathrm{K}=$ Analzelle, $\mathrm{H}=$ erste. $\mathrm{I}=$ zweite Basalzelle, $\mathrm{L}=$ Hilfizelle, $\mathrm{II}=$ Rudimentärzelle.

so daß sie gezähnt ausieht. Brim Männchen sind diese Zähne viel zarter; auberdem länft lier der Epipharynx in eimen medianen, mit feinsten liaren bedeckten Fortsatz aus:

3) der Hypopharyo ähelt in seiner Form dem Epipharynx; die Spitze ist jeduch an den Rändern feiner und dichter gezihnelt und nicht so stark verjüngt. sondern ailmählich zulantend, wie der lontur eines olivenlilattes. In der Hitte wird der Iypopharytix von einem feinen, his zur än bersten spitze (heim f) reiehenden Kanal durcheetzt, der mit dem Cuslührungsgang der speicheldrüsen kommuniziert;

$\gamma)$ die paarigen, lanzetteörmigen, nur an einem Rande der spitze gezăhnten Mandiheln:

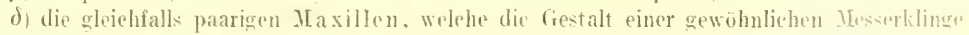
besitzen: die eine seite trägt an der spitze fünt starke borne, die andere in der Wirte fninme und dichter angeordnete Zähnchen.

Der Thorax ist zum Teil mit diehten, langen. in Büseheh angerodneten Hariron besetzt und zeigt eine starke Rückenkrimmung. dureh welche das Ineckt cin henelidiges 
Iuschen crhält. I'rothorax schr kurz, Mesothorax kräftig entwickelt, den crwähnten Buckel biklend und mit einem nach rüekwärts rorspringenden Scutellum verseben, Thutathorax relativ gnt ausgebifdet und bei geeigneter Präparation deutlieh zu sehen.

Die Beine besitzen eine exzessive Länge, sind sehlank, mit flachen Sehuppen dicht besetzt und endigen mit einem sehr zarten Klauenpaar. Das erste Beimpar ist kürzer als das zweite und dieses wieder kürzer als das dritte.

Fig. 3.

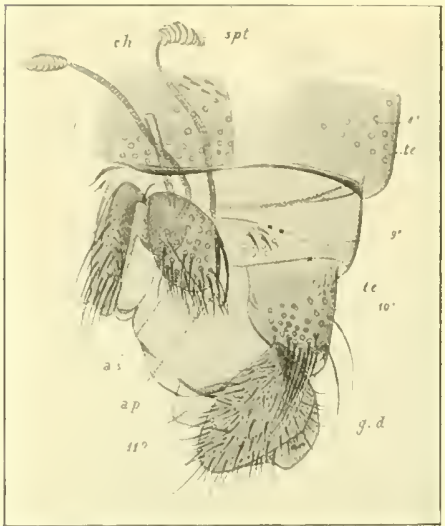

Fig. 4.

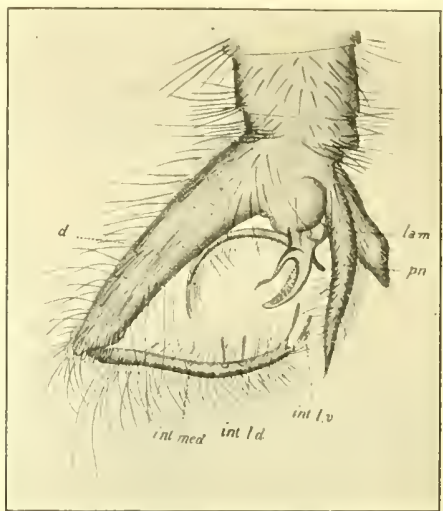

Fig. 3. Hinteres Abdominalende eines Weibchens, von der Seite gerehen (verkleinerte Koprie aus (irassi). Nan sieht die Sprrmatheken (spt) mit ihren Lusführmugsgängen und einen nnparen Clitinsstab (ch) durchscheinen, an dem sich starke Mhskeln anheften und der mit der Vagina in Verbindung steht. Tach Girassi ist dieses letztere Gebilde dem umpaaren Chistinstab in der Spermajmmpe des llänuchens ( $\mathrm{vgl}$. Fig. 5) homolog. $8^{\circ}, 9^{\circ}, 10^{\circ}, 11$ ? sind die Nummern der betreffenden Jlinterleibsisegmente; te $=$ clorsale Chitimplatte (Tergum), st $=$ ventrale Chitimplatte (stornum). Tyie mit 2 lireuzchen bezeichnete feine Limie markient die vordere tirenze des 10., zum Tril rom 9. hedeckten Segmentes; die mit einem Kreuzchen versehene Linie zeigt, wie weit sich das 9. über das 10. Segment erstreckt. as = oberlächliche paare Inhänge, ap= tiefe paare $A$., s. $d_{\text {. }}=$ dorsale Gonajophyse.

l'ig. 4. Hinteres Abdominalende eines Hännchens, von der seite gesehen, (Verkl. Kinpie aus Cirassi.) $d=$ Dolsale (ionapophysen (GRAss1) $=$ obere hlammen (NEWSTEAD); lam = Lamina subgenitalis mit 2 äuberen und 2 inneren Anlängen (GRAssI) = untere Llammern (XEWSTEAD): int med. - intermediäre mediale, int. $l_{\text {. }} \mathrm{d}_{\mathrm{a}}=$ intermediäre laterale dorsale, int. $\mathrm{l}, \mathrm{v}$. = internediïre laterale vestrale limapophysen (Grassi), alle drei Paare von Newstend unter ten Xiamen, ,intermediäre Inliänge" zusammengelabt; $p=$ Penes.

Inmerkung: In diese Profilzeichmung ist natiolich nur je eine der paarigen Gonajophysen resp. Aplenelices angetragen; vgl. Jierzu die Photogramme 6 und 8 anf Tafel 1 und die zugehörige bik]irnut.

Die firgüge (2.25 $\mathrm{mm}$ lang, $0,4 \mathrm{~mm}$ breit, nach Newsteıv beim Männchen erheblich schmälex als beim Woibchen) sind dicht behant; an den Rändern bikden die

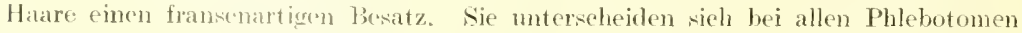
von den libigchn dor Kuliziden dureh das Fehkn von Schuppen (im distalen Teike), die doppette Gabelung der zweiten Längsader uml die proximale Anordnung der äuBerst zalrten Queradern. Entfernt man den Ilaarpelz dureh Jbpinseh (s. die Tafel 11, Fig. 7),

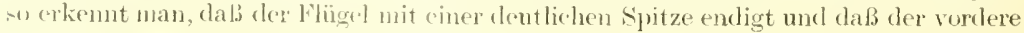
land rick stäker gekrimmt ist als der rickwärtige. 


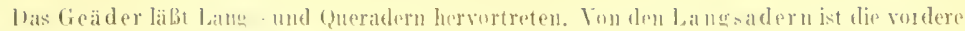

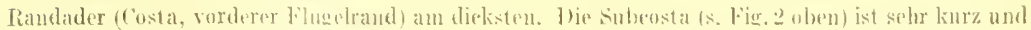

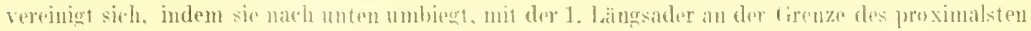

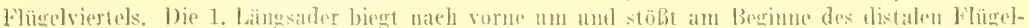

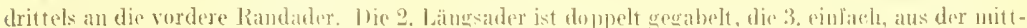

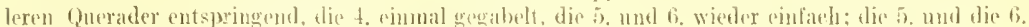

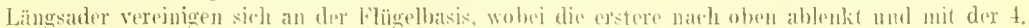

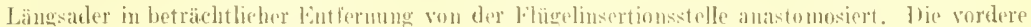

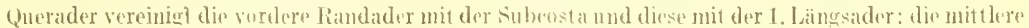

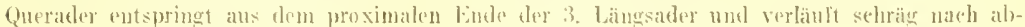

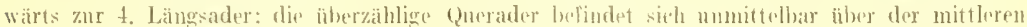

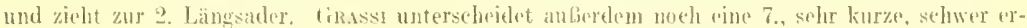

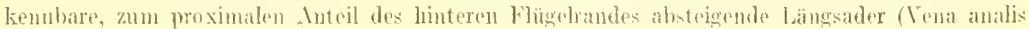

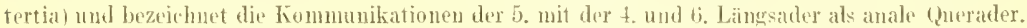

Das Abelonen bestcht aus zehn Śegnenten, von welwhen das erste wio In.i allen Nematozeren verdeckt ist, wälnend das letzte in dic Bildang des äuBeren Cirnitales eingelst, so daf sieh auf den ersten Blick nur acht Hinterlrjbsringe erkennen lasinen; sie

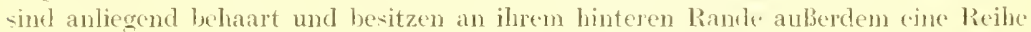
von längeren, ringförnig angeorlneten, abstelienden Haaren.

Die äuBeren Gesehleehtsorgane des Weibchens sind einfach gebut und aus zwei Paaren von flachgedriekten, klappenartigen, mit sinneshaaren besetzten Anlängen zusammengesetzt. Das obere Paar ist den dorsalen Gonapophyisen tes Männchens (s.u.) humolog und wird ron Gisssi daher aneh mit diexem Namen hezeiehnet; das untere, ventrale Paar liegt etwas mohr nach vorne, im bercich des neunten Abdominalsegnentes, begrenzt den Eingang zur Fissura genitalis naeh oben und besteht aus zwei l'aar lateralen und eimem inpaaren medianen Fortsatz. Bei den europaisehen Spezies ter Phlebotomen sind die weiblichen Genitalien sehr ährolieh und liefern keine differentialdiagnostisehen Anhaltsumle (XEwSTEAD); bei den exotischen bieten sie nach ter Gestalt und ten Größenverhältnissen wiehtige Arthiterien ( Ixx.xDILE).

Das äu Bere Genitale des Hännchens zeigt eine äuBerst komplizierte strulitur und int für die betreffende Spezies bei allen Inlebotomenarten am meisten charakteristisch. Die wesentlichen Merkmale destelben treten auch an getrockneter oder in Fanarlabalsam eingesehlossenen Exemplaren noeh deutlich hervor, während die weibliehen sexualorgane beim Trocknens stark schrumpfen und verzert werden (Axispale). Hinsichtlieh des Baues der weiblichen unl männlichen Sexualorgane von $P$. papatasiz rerweisen wir anf die zwei nebenstehenden Kopjen. die der klasischen Jlongraphie ron Grass . Riecrehe sui flebotoni" entlohnt sind, und auf das l'lotogranm Nr, 6 und s der 'Tafre; aus der Legende zu diesen Illustrationen kann auch das Detail der Nomenklatur entnommen werden.

\section{b) Innere Inatomie.}

Verdaunnesliaunl. Dje Mundhöhle liege an der Basis des Clipeus (TEwstesu) und geht in den 0 sophagus aher, der siele knapp vor dem hinteren Rande des hopfes in zwei Röbrohen

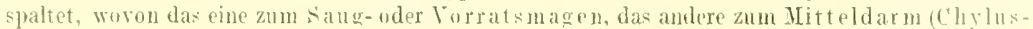

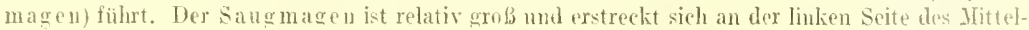

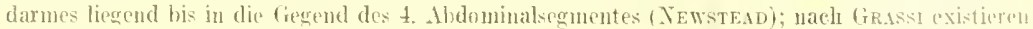
auberdem noch zwei kleine akzessorische saugmäen. Der Mitteldarm frhylusmarent stellt cinen nach vorne versehmälerten, nath hinten erweiterten sick dar, der sehr answlumugs-

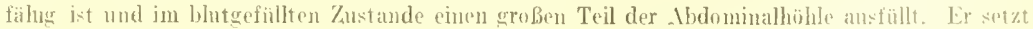
sich in den Hinterdarm fort; an der forenze der heiden barmabselnnitte mimelen. zu zuncuen rereint, die vies langen MLupleilisehen sehläuche. 
The speicheldrïsen belimden sich in den seitlehen Anteilen des Prothorax und stellen

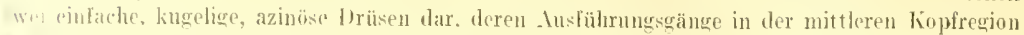

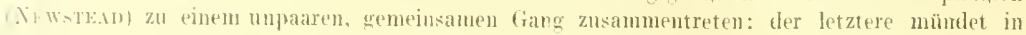
dali kiablehen des llypoptharynx (s.o.).

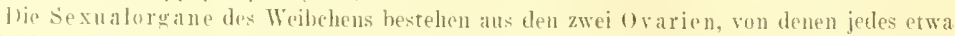
20) 25 bier futlält. Te nach ilrmm Entwickhngszustande okkupieren sie einen verschieten gro Ben Teil des l'eritonealkavums: sind sie villiur reif, so erscheint das . bdomen deutlieh gebläht. Ibe

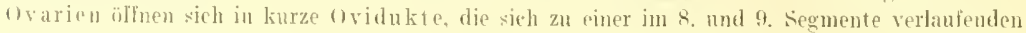
Vagina verwinen; diese geht obne deuthele frenze in den Vulvarspalt (Fissura genitalis) über. Au der dursalen Hand der Vulva mïnden die Mzugskanäle der beiden spermatheken und etwas distal davon der mpare duslührungsgang der beiden frandulae sebaceae (vgl. Fig 3).

The Sexmalorgane des Hänchens bestehen aus zwei ovalen Hoden, deren kurze Vasa deferentia in ein binfourmiges, mplares Hohlorean cintreten, welches mit Drusenepithel ausgekleidet zusheich als Plostata und Vesicula seminalis fungiert. Dieses oifnei sieh in den unpaaren, kurzen Duetus ejaculatorins, der mit einer klemen Erweiterung absehliebt, aus weleher wieder zwej pange, lange louctus ejaculatorij austreten; diese durchsetzen schlieblich zwei hohle, dunket gefuirbte, chitinöse, ventral gekiimmte Stacheln. die man als P'nes bezeirhnen kann, und sind innerhalb der-

Fig. 5.

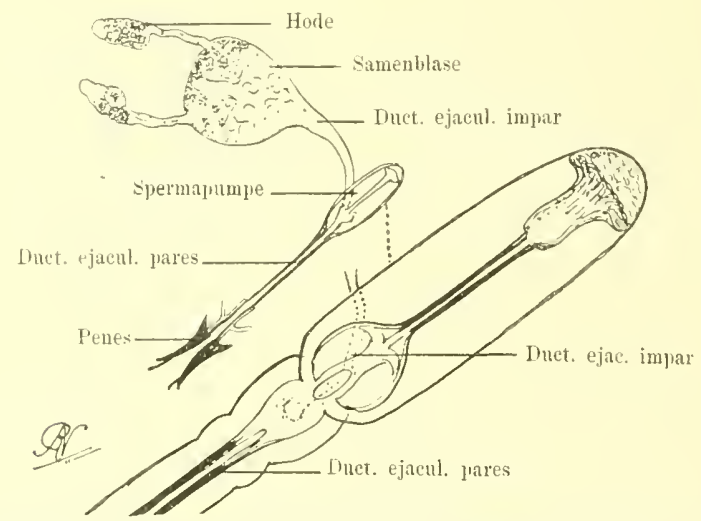

luncre lienitalorgane des Mannehens (Kopte aus Newstead). 1)ie untere Zejehnung gibt die Terhälnisse der spermapmmpe m stäker vergröbertem Wabstabe wieder. Zentral der in Fig. 3 erwälnte Chitinstab.

solben bewelich, so dab sic voryestreckt oder retrahient werden kümnen. Mit der Erweiterung, welehe zwisehn den upharen und den paargen Intril des Ductus ejaculatorius ejngeselualtet ist,

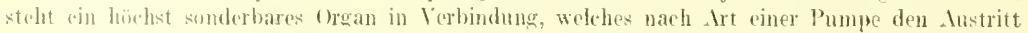

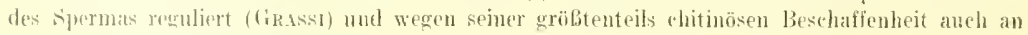
getrockueten uder in Kanadabalsam montierten Exemplaren wahrzunehmen jot.

\section{I.ebensagewohnhriten ves Inselites.}

bie Phlehotomen sind, wie es scheint, in Europa, Asien, Afrika und Amerika, vielleicht auch in Australienstark verbreitet. *) treten aber nur in ten heiben oler toch wärmern Gegenden dirser tidtrile auf. thr Gebjet wirl nördtich von 36., sïdlieh etwa rom 30. lineitegrad Jegrenzt; cler am weitesten naeh Norden vorgedrungene Vertreter des cents int jukenfalls der $P$. papatasii scop., der zur sommerszeit in

*) $s$ a. den . Irtikel .. Das l'aljmatakifieber" in diesem Handb. 


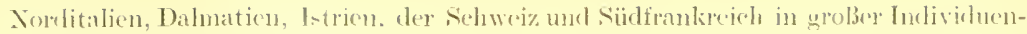
zahlil beobachtet wurle.

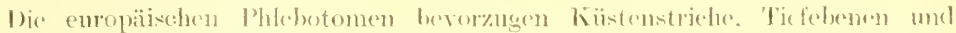
Fhlubtäler; mit steigender absoluter Höhe nimmt ihre Kahl rasch ab. viclleieht nicht

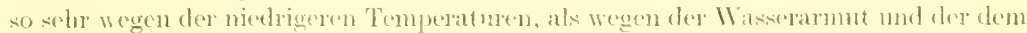

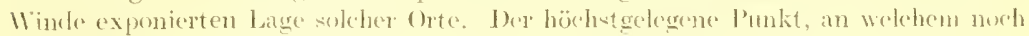

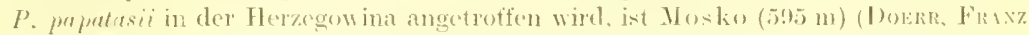

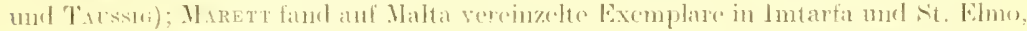

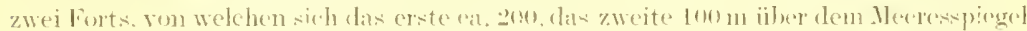

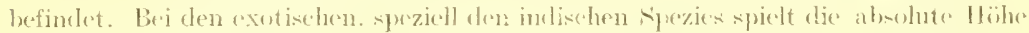

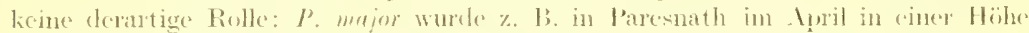

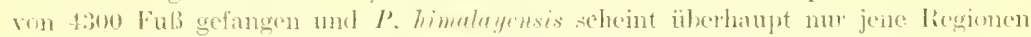

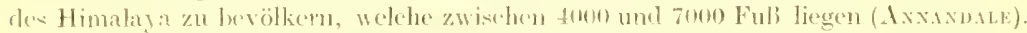

Der hejehtum an Vegetation (Wïlder. Buchwerk) hat auf die Verlneitung

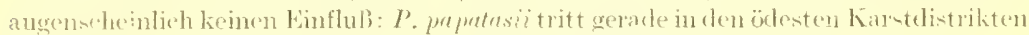
fer. Her\%egowina und Datmatiens in enermen Mengen anf.

Dideren scheint die Zahl der lhlebotomen an versehedenen P'unkton win und destelben Territoriuns von lokalen Nomenten bestimunt zu werden, elie sieh vorläntig gänzlieh unserer Konntnis antzichen. Ton zwei Ansirelungen, die cinander nahe benachbart sind und bei kritischester Wusterme keine Difterenz zeigen, der nam irgendeine berlentung zuschreiben kömte, jxt dor eine oft furchthar heimwesucht, der andere frei oder doch nahezu trei. Dieses merkwiudige l'orhalten geht

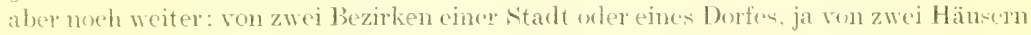
eines Blowkes oder einer Straße kann ein Objekt von Palphatacis überohwrmmt -ein. währent man in dem anderen nur auf wenige Exemplar ${ }^{2}$ stöbt. Sugar verseherfene Zimmer eincs stookwerkes kömnen solche Unterschiede alafweinon. Diese Tatsachen

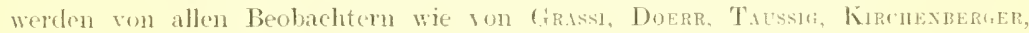
Newstesn, Miretr u. a. bestätigt. Verständlicher ist es sehen. dab die Pappratacis im Erdgexchols und ersten Stockwerk zahlreicher sind, als im zweiten; das hängt chen mit der geringen Flughöhe der Insektes mge zusammen.

Die emopäischen Phlebotomen ersheinen zu beginn der warmen dahreszeit,

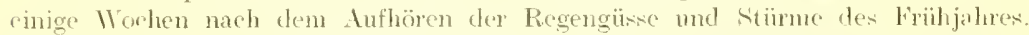
An gexchützten Plätzen kömnen die ersten Exemplare sehon llite llai ge:iehtet werden: iluge Kahl nimmt dam allmählieh zn und ereicht je nach dem Klima des lxetreffenden ()rtes früher oder später cin (r'stes Maximum, welches z. B. in Italien a uf das Ende drs duli (Grassi), in Malta auf den Juni (MARETt) zn fallen wheint. Hieranf werden cie spästicher und treten erst nach einem längeren Zwischenraum wieder reichlicher nuf, und zwar in groben Mengen; dieses zweite Maximum wurle in Italien um Mitte reptember (GRassl), auf llalta in der zweiten Hälfte eles Augunt bis Anfang September

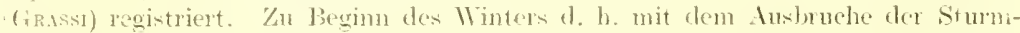
und Regenzeit versehwind.n sie völlig (in ltalien Anfang (1ktober, auf Malta Mitte Anvember); z̈berwintermele Individuen werden nie angetroffen (Cirass, Doskn und Rist, Mthets).

Dje Phlebotomen sind lichtschen und remeiclen jeden stärkeren Luftzug. bei kïhlem oder regnerischem Ifetter halten sie sich in ihren schlupfwinkeh verborgen: in heißen sommernächten, wemn absolute Windstille herrseht wher nur cin leichtor sirocen weht, verlassen sie ihre Brutplätze, die sich stets in der Nähe muschlidher Ansiedlungen befinden, und dringen in gatnzen Schwärmen in Wohnräume, rament -

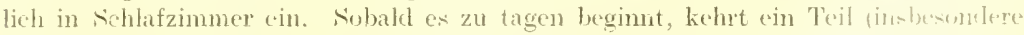

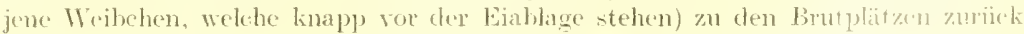
orler sucht an kühlen, dunklen und windgesehätzten Orten (in Kellern, untorirdischen 
(iewöllx, finsteren Korrituren) cine provisorische Zuflucht: ein Tcil verbleibt ther' in de'n Schlafrämmen mol zieht sich bloß auf Stellen zurück, welche dem direkten Thgesicht nicht ansgevetzt sind, romehmlich in rlunkle Zimmerecken am l'lafond, hinter Bilder, Vorhänge, Kleider usw. Sie verharren hier in absoluter Ruhe und sind wesen ihrer Kleinheit und hellen Farbe selbst für geübte Augen nicht leicht zu erkemnen; bei der geringsten Störmng machen sie einen kuren, äußerst raschen Flug zur Seite, nach links oler rechts, und lassen sich sofort wieder nieder, um wenn nötig vinen gleichen Flug im nächsten Angenblick zu wiederholen. Die Art. wie sie sich der. Terfolgung entzichen, hat die größte Thnlichkeit mit dem Wegspringen der Flöhe; sic sind dabei äußert behend und daher schwer zu fangen, bis anf Weibchen. dic eben litht gesogen haben und wegen ihrer Plumpheit mol Sohwere leicht mit einem Reagenzgläschen überdeckt werden können. Gelegentlich unternchmen die Phlebotomen auch längere Flüge, die nach rorwärts gerichtet sind und einen undulierenden charakter besitzen. so daß man sie in hinreichend belichteten Räumen leicht verfolgen ham

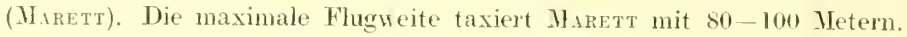

In der Ruhe sitzen oder viehmehr stehen die Phlebotomen anf einer Unterlage (Wanl) derart, daß der Kopf mit des I'roboszis nach abwärts gerichtot, das Abdominalcnle leicht gesenkt exscheint. Sehr charakteristich ist anch die Flügelstellung beim sitzenden Insekt, welehe Grass zutreffend mit der Art vergleicht, in der man die Flügel bex Engeln darzmstellen pflegt; die Flügel werten nämlich in divergicrender und sehräg nach aufwärts gerichtoter Lage gehalten, wobei die äußer'n Ränder gehoben, die inncren. einander näher stehenden gesenkt sind.

In der Gefangenschaft ohne Nahrung und Fouchtigkeit gehalten, stirbt $I^{\prime}$. pupatasii in 4-7Tagen. Gibt man in die Kätige Detritus von den Brutstätten und äberdeckt sic mit fenchten Tüchern, so leben beicle Geschlechter etwas länger, 10-If, vereinzelte Exemplare bis zu 28 Tagen (MAREtт, J)oerr).

Nur die W'eibchen saugen Bht nud zwar nicht hloß am Menschen, wndern an allen warmblütigen Tieren (Marett, Newstead), nach Howlett sogar an Kaltblütern, wic Föschen un Raujen. Beide Geschlechter scheinen aber auch Wasser zu trinken, oder aus Detritus, aus Früchten Feuchtigkeit zu saugen, die vielleicht auch Nahrungsstoffe enthält (MАRet'T). Die Pappataciweibchen stechen nur ausnahmsweise und an finsteren Orten bei Tag; gewöhnlich ïborfallen sie ilme Opfer bei Nacht und nur s.lten im Freien, meist in gemehlossenen Räumen (Fikassi, Doerr, Marett, Howlett, Ninstead). Die I'hlebotomen erzengen beim Fliegen nicht jenen hohen, singenden Tom, der ten Kuliziden und Anophelen eigen; sie nahen tem Schlafenden ohne jedes (ierïusch. Von dieser Eigentümlichkeit leitet sich die italienisehe Vulgärbezeichnung .. H'aplutaci" her. was so viel besagen will, als .,er friBt in der stille". Nach Pressat "revlen dic Thlebotomen Arabiens von den Einheimischen Akhl-ou-Skout genannt. eine arabische Übersetzung des italienischen "Pappataci".

Beim Stechen werden bestimmte Körperregionen, die knöchelgegenden der Fübe, die Fubrüken, dic Handgatenke, Beugeseiten der Vorderarme, Tnterschenkel, Kniekehlen bevorzunt, vielleicht wegen ihrex zarten Hant; daranf seheint wenigstens hinzudenten, dab Kinder im glejehen Sehlatranme stärker angegangen werden als Erwachsene. Der Stechakt vollzieht sich in der Weise, dalb das Weibchem üher die Hant scheretet und an rersehiedenen Orten die Proboszis eimenkt, bis eine ginstige Stelle gelunden ist, welche meist in der Xachbarschalt einer kleinen Hautvene liegt; dann werden die Beine weit auseinandergespreizt und die Proboszis inrer ganzen Länge naeh (ingehohrt, so dab das Tier anf dem liopfe zu stehen scheint (M.ıRETT). Taeh beendiutem Sangakt. wirel die Proboszis mühsam heransgezogen, wobei sich die Brieke auf ihren Beinpaaren gewissermaßen aulricluter; dann fliegt sio in knzen sprüngen zur Wand und ron da zur Zimmerdecke. In dor Gefangensehaft weigern sich dir Weiluehen zunähst zu stechen, wenn sje aber eimual Bhut aufgenommen haben, so heibens sie hei gebetener (ielegenheit täglich (MIRETT). 


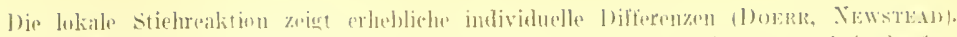

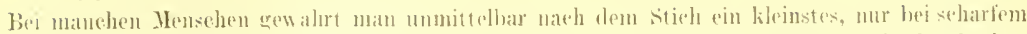

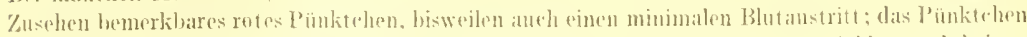

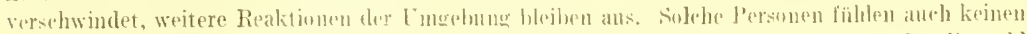

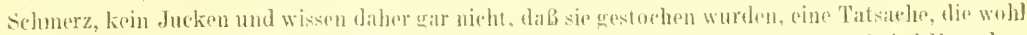

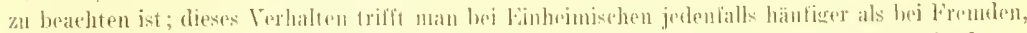

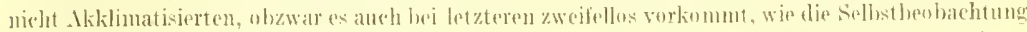

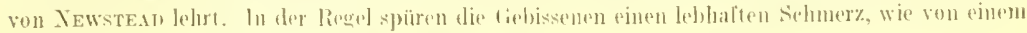

Jier. if.

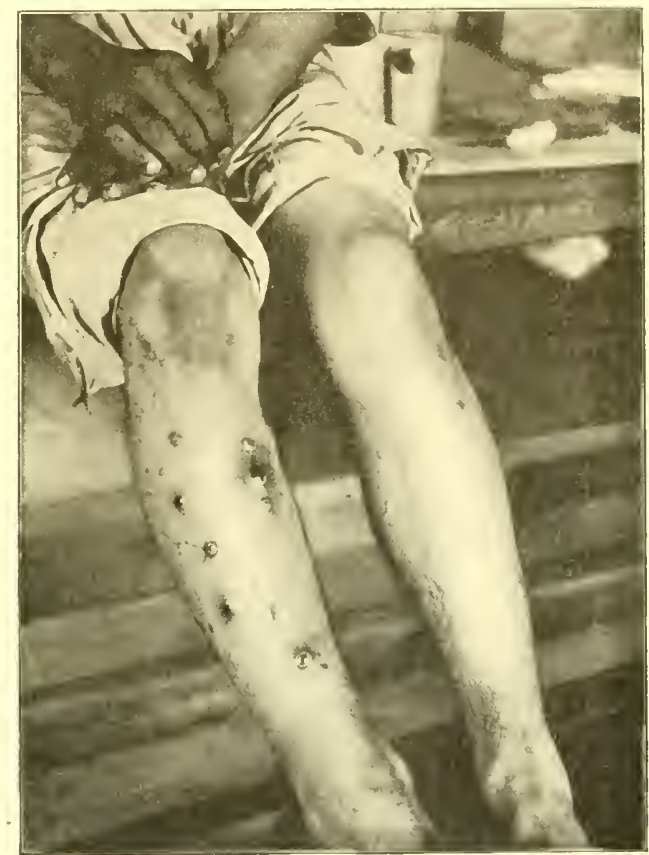

Hyperererische, blaschenlörmige und in suppuration ubletgegangene Reaktionen nach Phlebotomisustichen.

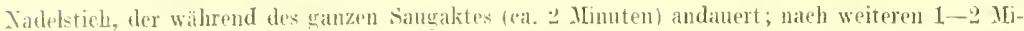
nuten entsteht eine weiße heller- his fünfkronenstijekgroße Quadele, genau wie nach Winzenbissen, wälrend die Haut in weirem l'mfange von behhaltem Jurken, znweilen anch von einem llüchtigen Ervthem befallen wird. The Quadulel verchwindet nak ra, einer Stunde und hinterlabt ein kleines Kinotehen (Papel), das anfangs lehhalt rot, fä̈ter livide gofärbt ist, noch 24 Stunden juckt und sieh erst nach mehreren Tagen (8 14) völlig verliedt. Hieser läufigste Verball kamn dureh den Juelireiz und tas Kratzen erheblich modiliziert werden. Endlin gibt es eine tritte Kategurie von lndividurn, welche aul Phlebotomenstiche exzessiv reagieren und zw ar in sehr merkwïrdiger Weise. Ws bildet sich um deu Stichkanal pine mächtige Quatlel, welehe sich in den folgenden 24 - 48 stunden in eine flammigweiche. kreislümige, $5-6 \mathrm{~cm}$ in burehmesier haltende Infiltration umwandelt. Im nächsten oder zwejtuäehsten Tage nach dem stiche erhebt sieh aul der Stiejstelle pin likeines, transparentes, mit hellgelbem serum gefibltes Bläschen, welehes raseh his zu brhsengrobe wnd tariuber 
warbst: platzt, sein Inhalt rimnt ans und an seine stelle tritt eine eintroeknende und abfallende kimste, hisweilen auch ein mit unrwelmabig zackigen Randern versebenes, speckig belegtes cie*hwir. In manchen Fillen tribt sich der lnbalt der Blasen und es entstelaen Fiterpusteln (sie-

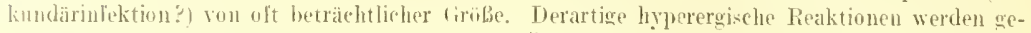
wähnlich von einem atsugebreiteten, entzïndlichen idem der betreffenden höperregionen hegleitet.

Einzelne Jenschen werden wegen ihre besonfleren Hautausdünstung von den l'blebotomen gemieden; sie bilden einen nicht genauer bextimmbaren Prozentsatz derjenigen. welele vom Pappatakfifieber verschont hleiben. und täusehen eine naturliche lmmunität gegen diese hrankheit vor.

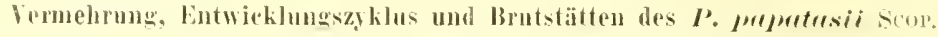

Die Kopulation danert 10-15 Minuten und kann sowohl im Freien als in der Gelangenschaft beobachlet werden; sie seheint meist ror der ersten Bhutmahlzeit des Weibehens stattzufinden (IIARET). Nännchen und Weibehen sitzen während des Aktes mit den Abcominalenden rerbunden derart auf der L'nterlage, daß ler Kopf des Männchens mach oben, der dos Weibchens nach abwärts gerichtet ist (Crrassi). Das hefruchtete Weibehen saugt in der Ciefangensehaft, wemn nöglieh jerlen Tag Bhut: die roll-tändige Vertamung einer Blutmahlzeit nimmt nur 2-3 Tage in Anspruch (MARETT).

Von der Befruchtung bic zur Eiablage verstreichen s-J0 Tage (MAretT). Mnati konnte im Freien Weibehen beobichten, welehe nit ilser Proboszis ein Loeh in lockeren betritus bohrten, indem sie sich um die versenkte Proboszis als Aehse herumdrehten: sie sehritten sodann ïber die crzeugte (iffnung und steckten in dieselbe das Abouminalende. MlretT glaubt, daß schließlieh an solehen Stchlen ein Ei deponicrt wird. Wem ihm alich die Auffindnug desselben wegen seiner winzigen Grölse nicht gedang. In der Gefangenschaft werelen die ersten 15-20 Eier einzeln ofler paarweise gelegt, der Rest als Hasse ausgestobon, bis aut die letzten zwei; dann stirbt das Insekt konstant. Die ganze Prozedur dauert ea. 12 stunden; jerler Expulionsalit seheint die Weibehen stark zu sehwäehen. siestrecken die Beine von sieh, fallen auf dje Scite, erholen sieh aher naeh der AusstoBung einzelner Eier immer wieder. bis die Ablage des kompaliten Konvolutes sie derart hernimmt, daß rer Tok eintritt. Die letzten zwai Eier steeken noeh immer im Körper des toten Inscktes (MARETT; NeWsten1r). Viese Vorgänge dürften auch dureh die nngünstigen Verhältnisse der Gefangenschaft stark beeinflußt sein; wenigstens sterben gefangene Weibehen mit reitem Ovar sehr häufig, ohne ein cinziges Ei gelegt zu haben, was in der Natur wahrscheinlich nieht ter fall ist.

Die Eier sind rom dem schleimigen Seliet der Glandulae sebaeeae iiberzegen. welches gegen Eintroeknumg sehiitzt, und nerden in der Gefungenschaft mit Hilfe descelhen an versehiedenen Stellen einer (xlashäche, an Detritus angekittet. Sie ind $36 \mu$ linge. $12 \mu$ breit, zylinelrisch, mit oval abgeruncleten Enflen; Farbe und strulitur variseren ju nach ihrein Alter. Frisch gelegte Eier haben eine weißlieh-opaleszente Farbe. sind transparent, ihr Inhalt ersebeint fliissig und homogen; naeh einigen Stmudcon werden ;e lichthram, die (berfläche zeigt eine netzartige \%eichnung, welehe sich aus doppelt kunturiorten, wellenförmigen, von einem Jol zum anderen verlaufenden. lejstenartigen Torliekungen der Kutikula zusammensetzt, die dureh zarte Queranastomosen nnitcinanter rrobunden sind (rgl. Fig. II auf Tafel I), in Inneren

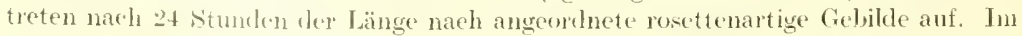
reifen Ei lassen sich dic Segmente der künftigen Larve erkennen (Grassi, Newstead, MIRETT: HOWLTTT).

Nach 6-9 Tagen werelen die Eier spröde, bekommen an einem Pol eine lïngsverlatufende Fisisur mul die Lare schliipt aus. Feuehtigkeit der Atmosphäre

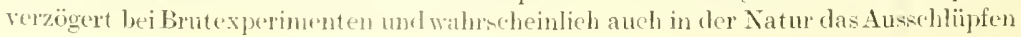




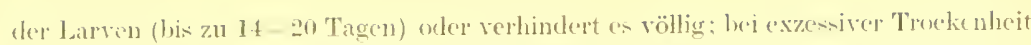

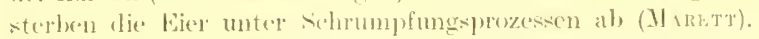

Die Larven lehen nicht. wie man frïhr allgemein annahm, in flï-cigen Mledien.

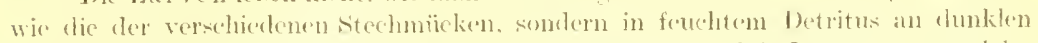

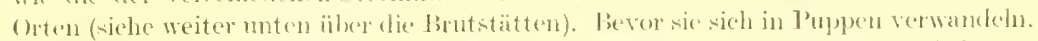

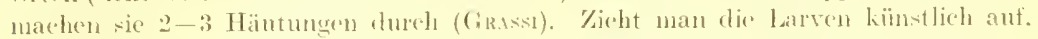

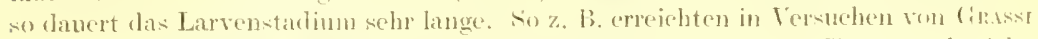
in der Gefangenschaft ausgeschlïpfte und ernährte Larven nach 50 Tagen noch nicht

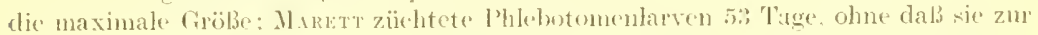

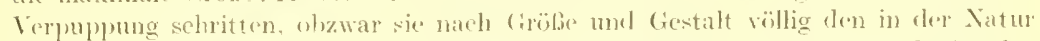
gefundenen. sich rasch repuppenden Exemplaten glichen. In Freien diirfte das IIachstmm viel rascher vor wieh gehen; hei den indischen Phlebotonensuezices solf das Larvenleben je nach der Temperatur und Jahreszeit lt bis ts Tage währen (HOWIETT).

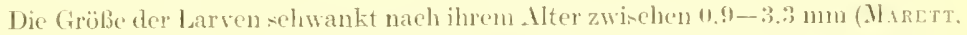
Newstew). Die Farbe ist hnaply nach dem An sehlüpfen ein durchecheinendes II rib: hald wird aber der hopt und die Kaudalborsten sehwarz und glänzend, und der Kä̈reer erscheint ron weiBhichgratier oder sehmutziggraner. hisweilen einen stich ins (iellliehe zeigender Farbe. wobei die Transparenz mehr oder weniger eldalten bleiht (Ciriksi, Mlirett, Newstelu).

Der Kopf der Larve ist klein und schwarz, die ventrale Fläcle abgeplattet. die dorsale stark lionves und mit einer Y-fömigen. hellen (nach M.Aret inkinstanten) \%ejehumg rersehen. Angen fehlen allen l'blebotomentarven (zum Cuterschiede ron sämtlichen anderen bisher bekannten Pssehodideen) vollständig. Die Antennen sincl linrze, sehwer sichtbare, dreigliederige, nach rorwärts gckrümute stummel. welehe dor-al hinter den Mondwerkzeugen stehen. Letztere sind liräftig entwiekelt. kompliziert gebaut und von cler Ventralfläehe aus sichtbar. - Der Körper ist zylindrisch. raupenähntich und besteht aus 13 (3 thorakalen um ! abdominalen) Siegmenten. Wahre Beine sind nicht rothanden; tagegen besitzt tas 1 . Wis 10. Segment eine ventrale, mediane, unpare saugscheilx. Die ersten 11 segmente tragen am hinteren Rande ihrer dor-alen und seitliehen Fläelıe je 6 anf Papillen sitzende, am finde rerdiekte Borsten (Fig. 14 auf Tafe] 12 ), welehe unter dem 1]ikroskop selbst wieder mit feinsten Härchen besetzt erscheinen. Das vorletzte Segment zeigt blob 4 solehe Borsten und ist wie das letzte dunkelbraun oder sehwärzlieh pigmentiert; das letzte setzt siel in zwei selnwärzliche l'apillen fort, von denen jede zwei starke. glänzond sehwarze, exzeswiy lange Kandalhaare trägt, die sehon mit treiem luge ohme weiteres sichtbar sind, da das metiale Par so lang ist wie die IJälfte, das laterale wie (in Drittel des gesamten Körpers. Die Traeheen öfnen sich mit 2 Stigmenparen an der seite des 2. und des vorletzten Leibesringes.

Die vorstehende Benchreibung bezicht sich anf dic ausgewachsene Larve. Bei jüngesen Exemplaren sieht man nur die medialen Kaudathaare, die lateralen sind dur l, kurze, behaarte Borsten ersetzt, wie sie sich am hinteren Dorsalrand des 1. - 1:. Negmentes vorfinden (s. o.); auch ist der vorletzte Leibesring noeh nicht pigmentiert (Girissi, MARETT).

Nach den Angahen ron Grissi und II IRET bewegt sieh tie Larve anl emer Tuterlage mit Hilfe ihrer Saugscheiben ganz ähnlieh wie die Raupe gewisier Lepichpteren. der sogenannten spanner; die Kaudalhaare werden dabei entweder nach rïckwärts gehalten oder im rechten Winkel zur Längsachse des Körpers anferericlutet. Die Xahrung besteht aus allerlei organischem Detritus, cinzelligen Algen (How ET . (irassi), nach 11 arett vornehmlich aus den Exkrementen von A-eln und Eidecheen. 
Vor der Vorpuppung wird die Nahrungsaufnalme und die Bewegung sistiert; die Torpmplung erfolgt stets während der Nacht.

Die P'uppe (rgl. die Tafel 12, Fig. 9, 10, 12 und 15) ist $3-5 \mathrm{~mm}$ lang und daran leicht zu erkennen, daß die zwei letzten Abrominalsegmente stets von den Resten der letzten, abgeworfenen Larvenhaut bedcckt sind, die eine dumkelbraune Färbung aufweisen und dazu dienen, die Puppe an der Wnterfläche von Stemen. Ziegehn, Kalkst tïcken, Mörtel u. dgl. anznheften. Die Puppe besteht aus Kopf, Thorax und Abdomen; sie gehört in die Kategorie der Pupae obtectae, bei welchen sämtliche Körperteile in besondere Ansbuchtungen der I'uppenhïlle eingeschlossen sind. Thre Farbe jst ('in helles Gelh. Die Augen sind groß und schwarz, der Kopf unter dem Thorax verJorgen, der Brust lorlb dreigliederig, das Abdomen gekrümmt (mit dorsaler Konkavität) und aus 10 Segmenten zusammengesetzt. Von der ventralen Fläche sieht man bloß 7 Abdominakegmente, la die ersten 3 von den Hüllen der Beine und Flügel überlagert erscheinen. Wird die Puppe durch Kontakt, Licht oder (hemikalien gereizt, so fühnt sie rasche Bewegungen aus. Nit zunehmender Entwieklung der Tmago

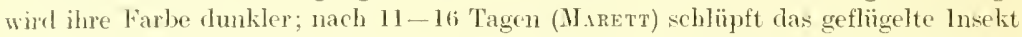
aus und zwar stets während der Nacht, wobei das freie Ende der Puppe stark eleviert wird. Nach dem Ausschlüpfen bleibt die leere, durch die C'berreste der Larvenhaut nnd die vier Kandahaare charakterisierte leere Puppenhïlle an der Unterlage festgeheftet zurïck (Fig. 15 anf Tat. 12).

Die Brutplätze der I'hlebotomen im allgemeinen, sowie auch im besonderen die Orte, an welchen P. papatasii seine Entwicklmig durchmacht, sind noch nicht mit wïnseheuswerter Genauigkcit und Vollständigkcit festgentellt. Man weiß hierüber nur folgendes:

Grassi fand die Jarven ron $P$. papatasii nur in sehmutzigen, dimklen und feuchten Lokalen, besonders in Kellem, in welchen Bammaterialien wie Steine, Ziegel, Mörtelstïcke aufgehäuft waren und wo rejellich organisehe Substanzen (fanlendes Holz, Stroh, Papier, vegetabilische Abfälle, Faezes von Herbivoren) mit Er(e vermischt an Boden lagen. Die Larven wurden stets auf der unteren Fläche von Steinen, Ziegeln u. dgl. angetroffen und komnten mur in äuBerst geringer Zahl gesammelt werden, welcher [mstand mit der ungeheuren Jenge der in nächster Nähe auftretenden Tmagines auffallend kontrastierte. Grassi glaubt, daß sich die Larven an solehen Stellen hauptaächlich zum Zweeke der Verpuppung einfinden, vornehmlich ans dem Grunde, weil die vorhandenen Exemplare stets groß und rerpuppungsreif waren unt weil sich an ihren Fundorten tatsächlieh anch Puppen entrlecken ließen; die ejgentlichen Entwicklungsstäten sucht er in Ventilationsröhren von Aborten und Fenkgruben, auber Betrieb gesetzten Fallröhren der Aborte, an Wandstellen ron Kanälen mut Senkgruben, welche oberhalb cles Flüissigkcitspiegels liegen u. dgl. Doch blicben sowohl seine eigenen Recherchen als die Nachforschmingen in Mlostar (Doerr und Russ) und in Nalta (Birt, Marett, Newstead) in dieser Hinsieht erfolglos.

MAKET crrichtete Ende April in Malta äber verschiedenen Objekten eine Art vom Fallen, wche aus Käfigen von engmasehigem Organtin bestanden und nach obch und nach den vier keiten geschlossen waren, während der Boden durch die freie Fläche des hetreffend on Objektes gebildet wurde. Auf diese Weice wurlen übordacht: eine kleine Felfurtic in einem Gartentejch mit angrenzender Wasserfläche, ein Stïck Gartenuaucr, aus welehem zuvor ein loser Stein entfemt worlen war, Wurzeln verschicdener Bäume mit der angrenzenden Erdpartie, lebende und abgestorbene Stïcke von Baumrinde, cine Parzelle eines aus losen Steinen und Erde aufgerichteten Walles, Brunnen, Latrinengruben, Ventilationssclı̈chte, Schießscharten militärischer Forts, eine Felsspalte in einem unterirdischen Keller eines Forts usw. Sammelten sich in diesen Fallen P'appatacis, so war der SchlnB gerechtfertigt, daB das Objekt, 
welehes die Lnterlage bildete und aus welehem allein die Inagines herribluren konnten,

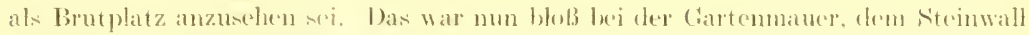

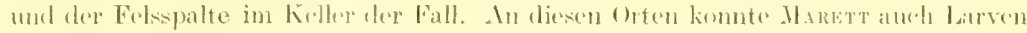

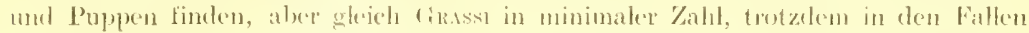

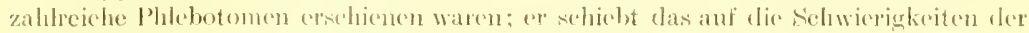
Suche nach so winzigen ()bjekten, sowie auf den Lustame, dabs sieh die Larven, die

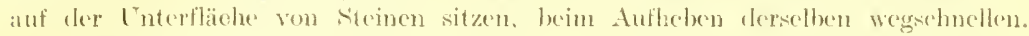

Larven können in fommer. Hertst nod Winter gefmelen werden; in letzteren Falte ersebeinen sie dorsalwärts geloüumt und unbeweglich. Da gedlügelte Inseliten rom Ende Norember bis April nicht anzutrelfexs wind, da weiter auch aus den im September ofler ()ktober gelegten Eiem binnen wenigen Tagen Larven ausshliphen,

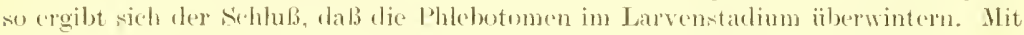

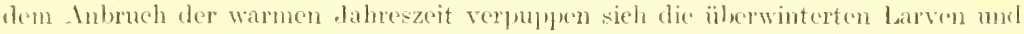
lieforn das erste Jaximum der Imagines (s.o.). Aus ihren fiern geht die zweite Generation hervor (2. Haximum nach Mratex), deren Nachkommen nach der Ansicht von MLrett bereits wieder als Larven ïberwintern. Grassi, welcher die (xeneratiomsdaner in der Natur für wesentlich kürzer hält als in der Cefangenschaft, nimmt für das südliche Italien eine Frühjahrs-, cine Sommer- und eine Herbstgencration an, fïr tas nörclliehe Itahion gleich Maret bloß zwei.

\section{Technik der Lntersuchung und kiinstliche Kucht.}

Getrocknete Phlelwtomen lassen sich in ciner schachtel knuservieren und versenden, verknäueh sich aber leicht, so dabstets eine gröbere Anzahl aufbewahrt werden unb, um auf tauglielee Exemplare rechnen zu kinmen. Auch lassen sich die friseh getöteten Vücken in Kanadalalsam wegen ihres geringen Wassergehaltes und ihrer Transibarenz einschleben fam hesten aul dem Hohlselilijf eines (ohjektträgers), olne daß nachträglich Verinderungen nder Triibungen aultreton; nur werden die lose sitzenden Haare nnd Schuppen dureh den zähfliissigen Balsam zum Teil abgestreift. Axxaxdane empfiehlt, die eben getöteten Exemplare leicht mit einem Kamelhatjoinsel zu herülren, an welchem sie haften bleiben; sie werden dann in einem schmalen, mit starkem s.jiritus:

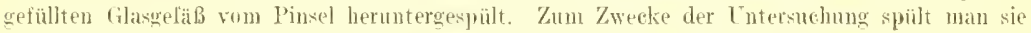
vorsiehtig in ein Lhrghas und kiun sie bier mit sehwacher Vergrößerung mustern; um Details zu bestimmen, bringt man sie für $1^{1}$. Stunden in ahsoluten Alkohol und von da bis zur völligen Aul-

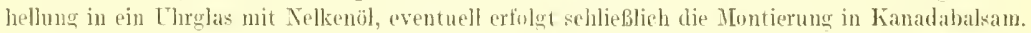
Die Flügel werden bei spiritusexemplaren mit einer feinen Sehere knapp am Körper abgetragen und sorgfältig in DELAFIELd 's Hämaltoxrin oder MAYER's Hämalann für 24 Stunden eingelegt;

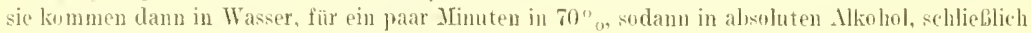
in Nelkenïl und Kanadatrajam (Axxaxdate).

Die Anlzuch gesehieht nach YLaretr am hesten so, dab man Reagenzröhrchen mit Makser ansspialt und die an den Wänden haltende Fenchtigkeit in denselben belibt. Hieraul beschiekt man dieselhen mit so viel frischen l)etritus, daß eine Seite der Eprouvette bedeckt wird, und stöpselt mit einem Wattepfropf zu. In sulchen Röhrehen fallen $75^{\circ}$ is der Fxperimente positiv aus, befruchtete Weibchen legen Eier, die mit Hiffe einer Lupe sichthar sind und aus welchen Larven auschlüujlen. Subald man das Vorhandensein der letzteren konstatiert, wäscht man die Röhrehen vorsichtig mit Leitungswasser ans und spült den Inhalt anf Filterpapier, mit welehem man eine Petrischaje ansugkleidet hat; die leicliteren Larven finden sich dam auf der Oberflïche des Detritus ulum des Filterpapieres. Das nasse Jilterpapier muB sofort von aller überschüssigen Fenchtigkeit loefreit werden, indem man es anf mehrere Lagren trockenen Filtrierpapieres anflegt: sonst sind dir Larven unfähig wegzukriechen und artrisken. Haben sieh die Larven erholt, so wird noch Iletritus in die Petrischalen gegeben, je mehr, desto besser, auf die Imenseite des Deckels wird femelite: F'iltriclpapier geheftet und die Sclalen bei Tag geseblossen, bei Nacht partiell geölfnet an einem dunklen Orte bei 22-260 C gehalten. Ns Nahrung eignet sieh unr Detritus von Brutstaitfen (ciartenmanern, Wällen, die aus losen Steinen und Erde hestehen), nicht aber gewöhnliche Lirde (ILARl:TT); es scheint demnach, dab sie sich anch im Freien nicht einfach in der lirde entwickehn (Ilnwrivit). 


\section{Prophylaxe.}

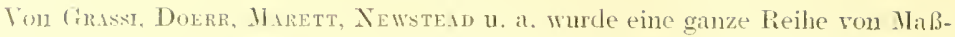
nahmen gegen die Phlebotomen vorgeschlagen, deren Wirksamkeit indes bisher noch nicht erprobt ist. Sollten sie sich bewihen, so wärden sie matïrtich auch eine planmäbige Bekämpfung des Pappatacifiebers (siehe daselbst) gestatten. Zweifellos mub nan aber Newstedo reeht geben. wemn er die Ausottung der Phlebotomen als cin weitaus sehwierigeres Problem bezeichnet, als den Kampf gegen andere Strehmücken, und als Gründe hierfïr die auberordenthehe Khomheit des lnsekten, seine fluhartigen Gewohnheiten, surje die enorme Ausbreitung der Territorien anführt, welche als Brutstätten benutzt werken können. Schematisch lassen sich die Wabnahmen zur Abwehr der I'h\}ebotomen einteilen: 1. in Mittel gegen die Stiehe der Weibchen, deren Anwendung Newstead für leicht realisierbar und deshalb für aussichtsvoll hält und 2. in die Zerstörung der Brutplätze.

ad 1. a) Gewiohliche Moskitonetze an den Fenstern, Türen nsw. passieren die Phlebotomem geschirkt und ohne Miihe; himreichend feimmaschige Netze behindern die Ventilation vïllig und nichen den schlaf in den whedies warmen Schlafzimmern der heiBen Kilimata mmmöglich, da sie dee kühleren Nachthuft den Zutritt verwehren (Doerr, Newstesd). Nach der Vermutung von Yewstead würden gewölnliche, aber mit $1^{\circ}{ }^{\circ}$ Formollösug besprengte Ioskitonetze die Pappiatalcis lernhalten, ohne die Ventilation zu stark an beeinträhtigen. Ther sehlaluetze siehe den Artikel ,Wreitagefieber" in tiesem Handbuch.

b) Sulben. Crawford (zit, nach Newstead) empliehlt eine Salbe von folgender Znsammensetzung: (1). Anisi, (1]. Euealypti, Ol. Terebinth. L'ng. Acirl. burate - Xach Grassi haben solehe Einreilsungen jedoch nur dan einen Effekt, wemn rlie Pappatacis spärlirh sind; bei großer Zahl der Quilgeister versagen sie gänzlich. Bestreicht man z. B. nur (iesieht und Hände, so kriechen die Tiere unter das Leintuch und stechen an Körperteilen, die sonst versthont bleiben, nder sie dringen gar in den äuberen Gehörgang oder die Tasenlöeher ein, wenn nicht anch diese mit dem Präparat ringesalht wurden.

(:) Räucliernngen shlheinen wenig zu nützen (tirkssi. Tewstead).

d) Tach Marett und Tewstead lewälurt sich dagegen Formalin vorzüghich, was merkwiirdiger ist, als andere Insekten, ja selbst die P'uppen der Pappatacis selbst, dureh Formalin gar nicht oder nur wenig leiden. Raumdesibiektionen mit Formaldehyd töten die Phfebotomen in großer Zahl; tighiehes feines Besprengen der dunklen Zimmerecken mit geringen Mengen $1 \%$ Formalinliosune vertreibt se ans den schlatrïmmen.

(4) Tageshieht vertragen die Phlebotomen nicht, durch künstliches Lieht werden sie dagegen angezogen. Die schlafrïnme sollen daher oft frisch nud weiß get incht werden nnd bis in die letzten Exken dem Lichte exponiert sein. Bei Xacht und geöfneten Fenster soll kein Licht angezünlet worten (Doerh, Newstead).

f) Seln empïndlich sind die Phlebotomen gegen Zughalt, was zuerst Doerr hervorhob. Es int daher zweckmibier, das Bett bei geöifneter Tür und offenen Fenstern mitten in den Lultstrom

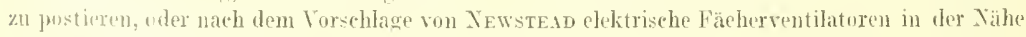

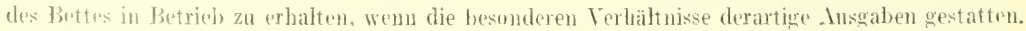

(2) Jallen. Inuen getschwärzte Pappschatehteln, deren Boden offen gehassen wird und die man

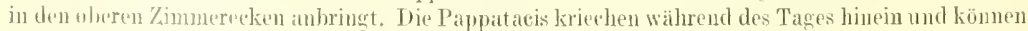

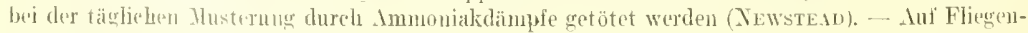

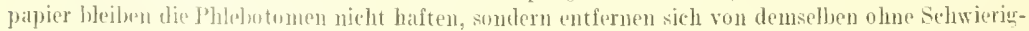
keit (TrRssis).

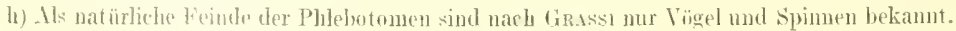
Paraten konnten in ihren libruen nicht nachewewesen werden.

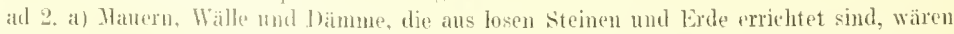

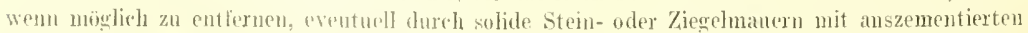

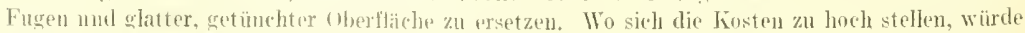
es gentigen, selche thjekte mit dimer starken Zementlage zu vorkleiden. Dämme könnten auch mit

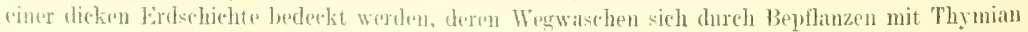




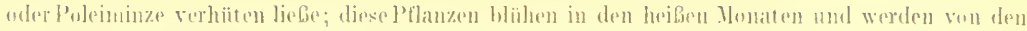

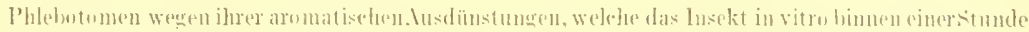

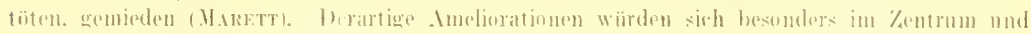

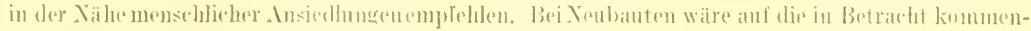
den Homente Räurkicht 2 m molumen.

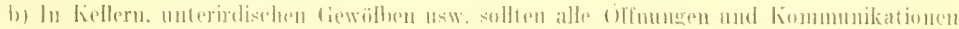

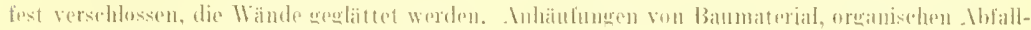

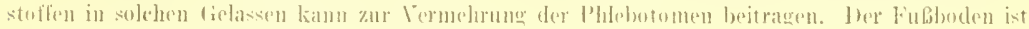

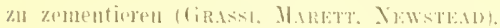

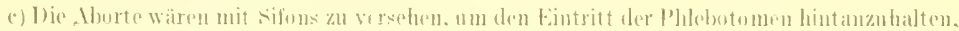

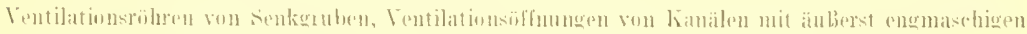

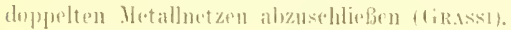

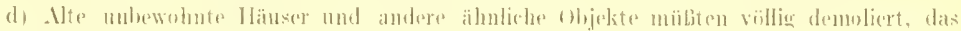

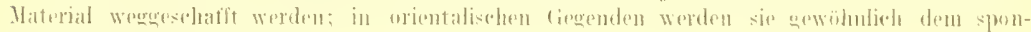
tameu lirfall überlas:ese.

\section{In $\mathrm{h}$ al $\mathrm{g}$.}

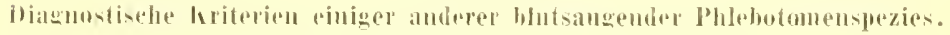

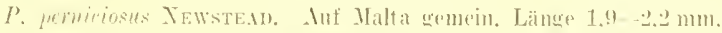

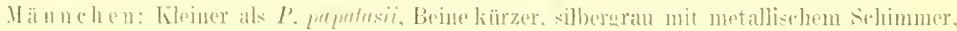

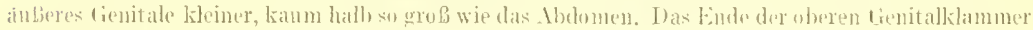

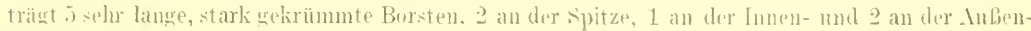
seite: die unteren Klammern sind terminal mit sehr langen, dünnen Haren lresetzt; statt der

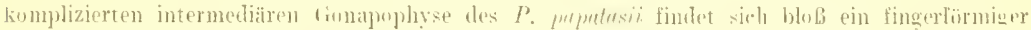

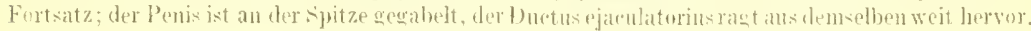

\section{Fin. T.}

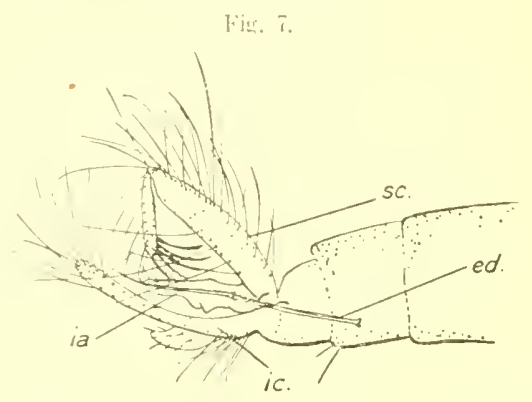

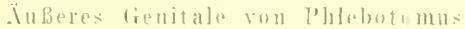
pernifiosus; ( linpie nateh Newstend). $s e=$ obere blammen oder dorsile fronatpuphyser; ic = motere Klanmern orler Laminat subsentalis; ia. = intrmediare Ipjendiers oder fomajublesen; od = Thuctus ejaculatorius. nate links in den l'enis übererlenel.

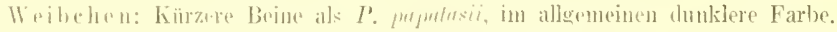

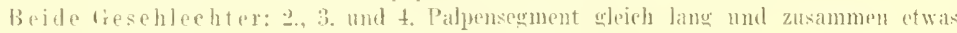
lïnger ils das 5 ; rorderer Flïgelrand schwäches grelirümmt als der hintere.

I'uppe: Ibdomen von der Fixations:telle stark nach abwärts, sodann senkrecht nach anf-

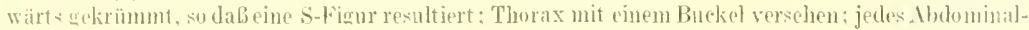

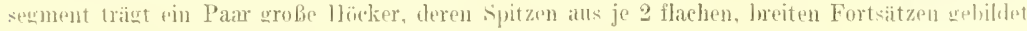
sincl. Die Korperobertäehe ist dicht mit selumpenartigen Dornen bedeedit.

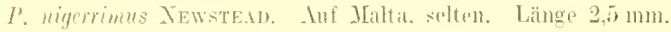

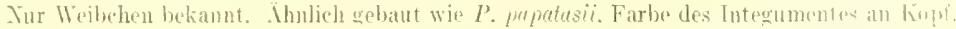

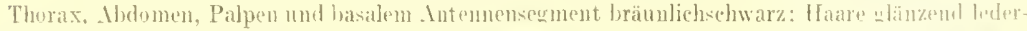

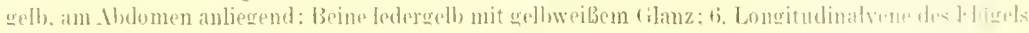

kiurzer als bei $P$. petputusii.

I. minules Rusdoxi (Nïderipa). 


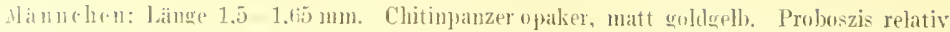

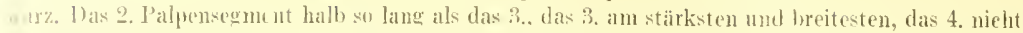

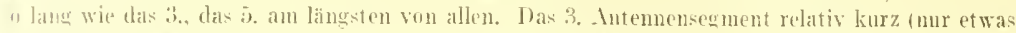

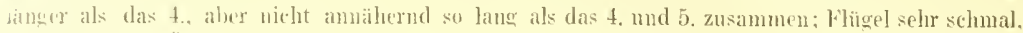
lamzettfömig. Auberes dienitale lilein. obere Klanmer mit 4 langen Borsten, intermediäre Gonapophrsen älumlich wie bei P. pmpatusii.

Weibchen: 2 mm. J tie Flïgel zeigen cine schwarze liandader und ehenso gefärhten fransenartigen Haarlesatz: auch auf der Flitgelfläche emzelue schwarze Haare unter den oekergelben. Beine: Femur ockergelb, Tibia und Tarsus schwärticlı nit silbergrauen schnpen. Die langen Haare der Antemen sind gegen die spitze der letzteren gerichtet, das 4. bis 4. Segment trägt je ein Paar winkelir abgebogener Dorne.

lhas Insekt ist viel lebhalter als andere enropäische Phlehotomen, wechselt fortwihrent seinen l'latz und zeigt anber sprungartigen Bewequngen die Wahigkeit, sich so rasch herumznwirledu. dab es zuzeiten fast unsichthar wirk. An seiner geringen tirobe, den anliegenden Abdominalhasen, den Palpen und der Kïrze des :. Antemnensegmentes, Jännchen auch am äuberen (renitale leicht zu erkennen.

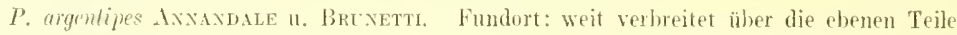
Indinıs. Länge 2 mm. Lipf und Aldomen bram, Vorsalseite des Thurax schwärzlich, Seite des Thorax, coxae und Trochanteren gelblich, Beine. Antemen und Palpen grau. Das ganze Insekt zeigt einen starken silberartigen tilanz. Hinterer Flïgehand viel stärker gekrummt als der vordere; der vorderste Lt der 2. Longitndinalader länger als die Distanz zwischen den beiden Gabehn dieser Ader uder zwisclien der hintesen tiahel und der mitteren Querader; die letztere Distanz kürzer als die zwischen beiden diabehn. Yännlicles fienitale: tie oberen klammern (mit 5 terminalen Borst'n) bestehen aus einem längeren proximalen und einem liüzeren distalen Cilied; die unteren Klammern sind schmal, länger als das basale (ilied der oberen, und an der Spitze mit eimem diehten Pinsel ans starken Haaren versehen: die intermediaren Appentizes klein, ans einem dursalen und einem ventralen Lappen bestehend, hopulationsorgan lang, ans einem Parr sehmaler seitlieher Lilappen bestehond, zwischen welchen die fadenformigen Enden dur Inuctus ejaenlatorii weit hervorgestreckt werden kümen.

P. babu Axxaxdale. Gemein in den thenen hadins. Länge 2,5 mm. Farbe silbergrau. Abdomen seitlich mit einem fransenartigen Bexatz von nach ruckwäts gekrimmten flaaren versehen. Flïgel schmalzugespitzt; die 3. Longitudinalader teilt den Flügel in 2 gleiche Hälften; der 1. Ast der 2. I. ongitudinalader ist fizst so lang wie der 2., aber kürzer als die l)istanz der beiden

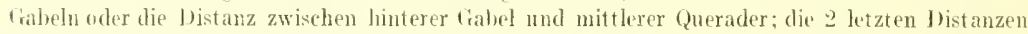
annähernd gleich; die hintere Gabel steht der Flügebbasis uäher als die Gabel der 4. Längsader. AuBeres Genitale des Mämohens: Basalghed der oberen klammer dick, zweimal so lang als das distale, mit 4 Bursten an der Spitze; intermediäre lilammern kurz, plump. untere so lang als das Basalugled der olveren. mit cingen chitinosen Bursten an der spitze und der ventralen Fläche. (ienauere betails und Beschreibungen anderer spezics bei X̌ewste.n und Axxandale.

\section{Literatur.}

$190 \times$ Axwayale, Rec. Ind. Hus. Tol. 11. p. 101.

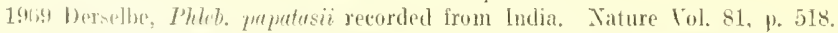

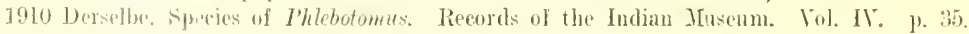

19n: Arstex, African bobodsucking lies. B. Y. London.

1911 B.tLfork, Jiver. in sudan. Welleomes Trop. Research Labor. Chartomm. N. Report p. 220.

1911 Derselbe, Som aspects of trupical sanitation. Ibidem siaplem. to IV. Rep.

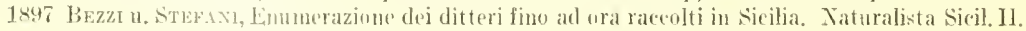

1908 Bnt, lixperimental investigations of simple continued feves. Journ. of R. Army med. Cords, p. 66.

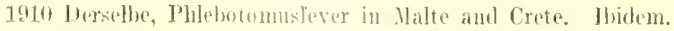

1910 Tersebbe, Sandlylever in India, ibidem August.

1910 Jerselbe, Phlebotomnis- ur Simillyfever. Brit. med. Journ. Il, p. 875.

1909 B baxchari. Qquelques noten sur ia Plehotomus. Areli. de l'aras. Vol. XIIl, No. 2.

1909 [rersellos, A propos des juldedotomus. Bull. Sore. Entomol. France, Paris Nr. 11, p. 192. 


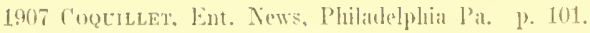

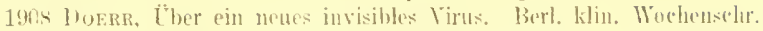

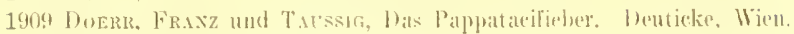

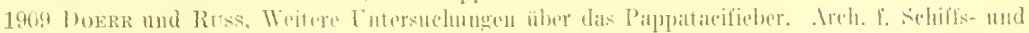
Trop.-1iyg. Bd. Xl1t.

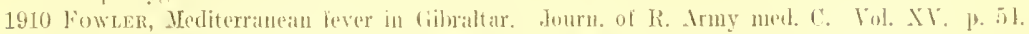

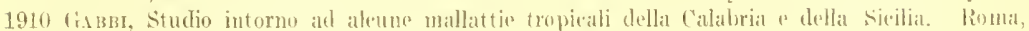
Filse. II, III.

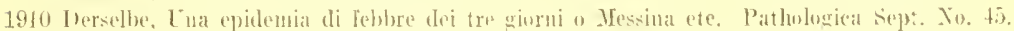

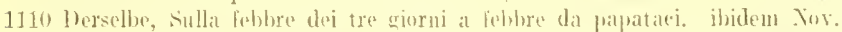

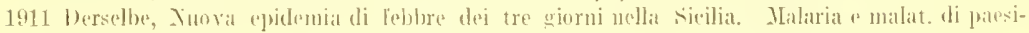
caldi. Vol. II.

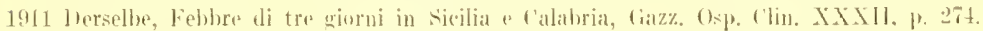

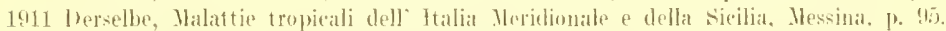

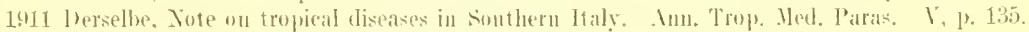

1911 Galli-Yalerio, centralbl, f. Bakt., Abt, 1, Orig.. Bd. 20, p. 362.'

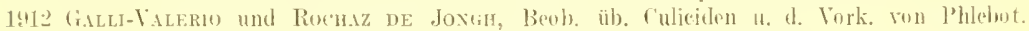
palpatasi scop. in Kanton Waadt (Schweiz) Ibiden, Bd. 63. p. 22.2.2.

1960? Cilles, Kandbook of the gnats or mosquitos. Lonton, 2. Aufl., p. 5.

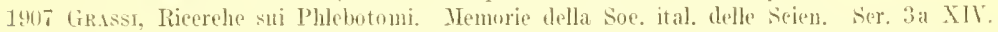

199k Derselbe. Intorno ad un nuovo Phlehotonno. Rent. Real. aecad. dei Lincei. ser. 5a XVll.

1909 Howlett, Indian Simdilips, Transaet. Bumbar med. Congr.

1903 Kertesz. P'sychodidue. Katalog der paliarlitischen Diptern.

1906 lisvo, Welleomes Trop. Research Labur. Chartum Il. Rep.

$1 ! 11$ Leber und Prow.dzer, Berieht üb. mediz. Beobalitungen anl siktai und Mammo. Areh. f. sehiffs- u. Trop.-Hyg. BiI. XV.

1910 Léox, Notes sur les diptères buveurs de sang de Remanic. Centrabbl. f. Bakt. Orim. Bd. 54.

1895 Lior, lijtteri italiani Mliano, H. Hoejli, p. s1.

1864 Loew. Fanna anstriaea. Dipt. 1I, p. 630.

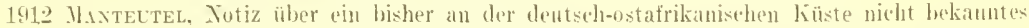
sommerlieber, Ireh, f. scliffs- u. Tropenlyyg. Bul. 16, H. 1s.

1910 M.arett, Preliminary report on the investigation in to the breeding places of the Sandfy in Malta. Journ. of R. Army med. C. Vol. XV.

1911 Derselhe, The life-listory of the Phtebotomus. Ibidem Vol. XYII.

1912 Derselbe, The Phlebotomus lilies of the Maltese Island. Ebendit Vul. V.

1907 M.nwell Lefroy, A preliminary account of the biting flies of lndia. Calcutta Bull. Mr. $\bar{T}$, 1. 15 .

1909 Yleijere, Blutsangende Mikro-Dipteren. Tijdtehr. voor Entom. Vol. CXI, p. 191.

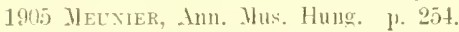

1906 I trerselbe, Naturaliste. F. 103.

1909 JICYEECE, Brit, met. Journ. II, p. 101.

1906 Tevel-Lemaire, Bull. Soc. zool. France. Vol. XXX̃I, p. 64.

1910 Newstend, Sandflies and fever in Malta. Brit. med. Journ. II. p. 66을

1911. Lerselbe, The Pappataciflies (Phlebotomus) of the IIaltese Island. Bull. of Entemol. researeh Jay und Annal. of trop. Medie, and Paras. Lugust.

191.2 Tervelbe, Journ. of Roy, Army med. ('. Bd. XTIlI. p. 613, Bd. XlX, p. 28.

1907 Theselbe, Dutrox u. Toud, Insects and other Arthropoda collected in the Congo fire sitate. Ann. trop. med. and Paras. Bd. I, p. 3.

1911 Хic lot, La fiève de trojs jours. Compt, rend. soc, mil, franc. 9. IV.

1910 Pinllipps, Sandfly fever in Cairo. Brit. med. Journ. 11, p. 963.

18 to Roxdra, Sopra una nuova speeie di insetto dittero, Memoria la, Parma.

1843 Derselbe, species It allieae generis flebotomi. Ann. Soe. Entomol. Franee. 2 n. ser. 1, p. 2033.

1911 Royers, La méd. orient. p. 318.

1912 Russ, los Pappataci- oder Phlebotomufieber (Doerr), Osterr. Sanitaitwescon Mr, 12.

1786 Scopoli, Deliciae taunae et florae insubricie ete.

1910 Speiser, 7oolog. Jahrb. Supjol. 12, H. 3. 


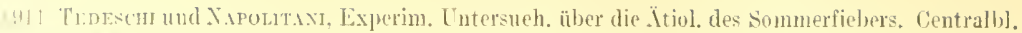
f. Balkt. ()rier. But. ōi.

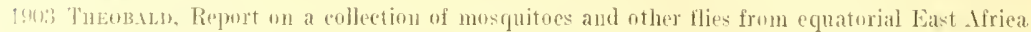

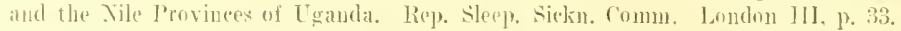

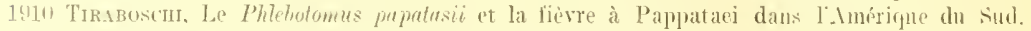
Arein. de Parasitol. Bd. XIY. H. ‥

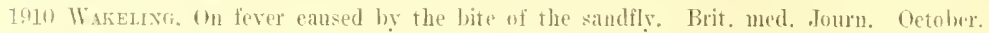

1911 Wald, sindily ferer in Clitral. Indian med. (iazette Tr. …

1910 WinzerLer, Dengue ur Phlehotomusferer? Ibidem August.

1910) Derselles: Sandilyterer. Ibidnn Tecember.

\section{Erklälung zu Tafel 11 und 12.}

Fig. 1. j von Phlebotomus paputasii Scop., in der Herzegowina getangen, im frischen Zustande in Kanadahalsam eingesehlossen. Nan beachte die Thoraxkrümmung und die dadurch bedingte stellung des lioples, die Haltung der Flügel, welche, wemn auch nieht ganz, der nitürlichen entspricht, die groben, als schwarze Flecke hervortretenden Augen, die Anordnung der Palpen un die Prohoszis, die Behaarung des Insektes nud dils hintere Abdoninalende.

Fig. 2. c. wie 1 . beliandelt. Iriölie.

Fig. 3. 3 Exemplare von Phlebot, pepatasi in Kanadabalsam, photographiert in nat ürlicher

Fig. t. Koul von Phleb. puputusii $f$ in Kandabalsam ron der Dorsalseite. Rechls und link die Antennen, dann folzen die in den Cielenken abgeknickten l'alperi, in der vitte links dre Tnterippe mit den terminalen Senioliven, rechts das stilett.

Fig. 5. Luph von der Ventralseite. Stilett linlss. Unterlippe mut Semioliven nach reedits verschoben: zu beiden sesten die Palpen, nach an ben von diestun die Antenuen, von welchen die eine (in der Fig. links) in der Sitte abgebrochen ist. Cnterlatb des liopfes Fragnente der Extremitaiten.

lig. 6. Jlinteres Ablominalende des Naimehens abgetrennt und derart auseinandergehreitet, dabs alle Gonilyophrsen und Inlänge sielitbar werden (mit der Lupe zu betrachten). Tach links oben erstreckt sich die lannina subgenitalis (GRAssi) mit 2 lateralen und 2 medialen Anlä̈ngen, von TewsTEAD als unterer Klammerapparat bezeichnet; nach rechts und links ziehen dic

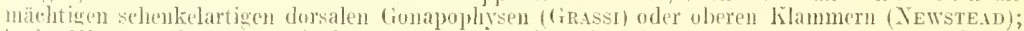
in der. Wit te gewalirt min zwei schwarze, kurze, terminal diverginende stachehn, die Penes; zwischen dieso und die schenkelartigen proximalen Anteile der dursalen Gonaphysen sind jederseits noch drei Finrsitze eingeschaltet, welche im linken Teil des I'hotogramms vou links nateh rechts wipe lolgt zus brodedment sind: die sjehelfornigen, an der honkavitit fransenartig behaarten intermediaren menlialen, die intermediaren lateralen dersalen und die internediären lateralen ventralen Gonapophysell, welehe letztere zwej zusammen eine Art Krebssehere bilden.

lige. 7. Flitgel, durch Abpinseln von Haaren und sichupen befreit, in Lult ejngebettet.

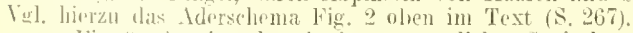

Fïg. S. Auseinandergebreitetes männliches Genitale. Ohen und nnten die dorsalen (innapophyson, nach links nutron umaklappt die Lamina sulhgenitalis, in der Mitte als schwarzes, faden-

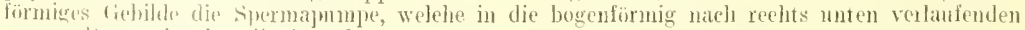

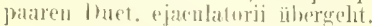

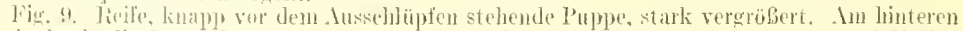

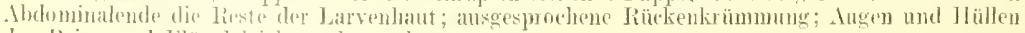
der Beine und lidaged Jejedat wahrannehmen.

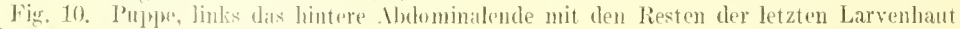
und den 4 liandallowsten der latro.

Fì. 11. llälfte eines lises.

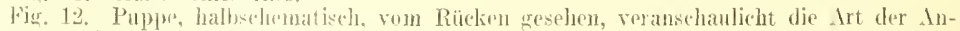

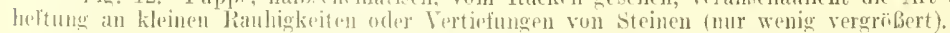

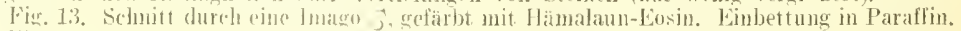
$\sin 1$

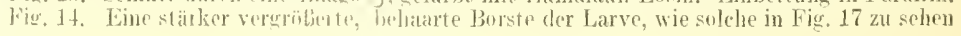



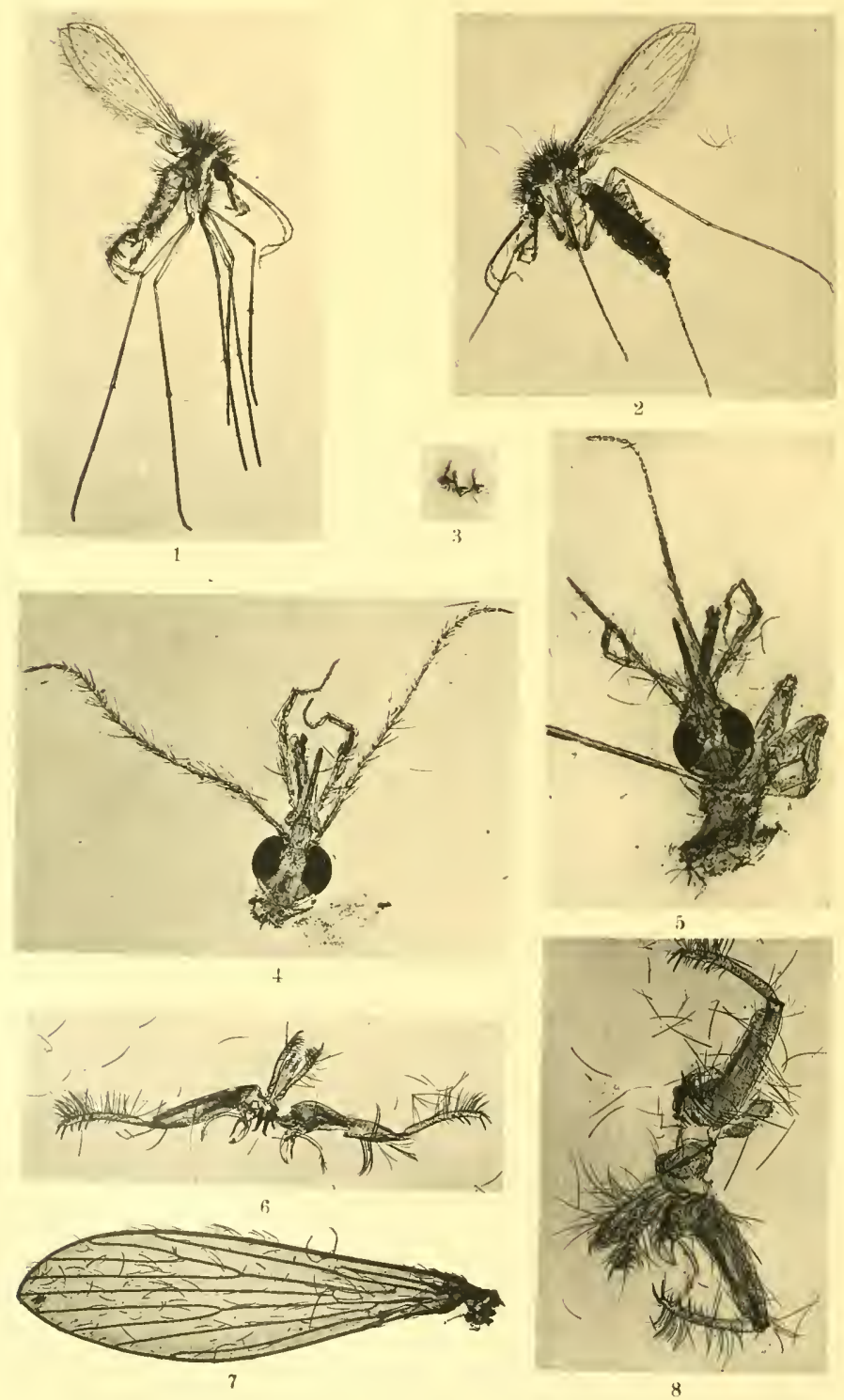

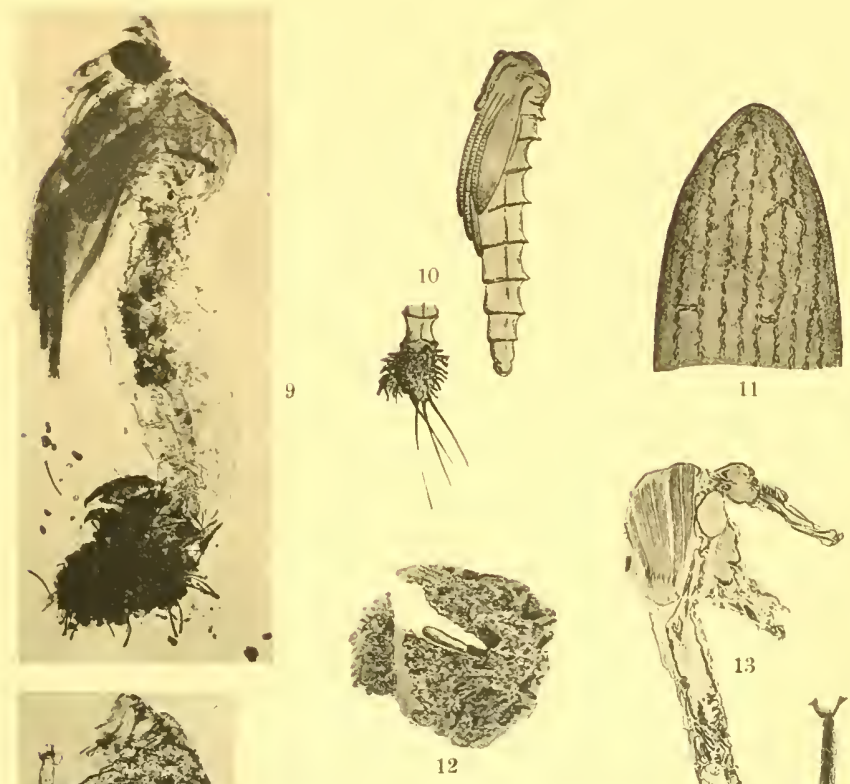

11
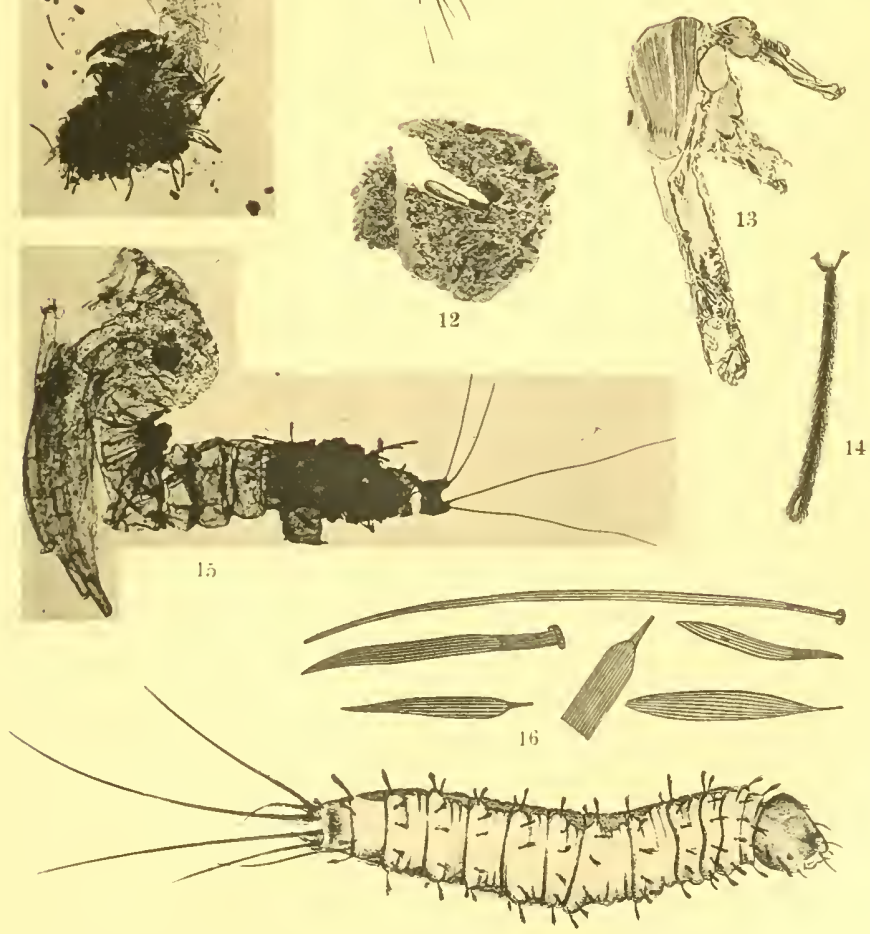



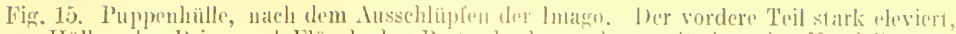

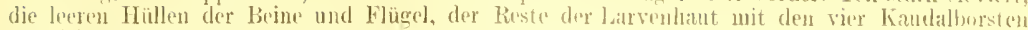
bentlich.

Fig. 16. Verselieden gestaltete Schuppen von dan Brinen und Füugehn des Inselites.

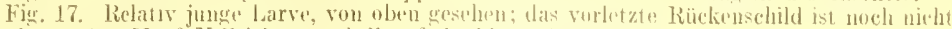
pigmentiert. Am kopf Y-Zeielmung (hell anf dunklem limmle).

Inmerkung: Für die Figr. 1, 2, 3, 4, 5, 6, 7, 8, 9, l:3 and 15 wuden (riginahphotoganme

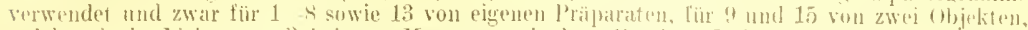

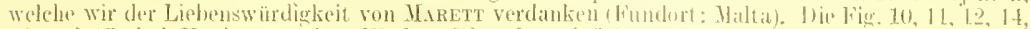

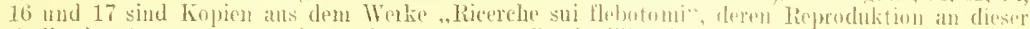

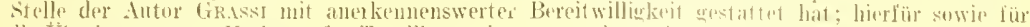

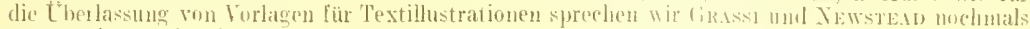
unseren besten l)ank aus. 


\section{Namenverzeichnis.}

1.

Abbamondi $25 \%$.

thed 145 .

tholf 145 .

Adam: 25s.

delie 145.

Arlulph 145.

Inasiz 3.

dgramonte 145. 172.

Aitken 145, 239

Albert 145 .

Aleuck 3, 145.

Nelrovandi 3.

Alexander 234.

Ascribaja 145.

Altamirano 239 .

Anyot 68.

Anderson 213.

d'Anfreville 145.

Angeny 145.

Angrier 145 .

Sant Luna 38.

Ammantale $263 \mathrm{f} ., 280$.

Amett 136,145 .

Arelibald 3.

de Arellano 14 j.

d'. Irenlere 145.

Arnold 258.

Arribalzaga 145 .

Artault 51, 239.

A.hhurm 145, 234. 3ㅗ.

Ashley-Emile 258.

Audouin 3, 22) f.

Augustinski 145 .

Austen 145, 194f., 1906, 2096., $214,224,258,280$.

Irers 145 .

de . Izeredo sidre 140.
B.

Bábak 146.

Bacelli 146 .

Bachmann 258.

Badaloni 146.

r. Baerensprung 6s.

Baggio 146.

Baker 78, 87.

Balfour 3, 53, 146, 221, 224, 258,280 .

Ballon 187 .

v. Bälz 233f. 239, 240.

Bancroft 146 .

Banks 2.2, 146 .

Barbezieux 1tti.

Barreto 146.

de Barros 1tt.

Barth 146,

․ Bassewitz $138,140$.

Bassett-Smit b 146 .

Bastianelli 146, 1 ริ.

Battara $1+6$.

Battesti 14ti.

de Beaurepaire-Aragão 38.

Beck 215.

Bell 14t).

Belli 146 .

ran Beneten 4, 231.

Bentley 146.

Bequaert 1961., 216, 280.

Berensberg $14 t 6$.

Berger 147.

Bergh 239.

Berliely $14 \pi$.

van Berlekom 175.

Berlese bs.

Beruegalu 147.

Berrio $25 \%$.
Berry 147 .

Bertarelli 147.

Bertels 147 .

Bertrand 147 .

Bettinetti 14s.

Betz 160.

Beyer $14 \pi, 170$.

Bezzi 147, 196, 214, 280.

Bignami 146, 15\%, 166.

Bigot 195, 209, 214, 222. 224.

Bilharz ․․ㄹ, 231 .

Billet $87,147 \mathrm{f}$.

Birch-Hirsehfeld 3.

Birdwood 147 .

Birt 265f., 280.

Blacklock $68,258$.

Blaisdell 147.

Blanchard 3, 14f., 38. 147, 231, $239,258,261,280$.

Blenkinsop 258.

Bleyer $147,258$.

Bludau 147 .

Boa: 3.

Bochicehio 147 .

Borddaert 147.

Buek $25 \%$.

Bombarda 147 .

Bongert 40.

Bomnefoy 148.

Bonnette 148.

Bordas 148.

Bordi 148 .

Bordoni-[litreducei 148 .

Borel 14'ff.

von dem Borne 148.

Börner 3.

Borthen 258.

Bosuryi 148. 
Buncles 87.

Bonet 134, 148, 214, 25s.

Bunliard 214.

Bonvier 2013, 214.

Borce 148.

Boyé gis!?

Bradslaw 21 f.

Brandic 238 .

Brandt 3, 20:

Brab 3.

Braner 14h, 196, 25?.

Bram1 :3, 148, 205.

Brazzola $14 x$.

Breinc lis.

Brenal 14s.

Bremene: 1tr.

Broden 330, 231.

Brouardel-cilbert 1.48

Brown 14s.

Bruce 214.

Bruck 14t.

Butker 239.

Brithl 51 .

Brimut 148, 169, 214.

Brาnwin 148.

Brunetti 205, 280

Buclanan 148.

van der Burg 148.

Burceb $14 \mathrm{~s}$.

Burmeister 3, 51, 63 .

Butin 148.

(1.

Calandruceio 14k, 258

('almette 14 s.

l'amail 148 .

l'ampbell 14s, 154 .

van Campenhout 149.

Canestrini 28.

Cano-Brusco 153.

Cantlie 149.

Car 258.

Cardamatis 144.

Carpanetti 147.

C'arrazi 6x'

carroll 147, 15\%, 172.

Carter $149,196,258$.

('arus 4.

l'asagrandi 14 !'.

Cassarmon 149.

Castellani 3, 214, 238, 234.

de Castelnau 21 f.

razalbun 188.

('ecelierel]i 150).
(') colorini 1.4?.

('elli 137, 14t.

Clayas 5.31., (5i) (is, 149 .

('lalmers 3,1491, t87, 231.

('lantemesse 14!.

f'lituplell liso.

l'base liso.

chatin 150 .

chatterjece $1 ; 00$.

Tlanchoye 1is0.

( heinisere 150.

('lijeo 150 ).

Chulodkmwsy 51, 214, 254.

('hichester 2as.

C'hristophers 5, 38, 40, 150, 160, 177, 17\%.

r'hristy $68,150,1 \times T, 250$.

Cioliti 1 iso.

Cijollone 258.

('lande 150.

Claus 150.

clans-frobben 3, 40.

Cleve gl3.

rluss 259 .

Cobbet 169 .

Coger 150.

('ogil] 150 ).

('olin 259 .

colledge 150.

Collingwood 150.

Colodkonsky $25 \%$.

('ondorelli Francaviglia $25 \%$.

Conte 150.

Conto 14t.

rook 150 .

Conper 39 .

Livpuere] $25 \%$.

corpuillet 150, 264 .

Cormwall 150.

forre 259.

C'orti 210 .

Cosolo 150.

Costa $260 \overline{0}$

Couvreur 150.

(raig 3, 145, 151, :34.

Crawford 278.

(respin 151.

('resinell 151.

(ropper 151.

Crossuard 259.

Cruz 5, 69.

('numingham 151.

Curie 151

curtice 34,39 .

cuvier 3.

Czygan 151.
I).

b) lill 87 .

[b]leren [il.

I)algetty 151, 2:39.

1) ถแm

['an!)l" $\$$.

banicls 3, 15.

lo lintee 3,151 , 25?

1)arling $2: 31$.

baruty de cranelure 151.

I) arwin 6s.

1)asenville 151 .

Jatvg:t list.

belouve 151.

1)ereorse 1.51 .

bedek 1 tho.

Jelatield $\div$ ĩ.

Delamare 1ij1.

Pelany $58,68$.

Deliboen 151.

Dempwolff 151. 239.

De jied 259 .

Desfoses 151.

Diamesis 149.

Jiexine 20, 231.

limmmock 15 ].

I)ionisi 151 .

lock 15:2.

Fodd 152, 18:.

bulime 159 .

Jönitz 35, 152.

lopter 152.

Horeall 152.

T)irr 183, :63, 281.

looty 152.

l)uboser $16 \mathrm{t}$.

Tubreuilh 3, 259 .

Duform 56, 214, 2.24.

Dugin 24, 87, 239.

Dilgnet 49 .

I)

Inprey 152, 259.

Dupuy 152.

Inrham 152 .

Ilutton 53, 136, 145, 152, 169. 199, 216. 259, 281.

I) yar 152.

I) yé 15\%, 268.

Iryepondt 149 .

E.

Eaton 153.

Eberle 15:

Edgerton 153.

Egidi 153. 
demmerez de tharmoy 151. $15 \%$.

Elliut 145.

linderlein 4t, 51. 68, 85, 87. Errenlani 3.

Exersmamn fil. fis. livell 1, 153, 112. vin Ezelorl 1\%?.

\section{F.}

Filbre 213.

Fabricius 4, 20, 59, 68, 153, $193 \mathrm{f} ., 223,236$

Fajardo 153 .

Fallén fis.

Fanzago : :of.

Finscek 214

Folelmann 15:3. 214.

Feletti 136 .

lint 153 .

Fermi 158.

Fernando 153.

Fibich 154 .

Ficalbi 154.

Fieber 6is.

Fink 154 .

Fimlay 154.

Fisch 154 .

lilemming 239 .

Fior 65.

Foley 40, 52, 154.

Folker 259.

Fontoment 154.

Forel 4, 154.

Forli 154 .

de Fossey 154.

Foster 25!?

lowler geit.

Fox 87.

Franca 니․

Franchini tis 154.

fränliel 2214.

ร. Frantzins 25!).

Fran\% $271,280$.

Friser 1:ti).

Freudenthal 154.

fiev 4.

Frieclenthal 47.

Friedmanm 154.

Fiedrichsen 154.

Frivile 4 .

lrogatt 154. 250

Friblith 200 .

lirost ?1s. lis $15 \pm$.

F ïlleborn 38. 8.3f.. 87. 136, I55, 231. 25?.

Fiirstenlerer $23 !$.

\section{Ii.}

(iablit \&7, 281.

fithritschewk 15i).

Gagliardi 155 .

(ralli 105 .

tralli-Valerio 155, 265, 281.

(ianguli lis.

(iann 259.

liarman 155.

fianier 155.

Gasperini 149.

Credoelst 4. 239.259.

te treer 4 , 48 , tis, $87,298$.

freoffroy 195.

(ierliardt 259.

Gerstaeclier 4.

liervais 4. 5) 235.

Fiand 214.

(iichel 51 .

Ciemsa 155, 151\%, 169.

Gilblas 1otj.

liiles $156,214,281$.

liill 156 .

Gilmour 15 ij.

(ijllot 40 .

Giolitti 15xt.

Giomefli $15 t$.

Girard 231.

Glatard 150 .

Glen-Lixton 156.

Goplui 15ti, 236 .

Coldberger 156, 173.

Croldschmidt 156).

Fonder 51.

liorgas $15 i$.

van Gorkom $15 \%$

frormamn 141, 184.

Gosio $15 \overline{7}$.

fiotschlich bis.

roudats $25 \%$.

Trowdes 157.

Giraber 4, 51 .

Cirablam 157.

v. Graff 4 .

Giraham 157.

firall 157.

Cirassi 136f., 146. 157. 2638.. $2 \times 1$.

d. firanatia 157.

(imanjux $15 \%$.
Girawitz 157.

lirat 157, 250

Giren $15 \%$.

Cirobben 3.

Cirober $15 \%$.

G]os 62, 68, 158 .

Grobbeck 155 .

Grube 214, 259.

iruby 230.

Cirü̈berg 158, 214. 259.

Ciickel 259 .

rudder 15s, 239.

Guérin-Vléneville 24.

Griart 4, $15 \%, 239$.

fruiteras 15s.

II.

de Haan 939.

d'Haenens 259.

Hahn bis.

Haller 13.

Hamilton $15 \mathrm{~s}$

Ilammone 184.

Hanan 254.

Händel bes.

llandlirset 4.

Hansen 214.

Hardy 259.

Harley 288.

Harmack 158.

Harris 158.

Harrison 259.

van der Harst 23!).

Hart 196.

Haller 158.

llavard 158.

Havelburg 158, 15?.

Haydon 159.

Hearsey gilt.

Hecker 159.

Hector 260 .

Hefferan 161.

Heider 4.

Heinicke 239 .

Heller 4.

Helin 239 .

Hemmeter 159.

llemeberg 260.

Henschen 259 .

Hentschel 4 .

llepper 53, 68 .

llermann 2381.

Herrera 159.

Horrich-schälfer 68.

llerritk 159. 
Ilortwig 4, 2:3!!

11 raring 2600 .

Ileselörltur ]

Hesse lou

llemlutk lis?.

Heymons s 8 .

Hickey 1.j!.

Higlet 15!?

Hilbert 15!?

Hill $15 !+$

Hindle :3x.

Hine 1?ti.

Hintze las?.

Hirscleberer losth.

Hirst 2:3s.

Hodder 15?!

Hoefnawel 4 .

Heiegh ätit).

rou der lloeven 4 .

Hoger 15!.

Holngren 214.

Hooke 44, 51, 79, 87, 154 .

Horniker 159 .

Horrocks 154 .

Horvath 159.

Howard 68, 159. 160, 199.

Howlett 2hif., 2si.

Huher : 130 .

Hiiber 160 .

Hubert 214 .

Hulshot-Pol 1(t).

Humboldt 220 .

Hunter tis.

Hurst 160 .

Husband 5.3, dis.

Husson 160.

\section{I.}

de Tharral 16i].

Jolesias 161 .

Imms 161 .

lusanna 161.

Inawara 235 .

Ivernault 154.

\section{J.}

Jackson 160.

Jacur 160).

Jaffé 160 .

James 1 tio.

Janesó 1 ijo.

Jansell 26j).

Jeansehne 16jl.

Jennings 161, 15.

Julanusen 161.
Iolnsoun 1til.

Juhnston lijl.

dumes Jil.

Jordans $\rightarrow 7,1+j 1$.

Jordamsky tix.

diordens 4.

Jo:(土p)] 2060 .

Jumrdran - grit).

\section{li.}

lianellis 1 ikl.

liaramitsak 16il.

liarlinsky lis.

Kalpelles -40.

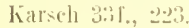

Kirsten 73, Ri.

kawakani 2931. 23:3.

Kayser 260).

Kiellog 161.

helsel 1 til.

liendall 1 bl.

fiemard 16il.

Kemmedy 15!!

liermorgand 16l.

Kersehbanmer 1ti.

liertész 161, 19i, 2.if.

Kieffer $16 \%$.

Kiewiet de Jonge 231.

kilborn 39.

Jing is, 162. 15T, 2小l.

Jinghorn tis, 214.

Kinoshital 16: 1ti

kirby 68, 71 .

Kirchenberger 271 .

kirk 215.

Kleemann 105, 1ii?.

Kleine 215.

kilemensiewicz 16.).

Klodnizky 08

linneus $1 \pm \vec{\imath}$.

lilet 260 .

linab 162 .

liny 162 .

liveh 2-2f, 3x, 16:, 215, 231.

Kinllbrugare 162 .

kimhlstock $11 \%$.

Kioll, 162,260 .

liolloe 4 .

Kinlenati $* 7,223,22 \pm$.

lioller 2to.

lioorevaar - $f$ iol.

kopke 16:.

kïjpen 162 .

Kirmöezi 16:-

liorschelt $t$. linos ltig.

limen :34.

linwalewsky ltiz.

liramer 1ti3, 2J1).

lirapelin se, syo.

liram(er $\rightleftarrows 20$.

liratus $160^{\circ}$

livatuse etijt).

hevenberes 16:-

Krijll 16:2.

Krïuer $1 t^{\circ}$.

Krullo 169.

Limulbhol\% 16:?

Kï̈chammister 4 . 241 .

Kitulı 16\%.

Kulaurin 16:2, 201.

Kï̈z 162, 2:31.

Kitmberg 260 .

kïncliel 69 .

linsmezow ziti).

I.

Lahoulbine $241 ., 215,240$.

de I accerda liti3.

Laeon' 163.

Laengure 231.

Jalilie $35,39$.

Lallier 260.

de Lamarek 4. 71. 20t;

lampert 4, 163.

Landois 51, 57. 69, 73, 88.

Lampholer 163.

Lapresa 163.

LaB RQ.

Latreille 4, 2.2f., 69, 71, 88, 194 . $221,2-24$.

Laudon 231.

de Launay 163.

lanrenes 163.

Laveran 140,163, J64, 2141 .

lawrie 16t.

lavet 164 .

lazear 172.

Leach $461,, 16 t, 217,224$.

Leall 4.

Leber $2 \times 1$.

Lehoenf 16t, 260 .

Lebredn 164.

Leenwenhoek so.

Legendre 164, 1s(t).

Learer 5. 14jt.

Lejper 1s:, 1!1f.

Leisemamn 34

Lemaire 240.

Lembert 164. 


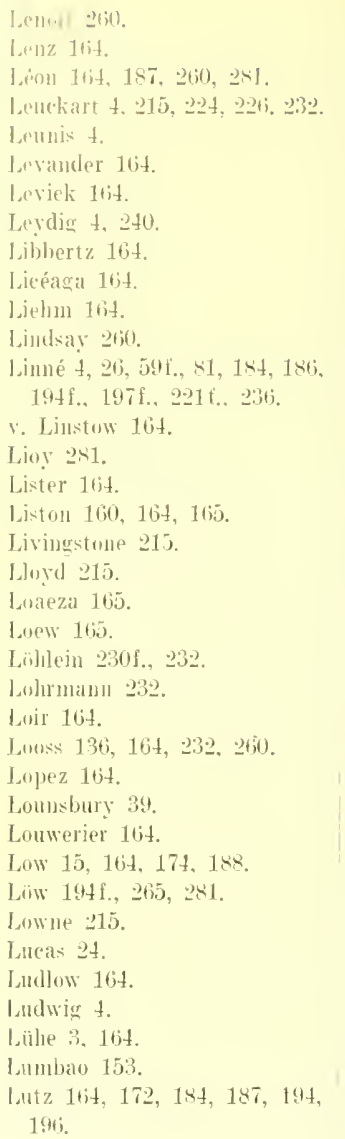

II.

Matedacto it?.

Natckie 40,53, 69

Malcaulay 160.

Macdonald 165 .

VIatoskie 165.

Iacquart 165. 1944!, 215.

te Magallates goto.

Maillard 260 .

Nialli 260.

Manders 165.

Maumll Ltis.

Mandie 165.

Ianfredi 16.5 .

Maıkiewiez $2(x)$
Mankowsi 160.

Mamabere 166.

Manning 53, 69.

Jauson 14ti, 166, 188.

Nanteule] 5. 40, 53, 69, 88, 2881.

Mancuat 1 biti.

Yamzella 160,165

Vauzi $166 \mathrm{~s}$.

Narelaal 160;

Marchiafava 166.

Varehonx 157. 166.

Narett 271\%. 281 .

Varey $101,166$.

Yarget 260 .

Mariani 166.

Mariotti-Bianchi $10 \mathrm{~s}$

Yark 16ti.

Narlatt 69

Мarpman! 260 .

Martinj 39, 166.

Martiny 5.

Yartirino 140, 160.

Marx 31

Vassalongo 167.

Massey 39.

Mussintuni $15 t$.

Massulat 224.

Natlis 5.

di Mattey 160.

Jauchamps 167.

Maturin 167.

Maxwell-Lefroy 281.

Maver $381 ., 69,155,167,275$.

Mazzolani 167.

עc Cracken 167.

He tribhon 167 .

Y. Intosh 16i.

Me Kiblen 167.

Ic Xeal $40,169$.

IIC Neece 281.

He Watters 53. 69 .

Mégnin 녀․ 39. ㄴ.40.

Meigen 16t6, 183I., 1931., 197 $217 \mathrm{f}$.

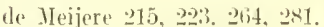

Meinert $40,167$.

Meisenlıeimer 160 .

Melnikow 51.

Melville-Javison 167 .

Mense 5, 82, 88, 138, 167, 21:3, 240.

de Merian 5.

Metalnikoff 167 .

II

Mlenier 167, 2014, 281.

Neyer $16 \pi$.
Viall 184.

vik 260 .

Milne 1 tit.

MiIton 173.

Miurlin $88,215$.

Wine 167 .

Iinett 18.2 .

Niıgazzini 167.

IItchell 167

Miyajima 167, 2965.

Wiyake $23 \bar{\imath}, 240$.

Le Moal $16 \pi$.

Nolder 39.

Molller 37.

Nöllers 39, 69.

Mollow 167.

Noniez 5, 237, 240.

Honticelli 167 .

Iontoro de Francesco $16 \bar{i}$.

Morean 167, 168.

Nori 167.

lloseletti 88.

Hosler 5.

Josny 168.

Joss 168 .

Motas 33.

Mouchet 260

Moufetius 5 .

Nould 168.

Iügrenburg 2:16, 22:4.

Miilılens 168 .

Mïller 168, 188

Murray 24.

Muzio 168.

Hyers 152.

\section{$x$.}

Xagal 260 .

Narbel 155.

Navarre 168.

Nipelitani 26.5.

Neave 216 .

Neiva 65f., 69, 168, 196.

Neulatus 294.

Хемиman! 131., 39, 168, 170, 232.

Teven-Lemaire 5, 69, 168, 169, $264,281$.

Newman 216.

Yewport 237.

Tewstead 40, 169, 216, 264f., 281.

Nichols 169

Niclot $169,281$. 
Xicolle tis.

Niles 187 .

Xitzech 51, 2.2.). 2.2.3.

Xec 1609,20 ,

Xinard 33.

Xorht 16:9, 21:3.

Xori $13 t, 15 \pi$.

Xotlunage! 5. 1 iti.

Nowy 40, $11: 9$.

Xutall 5. 21f.. 39. 53, 69, 145 , $16: 216$.

\section{0.}

(1) chiuzzi 1698.

(1) 'onnell 169.

Geata 2(i).

(1ken 5. 2.2., tis, 81.

(1)11 197 .

v. (Hilers 221, 204.

(1) एpl 169 .

(rppeuleim 49.

(1)permann 187.

(M⿻1丨. 170.

(1)horn 52 .

(): snont 170 .

()ten-Sacken 170, 195.

()te 170.

(Holemans 72, s8, 239,240 .

(1urens 232.

()zanue 260 .

vzard 170 .

\section{I'.}

Parenstecher 170.

Pagliani 170.

Pallas 5. 22.2.

Palm 240.

Panse 170.

Pintel 2 tio.

Pamzer 5.

Parkel 170.

Pascal 260.

Pascinale 260.

Pa-ciuini 170 .

Patterson 170).

Patton 53, 69, 170, 185, 195, 216.

l'awlowsy $43 f$., 52 .

Pazos y Caballero 17̃o.

Pearse 170.

Pease 221, 224.

l'eiper 5,260 .

Penel 170.

Pereira 170, 26il.

Perroncito 5, 140, 261 .
Perrone 170.

Peryasú 170.

leters 4.

Peterson 50.).

preiller 170.

Philippi 170.

Philipps 2.21.

l'jekerell 170.

Jieter gat.

Pilger 2zoi.

(e? Pino 14!.

Pittaluga 170.

Pirajai da silva 261.

Plaget 5:.

Plehn, .1., 171.

Plehtı, F. 16i2, 171.

l'omb 171.

Plumert 171.

Pueh 171.

Poli 171.

Polidoro 171.

Ponk 197, 22l6.

Poore 171.

Portschinsky 197, 261.

Postemplis 171.

Potaillion 181.

Pothier 170.

Potonié 171.

Powell 177, 24il.

Pratt 211; 2.24.

l'ressat 171.

Price 171 .

Proncareini 153, 171.

v. Prowazeli t), 171, 281.

Priner 232.

Pruvot 2lil.

Pulstinger 172.

Puton 69 .

\section{(2.}

Quate 17.2.

Quirien 172.

Ii.

de Rakalt 172.

Rahes 17:'

Räbiger 2294.. 232.

Rabinowitsch 69 .

Rade 172.

Riilılmann 2+0.

Raillet 5, 260).

Raspail 5.

v. Rititz 232 .

Ratzelmurg 3.
Riantopoulo: 172.

le liat 17:2.

te Rianmur 5, 105, 172. 21ti, 224.

Rerli 4s, 5.2.

Rend 1i\%.

Rees 172.

Reichard ts.

Ririucle 17.

Reindl 172.

Reinhardt 172.

Regnamed 161.

lieyulanlt 172.

Reuter 69.

Ribas 17:.

Ricelii 17\%.

Riley 240 .

Ristima \&s.

livas 172.

Roberts 173, 185 .

Robinean-Tesvody 173, 2001., 216 .

Robinson 39.

Rucluez 155.

v. Rölex 261 .

Rindhain 197, 216, 230, 231, 201.

Rodrigu(? 14 is.

Roger 173 .

liogers 49, 173.

Rovesle 173.

Rompel 173.

Risndimi 224, 2931., 281.

lioque 173.

Rose 173.

Rosenau 173.

vou Rosenhof 5, 77, 87, 48.

RoB 140, 166, 173, 174, 216.

Rossi 174.

Rothichild $79,87,88$.

Ronband 1:39, 149, 214, 216, 너1, 262.

Rousrelot-Bénaud $17 t$.

Roux 261.

Royers 281.

Rubiano 174.

Rudolph 226.

Ruge 5, 85, $140,174$.

RuB 183, 262, 281.

Russel $17 t$.

\section{$\mathrm{s}$.}

Sahunayeff 174.

Saitta 261 .

Salanowe-Ipin 5, 174. 
sillimben 1 (i)

Sialmon 89.

Signoret $6 !$

simon 52.

fiambon 1:iti. 174. 187, 2.281., simond 166 . 176. 23.2.

Šanson 261 .

Namways 174

Sillarelli $17 \%$

Siluchez $17 \overline{\text { iis. }}$

situdahl vił.

siandens 175.

Sinder 216.

Sangiorgi 53. 69, 84.

Santorini 175.

sitrafidi 175.

Sasaki 236 .

Navignt 5.

Sar ogl.

Sibaceli 175.

Schandim 106f., 175.

van der scheer 175.

sicheiber 261.

schellack t9.

sicherthe 5, $17 \overline{0}$.

sichill 175.

v. Srhilling 38. 39, 69, 173 , 175. 216.

Sichillings: $17 \overline{\text {. }}$.

Schiner 175, 185, 197. 216, 217. 224.

Seluödte 52.

Sichivardi 175.

fichmalz 261.

Sichee $34,175$.

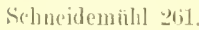

Silneider 175.

Sichoeh 나. 261.

Sichoo 140, 17.

sichrank 5 .

Solmbart 2:3.2.

fichuberg sis.

siohiltner 175.

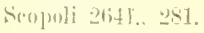

Sicordo lit".

Sxribar 2:37, 240.

Seichma 18:.

Seilfert 3, 2,20, $232,958$.

Semeleder 175.

Sienator 26il.

Serengent 5. 40, 52, 175, 176, 2)14, 224.

berueojs fist.

serville $6 \%$

Sewell 176.

sluma $17 \mathrm{t}$.

Shipley 10:4. 178, 232 .

v. Siviold 1!), 2Itj, 232.
Nimpson $17 t$.

Silirozki 176. 261.

Slimse 176.

simit 201 .

Smitl 39, 176, 176, 216, 258.

suyth 261.

Snellen van Tollenhoven bo.

sofer 177 .

Sokoloff 261.

Sionsino $17 \%$.

Soper 17\%.

Serel 177

Souchon 17\%.

Soulié 167, 177.

Speiser 177, 223, 224, 225, 281.

spence 68, 71.

spencer $17 \%$.

splendore 261.

fipring 261.

Spumier $17 \%$.

Sitrachan 261.

Sitral 62, 139.

Sitanley 216 .

Stanton 141, 160, 185.

Stephani 280.

de Stepani-Perez 177.

Stephens 5. 40, 71, 177, 178, 216.

sterling 178.

Sitenber 178.

siteudel 178, 213, 216.

Stiles 39, 23:.

Stroicescu 178.

Strachan 17s.

Strangeways-Pige 169.

Stromeyer 178.

Strunk 17s.

stoll 69.

Striekland 88, 216.

Ströblelt 52.

Stuhlmann 216.

suller 262 .

sunder 17s.

Sista 178.

Suzuki 178.

siwammerdam 5, 52, 178.

Swan 261.

Swollengrebel 81. 88.

T.

Takaki 5, 17s.

Tinaka 295i., 240.

Tasehenbergr 5, 77, 88.
TauBig 2T1. 2\$0.

Taute 217.

Taylor 178.

Tedaldi 17s.

Tedeschi 17s, 265, 2x-2.

Temple 178.

Terburgh 172. 178.

Testi 178.

Thaller 179.

Thébault 261 .

Theiler 33, 39, 217.

Theobald 179, $28 \%$.

Thiele $179,240$.

Thin 179.

Thiroux 139, 179, 232.

Thomson 17!.

Thompson \&s่, 179.

Tictin 53, 69.

Tirabosedi is, 88, 282.

Todd 68, 152, 169. 259, 281.

Torresse 179.

Torry 196.

Tousini 153.

Trautmanu 179.

Travers 179.

Tresling 180.

Treupe] 180.

Treutlein 180.

Trillat 180.

Trolard 180.

Trombetta 180 .

Tromessart 239, 240.

Tsuzmki 180.

Tulloch 217.

\section{I.}

Thlembuth 1s().

I7ner 5, 180 .

ITrieh 180 .

Lnderwood 180.

Irsin 180.

I.

Tagedes 180.

Valagussa 180.

Valentin 180.

Valentino 180.

Valerg-Havard 180.

Vallin 180.

Vandenbranden 197, 216.

Taney $150,180$.

Veazie 180.

Ventrillon 180, 181.

Terdim 181. 
Verjbitskr 53, 70.

zur Perth $85,181$.

Vialtha 70 .

Vilanova 181.

Vincest1 181.

Violat 181.

Virchow 232.

Vitonx 181.

Viwante 181.

te Toged 181.

Folhard 1si.

Vilkel 261.

Vonro 181.

II.

iV addell 181.

IVade 181.

IVilutier ss, 240.

Walluren is.

Thakeling 242.

de Walckenater 5 .

Waldow 181, 2291., 232?.

Walk 210.

Wall 28.2 .

Walker 181, 195, 211, 217, 261.

Warbuton 39.

Ward 181, 261.

v. Wasielewski 181.

Washburn 181.

Viaters 181.

Waterhonse 181 .
Watsun 1 is.

Weber 39. 233, 240.2.

Webser $1 \times 1$.

Wiede 202.

Wheed 181.

lleeks 1st.

Weger Isi.

Weidan\% 1Ni).

Weidemann Ist.

Weinberes 26.2 .

Weismann 10ti, 1ㄴ.

Treibentmerer IRI.

Wield 1.4.2, 23:2.

Welhman 3s, 399, $52,2,182,21 \bar{t}$. 262.

llellmer is.

Wenzel 1n:.

Wesclie IR:

Westwood 2014., 215, 217, 2.25.

IVestword st.

Wejdemaun 24.

Weyenberg 237.

White 2.2, 182.

Wiedemann 182, 194, 197, 200f. $216,217,22.2,2 \cdot 25$.

irilder 41).

Wilkinsun :3.

William 18.

Wilms 262 .

Wimberley $2 \times 2$.

Winge $26:$ ?

Winnelts 1s5.
Winter 1s.

Wise 18?.

Wohliahre 262 .

Woldert 18 ?

Wolferstan 18.2.

Wollhügel 18:.

Woodward 18:.

Wurnuliow it).

Wright 18\%.

Wulp 18:, 1s's, 1:4.

Wyman 는.

\section{1.}

de Yharra 153, 162.

Yorke 215.

Tounge 262.

Toll1 2202 .

\section{t.}

Zacharials 5, 18.

Zammit 18:

Zeller 195.

Zenker ‥92.

Zetterstedt 18:2.

Ziemann 182, 183. 197. 213, 217.

Zienet: 1 s 3 .

Zuntz 183.

Zupitza 183. 217.

Ziirn 6. 


\section{Sachverzeichnis.}

\section{A.}

Ieariua 6, 233.

Aedes viuereus $107 \mathrm{t}$.

1 kammshi-lirankhuit 234.

I kamushi- Milbe 233.

Imblyomua cooperi 30

- liehraemu 29.

- varigeatum 29.

Anopheles hifureatus 108.

- maenlipenuis 100\%., 116, 119\%.

Androctomus 245.

Imopheliden 103f.. 121.

Anllomusidar 254.

Ipousuma 30 .

Irameidae 240.

Irachnoidtar 6,226 .

Irgas persiens 2.2.

rollexus 2.2.

Iroasidoul 12.

Inthopulane 1 .

Isilialen 197.

Inclumeromial loterala 254.

\section{B.}

Bahresonen und Zerkeres 25, 33.

Benotomal grande (j).

Blepharoperidae $1 \times 7$.

BHutharuen und Kerken goj.

Buophilus- Irfoul 34 .

Bramla 2023 .

Brimison 18\%.

- und Trypanosell Jith.

Butluu-Irien 2to.

c.

radiceral 194.

Calliplorina" 251. ('cllia 1:5.

Croatoployllus fasciafus 81.

Cerafopogon-1jten 184.

Ceratojogonimate 183.

chimeanthinn $2+1$.

r'hironomidar 183 .

('hrysomyia macellaria 251.

('hlysopes 194.

limex loctularius 59 .

toleoplera 247.

fomorlijums mogistus $63 \mathrm{f}$.

Copra-Itcli 238.

Corly lobia antloropophasa 252.

Coreping disease 257.

C'rustacesa 6 .

C'temorephalus serraticeps 80.

C'ulex ammlatms 110.

pipiens 108, 116, 118.

Cylloplurus nigripes $108 \mathrm{f}$.

Crelopolia 223.

(yelops 6.

(imumia 254.

\section{D.}

Dassalitiogen 254.

lomulax 232.

H(m)orididar 2832.

Deruacentor retioulatus 31.

- varegatis 31.

Dermanysisus gallinae 238.

Jirusudiuis 238.

Dormallobia ryanis entris 256.

Diptrola 89.

E.

Emira 241.

Enpolidare 237. 
F.

Famia 25t.

Filarialarrin 135.

Filariasis und Bremsen 188.

und tyolops 6 .

- und strehminetien 135.

Flerligyphns und Länsp 40.

- und Wanzem 53.

Fliegenteiirtel 208.

Fliegenlarten 249.

Fliegruleim 213.

Flïlıי 71 .

Flöha und l'm.t $80 \mathrm{f}$.

Flohlialle si.

Flubiticher. japanisehes 234.

\section{G.}

Gialemeln 243

(iamasidae 237 .

fiellilieher und

(i]omilla 20200.

- lun $210 \mathrm{f}$.

- Iongipalpir -210.

- longipennis 210.

- morsilans 201. 208, 210f.

- palpalis 209f.

- pallicera 209.

- pallipid (י. 209.

- tachinuide-209.

Eils ciphan 239.

Ginizen 184.

\section{H.}

Hatrlinge is).

Hamaphysalio 30 .

- punctala 31.

Harmatopims, 40 .

Hacmalopola 195.

llatmotomyidium 1st.

I] albiliigher 53, 66 .

Hanthliagler 248 .

I]aแtman]wกrl 24 !

llanlwanzen 58.

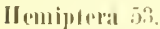

Ilexapouda to.

Hippohosea- Irten -201.

Ilistiogantor 2 ?:?

Ilolothy rus e:se.

llundebalieniose mol Zeeken 31.

llyalomma angyptimm 28.

- vrias'mm 20.

Himemoplera 24 .

Hypoderma bori iv 254.

- linealta $250 \%$
1.

dipan 234

Imekitell 4 ().

Johammsenicl]at 1 st.

Inometrits 245 .

lxosles ricinns 17, 26 .

Ixudilate 25.

\section{K.}

lílil-.lzar und Wanzen 53.

liantharidin 247 .

liarahurt 24?

liedani-lirankheil 234 .

- - Milhe 23:3.

lirankheiturreser unter den Arthropoden 1. $-2.25$.

lirankheit-iiherträgor mer den duthropoden 1, 6.

lirenzspinur $2+1$

lirimhelmiieken 185 .

lirustazeen 6.

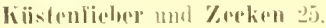

linlizidell 121.

L.

lathoblectes 242.

Lälus t6.

Lam-literen 217 .

Lepridoptera 2 ts

lapiluselaga t:15.

Jeptus amoricanns: 233.

antumnalis 233.

- irritans 233.

Linguatulat rhinaria 2064.

lingualicla ․ㅡㅇㅡ.

lipoptena rervi 21t, 22.2.

Lithobia 246 .

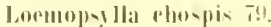

Lucilial catesar 251.

- nobilis 251.

- regina 201.

lateoxidar $2+1$.

Lymelia 22.?.

\section{M.}

Maculare caeruleate t?

Magalopmo 33.

Malaria und Inopheles 120, 136 .

Malluignatte 24 ?

Ilberi und Bremsen 185.

Jorarhinus 11 ?

II Mophagns- Irten 202-2.

- ovinn, 219, 221.

Intulbranacei 58.

Vilben 6. 232. 
llilzbrand und laimse 40

llnutal domextical 251.

romituria 251.

Wustala(" 195, 250).

IIntilla :24!.

Hecerolypus 184.

Myealidell 29 ?

Uyiais 29t9.

- exterma $25 \%$.

internal $25 \%$.

muscildal 250.

opstrosa 250 .

Myriapoda 246.

Myzomyia 119.

Jyzurhy nehus 119.

\section{N.}

Vilgana und 'l'setsefliegen $211 \mathrm{f}$.

lepar eincrea 57.

Vephrophagus 237.

Tirhopsyllidate 78.

licturia-Irtun 223.

\section{o.}

(1). ridare 254.

ohrmiln+ukraukheit ler Ziegen 232

(IIl'('rial :-2).

()ruilhomyia 22.2.

(o)eactal 184.

Mrniblodorns 23.

- moubata 24.

pavimenterses 24.

- aviguyi 24 .

Janlelus 247 .

pantinn: 2) 45.

J'angonia 194.

P’angoniina 144.

Preticulojdes venlrieasus 237.

Pedienlus rapitis 47 .

- resimanti 48 .

PAllasera und livebelmiicken $18 \overline{7}$.

Penicillidals 2030

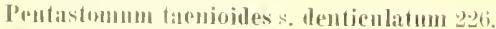

(*0)

Pest und r]älu sof. mud Itanzin is..

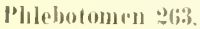

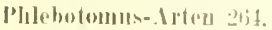
argentipes 2000 .

- habu 280.

- minulu 279.

- nigerrimus 270 . papatasij :(ti).
Phlebolomnus perniciosus 279.

Plithirins puljis th.

Porocephalus armillalus 228.

- moniliformis 228.

Psychodilae 183.

Pstlomorpha 71.

Pulex irritans 78 .

Pulicidat 78.

Pupipara 217.

Pyrethophorus 125.

\section{R.}

liaupen 2 is

lieduvidae 61.

lieduvills persomatus 61.

Rhipicentor hicornis 33.

lihipiceplialinar 30 .

Rhipicephafus loursa 31.

- sanguinens 31.

Riesenspimn! 242.

Rinderbabesiose und Kacken 33.

Riickfalliticher und Lïuse 40 .

- und Wanzen 53.

- und Kackin 22-24.

\section{S.}

vandlienan 185.

sindlitole 81.

Sarrophagidac 254 .

Sarenpsylla penctrans s1.

Narcojesyllidar \&1.

Silropulitare 232.

sallgalit bei Läısen 43 .

- bei Flöhen 76.

- bei stechiliegen 198.

- bei 1 anzen 55.

- bei stechminclien 105.

- bei Zerken 20.

sidalhabosiose und Zacken 33.

schlalkmankleit mel Tsotselliegen 210.

sichlangen mel Porocephalus 206.

seobopendra 246 .

Silvins 194.

simmlia $186 \mathrm{f}$.

Simuliidac 185.

viphunculata 40 .

solilingale 243.

sipinntertice 6, 226.

sebizotrypanose und (onorhinus 53.

sterlnmiirliwn 94.

- Eimfrilung 118, 124.

stemoptury yog.

Stegomyial 125.

stomoxyidar 198.

slomovxs 199 . 
Stuhrolliege 197.

surral und Bremsen 188.

\section{T.}

Tabantalae 158, 193.

'Tahatuinal 195.

TahatuI, 188t., 195.

T'arantrula 241.

Talmomemidatr 2037 .

Tausentriikler 2 tt.

Telegonा :

Temdipralistae 1s3.

Ternolas 184.

Tedrallye-Jidate 2306 .

Telramehus molestissimus 237.

- Trlarins 236.

Texaslipher und Zecken 25. 33, 35.

Theraphosa 243 .

Timprnchen und Tsetsefliegen $210 \mathrm{f}$.

- und Kekekn 20.

Toddkrankheit $2+7$.

Troehosal 24?.

Trombididar 233 .

Trombidim holunericenm 293. llasahuate 233 .
Trypanosen und Bremsen 185.

- und Tsedselliegen sole

und Wanzen 53.

'Tretse s. Gilosinit.

Tyalens 237.

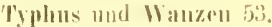

Tyrogly philae 238.

'Tyromphus longjor var. castellanii was.

\section{U.}

i harsehwemmumsfipher 234.

\section{W.}

Walzonspimuen 243 ,

Wassersucht. epidemische und Wanz"n 53 . Wanzen $53 \mathrm{f}$.

Wesprn 249 .

2.

Kecken sf.

Zweifliigler 89.

Zungenliege :00.

Zungenwiirmer y26. 





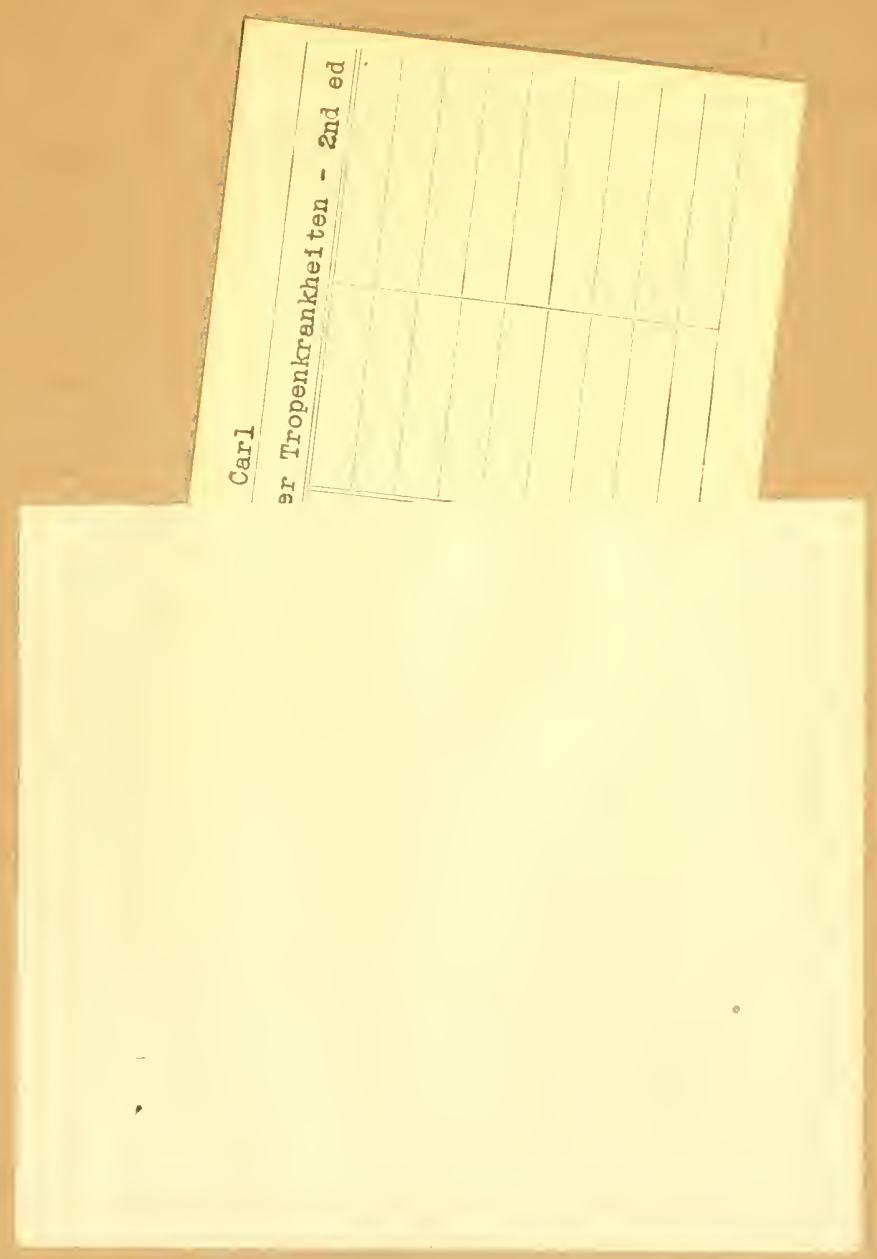


SMITHSONIAN INSTITUTION LIBRARIES
DII

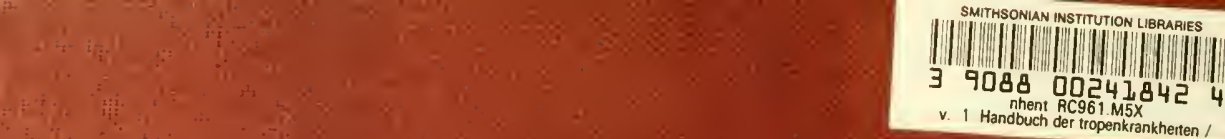

